\title{
EL PAPEL DEL MODELO EUROPEO DE EXCELENCIA EN LA SOSTENIBILIDAD DE LAS ORGANIZACIONES SANITARIAS PÚBLICAS
}

Félix Rivera Sanz

Directora/Tutora: Marta Gutiérrez Sastre 


\section{ÍNDICE}

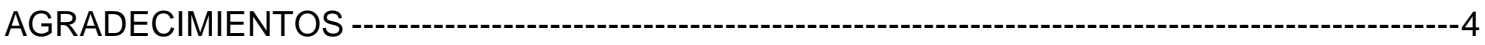

CONSIDERACIONES DEL AUTOR -

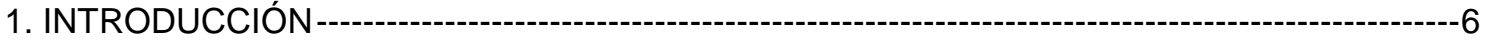

1.1 Contexto de la investigación -------

1.2 El sistema sanitario público---on

1.3 Consecuencias de la crisis en el sistema sanitario -- 19

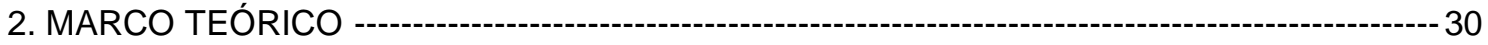

2.1 La sostenibilidad ----o- 31

2.1.1 El concepto de sostenibilidad -- 31

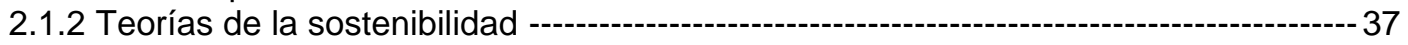

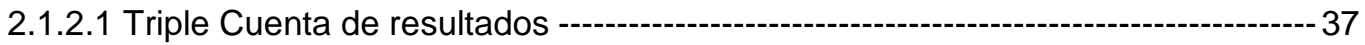

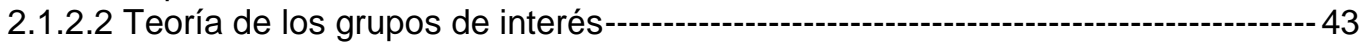

2.1.2.3 Rueda del cambio---on

2.1.2.4 Teoría del cubo de Rubik --o- 48

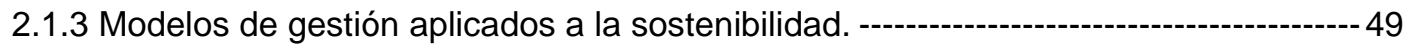

2.1.4 Sostenibilidad y cultura organizacional ----------------------------------------- 54

2.1.5 Modelos de sostenibilidad para el sector público ---

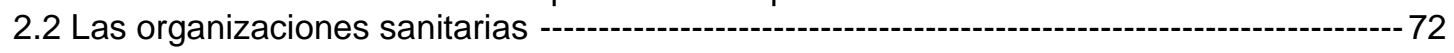

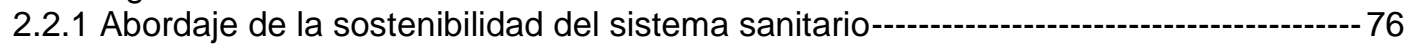

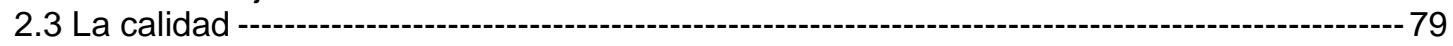

2.3.1 Calidad asistencial-------------------- 84

2.3.2 La Fundación Europea para la Gestión de la Calidad y el modelo EFQM ------------ 86

2.3.2.1 Los Conceptos Fundamentales ---------------------------------------- 88

2.3.2.2. Los criterios -------------------------------------------------------91

2.3.2.3. El Esquema lógico REDER ---oîn

2.3.3 Beneficios potenciales de la utilización del modelo EFQM ---

2.3.4 Dificultades para la implantación del modelo EFQM en las organizaciones ---------- 99

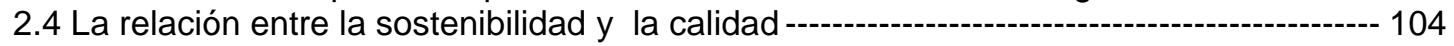

2.5 Indicadores de sostenibilidad - - 110

3. OBJETIVOS DE LA INVESTIGACIÓN--- 117

4 METODOLOGÍA-- 118

4.1. Selección de la metodología ----- 118

4.2. Selección de casos --orn 125

4.3. Diseño de la investigación cualitativa ----o- 128

4.3.1 Búsqueda bibliográfica---------------------------------------------------131

4.3.2 Contacto y primeras visitas a las organizaciones seleccionadas ------------------ 134

4.3.3 Observación directa y fotografías --- 135

4.3.4 Análisis documental ---on 135

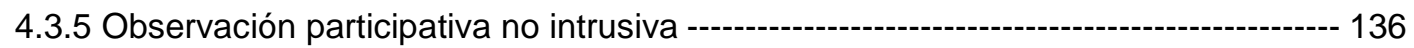

4.3.6 Entrevista abierta -------on 137

4.3.7 Diario del investigador ---on 140

4.4 Diseño de la investigación cuantitativa ---o- 140

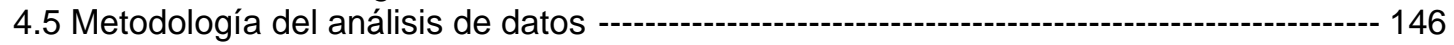

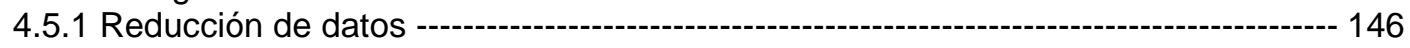

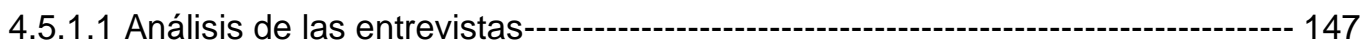

4.5.1.2 Análisis de Indicadores ---_- 147

4.5.2 Despliegue de los datos --- 148

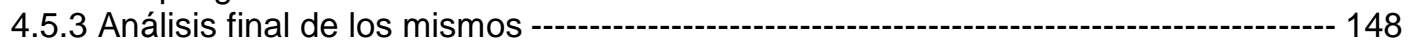

4.5.3.1 Cada caso---on 150

4.5.3.2 Entre casos ---o- 153

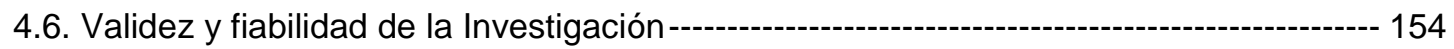

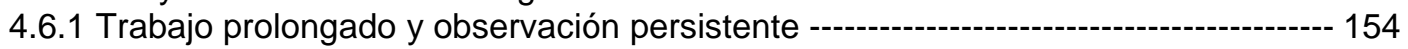

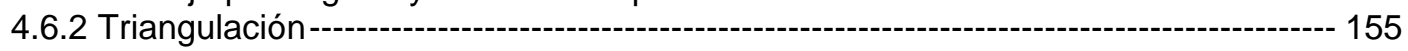

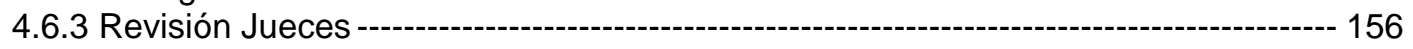

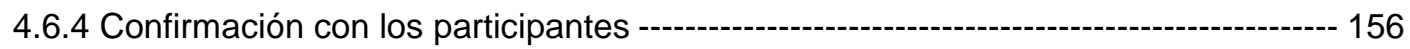

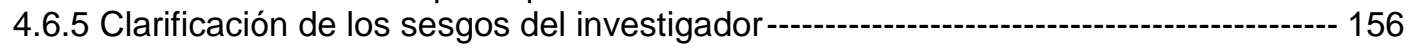


5. ESTUDIOS DE CASO ------ 158

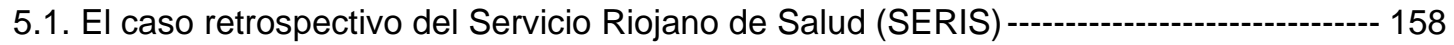

5.1.1 Descripción del contexto --on 158

5.1.1.1 Situación sociodemográfica---o- 158

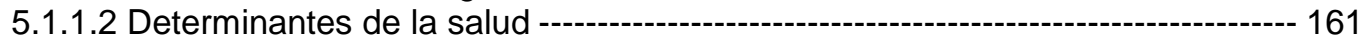

5.1.1.3 Resultados en salud---o-_- 161

5.1.1.4 Política sanitaria ----o-_- 164

5.1.1.5 Gestión de la Calidad --- 169

5.1.2 Resultados cualitativos ------------------------------------------------------ 176

5.1.3 Interpretación del investigador------------------------------------------------- 181

5.2. El caso retrospectivo de la OSI Bilbao-Basurto---o- 183

5.2.1. Descripción del contexto -

5.2.1.1 Situación sociodemográfica ---o- 183

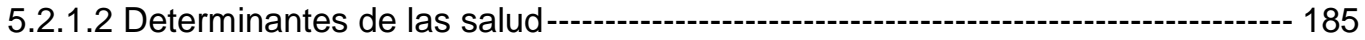

5.2.1.3 Resultados en salud--.-- 185

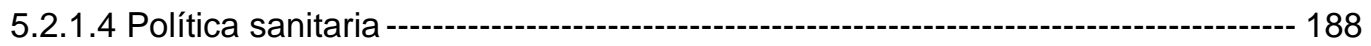

5.2.1.5 Gestión de la calidad -------

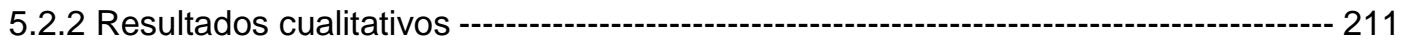

5.2.3. Interpretación del investigador --- 217

6. DISCUSIÓN. ANÁLISIS COMPARADO DE CASOS-------- 222

6.1. Contexto de las organizaciones -- 224

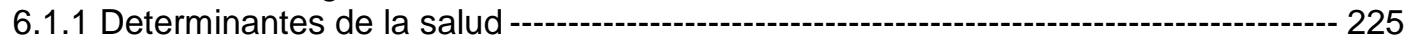

6.1.2 Gasto sanitario--- 226

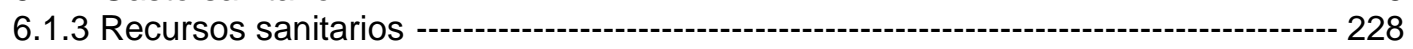

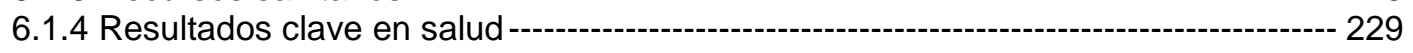

6.1.5 Satisfacción de los ciudadanos con el sistema sanitario --- 232

6.1.6 Seguridad de pacientes y cobertura sanitaria--- 233

6.2 Factores internos de las organizaciones -- 233

6.2.1 Procesos, productos y servicios -- 233

6.2.2 Liderazgo------------------------------------------------------------------------ 234

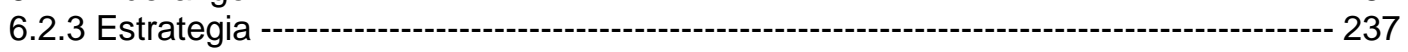

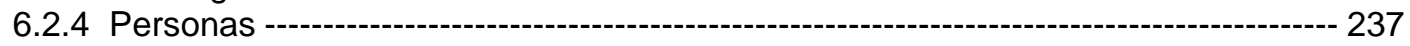

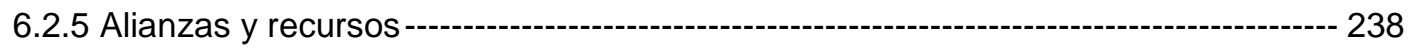

6.2.6 Sistema de gestión ------------ 240

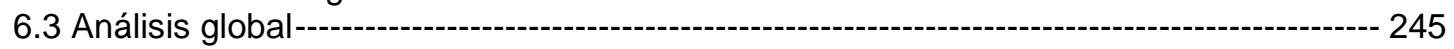

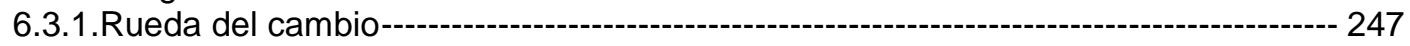

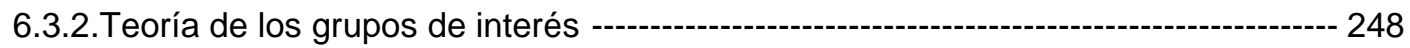

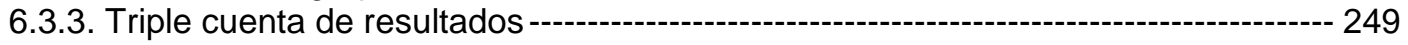

6.3.4 Diferencias encontradas--- 253

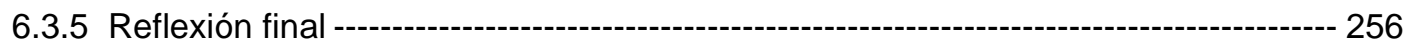

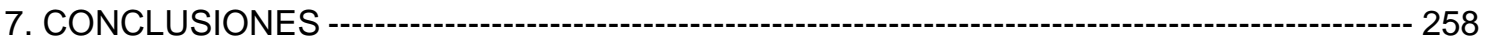

7.1 Conclusiones ---------------on 258

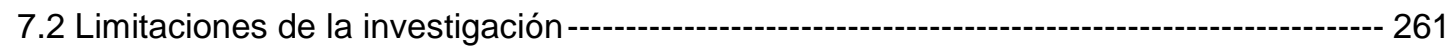

7.3 Futuras investigaciones --- 263

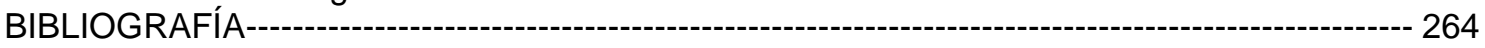

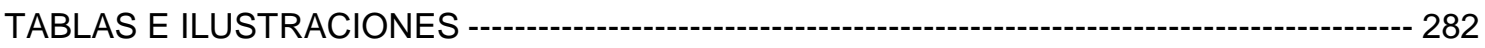

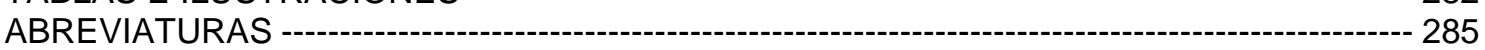

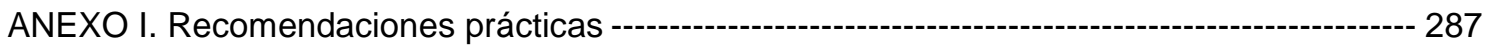

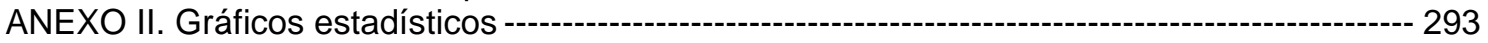

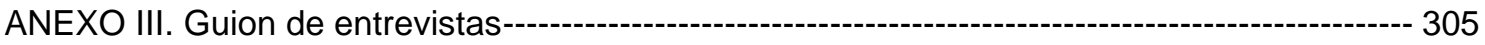

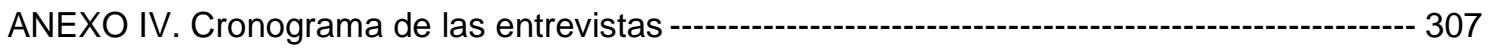




\section{AGRADECIMIENTOS}

Este trabajo de investigación no se hubiese podido realizar sin la ayuda inestimable y desinteresada de los profesionales de la Organización Sanitaria Integrada BilbaoBasurto y del Servicio Riojano de Salud.

Gracias a Antxón por su apoyo y su amistad.

Gracias a todas las que me han empujado y soportado, en todos los sentidos de la palabra, y me han mostrado el camino: Gotzone, Begoña, Merche, Rosa, Vicente...

Gracias a mi directora de tesis, Marta, por su esfuerzo y su guía a través del tunel.

Gracias a mis padres porque siempre han creído.

Gracias a Ander, Ángela y Óscar por ser mi motivación.

Gracias a ti, Maite, porque no eres la mitad, lo eres todo.

Un especial recuerdo para mi abuela Hilaria, que murió con 104 años mientras se realizaba esta investigación, y con su ejemplo me enseñó que también las personas sencillas pueden ser sabias. 


\section{CONSIDERACIONES DEL AUTOR}

La complejidad del sector sanitario, responsable de la salud, es un potente motor de investigación y producción científica, en el que trabajan miles de profesionales desde diferentes visiones. Esto supone un reto y una responsabilidad que aconseja trabajar con el máximo rigor, ilusión y motivación por parte de quienes de algún modo tienen en sus manos la posibilidad del mantenimiento y mejora de los servicios públicos en general, y sanitarios en particular.

La salud de las personas (su bienestar) es una condición "sine qua non" para contribuir al sostenimiento del propio país, para mejorar su productividad, nivel de vida, educación general y entorno de convivencia.

La experiencia y el conocimiento proporcionado por más de 25 años en el sistema público de salud, y principalmente en las áreas de gestión y calidad, añadiendo la visión holística de los profesionales de enfermería, son elementos fundamentales para haber intentado realizar una pequeña contribución a la mejora y sostenibilidad del mismo.

La experiencia en el campo de los sistemas de gestión en el ámbito sanitario ha sido determinante a la hora de trabajar en esta línea de investigación e intentar verificar que el tiempo y el esfuerzo de las organizaciones en la implantación y mantenimiento de los sistemas de gestión de la calidad tienen reflejo en la mayor capacidad de sostenibilidad gracias a la cultura organizacional de la que participan sus personas.

No obstante, la propia experiencia sobre el tema y las organizaciones objeto de estudio introducen una serie de elementos en la percepción del autor y en la elaboración de esta investigación que deben ser tenidos en cuenta.

- Relación del autor con la OSI Bilbao-Basurto:

- El autor nació en Bilbao y residió allí hasta los 22 años

- Alumno de la Escuela de Enfermería de Leioa de la Universidad del País Vasco. Realizó las prácticas clínicas, incluidas en el plan formativo, durante los años 1986 a 1989 en el Hospital de Basurto.

○ Realizó función asistencial en dicho hospital entre 1989 y 1992.

- Relación del autor con el Servicio Riojano de Salud:

- Residente en Logroño desde 1992

- Realizó función asistencial en diferentes centros de La Rioja.

- Actualmente Responsable de Calidad y Apoyo a las Unidades Docentes y de Investigación del Servicio Riojano de Salud desde mayo de 2012.

- Motivaciones personales. El autor apoya el derecho de los ciudadanos a una sanidad pública, universal y de calidad.

Este trabajo de investigación no ha recibido ningún apoyo económico por parte de ninguna de las instituciones citadas, ni por ninguna otra institución, organismo o empresa. 


\section{INTRODUCCIÓN}

El sistema sanitario español es una institución fundamental de servicio público y, a día de hoy, un instrumento social insustituible en el estado de bienestar que contribuye al mantenimiento de un marco de convivencia e igualdad (Oteo, 2010) en la sociedad española. No obstante, su sostenibilidad es una fuente constante de debate en esa misma sociedad.

El problema de la sostenibilidad en el sistema público de salud en un tema recurrente (Bacigalupe, 2015) y su abordaje se ha hecho en la mayor parte de las ocasiones desde el punto de vista cuantitativo, analizando datos y elaborando indicadores que muestran resultados sobre gastos, recortes, consumos, tasas, porcentajes, etc.

Para tratar de asegurar la continuidad del sistema público de salud el Gobierno aprobó el Real Decreto-ley 16/2012 de medidas urgentes para garantizar la sostenibilidad del Sistema Nacional de Salud.

Diversos estudios muestran diferentes formas de afrontar el entorno de contención de costes buscando de forma activa la sostenibilidad interna en los sistemas sanitarios; según Repullo (2012) la desinversión en todos los servicios que no añaden valor es una de las herramientas a utilizar. Durante el periodo de crisis solamente el País Vasco mantuvo su gasto sanitario público y aumentó la tasa de personal público en atención primaria y atención especializada en el periodo. El resto de las comunidades autónomas, excepto Cantabria, redujeron de forma relevante su gasto público, y excepto Cataluña y la Comunidad Valenciana, redujeron también su personal público (Bacigalupe, 2015).

Las consecuencias de la disminución del gasto público en sanidad, según el informe de la Organización para la Cooperación y el Desarrollo Económico (OCDE, 2013), pueden haber sido las causantes del aumento de las listas de espera, así como de efectos para la salud a largo plazo y de consecuencias económicas negativas para los más vulnerables. Las personas más desfavorecidas y con menos ingresos pueden llegar a renunciar a los cuidados sanitarios que necesitan, a sus medicamentos o al seguimiento y el control de sus enfermedades crónicas. Estas medidas también se han traducido en una importante regresión en los derechos sanitarios (Cantero, 2014) en tanto que se limitó el carácter de universalidad de la atención sanitaria.

El producto que elabora el sistema sanitario es la salud entendida como un estado de completo bienestar físico, mental y social, y no solamente la ausencia de afecciones o enfermedades (OMS, 1948). Para lograrlo, el sistema sanitario cuenta con organizaciones conformadas por profesionales que proporcionan a los ciudadanos este servicio directamente.

El sistema sanitario, en la medida en que puede ser comprendido de acuerdo con su propiedad de integrarse alrededor de valores comunes y compartidos (Chinoy, 1990), puede ser estudiado desde la perspectiva de las ciencias sociales. Podemos llamar organización social o estructura social a cualquier sistema interrelacionado de roles y status. Una organización sanitaria se compone de un cierto número de personas unidas 
por una red o sistema de relaciones sociales. Sus miembros interactúan entre sí de una forma, más o menos, estandarizada y aceptada por el grupo. Las relaciones de interacción se basan en gran parte en un sistema de roles y status interrelacionados.

Un hospital es una organización compleja en la que existe multitud de roles y status diferenciados y fácilmente identificables.

Para comprender la sostenibilidad de una organización es necesario conocer los aspectos esenciales, pero no visibles, constituidos por las políticas estrategias, objetivos, procedimientos, etc. que se manifiestan a través de planes o memorias, impregnan a las personas y se manifiestan a través de su comportamiento y cultura.

La cultura organizacional, de la que participan los diferentes trabajadores de las organizaciones sanitarias, puede estar influenciada o determinada en diferentes grados por la adopción de modelos organizativos. Este sistema de valores puede estar modelado por la introducción de herramientas, como el sistema de gestión de la Fundación Europea de Gestión de la Excelencia, e incorporar una serie de valores compartidos que favorezcan una actitud proactiva de las personas y de la organización hacia su sostenibilidad. En línea con este pensamiento, este trabajo quiere estudiar el papel del modelo europeo de excelencia (EFQM) en la sostenibilidad de las organizaciones sanitarias públicas.

El País Vasco apostó de manera institucional y estratégica por la implantación del modelo europeo de excelencia (EFQM) en sus centros sanitarios. Esta apuesta estratégica se extiende de forma continuada durante un periodo de tiempo prolongado que abarca el periodo precrisis y el de crisis económica. No obstante, el Servicio Vasco de Salud-Osakidetza no realizó, hasta 2016, un trabajo sobre el impacto de la implantación de EFQM en su organización (Matthies-Baraibar, 2016).

Por su parte, el Servicio Riojano de Salud (SERIS), durante este periodo, ha optado por una estrategia diferente orientada a la reducción del gasto como principal objetivo.

Estas diferentes formas de afrontar problemas semejantes, en circunstancias parecidas, durante el periodo de crisis económica vivida en los últimos años, permiten establecer una comparación entre las estrategias adoptadas e implantadas en los centros sanitarios de los sistemas públicos de salud de La Rioja y del Pais Vasco. Todo ello, con el objetivo de tratar de conocer el impacto de modelo europeo de excelencia en su sostenibilidad. 


\section{ANTECEDENTES}

\subsection{Contexto de la investigación}

El modelo sanitario español actual tiene su origen en el dispositivo asistencial sanitario la década de los cuarenta del siglo XX (Mompart y Durán, 2001). Este modelo, basado en la asistencia sanitaria vinculada al sistema de seguridad social, progresivamente fue ampliando su porcentaje de cobertura hasta alcanzar la práctica universalización a principios de la década de los noventa del siglo pasado.

La red sanitaria de la Seguridad Social fue complementada con diversas redes asistenciales vinculadas a las diputaciones provinciales, ayuntamientos, universidades, sanidad militar, etc., aunque en la mayoría de los casos con un carácter meramente testimonial desde el punto de vista de la cobertura poblacional. Estas instituciones, en su mayoría, se acabaron integrando en la red pública de la Seguridad Social gestionada por el Instituto Nacional de la Salud (INSALUD).

Posteriormente, como consecuencia del desarrollo de los derechos reconocidos en la Constitución y de la Ley General de Sanidad, se han constituido en cada una de las diecisiete Comunidades Autónomas los denominados Servicios Regionales de Salud, que gestionan la totalidad de la atención sanitaria pública prestada a su población.

Actualmente, y con independencia del sector público hegemónico en el modelo sanitario español, existen otros dispositivos asistenciales no públicos, de carácter benéfico en unos casos (Cruz Roja, órdenes religiosas) y lucrativo en otros (sanidad privada).

La Constitución de 1978 dedica distintos párrafos a las cuestiones de salud. En su apartado esencial, en lo relativo a los derechos de los ciudadanos, reconoce el derecho a la protección de la salud (artículo 43), lo que lleva aparejado el correspondiente deber de los poderes públicos de organizar, tutelar y mantener la salud pública mediante medidas preventivas y de las prestaciones y servicios necesarios. Asimismo y como consecuencia de la distribución territorial de España en autonomías, atribuye a estas la prestación y gestión de los recursos, reservando al Estado la sanidad exterior, el establecimiento de las bases y la coordinación general y el régimen económico de la Seguridad Social.

Al cumplimiento básico de dichos preceptos constitucionales responde la ley 14/1986, de 25 de abril, General de Sanidad, al establecer las bases del modelo sanitario como integral de cobertura generalizada. Este ofrece un nivel de prestaciones solo al alcance de los sistemas más desarrollados en la atención al bienestar social (Lledó 2005), formado por los servicios de salud de las autonomías, actualmente desarrollados en todo el territorio, y a partir de la que, se ha configurado el entramado de normas que regulan lo concerniente a la salud.

Entre todas ellas, y en lo que hace referencia a los derechos de los pacientes, la ley 41/2002, de 14 de noviembre, de autonomía del paciente, información e historia clínica 
que sustituyó, en parte a la Ley General de Sanidad, expone los principios subjetivos de la actividad asistencial cuyo carácter de ley básica garantiza los derechos que establece en todo el país.

Con todo ello, España consiguió avanzar de forma significativa en su modelo sanitario durante finales del siglo $X X$ y principios de $X X I$, y es gracias a eso, que, a pesar de la situación de crisis, hoy en día se dispone de una buena sanidad (Beltrán, 2009). Sin embargo, el sistema continúa enfrentándose a retos significativos de carácter financiero, de incremento de la demanda de atención y de escasez de recursos disponibles.

En un artículo de El País Elena Sevillano, redactora de la sección de investigación especializada en sanidad (2016) afirma que la sanidad ha sobrevivido a un recorte de 10.000 millones y su financiación sigue sin abordarse. El debate de la financiación y la sostenibilidad parece haber pasado de moda en la actualidad, más porque los recortes han dejado de estrangular al sistema que porque se haya solucionado el problema. En ese artículo se cita a José María Abellán, presidente de la Asociación de Economía de la Salud y vicerrector de la Universidad de Murcia, quien describe lo ocurrido estos años con una metáfora visual que vincula el sistema sanitario como un traje. "Las costuras no han llegado a reventar pero se han estirado", asegura.

El sistema sanitario actual tiene planteada hoy la necesidad de acometer reformas estructurales que aseguren su sostenibilidad a corto y a medio plazo. Por otro lado, probablemente hoy existe la sensibilidad, la necesidad y el ambiente propicio entre las distintas administraciones y agentes sociales para hacerlo posible. Existe una creciente demanda social para alcanzar un pacto por la sanidad que empiece a abordar de manera decidida y con acciones concretas los retos a los que se enfrenta el sistema.

Según Gutiérrez-Peñalver (2009), el sistema sanitario necesita y va a necesitar innovación y profundos cambios en las formas de financiación, gestión y provisión de los servicios. La calidad y la seguridad seguirán siendo, en este sentido, áreas críticas para su sostenibilidad. Todo ello, afirma, exigirá acciones valientes, estratégicas e innovadoras por parte de los responsables políticos, y buena voluntad e implicación para acompañar estos cambios por parte de todos los agentes implicados (grupos de interés) en la prestación de servicios sanitarios como directivos, gestores, clínicos, profesionales, por un lado y de los ciudadanos, usuarios y pacientes, comprometidos e informados, capaces de tomar decisiones y corresponsabilizarse en una asistencia de calidad, por otro (Gutiérrez y Peñalver, 2009).

La Ley General de Sanidad y la Ley de Cohesión y Calidad del Sistema Nacional de Salud recogen como una de las características fundamentales del sistema español de salud, "la prestación de una atención integral de la salud procurando altos niveles de calidad debidamente evaluados y controlados". Además, la Unión Europea recomienda a todos los estados miembros el desarrollo y puesta en marcha de sistemas de mejora de la calidad en los servicios de salud que recoge, entre otros aspectos, que los sistemas de calidad deberán ser objeto de control público bajo la forma de una evaluación objetiva realizada por organismos independientes. 
La Subcomisión Parlamentaria para la Consolidación y Modernización del Sistema Nacional de Salud incluye entre sus recomendaciones la necesidad de impulsar la mejora continua de la calidad de la asistencia a través de un sistema general de acreditación de centros y servicios sanitarios consensuado en el seno del Consejo Interterritorial.

En línea con todo esto, las reformas introducidas (Ley 15/1997, de 25 de abril, sobre habilitación de nuevas formas de gestión del Sistema Nacional de Salud), y los retos que plantea actualmente la sostenibilidad hacen de los sistemas de gestión de la calidad total una herramienta disponible para las organizaciones sanitarias.

La implantación de un sistema de evaluación externa, como se recoge en el Plan de Calidad de 2005 del Ministerio de Sanidad y Consumo puede jugar un papel importante como elemento de información en la toma de decisiones, tanto de las administraciones sanitarias como de los profesionales y usuarios de los servicios. Ya existen experiencias en España de centros sanitarios y servicios que han alcanzado la certificación por el modelo de la International Stardars Organization (ISO), basado en las denominadas normas ISO 9000, y hospitales que están acreditados por la Joint Commission o evaluados por el Modelo Europeo de la Calidad (EFQM).

Sin embargo a pesar de la necesidad percibida por todas las partes interesadas, los sistemas sanitarios son muy difíciles de cambiar, según Arenas (2012) por los siguientes motivos:

- El concepto de dependencia de senda o inercia. Es difícil cambiar el camino seguido por un sistema tan grande, complejo y con tantas inercias como el sistema sanitario público sobre el que convergen intereses profesionales, grupos de presión e ideologías políticas.

- La teoría del comportamiento político de las organizaciones y los seres humanos. Los grupos de privilegios y de poder de un sistema que están en la zona de confort (con baja exigencia frente a alto beneficio personal) frenan cualquier cambio que suponga una disminución de sus derechos y aumento de sus obligaciones.

- La teoría económica del comportamiento humano. El egoísmo y la actitud autointeresada tiende a maximizar el interés personal en detrimento del bien común, por lo que son imprescindibles elementos de control.

- La clase política tiene escasos conocimientos técnicos de la gestión sanitaria y las posibles soluciones para mejorar los sistemas sanitarios y no está dispuesta a asumir los riesgos derivados de una reforma del sistema. El análisis objetivo del sistema de salud es complejo.

Algunos otros ejemplos de herramientas ya utilizadas en la búsqueda de la mejora del SNS son la gestión clínica, la gestión de procesos, la evaluación continua con reingeniería de los procesos, la medicina basada en la evidencia, la evaluación de las tecnologías sanitarias, el benchmarking para compararse y aprender de los mejores, la reorientación del sistema hacia la cronicidad y la mejora de la calidad de vida, la telemedicina, el paciente experto, la sanidad 2.0, etc... 
Como se puede comprobar en nuestro entorno, desde hace varias décadas la calidad asistencial se ha convertido en uno de los elementos estratégicos para la transformación y mejora de los modernos sistemas sanitarios, formando parte de los objetivos asistenciales en todos los niveles de cualquier institución sanitaria. De esta manera, gestión y calidad parecen ser un binomio inseparable para conseguir organizaciones sanitarias más eficientes, seguras y coste-efectivas.

La calidad asistencial es definida en cada momento por la comunidad científica, por los profesionales, por los pacientes y la sociedad en general, y por las propias administraciones y organizaciones sanitarias, en función de prioridades establecidas conforme a determinados valores, necesariamente cambiantes y en permanente evolución. Todo ello dirigido a la sostenibilidad en el tiempo del propio sistema y a su mejora continua y adaptativa a las necesidades cambiantes de los grupos de interés.

Según indica Luis Ángel Oteo Ochoa (2010): "El sistema sanitario español, como institución fundamental de servicio público, es hoy un instrumento social insustituible en el proceso de legitimación del Estado de Bienestar. Sin embargo, en las difíciles circunstancias financieras y fiscales por las que atraviesa la mayoría de los países socialmente avanzados como consecuencia de la crisis económica, se hace obligado plantear políticas de contención y ajuste del gasto social para garantizar la sostenibilidad y la cohesión de los propios sistemas del estado benefactor, así como la consecución de un mejor equilibrio en el binomio eficiencia-equidad, lo cual exige desde la ética pública una gestión apropiada de los recursos disponibles y un mayor grado de corresponsabilidad de todos los agentes económicos y sociales"

Zardoya (2007) destaca la necesidad de la implantación en el sector público de sistemas de gestión de calidad, resaltando la importancia económica de dicho sector en las economías desarrolladas y analizando la relevancia de los sistemas de gestión de la calidad en la administración de las Instituciones Públicas, como herramienta para mejorar la eficiencia y solventar algunos de los problemas que, con frecuencia, son atribuidos a dicho sector.

Durante las recientes décadas, el sector público y los servicios que éste presta están incrementando, de forma considerable, su importancia en las economías desarrolladas. Así por ejemplo, el gasto sanitario público en el año 2015 en España supuso 65.565 millones de euros, lo que representa el 6,1 por ciento del producto interior bruto (PIB) y el gasto per cápita ascendió a 1.412 euros por habitante, según datos del ministerio (MSSSI, 2017).

Junto a esto, la importancia que se le concede al servicio público de sanidad queda respaldada por el creciente énfasis otorgado a la calidad del servicio prestado y a la satisfacción de los usuarios. Ya no sólo se trata de conseguir la calidad de las actividades o de los servicios públicos por imperativo legal, sino que es una necesidad cada vez más demandada por el ciudadano, que exige un nivel determinado de satisfacción sobre los servicios prestados por la administración pública, como contrapartida por las aportaciones económicas que realiza a través del pago de los impuestos (Castelló y Lizcano, 1997) y de las cuotas de seguridad social en el caso de los servicios sanitarios. La implantación de modelos de gestión de calidad en el sector público pretende dar respuesta a todas estas cuestiones planteadas y solucionar 
algunos de los problemas detectados aprovechando las numerosas ventajas de su aplicación que se han observado en su aplicación a otros sectores, tanto públicos como privados.

Por todo ello, las organizaciones han tenido, y tienen, un especial interés sobre la puesta en marcha de sistemas de gestión que permitan mejorar la calidad de los servicios prestados a los ciudadanos. Entre todos ellos destaca, de forma especial, el modelo europeo de excelencia (EFQM). A pesar de que el modelo EFQM ha tenido mayor presencia entre las empresas privadas, es aplicable también a las entidades públicas entre las que ya se han observado también efectos y resultados interesantes. Las mismas motivaciones que hicieron necesario el modelo para la empresa privada son las que hicieron que, en 1994, se organizase el grupo de trabajo de la EFQM para el sector público, apareciendo el modelo adaptado en 1995 (Rodríguez, 2001). La implantación de la versión adaptada del modelo EFQM ha ido creciendo y, a título ilustrativo, pueden destacarse la implantación del Modelo EFQM en diversas instituciones sanitarias en diferentes comunidades autónomas, como por ejemplo en Madrid, Castilla-León o el País Vasco.

\section{Los pacientes.}

Como ya se ha señalado, la salud es un derecho fundamental de todos los españoles. Además, el periodo de crisis económica ha puesto de manifiesto cómo el sistema de salud constituye una red indispensable de seguridad colectiva (Echaniz, 2014), que ha ayudado mucho a amortiguar los efectos de la pobreza (tabla1) en España.

Tabla 1. Riesgo de pobreza o exclusión social (indicador AROPE)

\begin{tabular}{|l|c|c|c|c|c|c|c|c|}
\hline & $\mathbf{2 0 1 5}$ & $\mathbf{2 0 1 4}$ & $\mathbf{2 0 1 3}$ & $\mathbf{2 0 1 2}$ & $\mathbf{2 0 1 1}$ & $\mathbf{2 0 1 0}$ & $\mathbf{2 0 0 9}$ & $\mathbf{2 0 0 8}$ \\
\hline País Vasco & 17,6 & 15,3 & 16,8 & 17,7 & 18,9 & 16,3 & 14,8 & 13,9 \\
\hline La Rioja & 22,1 & 20,1 & 22,2 & 22,6 & 26,1 & 27,3 & 19,5 & 19,6 \\
\hline España & 28.6 & 29.2 & 27.3 & 27.2 & 26.7 & 26.10 & 24.7 & 23.8 \\
\hline
\end{tabular}

Fuente: INE

No obstante, como ya se ha indicado, el sistema necesita introducir cambios si quiere seguir siendo referencia y apoyo para todos los ciudadanos. Para Arratibel (2014) el mayor cambio que tienen que acometer hoy los sistemas sanitarios es evolucionar, cambiar el modelo de organización sanitaria, deben ir desde el ámbito más especializado hacia un entorno más comunitario, más próximo al paciente.

Cada vez más, es un paciente informado y, como consecuencia del incremento del envejecimiento, es un paciente que tiene que aprender a envejecer, con lo cual es necesario que adopte hábitos de conducta, alimentación, ejercicios saludables, para envejecer adecuadamente (Olivan, 2014) .

El envejecimiento de la población, la cronicidad y el hecho de que las poblaciones desarrolladas tienen más necesidad de sentirse sanas, hace que la demanda sanitaria haya aumentado.

Una parte importante de las personas, mejorando la calidad asistencial, expectativas de vida y atendiendo mejor a cada paciente con los recursos adecuados, sobre todo en el 
ámbito sociosanitario, dejarían de necesitar los recursos sanitarios, con lo cual el gasto en este ámbito podría llegar a disminuirse (Olivan, 2014), o al menos a controlarse.

Para Echaniz (2014) el problema de la sostenibilidad del sistema sanitario es un problema político por la utilización de la sanidad como un elemento de confrontación más que una realidad de cómo se percibe la asistencia por parte de los ciudadanos. Echaniz propone profesionalizar la sanidad, despolitizarla y poner al frente de la gestión a personas competentes, independientemente de lo que piensen o de lo que voten.

\section{Los profesionales.}

Los propios profesionales sanitarios saben que es fundamental la búsqueda de la eficiencia en el sistema y hay que desarrollar instrumentos para mejorarla (Arenas, 2012).

La crisis ha supuesto un enorme sacrificio para los profesionales, una prueba de fuego para el SNS, de la que se puede decir que ha salido razonablemente airoso. Ha demostrado su resilencia, cualidad que se puede aplicar tanto a las personas como a las instituciones. La crisis ha servido para poner de manifiesto muchas deficiencias y errores de gestión del pasado, indicando con bastante claridad el camino a seguir para hacer las reformas necesarias (Echániz, 2014).

Muchos de los incentivos para las personas con los que se ha trabajado en el pasado no lograron su objetivo de motivación y resultaron contraproducentes. Por lo tanto, hacer una política de incentivos nueva e inteligente, y diseñada con la participación de los profesionales que tienen responsabilidad es necesario. Los incentivos deben ser económicos, de investigación, de capacitación, de formación, etc... (Echániz, 2014).

En resumen, se debe tratar de lograr que participen en la gestión de las organizaciones sanitarias todos los profesionales. El compromiso debe incluir adoptar la mejor decisión para cada paciente y para la organización pensando en que el sistema tiene que ser sostenible (Olivan, 2014).

\section{Los Gestores.}

José Soto, director gerente del Hospital San Carlos, citado por Adolfo Moreno (2015) dice: "organizativamente, para la gestión, es más fácil ejemplificar que nosotros tenemos recursos, tenemos un producto final que ofrecer, que es la mejoría del paciente, y que tenemos que aplicar los recursos en forma de procesos científicos estudiados para que den el producto final con el mínimo coste y la máxima calidad..... Cabe articular estrategias de gestión empresarial: gestión de procesos, gestión de recursos humanos, gestión de la motivación, gestión de calidad, gestión de medio ambiente, etc.”.

El principal reto al que se enfrentan los gestores es la limitación de recursos. La sanidad del futuro se tiene que pagar con los recursos existentes y España tendrá la sanidad que se pueda permitir con sus recursos (Echániz, 2014).

Una gran cantidad de recursos económicos se dedican a pagar la factura de medicamentos. No obstante, los intentos de un hospital para minimizar sus propios costes de medicación pueden, como una consecuencia no deseada, dar lugar a un aumento del gasto sanitario global de la comunidad a través de un aumento de los 
efectos secundarios (Vernaz, 2013). Al respecto, existen diferentes propuestas para hacerlo sostenible como las políticas de ahorro de costes fomentando las recetas de medicamentos genéricos

Por otro lado, y como una de las apuestas para la eficiencia del sistema sanitario, está la privatización de servicios y centros. Según Adolfo Moreno (2015), el barómetro de confianza institucional de los españoles, que realiza anualmente Metroscopia, mostraba que el porcentaje de ciudadanos que evaluaba positivamente la organización, el funcionamiento, de la sanidad pública cayó en tan solo un año, de julio de 2013 a julio de 2014 , del $73 \%$ al $49 \%$. Menos de la mitad de la población le daba el aprobado. Sobre cómo interpretar este dato se expusieron las reflexiones de expertos en la materia, aunque muchos señalaban que podría estar relacionado con la cada vez mayor presencia de empresas privadas que lograban las adjudicaciones para gestionar centros hospitalarios públicos en esa época.

Rafael Bengoa, exconsejero de Salud del País Vasco y asesor de los gobiernos de España, EEUU y la OMS en materia sanitaria dice: "lo que intenta hacer el modelo de gestión privada es alejarse de las barreras que supuestamente tiene el sector público para ser eficiente. Son modelos que intentan buscar la eficiencia de una manera no probada. Si estuviera probado que un modelo de gestión privada de una entidad pública fuera mejor, hubiéramos avanzado todos en esa dirección, pero no hay nada que indique que sea asi", asegura, aunque "tampoco indica lo contrario, porque no ha habido suficiente evaluación en España para confirmar una cosa o la otra", pero "si ha habido información en otros países para confirmar que la gestión privada no es necesariamente, ni mucho menos, le saca chispas a cada euro que le metemos al sistema". Según Bengoa lo que sí sabemos es que países como EEUU que tienen este modelo desde hace 40 años lo quieren abandonar porque crea desigualdades y crea ciudadanos de primera y de segunda.

Para Rafael Bengoa, citado por Adolfo Moreno (2015), los mayores errores en estos últimos años han estado en "concentrarse únicamente en una política de contención de gasto y no simultanear esa política con una política de transformación y reforzamiento del sector público", comenzando con cambiar el modelo asistencial con la estrategia de crónicos. Estamos en un modelo asistencial que se llama de rescate. No es un buen modelo porque es un modelo pasivo, y lo que se pretende es un modelo asistencial mucho más proactivo, es decir el paciente debería estar más en su entorno habitual, más en casa, más en la comunidad, más en Atención Primaria (AP) y menos en los hospitales.

Además, Bengoa (Moreno, 2015) también propone que el ministerio debiera asumir su papel de centro de conocimiento y saber qué está pasando en innovación, en resultados, en mejoras de la organización, gestión y clínicas en toda España y distribuir esos conocimientos. A esto José Soto (Moreno, 2015) añade que el ministerio también debería:

- Realizar dotaciones presupuestarias para los distintos subsistemas que forman la salud, no solo el sistema sanitario (determinante de la salud)

- Tratar de implicar a los ciudadanos en la toma de decisiones

- Articular formas de reconocimiento social para los profesionales: premios, encuentros, programas obligatorios de tv sobre salud, etc. 


\section{Retos del futuro.}

Independientemente de la crisis, el SNS necesita, al igual que la mayoría de los sistemas de salud de nuestro entorno, una profunda revisión para dar respuesta a los nuevos retos del envejecimiento, la cronicidad, el incremento del gasto sanitario, las nuevas tecnologías, etcétera. La crisis ha acelerado y agudizado el proceso, y nos ha recordado la necesidad de una revisión profunda del sistema. (SIGNO, 2014)

Pese a los recortes, y según el Barómetro Sanitario que mide una vez al año lo que opinan los españoles con respecto a su sistema sanitario, el sistema nacional de salud sigue siendo uno de los componentes del estado del bienestar mejor valorado por la población.

Según Abellán (Moreno, 2015), para saber si se ha resentido la calidad asistencial habría que medir el producto final del sistema, es decir, los resultados en la salud de los ciudadanos, y no las camas por habitante, los medios o el personal. Sin embargo, apenas hay indicadores que permitan establecer causa y efecto y, si los hay, tardan en ser visibles. "Tengo serias dudas de que los recortes realmente hayan repercutido negativamente sobre los resultados en salud de forma generalizada", afirma.

Y cita a otro experto, Guillem López Casasnovas, que distingue entre sostenibilidad y solvencia del sistema. "La sostenibilidad se decide en sede parlamentaria. La solvencia es otra cosa y guarda relación con la capacidad adaptativa del sistema. Lo que ha demostrado es que pese a los ajustes y recortes, el sistema es solvente, ha sabido adaptarse", concluye.

Además de los retos financieros, el sistema tiene planteados retos relacionados con su propia misión. La medicina hoy es muy compleja, avanza muchísimo, es un sector, que si algo lo define es la complejidad, muchísimos diagnósticos, procesos, tratamientos, funcionando 24 horas, 365 días al año, con unos perfiles y unos conocimientos muy elevados y, por tanto, cualquier cambio a implementar es también muy complejo (Arratibel, 2014)

Rafael Bengoa en su web (2014), citado por Adolfo Moreno explica que en el futuro se tiende inevitablemente hacia un modelo asistencial más proactivo y más eficiente en el SNS por razones de calidad y de sostenibilidad. Además ya se sabe cómo avanzar y se trata de aplicar el modelo que sirve de respuesta a los enormes retos actuales del sistema. Según Bengoa se trata de estratificar la población, de integrar los servicios asistenciales, de empoderar a los pacientes, de comprar valor además de volumen, de conectar con la población y los pacientes tecnológicamente y de adecuar los recursos humanos del sector a esta realidad. La suma de estas intervenciones permitirá estar en contacto continuo con los pacientes para poder intervenir antes de que se descompensen y seguirles de forma efectiva después el alta hospitalaria.

La conclusión para Arratibel (2014) es que no hacer nada es ir a peor. Si no se hace nada y se continúa manteniendo el statu quo, por la magnitud de los retos existentes, es ir a peor. 


\subsection{El sistema sanitario público}

Históricamente se ha definido sanidad como el conjunto de servicios gubernativos ordenados para preservar la salud de los habitantes de una nación, provincia o municipio. El concepto de sistema sanitario incluye la sanidad a cargo de las administraciones públicas, la privada, del voluntariado y de los hogares.

En el libro blanco sobre el sistema sanitario español de la Academia Europea de Ciencias y Artes (Rubia et al, 2011) se cuenta la historia del sistema sanitario público español cuyo primer paso fue la aprobación de la ley de 14 de diciembre de 1942 que creó el Seguro Obligatorio de Enfermedad (SOE), y que estableció un régimen de «protección frente a las situaciones de enfermedad que puedan presentarse a los trabajadores asegurados y a los familiares a su cargo».

La asistencia sanitaria del SOE incluía únicamente atenciones hospitalarias quirúrgicas y obstétricas, pero no médicas. Tampoco cubría la asistencia psiquiátrica, siendo gratuita la farmacia. Posteriormente se incorporaría la asistencia médica.

EI SOE se basaba en el aseguramiento obligatorio y se financiaba mediante un régimen de cuotas que trabajadores y empleadores debían aportar a partes iguales en proporción al salario. Este Seguro Obligatorio daba cobertura a los trabajadores por cuenta ajena sin otros recursos mayores de 14 años. En 1953 su cobertura alcanzaba al 30\% de la población.

Este seguro creó una red asistencial propia con personal propio. Esta situación determinó el total descarte del sistema de reembolso de los gastos médicos, generalizado en otros países europeos, que aceptaban el ejercicio profesional libre de la medicina asumiendo el reintegro de los gastos de la asistencia prestada por los hospitales y los médicos privados. De esa primera opción organizativa derivan buena parte de las diferencias que existen entre el sistema sanitario español y otros sistemas europeos de base mutualista o aseguradora, como el francés por ejemplo.

En el ámbito hospitalario formaban la red asistencial del Seguro las Ilamadas Residencias Sanitarias. Por su parte, la red de ambulatorios y consultorios integraban consultas de medicina general, así como de especialidades médicas y quirúrgicas de facultativos pertenecientes a la plantilla del SOE retribuidos mediante «cupo».

La Ley de Bases de la Sanidad Nacional de 1944 consolidó la separación entre las atenciones sanitarias asistenciales y las preventivas o de salud pública. Así, la Administración Sanitaria del Estado quedó encargada en exclusiva de las funciones de higiene y de salud pública, de la información e investigación epidemiológica y también de las atenciones sanitarias contra las enfermedades infecto-contagiosas, y sus servicios siguieron un camino paralelo respecto a los del SOE, con los que conectaban escasamente, manteniendo similar relación de alejamiento respecto de los servicios de la Beneficencia Pública, radicados principalmente en el ámbito competencial provincial.

Los cambios económicos y sociales que se sucedieron entre 1958 y 1965 implicaron un rápido crecimiento de la población asegurada, lo que a su vez determinó modificaciones organizativas importantes en la estructura sanitaria del SOE. 
La Ley de 28 de diciembre de 1963, de Bases de la Seguridad Social (LSS), reformó substancialmente el sistema de seguridad social, y su posterior desarrollo configuró la asistencia sanitaria como prestación de la Seguridad Social ante las contingencias de enfermedad común, accidente no laboral, maternidad, accidente laboral y enfermedad profesional ofrecida a trabajadores por cuenta ajena delimitados restrictivamente por un determinado nivel de renta.

La mayor innovación sanitaria establecida en este momento fue el reconocimiento del derecho de los asegurados a la hospitalización médica, lo que provocó la transformación de las instalaciones de la Seguridad Social, que pasaron a ser hospitales generales en lugar de centros meramente quirúrgicos.

Además, en la red hospitalaria propia de la SS se produjo la jerarquización de los servicios médicos y quirúrgicos, con lo que quedó separada y diferenciada la asistencia prestada en estos centros respecto de la medicina y de la cirugía llamada «de cupo».

Más adelante, en 1972 se eliminaron los topes máximos salariales como requisito para acceder a las prestaciones sanitarias de la SS. A partir de su promulgación todos los trabajadores por cuenta ajena tuvieron acceso a la acción protectora de la Seguridad Social con independencia de sus niveles retributivos. Además, entre 1975 y 1978 se crearon los regímenes de protección social y sanitaria de los funcionarios del Estado (MUFACE, ISFAS y MUGEJU).

En 1970, la cobertura de la asistencia sanitaria de la Seguridad Social llegaba ya al $63,87 \%$ de la población y en 1978 al $81,76 \%$. Si a esas cifras se añaden las correspondientes a los regímenes de protección sanitaria de los funcionarios, los porcentajes se situaban aproximadamente en el $90 \%$ de la población española.

En paralelo a esa extensión de la cobertura sanitaria pública, se produjo una disminución del número de personas protegidas por la beneficencia provincial y municipal.

A lo largo de los años de la transición (1975-1982), se produjo la modernización del sistema sanitario español implantando un sistema de gestión sanitaria basado en el régimen laboral de los trabajadores y el sistema de organización de los hospitales de la Seguridad Social, así como en la progresiva implantación del sistema de formación MIR.

En este momento se creó el Instituto Nacional de la Salud (INSALUD) como entidad pública responsable de la gestión de la asistencia sanitaria de la Seguridad Social, cuya cobertura creció entonces hasta el $84,5 \%$ de la población en 1982, lo que, unido a la cobertura proporcionada por las mutuas de funcionarios llegaba ya a una cobertura asistencial sanitaria pública de más del $95 \%$ de la población española.

La Constitución Española de 1978 definió la protección de la salud como principio rector de la política social y económica del Estado Español, a quien se impuso el compromiso de proveer de atención sanitaria a los ciudadanos, sin discriminaciones. Los artículos 43 y 49 reconocen el derecho de todos los españoles a la protección de la salud.

En 1982 se puso en marcha un proceso de reformas legales, organizativas y funcionales orientadas a configurar el servicio público sanitario español conforme al mandato constitucional del art. 43 de la constitución. 
En primer lugar, se crearon equipos multidisciplinares de atención primaria como primer escalón sanitario dentro de un área geográfica determinada, aprobándose como complemento las normas autonómicas que establecieron las delimitaciones territoriales potenciando la integración entre niveles asistenciales y la prevención.

Por otro lado también se trató de integrar en los Hospitales de la Seguridad Social a los especialistas dependientes de ésta pero que eran remunerados conforme al sistema de «cupo» sin estar adscritos a los servicios hospitalarios.

En esta época se inicia también el proceso de descentralización sanitaria, mediante la transferencia de las competencias a Cataluña y al País Vasco. Entre 1982 y 1986 se produjo la generalización de la transferencia de las competencias de Salud Pública e Higiene al resto de las CC AA, mientras que sólo algunas de ellas asumieron la gestión de los servicios asistenciales de la Seguridad Social, en un proceso que estuvo definido por su carácter asimétrico.

En este periodo, las Comunidades del artículo 151 y asimiladas (País Vasco, Cataluña, Andalucía, Galicia, Comunidad Valenciana, Canarias y Navarra) se situaron sucesivamente en el techo competencial máximo permitido por la Constitución, quedando en sus manos todas las funciones sanitarias, tanto preventivas como asistenciales, salvo las relativas a la salud laboral y las correspondientes a la sanidad exterior y a la ordenación farmacéutica.

El resto de Comunidades recibieron en esta fase únicamente las competencias y servicios incluidos en el capítulo «Sanidad e Higiene» en su versión más estricta. Por ello, la gestión de la asistencia sanitaria en Aragón, Asturias, Cantabria, Castilla y León, Castilla-La Mancha, Murcia, Extremadura, La Rioja, Baleares y Madrid, así como en las ciudades Autónomas de Ceuta y Melilla (aproximadamente el $41 \%$ de la población española) quedó en manos de la Administración Central (Insalud) hasta comienzos del año 2002.

Todo esto propició una nueva zonificación sanitaria en toda España a través de la publicación de los mapas sanitarios autonómicos permitiendo descubrir las situaciones de dotación y de equipamiento existentes en cada territorio y que ponía de relieve las diferencias de dotación de medios asistenciales existente entre las distintas regiones de España, así como las diferencias en calidad de los mismos.

La transformación definitiva y el cambio a un modelo sanitario plenamente adaptado a lo dispuesto en la Constitución se produjo formalmente a partir de la promulgación de la Ley General de Sanidad, de 25 de abril de 1986, norma que define un antes y un después en el sistema de salud español.

La Ley estableció un sistema sanitario público de carácter universal, financiado mediante aportaciones fiscales, que proporciona cobertura gratuita a toda la población española en condiciones de igualdad. Se integran en un nuevo y único marco institucional medios y estructuras asistenciales diferentes y de variada procedencia, tales como Insalud, Aisna, Corporaciones locales (básicamente, Diputaciones Provinciales), así como fundaciones y entidades benéfico-asistenciales. Ese sistema se configuró a partir de la integración en los servicios de salud de las Comunidades Autónomas. 
Sin embargo, la ley no ha logrado la articulación de un sistema sanitario público unitario en todo el país, si no que se han desarrollado diferentes sistemas con algunas características diferentes.

\subsection{Consecuencias de la crisis en el sistema sanitario}

Podría decirse que la salud es el bien más preciado. Una buena salud exige la existencia de un sistema de salud de buena calidad, universal, integral, equitativo, eficaz, receptivo y accesible. Como ya se ha señalado anteriormente, la propia constitución española reconoce el derecho a la salud.

En España el sector sanitario público es uno de los principales sectores productivos de la economía y representa más de un $5 \%$ del PIB. Su peso sobre el presupuesto de las autonomías supone aproximadamente 4 veces más que el correspondiente a infraestructuras. (Beltrán, 2009). Por tanto era un campo propicio para los ajustes durante la crisis que comenzó en 2008, como se demostró con la elaboración del Real Decreto-ley 16/2012.

El gasto por habitante (tabla 2) en España en educación y sanidad se recortó el 20\% durante la crisis (Bolaños 2015). El esfuerzo público en políticas sociales bajó un 10\% de 2009 a 2013 (Bolaños 2015).

Tabla 2. Gasto social por habitante:

\begin{tabular}{|l|c|c|c|}
\hline & $\mathbf{2 0 0 9}$ & $\mathbf{2 0 1 3}$ & Diferencia \\
\hline País Vasco & 3545 & 3026 & $-14,64 \%$ \\
\hline La Rioja & 3034 & 2471 & $-18,55 \%$ \\
\hline España & 2902 & 2307 & $-20,50 \%$ \\
\hline
\end{tabular}

Fuente: Fundación BBVA-Ivie. Publicado en El País/economía 04/05/2015

En conjunto, algo más de las tres cuartas partes del ajuste del gasto entre 2009 y 2013 se llevó a cabo en el bienio 2012-2013, y casi una cuarta parte en el bienio anterior. El gasto se redujo especialmente en farmacia ambulatoria, remuneraciones de personal tanto por la vía de los salarios como por la reducción de efectivos en hospitales- y en inversiones. Sin embargo, muchas de las medidas adoptadas en estos años de crisis pueden caracterizarse más como simples recortes que como verdaderos ajustes y, por tanto, es muy posible que una vez agotado su impacto más inmediato se ponga de manifiesto su escasa efectividad para mejorar la eficiencia del Sistema Nacional de Salud. (Bandrés 2015).

El proceso de reducción del gasto público sanitario se desarrolla en dos bienios caracterizados por su diferente intensidad. En 2010/2011 la disminución del gasto apenas alcanza una media anual del $-1,4 \%$, mientras que en $2012 / 2013$ la media desciende hasta el -4,8\%. (Bandrés 2015).

En el bienio 2010/2011 los recortes se producen en remuneraciones de personal (-8\% entre los dos años), farmacia $(-8,0 \%)$ y gastos de capital $(-38,4 \%)$; en el bienio 
2012/2013 las partidas afectadas fueron las mismas, pero con una mayor intensidad en personal $(-8,4 \%)$, en farmacia $(-15,6 \%)$, y en gastos de capital $(-43,5 \%)$ (Bandrés 2015$)$.

Entre los profesionales vinculados al Sistema Nacional de Salud, en solo dos años, entre 2012 y 2014 se perdieron 28.500 puestos de trabajo en la sanidad pública (Sevillano, 2016). Las bajas se han concentrado en la asistencia hospitalaria y especializada, siendo menor el impacto en atención primaria. A su vez, los ajustes en hospitales se han volcado sobre el personal de enfermería, técnicos sanitarios y personal no sanitario, con efectos apenas perceptibles en el caso de los médicos. (Bandrés 2015).

La crisis se ha afrontado de manera muy heterogénea en las diferentes CCAA (González, 2016), aunque si es cierto que ha habido una disciplina presupuestaria generalizada (tabla 3) donde Hacienda controla y las CCAA difieren en el cumplimiento del déficit, por ejemplo Aragón redujo su gasto per cápita un 19\% entre 2009 y 2013, mientras que Cantabria lo hizo sólo en un $2 \%$.

Tabla 3. Gasto sanitario total, público y privado. Millones de euros. España, 2010-2014

\begin{tabular}{|l|c|c|c|c|c|c|}
\hline & 2009 & 2010 & 2011 & 2012 & 2013 & 2014 \\
\hline Gasto sanitario total & & 99.899 & 99.167 & 96.174 & 93.856 & 95.722 \\
\hline Gasto sanitario público & 75.460 & 74.987 & 73.238 & 69.522 & 66.522 & 66.826 \\
\hline Gasto sanitario privado & & 24.912 & 25.930 & 26.963 & 27.334 & 28.895 \\
\hline
\end{tabular}

Fuente: MSSSI Sistema de cuentas de salud 2015 (junio 2016) (Tomado de González. XXXIV congreso nacional de la sociedad de calidad asistencial. 2016)

No obstante, las políticas sanitarias tienen en España un efecto redistributivo, por ello los efectos de la crisis iniciada en 2007 no se han notado inmediatamente en el empeoramiento de los índices de morbilidad y mortalidad (Durán, 2016). No obstante, los años de crisis económica han hecho que el sostenimiento del sistema público de salud haya pasado a ser uno de los principales problemas de la sociedad española y que aún no se hayan calibrado suficientemente los efectos de los ajustes en la salud de los españoles.

La crisis económica ha tenido una especial repercusión en el sistema sanitario público disminuyendo su financiación (tablas 4 y 5 ).

Tabla 4. Gasto sanitario total. España, 2010-2014.

\begin{tabular}{|c|c|c|c|c|c|}
\hline & 2010 & 2011 & 2012 & 2013 & 2014 \\
\hline Sanidad Privada & 24.9 & 26,1 & 28 & 29.1 & 30,2 \\
\hline Sanidad Pública & 75.1 & 73.9 & 72 & 70,9 & 69,8 \\
\hline
\end{tabular}

Fuente: Tomado de González. XXXIV congreso nacional de la sociedad de calidad asistencial. 2016

Tabla 5. Sustitución de gasto público por privado.

\begin{tabular}{|c|c|c|}
\hline Cambio 2010-2014 & $\%$ & Millones de Euros \\
\hline Gasto Público & $-11.4 \%$ & -8.634 \\
\hline Gasto Privado & $+16 \%$ & +4.983 \\
\hline
\end{tabular}

Fuente: Tomado de González. XXXIV congreso nacional de la sociedad de calidad asistencial. 2016

La crisis económica "per se" ha tenido impacto sobre la salud de los españoles (ilustración 1), pero la gestión política de la misma puede llegar a influir en el impacto 
que estas tengan sobre la salud de la población, las desigualdades sociales en salud o en la percepción sobre el funcionamiento del sistema sanitario (Bacigalupe, 2016).

Ilustración 1. Conceptualización de los efectos de las crisis económicas sobre la salud.

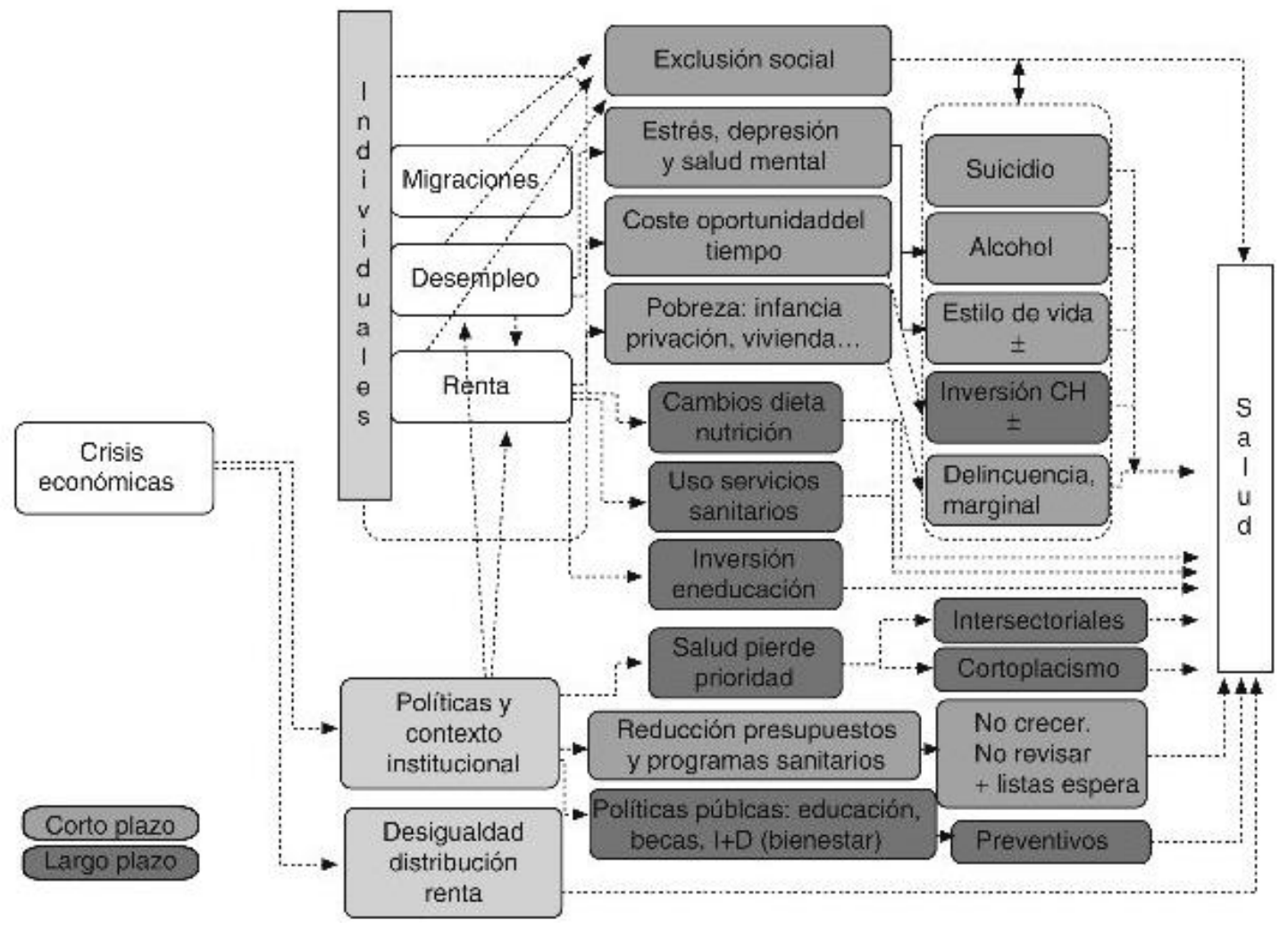

Para algunos autores, el sistema sanitario público no sólo ha sido un perjudicado por la crisis, sino que también se le puede considerar un agente activo, un agente patógeno. En los últimos 20 años, ha estado creciendo muy por encima de la economía, cuando el $\mathrm{PIB}$, la riqueza en nuestro país, crecía de forma sostenida al 3\%, los presupuestos sanitarios lo hacían a no menos del 10\% (Echaniz 2014). Cuando el sistema sanitario se podía financiar porque los crecimientos económicos eran importantes, la sanidad se expandía y no generaba problemas, en el momento que los ingresos han caído, además de expandirse el gasto, se genera un problema de déficit. (Echaniz 2014).

Según Echaniz (2014), el sistema sanitario está en crisis desde hace muchísimo tiempo. La crisis ha hecho que no haya más remedio que abordarlo, a lo mejor con demasiada premura, y tratar cuestiones que con más tiempo se podían haber hecho antes y mejor.

El sistema se encuentra en una encrucijada y según Beltrán (2009), el modelo actual no es sostenible a medio o largo plazo.

Existe controversia sobre los problemas del Sistema Nacional de Salud (SNS) y de la viabilidad del sostenimiento del mismo en nuestro país. Según la Federación de Asociaciones para la Defensa de la Sanidad Pública (2011) esta controversia está siendo animada fundamentalmente por intereses económicos, que pretenden la privatización del sistema sanitario. 
Además de que la situación financiera del sistema continua siendo muy complicada, la demanda de servicios sanitarios continua creciendo de forma muy importante, los recursos dedicados podrían llegar a no serán suficientes y generar un déficit insostenible. En España se producen anualmente más de cuatro millones de ingresos hospitalarios, con más de 30 millones de días de internamiento, una estancia meda de 6,6 días. Setenta y cinco de cada cien días de estancia hospitalaria lo son en hospitales públicos. (Durán, 2016)

La demanda de servicios sanitarios aumenta constantemente de forma considerablemente como consecuencia de:

- El envejecimiento de la población española supone que un número importante de ciudadanos tienen un coste sanitario entre 4 y 12 veces superior al del resto de la población.

- La cronificación de las enfermedades incrementa de forma importante los recursos destinados a estos pacientes, que suman más del $70 \%$ del total del gasto sanitario en la actualidad.

- Los nuevos tratamientos y tecnologías (avances en genética molecular, cirugías menos invasivas, medicina personalizada, etc.) fomentan una mayor demanda, al hacer posibles nuevas intervenciones y tratamientos.

La situación es complicada y puede llegar el momento en que los recursos sanitarios no serán suficientes si continuamos con el modelo actual.

Para González (2016), los problemas a los que se enfrenta la sostenibilidad del sistema sanitario tienen que ver con los costes salariales y el precio de los medicamentos (tabla 6)

Tabla 6. Gasto en medicamentos en 2015 en el SNS España (miles de millones euros)

\begin{tabular}{|l|c|c|}
\hline & Cantidad & Porcentaje \\
\hline Gasto en recetas médicas & 10.106 & $60.2 \%$ \\
\hline Gasto en medicamentos hospitalarios & 6.668 & $39.8 \%$ \\
\hline
\end{tabular}

Fuente: Informe Anual del Sistema Nacional de Salud 2015. Ministerio de Sanidad, Servicios Sociales e Igualdad

Un aumento de la responsabilización de todos los agentes es clave para revertir esta tendencia. Los datos indican que una de las claves para asegurar la sostenibilidad del sistema es aumentar la responsabilidad de pacientes, profesionales y gestores.

Los pacientes deben adquirir una mayor conciencia sobre su propia salud y sobre el uso que hacen del sistema, algunos ejemplos de esta situación son:

- En 2006 un español acudía al médico más de 8 veces al año, lo que supone un $40 \%$ más que el promedio del EU-15.18

- Más de 80 millones de visitas al año podrían evitarse o redireccionarse a canales más eficientes en coste. Así por ejemplo, 1 de cada 3 visitas al médico de familia podría ser innecesaria desde el punto de vista de la atención a la salud y entre un $30 \%$ y un $80 \%$ de las visitas de urgencia podrían no ser urgentes. 
- El gasto farmacéutico per cápita en España es un 40\% superior al de países similares. El $70 \%$ de las recetas se concentran en un $20 \%$ de la población que está exenta de pago (pensionistas).

- Los españoles suspenden en ser responsables de su propia salud.

- España es el segundo país de Europa en número de fumadores (1 de cada 4 españoles mayor de 15 años fuma)

- El número de personas con sobrepeso en los últimos años ha ido en aumento ( 1 de cada 2 españoles tiene sobrepeso).

Es necesario que los profesionales sean los catalizadores del cambio y ayuden a lograr un mayor equilibro entre los objetivos de calidad y eficiencia del sistema. No obstante los profesionales también tienen que modificar algunos aspectos:

- No siempre se observa un uso eficiente de los recursos por parte de los profesionales sanitarios. Existe gran variabilidad clínica, por ejemplo, las diferencias regionales en cuanto a pruebas diagnósticas es de hasta 3 veces para TAC, de hasta 5 para resonancias magnéticas y de más de 7 para mamografías.

- La variabilidad de resultados clínicos es una realidad tanto entre regiones como dentro de una misma región, como lo demuestran las tasas de mortalidad infantil, las cuales pueden variar hasta en un $80 \%$ entre CC.AA. Sin embargo, en muchos casos no es posible comparar el desempeño de los distintos servicios o profesionales, lo que dificulta establecer mecanismos que incentiven suficientemente a aquellos que mejor realizan su trabajo.

- La situación a lo largo de la vida profesional es muy desigual y somete a determinados grupos profesionales a condiciones de contratación muy precarias. Los médicos son el grupo profesional, científico y cualificado con porcentaje más elevado de trabajadores con contratos temporales $(10,5 \%$ frente al resto de sectores cuya distribución se encontraba entre el 0,3\%-3,3\%, en 2005).

- Más de la mitad de los médicos afirman no sentirse suficientemente valorados. Según una encuesta del Colegio Oficial de Médicos de Barcelona, el 53\% de los médicos se sienten mal valorados por quienes les emplean y el $58 \%$ por la sociedad.

Los gestores y administradores del sistema tienen que asegurar la utilización más eficiente y equitativa de los recursos públicos puestos a su disposición. Para muchas CC.AA. la sanidad pública es su mayor empresa tanto en número de trabajadores como en presupuesto de gasto y, como tal, debería incorporar las mejores prácticas probadas en otros sectores productivos y adaptarlas a las especificidades del sector sanitario (transparencia en los resultados, incentivos a los proveedores, uso de sistemas de información, técnicas de mejora de la productividad, etc.).

La productividad en los hospitales públicos, medida en actos quirúrgicos por médico, apenas ha mejorado desde 1995. A pesar de los avances en la tecnología, el crecimiento de la actividad se ha producido fundamentalmente gracias a aumentos en la plantilla. La variabilidad en la productividad es también muy elevada (hasta un $100 \%$ de diferencia entre regiones en el número de actos quirúrgicos por cama). 
El crecimiento del gasto en productos sanitarios y nuevos tratamientos no siempre se justifica por la mejora de salud real de la población. Por ello, es necesario analizar el coste-beneficio de las nuevas prestaciones y reforzar el rol de las agencias de evaluación creadas en nuestro país, para encontrar una solución óptima a este problema.

La sanidad pública tiene aún un amplio recorrido en cuanto a despliegue y aprovechamiento efectivo de tecnologías de la información (por ejemplo, la valoración de España en cuanto al uso de sistemas en las consultas y en la gestión de la información es un $40 \%$ inferior a la de países como Dinamarca, Finlandia, Suecia, Holanda y Reino Unido), sabiendo que mediante la tecnología y la adecuada gestión del cambio se consiguen grandes mejoras en la productividad (por ejemplo, $30 \%$ de reducción de visitas al hospital en Kaiser Permanente) y de calidad clínica (por ejemplo, $50 \%$ de reducción en reacciones a medicamentos en US Veterans Affairs).

Para algunos autores, la implicación del sector privado en la resolución de los retos de la sanidad pública no ha evolucionado en todo su potencial, y los gestores deberían impulsar nuevas formas de colaboración. En este sentido, en España y Europa existen algunos ejemplos de colaboración con el sector privado con resultados positivos para la gestión y para los pacientes. Los ejemplos engloban ámbitos muy diversos, desde una mayor coordinación en la provisión de servicios hasta el impulso activo de los seguros privados como vía de descarga del sistema sanitario público y como complemento al mismo (Beltrán, 2009).

Walter Sermeus (2012), director del Programa de Máster en Políticas Sanitarias de la Universidad Católica de Lovaina (Bélgica), añade que en el futuro podemos encontrarnos que cuando tengamos recursos económicos, probablemente no encontraremos trabajadores debido a los cambios demográficos. Esto conduce a una situación, probablemente realista, que deberíamos aceptar. En el futuro, contaremos aproximadamente con un $10-15 \%$ menos de presupuesto y de personal sanitario.

Según el premio Nobel William A. Haseltine (2016), el problema ya está aquí, pero está pasando lentamente. Según este autor el problema hay que solucionarlo desde la mejora de la organización, debe ser una cuestión de prioridad social y de asignación de recursos.

Pese a todos estos datos desalentadores, según la Federación de Asociaciones para la Defensa de la Sanidad Pública- FADESP (2011), resulta difícil de entender la preocupación en cuanto a sostenibilidad económica del Sistema Nacional de Salud, porque tiene unos gastos sanitarios modestos con buenos resultados, mejores en muchos casos que los de otros países con un gasto sanitario muy superior. Para González (2016) el sistema sanitario público español en estos años ha superado el Stress-Test que ha supuesto la crisis.

Tampoco para la ONU (2015) la solución al problema de sostenibilidad del sistema se limita al ámbito económico. Según este organismo, parte de la solución podría incluir un aumento de los recursos públicos y privados destinados a sanidad, pero también sería necesario asegurar un uso correcto de esos recursos por parte de todos los agentes. La oportunidad es considerable y es necesario identificar los puntos fuertes y las áreas de mejora de forma inmediata y comenzar a trabajar. 
Por tanto el problema parece estar también en otras esferas de la sostenibilidad. Para Bengoa (2016) los retos, expuestos en el XXXIV Congreso Nacional de Calidad Asistencial, a los que se enfrenta el sistema sanitario son, además de los económicos, demográficos, epidemiológicos, clínicos y de complejidad, fragmentación asistencial, adecuación a las expectativas ciudadanas y de seguridad clínica y calidad.

Según FADESP (2011) el Sistema Nacional de Salud tiene problemas de ineficiencia:

- Subfinanciación del sistema sanitario y falta de asignación finalista de los fondos.

- Gasto farmacéutico excesivo

- Sobreutilización tecnológica

- Gestión politizada

- Escasez de camas de media y largas estancia y de atención sociosanitaria

- Marginación de la Atención Primaria de Salud

- Privatización progresiva de la provisión sanitaria

- Falta de planificación e integración de las actuaciones del SNS

Todo ello en un ambiente de debate muy interesado en el que el sector privado, de carácter lucrativo, es crecientemente activo y reivindicativo y presiona para cambiar el modelo. Además dispone de experiencia ricas en gestión indirecta de la prestación sanitaria pública, aunque insuficientemente evaluadas (p.e. Hospitales públicos de gestión privada) (González, 2016),

Para DNV-GL (2014), entidad de certificación a nivel mundial, la asistencia sanitaria se enfrenta a problemas significativos, tales como el envejecimiento de la población, patrones de enfermedades emergentes, el cambio climático, aumento de costes, acceso desigual y un historial negativo de seguridad. Todo ello parece indicar que gestionar el sistema sanitario tal como se venía haciendo hasta ahora ya no es una opción.

A todo esto hay que añadir que las ciencias de la salud son muy complejas y existe un desarrollo importante de las técnicas de la imagen, nuevos medicamentos, genómica, medicina personalizada, biomarcadores, robotización, etc. La ciencia ha avanzado mucho y, probablemente, la gestión no lo ha hecho al mismo nivel (Arratibel 2014).

Como ya se ha citado, la gestión sanitaria ha de responder a una pluralidad de intereses que incluye a individuos, o grupos de individuos que se ven afectados o afectan al desarrollo de la actividad sanitaria, tanto pública como privada. (Lucena, 2010). A través del seguimiento y análisis de las relaciones que aparecen entre la organización y los distintos grupos sociales con los que interactúa, se pueden implementar estrategias que sean capaces de responder a las demandas de la sociedad en términos de sostenibilidad incluyendo el cumplimiento de los objetivos económicos (Lucena, 2010).

Las organizaciones sanitarias para ser sostenibles deben satisfacer no sólo las necesidades técnicas (eficacia, efectividad, adecuación, etc.) sino también otros aspectos relativos a la calidad percibida como seguridad, fiabilidad, capacidad de respuesta o empatía (Lucena, 2010). Es decir, la calidad se consigue no sólo diseñando, ejecutando y evaluando el proceso operativo asistencial (calidad intrínseca) sino también modificando la impresión que los usuarios tienen sobre la idoneidad de un servicio para satisfacer sus expectativas, es decir, la calidad percibida. En este sentido 
Donabedian (1984) considera que los pacientes contribuyen en gran medida a la definición de la calidad con sus valores y expectativas acerca del manejo del proceso interpersonal.

Los pacientes, individual y colectivamente, son los definidores primarios de qué significa calidad, así , Lucena (2010) propone emplear como un elemento de medida de la calidad asistencial, la visión del usuario con relación a tres componentes susceptibles de generar satisfacción en unos servicios accesibles: un componente interpersonal (amabilidad, comunicación, diferencias individuales, etc.), un componente del entorno y sus comodidades ( decoración, aspecto del personal, clima, etc. ) y un componente técnico (capacidad de respuesta, seguridad, etc.).

Por ello es necesario plantear toda organización sanitaria, como un conjunto de órganos y unidades prestatarias de servicios requeridos por los pacientes y la sociedad en su conjunto, que atienda la capacidad de elegir que tienen los ciudadanos y usuarios, y que sepa adaptarse a la evolución de sus exigencias de calidad en los servicios (Lucena, 2010). Esto implica, entre otras cosas, un movimiento desde el ámbito más especializado hacia un entorno más comunitario, más próximo al paciente, en el fondo significa cambiar el modelo de organización sanitaria que tenemos. Es decir, el mayor cambio que tenemos que acometer hoy en los sistemas sanitarios es evolucionarlos (Arratibel 2014).

Según indica Bengoa (2016) disponemos ya de un gran arsenal de gestión para encarar la sostenibilidad. Algunas de estas herramientas ya se está implementando, como por ejemplo, la historia clínica electrónica, la receta electrónica, la telemedicina, los telecuidados, la telemonitorización, la estratificación poblacional, los nuevos modelos de financiación, los cuidados integrados, la coordinación sociosanitaria, los nuevos roles profesionales (enfermería), el empoderamiento de pacientes (autogestión), el fortalecimiento del tercer sector, la transformación de los centros de agudos, las fórmulas para mayor participación de los profesionales y las nuevas formas de liderazgo distribuido/facilitador.

En línea con lo expuesto por Bengoa, Haseltine (2016) añade que en el futuro para hacer sostenible el sistema sanitario este deberá salir de los hospitales y llevar la salud a la comunidad y a la propia casa de los pacientes. La conexión con el médico será continua y el hospital será el recurso ante situaciones graves.

Sin embargo, la salud también depende de la participación de otros sectores y actores, y del diálogo con ellos, ya que sus actividades tienen un importante efecto sobre la salud. Se ha demostrado la eficacia de una colaboración coordinada e intersectorial en materia de medidas políticas. El planteamiento de la «Salud en todas las políticas», junto con la cooperación y las actividades intersectoriales, ofrece un enfoque prometedor para reforzar la rendición de cuentas de otros sectores en materia de salud, así como para promocionar la equidad sanitaria y una sociedad más integrada y productiva. Al tratarse de objetivos colectivos, la buena salud y el bienestar para todos deberían gozar de alta prioridad en el ámbito local, nacional, regional e internacional. (OMS, 2011). 
El conocimiento de las experiencias existentes y la generación de ideas innovadoras son las dos vías existentes para identificar cambios y tendencias, anticipando las transformaciones necesarias (Gutiérrez y Peñalver, 2009). Por lo que se refiere a la sostenibilidad, en los últimos años las ideas innovadoras han surgido en espacios de debate basados en modelos de aportación del conocimiento experto multidisciplinar y transversal, que integra el conocimiento médico y tecnológico, los proveedores de asistencia sanitaria, la industria y los clientes, (usuarios, pacientes y ciudadanos).

Durante estos años de crisis se han elaborado multitud de informes y de recomendaciones sobre la sostenibilidad del sistema sanitario público en España. Ya en 1990 la Comisión de Análisis y Evaluación del Sistema Nacional de Salud presidida por Fernando Abril Martorell elaboró un informe con 64 recomendaciones, que no llegaron a ser aplicadas en su totalidad, y que años más tarde parecen seguir vigentes, puesto que ya hablaba de la necesidad de alcanzar una mayor eficiencia en el uso de los recursos humanos y materiales dentro de un marco de autonomía responsable.

Desde el ámbito privado de la asesoría, PricewaterhouseCoopers (2006), y a partir de una serie de entrevistas realizadas a más de 50 directivos de instituciones sanitarias, apuntaba ya cómo comenzaba a percibirse la necesidad de trabajar en algunos ámbitos de mejora. Si bien este informe no estaba centrado en la sostenibilidad, si señala una serie de medidas que los directivos y responsables sanitarios deben adoptar para conseguir responder a las necesidades de los grupos de interés tales como fijar objetivos de calidad anuales y establecer prioridades, incorporar nuevas tecnologías y conocimientos e implicar al personal clínico y a los pacientes en la gestión

El libro blanco del sistema sanitario español (2011) coordinado por Francisco J. Rubia Vila es un análisis realizado dese el punto de vista corporativo, profesional y cercano a los colegios profesionales que añade, a lo señalado hasta ahora, la necesidad de garantizar la equidad y coordinación del Sistema Nacional de Salud, potenciar la gestión clínica y la autonomía de gestión y definir políticas de personal adecuadas a las necesidades de productividad social.

En 2010 el Consejo Económico y Social de España publicó un Informe (CES, 2010) con el análisis de la situación y entre sus conclusiones destacan las siguientes recomendaciones:

- La mejora de los sistemas de compras para influir en el sistema de fijación de precios de los insumos.

- La articulación y profundización en las medidas para el uso racional de los medicamentos.

- El desarrollo de sistemas de evaluación de tecnologías sanitarias para decidir su incorporación sobre la base de evidencia científica acerca de su eficacia.

- El impulso de las políticas de salud preventivas para garantizar estilos de vida saludables y prevenir enfermedades evitables.

- El refuerzo de los medios y la capacidad resolutiva de la atención primaria, y su conexión con los servicios sociosanitarios, particularmente los de atención a la dependencia. 
- El desarrollo de sistemas de información potentes que permitan evaluar el desempeño del sistema sanitario a la luz de los principios de eficacia, eficiencia y equidad.

Antares, una consultora especializada en salud en España, elaboró un informe sobre la sostenibilidad sanitaria (Gil, Barrubés, Álvarez y Portella, 2010) e incide en los siguientes aspectos:

1. Reforzar el papel de la evaluación de tecnologías sanitarias

2. Mejorar el rendimiento y la productividad de los profesionales

3. Incrementar el copago en medicamentos

4. Desarrollar el modelo de atención a pacientes crónicos

5. Desarrollar un espacio sociosanitario alternativo a la hospitalización de agudos:

6. Invertir decididamente en prevención y promoción de la salud

7. Generalizar los servicios compartidos entre proveedores, especialmente los de soporte clínico reduciendo los costes directos minimizando la duplicación de actividades y la burocracia y optimizando la gestión de recursos

8. Reordenar la medicina de tercer nivel y la oferta hospitalaria.

9. Impulsar decididamente las estrategias de seguridad del paciente.

10. Potenciar iniciativas que aceleren el retorno de la inversión de las TIC en salud.

Empresas Multinacionales como DNV-GL creen que el cambio es posible y propone un programa estratégico para llevarlo a cabo que contiene:

- Mejora de la seguridad mediante el uso de planteamientos basados en el riesgo, para rediseñar los servicios.

- Desarrollo de casos de seguridad para la gestión local de riesgos.

- Empoderar a los individuos para que tomen decisiones acerca de su atención sanitaria como socios activos.

- Organizar la atención en torno a las necesidades del individuo en lugar de en la enfermedad.

- Incentivar lo que importa, centrando los pagos en resultados y no en actividades.

- Integración de la atención entre las diferentes especialidades y proveedores.

- Invertir en tecnología, siempre y cuando ésta se apoye en enfoques de sistemas para la gestión del riesgo y el cambio.

- Invertir en adaptación al cambio climático.

- Mejora de la garantía de calidad y la previsión de riesgos con análisis de datos más inteligentes.

- Utilización de acreditación y normas para promover una atención centrada en la persona, reducir la variabilidad y mejorar la calidad.

- Creación de culturas y mentalidades comprometidas con la mejora continua de la calidad.

En un artículo publicado por la Sociedad Española de Directivos de la Salud (Arenas, 2012) se recomendaba que el SNS mantenga la financiación pública basada en impuestos y los principios de universalidad, igualdad y equidad.

Para el sindicato CCOO (Sánchez, 2013) solo integrando progresivamente la investigación e innovación, la formación de los profesionales, y la evaluación y aprobación de las tecnologías en el SNS se podrá conseguir un uso racional y 
transparente de los medicamentos y de las tecnologías médicas y recursos para fortalecer los hospitales y de forma especial la Atención Primaria, la promoción de la salud, la rehabilitación y la atención a la dependencia.

En línea con las propuestas anteriores la Federación de Asociaciones para la Defensa de la Sanidad Pública compuesta por ciudadanos, sindicatos y profesionales elaboró en 2011 un catálogo de 12 Propuestas para garantizar la sostenibilidad del SNS:

1. Mejora de la financiación sanitaria

2. Carácter finalista de la financiación

3. Mejorar la cohesión del SNS mediante el Plan Integrado de Salud

4. Rechazo al copago

5. Reducir el gasto farmacéutico

6. Disminuir la utilización tecnológica ineficiente y la variabilidad de la clínica

7. Incrementar el número de camas de media y larga estancia,

8. Potenciar la Atención Primaria de Salud.

9. Favorecer la integración de la Atención Primaria y la especializada

10. Despolitizar la gestión sanitaria

11. Revertir el proceso de privatización

12. Crear una agencia de compras del SNS

Para la Catedrática de Métodos Cuantitativos en Economía y Gestión de la Universidad de Las Palmas de Gran Canaria, Dra. Beatriz González López-Valcárcel (2016), las posibles soluciones para lograr la sostenibilidad del sistema pasan por:

- Mejorar la organización y potenciar el profesionalismo en todas las áreas de la gestión

- Integrar dispositivos. Crear organizaciones integradas de servicios que desarrollen estrategias de crónicos, hospitalización a domicilio, atención sociosanitaria

- Aprovechar las ventajas de la descentralización sanitaria. Existencia de multitud de diferentes experiencias

- Concentrar servicios. Volver a tener centros de referencia compartidos entre CCAA

- Potenciar el capital humano como el recurso más valioso del SNS

Los informes expuestos con anterioridad aportan la visión de diferentes grupos de interés (Pacientes, directivos, administración pública, trabajadores, expertos, empresa privada) sobre las medidas necesarias para que el sistema público de salud sea sostenible. Todos reconocen que es necesario el cambio para afrontar su sostenibilidad $y$, a pesar de la subjetividad que puedan aportar los intereses de los diferentes grupos de interés, se repiten una serie de propuestas que se exponen en el apartado 6.3 Recomendaciones prácticas.

Todos los cambios propuestos van en la línea de mejorar la eficiencia del sistema y hacerlo sostenible a medio y largo plazo; algunas ya se están realizando y otros aún quedan lejos debido a la inercia del sistema.

Si bien es cierto, como ya se ha indicado con anterioridad, que la política sanitaria difiere en función de las ideologías, parece que existe un consenso mínimo sobre algunos diagnósticos y medidas para lograr la sostenibilidad del sistema. 


\section{MARCO TEÓRICO}

El objetivo de este capítulo se concentra en contextualizar los aspectos teóricos que definen esta investigación. En primer lugar, se trata de profundizar en el tema de la sostenibilidad, con aportaciones sobre su definición, el cambio cultural que implica y los diferentes modelos y estudios relacionados con la sostenibilidad organizacional, y en concreto con la sostenibilidad del sistema sanitario público.

A continuación, se realiza una exposición breve de los modelos de gestión aplicados a la sostenibilidad y se presenta el modelo europeo de excelencia (EFQM), su aplicación y relación con la sostenibilidad en el ámbito sanitario.

Con este análisis se pretende concretar y contextualizar los diferentes conceptos utilizados en esta investigación y proporcionar una idea clara de cómo se encuentra la cuestión de la sostenibilidad y los sistemas de gestión en el ámbito sanitario.

Todo ello enmarcado en el debate sobre la sostenibilidad de la sanidad pública y el interés social que refleja el alto porcentaje de personas que considera como su principal preocupación el estado de la sanidad según indican los datos del Barómetro Sanitario (tabla7).

Tabla 7. Porcentaje de ciudadanos para quienes la sanidad es el área de mayor interés

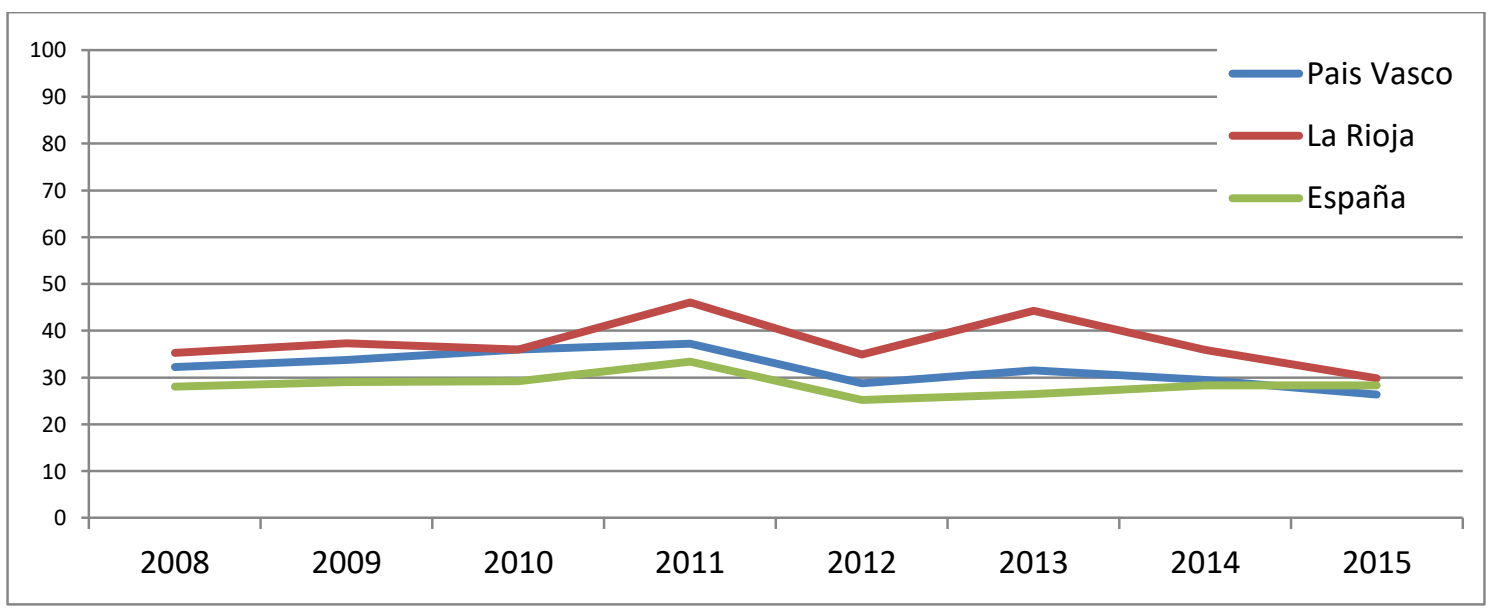

Fuente: Instituto de Información Sanitaria. Ministerio de Sanidad, Servicios Sociales e Igualdad. Barómetro sanitario 1995-2015 


\subsection{La sostenibilidad}

\subsubsection{El concepto de sostenibilidad}

La palabra sostenibilidad es un término muy utilizado en los últimos años en diferentes ámbitos y con matices diferentes. Conceptos relacionados con la sostenibilidad han ido apareciendo cada vez más reiteradamente en estudios académicos y científicos, en la agenda de los principales partidos políticos y en todas las propuestas normativas que tienen que ver con las políticas públicas, tanto cuando se trata de medioambiente como cuando se trata de economía, urbanismo, educación o sanidad. Este capítulo pretende explicar el concepto de "sostenibilidad" que se ha tomado como referencia en esta investigación.

El término sostenibilidad en sus orígenes está relacionado con la sostenibilidad ecológica, con el impacto del hombre en el medio ambiente y el impacto del consumo de recursos naturales, y sus repercusiones en la perdurabilidad de estos. Históricamente se comenzó a hablar de sostenibilidad en 1713 cuando un guardia forestal alemán puso como ejemplo el bosque: "si talamos un poco de madera de un bosque él solo se regenera y sigue produciendo más madera todos los años, pero si cortamos todos los árboles del bosque desaparece y nunca más volverá a producir madera". (Pedroza, 2013)

En 1987 la primera ministra de Noruega, Gro Harlem Brundtland, participó en la redacción de un informe para la ONU como consecuencia de la crisis mundial causada por el petróleo en la década de los 70 del siglo XX. En este informe se definía como sostenible "aquel desarrollo que satisface las necesidades del presente sin comprometer la capacidad de las generaciones futuras para satisfacer sus propias necesidades". Esta definición recoge lo que desde algunos años antes se venía tratando en la Comisión Mundial sobre el Medio Ambiente y el Desarrollo de la ONU que estimuló la filosofía del desarrollo sostenible. La sociedad ha de ser capaz de satisfacer sus necesidades en el presente sin comprometer la capacidad de las generaciones futuras para satisfacer las suyas.

El debate sobre medio ambiente y desarrollo, planteado intensamente durante las pasadas décadas (tabla 8), se viene centrando en los últimos años alrededor del concepto de "sostenibilidad" sobre el que se basa la doctrina del desarrollo sostenible. Las cuestiones básicas siguen centrándose, después de años de debate, en cómo los seres humanos deberían habitar este planeta teniendo en cuenta la existencia de unos límites (externos o ambientales, e internos o sociales) para satisfacer determinadas necesidades a lo largo del tiempo. La doble dimensión ambiental y social marca la necesidad de un nuevo estilo de desarrollo mundial. Aunque todavía seguimos siendo más conscientes del significado de la insostenibilidad de nuestros procesos de desarrollo, y modos de producción y consumo, que de lo que realmente queremos hacer sostenible, las respuestas estratégicas, en cualquier caso, se encuadran mayoritariamente en el nuevo marco conceptual de la sostenibilidad del desarrollo. Se trata de facilitar nuevos enfoques para redefinir las relaciones entre los sistemas humanos y ambientales con un sentido de globalidad, perdurabilidad y corresponsabilidad. (Jiménez, 2002). 
Tabla 8. Acontecimientos internacionales relacionados con la sostenibilidad.

\begin{tabular}{|c|c|c|c|}
\hline Acontecimientos & Año & Objetivos & Lugar \\
\hline $\begin{array}{l}\text { Conferencia Mundial sobre } \\
\text { Medio Ambiente (ONU) }\end{array}$ & 1972 & $\begin{array}{l}\text { Hito importante para los debates sobre el desarrollo y el } \\
\text { medio ambiente y el inicio de la búsqueda de pruebas de la } \\
\text { mitigación de los efectos del cambio climático }\end{array}$ & $\begin{array}{l}\text { Estocolmo. } \\
\text { Suecia }\end{array}$ \\
\hline $\begin{array}{l}\text { Programa de la ONU para el } \\
\text { medio ambiente (PNUMA) }\end{array}$ & 1972 & $\begin{array}{l}\text { Coordina las actividades relacionadas con el medio ambiente, } \\
\text { asistiendo a los países en la implementación de políticas } \\
\text { medioambientales adecuadas, así como fomentar el } \\
\text { desarrollo sostenible. }\end{array}$ & $\begin{array}{l}\text { Estocolmo. } \\
\text { Suecia }\end{array}$ \\
\hline $\begin{array}{l}\text { Directrices de la OCDE para } \\
\text { Empresas Multinacionales }\end{array}$ & 1976 & $\begin{array}{l}\text { Trata de garantizar que las actividades de empresas están en } \\
\text { armonía con las políticas gubernamentales, para fortalecer } \\
\text { las bases de la confianza mutua entre las empresas y las } \\
\text { sociedades. }\end{array}$ & Francia \\
\hline $\begin{array}{l}\text { Convenio de Viena para la } \\
\text { protección de la Capa de } \\
\text { Ozono }\end{array}$ & 1985 & $\begin{array}{l}\text { Protección de la salud humana y el medio ambiente contra } \\
\text { los efectos adversos resultantes de las modificaciones en la } \\
\text { capa de ozono }\end{array}$ & $\begin{array}{l}\text { Viena, } \\
\text { Austria }\end{array}$ \\
\hline Informe Brundtland (ONU) & 1987 & $\begin{array}{l}\text { Utilizó por primera vez el término sostenible: satisfacer las } \\
\text { necesidades del presente sin comprometer las necesidades } \\
\text { de las futuras generaciones. }\end{array}$ & $\begin{array}{l}\text { Ginebra, } \\
\text { Suiza }\end{array}$ \\
\hline Protocolo de Montreal (ONU) & 1987 & $\begin{array}{l}\text { Trata el tema relativo a las sustancias que agotan la capa de } \\
\text { ozono con el objeto de detenerla }\end{array}$ & $\begin{array}{l}\text { Montreal., } \\
\text { Canadá }\end{array}$ \\
\hline $\begin{array}{l}\text { Conferencia de Naciones } \\
\text { Unidas sobre Medio Ambiente } \\
\text { y Desarrollo }\end{array}$ & 1992 & $\begin{array}{l}\text { Trata de promover y recomendar políticas para un desarrollo } \\
\text { sostenible. Se aprobaron acuerdos como la Declaración de } \\
\text { Río sobre Medio Ambiente y Desarrollo, }\end{array}$ & $\begin{array}{c}\text { Río de } \\
\text { Janeiro, } \\
\text { Brasil }\end{array}$ \\
\hline Protocolo de Kyoto (ONU) & 1997 & $\begin{array}{l}\text { Compromisos de limitación y reducción de las emisiones de } \\
\mathrm{CO}_{2} \text { en la atmósfera. }\end{array}$ & Kyoto, Japón \\
\hline Pacto Mundial (ONU) & 1999 & $\begin{array}{l}\text { Propugna la implantación de diez principios básicos de } \\
\text { conducta y acción en materia de derechos humanos, trabajo, } \\
\text { medio ambiente y lucha contra la corrupción }\end{array}$ & Davos, Suiza \\
\hline $\begin{array}{l}\text { Declaración del Milenio de las } \\
\text { Naciones Unidas(ONU) }\end{array}$ & 2000 & $\begin{array}{l}\text { Trata el desarrollo sostenible, y considera el respeto a la } \\
\text { naturaleza y la responsabilidad común como valores } \\
\text { esenciales para las relaciones internacionales del siglo XXI }\end{array}$ & $\begin{array}{l}\text { Nueva York, } \\
\text { EEUU }\end{array}$ \\
\hline $\begin{array}{l}\text { Creación del Libro Verde } \\
\text { (CEE) }\end{array}$ & 2001 & $\begin{array}{l}\text { Fomenta un marco europeo para la responsabilidad social de } \\
\text { la empresa }\end{array}$ & $\begin{array}{c}\text { Bruselas, } \\
\text { Bélgica }\end{array}$ \\
\hline $\begin{array}{l}\text { Cumbre Mundial sobre } \\
\text { Desarrollo Sostenible (ONU) }\end{array}$ & 2002 & $\begin{array}{l}\text { Trata al multilateralismo como una estrategia clave en el } \\
\text { cumplimiento y la aplicación de los principios de Desarrollo } \\
\text { Sostenible }\end{array}$ & $\begin{array}{l}\text { Johannesbur } \\
\text { go, Sudáfrica }\end{array}$ \\
\hline $\begin{array}{l}\text { Stern Review Report on the } \\
\text { Economics of Climate Change }\end{array}$ & 2006 & $\begin{array}{l}\text { Informe relativo al impacto de la economía y los cambios } \\
\text { climáticos }\end{array}$ & Reino Unido \\
\hline $\begin{array}{l}4^{\circ} \text { Informe de Evaluación del } \\
\text { Panel Intergubernamental del } \\
\text { Cambio Climático }\end{array}$ & 2007 & $\begin{array}{l}\text { Informe que constata que la tierra está en un proceso de } \\
\text { calentamiento global por causas antropogénicas y } \\
\text { proporciona información científica, técnica y socioeconómica } \\
\text { pertinente para la comprensión del cambio climático }\end{array}$ & $\begin{array}{l}\text { Bangkok, } \\
\text { Tailandia }\end{array}$ \\
\hline Cumbre del G20 & 2009 & $\begin{array}{l}\text { Reforma del sistema financiero global para hacer frente a la } \\
\text { crisis económica }\end{array}$ & Londres \\
\hline $\begin{array}{l}\text { Objetivos de Desarrollo } \\
\text { Sostenible(ONU) }\end{array}$ & 2015 & $\begin{array}{l}\text { Objetivos Mundiales para } 15 \text { años. "Erradicar la pobreza. } \\
\text { Combatir la desigualdad y la injusticia. Solucionar el cambio } \\
\text { climático. En todos los países y para todas las personas" }\end{array}$ & \\
\hline $\begin{array}{l}\text { XXI Conferencia sobre } \\
\text { Cambio Climático (COP 21) }\end{array}$ & 2015 & $\begin{array}{l}\text { Establece medidas para la reducción de las emisiones de } \\
\text { Gases de Efecto Invernadero (GEI) a través de la mitigación, } \\
\text { adaptación y resilencia de los ecosistemas a efectos del } \\
\text { Calentamiento Global }\end{array}$ & $\begin{array}{l}\text { París, } \\
\text { Francia }\end{array}$ \\
\hline $\begin{array}{l}\text { Conferencia Partes de la } \\
\text { Convención Marco de la ONU } \\
\text { Cambio Climático(COP 22) }\end{array}$ & 2016 & $\begin{array}{l}\text { Recoge la voluntad de todos los asistentes en torno a las } \\
\text { acciones que implementarán antes de } 2020 \text { y cómo se } \\
\text { responderán las necesidades de los países más vulnerables. }\end{array}$ & $\begin{array}{l}\text { Marrakech, } \\
\text { Marruecos }\end{array}$ \\
\hline
\end{tabular}

Elaboración propia. Datos: http://www.un.org/

La sostenibilidad no debe ser vista solo desde una perspectiva medioambiental sino integral, es decir como una responsabilidad social donde la organización exista como contribuyente al bienestar económico y social. La sostenibilidad se ha entendido, no como una meta a alcanzar o como una moda, sino como procesos de cambio que 
pueden ser conducidos por ciertos principios, pero que tienen que ser construidos localmente con base en procesos de reflexión crítica y de acuerdo con los diferentes contextos (Huckle y Sterling, 1996; UNESCO, 2002).

El concepto de sostenibilidad representa un enfoque específico de hacer las cosas. Al desarrollar sus actividades las organizaciones promueven la inclusión social, optimizan la utilización de recursos naturales y reducen el impacto sobre el medio ambiente sin despreciar la viabilidad económica y financiera de la propia organización. Este enfoque junto con las mejores prácticas, crea valor para las personas y grupos con intereses en la organización y proporciona una mayor posibilidad de continuidad de la organización a largo plazo, mientras que al mismo tiempo contribuye al desarrollo sostenible para el conjunto de la sociedad. (Barcellos, 2011).

La sostenibilidad es un concepto relacionado con la capacidad de un sistema para seguir funcionando de forma permanente en todas sus dimensiones (Jiménez, 2002).

Pero la sociedad y los diferentes sistemas que la forman tienen dinámicas internas que provocan cambios a la vez que están sujetos a otras variaciones externas. Por lo tanto, más que un estado de «armonía fijo», como se afirmaba ya inicialmente en el Informe Brundtland (1987), o de un "equilibrio estático», se trata de mantener la capacidad de los sistemas sociales y naturales para hacer frente a las fluctuaciones y adaptarse a los cambios.

El concepto de sostenibilidad está más ligado a la idea de cambio que a la noción de estabilidad, comúnmente asociada a la de sostener un sistema de forma permanente. Es, sobre todo, un concepto dinámico y evolutivo, que no es consecuente con la idea de perpetuar una situación (statu quo), o de alcanzar un estado futuro estable sobre la base de un equilibrio estático, o un estado estacionario, según el pensamiento económico clásico. Más aún, el cambio y la adaptación pueden considerarse como propiedades constitutivas de la sostenibilidad, tal como lo es en los propios sistemas sometidos a dinámicas evolutivas. En los sistemas naturales y sociales en interacción, su sostenibilidad se entiende mejor como la capacidad de adaptarse a los cambios a través de equilibrios dinámicos para sobreponerse a las fluctuaciones, de acuerdo con sus propiedades de auto-organización y auto-regulación. Por lo tanto, la sostenibilidad se relaciona claramente con la habilidad de los sistemas (ecológico, económico o social), para seguir funcionando sin disminuir o agotar irreversiblemente los recursos claves disponibles (Jiménez, 2002).

Para lograr la sostenibilidad no sólo es imprescindible el mantenimiento de las capacidades de los ecosistemas, sino que es prioritario fomentar la habilidad de los sistemas humanos para crear dispositivos de sustentación sociales, económicos e institucionales que sean capaces de potenciar su resilencia auto-organizativa y su funcionamiento adaptativo.(Jiménez, 2002). El concepto de resilencia (Holling, 1973), como capacidad de recuperación y auto-organización de los sistemas cuando han sido sometidos a esfuerzos, se presenta como un elemento clave de la sostenibilidad.

Además es necesario tener en cuenta que las relaciones entre los sistemas se hacen más complejas y menos previsibles cuando se producen en periodos inestables como 
en el que nos encontramos (Jiménez, 2002). Ello nos lleva a considerar necesaria una nueva visión orientada por enfoques preventivos y adaptativos, que permitan administrar más racionalmente los sistemas complejos en transformación. Y ello es más pertinente cuando, como ahora se vislumbra, las incertidumbres son permanentes y el criterio de precaución se convierte en un principio básico de actuación, simplemente debido a la insuficiente capacidad y conocimiento humano ante el complejo y cambiante mundo real. (Jiménez, 2002)

Por otra parte, se plantea el aspecto de la escala de tiempo propio de los sistemas, según su longevidad. Cuando se dice que el sistema ha adquirido determinado nivel de sostenibilidad no puede concluirse que con ello se ha logrado garantizar una duración infinita, sino más bien una duración consistente con su escala de tiempo y espacio vital. Por lo tanto, un sistema se considera sostenible en un determinado contexto cuando alcanza su máxima duración de vida esperada o persiste en etapas de comportamiento superiores a su longevidad o tiempo de existencia esperado (Constanza et al., 1998).

Como la permanencia infinita no es posible, la cuestión es saber diferenciar los cambios que se deben a los límites normales y los cambios que quiebran la duración de vida del sistema. La aplicación estratégica del concepto de la sostenibilidad debería circunscribirse a una escala temporal, acorde con la variabilidad y capacidad de reajuste de los sistemas relacionados, y no en condiciones de procesos abruptos, irreversibles 0 colapsos. (Jiménez, 2002)

El hecho de hacer las cosas socialmente o medioambientalmente bien acaba dando más beneficio (Borrás, 2016). Para Elkington (1994) el desarrollo sostenible de una organización es aquel que contribuye a la gestión responsable mediante la entrega al mismo tiempo de beneficios económico, social y medioambiental. Las empresas que están más comprometidas con la sostenibilidad crecen más del $4 \%$ cada año a nivel global y las que no perciben un incremento inferior al $1 \%$.

Esa fue una de las principales conclusiones del más reciente informe de sostenibilidad de la consultora Nielsen (2015), en el que se expone por qué las empresas de todo el mundo están trabajando para incorporar a su política organizativa la sostenibilidad como un elemento clave. En ese mismo informe se añade que las grandes corporaciones deberían fortalecer su compromiso social en los países en los que operan para dar respuesta a sus clientes puesto que los consumidores están tratando de ser ciudadanos responsables con el mundo, y esperan que sus esfuerzos también lo estén realizando las empresas. Las marcas de consumo que no han abrazado la sostenibilidad están en riesgo de perder su reputación y esto produciría una reducción notable de la competitividad. Las empresas con reputaciones sólidas logran superar a las demás al momento de "atraer a los mejores talentos, inversores, socios de la comunidad y a todos los consumidores"(Nielsen, 2015).

El informe muestra que la confianza en la marca es el factor de mayor relevancia para los consumidores a la hora de adquirir cierto producto $(62 \%$ de las personas a nivel global). También es importante para los consumidores conocer si el producto tiene beneficios para la salud (el $59 \%$ de ellos coincidió en que este este es uno de los factores más importantes), si la marca es amigable con el medio ambiente (45\%) y comprometida 
en el campo social (43\%). Incluso, hay quienes tienen en cuenta que las compañías hayan realizado acciones concretas por su comunidad (41\%) y que las expongan a través de los medio de comunicación tradicionales (34\%). (Nielsen, 2015)

Uno de los retos más importantes que conlleva el desarrollo sostenible es que exige alternativas innovadoras y nuevas formas de pensar. Si bien los avances en conocimientos y tecnologías contribuyen al desarrollo económico, también tienen el potencial de ayudar a resolver los riesgos y amenazas de la sostenibilidad de nuestras relaciones sociales, del medio ambiente y de las economías. Los nuevos conocimientos y las innovaciones en materia de tecnología, gestión y políticas públicas brindan a las organizaciones la oportunidad de elegir nuevas alternativas sobre el modo en el que sus operaciones, productos, servicios y demás actividades influyen en el planeta, en la población y en las economías.

Los países desarrollados que pretenden orientar sus políticas (sean económicas, sociales o ambientales) hacia la sostenibilidad, saben que solo se podrá alcanzar trabajando eficazmente los procesos de participación pública. La participación pública se convierte en el camino a seguir para alcanzar ese preciado grial. Es por eso que el objetivo principal de desarrollo sostenible debe ser reformulado y reorientado hacia conseguir el compromiso de la Administración en el proceso de tener una población bien informada, participativa y comprometida con los objetivos de desarrollo y de calidad de vida que se definan (Sosa, 2003).

La clarificación del objetivo de la sostenibilidad es condición necesaria, pero no suficiente, para su efectiva puesta en práctica (Naredo, 1997). Para conseguir estos fines debemos entender que el proceso debe convertirse en un proceso de aprendizaje interactivo entre las autoridades que generen y gestionen los programas de desarrollo y sostenibilidad y los agentes sociales (Serrano, 1998), que actúen en el ámbito territorial y administrativo sobre el que se vaya a aplicar las propuestas de mejora (asociaciones de vecinos y afectados, ONG, institutos, universidades, sindicatos, partidos políticos y diversas asociaciones e Instituciones ...). Y que desde la Administración se pongan en práctica todos aquellos métodos que existen para conseguir ese dinamismo social participativo que requiere el objetivo de la sostenibilidad.

Se debe pasar siempre por un proceso de reflexión en el que intervengan agentes sociales, públicos y privados, junto con la Administración, con el fin de que los procesos de creación, imaginación y surgimiento de propuestas de actuación impliquen al medio social inmediato. La ampliación de la participación ciudadana en todo el proceso de alcanzar la sostenibilidad, se convierte en un reclamo necesario para llevar a buen fin sus objetivos (Sosa, 2003).

La transparencia acerca de la sostenibilidad de las actividades de las organizaciones tiene un interés prioritario para una amplia gama de grupos de interés entre los que se incluyen organizaciones empresariales, de trabajadores, ONG, inversores y auditores, entre otros. Por un lado, la urgencia y magnitud de los riesgos y amenazas existentes sobre nuestra sostenibilidad colectiva, y por otro lado el incremento de la gama de alternativas y oportunidades, harán que la transparencia del impacto económico, ambiental y social sea un componente fundamental en toda interacción con los grupos 
de interés de las organizaciones informantes, en las decisiones de inversión y en la relación con los mercados.

Para atender estas expectativas e informar sobre la sostenibilidad de una forma clara y abierta, se necesita un marco de trabajo común a nivel mundial, con un lenguaje uniforme y parámetros comunes que sirvan para comunicar de una forma clara y transparente las cuestiones relacionadas con la sostenibilidad. Este enfoque participativo en el que concurren múltiples agentes y grupos de interés ha dotado al marco de elaboración de memorias de sostenibilidad de una amplia credibilidad entre los distintos grupos de interés (WCED, 1987).

Todo ello se enmarca dentro de lo que se ha llamado Responsabilidad Social Corporativa (RSC). El Libro Verde sobre RSC de la Comunidad Europea (CEE, 2001) señala que la responsabilidad corporativa puede ser definida como la integración voluntaria, por parte de las organizaciones, de las preocupaciones sociales y medioambientales en su actividad y la relación con sus interlocutores.

La actual perspectiva integradora enfatiza tanto los vínculos entre las tres dimensiones básicas, como sus complementariedades, pero no puede olvidar sus intereses contrapuestos. Estas dimensiones presentan relaciones complejas con sinergias y compensaciones difíciles de establecer anticipadamente para alcanzar objetivos múltiples. Incluso, tomadas de dos en dos, las interacciones claves entre los sistemas, o las dimensiones básicas de la sostenibilidad, son suficientemente percibidas pero no son fácilmente cuantificables. En última instancia, si la sostenibilidad tiene que contemplarse de forma integral, la separación entre sostenibilidades parciales (económica, ecológica y social) puede distorsionar la consecución de los objetivos generales, ya que todas y cada una de ellas dependen sistemáticamente de las demás. Esto remarca el carácter interactivo de la sostenibilidad (Jiménez, 2002).

El carácter integral de la sostenibilidad se hace más evidente cuando se toma como referencia el conjunto de relaciones de los sistemas ambientales y humanos. La visualización del desarrollo sostenible parte, así, de una perspectiva integradora, y refuerza un enfoque sistémico para operar con un conjunto de relaciones entre sistemas (naturales y socioeconómicos), dinámica de procesos (energía, materia e información) y escalas de valores (ideas, ética, cultura).

Se pueden identificar varias dimensiones fundamentales de la sostenibilidad en términos de relaciones de sistemas básicos (ecológicos, económicos, sociales), con una cuarta dimensión ética envolvente (sistema de valores) (Jiménez, 2002).

Al mismo tiempo, los sistemas, aunque tienen relaciones entrelazadas, responden a lógicas distintas, priorizaciones diferentes y caminos y velocidades de evolución particulares (Köhn, 2001). A la hora de hacer más comprensible las políticas de desarrollo sostenible sería necesario entender estas peculiaridades de los sistemas humanos y ambientales y, sobre todo, la interrelación de sus procesos para tratar de alcanzar una coevolución mutuamente beneficiosa en el sentido expresado por Noorgard (1988). 


\subsubsection{Teorías de la sostenibilidad}

Como ya se ha indicado, la sostenibilidad y el desarrollo sostenible, conceptual y estratégicamente, se entienden mejor como procesos de cambio, adaptación, autoorganización y equilibrios permanentes para ajustar las relaciones de los sistemas ecológicos, económicos y sociales dentro de un sistema global y único. En la evolución conjunta de estos sistemas intervienen aspectos de jerarquía, incertidumbre e ignorancia que se entremezclan con otras consideraciones éticas, pero todos ellos son inherentes a la propia sustancia de la sostenibilidad (Jiménez, 2002).

La sostenibilidad es la garantía de supervivencia de cualquier organización y su abordaje se ha de realizar de forma holística, aunque para su estudio se pueda enfocar desde diferentes puntos de vista. En los últimos años se ha dedicado un número creciente de estudios científicos sobre el tema de la sostenibilidad y se han desarrollado diferentes conceptos y teorías.

1. Triple cuenta de resultados

2. Teoría de los grupos de interés

3. Rueda del cambio

\subsubsection{Triple cuenta de resultados (Triple Bottom Line)}

Se trata de un término usado por primera vez por John Elkington (1994) y que afirma que las organizaciones sólo pueden sobrevivir a medio-largo plazo si resultan económicamente viables, medioambientalmente sostenibles y socialmente responsables. El principio que se esconde detrás no es otro que lo que se mide es lo que se obtiene, debido a que lo medible es aquello a lo que se le presta atención. Por tanto, sólo cuando las organizaciones midan su impacto social y medioambiental se podrá decir que son organizaciones responsables.

El problema que surge con la Triple Cuenta de Resultados es que las tres cuentas presentadas en paralelo no se pueden agregar de manera sencilla. Es difícil medir las vertientes ambientales y sociales de la misma manera que la económica, que se mide en términos de cantidades de dinero. Resulta difícil de medir en términos monetarios el coste de un desastre ecológico por contaminar las aguas con residuos sanitarios o al negar la asistencia sanitaria a los inmigrantes sin papeles.

El objetivo del desarrollo sostenible es definir estrategias viables teniendo en cuenta los aspectos económico, social y ambiental (llustración 2) de las actividades humanas; "tres pilares" que deben tenerse en cuenta por parte de organizaciones.

1. Sostenibilidad ambiental: compatibilidad entre la actividad desarrollada y la preservación de la biodiversidad y de los ecosistemas.

2. Sostenibilidad económica: la actividad es financieramente posible y perdurable en el tiempo.

3. Sostenibilidad social: mantenimiento de la cohesión social y de la habilidad para trabajar en conseguir objetivos comunes. 
En el libro Triple Bottom Line, Andrew Savitz (2013) define una organización sostenible como "aquella que simultáneamente genera beneficios para sus accionistas, protege el medio ambiente y mejora la vida de todos aquellos con los que interactúa".

Ilustración 2. Las tres dimensiones de la sostenibilidad

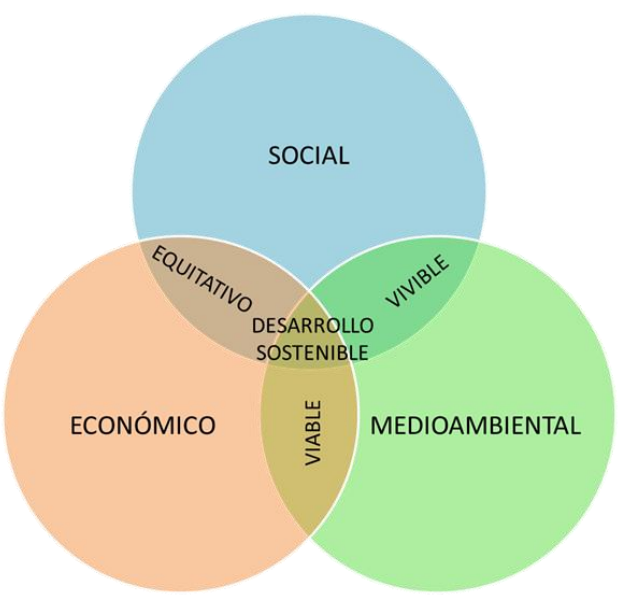

Fuente: Elaboración propia

\section{Sostenibilidad Ambiental}

La sostenibilidad ambiental es el equilibrio que se genera a través de la relación armónica entre la sociedad y la naturaleza que lo rodea y de la cual es parte. Esta implica lograr resultados de desarrollo sin amenazar las fuentes de nuestros recursos naturales y sin comprometer los de las futuras generaciones. En ese sentido, es importante considerar que el aspecto ambiental, más allá de tratarse de un área concreta del desarrollo humano, podría ser considerado el eje de cualquier forma de desarrollo.

La tierra dispone de una cantidad limitada de recursos y su uso o mal uso condicionan el futuro de las futuras generaciones. Las organizaciones sanitarias además, trabajan por la salud de las personas por lo que están además de su compromiso social deben pensar en la propia misión de su trabajo. Aunque los recursos no renovables son finitos y existe una preocupación lógica por la posibilidad de no disponer de cantidades suficientes para mantener el crecimiento económico y el desarrollo social en el futuro, la información manejada por la UE indica que el principal problema no es éste, sino aquél que se deriva del impacto de su utilización. (Cinco Días, 2005).

Asumiendo que existieran recursos suficientes para un periodo de tiempo considerable, lo que no está garantizado es la accesibilidad a los mismos, por razones geopolíticas. En el caso de la UE, éste es un factor estratégico, ya que en los próximos 20-30 años más del $70 \%$ de sus necesidades energéticas deberán cubrirse con productos importados.

En cuanto a recursos renovables, existe actualmente un amplio consenso en que el consumo actual sobrepasa su capacidad de regeneración. Esto es especialmente grave en el caso de los recursos pesqueros y del agua dulce, que en estos días se está manifestando como un problema de primera magnitud en nuestro país, pero que es un problema permanente en África. 
A escala mundial, sin embargo, el crecimiento de la economía es superior al aumento de la productividad de los recursos, lo que significará con toda seguridad un incremento de los impactos sobre el medio ambiente, especialmente en lo que se refiere a la emisión de gases de efecto invernadero, generación de residuos, ocupación de suelo, consumo de energía y reducción de los recursos pesqueros.

El impacto ambiental derivado de la utilización de los recursos figura entre los factores de riesgo para la salud humana que señala la Organización Mundial de la Salud. Así, entre los 25 factores de riesgo que causan las enfermedades figuran el aire ambiente, el aire en espacios cerrados, el plomo, el agua y el cambio climático, directamente ligados al empleo de los recursos. El uso sostenible de los recursos es una necesidad que debe abordarse como un reto a largo plazo para todas las organizaciones. El impacto de las organizaciones en su entorno condiciona la salud de la sociedad en la que están inmersos.

Los ámbitos de actuación que representan un mayor potencial para conseguir utilizar los recursos disponibles de una forma sostenible son según el diario Cinco Días (2005): - El uso de tecnologías más limpias y eficaces capaces que consuman menos recursos y generen menos residuos.

- El cambio de las pautas de consumo para reducir el empleo de algunos recursos.

- La mejora e innovación en los productos y servicios, para preservar los recursos y reducir el impacto.

- La gestión racional de los residuos evitando su eliminación descontrolada favoreciendo las opciones de valorización.

- La integración de los aspectos ambientales en las políticas económicas y sociales para tener una visión global del desarrollo sostenible.

- Mayor concienciación ciudadana, promovida desde las administraciones públicas, para cambiar hábitos actuales de consumo, y desarrollar individuos más responsables y exigentes en asuntos ambientales.

Las organizaciones deben tener una cultura de respeto al medio ambiente. Deben cumplir normas o buenas prácticas ambientales como parte de programas de responsabilidad social que incluyan, además de a la comunidad y los trabajadores, al medio ambiente. Para ello, pueden promover, por ejemplo, prácticas económicas ecoeficientes.

Los cambios que se están produciendo con respecto a la sensibilidad medioambiental obligan a las organizaciones a adoptar un nuevo enfoque respecto a este problema. Como señala Fernando Martínez Salcedo, Secretario General de Sostenibilidad de Abengoa (2009) "cada vez más inversores apuestan por empresas que pertenecen a índices de sostenibilidad, el riesgo reputacional asociado al incumplimiento de la legislación medioambiental es también creciente, así como las sanciones asociadas, y normas como la ISO 14064 no van a tardar en convertirse en un requisito imprescindible para estar en el mercado, como ya sucedió con las ISO 9000 e ISO 14000. En definitiva, todas las señales apuntan a una creciente presión de la que va a ser difícil escapar". 
Como consecuencia, si bien es cierto que alinear la estrategia de la organización y la sostenibilidad hoy puede parecer una ventaja, en breve va a convertirse en un requerimiento o una necesidad, de manera que aquellas organizaciones que no adopten un enfoque proactivo con respecto al medio ambiente, simplemente van a ser penalizadas por sus grupos de interés.

\section{Sostenibilidad económica}

Se refiere a la capacidad de generar riqueza en forma de cantidades adecuadas, equitativas en distintos ámbitos sociales, que sea una población capaz y solvente de sus problemas económicos tanto como fortalecer la producción y consumo en sectores de producción monetaria. Es un equilibrio entre el hombre y la naturaleza para lograr un desarrollo que satisfaga las necesidades del presente sin comprometer la capacidad de las generaciones futuras de satisfacer sus propias necesidades." (WCED, 1987)

Se trata de mejorar la calidad de la vida humana sin sobrepasar los límites de la capacidad de soporte de los ecosistemas de apoyo (WWF, 1991) o lo que es lo mismo, permitir a todas las personas realizar su potencial y mejorar la calidad de su vida mientras simultáneamente se protegen y mejoran los sistemas de apoyo a la vida de la Tierra." Forum for the Future 2006 (http://www.forumforthefuture.org.uk/)

El modelo económico dominante actualmente dice que la economía va bien cuando crece el producto interior bruto (PIB). EI PIB mide el valor de las mercancías producidas. Cuanta más producción, más crecerá el PIB; cuanto más crezca el PIB, mejor viviremos y más riqueza habrá. Este modelo no tiene en cuenta cuánto cuesta a la colectividad en términos ecológicos y sociales el crecimiento de un punto del PIB. La explotación de recursos naturales no renovables es finita, convirtiendo a las economías basadas en este modelo en finitas.

En segundo lugar del ranking de la ortodoxia económica aparecen otras variables socioeconómicas. La inflación, el déficit público, la deuda pública acumulada, la productividad, etc. Todos estos parámetros tradicionales miden la situación de un sistema desde un único punto de vista, prescindiendo de los demás factores.

Las organizaciones precisan recursos de financiación adecuados a sus necesidades de crecimiento y adaptación a los cambios que les proponen sus grupos de interés. El concepto incluye también el desarrollo de administraciones públicas que contribuyen a la sostenibilidad de la sociedad en que estén encuadradas siendo a su vez entes sostenibles en sí mismas. La sostenibilidad económica de la Administración Pública, al no ser una organización orientada a la venta de servicios, es difícil de establecer porque no puede recurrirse al básico mecanismo del beneficio económico.

El porcentaje de PIB que supone la producción de la actividad de la Administración y servicios públicos, es un modo de evaluación de la sostenibilidad económica. Según datos de la OCDE, podríamos considerar que la Administración Pública española se ha mantenido en una línea de sostenibilidad económica entre 1995 y 2007 . A pesar del innegable incremento del número de servicios prestados en este periodo, el coste de 
producción se ha mantenido estable en el $20 \%$ del PIB. Es significativo además, que el porcentaje del gasto público dedicado a pagar los salarios de los empleados públicos en España en ese periodo ha decrecido, a pesar que el número de empleados públicos haya aumentado. En comparación con otras administraciones públicas de la OCDE, España está situada en ambos conceptos, porcentaje de PIB que supone el coste de producción y porcentaje de fuerza laboral que suponen los empleados públicos, por debajo de la media de la OCDE.

Parece razonable pensar que a los indicadores macroeconómicos tradicionales se les debería añadir otros de carácter ecológico y social, para poder medir la sostenibilidad del sistema.

\section{Sostenibilidad Social}

El objetivo del desarrollo sostenible es "satisfacer las necesidades del presente sin poner en peligro la capacidad de las generaciones futuras para satisfacer sus propias necesidades". Como agentes clave de la sociedad, las organizaciones de todo tipo tienen un papel importante en la consecución de este objetivo.

Las organizaciones tradicionales, a la hora de evaluar su desempeño solo medían, evaluaban y comunicaban sus resultados económicos y financieros. Solo se interesaba por la dimensión económica de la sostenibilidad. Pero hoy en día, la información económica es insuficiente para responder a las nuevas necesidades y a la rendición de cuentas (Garay, 1995). Los diferentes grupos de interés de las organizaciones demandan cada vez más información sobre el impacto social.

Durante los últimos años se ha desarrollado en línea con las exigencias de responsabilidad a las empresas por parte de la sociedad y bajo el paraguas del concepto de la sostenibilidad, la Responsabilidad Social Corporativa (RSC). Se trata de la forma en que las empresas conducen sus negocios teniendo en cuenta todos sus efectos sobre sus clientes, empleados, accionistas, comunidades locales, medioambiente y sobre la sociedad en general. Esto implica el cumplimiento obligatorio de la legislación nacional e internacional en el ámbito social, laboral, medioambiental y de Derechos Humanos, así como cualquier otra acción voluntaria que la empresa quiera emprender para mejorar la calidad de vida de sus empleados, las comunidades en las que opera y de la sociedad en su conjunto.

Las organizaciones tradicionales deben transformarse en "organizaciones inteligentes" (Olcese, 2009) apoyándose para ello en tres ideas: el pensamiento sistémico, el sentido de comunidad y la consideración del largo plazo. De esta manera podrán alinear sus intereses con lo que le está exigiendo la sociedad y sus grupos de interés.

Además la empresa socialmente responsable debe esforzarse por conseguir un beneficio, obedeciendo la ley, siendo ética y siendo un buen ciudadano" (García Marza, 2004).

Por otro lado, las empresas privadas cada vez tienen más peso en la sociedad en detrimento de las empresas públicas. El sector privado está cada vez más involucrado en la prestación de servicios como el agua, la energía, la salud o la educación, servicios 
que tradicionalmente eran proporcionados por el sector público y que tienen un gran efecto sobre la vida de las personas. Este mayor poder que las empresas han acaparado, implica necesariamente una mayor responsabilidad sobre el estado actual y futuro del sistema físico y social en el que operan y la sociedad les está exigiendo que se comporten de acuerdo con dicha responsabilidad. Las organizaciones deben asumir su responsabilidad y comenzar a comportarse como un "Ciudadano corporativo" (Olcese, 2009)

Solo el $7 \%$ de la población española considera que las empresas están tomando medidas para lograr un desarrollo sostenible según un estudio del Club de la Excelencia en Sostenibilidad (2013).

En el caso de la Administración Pública debe considerarse que esta tiene la doble responsabilidad de involucrarse y asumir un papel activo en el fomento de la RSC, a través de la combinación de una serie de normas de intervención y de promoción, que regulen más allá de la voluntariedad de las empresas por un lado, y la propia asunción de criterios de RSC en sus propias políticas como parte esencial del rendimiento de cuentas de carácter público y su compromiso ético.

Las políticas públicas de este modo responden al papel activo que debe desarrollar la administración, en favor de la regulación de aquellas actuaciones y actividades que afecten al bien común (Observatorio RSC, 2014).

Las demografías de amplia base de población y baja longevidad frecuentes en el pasado han generado valores, leyes e incluso una ética y estética, congruentes con esa estructura demográfica. En el momento actual se está produciendo una transformación que hará desaparecer buena parte de la cultura que generaron. Están cambiando los conceptos y los límites de la juventud y la vejez, la organización de la familia, los diseños urbanos, la legislación. Todo ello lleva unido el cambio en aspectos importantes de la moral y de la estética. La población ya no estará tan afectada por enfermedades agudas que se curan, sino por enfermedades degenerativas y crónicas que persisten muchos años, para las que el objetivo es controlar los síntomas y que el enfermo no empeore. El diseño de las ciudades, del transporte y de las organizaciones sanitarias tendrá que adaptarse a la presencia de numerosos ciudadanos con las facultades de oír, ver y moverse disminuidas (Durán, 2016). 


\subsubsection{Teoría de los grupos de interés}

Cada vez adquiere mayor importancia la gestión de las relaciones con los grupos de interés. La inclusión activa de los grupos de interés da legitimidad a la empresa, generando credibilidad y confianza. Las empresas que buscan la sostenibilidad en sus actividades deben conocer a los grupos de interés, potenciar el diálogo, satisfacer demandas y expectativas, y ser transparentes en la rendición de cuentas de sus acciones. La empresa sostenible desencadena procesos de mejora continua e innovación y busca aceptación social para conseguir éxito en sus actividades. La Teoría del Stakeholder o de los Grupos de Interés es una pieza clave del éxito empresarial y de la sostenibilidad (Fernández, 2012).

La teoría de los Grupos de Interés (stakeholders) señala que la capacidad de una organización para generar riqueza sostenible a lo largo del tiempo viene determinada por sus relaciones con sus grupos de interés (Freeman, 1984). Según el mismo autor, el grupo de interés de una empresa es cualquier grupo o individuo que puede afectar 0 es afectado por el logro de los objetivos de la organización. Los grupos de interés de una organización son los individuos y colectivos que contribuyen, voluntaria 0 involuntariamente, a su capacidad y sus actividades de creación de riqueza y que, por lo tanto, son sus potenciales beneficiarios y/o portadores del riesgo (Post, Preston y Sachs 2002), En este grupo incluyen a los accionistas, trabajadores, clientes, comunidades locales, administración pública, ONG y proveedores.

En un principio las experiencias iniciales de las relaciones con los grupos de interés respondían a presiones externas, limitado a ciertos temas que generaban conflicto con los grupos de interés. Posteriormente las empresas han demostrado su potencial para aumentar el entendimiento mutuo, gestionar los riesgos y resolver los conflictos de manera más efectiva (Sánchez, 2012). Actualmente, las relaciones con grupos de interés permiten a las empresas alinear su desempeño social, ambiental y económico con su estrategia principal. (Gil Lafuente, 2011)

La Teoría de los Grupos de Interés (Carrión, 2009) propone que se deben generar estrategias y políticas a través de códigos de conducta internos que garanticen que el desarrollo de los procesos sea sostenible y no impacte contra los derechos sociales y ambientales de los grupos de interés implicados. El objetivo de la organización ha de ser lograr un equilibrio entre los intereses de todos los colectivos.

Tanto las organizaciones como los modelos de calidad que aplican ya han empezado a valorar las contribuciones de la participación de los grupos de interés en el aprendizaje y la innovación de productos y procesos, así como en el logro de la sostenibilidad de las decisiones estratégicas dentro y fuera de las compañías.

En la ilustración 3 podemos observar que las relaciones entre las organizaciones y sus grupos de interés son en ambas direcciones, y en una primera instancia estas se presentan de un modo equidistante del centro, sin embargo esto puede cambiar conforme se vaya analizando el tipo de relación que se tiene con cada uno de los interesados. Esta ilustración sirve para conocer y definir los diferentes grupos de interés que afectan a una organización y conocer en qué forma se está generando la relación, 
así mismo puede ayudar en la pauta de la priorización de las medidas y estrategias a desarrollar, pero no son los únicos factores a tomar en cuenta.

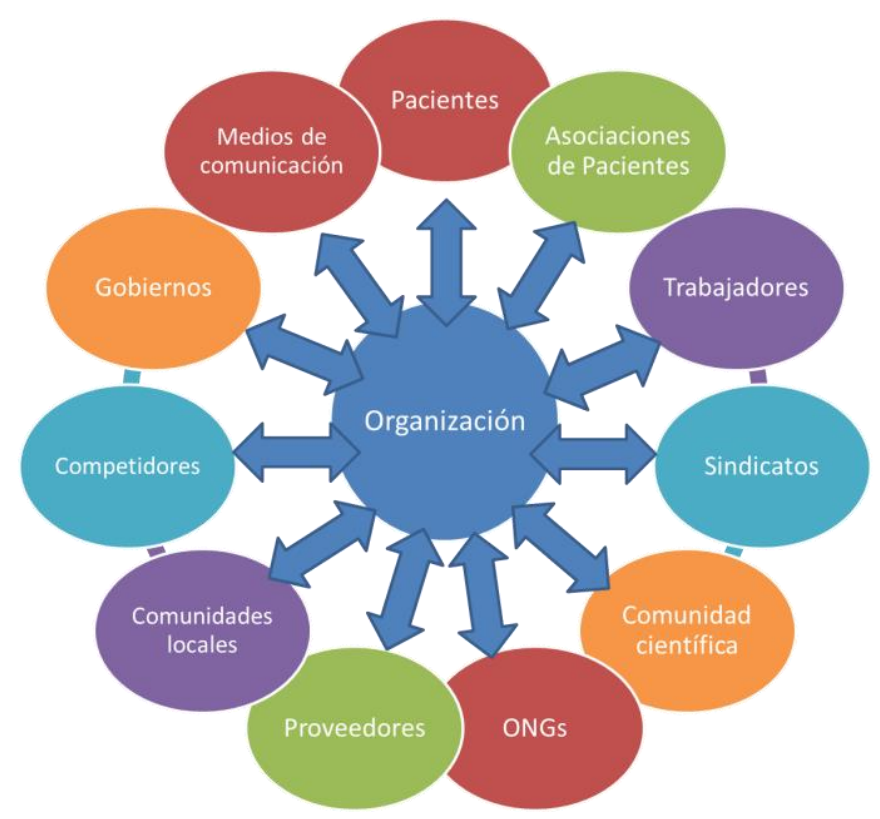

Fuente: Elaboración propia a partir de SÁNCHEZ, 2012)

Para identificar a todos los grupos de interés o stakeholders se debe considerar a todas las personas o grupos con intereses legítimos que participan en una empresa con el fin de que reciban algún tipo de beneficio y que no exista ninguna prioridad de inicio para alguno de los grupos de intereses o de los beneficios que obtendrán por encima de otros (Donaldson y Preston, 1995). Es importante reconocer que estos grupos, aunque puedan parecer ajenos o lejanos a la organización, forman parte del ecosistema de la misma y por esto deben de ser tenidos en consideración a la hora de determinar la estrategia y los procesos de la organización (Portales, 2009).

Para poder determinar quién sí es y quién no es grupo de interés, así como para lograr una correcta priorización de los mismos, es necesario definir en primera instancia aquellos grupos sobre los que recaen los beneficios que como organización se pueden brindar, y a cuales por consecuencia les toca algún tipo de obligación con la misma, en las organizaciones sanitarias esto incluye principalmente a los pacientes, los trabajadores, la administración pública y proveedores. Estos son legitimados también por la normativa y la organización tiene una obligación con ellos.

El hecho de que diferentes personas deseen diferentes cuestiones de la relación con las organizaciones hace que sea muy difícil identificar con exactitud lo que todos los grupos quieren, por ello es importante que la interacción con los grupos de interés sea responsabilidad de la dirección a todos los niveles de la organización (Portales, 2009) Es necesario que los directivos estén en constante contacto con los grupos de interés para poder tener una visión acertada de cómo lograr las metas organizacionales y poder identificar oportunidades y evitar conflictos antes de que se encuentren en una situación crítica (Phillips, 2004). Gracias a esta comunicación se pueden llegar a conocer las 
diferentes necesidades e intereses de cada uno de estos grupos, lo cual se verá reflejado en la toma de decisiones y en la puesta en marcha de estrategias a nivel organizacional de acuerdo a un balance adecuado de los recursos, en tiempo y dinero. Todo lo anterior con la intención de hacer que la organización tenga la capacidad de adaptarse a las expectativas y necesidades cambiantes de los diferentes grupos de interés para responder a los mismos de una forma coordinada, integrada y sostenible en el tiempo.

La tabla 9 presenta un ejemplo que puede ayudar en la priorización de estos grupos, tomando como base el impacto y las contribuciones que estos pueden brindar a la organización.

Tabla 9 Grupos de interés del Servicio de Alimentación del Hospital San Pedro de Logroño.

\begin{tabular}{|c|c|c|c|c|c|}
\hline \multirow{2}{*}{\multicolumn{2}{|c|}{ GRUPOS DE INTERÉS }} & \multicolumn{2}{|c|}{ NECESIDADES Y EXPECTATIVAS } & \multirow{2}{*}{ UTILIDAD } & \multirow{2}{*}{$\begin{array}{l}\text { PROCESOS } \\
\text { RELACIONADOS }\end{array}$} \\
\hline & & ESPECÍFICAS & COMUNES & & \\
\hline \multirow{6}{*}{ 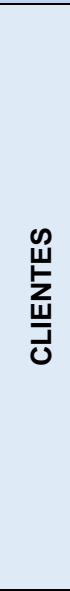 } & $\begin{array}{l}\text { Pacientes dietas } \\
\text { digestivas }\end{array}$ & Dietas progresivas & Información & \multirow{2}{*}{$\begin{array}{l}\text { Adecuar los menús y los } \\
\text { platos a su gusto y } \\
\text { necesidades derivadas de } \\
\text { su patología }\end{array}$} & $\begin{array}{l}\text { Satisfacción del } \\
\text { cliente }\end{array}$ \\
\hline & \multirow{2}{*}{$\begin{array}{l}\text { Pacientes déficit } \\
\text { neurológico y } \\
\text { psiquiátrico }\end{array}$} & Menaje seguro & $\begin{array}{l}\text { Buenas } \\
\text { características } \\
\text { organolépticas }\end{array}$ & & Solicitud de dietas \\
\hline & & $\begin{array}{l}\text { Alimentos } \\
\text { adecuados a sus } \\
\text { necesidades }\end{array}$ & $\begin{array}{l}\text { Cantidad } \\
\text { adecuada }\end{array}$ & \multirow[t]{2}{*}{ Evitar errores en dietas } & $\begin{array}{l}\text { Seguridad } \\
\text { alimentaria }\end{array}$ \\
\hline & $\begin{array}{l}\text { Pacientes dietas } \\
\text { metabólicas }\end{array}$ & $\begin{array}{l}\text { Dietas adecuadas a } \\
\text { sus necesidades } \\
\text { nutricionales }\end{array}$ & $\begin{array}{l}\text { Variedad de } \\
\text { menús }\end{array}$ & & \multirow{2}{*}{ Gestión de calidad } \\
\hline & $\begin{array}{l}\text { Pacientes } \\
\text { pediátricos }\end{array}$ & $\begin{array}{l}\text { Menús divertidos, } \\
\text { variedad, } \\
\text { adecuados a su } \\
\text { edad }\end{array}$ & $\begin{array}{l}\text { Alimentos } \\
\text { seguros }\end{array}$ & \multirow[t]{2}{*}{$\begin{array}{l}\text { Mejorar la distribución del } \\
\text { servicio }\end{array}$} & \\
\hline & $\begin{array}{l}\text { Pacientes } \\
\text { oncológicos }\end{array}$ & $\begin{array}{l}\text { Dietas } \\
\text { personalizadas }\end{array}$ & $\begin{array}{l}\text { Buenas } \\
\text { presentación de } \\
\text { los platos }\end{array}$ & & Expedición \\
\hline \multirow{7}{*}{$\begin{array}{l}0 \\
\text { O } \\
\text { 是 } \\
\frac{1}{4}\end{array}$} & \multirow{3}{*}{$\begin{array}{l}\text { Personal } \\
\text { Sanitario }\end{array}$} & Dietas prescritas & $\begin{array}{l}\text { Respuesta rápida } \\
\text { y completa }\end{array}$ & \multirow{3}{*}{$\begin{array}{l}\text { Mejorar la satisfacción del } \\
\text { paciente y proporcionar la } \\
\text { dieta que apoye la mejora } \\
\text { de su salud } \\
\text { Actualización continua del } \\
\text { catálogo de dietas }\end{array}$} & $\begin{array}{l}\text { Satisfacción del } \\
\text { cliente }\end{array}$ \\
\hline & & Extras pactados & información & & $\begin{array}{l}\text { Solicitud de dietas } \\
\text { Alianzas }\end{array}$ \\
\hline & & $\begin{array}{l}\text { Necesidades de } \\
\text { paciente }\end{array}$ & & & Expedición \\
\hline & \multirow{2}{*}{$\begin{array}{l}\text { Asociaciones de } \\
\text { pacientes }\end{array}$} & \multicolumn{2}{|c|}{$\begin{array}{c}\text { Cubrir necesidades y expectativas de } \\
\text { pacientes según patología }\end{array}$} & \multirow{4}{*}{$\begin{array}{l}\text { Conocer las necesidades } \\
\text { y expectativas de los } \\
\text { pacientes para adecuar } \\
\text { los menús y los platos a } \\
\text { su gusto y necesidades } \\
\text { derivadas de su patología }\end{array}$} & $\begin{array}{l}\text { Satisfacción del } \\
\text { cliente }\end{array}$ \\
\hline & & \multicolumn{2}{|c|}{$\begin{array}{c}\text { Colaboración en charlas, jornadas, } \\
\text { cursos formativos, ... }\end{array}$} & & Alianzas \\
\hline & \multirow[b]{2}{*}{ Familiares } & \multicolumn{2}{|c|}{ Satisfacción del paciente } & & \multirow{2}{*}{$\begin{array}{l}\text { Satisfacción } \\
\text { Alianzas }\end{array}$} \\
\hline & & \multicolumn{2}{|c|}{$\begin{array}{l}\text { Información diversa según necesidades } \\
\text { del propio Servicio }\end{array}$} & & \\
\hline \multirow{7}{*}{ 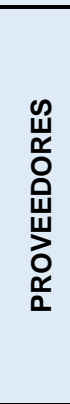 } & \multirow{4}{*}{$\begin{array}{l}\text { Proveedores } \\
\text { víveres }\end{array}$} & $\begin{array}{l}\text { Pago rápido y } \\
\text { completo }\end{array}$ & \multirow{2}{*}{$\begin{array}{l}\text { Comunicación } \\
\text { adecuada y } \\
\text { permanente }\end{array}$} & $\begin{array}{l}\text { Mejorar la logística y el } \\
\text { servicio }\end{array}$ & \multirow{4}{*}{$\begin{array}{l}\text { Almacén de } \\
\text { víveres }\end{array}$} \\
\hline & & $\begin{array}{l}\text { Transparencia en los } \\
\text { concursos }\end{array}$ & & $\begin{array}{l}\text { Calidad en materias } \\
\text { primas }\end{array}$ & \\
\hline & & $\begin{array}{l}\text { Criterios de } \\
\text { aceptación de } \\
\text { productos }\end{array}$ & Buen trato & & \\
\hline & & Comunicación fluida & & Eficiencia & \\
\hline & Servicio de & Comunicación fluida & & & Gestión de calidad \\
\hline & Limpieza & Información & & & \\
\hline & $\begin{array}{l}\text { Mantenimiento } \\
\text { de equipos }\end{array}$ & $\begin{array}{l}\text { Información en } \\
\text { tiempo y forma }\end{array}$ & Intormacion & & $\begin{array}{l}\text { Mantenimiento de } \\
\text { equipos }\end{array}$ \\
\hline 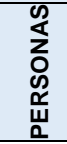 & $\begin{array}{l}\text { Cocineros, } \\
\text { pinches, dietistas }\end{array}$ & $\begin{array}{l}\text { Comunicación fluida, } \\
\text { escucha y empatía, r } \\
\text { atención. }\end{array}$ & $\begin{array}{l}\text { formación, } \\
\text { econocimiento, }\end{array}$ & $\begin{array}{l}\text { Control de medidas } \\
\text { preventivas }\end{array}$ & $\begin{array}{l}\text { Satisfacción } \\
\text { cliente }\end{array}$ \\
\hline
\end{tabular}


De acuerdo con Global Reporting Initiative (GRI, 2011), existen diversos grupos de interés para cada organización, que pueden catalogarse dependiendo de su relación con la organización. El modelo GRI de identificación prevé la división en dos grupos de interés. Se considera que las personas o grupos podrán ser afectados de manera directa o indirecta por la empresa. "Por ejemplo, un empleado podrá ser directamente afectado por decisiones relacionadas a las prácticas y políticas laborales. Por tanto, ello tendrá un interés directo en las acciones de su organización en estas áreas. Por otro lado, la familia y la comunidad del empleado serán indirectamente afectadas en la medida que la satisfacción del empleado en el trabajo, su salud y seguridad, y las oportunidades de desarrollo de su carrera irán a ejercer una influencia en la familia y en la comunidad

Otro método de identificación es el propuesto por el organismo Accountability y que de acuerdo con Krick et al. (2005) podemos identificarlos de acuerdo con el tipo de relación entre la empresa y sus grupos de interés. Este método constituye una herramienta de consenso en el proceso de identificación de los grupos de interés. En este caso la identificación de los grupos de interés puede realizarse en distintas dimensiones.

- Por responsabilidad: personas con las que tiene o tendrá responsabilidades legales, financieras y operativas según reglamentaciones, contratos, políticas o prácticas vigentes.

- Por influencia: personas que tienen o tendrán posibilidad de influenciar la capacidad de la organización para alcanzar sus metas, ya sea que sus acciones puedan impulsar o impedir su desempeño. Se trata de personas con influencia informal o con poder de decisión formal.

- Por cercanía: personas con las cuales interactúa la organización, incluyendo grupos de interés internos o con relaciones de larga duración con la organización, o aquellos de los que la organización depende en sus operaciones cotidianas y los que viven cerca de las plantas de producción.

- Por dependencia: se trata de las personas que más dependen de su organización, como, por ejemplo, los empleados y sus familias, los clientes cuya seguridad, sustento, salud o bienestar depende de sus productos, o los proveedores para quienes la compañía es un cliente importante.

- Por representación: personas que, a través de estructuras regulatorias o culturales/tradicionales, representan a otras personas. Por ejemplo, líderes de las comunidades locales, representantes sindicales, consejeros, etc.

Es importante destacar que la complejidad que ha adquirido la gestión de los grupos de interés en las empresas a través de la ampliación de los grupos, pone de manifiesto la necesidad de establecer el nivel de relación entre los diferentes grupos de interés y obtener las correspondientes afinidades.

Esto facilitaría la toma de decisión en función de las características que se consideren prioritarias en cada situación y momento.

Como se ha visto anteriormente, los cambios ocurridos en los diversos ámbitos (social, económico y ambiental) han afectado a las organizaciones y las relaciones con sus grupos de interés. Esta nueva realidad ha impulsado nuevos desafíos en las organizaciones en el diálogo hacia grupos de interés más amplios, como pueden ser las comunidades locales, trabajadores de la cadena de compras, familiares de los trabajadores, organizaciones de la sociedad civil y medio ambiente que, si bien existían 
ya en el ámbito sanitario, ha obligado a potenciarlas y mejorarlas.. Estos cambios también se extendieron a la manera en que la organización debe comunicarse con los grupos de interés, lo que ha generado nuevos desafíos hacia el diálogo y la colaboración a través de consultas, paneles de asesoramiento, retroalimentación online, redes, foros y alianzas de grupos de interés múltiples.

En este contexto, la empresa debe comprometerse con sus grupos de interés creando un mecanismo de diálogo y entendimiento mutuo para que las necesidades de todos los grupos sean tomadas en cuenta en el desarrollo sostenible de la empresa.

\subsubsection{Rueda del cambio}

Según esta teoría, la sostenibilidad de las organizaciones se alcanza cuando los procesos son diseñados para ser económicamente, socialmente y ecológicamente beneficiosos y no sólo con un menor consumo de recursos. La sostenibilidad a largo plazo no depende de hacer un sistema más eficiente sino en transformar el sistema para que todos sus productos, servicios y procesos sean seguros, saludables y regenerativos (McDonough 2005).

Esta teoría se basa en integrar la sostenibilidad como estrategia de la organización para generar un verdadero cambio hacia el desarrollo sostenible. A partir de esta idea, surge la teoría de la rueda de cambio (Doppelt, 2003) que se basa en un conjunto de siete principios que ha de cumplir toda organización que quiera triunfar a la hora de incorporar la sostenibilidad en su estrategia. Estos siete puntos surgen a partir del estudio de los problemas con que se encuentran las organizaciones a la hora de lograr un desarrollo sostenible y son los siguientes (tabla 10):

Tabla 10. Aspectos "The wheel of change"

\begin{tabular}{|c|c|}
\hline $\begin{array}{l}\text { PROBLEMAS/ organización no } \\
\text { sostenible }\end{array}$ & SOLUCIÓN \\
\hline $\begin{array}{l}\text { Organización vertical que lleva } \\
\text { a un falso sentimiento de } \\
\text { seguridad }\end{array}$ & $\begin{array}{l}\text { Cambiar la mentalidad dominante que ha creado el } \\
\text { sistema con el imperativo de alcanzar la sostenibilidad }\end{array}$ \\
\hline $\begin{array}{l}\text { Los temas medioambientales y } \\
\text { socioeconómicos se aíslan, no } \\
\text { hay relación entre ellos }\end{array}$ & $\begin{array}{l}\text { Reordenar las partes del sistema mediante grupos de } \\
\text { transición }\end{array}$ \\
\hline $\begin{array}{l}\text { No hay una visión clara de la } \\
\text { sostenibilidad }\end{array}$ & $\begin{array}{l}\text { Alterar las metas del sistema creando una visión hacia } \\
\text { la sostenibilidad }\end{array}$ \\
\hline Confusión sobre causa y efecto & Reestructurar las reglas de compromiso del sistema \\
\hline Falta de información & $\begin{array}{l}\text { Cambiar los flujos de información del sistema } \\
\text { comunicando incansablemente la necesidad, la visión } \\
\text { u las estrategias para alcanzar la sostenibilidad }\end{array}$ \\
\hline $\begin{array}{l}\text { Mecanismos de aprendizaje } \\
\text { insuficientes }\end{array}$ & $\begin{array}{l}\text { Corregir los bucles de retroalimentación animando y } \\
\text { recompensando el aprendizaje e innovación }\end{array}$ \\
\hline $\begin{array}{l}\text { Fallo en la institucionalización } \\
\text { de la sostenibilidad }\end{array}$ & $\begin{array}{l}\text { Ajustar los parámetros del sistema alineando sistema, } \\
\text { estructuras, políticas y procedimientos con } \\
\text { sostenibilidad }\end{array}$ \\
\hline
\end{tabular}

Fuente: Doppelt, 2003 
Estas siete soluciones que vemos en el cuadro como una secuencia lineal (Ilustración 4), en realidad no funcionan así ya que es un proceso que implica movimientos hacia atrás y hacia delante continuamente debido a la relación que hay entre todos ellos. Cada bloque prepara los cimientos para la próxima acción, si algo cambia en una de ellas hay que volver a revisar todas las demás. El esquema, tal como lo representa su autor tiene forma de una rueda, de ahí su nombre.

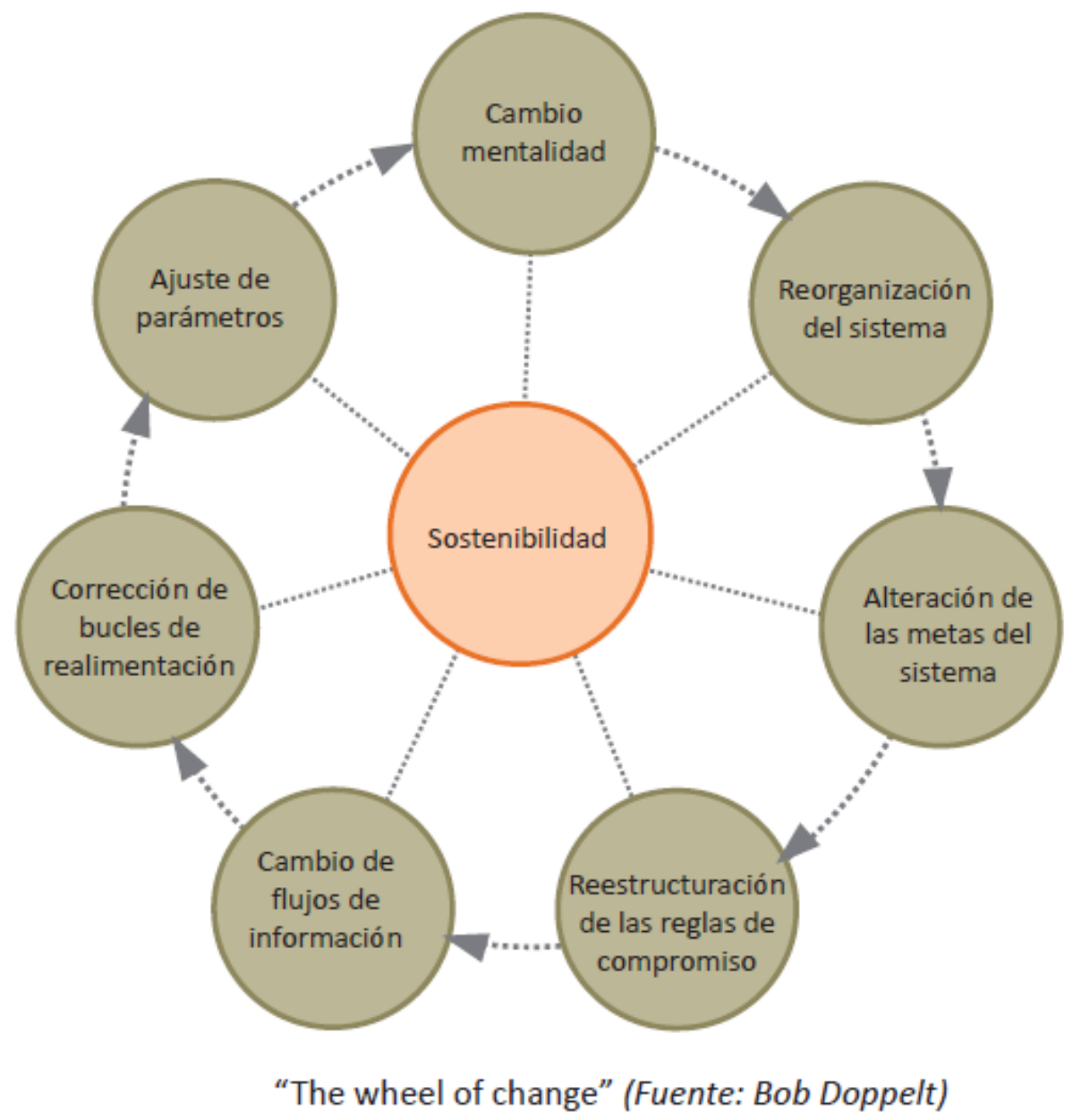

\subsubsection{Teoría del cubo de Rubik}

Una vez vistas las diferentes teorías sobre la disponibilidad parece evidente que en ninguna forma se contraponen sino más bien que pueden ser complementarias. Parece evidente que una organización que quiera perdurar en el tiempo debe pasar por diferentes etapas de crecimiento detectando y trabajando las necesidades de sus grupos de Interés logrando un equilibrio económico, ambiental y ético.

Es por ello que en este trabajo proponemos una explicación del camino a la sostenibilidad que integra las teorías antes expuestas y que sirve para facilitar el camino hacia la misma de las organizaciones (ilustración 5). 


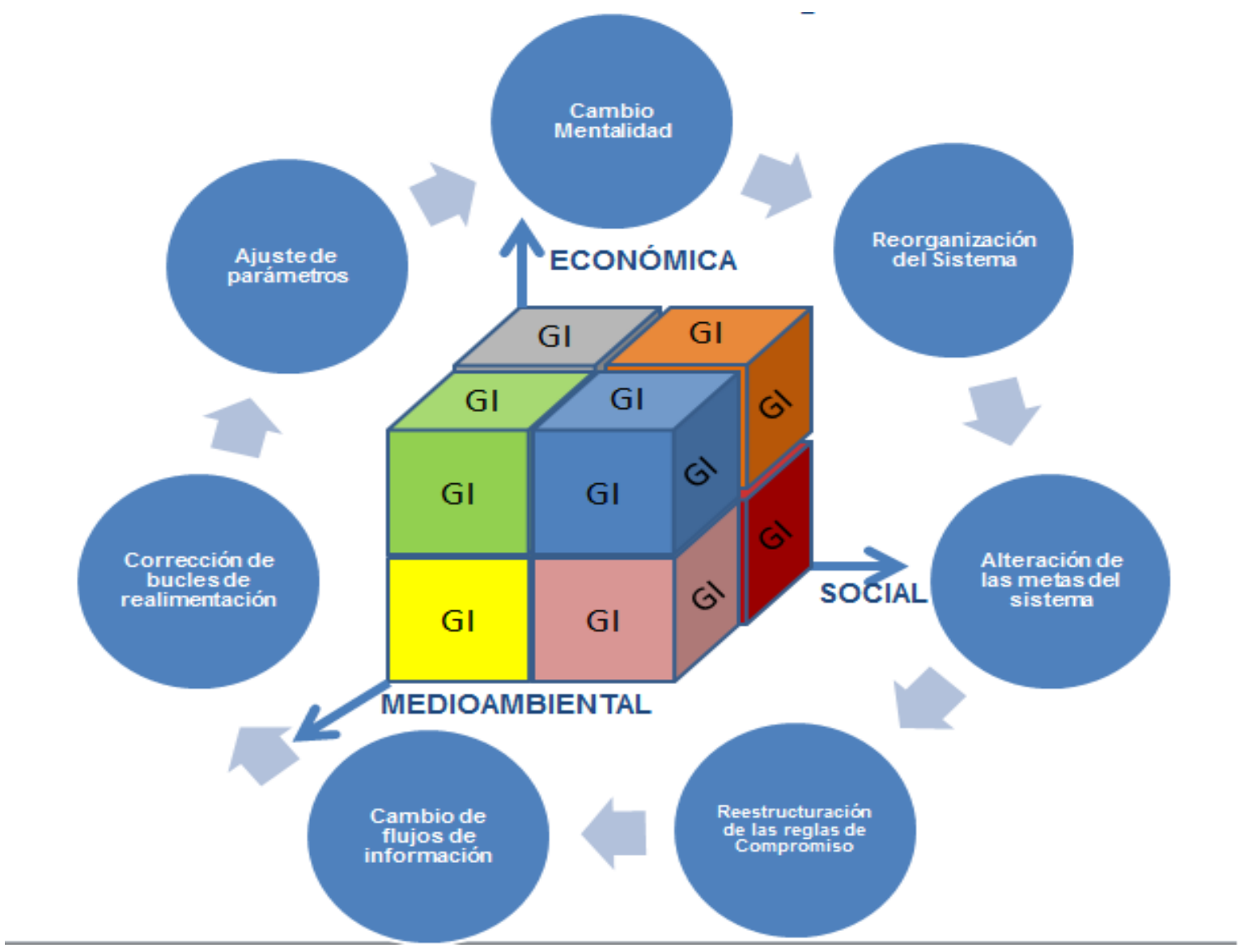

Fuente: Elaboración propia. Integración de las teorías de la sostenibilidad en un solo modelo basado en el modelo tridimensional de la inteligencia de Guilford (1967)

Esta ilustración expone la necesidad de que las organizaciones trabajen siguiendo una metodología determinada y dentro de los tres ejes principales (Sociedad, medioambiente, economía) la mejor "colocación" o respuesta a cada uno de sus grupos de interés.

\subsubsection{Modelos de gestión aplicados a la sostenibilidad.}

Como ya hemos visto el concepto de sostenibilidad representa realizar un nuevo enfoque de la organización. Al desarrollar sus actividades las organizaciones promueven la inclusión social, optimizan la utilización de los recursos naturales y reducen el impacto sobre el medio ambiente, preservando la integridad del planeta para las generaciones futuras sin descuidar la viabilidad económica y financiera de la organización (Sánchez, 2012)

La sostenibilidad es una manifestación o un resultado de las organizaciones exitosas, que son aquellas que perduran en el tiempo porque producen valor añadido, no tienen conflictos duraderos, tienen una cultura que les da una identidad propia y además son innovadoras, flexibles, admiradas e inspiradoras, y son consideradas como los mejores lugares para trabajar. (Chiavenato, 2004) 
Las organizaciones exitosas deben:

- Conocer a sus clientes. Saber el que los clientes quieren permite crecer donde es más fácil y barato y en la base de los consumidores ya conquistada.

- Evitar las prisas, actuar con calma y moderación. Las organizaciones con crecimiento sostenible crecen de manera orgánica.

- Tener sentido de la oportunidad. No basta estar en el lugar cierto y en la hora cierta

- Insistir en la estrategia y ser capaz de detectar las oportunidades.

- Ser innovadoras. Aunque las grandes innovaciones pueden resultar espectaculares se trata de integrar pequeñas innovaciones de forma constante para que produzcan el crecimiento sostenido.

- Implantar sistemas de reconocimiento de personas. Las personas deben tener metas ligadas al crecimiento de la organización y son remuneradas por su implicación y valía.

Las organizaciones exitosas tienen diferente formas de trabajar y demostrar su sostenibilidad. Existen diferentes índices para medir la sostenibilidad de las organizaciones.

- Índices Bursátiles de sostenibilidad.

No se trata propiamente de un modelo de gestión, pero sirve de referencia para gestionar empresas.

A partir de los años 90 del pasado siglo el mercado de capitales mundial desarrolló índices bursátiles relacionados con la sostenibilidad. Esta tendencia demuestra que los inversores se dirigen hacia empresas socialmente responsables, sostenibles y rentables. Estos índices recogen las empresas con mejor comportamiento social, económico y medioambiental, y el rendimiento de las inversiones que incorporan criterios de responsabilidad social (Olcese et al, 2008). Las empresas que participan de los índices son evaluadas en las tres dimensiones de la sostenibilidad (económica, medioambiental y social). De esta manera la empresa sostenible está legitimada por la sociedad para sobrevivir a medio y largo plazo. Las empresas pretenden estar en el índice para tener cualificación de empresa sostenible, y además adquirir un activo intangible como la reputación.

Los tres índices bursátiles principales relacionados con la sostenibilidad con los Dow Jones Sustainability Indexes, los FTSE4 Good, el Domini \$00 Social Index y el índice de Sostenibilidad Empresarial de Brasil.

- Guías y estándares aplicados a la sostenibilidad.

La Organización Internacional de Normalización (ISO) está participada por representantes de más de 150 países y tiene su sede en Suiza. La presencia española está representada por AENOR.

La ISO promueve mediante normas y actividades la colaboración entre países y la estandarización. Aunque la gran mayoría de normas ISO son muy específicas para un determinado producto, material o proceso de fabricación, a partir de la década de los 80 también comenzó a trabajar en el área de gestión y garantía de la calidad.

En 1987 se aprobó la norma ISO 9001 de sistemas de gestión de calidad. Esta norma, actualizada en varias ocasiones (última versión 2015), hace que la organización 
implante un sistema para gestionar sus servicios o productos de cara a cumplir con los requisitos del cliente y el cumplimiento de la normativa.

En 1996 siguiendo las recomendaciones de la CNUMAD, el comité técnico de expertos de ISO publicó la norma ISO 14001 de sistemas de gestión medioambiental.

Además de estas normas internacionales, otras instituciones han desarrollado estándares de gestión en diferentes ámbitos relacionados con la sostenibilidad (tabla11).

Tabla 11. Normas y Estándares relacionados con la sostenibilidad.

\begin{tabular}{|c|c|c|}
\hline $\begin{array}{c}\text { Norma } \\
\text { Estándar }\end{array}$ & $\begin{array}{c}\text { Organización } \\
\text { impulsora }\end{array}$ & Contenido \\
\hline ISO 9001 & ISO & Sistema de gestión de la calidad \\
\hline ISO 14001 & ISO & Sistema de gestión medioambiental \\
\hline CE EMAS & $\begin{array}{l}\text { Comisión } \\
\text { Europea }\end{array}$ & \\
\hline SA 8000 & & Derechos sociales \\
\hline BS 8900 & $\begin{array}{l}\text { British } \\
\text { Standard } \\
\text { Institution }\end{array}$ & Responsabilidad social \\
\hline $\begin{array}{l}\text { OHSAS } \\
18001\end{array}$ & $\begin{array}{l}\text { British } \\
\text { Standards } \\
\text { Institution }\end{array}$ & Salud y seguridad en el trabajo. \\
\hline ISO 37001 & ISO & Primera norma mundial antisoborno \\
\hline ProSustain & DNV-GL & $\begin{array}{l}\text { Garantizar la sostenibilidad en el diseño, desarrollo, } \\
\text { producción y entrega de productos. }\end{array}$ \\
\hline NIAHO & $\begin{array}{l}\text { DNV-GL } \\
\text { /Medicare y } \\
\text { Medicaid }\end{array}$ & $\begin{array}{l}\text { Desarrollo y mejora continua de la calidad de la } \\
\text { asistencia sanitaria y la seguridad del paciente en } \\
\text { organizaciones sanitarias. También aborda la } \\
\text { seguridad general para trabajadores, pacientes y } \\
\text { otros visitantes. }\end{array}$ \\
\hline ISO 26000 & ISO & Responsabilidad social \\
\hline SGC 21 & $\begin{array}{l}\text { Foro para la } \\
\text { Evaluación de } \\
\text { la Gestión } \\
\text { ética } \\
\text { (FORÉTICA) }\end{array}$ & $\begin{array}{l}\text { Primer sistema de gestión de la responsabilidad } \\
\text { social europeo, que permite, de manera voluntaria, } \\
\text { auditar procesos y alcanzar una certificación en } \\
\text { gestión ética y responsabilidad social corporativa }\end{array}$ \\
\hline
\end{tabular}

Fuente: Elaboración propia

Las normas son útiles para las organizaciones de todos los tamaños y de diferentes ámbitos. Las normas existentes proporcionan a las organizaciones un amplio abanico de posibilidades sobre herramientas de gestión que se puede utilizar para realizar una planificación del desarrollo sostenible. Por tanto son parte de la estrategia de las organizaciones.

Estas normas logran comprometer y movilizar a las personas de las organizaciones para cumplir los requerimientos que exigen y orientan a la organización. Para Olcese (2008) estas metodologías y herramientas han sido elaboradas con el objetivo de lograr la 
adhesión de las empresas al desarrollo sostenible y la responsabilidad corporativa, y de mejorar su impacto social y reputación.

- Guías de códigos de conducta y principios éticos.

El Pacto Mundial propiciado por la ONU en 2000 es un marco de acción encaminado a alinear las estrategias y operaciones, de las empresas que se comprometan

voluntariamente, con los principios de derechos humanos, estándares laborales, medio ambiente y anti-corrupción.

El 25 de septiembre de 2015, impulsado por la ONU 193 líderes mundiales se comprometieron con 17 Objetivos Mundiales para lograr 3 cosas extraordinarias en los próximos 15 años. "Erradicar la pobreza extrema. Combatir la desigualdad y la injusticia. Solucionar el cambio climático. Los objetivos mundiales podrían lograr estas cosas. En todos los países. Para todas las personas. Para alcanzar estas metas, todo el mundo tiene que hacer su parte, tanto los gobiernos, como el sector privado, la sociedad civil y personas.

Los Objetivos de Desarrollo Sostenible (ODS), también conocidos como Objetivos Mundiales, son una llamada a la adopción de medidas para poner fin a la pobreza, proteger el planeta y garantizar que todas las personas disfruten de paz y prosperidad. Estos 17 Objetivos se basan en los logros de los Objetivos de Desarrollo del Milenio, aunque incluyen nuevas esferas como el cambio climático, la desigualdad económica, la innovación, el consumo sostenible y la paz y la justicia, entre otras prioridades. Los Objetivos están interrelacionados, con frecuencia la clave del éxito de uno involucrará las cuestiones más frecuentemente vinculadas con otro.

Los ODS conllevan un espíritu de colaboración y pragmatismo para elegir las mejores opciones con el fin de mejorar la vida, de manera sostenible, para las generaciones futuras. Proporcionan orientaciones y metas claras para su adopción por todos los países en conformidad con sus propias prioridades y los desafíos ambientales del mundo en general. Naciones Unidas presta apoyo a los gobiernos para que integren los ODS en sus planes y políticas nacionales de desarrollo. Esta labor ya está en marcha, mediante el apoyo a muchos países para consolidar los progresos ya alcanzados en virtud de los Objetivos de Desarrollo del Milenio.

- Guías de informes sociales o sistemas de información.

- La norma AA1000 creada en el Reino Unido, en 1999, por el ISEA (Institute of Social and Ethical Accountability) establece un proceso sistemático de participación de los grupos de interés que genera indicadores, metas y mecanismos de presentación de informes para asegurar su eficacia. Las organizaciones que se someten a esta norma se comprometen a considerar y responder de manera coherente a las necesidades de sus grupos de interés y a identificar y comprender su impacto y sus resultados medio ambientales, sociales y económicos.

- El Global Reporting Initiative (GRI) es una institución independiente cuya misión es desarrollar y difundir guías para realizar informes de sostenibilidad a nivel global. La primera versión de la Guía para la elaboración de memorias de sostenibilidad se publicó en el año 2000. Desde la tercera revisión de la Guía (G3) 
se considera como la referencia internacional por excelencia utilizada por las organizaciones para la elaboración de memorias de sostenibilidad y el control interno de la Responsabilidad Social Corporativa (RSC). Esta Guía señala unas directrices que ayudan a medir, comprender y mejorar el desempeño social, económico y medioambiental de las organizaciones de forma sistemática.

\section{- $\underline{\text { Responsabilidad social corporativa. }}$}

Las noticias relacionadas con actividades éticamente cuestionables de todo tipo de organizaciones están en los periódicos de todo el mundo. No hay sector que escape a este hecho, arrastrando a todos los grupos de interés relacionados con las organizaciones que las protagonizan. "Igual que la bajada de la marea descubre la suciedad del fondo del mar, la crisis económica ha aflorado las malas prácticas de las empresas", explica Joan Fontrodona, profesor de ética de IESE Business School (Blázquez, 2016).

La Responsabilidad Social Corporativa (RSC) es la contribución activa y voluntaria de las organizaciones al bienestar social, económico y ambiental, con el objetivo de mejorar su situación competitiva y su valor añadido. La RSC va más allá del cumplimiento de las normativas y las leyes y cada vez es más percibido como un aspecto necesario en las organizaciones. Su objetivo es integrar las preocupaciones sociales y medioambientales en el quehacer de las organizaciones y en su relación con sus grupos de interés.

Según Carrol (1999) la RSC está compuesta de tres áreas:

- Responsabilidad económica. Trata de lograr el máximo beneficio para los inversores mejorando la eficiencia y la productividad

- Responsabilidad sociocultural. La organización se compromete a la realización de obras de interés social y el respeto a la ley, las costumbres y la herencia cultural.

- Responsabilidad medioambiental. Trata de cuidar y preservar el entorno y la naturaleza en su conjunto

Existen otras actuaciones dentro del ámbito privado para evaluar la sostenibilidad de las empresas con el objetivo de facilitar su visibilidad para inversores tales como el Anuario de la Sostenibilidad elaborado por RobecoSAM, gestora especializada en Inversión Sostenible que forma parte del consejo del Dow Jones Sustainability Index (DJSI) y que reúne a las empresas con mejores criterios de sostenibilidad corporativa del mundo. En 2016, 20 empresas españolas figuraron en él. Este Anuario, presentado durante el World Economic Forum de Davos (Suiza) analiza el rendimiento en términos de sostenibilidad de las compañías con criterios ASG (Ambientales, Sociales y de Buen Gobierno), identificando al $15 \%$ de las mejores de cada industria, y galardonándolas con las medallas de Oro, Plata y Bronce (La Vanguardia, 2016).

La responsabilidad social corporativa se impone en los consejos de administración empresariales, que crean comisiones específicas para integrarla en la estrategia, haciendo a España pionera en este campo. (Blázquez, 2016) 


\subsubsection{Sostenibilidad y cultura organizacional}

Para ser sostenible, el sistema sanitario debe estar organizado y gestionado de tal forma que sea capaz de generar entre sus miembros una cultura de sostenibilidad, entendiendo esta como el conjunto de saberes, creencias y pautas de conducta de un grupo social, incluyendo los medios materiales que usan sus miembros para comunicarse entre sí y resolver las necesidades de todo tipo (Sanabria, 2015). En esta misma línea la teoría psicosocial de Erik Erikson explica los componentes socioculturales del desarrollo personal en los que cada miembro de la organización podría acceder a la cultura organizacional desde una fuente común, que debe poder ser incrementada y ha de resultar universalmente compartible por todos.

Toda organización precisa de una cultura que las orienta hacia un lugar u otro. Dentro del paradigma funcionalista se plantea la cultura como una variable interna, ya que es la propia organización la que además de productos y servicios crea también una cultura. La cultura es entendida normalmente como una especie de cola que mantiene a la organización unida y le proporciona estabilidad (Brunet, 2016).

La cultura es el conjunto de formas y expresiones que caracterizarán en el tiempo a una sociedad determinada. Por el conjunto de formas y expresiones se entiende e incluye a las costumbres, creencias, prácticas comunes, reglas, normas, códigos, vestimenta, religión, rituales y maneras de ser que predominan en el común de la gente que la integra. El término cultura tiene un significado muy amplio y con múltiples acepciones. En el contexto de una comunidad de personas, cultura se aplica con un sentido muy general, al hacer mención a las ideas, valores, creencias y tradiciones que la conforman. En un sentido general, la cultura no es una realidad acabada, sino que es totalmente dinámica y cambiante.

Como cultura organizacional se entiende al conjunto de creencias, hábitos, valores, actitudes, tradiciones entre los grupos existentes en todas las organizaciones. El término cultura organizacional es una expresión muy usada en el contexto empresarial. La expresión cultural organizacional forma parte de las ciencias sociales y adquirió gran importancia a mitad del siglo XX después de que algunos investigadores en el área de Gestión y Estudios Organizacionales empezaran a defender los beneficios de estudiar la cultura organizacional. Sin embargo, la cultura organizacional ya era estudiada anteriormente por la sociología, las relaciones humanas dedicaban su tiempo en dictar estudios del aspecto humano de la empresa y era precursora de la cultura organizativa.

Los autores que más fuerza le han brindado a esta materia son: Edgar Schein, Roger Harrison, M. Thevenet, Deal y Kennedy, entre otros. Edgar Schein (1988) fue quien presentó por primera vez un concepto claro y práctico de cultura organizacional, estableció que la cultura organizacional está formada por 3 niveles de conocimientos: supuestos inconscientes, se refiere a las creencias que son adquiridas en relación a la empresa y la naturaleza humana, valores forma parte de los principios, normas y modelos importantes que dirige el comportamiento de quienes conforman la empresa y artefactos identifica a los resultados obtenidos de la acción de una empresa. 
Según Schein (1988), cultura organizacional es el conjunto de hipótesis fundamentales que un grupo ha inventado, descubierto o constituido, aprendiendo a resolver sus problemas de adaptación a su entorno y de integración interna. Estas hipótesis han sido suficientemente confirmadas en la acción de modo que se puedan considerar válidas y enseñar a todo nuevo miembro del grupo, presentándolas como la manera apropiada de percibir, pensar y sentir los problemas de la acción colectiva. Dado que la cultura organizacional se constituye con percepciones del mundo y productos simbólicos, entonces llega a ser ésta un contexto dinámico cargado de símbolos, cogniciones funcionales o una estructura mental profunda y subconsciente" (Abravanel, 1992), es por tanto que se hace necesario acudir al discurso de quienes participan de esta investigación.

Según Robbins (1999), la cultura organizacional de una empresa puede ser fuerte como débil. Las culturas fuertes se caracterizan porque los valores de la organización son firmes y aceptados por todos los integrantes de la misma, en cambio, una cultura débil ocurre todo lo contrario, esto se observa en que el personal posee poca libertad en su trabajo, la gerencia muestra poco interés por su personal, no hay métodos de estimulación hacia el empleado, no existe incentivos por el nivel de productividad del trabajador, entre otros, es decir, se observa un desinterés por los empleados que son los elementos más importantes para llevar a cabo el funcionamiento de la organización y cumplir sus metas planteadas.

En referencia a lo anterior, los fundadores de una cultura deben de transmitirla con el tiempo a sus miembros que forman parte de la empresa y realizar actividades que conserven la cultura organizacional como por ejemplo: otorgar premios, incentivos económicos, materiales, seminarios o diferentes cursos de preparación esto es con el fin de fortalecer los valores, creencias, hábitos y filosofía que conforma la organización desde sus fundadores.

La cultura organizacional determina la forma como funciona una organización y, esta se observa a través de sus estrategias, estructuras y sistema. Una buena organización formada de valores y normas permite a cada uno de los individuos identificarse con ellos $\mathrm{y}$, poseer conductas positivas dentro de la misma obteniendo mayor productividad por parte de los mismos, así como fuera proyectando una imagen positiva de la organización.

De acuerdo a Stephen P. Robbins (1999) la cultura desempeña numerosas funciones dentro de la organización:

- Tiene un papel de definición de fronteras, es decir, crea distinciones entre una organización y las demás.

- Transmite un sentido de identidad a los miembros de la organización.

- Facilita la generación de un compromiso con algo más grande que el interés personal

- Incrementa la estabilidad del sistema social. 
Cada cultura organizacional está compuesta de ciertas características que son claves para ser diferente una de las otras que ayudan a demostrar una imagen positiva de la empresa revistiéndola de prestigio y reconocimiento. Entre las cuales tenemos:

- La responsabilidad e independencia que posee cada individuo.

- El control que existe hacia los empleados.

- El grado de identidad e identificación que posee los empleados con la organización.

- El sistema de incentivo que tiene una empresa con sus empleados que permite que estos trabajen con un mejor rendimiento y optimismo para lograr los objetivos planteados por la empresa.

- El ánimo que poseen los empleados por innovar y mejorar la prestación de servicios donde laboran y asumir el riesgo de la misma.

- El grado de tolerancia que poseen los integrantes de la empresa para resolver los diferentes problemas que se pueden suscitar y buscar un ambiente tranquilo, respetuoso y sano para ellos mismos y los clientes o visitantes.

Chiavenato (2004) comparó la cultura organizacional con un iceberg en el que la parte es pequeña y la parte sumergida representa la mayor parte y, en el caso de la cultura organizacional la parte visible es pequeña y es sustentada por la parte invisible, es decir, por los fenómenos internos de la empresa.

La consultora SustainAbility (ComunicaRSEweb, 2016) presentó una Investigación que destaca cinco formas en que se puede integrar la sostenibilidad en la organización: utilizando el pensamiento del modelo de negocio, aplicando el análisis de materialidad, aplicando el enfoque de la sostenibilidad en los productos y servicios, impulsando mayores niveles de transparencia y creando una cultura interna de la sostenibilidad. Esta investigación sugiere que para que se integre la sostenibilidad en el negocio y en la toma de decisiones de la organización es necesario construir una cultura interna que permita que el empleado entienda lo que significa la sostenibilidad y cuál es su papel en este sentido. Se necesita construir un conjunto de valores claros y una comprensión compartida de ellos.

Un aspecto importante de la cultura en el contexto de la integración de la sostenibilidad es la apertura al cambio y a la innovación. Los aspectos de la cultura que permiten la innovación son el apoyo del liderazgo por la alta dirección, la creación de estructuras no jerárquicas y la implantación en la organización de valores que promuevan la colaboración y la pérdida de miedo al fracaso.

El informe cita el ejemplo de Barclays que cambió su cultura corporativa mediante el uso de una herramienta de toma de decisiones, la Lente de Barclays, desarrollada en 2013 para incorporar consideraciones ambientales y sociales en las decisiones. La herramienta se compone de cinco preguntas diseñadas para ayudar a los empleados a considerar los impactos más amplios de sus decisiones sobre el medio ambiente y lo social. A finales de 2015, Barclays había superado su objetivo inicial y había formado a más de 10.000 de sus empleados a nivel mundial para utilizar la herramienta. 
Para estar en correspondencia con los principios de desarrollo sostenible la organización debe propiciar una cultura organizacional convergente con la estrategia dirigida a:

- Propiciar el compromiso con la calidad

- Crear valor económico, social y ambiental, a corto y largo plazo

- Potenciar el aprovechamiento de los recursos destinados a la elaboración de sus productos y a la prestación de sus servicios

- Promover el bienestar y la evolución de las generaciones presentes y futuras, en sus entornos operativos, en su contexto social inmediato y general.

- Perdurar con vitalidad renovada, que va más allá de simplemente sobrevivir, sino saber adaptarse a las cambiantes necesidades socio-económicos

- La organización debe cuidar además la salud, seguridad, el desarrollo personal y profesional de las personas que laboran en la misma, entre otros aspectos significativos. Una organización sostenible es aquella que crea valor económico, medioambiental y social a corto y largo plazo y hace considerar además, que es necesario el estudio y profundización de elementos esenciales de su cultura, que le permita trabajar hacia un futuro basado en valores que sean soporte en su desarrollo sostenible.

Los aspectos importantes a tener en cuenta en la cultura organizacional que permiten potenciar el desarrollo sostenible de la organización son aquellos que:

- Marcan el comportamiento habitual o deseado de los miembros de la organización.

- Contribuyen a conformar el sistema de estímulos y sanciones.

- Funcionan de control organizacional de acuerdo con el consenso

- Son soporte de la estrategia organizacional.

La sostenibilidad, en consecuencia, no puede convertirse en un fundamento absoluto, sino en un conjunto de principios orientadores que permita conseguir el fin último de lo que realmente se quiere hacer sostenible. (Jiménez, 2002)

Por otro lado, el clima organizacional hace referencia a las percepciones que tienen los empleados. Existen diferentes tipos de variables que forman el clima organizacional como: físicas, estructurales, sociales, personales, entre otros y, las mismas son percibidas por el individuo y definen su forma de intervenir en la organización.

No obstante, las culturas organizativas comparten rasgos comunes:

- En primer lugar, la cultura es compartida por un grupo (en este caso, los miembros de una organización); por lo tanto, tiene que ver sobre todo con personas. Dependiendo del tamaño y la cohesión que muestre la organización, puede haber varias culturas internas, que a veces incluso entrarán en competencia entre ellas.

- En segundo lugar, la cultura suele considerarse el lado informal de la organización. Engloba todas las costumbres, actitudes y creencias. Las manifestaciones de la cultura (historias, símbolos, rutinas, rituales, mecanismos 
de control y estructuras organizativas) son los aspectos visibles de los valores organizativos básicos (ilustración 6).

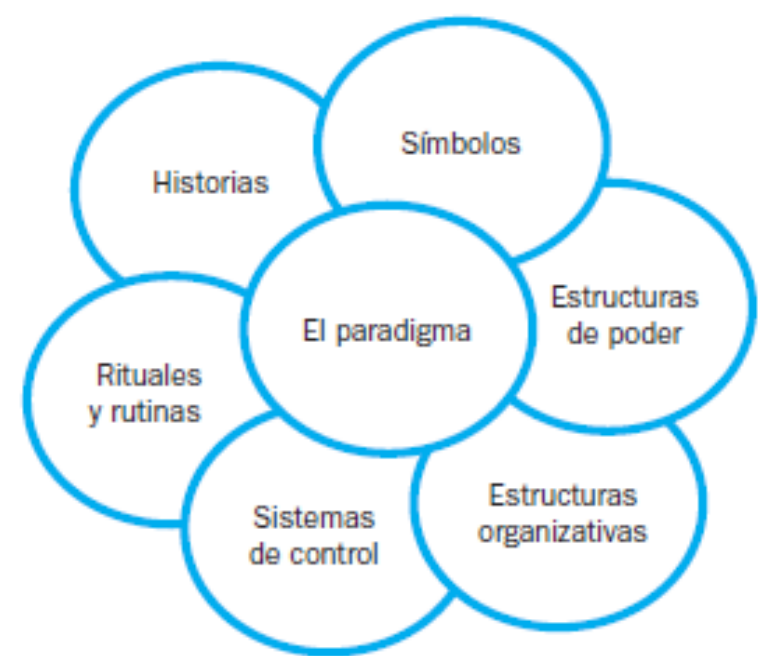

Fuente: Johnson et al. en Senior, B.; Fleming, J. (2006). Organizational Change. Harlow: Prentice Hall.

La cultura se centra en los valores compartidos de un grupo concreto (llustración 6) y no está necesariamente plasmada por escrito, por lo que resulta difícil su comprensión para las personas externas a dicho grupo. Como apunta Schein (2004) son los propios miembros del grupo los que descubren y desarrollan las culturas organizativas, lo cual hace que la cultura sea dinámica y siempre en evolución. Este mismo autor afirma que las nuevas creencias pueden ser enseñadas a los nuevos miembros; de ello se puede deducir que la cultura, si puede aprenderse, también puede modificarse.

La transformación de la cultura organizativa desempeña un papel fundamental en las iniciativas de cambio hacia la sostenibilidad. La sostenibilidad representa una nueva concepción de los modelos organizativos alejada del tradicional paradigma industrial dominante. Es un modelo que opta por un sistema de producción circular y regeneradora. Modos distintos de pensar traen consigo modos distintos de comportarse. En consecuencia, si lo que se pretende es influir en las acciones de quienes trabajan en las distintas partes de la organización, primero habría que convencer a estas mismas personas de que transformen sus valores y su modo de ver las cosas. La sostenibilidad no es un modelo fácilmente aplicable a cualquier organización, por lo que las personas deben crear métodos de trabajo que sean innovadores y se adecúen a las especificidades de esta. Tal flexibilidad puede crearse por medio del cambio cultural.

Para que el cambio cultural sea profundo y duradero, la literatura especializada en gestión del cambio y la sostenibilidad propone centrar los procesos de cambio en cuatro elementos catalizadores:

1. Diseño de una visión. Una reflexión profunda sobre la naturaleza exacta de las ambiciones que abriga la organización y el diseño de una visión que explique la necesidad del cambio y los resultados esperados es uno de los pasos más habituales en los inicios del cambio cultural. Peter Senge (2008) afirma que las 
visiones son una forma convincente de atraer a más personas y de unificar puntos fuertes. Para Bob Doppelt (2003), la visión de la sostenibilidad da lugar a un conjunto compartido de creencias y de imágenes mentales comunes, y debería "mostrar una imagen positiva del futuro".

2. Una mayor comunicación durante el proceso de cambio. Una visión convincente y positiva en la que se incluya la sostenibilidad en el proceso de cambio, no es un fin en sí misma. La visión aporta un sentido de dirección pero solo resulta útil cuando es conocida por todos los miembros de la organización.

3. El desarrollo de programas de formación y el enfoque en las personas. Bob Doppelt (2003) habla de la importancia que tiene el aprendizaje permanente como método de especial eficacia para generar la información adecuada y planear acciones adaptadas a la sostenibilidad. La formación puede ayudar a transmitir los nuevos valores de la sostenibilidad y mantener su actualización. La formación, el aprendizaje permanente y la educación proporcionan a las personas la sensación de una mayor capacidad para la innovación.

4. Garantizar la integración a través del liderazgo. Solo puede formularse y transmitirse una visión convincente si el nuevo pensamiento de la sostenibilidad es aceptado por la Alta Dirección, que es la única parte con capacidad suficiente para alinear con éxito a toda la organización. La sostenibilidad "no es una tarea secundaria que deba relegarse al departamento de relaciones públicas o al de $R S E$, pues tiene que ser dirigida por el CEO y coordinada en el conjunto de la organización" (Cameron, 2007).

Las organizaciones son sistemas en los que todas las partes están interconectadas. En consecuencia, el proceso de cambio no puede abordarse únicamente mediante la transformación de una de las partes, sino más bien integrando las modificaciones efectuadas en el conjunto de la organización. Las organizaciones son sistemas complejos en los que todas las partes están interconectadas. Según este planteamiento, el cambio es un proceso. No se trata de un plan mecanicista a corto plazo, sino de un proceso de mejora de largo recorrido.

Una de las principales causas de fracaso entre las iniciativas que promueven el cambio es la resistencia interna al propio cambio. El análisis del campo de fuerzas elaborado por Lewin (Marx, 1980), es una de las contribuciones más destacadas en esta materia, intenta dar una solución al problema buscando un equilibrio entre las fuerzas que impulsan el cambio y las que se muestran reacias a él. Kurt Lewin (Marx, 1980) defiende la idea de que un proceso de cambio únicamente puede salir bien si el peso de las fuerzas internas que lo impulsan es mayor al de las fuerzas internas que se resisten a él. El autor opina que en la gestión tradicional se recurre a la fuerza impulsora del cambio y afirma que cuanta más energía se utilice para forzarlo, más resistencia aflorará. Como alternativa sugiere que se intente comprender la naturaleza de la resistencia, ¿por qué se opone la gente al programa de cambio?, ¿se siente amenazada?, ¿entiende la necesidad de llevarlo a cabo? Según Lewin, el equilibrio necesario para lograr el cambio puede alcanzarse siempre que la prioridad sea entender y abordar los obstáculos y fuerzas que se oponen a él, y nunca forzarlo mediante el uso del poder. 
Para Marx (1980), el esquema de Lewin demuestra que la realidad de la gestión del cambio es más compleja de lo que aparenta, ya que está basada en un equilibrio frágil. Para que las iniciativas de cambio funcionen, garantizar el compromiso resulta más eficaz que emplear el poder y la fuerza.

Según Kotter (1996) el principal error que cometen los gestores al llevar a la práctica una iniciativa de cambio es mostrar una excesiva autocomplacencia con respecto a los motivos que explican la transformación. Para evitar este escollo, Kotter aboga por que se instaure una sensación de urgencia, básicamente comunicando los riesgos que implica mantener el statu quo y explicando al mismo tiempo las oportunidades que conlleva la adopción de un nuevo enfoque. Las oportunidades deberían cristalizar en el desarrollo de una nueva visión. Para este autor, una buena visión se ciñe a tres objetivos: primero, clarificar el objetivo general y dibujar un panorama positivo de cara al futuro; en segundo lugar, motivar e inspirar a las personas para que trabajen en favor del proyecto; y, tercero, trabajar en sinergia para canalizar todos los esfuerzos en la misma dirección.

Son muchos los que opinan que esta visión, para ser eficaz, debería ser forjada por las personas que después la pondrán en práctica. Desde una perspectiva más amplia, la nueva dirección de la organización debería recibir también el apoyo del mayor espectro posible de personas pertenecientes a ella.

Para Kotter, lo más eficaz sería una "coalición orientadora"; dicha coalición debería estar integrada por un número suficiente de cargos directivos y representar los distintos tipos de competencias técnicas necesarias en la organización, además de tener suficiente credibilidad en el seno de esta y contar con un número suficiente de dirigentes que se hicieran cargo de las nuevas estrategias.

Por último, y quizás sea este el factor más decisivo para lograr un cambio de cultura, resulta de vital importancia "insistir en el cambio como propiedad colectiva" (Cameron 2007) De hecho, las personas van a ser claves para el buen o mal resultado del proceso de cambio, ya que a lo largo y ancho de la organización transformarán (o no) su modo de trabajar con el fin de convertir la visión en una realidad. Este es el motivo por el cual las personas deben participar en el proceso desde el principio y, después, tener la posibilidad de adoptar las decisiones pertinentes en favor del programa de cambio.

Los elementos simbólicos que conforman la cultura de una organización se manifiestan en todos los niveles y departamentos de esta, desde las relaciones personales y sociales hasta las normas y procedimientos de trabajo. Mediante los elementos simbólicos de la cultura, la organización y sus miembros establecen procesos de identidad y exclusión.

Los "supuestos implícitos y explícitos que los miembros tienen respecto de cuál es el comportamiento legitimo dentro de la organización",3 permiten hallar diversos grupos de trabajo dentro de la organización que manifiestan su propia cultura (subcultura) que traduce en uso de jergas, maneras de interactuar, tipo de procedimientos que se pueden omitir (hacer la vista gorda), etc. Dichas subculturas afectan, hasta cierto punto, a todo 
el sistema y pueden competir por imponerse a otras como parte de los juegos de poder tradicionales que se manifiestan al interior de las organizaciones.

La cultura organizacional tiene varios efectos sobre el comportamiento de sus miembros. En primer lugar, en los procesos de atracción y selección, lo que perpetua aún más la cultura existente. También tendrá efectos sobre los procesos de retención y rotación voluntaria, de manera que en la medida que haya una mayor correspondencia entre los valores de los trabajadores y la cultura organizacional, mayor será el compromiso del trabajador hacia la organización, y menor la tasa de rotación o abandono voluntario. Los estilos de liderazgo y toma de decisiones se verán también afectados por contingencias culturales así como las conductas emprendedoras.

La cultura de una empresa no es permanente, ni rígida, sino que va cambiando constantemente. Si no hay cambios y es rígida, le costará adaptarse al medio externo (mercado). A nivel de las organizaciones sanitarias, es necesario trabajar en una dinámica de inestabilidad limitada, manteniendo altos niveles de flexibilidad y aprendizaje que permitan, en lugar de anticipar el futuro, crearlo a partir de las propiedades emergentes de la organización. El éxito requiere de una creatividad continua, y la organización debe fomentarla mediante una destrucción creativa, generando incertidumbre de manera deliberada para favorecer la creatividad y la innovación (Gutiérrez y Peñalver, 2009).

De las distintas aproximaciones al estudio de las diferencias culturales y repercusiones en el comportamiento organizacional, quizá sean los trabajos de Zarko Butrich (1980) los que mayor repercusión han tenido, incluso en la actualidad. Este autor construyó su modelo a partir de una macro-encuesta realizada a 116.000 trabajadores en delegaciones de 64 países distintos de la empresa multinacional IBM. Tras el análisis de los datos, el autor propuso que existían valores compartidos en todos ellos aunque con diferencias en los rangos de cada uno de ellos según países. Estos valores fueron agrupados inicialmente por el autor en cinco grandes dimensiones:

- Individualismo-colectivismo, es el grado en que la cultura enfatiza la independencia y necesidades individuales frente al colectivismo que enfatiza la satisfacción de necesidades grupales.

- Distancia de poder, es el grado en que la cultura y sus integrantes aceptan una mayor o menor distancia y diferenciación entre las personas que tienen el poder y el resto.

- Masculinidad-feminidad, es el grado en que una cultura enfatiza la asertividad, la independencia y la dominación (masculinidad) o el cuidado y el apoyo a otros (feminidad).

- Evitación de la incertidumbre, es el grado en el que la cultura nacional tolera la desviación de normas y valores establecidos.

- Enfoque u orientación temporal; el grado en que la organización o sus miembros se orientan en el horizonte temporal; desde la más restringida (corto plazo) hasta la visión a largo plazo. Por su función, la Administración Pública pone en contacto directo a la ciudadanía con el poder político, satisfaciendo los intereses públicos de forma inmediata, por contraste con los poderes legislativo y judicial, que lo hacen de forma mediata. 
Como ya hemos visto en anteriores apartados, el crecimiento económico en sí mismo no es el objetivo de la sostenibilidad. La sostenibilidad abarca un concepto más amplio que hace referencia al desarrollo. El desarrollo y el crecimiento no son sinónimos, ya que el objetivo del desarrollo no es tener más, sino vivir mejor. La filosofía de la sostenibilidad pone el acento en un tipo de desarrollo que habría que considerar integral, en un concepto mucho más ambicioso que el simple crecimiento económico.

La organización tradicional, a la hora de evaluar su desempeño solo mide, evalúa y comunica sus resultados económicos y financieros. Solo se interesa por la dimensión económica de la sostenibilidad. La información económica y financiera es insuficiente para responder a las nuevas necesidades y a la rendición de cuentas a los grupos de interés (Garay, 1995).

La sostenibilidad económica y medioambiental para ser real tal debe ir acompañada de la equidad, producir cambios de mentalidad y de paradigma económico y provocar la reorientación de la tecnología hacia objetivos de eficiencia (Fernández Buey, 2004)

También Implica que la organización debe tener en cuenta las tres dimensiones de la sostenibilidad: económica, social y ambiental (Paternoster, 2011)

Para llegar a ser una organización sostenible debe interiorizar valores y principios tales como la visión sistémica, el bien común y la holarquía. Schwartz (2002) propone un conjunto de seis normas morales universales que incluyen confiabilidad, respeto, responsabilidad, equidad, atención y ciudadanía.

La holocracia es un sistema de organización en el que la autoridad y la toma de decisiones se distribuyen de forma horizontal en lugar de ser establecidas por una jerarquía de gestión. La holocracia es altamente compatible con la teoría de los participantes o grupos de interés (stakeholder theory) en la medida en que su estructura directiva permite que múltiples partes interesadas sean representados en el gobierno de una organización y para que múltiples organizaciones con intereses compartidos puedan estar vinculados a nivel de gobierno. Las ideas se desarrollan con más rapidez, hay menos burocracia y cada trabajador adquiere responsabilidad plena sobre los proyectos que le son designados. Empoderamiento y responsabilidad son las dos palabras clave para que el sistema funcione. (Oliver, 2016). Pero todo ello requiere de un cambio cultural que se refleje en un cambio organizativo.

Aunque seguramente no es la cultura el primer elemento que se viene a la cabeza al hablar de sostenibilidad, según Doppelt (2009), es que es uno de los factores clave para el éxito de un proceso de cambio hacia la sostenibilidad. Alterar los valores y normas que rigen las elecciones de cada aspecto de una organización es la clave (Doppelt, 2009).

Pese a haberse presentado por diferentes autores que la cultura es fundamental para la buena marcha del proceso de cambio hacia la sostenibilidad, en un estudio elaborado por McKinsey sobre la percepción que tienen las empresas del cambio climático se afirma que más del $70 \%$ de los directivos no tienen en cuenta entre sus estrategias de gestión de personal los objetivos de cambio climático y sostenibilidad (Arenas, 2010).

El cambio en las organizaciones sanitarias hacia la sostenibilidad tampoco es un camino fácil. El problema básico con que se encuentran es la resistencia al cambio. De forma 
natural las personas tienden a mostrarse reacias al cambio, para vencer esta resistencia hay que comprender su naturaleza y abordar los obstáculos y fuerzas que se oponen a él y nunca forzarlo mediante su imposición, siempre mediante el dialogo.

Las organizaciones con mayores índices de participación y una comunicación constante entre la dirección y el personal, son las que se encuentran con menos resistencia y por lo tanto avanzan a una velocidad mayor.

Si las personas de la organización tienen los conocimientos y el sentimiento de que pueden hacer algo para mejorar el futuro, lo harán. Por ello, lo primero es clarificar el objetivo general y dibujar un panorama positivo de cara al futuro; en segundo lugar, motivar e inspirar a las personas para que trabajen a favor de la sostenibilidad del sistema sanitario público; y por último, trabajar en sinergia para canalizar todos los esfuerzos en la misma dirección.

La organización debe ceder autoridad a los empleados para favorecer la creatividad para afrontar los problemas y el aprendizaje. Las estructuras organizacionales deben ser flexibles para aumentar la polivalencia de los profesionales y los grupos autogestionados. También debe favorecerse la coexistencia de elementos diversos que generen diálogo y aprendizaje (Gutiérrez y Peñalver, 2009).

Otro de los problemas importantes con los que las organizaciones pueden encontrarse es el inmovilismo o insensibilidad de las administraciones públicas o de las políticas que estas desarrollan. Incluso las hay que pecan de inercia activa insistiendo con ahínco en los mismos modelos que antes les funcionaron, a pesar de ser obsoletos y no válidos en el escenario actual.

Para Gutiérrez y Peñalver (2009) las organizaciones sostenibles deben estructurarse como sistemas dinámicos, complejos y no lineales, caracterizados por la existencia de un gran número de elementos que interactúan de manera compleja entre sí y con el entorno, que evolucionan a lo largo del tiempo generalmente alejadas del equilibrio, que son dependientes de su pasado, en las que nacen propiedades emergentes y cuya evolución futura es difícilmente predecible, aunque simultáneamente muestren la existencia de patrones ordenados

Según estos autores las organizaciones sanitarias responden a esquemas propios de los denominados sistemas complejos adaptativos, cuyos patrones de comportamiento y la estructura de sus unidades y servicios suelen ser difícilmente inteligibles desde un punto de vista estrictamente racionalista. Para ellos la arquitectura organizativa de las organizaciones sanitarias hace que, con frecuencia, su desarrollo y evolución sean poco predecibles, y la respuesta a las propias intervenciones de gobierno sanitario de los gestores y administradores puede resultar paradójica e incluso contradictoria.

En el momento actual, como ya se ha dicho en repetidas ocasiones, las instituciones sanitarias se encuentran en un contexto de cambio y transición desde unos esquemas previos de funcionamiento burocrático hacia modelos organizativos más flexibles, descentralizados, interactivos y comprometidos con la mejora continua de los 
resultados, para adaptarse a las realidades sociales y expectativas cambiantes de los ciudadanos y usuarios de los servicios de salud.

Las organizaciones sanitarias, cuyo activo fundamental es el conocimiento experto y que están sometidas a cambios tecnológicos rápidos, son posiblemente el paradigma de la autoorganización (Gutiérrez y Peñalver, 2009). La autoorganización se manifiesta en las organizaciones a través de estructuras formales e informales, y de redes de relación más o menos visibles o cambiantes. Entender esta realidad, y saber ponerla al servicio del buen funcionamiento de los sistemas, es una de las garantías más importantes del éxito en los proyectos de gestión (Gutiérrez y Peñalver, 2009).

Las organizaciones deben favorecer el aprendizaje complejo y la auto organización, para lo cual se deben plantear nuevas situaciones y problemas de manera activa y cambiante, además de favorecer el diálogo, las relaciones, el cuestionamiento de las posturas y la modificación de las mentalidades.

La iniciativa de cambio cultural puede surgir tanto dentro como fuera de la organización, de arriba abajo o viceversa. Para que se produzca este cambio de mentalidad es básico que todos los grupos de interés estén informados de los impactos que cada proceso conlleva y además se han de sentir capaces de convertirse en agentes de cambio. Según Olceste (2008) una práctica emergente entre las organizaciones líderes en sostenibilidad debe ser la integración de los grupos de interés internos y externos en el proceso de elaboración o revisión de sus códigos de conducta.

Uno de los fallos más comunes de las iniciativas sostenibles es la falta de comunicación entre las organizaciones y sus grupos de interés. Si queremos que se produzca el cambio, la comunicación ha de tener doble sentido, ha de ser activa e involucrar a la gente. Esto significa que ha de implicar personalmente tanto al emisor como al receptor, para que haya un flujo continuo de información. El resultado es que la visión y estrategia de sostenibilidad son internalizados y la gente reflexiona sobre lo que estos cambios significan para ellos personalmente.

Todos los individuos y grupos de interés no son iguales por lo que la información que han de recibir tampoco es la misma. Hay que entender a la audiencia para que la información que se les proporcione sea capaz de movilizar actitudes, creencias y comportamientos. La información ha de ser clara y fácil de entender ya que si no es así, si supone un esfuerzo mental elevado las personas tienden a desconectarse y por lo tanto será un esfuerzo perdido.

La sostenibilidad puede dar lugar a ciertos beneficios de reputación. En primer lugar, las organizaciones sostenibles tienen una mayor capacidad para atraer y retener a empleados de alta calidad (Turban, 1997). También pueden obtener beneficios en términos de negocio porque los clientes cada vez son más sensibles a las cuestiones de sostenibilidad (Russo, 1997).

La reputación juega un importante papel en mejorar el valor de la organización, la percepción de la calidad del producto, la moral de los empleados, la productividad, el reclutamiento y la retención (Barcellos, 2011).

Las predicciones a largo plazo sobre la sostenibilidad de las organizaciones sanitarias son muy complicadas en términos cuantitativos, por ello es necesario desarrollar un 
pensamiento estratégico continuado basado en modelos cualitativos generales acerca de la estructura y posición que mantiene la organización. Esta posición debe responder a lo que la sociedad demanda, y más en el ámbito público, la existencia de ciertos valores éticos. Es por todo ello por lo que los directivos deben favorecer la vocación de servicio al cliente, los valores democráticos y ecológicos, así como la búsqueda continua de la calidad y la excelencia (Gutiérrez y Peñalver, 2009).

Otro tema importante para entender el funcionamiento de las organizaciones sanitarias es su organización jerárquica y funcional. En las organizaciones sanitarias, los mandos intermedios son figuras claves. La influencia del mando intermedio sobre el personal es mucho más determinante que la de los directivos. Dichos puestos cada vez más son gestores y es necesario que los ocupen personas con habilidades de gestión para gestionar recursos humanos y materiales, sin embargo se sigue dando la paradoja de hacer nombramientos de jefes de servicio o sección en función de sus habilidades y conocimientos clínicos casi exclusivamente (Arenas, 2012) o de su antigüedad en el servicio u organización.

Algunos jefes tienen su plaza ganada por oposición y "de por vida"; amparados en la legislación anterior, y que, a menos que tengan alguna actitud claramente delictiva, no van a ser cesados de sus funciones; pueden no seguir las directrices institucionales y no cumplir los objetivos de la organización, y a pesar de ello son prácticamente "intocables". Todo queda a decisión personal del jefe y motivado por su compromiso personal con la institución.

En general, las organizaciones sanitarias públicas tienden a que sean nombrados jefes los profesionales más colaboradores con la institución y la dirección, y su nombramiento es provisional y de libre designación y por tanto pueden ser relevados de sus puestos de manera discrecional si no están alineados con los objetivos institucionales.

El profesional en este sistema sanitario jerarquizado suele establecer como prioritarios a la hora de ofrecer su lealtad y colaboración primero al grupo antes que a la institución (Arenas, 2012). Es consciente de que su continuidad laboral y su promoción no dependen tanto de la adherencia a los valores y fines de la institución como a los del grupo profesional concreto al que pertenece. Según Arenas (2012) las relaciones laborales en la gestión pública vienen perfectamente definidas hasta el más pequeño detalle, incluyendo los regímenes retributivos y las funciones de cada colectivo, lo que puede dar lugar a conflictos.

Todo ello hace que en las organizaciones sanitarias públicas sea más difícil conseguir que todo el personal (estatutario fijo) siga indicaciones de coste-eficiencia o conseguir la adherencia a las vías clínicas, guías de práctica clínica, procedimientos y protocolos institucionales, que permitan mejorar de forma continuada los procesos asistenciales.

En la asignación de recursos humanos y el establecimiento de plantillas en las diferentes organizaciones han influido a veces más los criterios de poder organizacional y profesional que las necesidades reales (Arenas, 2012). Esto demuestra que la política predominante en muchas organizaciones públicas es interés de los grupos de profesionales con más poder en el centro, entendiendo poder como capacidad de influir decisivamente sobre los indicadores clave o sobre la institución: demoras, estancia 
media, índice de ambulatorización, gasto farmacéutico per cápita..., etc. Esto explica por qué las plantillas de enfermería están en cierta medida tan infradimensionadas.

Por otro lado, el gestor público tiene que asumir unos presupuestos dados, cerrados y normalmente escasos, sin la capacidad legal de negociación con proveedores. Todo debe someterse a la ley de contratos de las administraciones públicas para asegurar la transparencia y la ética de sus actuaciones, aun a costa de perder capacidad negociadora.

La gestión pública durante la crisis buscaba gestores capaces de ajustarse al presupuesto para disminuir el déficit, sin embargo en circunstancias nos tan críticas económicamente se ha primado como factor determinante para la actuación de los gestores de la sanidad pública el que no provoquen conflictos internos o externos con sus medidas. El control de gestión en las organizaciones sanitarias públicas tiende a ejercerse mediante normas, dirección por objetivos, evaluación de los mismos y tratar de dar unos incentivos generalmente escasos.

Según explica Arenas (2012) al no haber muchos incentivos hacía la racionalización para el profesional hay una hiperinflación de las indicaciones de pruebas y tratamientos. Esto genera un mayor uso de la tecnología y de tratar de tener siempre la mejor tecnología disponible disparando los gastos y poniendo en duda la eficiencia económica de la organización.

Buscando mejores fórmulas de gestión para intentar mejorar principalmente la eficiencia del sistema público de salud se han elaborado y puesto en marcha diferentes fórmulas de externalización de la gestión. En las fundaciones, concesiones administrativas u otras fórmulas legales, la financiación y el control de la prestación que se ofrece siguen siendo públicos pero la gestión de la misma es privada o pública con otro régimen normativo diferente, con lo cual hay una autentica transferencia de maniobrabilidad y riesgo hacía la organización. Existe la posibilidad de ofrecer incentivos muchos más potentes a los profesionales para potenciar el cumplimiento de objetivos estratégicos (calidad, demoras, coste-eficiencia) y aumentar su implicación en la gestión clínica trasmitiéndoles responsabilidades gestoras.

\subsubsection{Modelos de sostenibilidad para el sector público}

La sostenibilidad está siendo cada vez más un valor en alza en el sector público, en el momento en el que se ha convertido en fundamental para las empresas privadas. En estas tiene un claro incentivo empresarial para mejorar su comportamiento socialmente responsable respondiendo a las demandas de los consumidores. La crisis económica y financiera reciente ha hecho que también en el ámbito público crezca la necesidad de adoptar políticas de sostenibilidad y herramientas que las posibiliten

Existen diferentes trabajos que tratan el tema de la sostenibilidad dentro del Sector Público. En este apartado varios a exponer diferentes estudios que de una forma directa o parcialmente tocan el tema de la sostenibilidad. Para ello se considera que un aspecto importante en la sostenibilidad del Sector Público tiene que ver con el mantenimiento en el tiempo de los esfuerzos para mejorar, y lograr la integración en la cultura de las 
organizaciones de la mejora continua y la innovación como elementos básicos para adaptarse a los cambios.

En un estudio realizado en Hong Kong (Dale, 1994), se propone un esquema teórico para la mejora de la calidad de los servicios del sector público. Su esquema teórico, presenta cuatro elementos claves: organización, medición y feedback, cambio cultural y sistemas y técnicas, que pueden resultar muy útiles en la mejora de los servicios públicos. Para cada uno Dale, describe diferentes actividades a realizar o técnicas a aplicar para la puesta en marcha del esquema teórico.

Otro trabajo que presenta el sector público, y más específicamente un gobierno local es el de Loomba y Spencer (1997). Basados en diferentes estudios analizaron los factores o variables de éxito de la implementación de herramientas de calidad total en el sector público. Después de recolectar y analizar los resultados de las encuestas propusieron un modelo teórico para la implantación del TQM en administraciones públicas (ilustración 7)

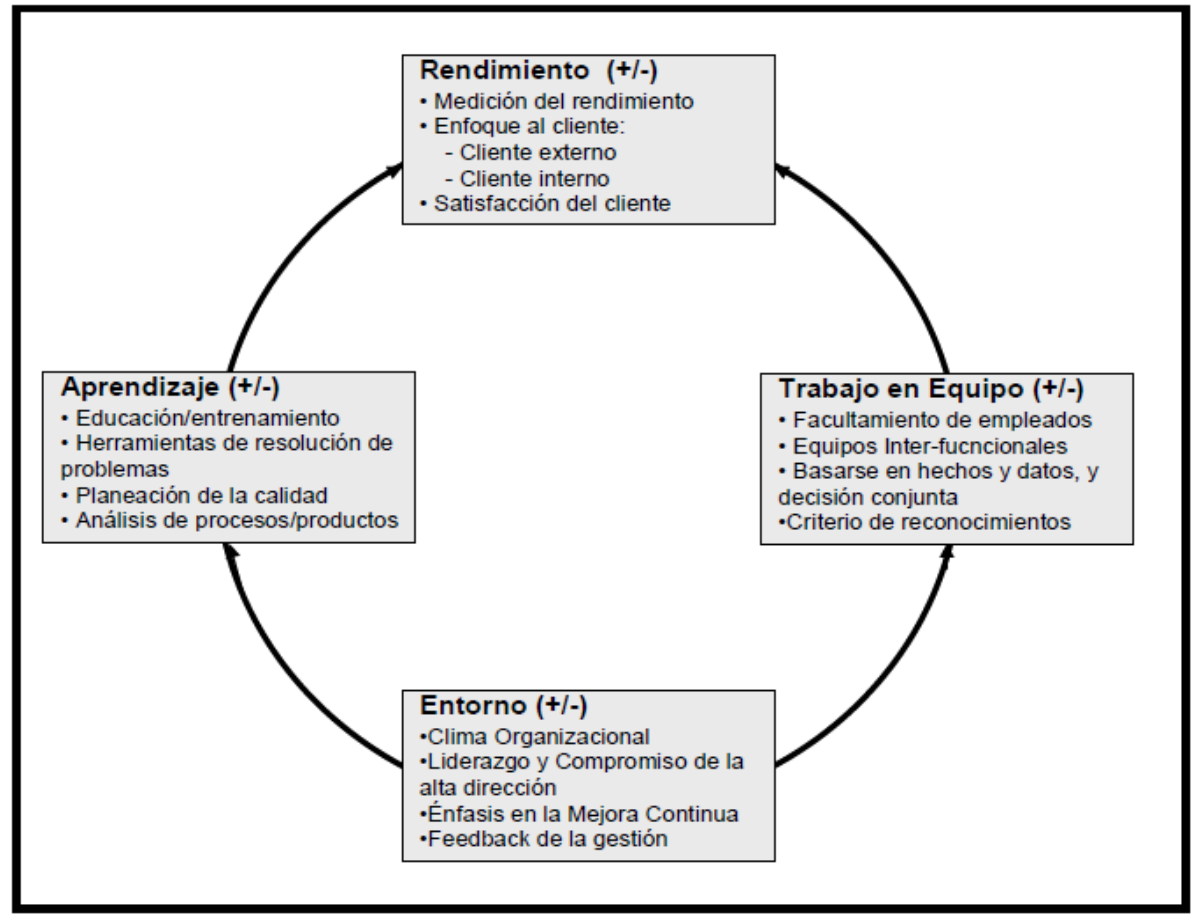

Fuente: Loomba, A. and M. Spencer (1997)

Tal y como se observa, el modelo de estos investigadores consta de cuatro elementos básicos (rendimiento, trabajo en equipo, aprendizaje y entorno), similares a lo propuesto por Dale, que enmarcan una serie de actividades de mejora, que son aplicadas para la consecución de estos elementos.

Los cuatro elementos que forman el ciclo del modelo, pueden proveer un reforzamiento tanto positivo como negativo al éxito de la implementación del TQM (Loomba y Spencer, 1997). Aunque este modelo no trata el tema de la sostenibilidad de manera directa, si 
existen suficientes experiencias positivas derivadas de su aplicación para que el rendimiento general de la administración pública se pueda ver impactado positivamente.

En otra investigación (McAdam et al., 2002) analizaron específicamente el tema de la sostenibilidad con diferentes modelos aplicados en el sector público en el Reino Unido. Según esta investigación el $33.8 \%$ de las instituciones públicas del Reino Unido ha sostenido un esfuerzo de mejora basado en modelos de calidad y excelencia durante más de cuatro años. Los autores afirman que se perciben efectos positivos en el rendimiento general de las administraciones públicas del Reino Unido que han utilizado modelos de excelencia.

Otro caso relevante de investigación cercano al tema de la sostenibilidad, es el presentado por Jones (2000) que realizó una investigación cualitativa acerca de la gestión de la calidad en un servicio público de una administración local del Reino Unido (gestión de parques y jardines). La investigación duró nueve años (1988-1997) y analizó el período de tiempo en el que la administración local pasó de gestionar mediante un modelo tradicional a uno basado en el TQM. Las conclusiones de este estudio señalan que la aplicación de modelos de TQM, ayudan a mejorar y a crear valor en los procesos de gestión, permitiendo así, establecer relaciones a largo plazo con los diferentes grupos de interés. Para Jones (2000), la aplicación sostenida de estos modelos de mejora permiten crear nuevas visiones de trabajo referente a la gestión de un servicio público generando mecanismos de participación de todos los actores involucrados (grupos de interés /stakeholders) en una nueva definición de lo que representa un servicio.

Por otra parte, Robertson y Ball (2002) realizaron un estudio cuantitativo y cualitativo para conocer el impacto del TQM en la mejora de los servicios públicos de un gobierno local en Canadá. Sus conclusiones con respecto al tema de la sostenibilidad fueron que si se aplican de manera sostenida la innovación y la mejora continua ayudan a incrementar con éxito, la calidad de los servicios públicos que ofrecen.

Algunos autores señalan que gran parte de este cambio y mejora en la gestión de la administración pública necesita el liderazgo y el rol crítico que juegan los gerentes, funcionarios públicos y mandos intermedios de la organización, como generadores y potenciadores de estos cambios. (Losada, 2007).

Otros autores han indicado que los esfuerzos para mejorar continuamente el sector público, deben centrarse en un pensamiento a largo plazo sostenido, en el que los empleados públicos previamente formados y motivados, vayan consiguiendo de manera incremental pequeños cambios en los procesos de trabajo, que mantengan un reto continuo para seguir en el camino de la mejora (Vonk, 2005).

Moore (2005) indica al respecto que para poder aplicar la mejora de los procesos de trabajo en el sector público de manera eficaz y sostenida deben utilizarse dos métodos u aproximaciones de mejora:

- Rediseño de procesos

- Mejora continua incremental

Bessant (2005) afirma que las organizaciones del sector público deben aprender cómo gestionar las mejoras y la innovación tanto a corto como a largo plazo. Este aprendizaje puede convertirse en un mecanismo de ayuda necesario para afrontar los retos que se 
plantean, con respecto a la oferta de nuevos servicios, a mantener los niveles de calidad de los ya existentes, y a mejorar la eficiencia operativa de sus procesos.

Conseguir que el trabajo con TQM se sostenga en el tiempo, requiere de la adaptación a las particularidades y necesidades de cada organización pública, y por tanto, es fundamental crear los mecanismos, infraestructuras y soportes políticos y técnicos necesarios con el fin de generar una nueva cultura.

La aplicación de TQM en una administración pública impacta de manera directa en la mejora de la eficiencia y genera motivación y participación de los empleados públicos, creando una cultura o entorno orientado a la mejora continua, que lentamente sustituya a cualquier entorno previamente establecido, institucionalizando el esfuerzo de mejora (Houston y Katavic, 2006).

Pollit (2006) identifica qué fallos hacen que la mejora de la calidad de los servicios públicos no se sostenga en el tiempo:

- Implantarlo sólo para obtener publicidad que ayude a consolidar posibles victorias en las elecciones o algún otro tipo de reconocimiento de esa índole.

- No tener en cuenta a las personas de la organización como técnicos conocedores de los procesos. La calidad requiere de decisiones conjuntas para su éxito y sostenibilidad.

- Resistencia al cambio de las personas de la organización que ya trabajan con un método y procedimientos establecidos.

- La elección inicial de la norma o el modelo no es adecuada para el contexto público dónde se piensa aplicar.

- Para la implantación se utilizan recursos financieros y humanos adicionales, y cuando estos recursos desaparecen el proyecto se desvanece.

- Cuando se plantean objetivos demasiado ambiciosos y cuando comienzan a llegar los resultados que son más modestos, la gente comienza a desilusionarse y a perder la motivación

- Formación a equipos reducidos, lo que provoca que cuando los integrantes de estos equipos, previamente formados son traslados o cambiados, se pierde el conocimiento y experiencia adquirida.

- No se gestiona el despliegue de los resultados que se van obteniendo en la institución, la finalidad de hacerlo ayudaría a convencer a las mayorías o minorías que todavía se resisten al cambio.

- Reforma de modernización basado en modas en los gobiernos.

- Conversión del sistema en un esquema burocrático y formalizado, que pierde la esencia de participación de los actores involucrados.

Para Juan Ignacio Martín-Castilla (2007) los enfoques basados en la excelencia o calidad total permiten a las organizaciones tener conciencia del efecto que las acciones de la organización provocan sobre los grupos de interés. Estos enfoque proporcionan una interpretación holística de la realidad, ocupando un lugar fundamental la visión finalista de los grupos de interés (a cuya satisfacción orienta su actividad la organización), la asunción de responsabilidades, la implicación de las personas que integran la organización, la orientación a los clientes y a los resultados, el liderazgo 
efectivo y la coherencia con los objetivos que persigue la organización, y la adopción de una cultura de la mejora continua.

Además según Martín-Castilla (2007), el carácter inalcanzable de la excelencia, hace que las organizaciones tengan que estar siempre atentas al entorno, a las necesidades del mercado, y a sus propios recursos, capacidades y rendimiento, con la intención de mejorar continuamente y adaptarse a los diferentes escenarios de forma sostenible.

En todos estos trabajos presentados es fundamental la participación de los grupos de interés. Como ejemplo de esto, el Gobierno Vasco lideró el proceso de elaboración de la primera Estrategia de Desarrollo Sostenible al año 2020 (Uriarte, 2011) con el objetivo de situar Euskadi entre las regiones más avanzadas de Europa en materia de sostenibilidad. El objetivo de esta iniciativa fue elaborar una hoja de ruta sobre aspectos de prosperidad económica, equidad y cohesión social, y protección del medio ambiente construida fundamentalmente de abajo a arriba. El proceso de elaboración de la Estrategia se diseñó desde su inicio con el objetivo de alcanzar la máxima participación posible incluyendo a la administración pública en su conjunto (Gobierno Vasco, Diputaciones Forales y Ayuntamientos), a los agentes socio-económicos y a la ciudadanía en general. Con la participación directa en sesiones de trabajo presenciales de más de 4.000 personas (jóvenes. agentes sociales, agentes económicos, agentes institucionales...); la contribución a través de grupos focales y encuestas de 1.272 ciudadanos y ciudadanas; y el acercamiento a través de medios virtuales de más de 700 personas Todo el proceso participativo se realizó cuidando especialmente la transparencia y la construcción de consensos básicos en torno a la sostenibilidad.

Siguiendo el propio modelo EFQM y tomando como referencia los conceptos fundamentales, AEVAL (2013) afirma que para crear un futuro sostenible, las organizaciones excelentes producen un impacto positivo en el mundo que les rodea porque incrementan su propio rendimiento al tiempo que mejoran las condiciones económicas, ambientales y sociales de las comunidades con las que tienen contacto.

En la práctica las organizaciones excelentes:

- Aseguran el futuro de la organización al definir y comunicar su objeto fundamental de servicio público, que constituye el fundamento de la Visión, Misión, valores, principios éticos y cultura.

- Interpretan sus competencias clave y cómo pueden generar valor compartido en beneficio de la sociedad en general.

- Integran los conceptos de sostenibilidad (económica, social y ambiental) en su estrategia fundamental, cadena de valor y diseño de procesos, asignando los recursos necesarios para hacer realidad estos objetivos.

- Toman como referencia las tres dimensiones económica, ambiental y social a la hora de equilibrar las políticas públicas que afrontan.

- Animan a sus grupos de interés a participar en actividades en beneficio de la sociedad en general.

- Asignan recursos según las necesidades a largo plazo y no sólo la rentabilidad a corto y, cuando la competitividad es relevante, asignan recursos para que la organización sea y se mantenga competitiva.

- Diseñan su cartera de productos y servicios públicos y gestionan activamente todo su ciclo de vida de manera responsable. 
- Demuestran que miden y optimizan el impacto de operaciones, servicios públicos y ciclo de vida de los productos sobre la salud pública, la seguridad y el medio ambiente.

- Promueven activamente los estándares económicos, ambientales y sociales en su sector.

Otros autores (Castillo y Alonso, 2011) también plantean el uso de memorias de RSC como herramienta para conocer cómo influyen y se aplican en la Administración Pública las distintas políticas relacionadas con la responsabilidad social y la sostenibilidad, asumiendo que, como organización pública, deben dar ejemplo al respecto. Este estudio destaca la importancia de una implantación gradual y de un esfuerzo de sensibilización y formación, especialmente en los niveles directivos de cada organización y particularmente en las fases iniciales del proceso de implantación. Los informesmemoria correspondientes permiten tener una foto que aporta información de interés para la sociedad y representa un reto y una motivación expresa para que los distintos departamentos de la Administración Pública, asuman, de una manera general, la sostenibilidad como un objetivo compartido y comiencen a establecer unos mecanismos y una infraestructura para su promoción y seguimiento interno.

Para la Agencia Estatal de Evaluación de las Políticas Públicas y la Calidad de los Servicios (AEVAL, 2011) existen diferentes modelos de trabajar la sostenibilidad (principios, guías, normas y sistemas de medición aplicables a los Servicios Públicos (tabla 12)

Tabla 12. Estructura de los modelos de sostenibilidad. AEVAL

\begin{tabular}{|c|c|c|}
\hline Propósito & Objetivo & Algunos ejemplos \\
\hline $\begin{array}{l}\text { Modelos } \\
\text { Normativos (qué } \\
\text { hacer) }\end{array}$ & $\begin{array}{l}\text { Proporcionar orientación básica } \\
\text { sobre lo que se entiende por } \\
\text { niveles aceptables de } \\
\text { sostenibilidad }\end{array}$ & 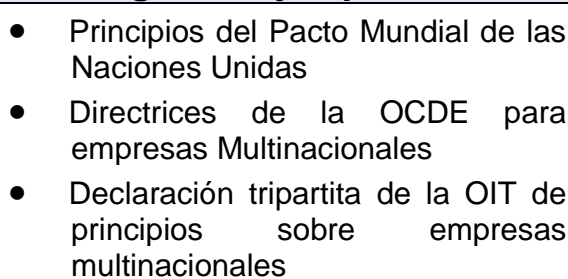 \\
\hline $\begin{array}{l}\text { Guías operativas } \\
\text { (cómo medir y } \\
\text { comunicar } \\
\text { sostenibilidad) }\end{array}$ & $\begin{array}{l}\text { Hacer posible la medición, el } \\
\text { aseguramiento y y la } \\
\text { comunicación de las practicas } \\
\text { sostenibles de la organización }\end{array}$ & $\begin{array}{l}\text { - Guías de la GRI para la elaboración } \\
\text { de memorias de Sostenibilidad } \\
\text { (suplemento para el sector público) } \\
\text { - } \quad \text { Norma de aseguramiento AA 1000 } \\
\text { - SROI (retorno social de las } \\
\text { inversiones) } \\
\text { - Modelo de CIPFA (Reino Unido) } \\
\text { para la elaboración de Memorias } \\
\text { para el sector público }\end{array}$ \\
\hline $\begin{array}{l}\text { Modelos Genéricos } \\
\text { de Gestión que } \\
\text { incluyen la } \\
\text { sostenibilidad (forma } \\
\text { de integrar la } \\
\text { sostenibilidad en el } \\
\text { sistema de gestión) }\end{array}$ & $\begin{array}{l}\text { Proporcionar modelos de } \\
\text { gestión integrada (o de } \\
\text { autoevaluación) para gestionar } \\
\text { los impactos ambientales, } \\
\text { sociales y económicos }\end{array}$ & $\begin{array}{l}\text { - Cuadro de Mandos Integral de la } \\
\text { Sostenibilidad } \\
\text { - } \quad \text { Modelos de Excelencia (EFQM) }\end{array}$ \\
\hline $\begin{array}{l}\text { Sistemas } \\
\text { específicos de } \\
\text { gestión de la } \\
\text { sostenibilidad } \\
\text { (cómo enfocar mejor } \\
\text { la sostenibilidad) }\end{array}$ & $\begin{array}{lr}\text { Proporcionar } & \text { directrices } \\
\text { específicas } & 0 \\
\text { autoevaluación que se centran } \\
\text { en la sostenibilidad }\end{array}$ & $\begin{array}{l}\text { - Guía ISO/DIS } 26000 \text { sobre } \\
\text { responsabilidad social } \\
\text { - BS } 8900 \text { para guiar el desarrollo } \\
\text { sostenible }\end{array}$ \\
\hline
\end{tabular}

Fuente: Tomado de AEVAL, (2011). Adaptado de Ligteringer y Zadek, (2005) 
Para AEVAL la medición de la sostenibilidad puede realizarse desde diferentes modelos reconocidos internacionalmente. Cada modelo tiene una filosofía diferente. Todos los modelos tienen ventajas e inconvenientes, pero su aportación a la mejora de la sostenibilidad depende del grado de entusiasmo con el que la organización aborde el tema y los resultados concretos que pueda aportar.

AEVAL abogaba ya en 2011 por la creación de un modelo simplificado para medir la sostenibilidad mediante evaluaciones internas y memorias basadas en un reducido conjunto de indicadores clave centrados en el rendimiento sostenible de la organización y en el impacto de las políticas y servicios públicos. Añade que este modelo podría utilizarse en combinación con los modelos de excelencia organizativa como EFQM. Esto permite la integración efectiva de la sostenibilidad en el sistema de gestión de las organizaciones.

\subsection{Las organizaciones sanitarias}

Las organizaciones son modalidades específicas y transitorias de estructuración de las instituciones y constituyen una herramienta o instrumento para alcanzar unos fines específicos de manera colectiva y organizada (Brunet, 2016), en este caso preservar la salud.

Según Brunet (2016) el concepto de organización se configura en torno a estas seis ideas básicas:

1. Es un sistema abierto. Un conjunto de elementos interrelacionados entre sí y con el entorno.

2. Es una construcción social formada por personas, aunque también se necesitan otros recursos

3. Está coordinada de forma consciente. Es necesaria la función directiva o administrativa para coordinar esfuerzos y tomar decisiones

4. Tiene unos límites definidos. Se conoce quién o qué pertenece a ella y quién o qué no.

5. Se crean con voluntad de continuidad y permanencia

6. Buscan alcanzar su misión. Unos objetivos comunes que no se podrían alcanzar individualmente o que se alcanzan más eficientemente de forma colectiva y organizada.

La organización actual de la sanidad es el resultado de los cambios sociales y políticos del siglo XIX y XX (Durán, 2016)

La institución más característica de la organización sanitaria moderna es el hospital. La medida en que la organización cumple sus objetivos constituye su nivel de eficacia. Que la organización sea más eficaz que otra depende sustancialmente del modo y manera en que haya sido estructurada y que permite medir su nivel de eficiencia. (Brunet, 2016). La eficiencia de una organización depende principalmente, aunque no exclusivamente, de su estructura. La estructura de la organización constituye el instrumento operativo 
para conseguir los objetivos y, por tanto, el cambio de los objetivos se traduce en un cambio estructural para responder a los retos planteados por el entorno. (Brunet, 2016)

El organigrama de un hospital revela el tipo de estructura que determina sus relaciones y procesos sociales. En base a ello actualmente se pueden identificar diferentes tipos de instituciones sanitarias.

Podríamos considerar el organigrama tradicional de carácter vertical el que se muestra en el siguiente esquema (ilustración 8).

Ilustración 8. Organigrama del Hospital Provincial de Madrid (Gregorio Marañón) en 1980

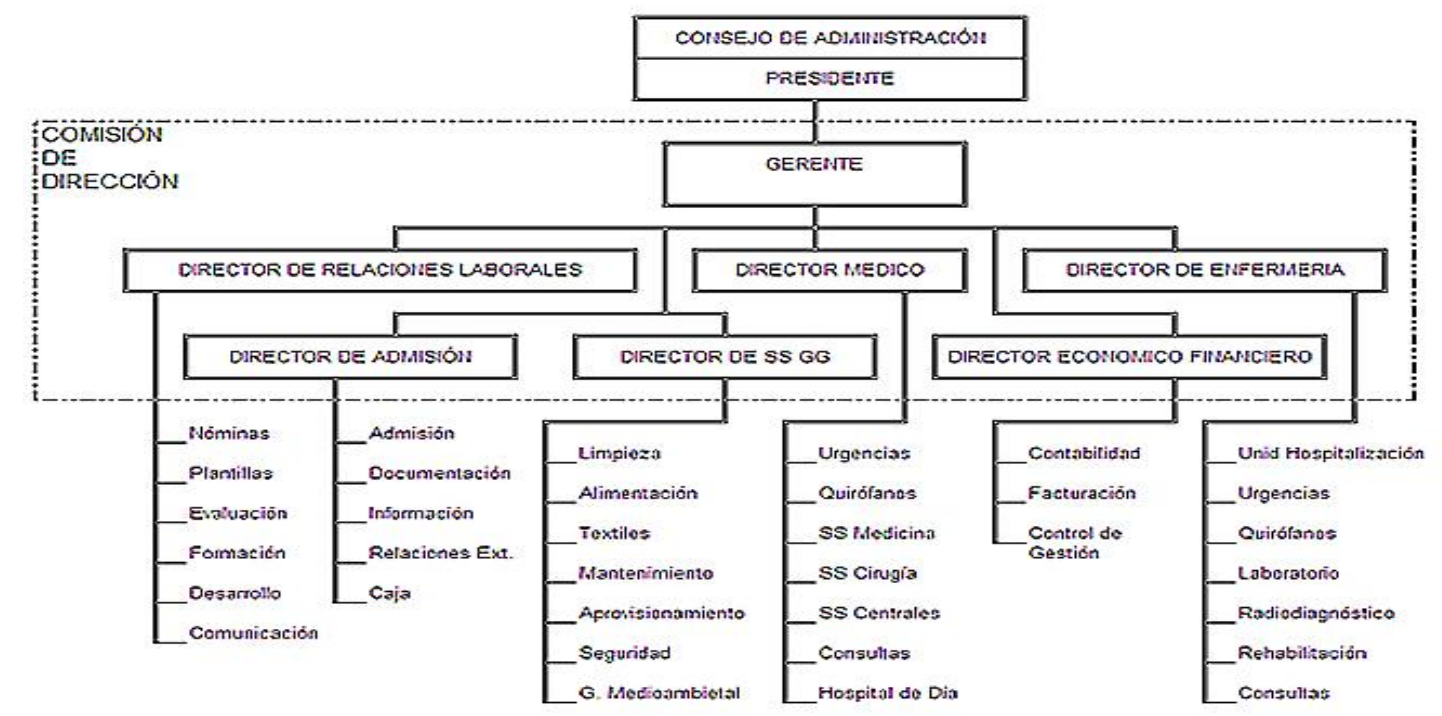

Fuente: Dr. D. José Antonio Moreno. Disponible en http://www.ceem.org.es

Como se puede apreciar también en el organigrama anterior, los hospitales se organizan por servicios asistenciales, de gestión y de apoyo, Los servicios asistenciales están organizados en torno a las diferentes especialidades médicas y suelen contar con un jefe de servicio, adjuntos y en algunos casos residentes en el área médica y con supervisora, enfermeras y auxiliares en el área de los cuidados. Desarrollan su labor en hospitalización, consultas y quirófanos u otros dispositivos en función de la especialidad.

Los servicios de apoyo tienen que ver con la hostelería, la informática o el mantenimiento, aunque en muchos caos estos servicios se han externalizado. Por otra parte los servicios de gestión son los responsables de la gestión de personas y económica.

En las organizaciones sanitarias se ha recorrido un largo camino tratando de hacer tangible aspectos tan subjetivos como la calidad de servicio, otros no tanto como la calidad científico- técnica o la accesibilidad, para acabar asumiendo que todas las actividades y componentes de la organización han de orientarse hacia las necesidades y expectativas de los pacientes y, hacia los resultados a través de un liderazgo ejemplar, implicando a todos los grupos de interés, organizando eficientemente los procesos e innovando, aprendiendo y mejorando continuamente. EFQM define la excelencia como «aquella manera sobresaliente de gestionar una organización capaz de obtener resultados permanentes en el tiempo para todos los grupos de interés, mediante la 
aplicación de los ocho conceptos fundamentales de la excelencia». Por lo tanto, EFQM insiste en que la excelencia es una estrategia de gestión que engloba a la totalidad de la organización. Como ya se ha señalado, en el ámbito sanitario supone pasar de aspectos concretos científico-técnicos, a la consideración de la globalidad, de todos los procesos del centro asistencial.

Desde la década de los 80 la tendencia es a sustituir la tradicional organización por funciones por la organización por procesos recogida en diferentes modelos de gestión entre los que se encuentra el EFQM. Se trata de reducir la ineficiencia interna de la organización funcional unificando actividades en torno a los procesos (Brunet, 2016).

Una de las ventajas que ofrece la organización basada en procesos u horizontal es su flexibilidad, pues no se encuentra sometida a las tradicionales divisiones estructurales, de tal modo que la misma persona puede desempeñar varias tareas. Permite agrupar tareas en función de la disponibilidad del personal y sus posibilidades. (Brunet, 2016).

La organización horizontal elimina la jerarquía vertical y los límites de los departamentos funcionales. Los procesos y los proyectos responden a áreas de actividad integrales perfectamente identificadas que enlazan todas las tareas conducentes a un determinado resultado. En cada proceso pueden existir diferentes tipos de trabajo que son coordinados bajo un liderazgo que coordina. (Brunet, 2016). Son equipos autónomos multifuncionales, multiprofesionales, y altamente cualificados que requieren de una actualización constante (Brunet, 2016).

Las organizaciones gestionadas por procesos tienen un organigrama similar al que se muestra a continuación (ilustración 9).

Ilustración 9. Organigrama del Hospital San Nicolás

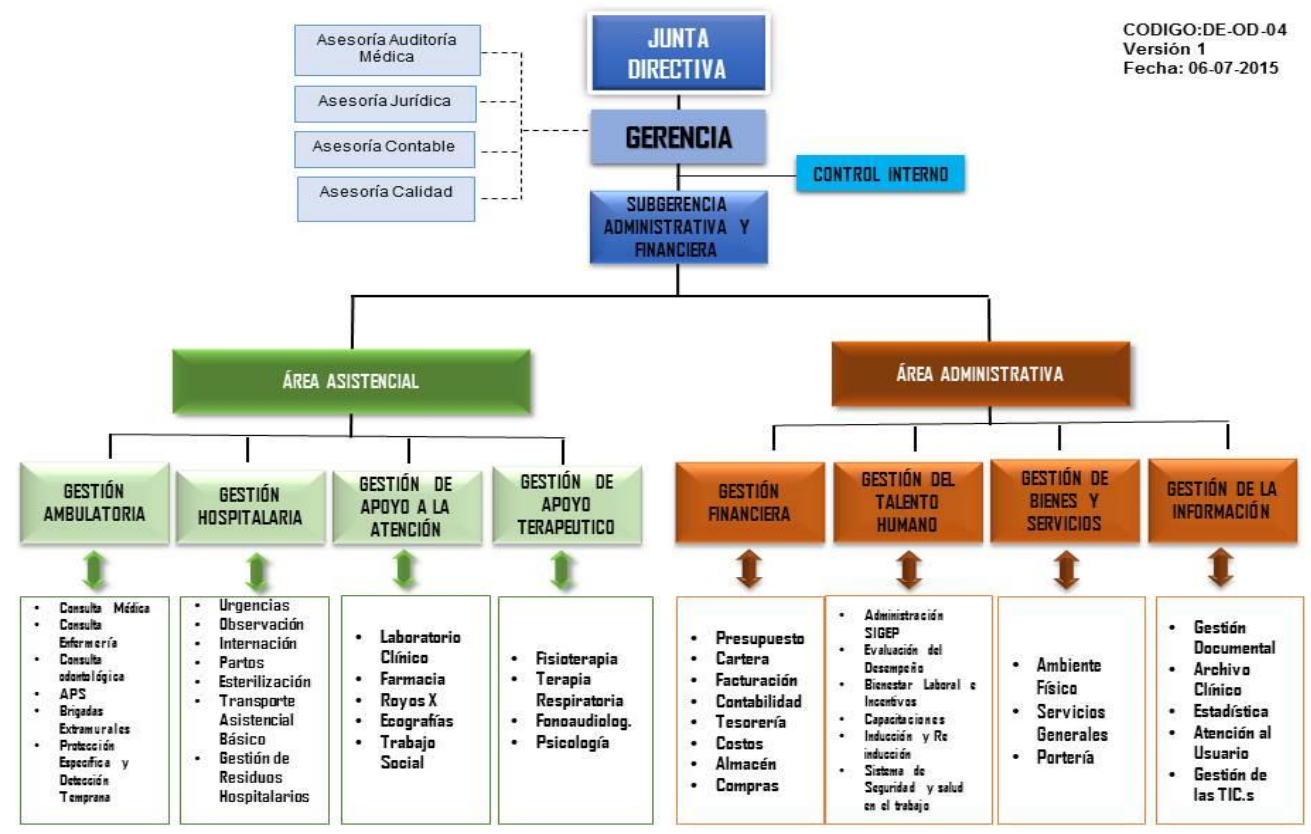

Fuente: Disponible en http://www.hospitalsannicolasese.org/organigrama.html.Visitado: 14/08/2017

También, a finales del siglo XX se desarrolló la idea de las áreas de gestión. La mayoría de los hospitales públicos españoles, como ya se ha mostrado, disponían de una 
estructura vertical bajo directrices centralizadas, basadas en los postulados del derecho administrativo, incluso después de haberse transferido las competencias asistenciales a distintas comunidades autónomas. Como consecuencia, la estructura de gestión, organización y financiación de la organización estaba orientada más al cumplimiento de los procedimientos formales de la función pública que al logro de resultados mediante la optimización de recursos humanos y materiales. Esta situación da lugar a una organización rígida, que diluye la responsabilidad de los equipos directivos y no es capaz de resolver los conflictos que plantean las relaciones laborales (Castro Beiras, 1998).

Por todo ello se propuso la creación de áreas autogestionadas (Ilustración 10), con la mayor autonomía de funcionamiento posible, consigue la participación del personal asistencial en la organización y consecución de los objetivos clínicos y económicos, haciendo que el eje de toda esta transformación sea el paciente.

De esta forma, podemos afirmar que el objetivo estratégico de este modelo organizativo es incrementar la eficiencia y calidad de las prestaciones sanitarias dispensadas por las áreas asistenciales.

Ilustración 10. Organigrama del área del corazón del complejo hospitalario Juan Canalejo

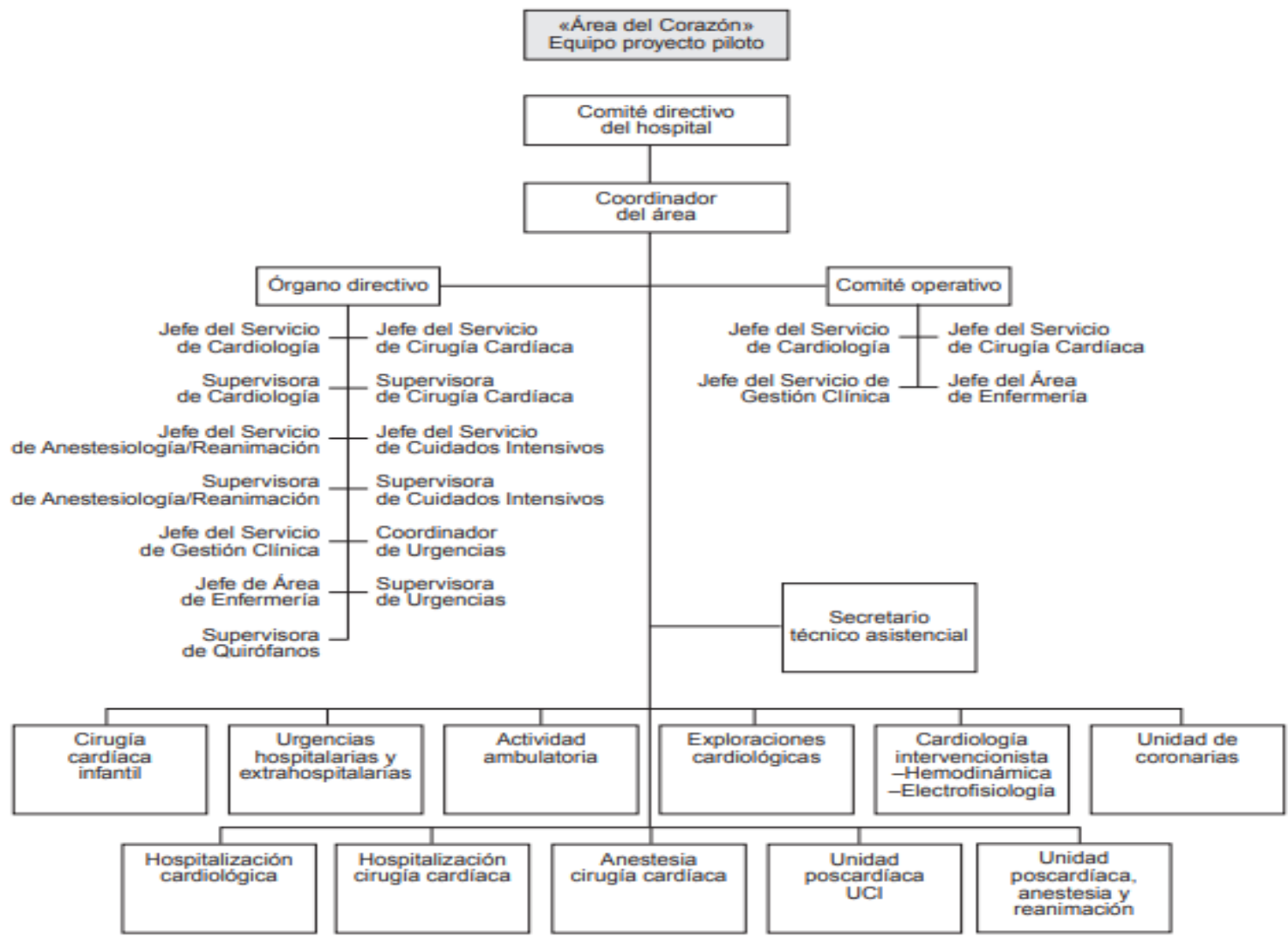

Fuente: Rev Esp Cardiol. 1998;51:611-9 - Vol. 51 Núm.8

Actualmente la tendencia más extendida, y hacia la que parece que se dirigen las organizaciones sanitarias, son las organizaciones integradas (Ilustración 11). Se trata de facilitar la relación entre atención primaria y atención especializada facilitando la optimización de recursos y la comunicación entre profesionales para dotar a la asistencia a los pacientes de unidad de criterios y continuidad asistencial. 


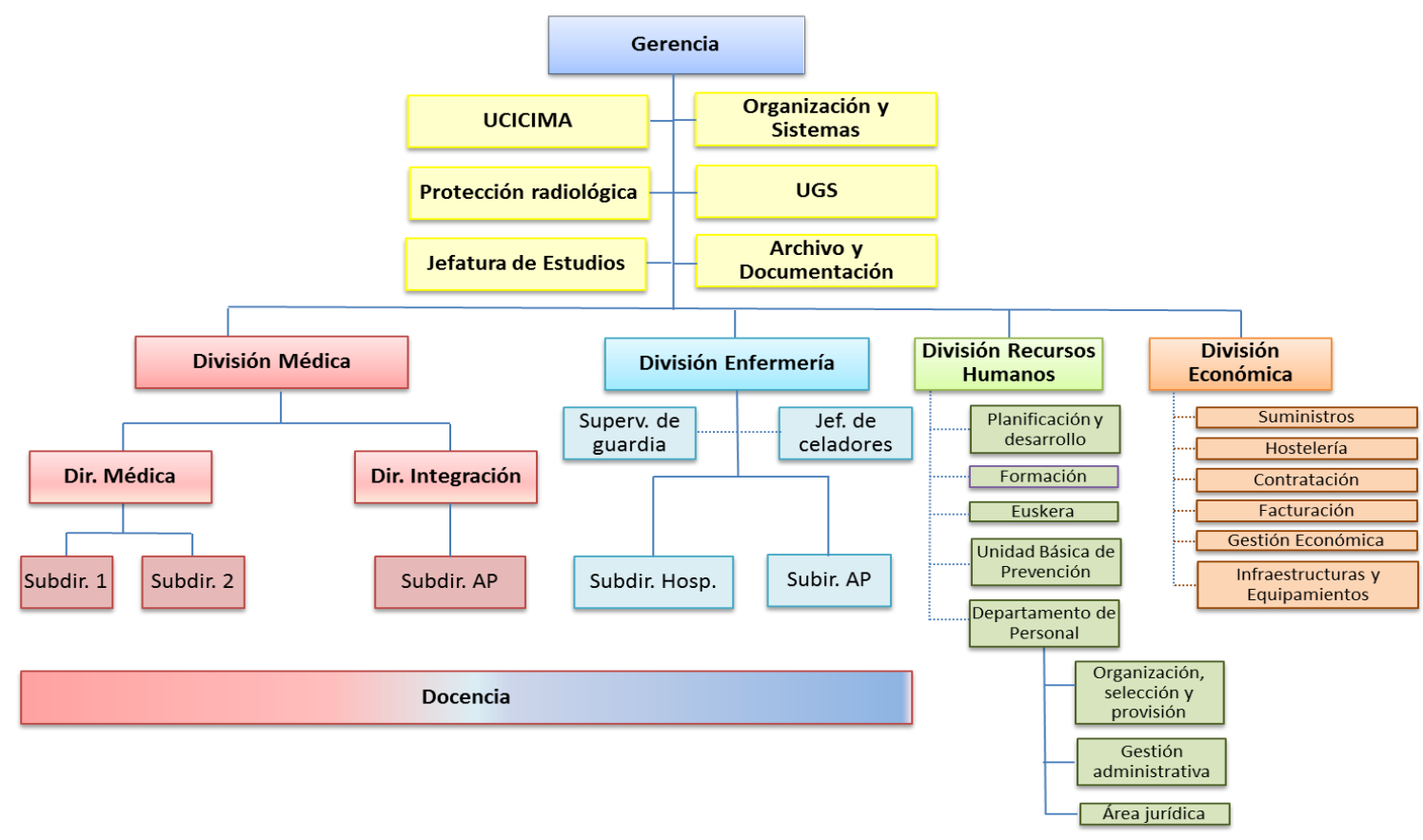

\subsubsection{Abordaje de la sostenibilidad del sistema sanitario}

Una vez conocidos los elementos necesarios de cambio se plantea la forma de implantarlos de una forma coordinada, priorizada, comunicada, organizada, midiendo su eficacia e implicando a todos los grupos de interés. Es en este momento en el que surge el trabajo con el modelo EFQM como una oportunidad que puede permitir llevar a cabo esta transformación del SNS de una forma organizada y suficientemente validada en otros ámbitos e incluso en el propio ámbito de la salud. La aplicación continuada de un modelo de gestión de la calidad, como el EFQM, puede facilitar la introducción progresiva de mejoras que desembocan en una verdadera sostenibilidad (GonzálezLombide E. 2009).

En el ámbito sanitario, el modelo EFQM tiene defensores. Así, por ejemplo Arcelay (2000) señala que se trata de un modelo ampliamente utilizado y que, por tanto, permite comparar estrategias. Además su contenido es tan genérico que cada sector, incluido el sanitario, debe adecuar ciertas partes del modelo a su particular situación para poder aplicarlo y permitir introducir herramientas que faciliten el salto hacia una cultura de la calidad en las organizaciones sanitarias.

Asimismo presenta un indudable valor didáctico. Si lo utilizan los clínicos, pueden identificar de forma sencilla aspectos que tienen que tener en cuenta para gestionar un grupo humano y unos recursos materiales.

El modelo en el ámbito de la salud ha sido ampliamente testado y ha ganado en experiencia, en rodaje, en madurez, y cuenta con el aval de evaluadores y evaluados convirtiéndose en una herramienta certera y fiable (tabla 13), una especie de GPS hacia la excelencia (Arcelay, 2010). 
Puede integrar las diferentes iniciativas que esté desarrollando la organización, actuando como marco de referencia y coordinando esfuerzos

Tiene un enfoque que equilibra el peso de los agentes (Qué se hace) y el de los resultados obtenidos (Qué se logra)

La autoevaluación determina sus puntos fuertes y áreas de mejora

Tiene un planteamiento a largo plazo

Potencia el liderazgo efectivo y la colaboración entre personas

La estrategia de la organización está presentes en todas las actividades

Favorece el trabajo con otros y, permite realizar gestión de riesgos en todos los ámbitos

Estimula a las organizaciones a compararse con los mejores

Impulsa el desarrollo de la mejora continua por encima de la consecución de logro Permite a la organización demostrar sus tendencias positivas, tanto en los resultados, como en la percepción de todos sus grupos de interés

Elaboración propia. Tomado de Fortuny (2009)

Para Arcelay (2010) el camino de la excelencia en las organizaciones sanitarias (y públicas) es un camino lleno de conceptos fundamentales como, la transparencia, la sostenibilidad, los valores compartidos, la rendición de cuentas y por supuesto los resultados equilibrados y el valor para los clientes, que en definitiva constituyen los principales atributos de la ética en las organizaciones.

En línea con esto Matthies-Baraibar (2014) señala que el avance de las organizaciones de salud en la aplicación del modelo EFQM de Excelencia está asociado con el aumento de la satisfacción de sus empleados en aquellos aspectos que pueden ser manejados por la propia organización, mientras que en los que no tiene capacidad de decisión la propia organización no se han encontrado diferencias estadísticamente significativas con organizaciones no EFQM.

El estudio de Matthies-Baraibar y otros (2014) muestra la evidencia que muestra el impacto a largo plazo de una intervención de organización compleja tales como la adopción del modelo EFQM en una serie de las organizaciones de salud dentro de una sola entidad pública, Osakidetza.

Todas las organizaciones de salud dentro de Osakidetza han estado expuestas al modelo EFQM y que todas ellas lo han adoptado, en mayor o menor medida.

Los progresos realizados por las organizaciones de salud de Osakidetza en la aplicación del modelo EFQM se asocia con un mayor nivel de satisfacción de los empleados en los campos que se pueden administrar de forma independiente por cada organización, mientras que no se observaron diferencias significativas en aquellos aspectos que son más homogénea y centralmente administrados a través del servicio regional de salud y en el que cada organización tiene menos posibilidades de autogestión.

Este estudio también muestra que cuanto mayor es el avance en la implementación del modelo (como en el caso de las organizaciones con Premios $Q$ de oro en comparación con aquellos con premios de plata $Q$ ), mayores son las diferencias en términos de satisfacción del personal con las organizaciones menos avanzados (los que no tienen ningún tipo de reconocimiento externo) y en una gama más amplia de dimensiones. 
Según Zardoya (2007), una gestión basada en la calidad total alcanza su mayor efectividad cuando la calidad se convierte en una parte esencial de la política corporativa. Utilizar el modelo europeo de excelencia, o cualquier otro sistema o herramienta de calidad, es una decisión estratégica que puede aportar una serie de beneficios a las organizaciones sanitarias que deciden optar por el modelo (Narbate, 2007). 


\subsection{La calidad}

La calidad ha sufrido multitud de cambios y desarrollos antes de llegar al concepto que tenemos hoy en día de ella. Para lograr una mejor comprensión de qué es calidad y cuál es su importancia, el primer paso debe ser que conozcamos cómo y porqué estamos en el punto en el que estamos (tabla 14)

Tabla 14. Resumen de la evolución histórica de la calidad

\begin{tabular}{|c|c|c|}
\hline Etapa & Concepto & Finalidad \\
\hline $\begin{array}{l}\text { Edad Media } \\
\text { (Artesanos) }\end{array}$ & $\begin{array}{l}\text { Hacer las cosas bien, } \\
\text { Independientemente del coste o } \\
\text { esfuerzo necesario para ello. }\end{array}$ & $\begin{array}{l}\text { Satisfacer al cliente. } \\
\text { Satisfacer al artesano, } \\
\text { por el trabajo bien hecho } \\
\text { Crear un producto único. }\end{array}$ \\
\hline $\begin{array}{l}\text { Revolución } \\
\text { Industrial }\end{array}$ & $\begin{array}{l}\text { Hacer muchas cosas no } \\
\text { importando que sean de calidad } \\
\text { (Se identifica producción con } \\
\text { calidad). }\end{array}$ & $\begin{array}{l}\text { Satisfacer una gran demanda } \\
\text { de bienes. } \\
\text { Obtener beneficios }\end{array}$ \\
\hline $\begin{array}{l}\text { Segunda } \\
\text { Guerra } \\
\text { Mundial }\end{array}$ & $\begin{array}{l}\text { Asegurar la eficacia del } \\
\text { armamento sin importar el costo, } \\
\text { con la mayor y más rápida } \\
\text { producción (eficacia + plazo = } \\
\text { calidad) }\end{array}$ & $\begin{array}{l}\text { Garantizar la disponibilidad de } \\
\text { un armamento eficaz en la } \\
\text { cantidad y el momento } \\
\text { preciso. }\end{array}$ \\
\hline $\begin{array}{l}\text { Posguerra } \\
\text { (Japón) }\end{array}$ & Hacer las cosas bien a la primera & $\begin{array}{l}\text { Minimizar costes } \\
\text { mediante la calidad } \\
\text { Satisfacer al cliente } \\
\text { Ser competitivo }\end{array}$ \\
\hline $\begin{array}{l}\text { Postguerra } \\
\text { (Resto del } \\
\text { mundo) }\end{array}$ & Producir, cuanto más mejor & $\begin{array}{l}\text { Satisfacer la gran demanda de } \\
\text { bienes causada por la guerra }\end{array}$ \\
\hline $\begin{array}{l}\text { Control de } \\
\text { calidad }\end{array}$ & $\begin{array}{l}\text { Técnicas de inspección en } \\
\text { Producción para evitar la salida de } \\
\text { bienes defectuosos. }\end{array}$ & $\begin{array}{l}\text { Satisfacer las necesidades } \\
\text { técnicas del producto }\end{array}$ \\
\hline $\begin{array}{l}\text { Aseguramiento } \\
\text { de la calidad }\end{array}$ & $\begin{array}{l}\text { Sistemas y procedimientos de la } \\
\text { organización para evitar que se } \\
\text { produzcan bienes defectuosos }\end{array}$ & $\begin{array}{l}\text { Satisfacer al cliente. } \\
\text { Prevenir errores. } \\
\text { Reducir costes. } \\
\text { Ser competitivo }\end{array}$ \\
\hline Calidad total & $\begin{array}{l}\text { Teoría de la administración } \\
\text { empresarial centrada en la } \\
\text { permanente satisfacción de las } \\
\text { expectativas del cliente. }\end{array}$ & $\begin{array}{l}\text { Satisfacer tanto al cliente } \\
\text { externo como interno. } \\
\text { Ser altamente competitivo. } \\
\text { Mejora continua }\end{array}$ \\
\hline
\end{tabular}

\section{Edad Antigua.}

El interés por la calidad ha existido desde antiguo. Si se hace un estudio de la historia veremos que el interés por la calidad siempre ha acompañado al hombre. Ya en el año 2150 a.c., en el código de Hammurabi se puede leer: "Si un albañil ha construido una casa insuficientemente sólida y ésta se hunde y mata a sus ocupantes, el albañil será ejecutado"

La importancia del concepto de medida se ve reflejada en la tumba de Rexh-Mi-Re en Tebas (1450 a.c.), dónde podemos observar el relieve de un inspector comprobando la perpendicularidad de un bloque de piedra con ayuda de una cuerda.

Por otro lado, pueblos como los fenicios, los cartagineses o los mismos griegos y romanos introdujeron sus propios procedimientos de comercio y sus normas y leyes respecto a las medidas, intercambios comerciales o primeros códigos que hacen referencia a la calidad de las construcciones, de los productos, etc. 


\section{Edad Media}

En esta época los productos los elaboran los artesanos, y eran los mismos quienes evaluaban la calidad de su trabajo. Si estaban conformes con el resultado, lo consideraban como un trabajo bien hecho. Tenían una relación directa con sus clientes, conocían de primera mano tanto los deseos como las quejas de los mismos. No existía un sistema de calidad ya que el artesano desarrollaba todas las fases del producto, desde la compra de las materias primas hasta las labores de venta del producto terminado. El único elemento de supervisión era el propio artesano y su principal preocupación lograr su propia satisfacción y la de sus clientes

\section{Revolución Industrial.}

Durante la Revolución Industrial (finales del siglo XIX) los artesanos desaparecen para ser sustituidos por trabajadores en fábricas. En la mayor parte de los casos, estos trabajadores realizaban únicamente una parte del proceso para la consecución del producto final. Con este cambio se pierde el concepto de "orgullo profesional" y se requieren nuevas estrategias y herramientas para lograr un resultado final satisfactorio. La participación de más de un trabajador en la fabricación de un producto obliga a determinar y establecer las características que debe cumplir el mismo. Nacen así los conceptos de estandarización y las especificaciones.

Naturalmente se hace necesario comprobar que los productos se corresponden con los modelos determinados, por lo que se produce la inspección (comparación del producto con las especificaciones). El gran volumen de productos obliga también a que estas inspecciones se lleven a cabo mediante muestreos estadísticos

\section{Taylorismo.}

Con la aparición del Taylorismo (finales del siglo XIX), se separa la planificación de la ejecución, el obrero (que no piensa) ejecuta, mientras que la dirección piensa, dirige y organiza. Este sistema supuso un incremento de producción pero, a su vez, una disminución de la calidad, motivo por el cual se crearon grandes departamentos de inspección.

\section{La calidad en el siglo XX.}

En el siglo XX se produce una aceleración importante del desarrollo de la calidad (llustración 12) y se inicia la edad moderna de la calidad.

Ilustración 12. La calidad en el siglo XX.

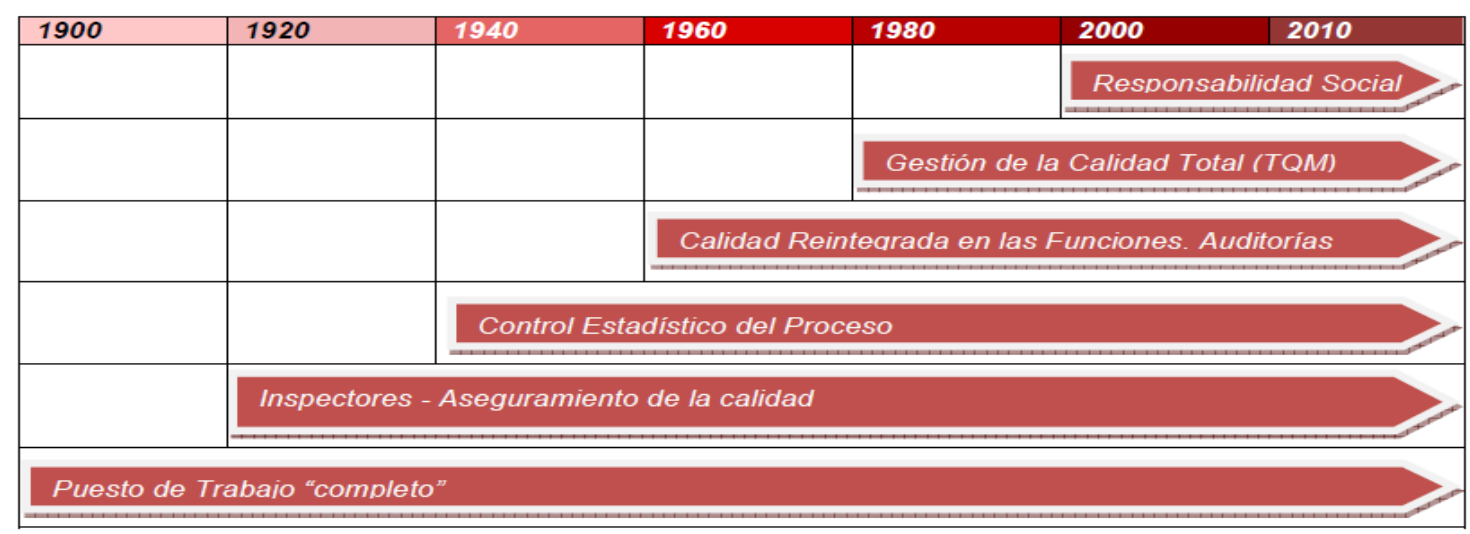

Fuente: Elaboración Propia a partir de Sangüesa, M (2003). 
Hacia 1920 se produce una división entre producción e inspección (estos últimos son los encargados de mantener la calidad del producto). La especialización de las tareas generó aumentos de la productividad. Con el aumento de la producción industrial la situación varió significativamente. La compra de materias primas, producción y distribución se convierten en actividades realizadas por distintos departamentos. Las reclamaciones de los clientes ya no son directamente recibidas por el productor, es decir, se rompe definitivamente la relación productor-cliente. Henry Ford lleva el Taylorismo al extremo, apareciendo la producción en cadena, lo que supuso la separación definitiva de las funciones de planificación, ejecución e inspección.

Con el incremento de la producción con motivo de la Segunda Guerra Mundial aumentaron también las necesidades de inspección en las industrias correspondientes. Pero el incremento del coste hizo que se plantearan la reducción del número de inspectores y para ello se introdujeron por primera vez en EEUU las técnicas estadísticas. A partir de 1941 se ofrecían en las universidades americanas cursos sobre métodos estadísticos aplicables a la producción y en el año 1946 se fundó la American Society of Quality Control.

En esta época las aportaciones de W. Edwards Deming se centran en el ámbito de la estadística en el control y mejora de la calidad. Sus ideas fueron ignoradas en EEUU (su país de origen), sin embargo en 1950 es invitado a dar una ronda de conferencias en Japón y logró tal éxito que se quedó en este país impartiendo sus ideas. Es conocido por establecer "los 14 puntos para la gestión", "el ciclo Deming o PDCA". En Japón el premio a la calidad se denomina en su honor "Premio Deming".

Al igual que pasó con Deming, las ideas de Joseph $M$. Juran no fueron reconocidas hasta no llegar a Japón. Su aportación más destacada es "la Trilogía de Juran" planificación, control y mejora de la calidad.

A comienzos de los años 60 se introduce la idea de la calidad integral, es decir, la calidad no es sólo un problema de los inspectores, sino que todos los departamentos deben preocuparse por lograr los estándares de calidad requeridos. Se cuestiona la validez de la inspección tal y como era entendida hasta entonces.

En la década de los 60 y 70 destacan:

- Philip B. Crosby. Conocido sobre todo por impulsar la cultura de los cero defectos, con la que se logra reducir en gran medida las actividades de inspección.

- Genichi Taguchi. Conocido especialmente por la función de pérdidas de Taguchi y por sus aportaciones al diseño de experimentos.

- Armand V. Feigenbaum. Introdujo la idea de que la calidad no era sólo un problema del departamento de producción sino de toda la organización

- Kaoru Ishikawa. Conocido por su recopilación de herramientas de la calidad Q7 y muy en especial por desarrollar una de ellas, el diagrama de pez o diagrama de Ishikawa. También extendió los círculos de calidad. 
Desde aproximadamente 1980 se introduce el concepto de calidad total o gestión total de calidad. Se pretende que la calidad no sea responsabilidad de un departamento concreto de la empresa, sino trasladar esta responsabilidad, a todos los integrantes de la organización. Sólo si se esfuerzan en lograr calidad, se conseguirá realmente. Además, no se habla ya solamente de calidad del producto, sino que se avanza un paso más y se comienza a hablar también de la calidad de los procesos y de la calidad de los sistemas. Es decir, por fin se reconoce que para lograr un producto final de calidad, también los procesos y sistemas empleados en la ejecución del producto deben ser de calidad.

Por tanto el Total Quality Model (TQM) es la implantación de la calidad en todos los niveles de la organización, conseguir que hasta el último empleado de nuestra empresa esté empeñado en el logro de la calidad.

El concepto clásico de calidad se centraba exclusivamente en el producto y, a lo sumo, en el servicio. La nueva definición de calidad como adecuación al uso supone un avance considerable. Ya no se trata solamente de obtener productos de calidad técnica, ajustados a sus especificaciones técnicas. Ahora, estas especificaciones de calidad las hace el cliente. Éste posee unas expectativas que deben cubrirse mediante un diseño adecuado que las tenga en cuenta. Más que tenerlas en cuenta, que gire sobre ellas.

Por tanto el producto y/o el servicio, además de ser técnicamente buenos, deben responder a las necesidades del cliente.

En el siglo XX surge el concepto de calidad total. La gestión de la calidad total (TQM) se puede definir como la gestión integral de la organización centrada en la calidad. EI calificativo de total hace referencia a la gestión antes que a la calidad.

La TQM supone aplicar el concepto de calidad al conjunto de las actividades, sin importar el lugar de la organización donde se realicen, a través de las cuales se alcanza la aptitud de uso y la satisfacción de las necesidades y expectativas del cliente.

La calidad total de una organización se basa en el concepto de calidad basado en la participación de todos sus miembros, orientada a la sostenibilidad a largo plazo a través de la satisfacción del cliente proporcionando beneficios a todos los miembros de la organización y a la sociedad, en general, es decir a todos sus grupos de interés.

Supone una actitud directiva que implica la participación general del personal de la organización, cualquiera que sea su nivel, y que pone el énfasis en la satisfacción del cliente y la mejora continua.

Por tanto, la TQM se puede definir como una estrategia para asegurar el mejoramiento continuo de la calidad, o como el programa para asegurar la continua satisfacción de los clientes externos e internos mediante el desarrollo permanente de calidad del producto y sus servicios. Es un concepto que involucra la orientación de la organización a la calidad manifestada mediante la calidad de sus productos y servicios que proporciona, el desarrollo de su personal y la contribución al bienestar general.

En un primer momento se habla de control de calidad, primera etapa en la gestión de la calidad que se basa en técnicas de inspección aplicadas a Producción. Posteriormente nace el aseguramiento de la calidad, fase que persigue garantizar un nivel continuo de la calidad del producto o servicio proporcionado. Finalmente se llega a lo que hoy en día 
se conoce como calidad total, que incluye las dos fases anteriores. Los principios fundamentales de este sistema de gestión son los siguientes:

- Satisfacer las necesidades y expectativas del cliente (interno y externo).

- Desarrollar de un proceso de mejora continua en todas las actividades y procesos llevados a cabo en la organización.

- Alcanzar el compromiso de la dirección y un liderazgo activo de todo el equipo directivo.

- Potenciar la participación de todos los miembros de la organización y fomento del trabajo en equipo.

- Involucrar a los proveedores reconociendo el papel fundamental de estos en la consecución de la calidad en la organización.

- Identificar y gestionar los procesos clave de la organización, superando la organización vertical y los departamentos estancos.

- Tomar decisiones de gestión basada en datos y hechos objetivos.

En resumen, la filosofía de la calidad total proporciona una concepción global que fomenta la mejora continua en la organización y la implicación de todos sus miembros, centrándose en la satisfacción tanto del cliente interno como del externo. Gestión de la calidad total significa que el equipo directivo está totalmente comprometido junto con todas las personas de la organización para responder a las necesidades del cliente y los grupos de interés

Para introducir la gestión de la calidad total se crearon diferentes modelos en función del país y del momento asociados a premios a las organizaciones que mejor aplicasen estos principios:

- Fundación JUSE. Japón, 1950

- Malcolm Baldrige Qualit Award Model. EE.UU., 1987

- Modelo EFQM. Europa, 1988

- Premio Australiano a la Calidad, 1991

- Modelo Iberoamericano, 1999

En Europa los objetivos de la EFQM son promocionar la gestión de la calidad total y demostrar los resultados que se pueden conseguir. El modelo EFQM se basa en la premisa de que los resultados excelentes con respecto al rendimiento, clientes, personal y sociedad se logran a través del liderazgo, las personas, la política y la estrategia, las alianzas y los recursos y los procesos. El modelo Iberoamericano de excelencia posee una premisa muy similar debido a que los resultados excelentes se consiguen no sólo con el liderazgo, sino también con un estilo de dirección y procesos adecuados. E modelo gerencial Deming tiene como misión crear un sistema organizativo que fomente la cooperación, tanto interna como externa así como un aprendizaje que facilite la implementación de prácticas de gestión por procesos. Esto lleva a una mejora continua de los procesos, productos y servicios, así como de la satisfacción del trabajador, fundamental para la satisfacción del cliente y para la supervivencia de la organización. Por su parte, el método de Malcolm Baldrige se basa en un sistema de liderazgo, planificación estratégica y enfoque hacia el cliente y mercado (Nieves, 2006).

Todos los modelos hacen hincapié en un método dirigido a quienes apuestan y arriesgan por la empresa, es decir, un método que defina los resultados para los clientes, empleados, sociedad y todos aquellos que tienen interés en la organización. (Nieves, 2006) 
A pesar de sus diferencias y a que cada uno está orientado a una cultura diferente, todos comparten los siguientes principios (Lorenzo, 2000):

- Se basan en el concepto de calidad total

- Presentan interrelación entre los criterios que los constituyen

- Introducen sistemas de evaluación basados en lo que se gestiona y los resultados que se obtienen

- Buscan conseguir una organización más efectiva y eficiente que se ajuste a las necesidades de sus grupos de interés

- Los modelos no son prescriptivos y deben adaptarse a cada organización

La historia nos enseña que el avance en el concepto de la calidad ha ido sumando herramientas, técnicas y modelos. En estos momentos podríamos estar en una nueva fase. En la fase de superación del modelo de calidad total incorporando más elementos como la sostenibilidad pero sin dejar de hacer nada de lo anterior.

\subsubsection{Calidad asistencial}

Donabedian (1991) indica que el objetivo de la asistencia sanitaria es mantener, restaurar y promover la salud (razón de ser de la organización). Más exactamente, el objetivo es conseguir el grado de mantenimiento, recuperación y promoción máximos dentro de las posibilidades que ofrecen las ciencias de la salud. Para lograrlo se realizan una serie de intervenciones técnicas, sicológicas y sociales. Estos medios se juzgan por su efectividad (es decir, su contribución a la mejora de la salud), por su coste y por el grado en que sus otros atributos son aceptados por los pacientes y por la sociedad.

Por lo tanto, la calidad de la asistencia sanitaria se puede definir como el nivel de utilización de los medios más adecuados para conseguir las mejoras en la salud. Aspecto este que forma parte importante del concepto de sostenibilidad y su relación con los grupos de interés.

Esta idea es apoyada por Álvar Net y Rosa Suñol (2003) quienes exponen que las motivaciones por las cuales puede plantearse la mejora de la calidad son de distinto origen tal y como ocurre con el tema de la sostenibilidad. De un lado, la transgresión o no adecuación de los valores éticos en una situación concreta como la actual, aconseja un cambio hacia otra situación de mayor calidad, acorde con los valores éticos o los códigos deontológicos. Por otra parte, la mejora de la calidad puede ser impulsada por los políticos, por ejemplo, al dictar leyes de acreditación de los centros sanitarios que contengan unos requisitos de mínimos para determinadas actividades. La mejora de la calidad también puede deberse a una motivación social en cuanto que la organización sanitaria pueda tener una mala reputación relacionada con aspectos de su imagen dentro de la comunidad. Por fin, los motivos económicos, en general, y el control de los costes, en particular, pueden ser también quienes provoquen la necesidad de mejorar la calidad de la organización.

Para ello es necesario de una parte, la mejora de la asistencia sin que los clínicos pierdan su responsabilidad y protagonismo y, de otra, la mejora de la calidad asumiendo que los proveedores de servicios tienen que satisfacer las preferencias y necesidades 
de sus clientes por un lado y responder a las demandas sociales de menos recursos y más eficiencia.

Como dice también Donabedian (1991), las consecuencias de la asistencia suceden en el futuro, por lo que estamos juzgando son las presunciones de los resultados. Aunque dándole la vuelta a la idea podemos en esta investigación ver los resultados de lo que se ha trabajado en calidad en años previos y así valorar su contribución a la sostenibilidad del sistema.

No sólo se trata de conseguir la calidad de las actividades o de los servicios públicos por imperativo legal, sino que es una necesidad cada vez más demandada por el ciudadano, que exige un nivel determinado de satisfacción sobre los servicios prestados por la administración pública, como contrapartida por las aportaciones económicas que realiza a través del pago de los impuestos (Castelló y Lizcano, 1997) y de las cuotas de seguridad social en el caso de los servicios sanitarios. Además, con la implantación de modelos de gestión de calidad en el sector público se pretende solucionar algunos de los problemas detectados en dicho sector. Y, además, aprovechar las numerosas ventajas de su aplicación, y que se han constando en su aplicación al caso del sector privado.

En el sector salud al igual que en otros sectores, el modelo de la Fundación Europea para Gestión de Calidad (EFQM) es un marco de auto-evaluación, utilizado por instituciones/servicios como aplicación para su revisión externa en orden a la obtención del galardón europeo de calidad o galardones nacionales o regionales. En otros países europeos el modelo se ha implantado con éxito en el sistema sanitario (Legido-Quigley 2006). Son ejemplos de ello el Centro Flamenco de Calidad Asistencial que apoya la calidad asistencial integral y promueve el modelo EFQM; en Hungría diversos servicios hospitalarios han decidido agregar a sus actividades existentes la técnica de autoevaluación de la EFQM; en Italia instituciones sanitarias implantaron un proyecto de estandarización basado en la aplicación del modelo de Excelencia EFQM. En Luxemburgo el Ministerio de Sanidad propone trabajar desde 2006 con el modelo de la EFQM en su relación con la Asociación de Seguros Sanitarios.

En el entorno sanitario español, la aplicación del modelo EFQM, aunque desigual, queda constatada en los originales que han ido apareciendo en diferentes publicaciones del ámbito sanitario (Fortuny, 2009).

En general, el número de centros que han desarrollado experiencias en los sistemas sanitarios de las diferentes comunidades autónomas es desigual. La experiencia de los centros de Osakidetza, que desde 1995 han incorporado la autoevaluación mediante el modelo EFQM como herramienta de desarrollo es importante en cuanto que ha supuesto una apuesta estratégica clara desde el propio gobierno y ha recibido el apoyo institucional materializado a través de Euskalit.

Por todo ello, las tendencias en este sector reconocen un especial interés sobre la puesta en marcha de sistemas de gestión que permitan mejorar la calidad de los servicios prestados a los ciudadanos y entre los que destaca, de forma especial, el modelo EFQM. Dentro del ámbito en el que se contextualiza el presente trabajo, el modelo propuesto por EFQM se constituye en el más difundido en el ámbito empresarial 
e institucional. Como consecuencia, centramos nuestro estudio en el modelo EFQM de excelencia y su adaptación e implantación en organizaciones del sector público.

\subsubsection{La fundación europea para la gestión de la calidad y el modelo EFQM}

Como consecuencia del aumento de la competitividad mundial y la amenaza a la posición europea en los mercados, en 1988, catorce de las más importantes empresas europeas, decidieron crear la Fundación Europea para la Gestión de Calidad (EFQM).

EFQM es una organización sin ánimo de lucro cuya misión es "ser la fuerza que impulsa en Europa la excelencia sostenida". Asimismo, tiene como visión "un mundo en el que las organizaciones europeas sobresalgan por su excelencia".

En la actualidad, EFQM cuenta con miembros, procedentes de todos los sectores y países europeos, comprometidos con la calidad total que persiguen la excelencia organizacional. Su misión es ser la fuerza que impulse en Europa la excelencia sostenida. Asimismo, tiene como visión un mundo en el que las organizaciones europeas sobresalgan por su excelencia.

Los objetivos fundamentales de esta fundación son:

- Ayudar a las empresas europeas a mejorar su posición competitiva.

- Acelerar la aceptación de la calidad como estrategia.

- Estimular y ayudar a las actividades de mejora.

- Promover el intercambio de experiencias de éxito.

En 1991, la Fundación Europea creó el modelo EFQM de excelencia, cuyo objetivo es ayudar a las organizaciones (de cualquier tipo, tamaño, sector, etc.), a conocerse mejor a sí mismas y así mejorar su funcionamiento. La idea básica del modelo de excelencia es proporcionar a las organizaciones una herramienta de mejora de su sistema de gestión. El Modelo Europeo de Excelencia se desarrolló, en consonancia con los modelos Malcolm Baldrige en los EEUU y el premio Deming en Japón, como marco para la Autoevaluación de la organizaciones y, como base para evaluar las solicitudes al premio europeo de la calidad, que fue concedido por primera vez en 1992. La EFQM fomenta el establecimiento de alianzas a nivel nacional con organizaciones similares a ella, a fin de promover la excelencia sostenida. Estas organizaciones o partners, colaboran con la EFQM para promocionar el modelo EFQM de excelencia. En España, el Club Excelencia en Gestión (CEG), es el «National Partner Organization» de la EFQM $y$, por tanto representante en exclusiva de la EFQM en España.

En 2003 se revisó el modelo que pasó a denominarse Modelo EFQM de Excelencia. La versión actual del modelo es de 2013. El modelo se utiliza como base para otorgar los premios europeos de calidad, utilizando para ello el sistema de puntuación establecido para cada uno de sus 9 criterios. 
El modelo EFQM es una herramienta práctica que puede ser utilizada:

- Como guía para realizar una autoevaluación para la identificación de áreas de mejora.

- Como herramienta de aprendizaje mutuo (benchmarking) con otras organizaciones.

- Como método para medir la evolución de la excelencia en una organización.

- Como base para utilizar un lenguaje y forma de pensar común en la organización.

- Como base para analizar la estructura del sistema de gestión.

- Como guía para presentarse a premios de calidad otorgados por EFQM u otras entidades (autonómicas, nacionales o europeas), o para la obtención de sellos de excelencia.

Utilizar el modelo EFQM como herramienta de mejora proporciona una guía que lleva a examinar la organización de forma sistemática en todos los aspectos de su funcionamiento. El modelo no es normativo ni prescriptivo, no dice cómo hay que hacer las cosas, respetando así las características propias de cada organización y la experiencia de sus miembros.

El modelo EFQM plantea un método para autoevaluar la gestión de cualquier organización, reconociendo que hay diferentes formas de enfocar la excelencia en cualquiera de los 9 criterios planteados. Permite una considerable libertad de interpretación a la hora de reflejar las estrategias adecuadas para cada organización, teniendo en cuenta su origen, tamaño, nivel de modernización o cultura, entre otras.

El modelo EFQM de excelencia tiene como horizonte permanente la idea de una organización eficaz, operativa, evaluable y capaz de responder a su misión. Para ello, se fundamenta en una epistemología, una metodología y una ética (tabla 15).

Tabla 15.Conceptos que fundamentan el modelo. (Aragón, 2001)

\begin{tabular}{|c|l|}
\hline $\begin{array}{c}\text { Fundamento } \\
\text { epistemológico }\end{array}$ & $\begin{array}{l}\text { Abarca a las organizaciones forma global. } \\
\text { Se analizan los distintos niveles, se estudian los } \\
\text { procesos y se insertan en el todo al que } \\
\text { pertenecen }\end{array}$ \\
\hline Fundamento metodológico & $\begin{array}{l}\text { La realidad se analiza desde datos y evidencias } \\
\text { Es un procedimiento científico y auto correctivo }\end{array}$ \\
\hline Fundamento ético & $\begin{array}{l}\text { Revaloriza la ética de la responsabilidad. } \\
\text { Busca la satisfacción de las personas que } \\
\text { intervienen en el proceso. } \\
\text { Subraya la adhesión del personal implicado a un } \\
\text { proyecto colectivo e individual de mejora. }\end{array}$ \\
\hline
\end{tabular}

El modelo remite constantemente a la idea de una organización eficaz, operativa, evaluable y capaz de responder a su misión. (Aragón, 2001)

La EFQM define como organizaciones excelentes, a las que logran y mantienen niveles sobresalientes de rendimiento que satisfacen o exceden las expectativas de todos sus grupos de interés. En consecuencia se puede definir el nivel de excelencia de una organización, en cuanto a su capacidad de añadir valor a todos sus grupos de interés, 
de forma eficiente y sostenible. (CEG, 2014). El modelo aporta una visión global de la estructura organizativa orientada a generar valor para los grupos de interés.

La estructura del modelo está basada en 3 componentes, los cuales forman un sistema coherente, que se mejora de manera continua y que hace realidad la estrategia de la organización:

1. Los conceptos fundamentales de excelencia (ilustración 13). Describen los atributos de una cultura orientada a la excelencia, entendiendo cultura como el conjunto específico de valores y normas que comparten las personas que conforman una organización. Facilitan la creación de una visión compartida y un lenguaje común de cuáles son los atributos que conforman una cultura de excelencia.

2. Los criterios del modelo. Los atributos de los conceptos fundamentales, se trasladan a la operativa del sistema de gestión a partir del conjunto de elementos propuestos por el modelo

3. El esquema lógico REDER. Proporciona las directrices a aplicar en el desarrollo del sistema de gestión, para orientar a la organización a generar valor para sus grupos de interés, con una operativa orientada a la mejora continua de resultados y gestionada de forma flexible y sistemática (Cómo hacer).

Ilustración 13. Conceptos fundamentales de la excelencia

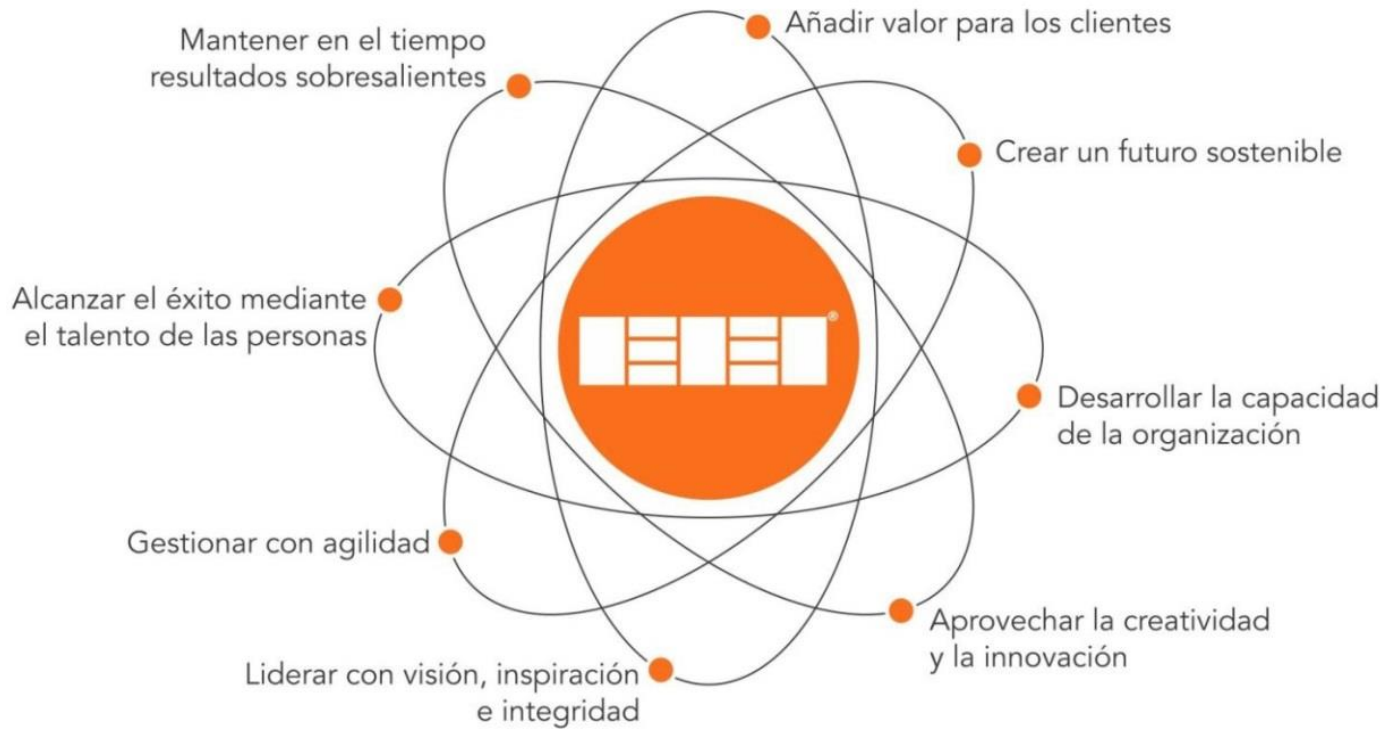

Fuente: Guía de Interpretación para el sector sanidad del modelo EFQM de Excelencia 2013. Foro de Excelencia en Sanidad (CEG, 2014)

\subsubsection{Los conceptos fundamentales}

Los conceptos fundamentales de la excelencia forman la base filosófica sobre la que se asienta el modelo (CEG, 2014). Los conceptos fundamentales describen los cimientos esenciales para que cualquier organización alcance una excelencia sostenida, y pueden utilizarse como base para describir los atributos de una cultura excelente. Existen 8 conceptos fundamentales: 
- Añadir valor para los clientes. Las organizaciones excelentes añaden constantemente valor para los clientes comprendiendo, anticipando y satisfaciendo necesidades, expectativas y oportunidades.

- Crear un futuro sostenible. Las organizaciones excelentes producen un impacto positivo en el mundo que les rodea porque incrementan su propio rendimiento al tiempo que mejoran las condiciones económicas, ambientales y sociales de las comunidades con las que tiene contacto.

- Desarrollar la capacidad de la organización. Las organizaciones excelentes incrementan sus capacidades gestionando el cambio de manera eficaz dentro y fuera de ellas.

- Aprovechar la creatividad y la innovación. Las organizaciones excelentes generan mayor valor y mejores resultados a través de la mejora continua y la innovación sistemática, aprovechando la creatividad de sus grupos de interés.

- Liderar con visión, inspiración e integridad. Las organizaciones excelentes tienen líderes que dan forma al futuro y lo hacen realidad, actuando como modelo de referencia de sus valores y principios éticos.

- Gestionar con agilidad. Las organizaciones excelentes se reconocen de manera generalizada por su habilidad para identificar y responder de forma eficaz y eficiente a oportunidades y amenazas.

- Alcanzar el éxito mediante el talento de las personas. Las organizaciones excelentes valoran a las personas que las integran y crean una cultura de delegación y asunción de responsabilidades que permite alcanzar tanto los objetivos personales como los de la organización.

- Mantener en el tiempo resultados sobresalientes. Las organizaciones excelentes alcanzan resultados sobresalientes que se mantienen en el tiempo y satisfacen las necesidades a corto y largo plazo de todos los grupos de interés, en el contexto de su entorno operativo

Para el Foro de Excelencia en Sanidad (2014), los ocho conceptos fundamentales de la excelencia (ilustración13) pueden ser considerados como el compendio de las «mejores prácticas» en el ámbito de la gestión de organizaciones sanitarias. Añaden que para que la aplicación del modelo sea eficaz y consiga los objetivos pretendidos, estos principios deberían ser asumidos totalmente por los directivos de la organización, de lo contrario su aplicación carecerá de sentido, señalando que "El papel de la dirección es lograr que esta estrategia de gestión se despliegue por toda la organización, asumiendo el liderazgo del proyecto para conseguir que se integre en la cultura organizacional, entendiendo cultura como el conjunto específico de valores y normas que comparten las personas que conforman la organización".

Los conceptos fundamentales describen los atributos de una cultura orientada a la excelencia. Facilitan la creación de una visión compartida y un lenguaje común de cuáles son los atributos que conforman una cultura de excelencia (Foro de Excelencia 2014). Como ya se ha dicho, esta cultura debe transmitirse desde la dirección al resto de la organización sanitaria, siendo condiciones indispensables, que en primer lugar defina su compromiso con la excelencia y, que posteriormente sus actuaciones muestren coherencia entre el compromiso teórico y la realidad práctica. Esta coherencia 
tiene que manifestarse en la manera de priorizar y asignar medios como comunicación, formación, fondos para equipos de mejora, tiempo, apoyo metodológico, entre otros.

Para aplicar y desplegar estos principios en una organización, se debe comenzar identificando a todos los grupos de interés relevantes (stakeholders) como propietarios, políticos, clientes, trabajadores, directivos, proveedores, la comunidad. Una vez identificados se deben conocer de forma estructurada y sistemática sus expectativas, para poder crear mecanismos transparentes que sean capaces de equilibrarlas y satisfacerlas.

Los atributos de los conceptos fundamentales se trasladan a la operativa del sistema de gestión a partir del conjunto de elementos propuestos por el modelo, tal y como se evidencia en la relación entre subcriterios y conceptos fundamentales (ilustración14).

Ilustración 14. Relación entre subcriterios y conceptos fundamentales.

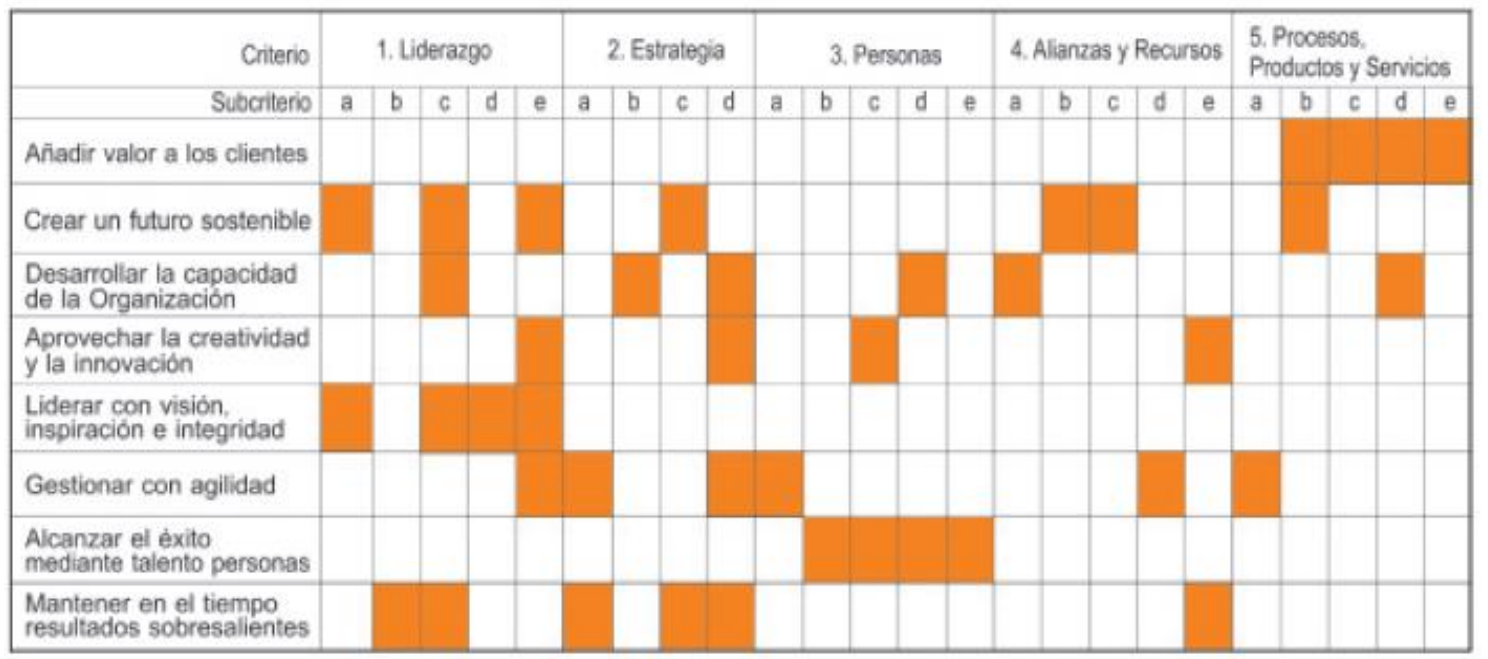

Fuente: Guía para la interpretación del modelo EFQM 2013. Club excelencia gestión.

Asimismo, una lectura horizontal de la tabla a partir de los conceptos, evidencia que los mismos se integran en el sistema de gestión a partir de varios subcriterios. Esto implica un sistema de gestión transversal que gestiona las vinculaciones existentes.

Por lo tanto, aplicar los conceptos de la excelencia en el ámbito sanitario, supone buscar resultados satisfactorios para todos ellos. Los resultados de un centro sanitario no se pueden valorar aisladamente en sus parcelas clínicas o económicas, sino que deben tenerse en cuenta también, los aspectos de aprendizaje de la propia organización y los de servicio a la sociedad.

Estos conceptos fundamentales, al igual que el resto del modelo han sido modificados y adaptados con el paso de los años (tabla 16) para tratar de afinar el modelo y dar respuesta a las mejoras que demandaban las organizaciones. Toda la información sobre el modelo EFQM expuesta en este trabajo pertenece a la última revisión del modelo de 2013. 
Tabla 16. Evolución del concepto de sostenibilidad en el modelo EFQM

\begin{tabular}{|c|c|c|c|}
\hline Versiones & 2013 & 2010 & 2003 \\
\hline $\begin{array}{l}\text { Conceptos } \\
\text { fundamentales }\end{array}$ & Crear un futuro sostenible & $\begin{array}{l}\text { Asumir la } \\
\text { responsabilidad de } \\
\text { un futuro sostenible }\end{array}$ & $\begin{array}{l}\text { Responsabilidad } \\
\text { Social } \\
\text { Corporativa }\end{array}$ \\
\hline $\begin{array}{l}\text { Interpretación: } \\
\text { Describen los atributos } \\
\text { de una cultura } \\
\text { orientada a la la } \\
\text { excelencia y facilitan la } \\
\text { creación de una visión } \\
\text { compartida y un } \\
\text { lenguaje común de } \\
\text { cuáles son los atributos } \\
\text { que conforman una } \\
\text { cultura de excelencia }\end{array}$ & $\begin{array}{l}\text { Las organizaciones } \\
\text { excelentes producen un } \\
\text { impacto positivo en el } \\
\text { mundo que les rodea } \\
\text { porque incrementan su } \\
\text { propio rendimiento al } \\
\text { tiempo que mejoran las } \\
\text { condiciones económicas, } \\
\text { ambientales y sociales de } \\
\text { las comunidades con las } \\
\text { que tienen contacto }\end{array}$ & \begin{tabular}{lr}
\multicolumn{2}{l}{ Responsabilizarse } \\
activamente de la \\
conducta y de las \\
actividades de la \\
organización & y \\
gestionar & su \\
impacto en & la \\
comunidad & en \\
general. &
\end{tabular} & \\
\hline
\end{tabular}

Fuente: Elaboración: propia. A partir de la: Guía de Transición al modelo EFQM 2010 (Author: Paul Gemoets, EFQM Version: 1.0 Published: 25/09/2009, (c) EFQM 2009) / Guía interpretación para el sector sanidad del modelo EFQM 2013.......)

El principal cambio incorporado al actualizar la versión en 2013 hace referencia a la sostenibilidad, haciendo mayor énfasis en la idea de que las organizaciones excelentes producen un impacto positivo en el mundo, y que su crecimiento tiene incidencia en las condiciones económicas, ambientales y sociales.

\subsubsection{Los criterios}

Los criterios aportan el marco para ayudar a las organizaciones a trabajar los conceptos fundamentales en la práctica. Los criterios del modelo se dividen en agentes y resultados (llustración 15).

Los criterios agentes son aquellos que la organización planifica y realiza.

- Criterio 1. Liderazgo. Las organizaciones excelentes tienen líderes que dan forma al futuro y lo hacen realidad, actuando como modelo de referencia de sus valores y principios éticos e inspirando confianza en todo momento. El liderazgo es flexibles, permitiendo a la organización anticiparse y reaccionar de manera oportuna con el fin de asegurarse un éxito continuo.

- Criterio 2. Estrategia. Las organizaciones excelentes implantan su misión y visión desarrollando una estrategia centrada en sus grupos de interés. Las organizaciones desarrollan y despliegan políticas, planes, objetivos y procesos para hacer realidad la estrategia.

- Criterio 3. Personas. Las organizaciones excelentes valoran a las personas que las integran y crean una cultura que permite lograr los objetivos personales y los de la organización de manera beneficiosa para ambas partes. Desarrollan las capacidades de las personas y fomentan la equidad e igualdad. Se preocupan por las personas de la organización, potencian la comunicación interna, recompensan y dan reconocimiento a los esfuerzos para motivarlas e 
incrementar su compromiso con la organización y favorecer que usen sus capacidades y conocimientos en beneficio de la misma.

- Criterio 4. Alianzas y recursos. Las organizaciones excelentes planifican y gestionan las alianzas externas, proveedores y recursos internos, para apoyar su estrategia, así como el eficaz funcionamiento de sus procesos. También se aseguran de gestionar eficazmente su impacto social y ambiental.

- Criterio 5. Procesos, productos y servicios. Las organizaciones excelentes diseñan, gestionan y mejoran sus procesos, productos y servicios para generar cada vez mayor valor para sus clientes y demás grupos de interés.

Los criterios resultados recogen los resultados que las organizaciones alcanzan y mantienen en el tiempo y que satisfacen o exceden las necesidades y expectativas de sus grupos de interés, y son:

- Criterio 6. Resultados en los clientes. Las organizaciones excelentes alcanzan y sostienen en el tiempo resultados sobresalientes que satisfacen o superan incluso las necesidades y expectativas de sus clientes.

- Criterio 7. Resultados en las personas. Las organizaciones excelentes alcanzan y sostienen en el tiempo resultados sobresalientes que satisfacen o superan incluso las necesidades y expectativas de las personas.

- Criterio 8. Resultados en la sociedad. Las organizaciones excelentes alcanzan y sostienen en el tiempo resultados sobresalientes que satisfacen o superan incluso las necesidades y expectativas de los grupos de interés relevantes de la sociedad.

- Criterio 9. Resultados clave. Las organizaciones excelentes alcanzan y sostienen en el tiempo resultados sobresalientes que satisfacen o superan incluso las necesidades y expectativas de los grupos de interés que aportan la financiación.

Ilustración 15. Criterios EFQM (CEG, 2014)

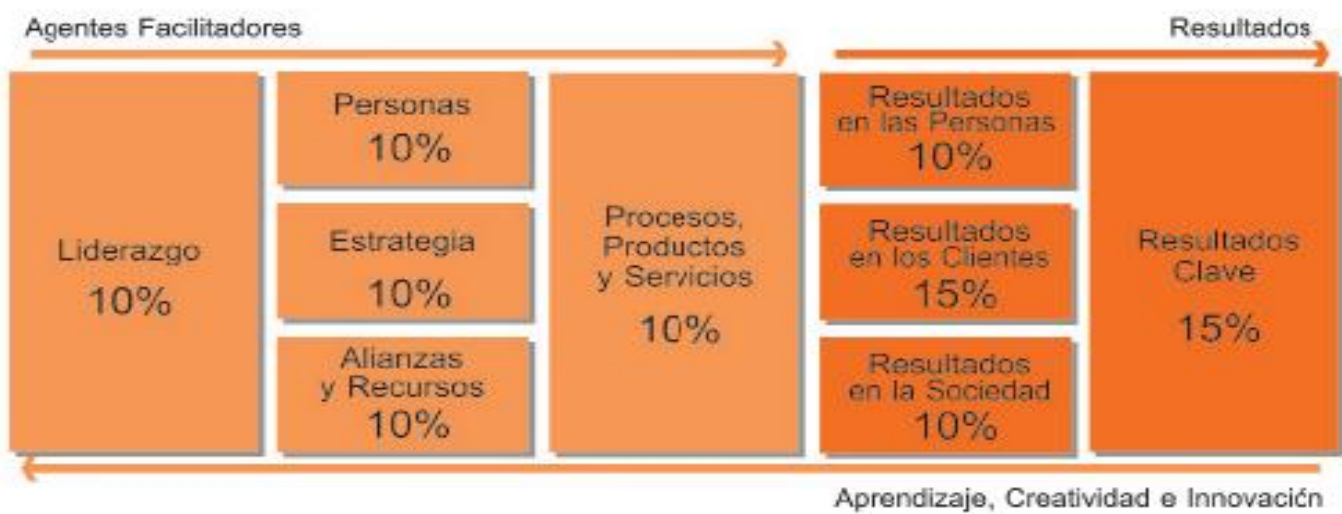

Fuente: Guía de Interpretación para el sector sanidad del modelo EFQM de Excelencia 2013. Foro de Excelencia en Sanidad (CEG, 2014)

Las flechas del modelo (ilustración 15) quieren resaltar la naturaleza dinámica del mismo. Mostrando que la innovación y el aprendizaje, potencian la labor de los agentes facilitadores y, por tanto, a unos mejores resultados. Como puede observarse, en la 
misma ilustración, esta formulación no es muy diferente de la clásica conceptualización de estructura, proceso y resultados propuesta por Donabedian (1991) y que resulta propia de los servicios sanitarios

La estructura de criterios, base del modelo original de la EFQM, es un marco de trabajo para abordar estrategias de calidad en los centros sanitarios ya que sobre ellos se pueden agrupar todos los elementos relacionados con la gestión de la calidad en una organización. La priorización de diferentes indicadores de calidad en torno a los nueve elementos del modelo representa una forma válida y sencilla de abordar las principales áreas a tener en cuenta para mejorar la calidad en los centros sanitarios (Ignacio, 2007).

Los nueve criterios están relacionados con todas las áreas de gestión y de medición de resultados de las organizaciones sanitarias. El planteamiento genérico de cada uno de los criterios se especifica mediante un conjunto de subcriterios que detallan su contenido. De igual forma en cada subcriterio se recogen las llamadas áreas a abordar o de interés que aclaran, a modo de ejemplo las mejores prácticas de gestión, cuál es el significado y el alcance de cada criterio.

Los criterios y los subcriterios, al igual que el resto del modelo, han sido modificados y adaptados con el paso de los años (tabla 17) para tratar de afinar el modelo y dar respuesta a las mejoras que demandaban las organizaciones.

Tabla 17. Evolución del modelo en relación a la sostenibilidad.

\begin{tabular}{|c|c|c|}
\hline Subcriterio (versión2013) & $\begin{array}{c}\text { Cambio de } \\
2010 \text { a } 2013 \\
\end{array}$ & Cambio de 2003 a 2010 \\
\hline $\begin{array}{l}\text { 1.a Los líderes desarrollan la misión, } \\
\text { visión y valores y principios éticos y } \\
\text { actúan como modelo de referencia }\end{array}$ & \multirow{7}{*}{$\begin{array}{l}\text { Sólo se } \\
\text { producen } \\
\text { cambios en el } \\
\text { título de algunos } \\
\text { subcriterios, se } \\
\text { elimina "de las } \\
\text { organizaciones } \\
\text { excelentes". }\end{array}$} & $\begin{array}{l}\text { 1a La 'ética' se añade como una faceta de } \\
\text { ser modelo de referencia }\end{array}$ \\
\hline $\begin{array}{l}\text { 1.c Los líderes se implican con los } \\
\text { grupos de interés externo }\end{array}$ & & $\begin{array}{l}\text { 1c Incluye razones por las que los líderes } \\
\text { deben involucrarse con grupos de interés y } \\
\text { la necesidad de transparencia y de } \\
\text { informar }\end{array}$ \\
\hline $\begin{array}{l}\text { 1.e Los líderes se aseguran de que la } \\
\text { organización sea flexible y gestionan } \\
\text { el cambio de manera eficaz }\end{array}$ & & $\begin{array}{l}\text { 1e Integra el factor 'flexibilidad' y la } \\
\text { 'capacidad de tomar decisiones' de los } \\
\text { Líderes a la hora de comprender e } \\
\text { impulsar el cambio }\end{array}$ \\
\hline $\begin{array}{l}\text { 2.c La estrategia y sus políticas de } \\
\text { apoyo se desarrollan, revisan y } \\
\text { actualizan }\end{array}$ & & $\begin{array}{l}\text { 2c Sostenibilidad' se integra en la } \\
\text { estrategia y se añade la comprensión de } \\
\text { 'modelo de negocio/impulsores' }\end{array}$ \\
\hline $\begin{array}{l}\text { 4.b Gestión de los recursos } \\
\text { económicos y financieros para } \\
\text { asegurar un éxito sostenido }\end{array}$ & & $\begin{array}{l}\text { 4b Enfocado más claramente en la } \\
\text { financiación para 'asegurar' el éxito y se } \\
\text { añade 'coherencia en la planificación } \\
\text { financiera a corto y largo plazo' }\end{array}$ \\
\hline $\begin{array}{l}\text { 4.c Gestión sostenible de edificios, } \\
\text { equipos, materiales y recursos } \\
\text { naturales }\end{array}$ & & $\begin{array}{l}\text { 4c Añade el concepto de 'recursos } \\
\text { naturales' y la capacidad de demostrar la } \\
\text { 'huella' }\end{array}$ \\
\hline $\begin{array}{l}\text { 5.b Los productos y servicios se } \\
\text { desarrollan para dar un valor óptimo a } \\
\text { los clientes }\end{array}$ & & $\begin{array}{l}\text { 5b El nuevo } 5 b \text { es una versión mejorada } \\
\text { del antiguo } 5 c\end{array}$ \\
\hline
\end{tabular}

Fuente: Elaboración: propia. A partir de la Guía de Transición al Modelo EFQM 2010 (Author: Paul Gemoets, EFQM Version: 1.0 Published:25/09/2009, (c EFQM 2009) / Guía interpretación para el sector sanidad del modelo EFQM 201.) 


\subsubsection{El Esquema lógico REDER}

En los fundamentos del modelo se encuentra un esquema lógico que se denomina REDER formado por cuatro elementos:

- Enfoque. Lo que una organización planifica hacer y las razones para ello. En una organización excelente, el enfoque está sólidamente fundamentado, es decir, tiene una lógica clara, procesos bien definidos y desarrollados y una clara orientación hacia las necesidades de todos los grupos de interés; además, está integrado apoyando la política y estrategia.

- Despliegue. Lo que hace una organización para desplegar el enfoque. En una organización considerada excelente, el enfoque se implanta en las áreas relevantes y de un modo sistemático.

- Evaluación y revisión. Lo que hace una organización para evaluar y revisar el enfoque y el despliegue de dicho enfoque. En una organización excelente, el enfoque y su despliegue están sujetos a mediciones regulares y se realizan actividades de aprendizaje, empleándose el resultado de ello en identificar, establecer prioridades, planificar e implantar la mejora.

- Resultados. Son los logros alcanzados por una organización excelente, muestran tendencias positivas y/o un buen rendimiento sostenido, los objetivos son adecuados y se alcanzan, y el rendimiento es bueno comparado con el de otras organizaciones y es una consecuencia de los enfoques. Además, el ámbito de aplicación de los resultados aborda las áreas relevantes.

El esquema lógico REDER (ilustración 16) es la herramienta de evaluación y gestión utilizada por las organizaciones que desean realizar autoevaluaciones o para actividades de benchmarking. También se utiliza para puntuar las memorias de las organizaciones que se presentan al premio EFQM a la excelencia y a premios nacionales y regionales basados en este modelo.

Ilustración 16. Esquema Lógico REDER

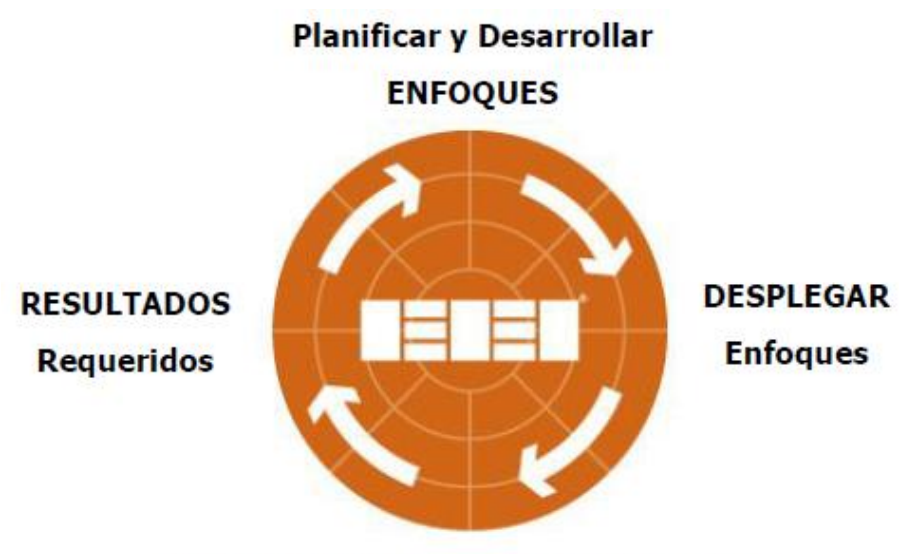

EVALUAR, REVISAR Y PERFECCIONAR

Enfoques y Despliegue

Fuente: Guía de Interpretación para el sector sanidad del modelo EFQM de Excelencia 2013. Foro de Excelencia en Sanidad (CEG, 2014) 
La sistemática que incorpora (REDER) redunda en una planificación más sólida, fundamentada y acorde a las necesidades detectadas. REDER asigna un $50 \%$ del total de puntos a los agentes facilitadores y el $50 \%$ restante a los resultados, lo que garantiza la capacidad de la organización para mantener su rendimiento en el futuro.

Al puntuar una organización mediante REDER, se asigna a cada uno de los subcriterios del modelo una puntuación para calcular el número total de puntos asignados a la organización. A continuación se combinan estas puntuaciones para puntuar el criterio en cuestión y se determina la puntuación total en una escala de 0 a 1000 puntos.

\subsubsection{Beneficios potenciales de la utilización del modelo EFQM}

El modelo EFQM es un instrumento práctico que ayuda a las organizaciones a establecer un sistema de gestión apropiado, sin importar el sector al que pertenezca o el tamaño, la estructura o la madurez de la propia organización. Mide en qué punto se encuentra dentro del camino hacia la excelencia, identificando posibles carencias de la organización y definiendo acciones de mejora. (ADER, 2013)

Según un estudio realizado por Hendricks (2000) de la Universidad de Western Ontario por Vinod Singhal del Instituto Tecnológico de Georgia y, en el que participaron durante 5 años 600 empresas ganadoras de premios de calidad y un grupo de control integrado por organizaciones del mismo sector y tamaño similar, las empresas que habían ganado premios de calidad obtenían mejores resultados en rentabilidad de acciones $(+39 \%)$, ingresos operativos $(+48 \%)$, ventas $(+37 \%)$, número de empleados $(+16 \%)$ y en el total de activos $(+42 \%)$.

Según un estudio realizado por Boulter y otros (2005) de la Universidad de Leicester, en el que participaron durante 11 años 120 empresas ganadoras de premios de calidad y un grupo de control integrado por organizaciones del mismo sector y tamaño similar, se observó que los resultados en el incremento de ventas y la disminución de costes, eran relevantemente mejores en las empresas ganadoras de premios.

Este estudio también demostró que se requiere de cierto tiempo para que las empresas ganadoras vean resultados respecto al grupo control, aunque sin embargo tanto a corto plazo como a medio plazo es evidente que las empresas ganadoras de premios obtienen mejoras respecto al grupo control.

Implantar el modelo según ADER (2013) aumenta la competitividad de la organización:

- Siendo más rentables

- Logrando un buen clima de trabajo

- Ofreciendo una excelente calidad de servicio, teniendo en cuenta tanto los requisitos legales como las necesidades y expectativas de los clientes

Para la Agencia de Desarrollo Económico de La Rioja (2013) el modelo aporta una serie de ventajas tales como:

- Proporcionar un marco de referencia que pueden utilizar para ayudarse a desarrollar su visión y las metas para el futuro de una manera tangible. 
- Identificar y entender la naturaleza de la organización y su negocio, es decir, de las relaciones entre los distintos agentes presentes en la actividad, y de las relaciones causa-efecto.

- Establecer un mismo lenguaje y modo de pensar en toda la organización.

- Proporcionar una herramienta de diagnóstico para determinar la salud actual de la organización, detectando puntos de mejora e implantando acciones que le ayuden a mejorar.

- Aprender de otras organizaciones reconocidas como excelentes (tabla 18) y promoverlas como modelos basándose en el proceso de evaluación EFQM.

Tabla 18. Cambios organizacionales que origina el modelo

\begin{tabular}{|l|l|}
\hline Modelo Tradicional & Modelo EFQM \\
\hline Desconocimiento del cliente & El cliente es el que manda \\
\hline Gestión cualitativa & $\begin{array}{l}\text { Gestión con datos, los indicadores señalan } \\
\text { oportunidades de mejora }\end{array}$ \\
\hline Los jefes son los que deciden & Los líderes delegan \\
\hline Los empleados buscan satisfacer a los jefes & $\begin{array}{l}\text { Toda la organización busca satisfacer a los } \\
\text { clientes }\end{array}$ \\
\hline $\begin{array}{l}\text { La calidad se refiere a la producción ya las } \\
\text { materias primas }\end{array}$ & $\begin{array}{l}\text { La calidad concierne a todas las personas } \\
\text { de la organización }\end{array}$ \\
\hline $\begin{array}{l}\text { El departamento de calidad es el que asegura } \\
\text { la calidad }\end{array}$ & Cada empleado garantiza la calidad \\
\hline Existe una reticencia hacia el cambio & $\begin{array}{l}\text { El entorno es cambiante por lo tanto el } \\
\text { cambio es natural en las empresas }\end{array}$ \\
\hline $\begin{array}{l}\text { La organización está dividida en } \\
\text { departamentos }\end{array}$ & $\begin{array}{l}\text { La organización está integrada y } \\
\text { cohesionada }\end{array}$ \\
\hline No hay involucración entre departamentos & Existe en la conciencia de cliente interno \\
\hline $\begin{array}{l}\text { La participación y la involucración no es } \\
\text { prioritario e incluso es sancionada }\end{array}$ & $\begin{array}{l}\text { Se estimula y se premia la participación y la } \\
\text { involucración }\end{array}$ \\
\hline Fuente: Agencia de Desarrollo Económico de La Rioja (2013)
\end{tabular}

Una organización que decide utilizar este modelo de autoevaluación puede lograr según ADER (2013):

- Identificar las áreas de mejora más relevantes de su organización de una manera consensuada.

- Conocer cuáles son sus puntos fuertes en la gestión de su organización.

- No olvidar en el análisis de su organización áreas de gestión que de otra forma no se tendrían en cuenta por desconocimiento o por determinadas actitudes o políticas.

- Reducir considerablemente la subjetividad que supone valorar un concepto como la excelencia en una organización con varias personas.

- Involucrar en el proceso de autoevaluación al personal de la organización, introduciendo en la misma, conceptos y valores relacionados con la excelencia.

- Comunicar al resto del personal los cambios significativos seleccionados para su organización.

- Fomentar el trabajo en equipo y aumentar la participación efectiva de todos sus colaboradores ante un reto común. 
Para Zardoya (2004) la razón más importante para que las organizaciones inicien un proceso de autoevaluación, es "impulsar la mejora continua" e "identificar las áreas de mejora". El proceso de Autoevaluación no debe terminar al identificar las fortalezas y debilidades o áreas de mejora, también debe aprovechar los puntos fuertes para alcanzar mejores resultados, cualitativos y cuantitativos.

Entre otros puntos fuertes Zardoya (2004) destaca en su trabajo que la organización que implementa el modelo EFQM desarrolla una cultura organizacional en la que el protagonismo está representado por la dirección de la política y estrategia del hospital orientado a la preocupación creciente con el nivel de satisfacción y seguridad de sus clientes internos y externos. Estas organizaciones aumentan la participación de las personas y su producción científica, crean una conciencia del impacto medioambiental y mejoran la gestión de residuos y el consumo de electricidad y gas, además de mejorar la percepción de los clientes.

Por otro lado, en línea con la RSC y la sostenibilidad, el modelo EFQM ofrece a las organizaciones un marco óptimo en el que encaja perfectamente la gestión ética, gracias a una de sus principales virtudes, su carácter orientativo y no prescriptivo en cuanto a la forma de enfocar y desplegar cada uno de los subcriterios. Dicho carácter orientativo permite una interpretación abierta, que permite albergar también una perspectiva ética de cada uno de los 32 subcriterios en que se subdividen los 9 criterios del Modelo EFQM (Martín-Castilla, 2002). El marco EFQM para la Sostenibilidad de 2015 describe los criterios de éxito para la Sostenibilidad y los asigna al modelo EFQM de excelencia, lo que garantiza un enfoque integral y equilibrado en la planificación e implementación de la sostenibilidad.

El modelo EFQM está basado de un enfoque orientado a las personas que sitúa al cliente (entendido en un sentido amplio) como centro o razón última de la actividad de la organización, poniendo especial énfasis en el papel de ésta como miembro responsable de la sociedad, adoptando un enfoque ético, como modo de mejor servir de forma sostenible a los intereses a largo de plazo de la organización y de las personas que la integran, satisfaciendo sus necesidades y expectativas.

Según Martín- Castilla (2002) el modelo EFQM de excelencia es un modelo vivo, abierto y flexible, con un enfoque orientado hacia la persona y el papel social de la organización, que puede constituir el marco adecuado para la profundización en la gestión ética de las organizaciones.

Es importante destacar la utilización por EFQM de la palabra autoevaluación y no de la palabra evaluación. Efectivamente, el modelo ha sido concebido como una herramienta de autoevaluación. Es decir, una herramienta con la que una misma organización analiza, descubre y consensua sus propios puntos fuertes y áreas de mejora. En definitiva una organización que recorriendo "el camino" de la autoevaluación aprende sobre sí misma.

En algunas ocasiones se contacta con evaluadores externos para que realicen evaluaciones a las organizaciones e indiquen e estas las áreas de mejora que deben abordar. Las evaluaciones externas, dentro del contexto de EFQM, tienen la misión de conceder o no un premio o un sello de excelencia. 
Si una organización con su evaluación opta a un premio o reconocimiento o a los sellos de excelencia, consigue:

- Estimular al equipo de trabajo con la consecución de un objetivo común cuantificable, el reconocimiento externo.

- Obtener información complementaria a la autoevaluación a través del equipo de evaluadores externos sobre los puntos fuertes y las oportunidades de mejora en cada uno de los criterios y subcriterios del modelo europeo de excelencia.

- Poder compararse a nivel global con otras organizaciones.

En línea con lo anterior el Club de Excelencia (2014) señala que un reconocimiento basado en el modelo EFQM aporta aspectos positivos para diferentes grupos de interés.

- Para el cliente:

- Es la garantía de que se trata de una organización con valores

- Asegura la confianza en una organización comprometida con la mejora continua

- Garantiza el acceso a productos y servicios con valor añadido

- Incrementa su satisfacción y busca la superación de sus expectativas.

- Es una garantía de empresa que apuesta por la innovación

- Para la dirección:

- Permite un conocimiento profundo de la organización

- Supone una ocasión para revisar la estrategia y transcender el día a día

- Facilita definir las acciones necesarias para aumentar la competitividad

- Prioriza las actividades basadas en los objetivos estratégicos de la organización

- Es un reconocimiento público de una Gestión Excelente

- Para las personas:

- Permite mejorar los resultados de la organización

- Mejora su posicionamiento dentro de su sector

- Es una equiparación con las empresas europeas más competitivas

- Es una ayuda en la necesidad permanente de lograr mejoras en la gestión

- Facilita la implementación de una cultura de la Excelencia

- Para la Organización: tiene efectos positivos, ya que contribuye a la reducción de costes, errores y defectos y de los plazos, así como el aumento de la seguridad.

Toda organización que quiera alcanzar el éxito tiene que conseguir que sus empleados se sientan motivados e integrados en ella, conozcan y comprendan los procesos que tienen lugar en la misma, se impliquen y participen activamente en la consecución de sus objetivos(Cilla, 2005). El principal capital de toda organización es el humano y el $60 \%$ de la productividad de las organizaciones está vinculada al talento (CLUBEXCELENCIA, 2014) 
La gestión de personas en las organizaciones excelentes (CLUBEXCELENCIA, 2014):

- Desarrolla las capacidades de las personas y fomenta la equidad y la igualdad

- Apoya los planes de gestión de las personas en la estrategia de la organización

- Asegura las disponibilidad de recursos y oportunidades para maximizar sus capacidades

- Recompensa, reconoce y presta atención a las personas de la organización

- Crea una cultura que permite alcanzar objetivos personales y de organización de manera beneficiosa para ambos

El hecho de potenciar valores como la creatividad, la innovación, la comunicación abierta, el respeto a las personas, la formación, el desarrollo, la delegación, la ética y la equidad no debe ser realizado con un fin meramente instrumental encaminado a la obtención de más beneficios, sino atendiendo al propio desarrollo personal y profesional de todos los miembros de la organización (Cilla, 2005).

El modelo EFQM integra la perspectiva del cliente en su sistema de medición, análisis y mejora. En esta participación activa de los usuarios de los servicios sanitarios públicos, la satisfacción de los mismos es vista como uno de los resultados de la asistencia sanitaria, y los métodos dirigidos a medir esta satisfacción se han convertido en un elemento clave de las organizaciones sanitarias modernas, permitiendo obtener información relevante sobre la percepción de los usuarios y sobre las actuaciones que deben realizarse para aumentar la calidad de las prestaciones (Lucena, 2010) y la sostenibilidad de las organizaciones.

\subsubsection{Dificultades para la implantación del modelo EFQM en las organizaciones}

Pero no todos son luces en el modelo EFQM. Algunos autores han planteado también problemas que pueden surgir a la hora de trabajar este modelo de gestión.

El convencimiento, el apoyo y la voluntad política de la dirección resultan esenciales en la implantación, el mantenimiento y la mejora continua de un estilo de dirección participativo, basado en el respeto y en la confianza entre todos los miembros de la organización, de manera que potencia el éxito organizacional y el bienestar de sus trabajadores (Cilla, 2005).

El enfoque sistémico implica que los líderes de las organizaciones deben estar comprometidos con los conceptos básicos con el fin de aprovechar las ventajas de las prácticas consideradas en los criterios de EFQM (Bou-Llusar, 2008). Un compromiso general y la aceptación de los principios de la calidad total son esenciales para beneficiarse de la aplicación de los criterios de EFQM. De lo contrario, los administradores sólo tendrían un conjunto de prácticas no relacionadas e incoherentes.

Los resultados del trabajo de García-Bernal et al. (2004) muestran que la mejora de la gestión debe ser en todos los criterios de forma simultánea ya que la adopción de un modelo de gestión de la calidad no conlleva necesariamente la obtención de resultados superiores, si la implantación no se hace de forma integrada. No obstante, a lo largo de todo el proceso de implantación de un modelo de gestión de la calidad, debe tenerse en 
cuenta el problema de la continuidad, que en el sector público representa un condicionante en la mayoría de las ocasiones por la falta de continuidad de sus líderes políticos, aspecto que no depende de la organización ni de los logros alcanzados en etapas anteriores.

Bermúdez (2012) señala que las mayores dificultades para la implantación de un sistema de gestión de la calidad son:

- En mayor medida, en la incorrecta asunción de la dirección y el liderazgo a la hora de realizar la implantación.

- En la mentalidad y la cultura organizacional arraigada en la empresa, que actuaba de barrera para el correcto desarrollo e implantación.

La experiencia demuestra que los problemas terminan por repetirse en todas las organizaciones. Pero en cualquier caso, todos estos obstáculos son salvables. Se hace pues imprescindible tomar conciencia de que verdaderamente la implantación de un sistema de gestión de la calidad, no es siempre un camino de rosas. Se debe tener presente el objetivo, y la motivación, es decir lo que queremos, y el por qué lo queremos. $\mathrm{Y}$ antes de comenzar, analizar si verdaderamente estamos en disposición de poder acometer con éxito el proyecto. De lo contrario nos encontraremos con sistemas incorrectamente desarrollados e implantados, que no repercuten los beneficios esperados.

A priori existen algunas dificultades al recurrir al modelo EFQM como referente en el sector sanitario (Arcelay, 2000):

1. El propio lenguaje que utiliza para describir el contenido de los criterios, que para muchos resulta confuso y distante

2. Las dificultades de tiempo y dedicación que requiere su análisis y la evaluación que propone, y que solo puede resolverse mediante el liderazgo del equipo directivo

3. El cambio cultural que implica recurrir a un modelo que busca el análisis de cada una de las áreas de gestión de la organización. Entraña una alta capacidad de autocrítica.

4. No siempre es posible actuar sobre las diferentes áreas de interés del modelo en organizaciones sanitarias públicas. Deberá ser el equipo directivo quien priorice

Por otro lado, la relación entre sostenibilidad y el modelo EFQM viene desde los inicios del propio modelo. Cuando se elaboró el modelo EFQM por primera vez en 1992, la inclusión de un criterio llamado "Impacto en la Sociedad" causó la mayoría de las discusiones porque no se comprendía bien qué significaba y por qué se le daba importancia. Desde entonces, el conocimiento y la comprensión de temas como 'Responsabilidad Social Corporativa' y 'Sostenibilidad' han progresado significativamente y la mayoría de las organizaciones realizan algún tipo de actividades de sostenibilidad. Existen diversas herramientas, iniciativas y estructuras de información para ayudar a las organizaciones a desarrollar estrategias y políticas en esta área. Pero estas deben integrarse en la organización y en "su forma de trabajar". Según los evaluadores EFQM después de más de 20 años trabajando con el modelo, éste sigue 
siendo el área en la que la gran mayoría de las organizaciones tienen la mayoría de las oportunidades de mejora (EFQM, 2015).

El modelo permite que cada organización, en función de las características, cultura y objetivos, pueda elegir el método que más se adapte a sus condiciones. Los diferentes enfoques se utilizan en función de la madurez y el esfuerzo necesarios en la organización, para realizar la evaluación.

En las organizaciones sanitarias que se han limitado a realizar una evaluación, sin haber iniciado un cambio cultural, los planes de mejora están poco integrados en la actividad diaria y pocas veces aportan una mejora significativa y permanente. Por otro lado, el procedimiento de evaluación exige un gran esfuerzo, tiempo y dedicación por parte de los equipos directivos y es lo bastante complejo como para necesitar previamente una formación específica e incluso la ayuda de asesores externos, como en el caso de Euskalit con las organizaciones de Osakidetza.

Existe el peligro de que la aplicación del modelo EFQM se limite a la publicidad de las organizaciones mediante los resultados de la evaluación, sin que posteriormente se elabore, implanten, sigan y valoren los planes de mejora. La evaluación por sí sola no asegura la mejora continua y el verdadero reto reside en la instauración de acciones correctoras y la evaluación periódica del progreso que se consigue. En ningún caso se tiene que tomar el modelo EFQM, como una amenaza sino como una verdadera oportunidad, sin traumatismos, sin «ir a por nota», pero aprovechando su utilidad, en forma de áreas de mejora, y de cambio cultural en la propia organización.

De igual forma, los estudios que hablan de su utilización también alertan sobre las barreras, limitaciones y precauciones a tener en cuenta en la elaboración del plan de implantación del modelo. El origen "empresarial" del modelo origina ciertas dificultades en lo que se refiere a la terminología utilizada, poco habitual en el ámbito sanitario, y también en cuanto a las diferentes características de las organizaciones empresariales en comparación con las organizaciones sanitarias públicas, especialmente en lo relativo a la estrategia de gestión. Razones todas ellas que han llevado a diferentes adaptaciones del modelo teniendo en cuenta las peculiaridades del sector sanitario, como por ejemplo la realizada en el año 2003 por la Oficina Regional de la OMS en Europa quien impulsó el proyecto PATH (Performance Assessment Tool for Quality improvement in Hospitals). El objetivo era adaptar los ocho conceptos fundamentales de la Excelencia, a la atención de la salud. Este estudio fue encargado a 31 expertos y, el resultado de su trabajo, fue publicado en 2006. Aquí en España, entre otros, en 2014 se elaboró la "guía de interpretación para el sector sanitario del modelo EFQM de excelencia 2013" por el Foro de Excelencia en Sanidad conformado por el Club Excelencia en la Gestión y la Sociedad Española de Calidad Asistencial.

En todo caso, para poder adaptar este modelo de procedencia empresarial a las características propias de las organizaciones sanitarias, es necesario tener en cuenta las peculiaridades de estas organizaciones a la hora de trabajar en cada uno de los criterios del modelo:

- Criterio 1. Liderazgo. Se debe diferenciar el papel de los líderes políticos del de los líderes que gestionan las organizaciones. El modelo no busca evaluar la "calidad" de las medidas políticas tomadas, sino el nivel de la excelencia de la gestión que se lleva a cabo dentro de las organizaciones. 
Es fundamental equilibrar los objetivos políticos y los objetivos orientados hacia el paciente. Los líderes deben conocer claramente a sus distintos clientes y sus necesidades y ser capaces de equilibrarlos con los aspectos políticos, demostrando de este modo un compromiso claro con los ciudadanos, los trabajadores y también con los políticos.

- Criterio 2. Estrategia. La estrategia debe tener en cuenta la cultura interna, la estructura y los procesos teniendo en cuenta las prioridades, el rumbo que sigue la organización y las necesidades de pacientes y los demás grupos de interés (GI).

La estrategia debe reflejar los principios de gestión de calidad total de la organización y el modo de alcanzar sus objetivos a través de estos principios. Las organizaciones deben establecer y describir su política y estrategia, incluidos sus procesos y planes, y adecuarlos, como un todo coherente, a sus circunstancias particulares y a las necesidades de sus Gl.

- Criterio 3. Gestión de personal. Las personas de la organización son todos los empleados y las demás personas que directamente o indirectamente ofrecen un servicio a los clientes. En el sector sanitario público existen restricciones a la gestión de personas. Esto implica que sólo pueden operar dentro de unos límites definidos. Las organizaciones deben conocer las restricciones que se les ha impuesto y buscar el cumplimiento de la normativa y las oportunidades que trabajar dentro de dichos límites para obtener un rendimiento óptimo de sus personas.

- Criterio 4. Alianzas y recursos. Las organizaciones del sector sanitario público tienen también que cumplir una serie de regulaciones legislativas de obligado cumplimiento que pueden dificultar la gestión de sus recursos económicos y financieros en mayor medida que el sector privado. Las organizaciones sanitarias públicas tienen un control limitado sobre la obtención de sus recursos, por lo que la organización no debe centrarse en medir si los recursos o las asignaciones son los adecuados sino como, dentro de los límites establecidos, se gestionan los recursos en apoyo de la política y estrategia.

- Criterio 5. Procesos, productos y servicios. En el sector sanitario, los procesos críticos son los que guardan relación directa con la prestación de los servicios asistenciales y los procesos de apoyo esenciales para el funcionamiento de la organización. Una de las clave para identificar, evaluar y mejorar los procesos es conocer su contribución y efectividad en lo que respecta a la misión de la organización, a la producción de "salud".

- Criterio 6. Resultados en los clientes. Los clientes externos son los destinatarios o los beneficiarios de la actividad, productos o servicios de las organizaciones del sector público. En el caso de las organizaciones sanitarias, los destinatarios evidentes son los pacientes y sus personas cercanas, aunque también es necesario tener en cuenta, y no solo desde el ámbito de la Salud Pública o la Atención Primaria, al entorno y a la sociedad en general. Aunque esta última entra ya en el ámbito del criterio 8. 
- Criterio 7. Resultados en las personas. Este criterio debe abordar la satisfacción de todas las personas que formen parte de la organización y debe vincularse al criterio 3, Gestión del Personal. La libertad de la organización en esta área se ve a menudo limitada por restricciones externas. Por tanto, las organizaciones deben conocer de manera clara cuáles son estas limitaciones y qué esfuerzos realizan para influir sobre ellas. Por consiguiente, las mediciones deben centrarse en las áreas donde la organización goza de libertad.

- Criterio 8. Resultados en la sociedad. Las organizaciones del sector sanitario público inciden en la sociedad debido a la naturaleza misma de su misión. Los resultados de estas actividades básicas se representan en los criterios 6, satisfacción del cliente, y 9, resultados de la organización. No obstante, este criterio debe medir el impacto de la organización en la sociedad en los temas que no se contemplan ni en su misión directamente, como por ejemplo su impacto medioambiental o la investigación y difusión del conocimiento.

- Criterio 9. Resultados clave. Este apartado incluye aquello que la organización considera como logros importantes y medibles para el éxito de la organización a corto y largo plazo. Los resultados clave son las mediciones realizadas de la efectividad y eficiencia en la prestación de servicios y en el logro de objetivos y metas, incluidos los objetivos específicos de carácter político. Estas medidas suelen ser tanto de tipo económico como no financiero, vinculándose a la estrategia (criterio 2) y a los procesos críticos (criterio 5).

Alberto Pardo (2015), Subdirector de Calidad del Servicio Madrileño de Salud señala en una comunicación en 2015 que después de haber trabajado con el modelo desde 2003 y después de varios ciclos de mejora ha aprendido que:

1. El liderazgo debe ser reforzado incluyendo la excelencia como un objetivo institucional

2. La organización debe adoptar y ser consciente de las consecuencias de optar por el modelo EFQM

3. Deben proporcionarse la formación y las herramientas de apoyo necesarias.

4. Debe hacerse una planificación que incluya objetivos anuales

5. Durante este camino que no es corto se debe insistir en la flexibilidad de los centros y mediante el aprendizaje alcanzar la madurez de la organización

Pardo (2015) también ha identificado algunos inconvenientes en la implantación del modelo:

- El origen empresarial del modelo. Usa un lenguaje especializado.

- La necesidad de realizar formación específica en las organizaciones para su utilización.

- El esfuerzo y el tiempo necesarios para realizar la autoevaluación y la mejora

- A veces el sistema por sí mismo no es suficiente y puede necesitarse cierta experiencia para obtener mejor rendimiento.

- Utilizar el modelo como un método solo de autoevaluación.

- La organización necesita un liderazgo efectivo y la continuidad del modelo.

- La dificultad en obtener datos para comparar y hacer benchmarking 
Como ejemplo reciente, el modelo de integración de la Gerencia Integrada de Soria (Delgado, 2015) se adapta a las condiciones de la provincia, utilizando todas estas estrategias en un proceso de mejora continua basado en el modelo EFQM, tras una sostenida planificación estratégica a largo plazo.

Según Delgado, "ha aumentado la capacidad resolutiva, la autosuficiencia y la eficiencia, quedándonos siempre la duda de si los cambios y tensiones a los que estamos sometidos, permitirán su completo desarrollo".

En conclusión, el modelo EFQM de Excelencia, señala que la satisfacción de pacientes y profesionales, y la obtención de un impacto positivo en la sociedad se consiguen mediante un adecuado liderazgo de los directivos en el proceso de transformación de la organización sanitaria, mediante el establecimiento de oportunas políticas y estrategias, un adecuado aprovechamiento de los recursos y alianzas de todo tipo y una buena gestión de sus procesos, todo lo cual lleva a conseguir la visión de la organización con excelentes resultados, siendo este un difícil camino en las organizaciones sanitarias por resistencia al cambio de unas organizaciones complejas, los liderazgos ineficientes y falta de políticas estables.

No obstante, a veces la calidad puede aparecer como un proceso de burocratización en el que los participantes no llegan a ver resultados claros o los procedimientos no han sido consensuados y se lanzan prácticas de arriba abajo que los afectados no entienden o no comparten.

También en algunas organizaciones la implementación del modelo EFQM aparece como un proceso circular en el que lo importante es el procedimiento y pueden olvidarse los resultados.

\subsection{La relación entre la sostenibilidad y la calidad}

La sostenibilidad siempre ha formado parte de los postulados de la calidad total. Se trata de una cuestión intrínseca a este planteamiento. Ya en 1986 William E. Deming (Camisón 2006) expuso el principio de "constancia en el propósito de mejorar productos y servicios" como uno de los 14 Principios en los que se basa su modelo de gestión. Deming sugiere una nueva y radical definición de la función de las organizaciones, "más que hacer dinero, es mantenerse en el negocio y brindar empleo por medio de la innovación, la investigación, la mejora constante y el mantenimiento". Este principio es válido y seguirá siendo válido durante toda la existencia de la organización, pues la mejora en productos y servicios nunca debe acabar si la organización pretende ser sostenible en el tiempo.

La búsqueda de la excelencia es un proceso sin fin, que supone una "planificación adaptativa» a lo largo del tiempo, resultado de la evaluación de los resultados obtenidos en cada ciclo y de la introducción de los correspondientes ajustes en la planificación y estrategia de la organización. El carácter inalcanzable de la excelencia, constituye el corazón que mantiene a la organización siempre atenta al entorno, las necesidades del 
mercado, y sus propios recursos, capacidades y rendimiento, con el objetivo de mejorar continuamente y adaptarse a los diferentes escenarios.

Holling (1987) insiste en que los modelos de gestión y las políticas basadas en ellos no se deben considerar como acciones finales, sino más bien como un proceso de experimentación orientativo y adaptativo entre los sistemas que se están gestionando y que recalca la importancia de los procesos de retroalimentación. Hacer más sostenibles los sistemas que son considerados complejos y también adaptativos (donde se pueden incluir los sistemas naturales y humanos que interactúan sistémicamente) depende esencialmente de comprender los problemas y restricciones de su dinámica evolucionista (Constanza 1998).

El término sostenibilidad, cuyo origen se encuentra en la gestión medioambiental, hace referencia también a los aspectos económicos y sociales de las organizaciones en el desarrollo de sus competencias y actuaciones, y las relaciones no sólo con su entorno sino con los agentes internos. En dicho sentido se interrelaciona estrechamente con la teoría de la teoría de los grupos de interés o stakeholders, íntimamente unida a la filosofía de la excelencia.

La excelencia o calidad total constituye un instrumento metodológico y una filosofía transformadora que puede permitir a las organizaciones el desarrollo en el tiempo de mejoras en la gestión de la actividad y en el servicio prestado al paciente. La adopción de la filosofía de excelencia pude facilitar las herramientas necesarias para poder interpretar la realidad de una organización, explorando las necesidades y expectativas de los diferentes grupos con algún interés y poniendo en marcha una gestión que dé respuesta a sus necesidades. Los grupos de interés (stakeholders) de la sanidad pública no son sólo los pacientes, sino también todos aquellos agentes relevantes interesados o potencialmente afectados por la actividad de la organización (incluyendo las personas que la integran y que tienen unas determinadas necesidades y expectativas con respecto a la organización, los aliados con los que establece relaciones de colaboración y cooperación, la sociedad en su conjunto, así como todos aquellos que tienen intereses económicos en ésta).

Los grupos de interés (stakeholders) no son sólo los clientes últimos, sino también todos aquellos agentes relevantes interesados o potencialmente afectados por la actividad de la organización (incluyendo las personas que la integran y que tienen unas determinadas necesidades y expectativas con respecto a la organización, los aliados con los que establece relaciones de colaboración y cooperación, la sociedad en su conjunto, así como todos aquellos que tienen intereses económicos en ésta).

Los enfoques basados en los grupos de interés permiten tener conciencia del efecto que las acciones de la organización provocan o pueden provocar sobre las personas en sus diferentes niveles de participación, y sea como pacientes o como trabajadores, aliados, proveedores, políticos o la propia sociedad en su conjunto. Para las organizaciones orientadas hacia la excelencia, la satisfacción equilibrada de los requerimientos de cada uno de los integrantes de los grupos de interés constituye la idea básica sobre la que se articulan los procesos lógicos de razonamiento y de decisión (Martín-Castilla JI, 2007). En la interpretación holística de la realidad propuesta por el modelo EFQM de Excelencia ocupan un lugar fundamental la visión finalista de los grupos de interés (a 
cuya satisfacción orienta su actividad la organización), la asunción de responsabilidad, la implicación de las personas que integran la organización, la orientación a los destinatarios y a los resultados, el liderazgo efectivo y la coherencia en los objetivos que persigue la organización, y la adopción de una cultura de la medición, evaluación de resultados y mejora continua. (Martín-Castilla Jl, 2007).

Para Juran (1990), una vez que se ha planificado la calidad (adaptando los procesos a los requerimientos del cliente), controlado la calidad del proceso y del producto mediante control estadístico, y tratando las no conformidades que se encuentren durante este control, es necesario sostener lo ganado. Es decir, mantener lo ganado precisa mejorar la eficacia de los procesos, satisfacer a los clientes, y generar ahorros en recursos y costes (eficiencia). Para todo ello es indispensable también fortalecer las habilidades del personal a través de una formación efectiva (Dale, 1993).

En línea con esta idea de "sostener lo ganado", se han realizado diferentes aproximaciones al concepto de la sostenibilidad en relación con la calidad.

Para Zairi (2005), la sostenibilidad de una organización depende de su habilidad de una para adaptarse a los cambios de su entorno con el fin de obtener y aplicar las mejores prácticas, metodologías y técnicas que aseguren y sostengan un rendimiento óptimo de sus procesos. Según este autor, el desarrollo de una cultura de mejora continua y aprendizaje sólo se consigue a través de la aplicación sostenida de innovaciones en los procesos de la organización. Esto no implica una posición fija en el tiempo, sino que se presenta a través de diferentes escenarios que son potenciados o inhibidos por diferentes factores o variables, es decir, la organización debe ser muy consciente de los entornos en los que se mueve y adaptarse continuamente a ello.

Para Dale et al. (1997), la sostenibilidad implica el mantenimiento de un proceso de mejora continua de la calidad. El enfoque es el mantenimiento constante de un proceso de mejora continuo. El énfasis se realiza en la búsqueda de oportunidades de mejora, no sólo en mantenerse. El enfoque se encuentra en planificar, prevenir y anticipar la caída del sistema.

Dale (1997) sostiene, que la sostenibilidad se centra en tres elementos básicos, que se encuentran interrelacionados y vinculados, y que además son influidos por la cultura organizacional y el estilo de gestión y dirección de cada organización. Dichos tres elementos son:

1) Elementos individuales, tales como el liderazgo, las infraestructuras, mejor continua, la medición de la actuación de los procesos, y la comunicación

2) La mejora de procesos, sustentada en el rediseño de las tareas que agreguen valor en los procesos, así como, la medición de la actuación de los mismos a través de indicadores

3) Sostener lo ganado, en términos simples, asegurar que las mejoras obtenidas se mantengan. Mantener lo ganado es un elemento inseparable de la sostenibilidad. 
Se han analizado algunos elementos individuales de las organizaciones para definir la sostenibilidad. (Dale et al., 1997), mediante auditorías en organizaciones de Alemania, Reino Unido y España identificándose cinco categorías de la sostenibilidad:

1) Medio ambiente interno/externo

2) Estilo de gestión

3) Políticas

4) Estructura Organizacional

5) Procesos de Cambio.

Estos autores señalan que la falta o la aplicación inadecuada de las cinco categorías impactan negativamente en la sostenibilidad. Entre los principales fallos encontrados se encuentran un inadecuado liderazgo, el miedo y la resistencia al cambio, la falta de habilidades para la solución de problemas, la falta de constancia, la falta de recursos, y un inadecuado flujo de información y análisis de la misma (Suarez, 2007).

En otro estudio, Schneider y otros (1996), señalaron también la importancia de crear un clima o entorno cultural que reuniese las condiciones necesarias para que poder generar un cambio organizacional sostenido.

En resumen, en un entorno tan cambiante y competitivo como el actual, para ser sostenible no basta sólo con implantar un modelo de gestión de calidad, sino que es necesario trabajar en mantener lo ganado después de aplicarlo, para que la organización simplemente pueda competir y sobrevivir (Van der Wiele y Brown, 2002). Algunos autores han señalado que la función básica que necesita ejercer una organización (privada o pública) es sostener el rendimiento de sus procesos operativos, para posteriormente mejorarlos y nuevamente mantenerlos.

Sin el mantenimiento y la mejora de los mismos, el rendimiento de los procesos puede estancarse y comenzar a declinar, deteriorarse, hasta colapsarse

Para estos autores esta declinación o deterioro del rendimiento de los procesos a lo largo del tiempo tiene un efecto directo en el rendimiento de la organización, que se puede observar en el gasto de recursos (materiales, financieros, etc.), el incremento de los costes operativos, el incumplimiento de los requisitos de calidad de los productos y servicio (en tiempo y forma), hasta la generación de mayores problemas de comunicación, coordinación, e incluso la disminución de la motivación y el entusiasmo por parte del personal que opera los procesos (Dale, 1996; Harkness et al., 1996).

Para Martín-Castilla (2007), la organización debe orientar sus procesos y actividades a satisfacer las necesidades y expectativas de sus clientes (tanto las presentes como las futuras que pudieran surgir), de forma coherente con sus valores, visión y estrategia. Los clientes constituyen la razón de ser de la organización y son, en última instancia, los árbitros de la calidad del servicio. Dicha satisfacción debe buscar una relación honesta, mutuamente beneficiosa y, en su caso, la sostenibilidad de la misma.

Asimismo, la organización deberá de garantizar el buen gobierno y someterse al control interno y externo, colaborado de forma clara y honesta, y comunicado de forma transparente y veraz sus resultados tanto económico-financieros, como de responsabilidad social y ambiental. . (Martín-Castilla J.I., 2007). 
En la interpretación holística de la realidad propuesta por los enfoques de excelencia, como el modelo EFQM, ocupan un lugar fundamental la visión finalista de los grupos de interés (a cuya satisfacción orienta su actividad la organización), la asunción de responsabilidad, la implicación de las personas que integran la organización, la orientación a los destinatarios y a los resultados, el liderazgo efectivo y la coherencia en los objetivos que persigue la organización, y la adopción de una cultura de la medición, evaluación de resultados y mejora continua.

La búsqueda de la excelencia es un proceso sin fin, que supone una planificación adaptativa a lo largo del tiempo, resultado de la evaluación de los resultados obtenidos en cada ciclo y de la introducción de los correspondientes ajustes en la planificación y estrategia de la organización. El ciclo PDCA o ciclo de Deming es el principio operativo de la mejora continua que se usa como referencia tanto para EFQM como para normas ISO y otros modelos.

La implantación de los principios de gestión de la calidad total a través del modelo EFQM y la integración de las preocupaciones sociales y medioambientales en la estrategia y operaciones de la organización supone para las organizaciones una posibilidad manifiesta de lograr establecer ventajas competitivas a largo plazo que les permitirá además, lograr la excelencia siendo socialmente responsables.

El modelo EFQM de Excelencia dispone de gran número de conexiones con la Responsabilidad Social Corporativa, por su orientación hacia la correcta gestión de personas de la organización, la preocupación por la gestión ambiental y la transparencia en las operaciones (Vidal, 2012)

Robertson y Ball (2002), realizaron un estudio cuantitativo y cualitativo para conocer el impacto de un modelo de gestión de la calidad en la mejora de los servicios públicos de un gobierno local de Canadá. Sus conclusiones con respecto al tema de la sostenibilidad, se centraron en indicar que los gobiernos locales de este país, han visualizado a la innovación y a la mejora continua como programas, que si se aplican de manera sostenida, entonces ayudan a incrementar con éxito, la calidad de los servicios públicos que ofrecen (Robertson y Ball, 2002).

Otros autores han señalado que conseguir que los esfuerzos de adaptación y mejora se sostengan en el tiempo, requiere de una adaptación a las particularidades y necesidades de cada organización, e indican que es fundamental crear los mecanismos, infraestructuras y soportes políticos y técnicos necesarios con el fin de generar una nueva cultura o entorno orientado a la mejora continua, que lentamente sustituya a cualquier entorno previamente establecido, institucionalizando el esfuerzo de mejora ( Houston y Katavic, 2006).

Además de lo anterior, Pollit (2006) propone vigilar que no se cometan los siguientes errores para conseguir que la mejora de la calidad de los servicios públicos se sostenga en el tiempo:

- Concebirlo como un proyecto político, lanzado sólo para obtener publicidad que ayude a consolidar posibles victorias en las elecciones.

- Implementar el sistema sin considerar a las personas de la organización. 
- No reconocer y valorar la resistencia al cambio y la dificultad de abandonar métodos y procedimientos establecidos.

- Mala elección inicial de la aproximación o técnica para el contexto de la organización

- El esfuerzo de mejora es lanzado e implementado con recursos financieros y humanos adicionales, y si estos recursos desaparecen el proyecto puede desvanecerse.

- Crear unas expectativas previas demasiado elevadas en la organización. Si comienzan a llegar resultados que más modestos, la gente puede desilusionarse y perder la motivación.

- Sólo se brinda formación al equipo responsable, lo que puede provocar que cuando los integrantes de este equipo, previamente formados son traslados o cambiados a otras áreas $u$ otros puestos de la organización, se pierde el conocimiento y experiencia adquirida y la continuidad del sistema peligra.

- No gestionar el despliegue de la comunicación de los resultados que se obtienen en la organización.

- Tomárselo como una moda a seguir.

- El sistema de gestión de calidad se convierte en un esquema burocrático y formalizado, que pierde la esencia de participación de los grupos de interés.

Fortuny (2009) señala que las organizaciones, y en especial las organizaciones sanitarias públicas deben estar atentas a su entorno y ser capaces de identificar todos aquellos factores internos y externos que intervienen en la sostenibilidad de las organizaciones (ilustración 17).

Ilustración 17. Análisis del entorno sanitario

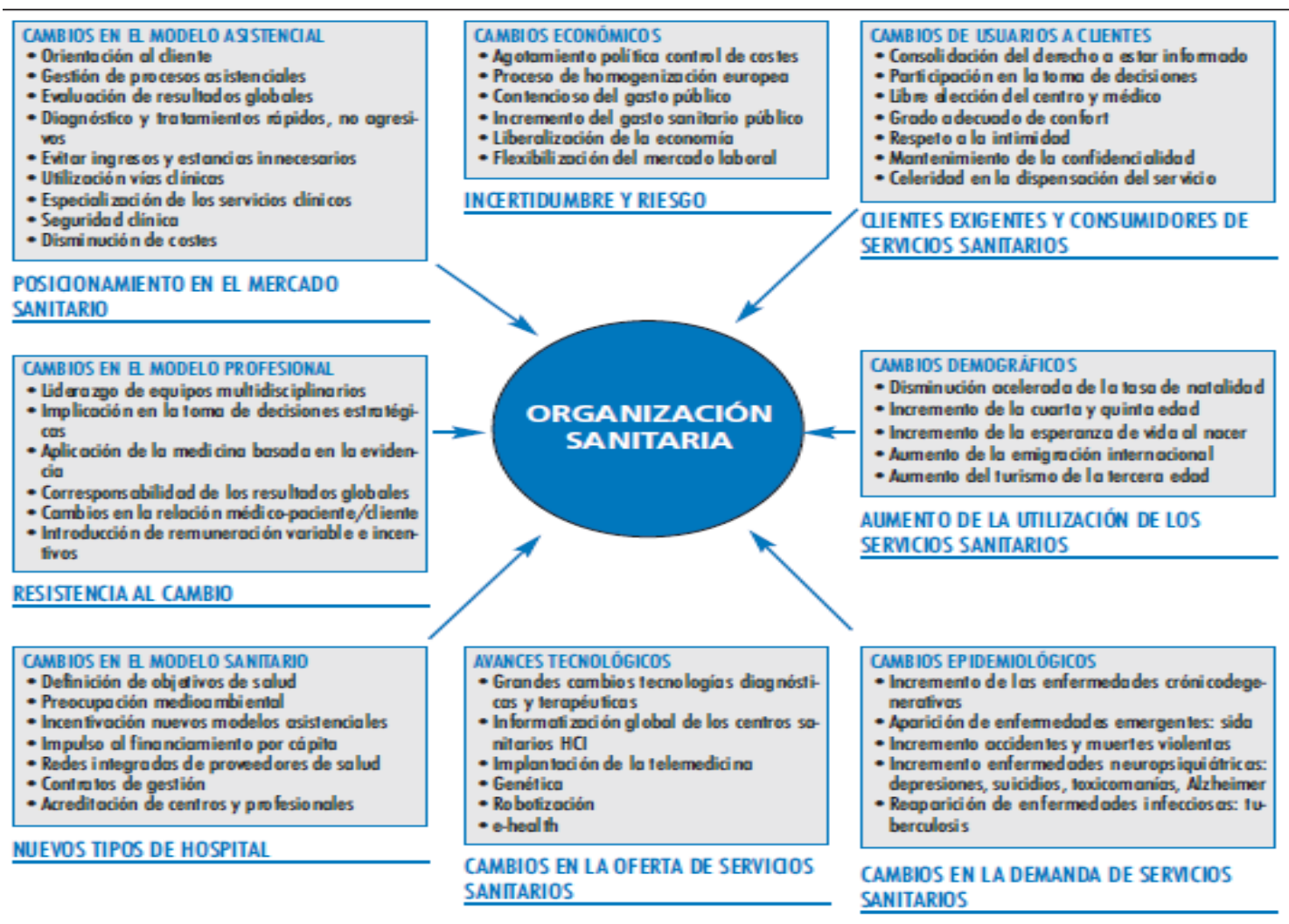

Fuente: Fortuny B. (2009). La gestión de la excelencia en los centros sanitarios. PFIZER . Madrid. 
Respecto al impacto del modelo en las personas de la organización, el estudio de los progresos realizados por las organizaciones de salud de Osakidetza en la aplicación del modelo EFQM (Matthies-Baraibar, 2014), identifica un mayor nivel de satisfacción de los empleados en los campos que son gestionados de forma independiente por cada organización, mientras que no se observaron diferencias significativas en aquellos aspectos que son más homogénea y gestionado de manera centralizada a través del servicio de salud regional en el que cada organización tiene menos posibilidades de autogestión.

Este estudio también muestra que cuanto mayor es el avance en la implementación del modelo (como en el caso de las organizaciones con Premios $Q$ de oro en comparación con aquellos con premios de plata $Q$ ), mayores son las diferencias en términos de satisfacción del personal con las organizaciones menos avanzados (los que no tienen ningún tipo de reconocimiento externo) y en una gama más amplia de dimensiones.

También hay estudios que relacionan las diferentes prácticas de la gestión de la calidad total con tipos de cultura organizacional. Así, por ejemplo consideran que las organizaciones se pueden catalogar como de cultura comportamental si hacen énfasis en prácticas asociadas con la medición de la calidad, el control de procesos, la estandarización y el control estadístico, y como organizaciones de cultura cognitiva si ponen el acento en las prácticas de la gestión de la calidad relacionadas con los estilos de gerencia, trabajo en grupo, autonomía y responsabilidad (Perdomo, 2004).

\subsection{Indicadores de sostenibilidad}

Los sistemas de indicadores de sostenibilidad permiten evaluar el grado de avance o el logro de las metas propuestas y de las políticas de acción formuladas para su cumplimiento (Antequera y González, 2005), convirtiéndose en una herramienta que permite a todos los interesados orientar sus decisiones hacia el logro del desarrollo sostenible de las organizaciones.

Cualquier sistema concebido por el ser humano está pensado para el logro de una meta determinada (ganar más dinero, proporcionar salud, producir, sostenibilidad, etc.). En general se puede decir que todas las metas apuntan al logro de la viabilidad del sistema como un todo, es decir, al mantenimiento de su identidad a través del tiempo (Antequera y González, 2005)

La autonomía de las organizaciones y su interacción con el entorno (al que también terminan afectando), condicionan su viabilidad, obligando a las organizaciones a adaptarse continuamente, proceso en el que es imprescindible la posesión de una cierta capacidad de procesamiento de la información (Antequera y González, 2005) que permita anticiparse a los problemas.

La anticipación implica necesariamente la habilidad de obtención y procesamiento de la información, así como la capacidad de realizar acciones de respuesta. (Antequera y González, 2005)

Todo esto hace necesaria la existencia de la capacidad que permita las correcciones necesarias para que las condiciones de viabilidad se mantengan dentro de ciertos 
límites, los cuales pueden ser tanto internos como externos a la organización. Toda organización necesita un sistema de medidas para ser gestionado orientándolo hacia el cumplimiento de su finalidad (misión). Es decir, toda organización necesita un sistema de indicadores.

Un indicador es un signo típicamente medible, que puede reflejar una característica cuantitativa o cualitativa, y que es importante para hacer juicios sobre condiciones actuales, pasadas o futuras. La formación de un juicio o decisión se facilita comparando las condiciones existentes con un estándar o meta existente (Rayén, 2001). Los indicadores son un medio de simplificar una realidad compleja centrándose en ciertos aspectos relevantes, de manera que queda reducida a un número manejable de parámetros (Bermejo, 2001).

Un sistema de indicadores de sostenibilidad funciona como una herramienta que permite evaluar el grado de avance o logro de las metas implícitas en un marco teórico, así como también de las políticas de acción formuladas para el cumplimiento de estas, constituyéndose de esta manera en una guía de referencia para facilitar la toma de decisiones (ONU, 2001).

Tal y como hemos visto en anteriores apartados de este trabajo, la sostenibilidad está integrada por diferentes aspectos económicos, sociales y ecológicos. La taxonomía clásica de indicadores de Desarrollo Sostenible diferencia entre indicadores ambientales, sociales (o socio-políticos) y económicos (Hanley, Moffat, Faichney, \& Wilson. 1999). No obstante, cuando se habla de sostenibilidad de las organizaciones suele ser en términos económicos y financieros. Esto hace que la mayoría de los indicadores utilizados sean de carácter económico y no permiten reflejar fielmente la realidad del bienestar y la sostenibilidad. Sin duda, la economía es fundamental para la sostenibilidad de las organizaciones, pero su medición basada en factores puramente económicos y menos humanizados puede ocultar importantes indicadores sociales y ambientales. En línea con esto, organismos como Naciones Unidas, gobiernos, universidades, ONG's o entidades financieras utilizan diferentes indicadores para medir el bienestar común y reconciliar el crecimiento económico con el progreso social ante la necesidad de identificar un fin moral para la economía que asegure la sostenibilidad de las organizaciones. Según muchos expertos, la incorporación de estos indicadores a los estudios que miden el bienestar podrían ofrecer una imagen mucho más cercana a la realidad de las personas (Acciona, 2016)

En el plano social se presentan muchos indicadores para medir la sostenibilidad. Factores como el nivel de educación, colaboración con ONG's o grupos vulnerables, la calidad del empleo, la cantidad de tiempo libre, la violencia en el trabajo, la normativa contra el acoso o la discriminación, la seguridad física, la tasa de absentismo o la buena gobernanza facilitan un entorno adecuado para la convivencia.

Por otro lado, los indicadores ambientales como la huella ecológica, el nivel de contaminación, el consumo de agua y energía, o el cuidado del medio ambiente en general son factores determinantes y transversales que afectan a otras muchas áreas básicas, como puede ser la salud, el agua y la alimentación. El impacto en el entorno en el que vivimos influye directamente en la sostenibilidad, por ello estos indicadores son 
importantes a la hora de evaluar el bienestar de las comunidades en las que se enmarcan las organizaciones.

Dentro del grupo de los indicadores económicos, aparte del PIB per cápita, existen indicadores que nos pueden dar información sobre la realidad como el Coeficiente de Gini, el porcentaje de activos bancarios respecto al PIB, la opacidad financiera, el porcentaje de gasto militar, la sostenibilidad y desarrollo económico, la dependencia de la deuda externa, etc. Estos indicadores también son clave a la hora de analizar el bienestar social más allá de los fríos números del Producto Interior Bruto, al incidir directamente en la contribución fiscal de los habitantes de un país y la contrapartida recibida.

El crecimiento del gasto sanitario y unas perspectivas de la atención de salud cada vez más centradas en el ciudadano como eje del sistema, están llevando a los sistemas sanitarios a buscar mecanismos para crear servicios más eficientes, de mejor calidad y con una mayor efectividad en las prácticas médicas ( Cabasés et al, 2003).

Los sistemas sanitarios suponen cada vez un mayor porcentaje del PIB de los presupuestos nacionales. Desde los años 50 el gasto sanitario se incrementa anualmente por encima del PIB nacional en los países desarrollados, pero hay estudios que demuestran que un mayor gasto no se corresponde con unos mejores resultados de salud (Lalonde, 1974) y que llegado a cierto punto a mayor gasto sanitario no aumentan la expectativas de vida ni la calidad de vida de los ciudadanos. Es en este punto donde se muestran los llamados Determinantes de la Salud (ilustración 18).

Ilustración 18. Determinantes de la salud

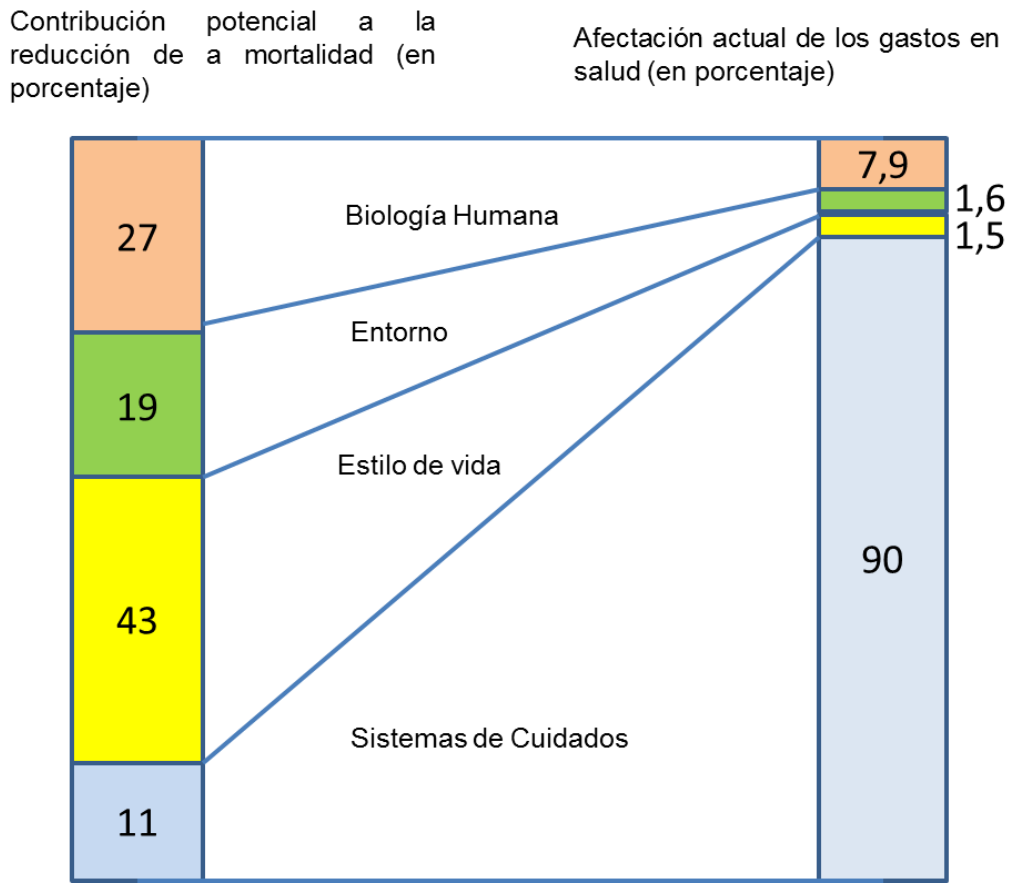

Fuente: Tomado de Denver (1976)

Además, según la Fundación BBVA (Abellán, 2013), aunque es necesario implementar reformas encaminadas a incrementar la eficiencia del sistema sanitario público que redunden, en último término, en un menor crecimiento del gasto sanitario, la 
sostenibilidad económica del SNS estaría garantizada, para un importante número de comunidades y para el promedio nacional, a partir de 2014, si se cumplían las previsiones de crecimiento económico que sobre España habían realizado organismos internacionales como el FMI (tabla 19). Resulta, por tanto, aconsejable que las reformas tengan en cuenta los problemas de sostenibilidad económica del sistema sanitario público para buena parte de las comunidades autónomas pero no deben centrarse exclusivamente en ellos.

Tabla 19. Crecimiento económico de España (Incremento del PIB en \%):

\begin{tabular}{|c|c|c|c|c|c|}
\hline & $\mathbf{2 0 1 3}$ & $\mathbf{2 0 1 4}$ & $\mathbf{2 0 1 5}$ & $\mathbf{2 0 1 6}$ & $\mathbf{2 0 1 7}$ \\
\hline Previsión FMI & -1.2 & 1.4 & 3.2 & 3.2 & 2.3 \\
\hline Crecimiento real & 0.2 & 2.1 & 3.5 & 3.4 & -- \\
\hline
\end{tabular}

Fuente: Elaboración propia con datos de INE y FMI

Por otra parte en nuestro sistema sanitario, por imperativos legales, éticos y de justicia social, se necesita mantener la igualdad de acceso (equidad), mejorar la rapidez en la atención (control de las listas de espera), mejorando la humanización, y la personalización en el trato, todo ello con la máxima calidad. Todo esto son demandas universales que influyen en las opciones políticas de los ciudadanos (Arenas, 2012). El componente de demanda social y de derecho de los ciudadanos se sobrepone al factor económico por lo que el aspecto económico pasa a un segundo plano en la prioridad de la sociedad y sus representantes políticos.

El desarrollo de metodologías rigurosas, transparentes y reproducibles de medidas de eficiencia de organizaciones sanitarias y particularmente de hospitales en un elemento fundamental de cualquier agenda política o de gestión que pretenda mejorar de forma sostenible en el tiempo los niveles de eficiencia, calidad y resultados de las organizaciones (Peiró, 2002). Se hace imprescindible el empleo de indicadores (tanto referidos a los recursos, a la capacidad, a la actividad, a los resultados y a la eficiencia) en el sector público (Peiró, 2006), con el objetivo de valorar su actividad como organizaciones productoras de servicios, y con el fin de analizar el funcionamiento y mejorar de su eficiencia.

Los sistemas sanitarios buscan medidas que garanticen la eficiencia, al tiempo que se encuentran comprometidos con la mejora de la atención sanitaria que reciben los pacientes, tanto desde el punto de vista de la efectividad clínica como de la percepción que poseen los pacientes de cómo es su sistema sanitario. En esta línea, se acuñó en EE. UU. (Berwick, 2008) el término «triple meta» para referirse a un enfoque de gestión orientado a la ganancia en salud, a la mejora de la experiencia del conjunto del sistema y de la atención por parte del paciente y a la reducción de los costes per cápita. La triple meta como respuesta a un crecimiento del gasto sanitario imparable y una visión economicista, que a pesar de todo no logra mejores resultados en la efectividad clínica o en la percepción de los pacientes. En España, el proyecto SENECA propuso una relación de estándares de cuidados a nivel hospitalario. En 2011, la Sociedad Española de Calidad Asistencial (Parra el al, 2011) lideró un amplio estudio para identificar indicadores de calidad a nivel hospitalario.

En 2013 Nebot-Marzal y otros publicaron en la Revista de Calidad Asistencial el trabajo titulado "Conjunto de indicadores de calidad y seguridad para hospitales de la Agencia 
Valenciana de Salud" en el que se proponían un conjunto de indicadores de calidad y seguridad. El objetivo de este estudio fue definir una batería de indicadores hospitalarios de calidad, seguridad y sostenibilidad, combinando aspectos económicos o de gestión, específicos de la atención enfermera y propiamente clínicos. (Nebot- Marzal, 2023) En este caso se definieron 65 indicadores, $30(46,15 \%)$ de los cuales coincidían con los propuestos por SECA (Parra, 2011), 22 (33,85\%) y con los utilizados en el proyecto Séneca (MSSSI, 2009). Otro aspecto importante propuesto por estos autores es que los sistemas de información permiten la monitorización de los indicadores y aseguran su fiabilidad y su pertinencia para diferentes perfiles de hospitales. En abril del $2013 \mathrm{se}$ condujo un estudio de investigación cualitativa para buscar y lograr consenso entre 23 coordinadores de calidad de 12 comunidades autónomas y los representantes en SECA de las sociedades autonómicas de calidad asistencial sobre un conjunto mínimo de indicadores que permitieran comparaciones entre servicios de salud en términos de su eficiencia (García et al, 2014)

Las organizaciones sanitarias precisan de un sistema de indicadores multidimensional para sus procesos de decisión, en el que la eficiencia es sólo una de las dimensiones a considerar. Los indicadores son criterios cuantitativos para evaluar y monitorizar la calidad y la eficiencia de los sistemas de salud o las organizaciones y proveedores de servicios de salud (Peiró, 2006). Su objetivo es proporcionar información útil a los diferentes agentes del sistema sanitario para facilitar sus elecciones e intentar que sus expectativas se vean satisfechas (Peiró y Casas, 2002). Idealmente, para que éstos sean útiles, han de adecuarse a una serie de requisitos (Peiró, 2006) como la atribución al sistema de atención, la relevancia, la racionalidad, la robustez, la sensibilidad a los cambios, la factibilidad con un coste razonable, disponible en el tiempo, y contener incentivos positivos, no favorecer el traslado de problemas entre niveles de atención, incluir modelos de ajustes de riesgos, estar soportados por evidencia científica y poder ser evaluados longitudinalmente. Aunque cada conjunto particular de indicadores proporciona una información diferente al sistema sanitario, o a sus componentes, existe un amplio consenso en no separar las medidas de productividad, de calidad y de resultados clínicos (Peiró y Casas, 2002).

El desarrollo de los sistemas de información y la tecnología de información ponen al alcance de todos los usuarios del sistema un conjunto de datos relevantes para la toma de decisiones, y permiten la creación de indicadores capaces de monitorizar las dimensiones más importantes de la atención sanitaria, tanto a nivel hospitalario, como en atención primaria y salud pública (Gonzalez-Outón, 2009). En España, estos sistemas de información y de gestión, en especial el CMBD, han supuesto un desarrollo en la utilización de cuadros de mando para monitorizar la eficiencia y calidad en los diferentes Servicios de Salud, en un entorno, en el que la efectividad y seguridad de las prácticas clínicas, esto es, la calidad asistencial sanitaria, constituyen uno de los elementos claves del sistema sanitario (Peiró, 2006).

En general, todos los Servicios de Salud han desarrollado cuadros de mando a partir de sistemas de información de costes, actividad y algunas medidas de calidad, sin embargo, la gran diversidad, que se presenta entre Comunidades Autónomas, complica la creación de una única estrategia global para evaluar la eficiencia de la totalidad de los hospitales que constituyen el Sistema Nacional de Salud (SNS). 
En la actualidad, existen diferentes acercamientos a la medición de la sostenibilidad de las organizaciones sanitarias mediante cuadros de indicadores que permiten la comparación entre centros.

Uno de ellos es el Top 20 que constituye un marco global para la evaluación de los hospitales del SNS, y permite la comparación entre hospitales del mismo nivel basándose en indicadores objetivos, obtenidos a partir de datos que se registran de forma rutinaria. Pueden participar tanto hospitales públicos como privados y la participación es gratis, voluntaria y confidencial. Se analizan más de 30 procesos con más de 120 indicadores, en 8 áreas clínicas: nervioso, respiratorio, corazón, digestivo, musculoesquelético, riñón y vías urinarias, mujer y atención al paciente crítico (IASIST, 2016). En el año 2013, el diario ABC publicaba los resultados que mostraban que los centros TOP mantenían un elevado nivel de calidad asistencial y de eficiencia económica a pesar de la situación de crisis y de las restricciones presupuestarias. Los hospitales públicos TOP mostraban un $27 \%$ más de productividad de la plantilla con unos costes un $32 \%$ inferior al resto de centros. Además, mantenían una mayor calidad asistencial, con un $21 \%$ menos de mortalidad y de complicaciones, y una gestión más eficiente de la estancia hospitalaria. En el caso de los hospitales privados galardonados con los TOP, la mayor diferencia estaba en la eficiencia, ya que presentan unos costes un $42 \%$ inferior al resto. La distancia entre los hospitales TOP y el resto de centros no se había reducido ni en productividad ni en eficiencia, a pesar de las restricciones presupuestarias que se estaban llevando a cabo.

También se realiza el seguimiento de la sostenibilidad mediante el Monitor de Reputación Sanitaria (MRS) que se realiza en España, avalado por Análisis e Investigación, instituto independiente de investigación de mercado de España. Este estudio lo realiza KPMG según la norma ISAE 3000 y la metodología es pública disponible en la página web www.merco.info. Entre los diversos indicadores, se han tenido en cuenta, por ejemplo, los recursos humanos y materiales con los que cuenta cada servicio médico, los resultados conseguidos con los mismos, intervenciones quirúrgicas, estancia media, técnicas diagnósticas y terapéuticas, tasa de cesáreas, de mortalidad, de infecciones nosocomiales, tiempos de espera, etc. Se analizaron 14 especialidades, que en su conjunto representan el $85 \%$ de la actividad hospitalaria, y medicina familiar y comunitaria. En todas ellas, ya sea cardiología, aparato digestivo u obstetricia, entre los primeros cinco puestos casi siempre aparecen: La Paz (Madrid), el Hospital Clínic (Barcelona), Gregorio Marañón (Madrid), 12 de Octubre (Madrid) y Vall d'Hebron (Barcelona). Todos públicos. "La sanidad pública en España goza de buena salud", señala Jesús Antonio Álvarez, director médico del estudio.

El periódico El Mundo publicó en 2014 que a diferencia de otros informes similares, este es "el primer estudio científico que valora con rigor, transparencia e independencia (está financiado por la empresa que lo desarrolla, Merco, un instrumento de evaluación de la reputación, sin ninguna inversión o patrocinio ni pública ni privada)" la opinión de sanitarios y pacientes además de una serie de indicadores (186) de calidad y rendimiento asistencial", (obtenidos de los propios hospitales, consejerías y el Ministerio de Sanidad)", explica José María San Segundo, director técnico del estudio. La reputación de una organización es un importante aspecto de su sostenibilidad. La reputación de una organización es consecuencia del reconocimiento que logra en los diferentes grupos de interés (profesionales, pacientes, prensa) y de su excelencia en los 
indicadores objetivos de calidad y gestión clínica. Es por tanto una mezcla de percepción informada y de la objetividad de los indicadores de excelencia

El Consejo Interterritorial del SNS aprobó, en marzo de 2007, un conjunto de 110 indicadores clave con una actualización anual. Los indicadores clave del sistema nacional de salud (INCLASNS) son extraídos de los miles de datos que componen el sistema de información del Sistema Nacional de Salud, que incluye los datos proporcionados por todas las CCAA, y que están disponibles en el Portal estadístico del Ministerio de Sanidad, Servicios Sociales e Igualdad acompañados de indicadores de salud extraídos de otras fuentes (Instituto Nacional de Estadística, Centro Nacional de Epidemiología, Agencia Española de Medicamentos y Productos Sanitarios, etc.). Estos indicadores clave proporcionan una imagen del estado de salud de la población de España, los factores determinantes de la misma, la respuesta del sistema sanitario a las necesidades de la población e información de contexto sociodemográfico para entender la imagen. Permiten monitorizar el funcionamiento del SNS, en su conjunto y por Comunidades Autónomas, comparando diversas dimensiones y viendo en qué medida el SNS está cumpliendo su misión. (MSSSI, 2016)

En 2016 se realizó una revisión del panel con la intención de reformularlos o incluir nuevos indicadores. La lista completa contiene 247 indicadores clave. De ellos, 50 se clasificaron como esenciales (lista corta) y el resto como auxiliares Los indicadores de la lista corta, permiten dar un vistazo general a las principales características del SNS, mientras que el resto permiten una visión más detallada de sus dominios y dimensiones: accesibilidad, biológicos, determinantes sociales, estilos vida, gasto, morbilidad, mortalidad, opinión, pertinencia, recursos, resultados, salud general, seguridad, sociodemográfico y uso.

Toda la información está incluida en un único repositorio facilitando el acceso y la consulta de los datos de todo el SNS de forma centralizada y su visualización mediante tablas, ilustraciones y mapas. Los indicadores clave permiten la comparabilidad al ser unos indicadores que se basan en definiciones ya estandarizadas y de uso extendido a nivel nacional e internacional.

En resumen, todas las formas de medición, todos los indicadores y estándares utilizados por las diferentes organizaciones están dirigidos a identificar los cambios en la organización y en el entorno, y ser capaz de responder a los retos planteados y poder así perdurar en el tiempo y ser sostenibles. 


\section{OBJETIVOS DE LA INVESTIGACIÓN}

Este estudio sobre organizaciones sanitarias se ha planteado con un enfoque de carácter sociológico y se llevado a cabo como un estudio de caso (Yin, 2009). Esta investigación parte de datos cuantitativos y busca explicaciones a través del uso de metodología cualitativa. Este trabajo ayuda a potenciar investigaciones que ahondan en la complejidad de los contextos incluyendo las necesidades y expectativas de salud desde la perspectiva de los afectados.

Como se ha descrito, el Sistema Nacional de Salud podría ver peligrar su sostenibilidad por sobredemanda, deudas con los proveedores, crecimiento desmesurado e incontrolado del gasto sanitario o pérdida de legitimidad ciudadana.

En esta línea, esta investigación pretende contribuir a reflexionar sobre los cambios en el sistema actual y promover el debate sobre las medidas que sirvan para avanzar en el camino de la sostenibilidad y sean referentes para implantar cambios en el sistema.

Como señala Beltrán (2009), la finalidad de estos cambios es hacer sostenibles y preservar las señas de identidad esenciales de un modelo que es ejemplo en muchas partes del mundo.

El modelo EFQM lleva años implantado pero no se ha evaluado suficientemente su verdadero impacto. Muchas organizaciones han abandonado y otras han cambiado 0 adaptado el modelo (p.e. Osakidetza). El modelo EFQM de Excelencia permite comprender la relación causa-efecto de las relaciones entre lo que hacen las organizaciones (agentes facilitadores) y los resultados conseguidos.

Por todo ello, este trabajo de investigación parte de la hipótesis de que los modelos basados en la gestión de la calidad total, y en concreto el modelo de excelencia europeo (EFQM), se muestran como modelos sostenibles.

El objetivo general de este trabajo es conocer el impacto del modelo europeo de excelencia (EFQM) sobre la sostenibilidad en dos organizaciones sanitarias públicas.

Los objetivos específicos están orientados a identificar, en primer lugar los factores diferenciadores en las organizaciones estudiadas, y en segundo, a estudiar los cambios organizacionales que aporta el modelo EFQM para desarrollar el modelo.

Para realizar este estudio se ha planteado un análisis comparado de dos organizaciones sanitarias de diferentes comunidades autónomas (La Rioja y País Vasco) con diferentes estrategias, lo cual ha planteado la necesidad de estudiar datos de las propias organizaciones y de sus comunidades autónomas.

El resultado final de la investigación quiere aportar una explicación de los porqués de las diferencias entre organizaciones, tanto a nivel cuantitativo como cualitativo, exponiendo los factores que intervienen y elaborando una propuesta de batería de ideas que puedan ser incorporadas a la planificación estratégica de las organizaciones que quieran ser sostenibles y caminar hacia la excelencia. 


\section{METODOLOGÍA}

\subsection{Selección de la metodología}

El objeto de este trabajo de investigación ha sido estudiar la implementación de los sistemas de calidad en dos centros sanitarios pertenecientes al SNS. Este estudio pretende adquirir y generar conocimientos y para ello la elección del método adecuado que permitiese conocer la realidad estudiada fue fundamental (Álvarez, 1996).

Para realizar este estudio se ha optado por una metodología pluralista a la que Ortí (1995) llama "complementariedad de metodologías por deficiencia", a través de la que incorpora las posibilidades y los límites de cada metodología y el reconocimiento de sus deficiencias en la representación y análisis de la realidad investigada. En esta línea Ortí también señala que como el objeto de este estudio no es unidimensional, le corresponde por tanto variedad de herramientas de trabajo.

En este mismo sentido, dentro del marco de las investigaciones multimétodo, Alvira y Serrano (2015) hablan de la complementación concurrente con retroalimentación como uno de los modos de usar conjuntamente técnicas cualitativas y cuantitativas. Para ello las diferentes técnicas abordan diversos aspectos del mismo fenómeno de forma paralela e integrando sus resultados en las conclusiones del estudio, tal y como se plantea hacerlo en el presente trabajo.

En las investigaciones relacionadas con la salud se han incorporado como una vía de conocimiento relevante y creciente las técnicas de investigación cualitativa aprendiendo de las ciencias sociales, la antropología, la sociología y la psicología.

La evidencia que generan los estudios cualitativos en el campo de la salud ofrece nuevas perspectivas con las que trabajar. La investigación cualitativa muestra las evidencias de los valores, las motivaciones, los comportamientos (Ortí, 1999), es decir, del componente complejo de la realidad humana que se escapa a los instrumentos numéricos pero que se deben intentar conocer con rigor y sistematización si se quiere responder mejor a las necesidades de los pacientes y de la sociedad.

El campo de la investigación cualitativa es plural en cuanto a corrientes, métodos, técnicas, y también en cuanto a definiciones. En algunos casos se expone como "los modos de investigación que se ocupan de comprender a los seres humanos, de su interacción entre sí y con su medio, en otros se plantea como el "intento de dar respuesta a cuestiones sobre las experiencias y realidades humanas a través del estudio de las mismas en contacto con la gente y en su ambiente. Sus resultados son datos descriptivos y ricos que ayudan a comprender los fenómenos de la vida cotidiana"; otros subrayan cómo "la investigación cualitativa ofrece la oportunidad de hallar respuestas a preguntas que se centran en la experiencia social, cómo se crea y cómo da significado a la vida humana". En cualquier caso, se trata de una perspectiva de conocimiento científico dinámica, abierta, desde el contexto natural de los participantes, que intenta capturar los fenómenos en su profundidad, buscando su riqueza e intentando explicar su complejidad de forma holística. 
Haber optado por la metodología cualitativa de las ciencias sociales en un tema relacionado con las ciencias de la salud conlleva también asumir ciertas opciones, como señala Alonso (1998), entre las que habría que resaltar el cambio en la sensibilidad investigadora, la función de la teoría como guía de la investigación y la importancia de la participación.

Por todo ello se optó por elegir el método de caso comparativo por tratarse de un análisis profundo de dos organizaciones sanitarias que han implementado de manera diferente el modelo EFQM.

Algunos consideran el estudio de caso como un método, y otros como un diseño de la investigación cualitativa. Como dice Yin (2009), el estudio de caso no tiene especialidad, pudiendo ser usado en cualquier disciplina para dar respuesta a preguntas de la investigación para la que se use.

Un estudio de caso es, según la definición de Yin (2009), "una investigación empírica que estudia un fenómeno contemporáneo dentro de su contexto de la vida real, especialmente cuando los límites entre el fenómeno y su contexto no son claramente evidentes. (...) El método de caso es una estrategia de investigación de un fenómeno y es el producto de esa investigación (Yin, 2009).

El uso de múltiples fuentes de información dentro del método de caso permite reducir la posibilidad de pérdida de datos y aumentar la verificación de los mismos y tener una visión completa y holística del fenómeno.

El método del caso (Yin 2009) es recomendable cuando el investigador:

- Pretende responder al tipo de preguntas ¿cómo? y/o ¿por qué?

- Cuando no tiene control sobre el comportamiento del fenómeno.

- Cuando estudia hechos actuales.

- Cuando la relación entre el fenómeno estudiado y el contexto no es claro.

Utilizar el método de caso para investigación tiene como propósito la exploración, la construcción de teoría, la comprobación de la teoría y la extensión y el refinamiento de la teoría (Pettigrew, 1990). Así, con el uso de este método en esta investigación se trató de comprender de una manera más profunda el fenómeno planteado en la revisión de la literatura. En otras palabras, se trató de comprender los procesos organizacionales para desarrollar conceptos teóricos a partir de los casos investigados e identificar áreas de mejora.

La elección del Método de Caso se apoyó principalmente en el propósito de esta investigación, que como ya se indicó, es aumentar la comprensión de un fenómeno poco estudiado y complejo como es el impacto del modelo EFQM como apoyo de la sostenibilidad de las organizaciones sanitarias. El método además aportó la ventaja de permitir obtener un enfoque holístico de los hechos y sus relaciones que permitían generar teorías (Siggelkow, 2007), sin descuidar la rigurosidad apoyando la credibilidad del estudio realizado. 
El método del estudio de caso se centra en analizar hechos contemporáneos, aunque la problemática pueda venir desde mucho tiempo atrás. No se trata de que la historia no sea importante para los casos, sólo que se debe distinguir entre investigar hechos que están en el pasado "vivo" (entendido como hechos del pasado que tienen efectos en el presente o cuyos actores siguen activos), frente a hechos del pasado "muerto" dónde el método de caso no es la alternativa porque los eventos ya no tienen relevancia con el fenómeno presente que se estudia (Yin, 2009).

El análisis de los casos se planteó siguiendo dos enfoques de investigación: el longitudinal y el retrospectivo (Leonard-Barton, 1990).

El enfoque longitudinal permite entender procesos continuos de cambio en su propio contexto e interpretar los significados que se hacen a varios niveles de análisis (Pettigrew, 1990) proporcionando una visión holística del proceso. El enfoque longitudinal se planteó como especialmente importante para esta investigación porque se pretendía comprender el esfuerzo de cambio o mejora a lo largo del tiempo, es decir, desde una perspectiva organizacional cómo se obtuvieron resultados de sostenibilidad. Con ello se planteó la posibilidad de identificar "mejores prácticas" relacionadas con la aplicación de actividades de mejora de un centro sanitario público que ha sostenido su esfuerzo durante varios años guiado por el modelo EFQM. Esto es analizar los episodios de su vida organizacional en los cuales el modelo EFQM ha jugado un papel fundamental a lo largo del tiempo.

Sin embargo, los estudios longitudinales pueden presentar problemas (Leonard- Barton 1990) relacionados con:

- La participación del investigador en actividades del centro. Puede generar sesgos en la objetividad en el momento de la recopilación e interpretación de los datos debidos a aspectos emocionales y a la interrelación con los actores y el caso investigado

- La falta de eficiencia. Como consecuencia del tiempo que se necesita (reuniones, gestiones internas, y traslados), además del riesgo de recolectar datos excesivos y poco valiosos para el estudio.

Por todo lo anterior y siguiendo lo indicado por Leonard Barton (1990) de utilizar una metodología dual que ayude a incrementar la sinergia entre los casos de estudios analizados, se planteó usar el enfoque retrospectivo en el mismo objeto de estudio (cada organización). El enfoque retrospectivo tiene la ventaja de que permite controlar la selección de los casos y recolectar datos históricos del fenómeno en cuestión de una manera más eficiente, porque durante una o dos visitas se pueden recopilar y aplicar diferentes métodos de manera simultánea. Además, de que este enfoque permite el reconocimiento de patrones desde una visión general del proceso analizado (LeonardBarton, 1990).

No obstante, es importante destacar que los estudios retrospectivos también pueden tener peligros que afecten a la credibilidad del estudio. Ante el riesgo de que los participantes no recordaran con precisión los eventos más importantes se planteó la búsqueda de documentos (memorias, informes) con el fin de evitar percepciones subjetivas (Leonard-Barton, 1990) y contrastar los datos históricos obtenidos. 
A ello se suma que la sostenibilidad de las organizaciones es un proceso de flexibilidad organizacional que lleva a la adaptabilidad a largo plazo (Alonso, 2004), lo que hace que se trate de casos vivos y de situaciones dinámicas y cambiantes que estudiamos en el presente pero que tienen sus raíces en el pasado y tienen un gran interés para el futuro.

La elección correcta de los casos a comparar fue una parte fundamental para el entendimiento correcto del fenómeno, para realizar una correcta selección se deben utilizar criterios que permitan saber que los casos elegidos (ver apartado 3.2) son los que proporcionan la mejor oportunidad de aprender sobre el fenómeno a estudiar, teniendo relación directa con la pregunta de investigación formulada (Yin, 2009).

Para Fideli (1998) el método comparativo es una forma de confrontar dos o varias propiedades enunciadas en dos o más objetos, en un momento preciso o en un arco de tiempo más o menos amplio. De esta forma, se pueden comparar procesos $u$ organizaciones en un periodo de tiempo que se considera igual (sincronismo histórico) Utilizar el método de caso tiene la ventaja de que se pueden hacer comparaciones con otros casos, e identificar áreas de mejora concretas en un ejercicio de benchmarking entre organizaciones que nos permite enriquecer el entendimiento del fenómeno y la construcción de teorías (Suarez, 2007). Para Sartori (2002) el método comparativo tiene como objetivo la búsqueda de similitudes y diferencias entre lo que pertenece a la misma clase o especie. De acuerdo a Yin (2009), la multiplicación de los casos es comparable con el desarrollo de experimentos múltiples, aunque para Pettigrew (1997) la importancia no radica en el número de casos, sino en el estudio en profundidad de cada uno de ellos y en las evidencias recogidas.

En todo caso, la comparación entre organizaciones se planteó con el objetivo de comparar la situación de dos organizaciones con diferentes situaciones con la intención de averiguar si una organización era más sostenible que la otra (Alonso 2004). Por otro lado, a nivel cualitativo se trata de identificar qué cultura organizacional existe en cada centro y si esta está influenciada por el modelo EFQM.

En este estudio se parte del supuesto de que, como consecuencia de la realidad organizacional de los centros sanitarios, estos son una suerte de pequeñas sociedades inmersas en un proceso cambiante. Independientemente de que el problema de la sostenibilidad pueda llegar a ser objetivo y pueda ser cuantificado, la interpretación que se hace del mismo desde los individuos y las instituciones públicas constituye un aspecto de tanta importancia como los mismos resultados cuantitativos. Para Bob Doppelt (2003), la visión de la sostenibilidad da lugar a un conjunto compartido de creencias y de imágenes mentales comunes, y debería "mostrar una imagen positiva del futuro. Dado que la investigación explora el impacto de las formas de gestión a partir de la realidad de los centros sanitarios, se ha utilizado una metodología cualitativa con apoyo cuantitativo para el desarrollo de esta investigación (Amezcua y Gálvez 2002).

En este trabajo se ha huido de la controversia entre método cuantitativo y cualitativo y del mayor uso que se da en las ciencias biomédicas al método cuantitativo (Pita, 2002) para orientarlo a la comprensión de cómo las organizaciones sanitarias integran la 
sostenibilidad (Doppelt, 2003) en el momento histórico actual y su relación con el uso del modelo EFQM en la sanidad pública.

Se utilizó como metodología la investigación de base cualitativa complementada con un análisis cuantitativo de los datos de indicadores que refuerzan la consistencia de los hallazgos y pudieran corregir los sesgos propios de cada método (Pita, 2002). La razón para elegir una combinación de técnicas cuantitativas y cualitativas se basa en el tipo de fenómeno estudiado, así como en el propósito de esta investigación y las preguntas asociadas al objetivo.

Investigaciones previas sobre las asociaciones entre la cultura organizacional, la estructura organizativa y la calidad ya indican que los estudios deberían utilizar un diseño de investigación de métodos mixtos que combinen tanto enfoques cuantitativos como cualitativos (Wagner, 2014). Es frecuente la combinación (Bernard, 2013) o la complementariedad entre ambos métodos (Villasante 1994), favoreciendo la triangulación de la metodología cuantitativa y la cualitativa.

La triangulación, definida por Denzin (1978) como la combinación de metodologías para el estudio de un mismo fenómeno, supone una forma de superar las limitaciones de cada una de las metodologías y de sumar sus fortalezas, en el esfuerzo por entender los hechos de la manera más holística posible minimizando los posibles sesgos.

Los datos objetivos presentan la ventaja de cuantificar los hechos y proteger las evidencias frente a las percepciones individuales, a la vez que representan la posición oficial de la organización (Alonso, 2004). Con la investigación cuantitativa se buscan relaciones causales mediante el análisis de variables (Denzin y Lincoln, 2011). Estas no recogen la variedad de perspectivas y experiencias de las personas estudiadas y se limitan a recoger información que pueda ser procesada con base en unos números asignados. La validez del estudio depende de la elaboración cuidadosa del instrumento y su ventaja es que puede ser aplicado a un gran número de personas y organizaciones facilitando su comparación con el uso de herramientas estadísticas. Los métodos cuantitativos son usualmente las encuestas los cuestionarios, las estadísticas oficiales y los experimentos.

Por otro lado, la investigación cualitativa ofrece una visión desde un punto de vista individual que acerca la realidad y la presenta de una forma holística. El investigador es el «instrumento» de realización del estudio y estudia un limitado número de personas 0 casos particulares. El trabajo está basado en descripciones que permiten un análisis en profundidad y detallado y no en generalizaciones (Patton 2002; Ritchie et al Lewis, 2013).

La investigación cualitativa permite identificar explicaciones directamente relacionadas con el objeto estudiado y es adecuada cuando el objeto de la investigación es la exploración-descripción de un hecho o situación y para la construcción de hipótesis que expliquen las relaciones, los "porqués" y los "cómos" (Patton, 2002). Los métodos cualitativos son usualmente las entrevistas, la observación, el análisis de fotografías, la participación, etc. Todo ello con la pretensión de inducir y generar hipótesis más que 
de probarlas (Silverman, 2000). Se trata de tomar a las personas de las organizaciones estudiadas como fuentes del conocimiento necesario para comprender los acontecimientos, para producir conocimientos y tratar de convertir sus palabras en elementos centrales de la investigación (Kornblit, 2007).

Hay que añadir que el significado de los conceptos de calidad y sostenibilidad dentro de la Sanidad Pública ha ido variando a lo largo del tiempo. El uso de metodología cualitativa permite recoger las diferentes interpretaciones que se hacen de los conceptos en la organización (Pettigrew, 1990).

Por otro lado, en el campo de estudio de la sostenibilidad en el sector sanitario público existen por lo menos dos características que hacen al tema un área de estudio susceptible de técnicas cualitativas:

- Complejidad. La realidad organizacional de una institución sanitaria pública es compleja en sí misma, y esto se ve potenciado cuando para comprender la gestión de la organización es necesario recurrir a otras áreas del conocimiento (Ingeniería, Economía, Ciencias Políticas, Ciencias de la Salud) (AguilarVillanueva, 2006). En situaciones complejas en las que el cambio forma parte de la vida organizativa, las metodologías cualitativas permiten capturar la multiplicidad de matices incorporándolas a sus resultados. Las preguntas de investigación amplias «abren» el fenómeno de estudio al investigador y eso permite analizar tanto el contexto global como el detalle (Pettigrew, 1990).

- Novedad. Aunque ya se han realizado estudios sobre la implantación de sistemas de gestión de la excelencia, su impacto a lo largo de los años en las organizaciones y la relación con la sostenibilidad es un tema en el cual se ha avanzado poco. El concepto de sostenibilidad en el ámbito de la sanidad pública continúa debatiéndose como tema que se ha reforzado con la crisis. Cuando se sabe poco de un área del conocimiento, la metodología cualitativa permite interpretar el campo de estudios y de esa forma, se descubrirán patrones y relaciones desconocidas (Morse y Richards, 2002).

Además de estas características se debe atender, en pie de igualdad, la relevancia social y teórica del tema, con el interés particular del investigador (Sandoval, 1996). Debido a la formación y al trabajo desarrollado profesionalmente esta investigación es motivadora y relevante y permite aportar los conocimientos y la experiencia adquiridos. La facilidad de la interacción con los investigados es otra razón más de peso para que este trabajo se desarrolle eminentemente mediante técnicas cualitativas.

El papel del investigador al aplicar investigación cualitativa ha sido formar una imagen lo más nítida del fenómeno estudiado uniendo todas las piezas. El investigador se ha enfrentado a un proceso que es iterativo y dinámico (Miles y Huberman, 1994). Además, el investigador ha utilizado diferentes métodos que le han permitido una comprensión profunda del fenómeno, dándole una mayor riqueza, validez y complejidad al estudio (Denzin y Lincoln, 2011). 
Por otro lado, y como ya se ha señalado anteriormente para complementar y reforzar la metodología cualitativa se estimó necesario un estudio cuantitativo cuyo interés fuese aportar valor añadido a los hallazgos y teorías que surjan del análisis de la situación de una organización tan compleja como la sanitaria.

En el año 2005 la European Fundation for Quality Management (EFQM) promovió un trabajo de investigación independiente basada en indicadores cuantitativos cuantificables para analizar la relación existente entre la aplicación de modelos de calidad total y los resultados de las organizaciones. Este trabajo fue llevado acabo por un grupo de expertos del Centre of Quality Excellence de la Universidad de Leicester. Este trabajo demostró que las organizaciones ganadoras de premios EFQM mejoran porque les permite medir su posición en el camino de la excelencia, detectar sus áreas de mejora, identificar potenciales soluciones y medir su eficacia.

Anteriormente se habían realizado trabajos similares en otras partes del mundo que también apoyaban la idea de que las organizaciones que trabajan con modelos de calidad total o excelencia sus resultados mejoran tanto en el corto como en el largo plazo (Hendricks y Singhal, 1997).

La comparación cuantitativa que se pretende en este trabajo es similar a la utilizada en los citados trabajos de la Universidad de Leicester en 2005 y de Singhal/Hendricks en 1997. Estos trabajos centraron su atención en los resultados a lo largo de un periodo de tiempo determinado comparándolos en organizaciones similares. Por tanto, el estudio cuantitativo se introdujo en esta investigación para, mediante datos objetivos, públicos y publicados, valorar el grado de respuesta a las necesidades de los grupos de los resultados de cada organización en el periodo 2008-2015, complementando el estudio cualitativo que permitió averiguar el porqué y el cómo (Yacuzzi, 2005) y qué relación tenía con el uso del modelo EFQM (Boulter, 2005).

Siguiendo este modelo se plantea la necesidad de:

- Analizar datos de acceso público porque son indicativos de la transparencia

- Analizar datos que permiten comparar a las organizaciones, es decir que se refieran a los mismos hechos y utilicen escalas y formas de medición semejantes.

- Analizar datos validados por un tercero que aporte objetividad e imparcialidad (Ministerio de Salud, organizaciones independientes)

Como indicadores clave en las organizaciones relacionados con la calidad y sostenibilidad (Nebot-Marza, 2014) se planteó la necesidad de seleccionar indicadores de cliente, personas, sociedad y clave de la organización relacionados con la sostenibilidad (Ferrándiz-Santos, 2010) y que midiesen resultados, actividad, costes, satisfacción de los pacientes y de las personas. Los indicadores seleccionados proporcionan información sobre el periodo 2008-2015. 


\subsection{Selección de casos}

Dentro del ámbito sanitario y en el marco del sistema sanitario público existen diferentes formas de gestión y diferentes niveles de competencias, organismos e instituciones. Para alcanzar los propósitos de esta investigación, se seleccionaron instituciones sanitarias públicas en España, lo cual representó el primer criterio de selección de los casos. Se siguió la propuesta de Lijphart (1971) que indica que el foco de la comparación debe centrarse en aquellos casos que realmente puedan ser comparados, que presenten variables similares que se puedan considerar constantes y variables diferenciadoras que merezcan ser contrastadas. A partir de estas ideas se definieron como variables similares para el estudio ciertas características de las organizaciones (tabla 20).

La variable diferenciadora de las organizaciones seleccionadas es la implantación del modelo de excelencia europea o modelo EFQM. Es decir, se trató de identificar un centro con un historial de gestión de calidad importante y previa a la crisis y otro centro que no hubiera trabajado con el modelo de forma constante ni generalizada en toda la organización.

También se fijó como elemento esencial para determinar la muestra fijar un arco de tiempo que facilitase la comparación (Tonon, 2011). Este arco de tiempo se estableció en el periodo de crisis económica vivido en España (2008-2015) y que ha supuesto una prueba de estrés para las organizaciones sanitarias públicas. Por tanto, se decidió comparar organizaciones que entraron y afrontaron este periodo con diferentes grados de implantación y reconocimientos EFQM. No obstante y para facilitar el conocimiento y comprensión de las organizaciones también se estudiaron hechos anteriores a ese periodo que dejaron su impronta en las organizaciones y que formaran parte de su "cultura" actual.

El estudio de datos cuantitativos se amplió a todo el sistema público de salud de cada comunidad autónoma por entenderse que las organizaciones estudiadas forman parte de un sistema con el que interactúan, del que forman parte y que determina aspectos tan importantes como la cartera de servicios, las inversiones y los presupuestos la política estratégica sanitaria e incluso los recursos humanos. Respecto a Osakidetza, dispone de una política estratégica común para todos los centros y casi cualquier organización sanitaria podría considerarse una muestra o ejemplo de lo que ocurre en todos los centros de la red pública vasca, en línea con el informe de Impacto de la implantación de EFQM en Osakidetza (Osteba, 2016). Este informe expone la homogeneidad de Osakidetza en cuanto a la implantación del modelo EFQM.

Por la proximidad, la facilidad de acceso y la posibilidad de identificar e implantar mejoras se optó por el Servicio Riojano de Salud (SERIS) y el Hospital San Pedro de Logroño (SERIS) como una de las organizaciones a estudiar. Además se presentó la oportunidad de realizar el estudio por la buena disposición al cambio que se percibía en la nueva dirección de la organización. En La Rioja, el Hospital San Pedro es el único hospital general, por los que los datos de la Comunidad Autónoma son fácilmente asumibles 
Para la selección de otras organizaciones se realizó una búsqueda en el registro de la Sociedad Española de Calidad Asistencial (RECAS) y mediante la consulta de las memorias de centros y listados de reconocimientos y premios tanto de la propia EFQM como de organismos regionales. El análisis de este apoyo documental, permitió identificar el sistema público de salud de País Vasco como uno de los que contaba con más reconocimientos. En este sentido, siguiendo estas pautas se seleccionaron algunos centros que pudiesen ser comparados con el SERIS:

$\begin{array}{ll}\text { - } & \text { Población de referencia } \\ \text { - } & \text { № de camas } \\ \text { - } & \text { Tipo de Población } \\ \text { - } & \text { Especialidades } \\ \text { - } & \text { Organciación } \\ \text { - } & \text { Actividad Docente } \\ \text { - } & \text { Plantilla } \\ \text { - } & \text { Calidad y gestión }\end{array}$

Como ya se ha indicado, dada la naturaleza de la metodología y las preguntas de investigación, se planteó la selección de una organización perteneciente a la red pública vasca de salud (Osakidetza) junto al ya citado Hospital San Pedro de la red pública de salud de La Rioja (SERIS), siguiendo el criterio de muestreo teórico (Ritchie et al 2013), en el cual el investigador selecciona los casos, basándose en su potencial de contribución. Este tipo de muestreo representa un proceso iterativo, en el cual el investigador selecciona un caso inicial, analiza los datos, y posteriormente selecciona otro caso que ayude a refinar los resultados encontrados. Este proceso puede continuar con otros casos hasta que el investigador encuentra "saturación en los datos» 0 simplemente cuando el investigador llega un punto en que no se encontrarán más resultados aunque se siga el muestreo (Ritchie et al 2013).

Además de la revisión de documentación para tratar de identificar las organizaciones que fuesen los casos de estudio se realizó una observación preliminar de la situación con algunas entrevistas a "informantes clave". Se trató de buscar la organización dentro de Osakidetza que mejor se pudiera comparar con el Hospital San Pedro de Logroño y que quisiera y pudiera colaborar. Para ello se contactó con el Hospital de GaldakaoUsansolo como primera opción. Tras comprobar la falta de disponibilidad de este centro, se contactó con el Responsable de Calidad de la Organización Central de Osakidetza quien identificó aquellas organizaciones relevantes y comparables. Tras debatir la idoneidad de diferentes organizaciones con el apoyo de la Responsable de Calidad del Hospital de Cruces se optó por la Organización Sanitaria Integrada (OSI) BasurtoBilbao. La observación preliminar se completó con una entrevista de presentación del proyecto y conocimiento previo de esa organización con el Subdirector de Calidad

Se seleccionó la OSI Bilbao-Basurto (OSIBB) porque, además de permitir una comparación razonable, daba mayores facilidades para elaborar el trabajo y contaba con un reconocimiento objetivo en la implantación del modelo europeo de excelencia y una larga historia demostrada, consolidada y visible. (Eriksson y Garvare, 2005), es 
decir, un centro que ha sido reconocido por su sistema de gestión de la excelencia por la aplicación del modelo y que ha sido certificado por organismos externos.

La OSIBB está formada por el Hospital Universitario de Basurto y la Comarca Bilbao de Atención Primaria. El Hospital de Basurto perteneció hasta la década de los 80 del Siglo XX a la Diputación Foral de Vizcaya y tras la creación de Osakidetza el Hospital se incorpora al Primer Plan Integral de Calidad en 1992. La Comarca Bilbao inició su andadura en 1989 como responsable de la asistencia sanitaria extrahospitalaria del municipio de Bilbao incluyendo atención primaria, atención especializada ambulatoria y salud mental. En 1997 pasa a ser una organización exclusivamente de servicios de atención primaria de salud.

En 2014 se decide la integración de ambas organizaciones en una sola estructura creándose la OSI Bilbao-Basurto para facilitar la optimización de recursos y la continuidad de los cuidados. Su pertenencia a Osakidetza permite ventajas importantes al compartir estrategias comunes y la utilización de herramientas conjuntas. Además la transmisión de conocimientos y la posibilidad de aprendizaje de otros grupos, procesos o centros del sistema constituyen también una fuente continua de aprendizaje y posibilidad de mejora. EI Servicio Vasco de Salud (Osakidetza) y por añadidura la OSI Bilbao-Basurto son un referente a nivel estatal y un servicio muy bien valorado entre la población vasca

El estudio de la OSIBB permite la comparación con el Servicio Riojano de Salud en cuanto al tamaño de su población de referencia y en cuanto a que están formados por una estructura y unos recursos de atención especializada y de atención primaria que comparten el mismo equipo directivo.

La OSIBB pertenece a otra organización más grande como es Osakidetza y eso hace que disponga, a priori, de un menor margen de maniobrabilidad por un lado, pero también le permite tener otros recursos compartidos de los que el SERIS es deficitario.

Existen diferencias entre ambas organizaciones que serán tenidas en cuenta a la hora de las conclusiones, pero también existen similitudes que hacen que sean comparables y permitan extraer unos resultados válidos (tabla 20).

Para cada caso se definió el enfoque metodológico en función de lo indicado por Leonard Barton (1990) y se utilizó una metodología dual que ayuda a incrementar la sinergia entre los casos de estudios analizados para tratar de identificar las diferencias y similitudes en el camino de ambas organizaciones en busca de la sostenibilidad.

Para realizar una observación adecuada de las organizaciones seleccionadas se planteó como aspectos a examinar.

- Descripción de la situación

○ Situación sociodemográfica

Resultados en salud

Política sanitaria

- Gestión de la calidad

- Resultados de las entrevistas (Verbatines) 
Tabla 20. Características de los centros seleccionados como casos de estudio

\begin{tabular}{|c|c|c|}
\hline CARACTERÍSTICAS & OSI Bilbao- Basurto & SERIS \\
\hline $\begin{array}{l}\text { Población de } \\
\text { referencia (2013) }\end{array}$ & $\begin{array}{l}350.620 \text { hab } \\
\text { Mujeres: } 53 \% \text {, } \\
\text { Población con más de } 65 \\
\text { años: } 23 \%\end{array}$ & $\begin{array}{l}319.006 \text { hab. } \\
\text { Mujeres: } 50.6 \% \\
\text { Población mayor de } 65 \text { años: } \\
19.07 \%\end{array}$ \\
\hline $\begin{array}{l}\text { № de camas } \\
\text { hospitalarias }\end{array}$ & 667 camas & 630 camas \\
\hline $\begin{array}{l}\text { Año Construcción } \\
\text { hospital }\end{array}$ & 1908 & 2006 \\
\hline Tipo de Población & $\begin{array}{l}\text { Población eminentemente } \\
\text { urbana. } \\
\text { Población envejecida }\end{array}$ & $\begin{array}{l}\text { Población eminentemente rural y } \\
\text { ciudades pequeñas. } 50 \% \\
\text { población en Logroño. Resto en } \\
\text { ciudades pequeñas y poblaciones } \\
\text { dispersas geográficamente. } \\
\text { Población envejecida }\end{array}$ \\
\hline Especialidades & Todas & Todas \\
\hline Financiación & Pública & Pública \\
\hline Organigrama & Engloba AP y AE & Engloba $A P$ y $A E$ \\
\hline Actividad Docente & $\begin{array}{l}\text { Especialidades médicas y de } \\
\text { enfermería. } \\
\text { Pregrado medicina, } \\
\text { enfermería y FP sanitarias }\end{array}$ & $\begin{array}{l}\text { Especialidades médicas y de } \\
\text { enfermería. } \\
\text { Pregrado enfermería y FP } \\
\text { sanitarias }\end{array}$ \\
\hline Plantilla & 4500 profesionales. & 4000 \\
\hline Calidad y gestión & $\begin{array}{l}\text { Q plata } 2005, \text { varias unidades } \\
\text { y servicios certificados con } \\
\text { ISO9001, Certificación } \\
\text { ISO14001, RSC,..... }\end{array}$ & $\begin{array}{l}\text { No ha trabajado con el modelo de } \\
\text { forma global. No dispone de una } \\
\text { política de calidad en vigor }\end{array}$ \\
\hline $\begin{array}{c}\text { Enfoque } \\
\text { metodológico }\end{array}$ & $\begin{array}{l}\text { Retrospectivo (Indicadores } \\
\text { cuantitativos /Memorias) } \\
\text { Longitudinal: Entrevistas, } \\
\text { visitas al centro. }\end{array}$ & $\begin{array}{l}\text { Retrospectivo (Indicadores } \\
\text { cuantitativos /Memorias) } \\
\text { Longitudinal: Entrevistas, visitas } \\
\text { al centro, participación en actos }\end{array}$ \\
\hline
\end{tabular}

\subsection{Diseño de la investigación cualitativa.}

Este estudio de investigación se diseñó con una serie de etapas que siguen un esquema estructurado y cronológico. No obstante y debido a las características propias de la metodología cualitativa frecuentemente se alteran y se retroalimentan, haciendo difícil separar algunas de ellas y seguir un orden cronológico estricto. Esto ocurre principalmente en la recolección y análisis de datos, que prácticamente se fue realizando al mismo tiempo que se iban obteniendo resultados, que tenían que ser confrontados con las diferentes personas que participaban en el estudio y con organización a analizar (Marshall y Rossman, 1989).

Por ello se decidió seguir la propuesta metodológica del "ciclo iterativo deductivo e inductivo" (Pettigrew citado por Suarez 2007).

El modelo de investigación que propone Suarez (2007) plantea el estudio a través de una continua iteración de procesos inductivos y deductivos que tienen siempre como guía el resultado final que se desea obtener, el cual debe resultar importante, 
fundamental e interesante para la investigación. Tomando el ciclo iterativo de inducción y deducción como referencia para esta investigación se siguieron las siguientes etapas (ilustración 19):

1. Definir las preguntas y objetivos de la investigación a través de la revisión de literatura inicial

2. Recopilar información documental preliminar a través de la observación directa, la observación participativa no intrusiva, el análisis documental y las entrevistas en profundidad semiestructuradas. Con esta recopilación de datos preliminar utilizando la triangulación de los mismos establecer el primer reconocimiento de patrones y los primeros resultados del análisis comparativo de los casos.

3. Elaborar una primera redacción de cada caso, y el análisis de temas y patrones en una primera aproximación. Se repitió en un continuo seguimiento de recolección y análisis de datos adicionales, yendo y viniendo entre los casos de estudio seleccionados, manteniendo la lógica del ciclo iterativo deductivo e inductivo de Pettigrew expuesto por Suarez (2007).

4. Finalmente, realizar el análisis comparativo final entre los casos (cruce de casos), para obtener los resultados y hallazgos de esta investigación.

llustración 19. Diagrama de flujo de la investigación.

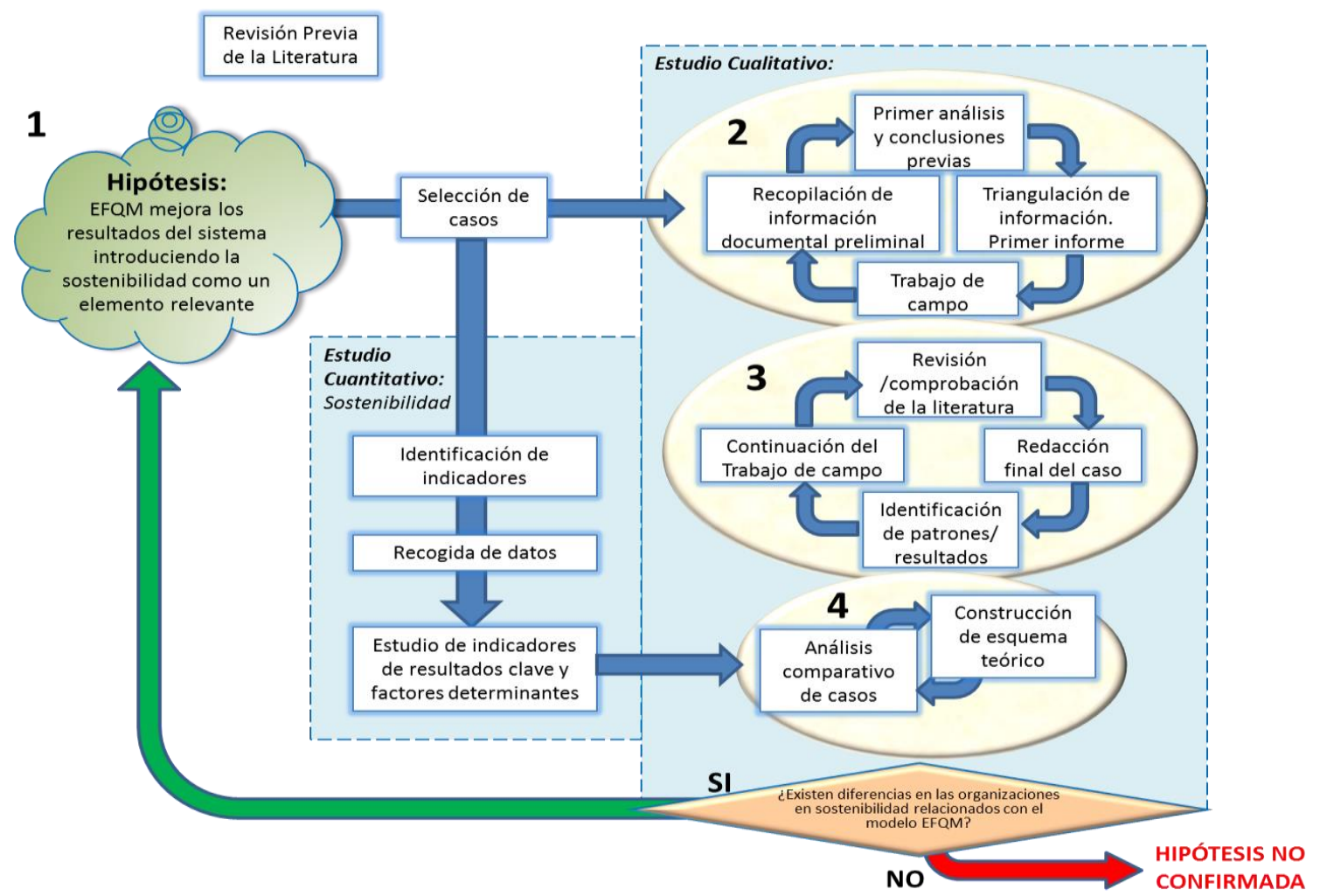

Fuente: Elaboración propia

El diseño de ciclo iterativo deductivo e inductivo durante el trabajo de campo permitió establecer comparaciones con el marco teórico inicial previo, dando la posibilidad de incorporar nuevos elementos teóricos de comparación y marcos de referencia que no habían sido considerados en el análisis inicial de la literatura. 
Para recopilar toda la información relacionada con la investigación y el objetivo de la misma, se aplicaron diferentes técnicas de recolección de datos (Yin 2009):

1. Búsqueda bibliográfica.

2. Contacto y primeras visitas a las organizaciones seleccionadas

3. Observación directa y fotografías.

4. Análisis documental.

5. Observación participativa no intrusiva.

6. Entrevistas en profundidad semi-estructuradas.

7. El diario del investigador.

Estas técnicas se distribuyeron para la obtención de las diferentes informaciones tal y como se refleja en la tabla 21.

Tabla 21. Información y métodos de obtención

\begin{tabular}{|c|c|c|c|c|c|c|}
\hline \multirow[b]{2}{*}{ Información } & \multicolumn{5}{|c|}{ Métodos de obtención } & \multirow[b]{2}{*}{ Justificación } \\
\hline & 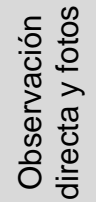 & 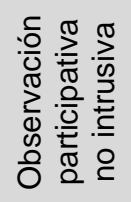 & 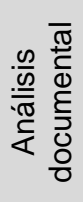 & 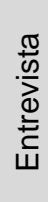 & 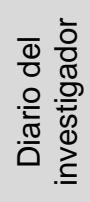 & \\
\hline \multirow{3}{*}{$\begin{aligned} & \text { Antecedentes } \\
& \text { - } \text { Contexto } \\
& \text { sociosanitario } \\
& \text { - } \text { Estructura } \\
& \text { organizacional } \\
& \text { - } \text { Historia }\end{aligned}$} & $X$ & & $X$ & $\mathrm{X}$ & $X$ & \multirow{3}{*}{$\begin{array}{l}\text { Conocer el contexto } \\
\text { social, organizacional y } \\
\text { sanitario información } \\
\text { necesaria para el estudio } \\
\text { retrospectivo para situar } \\
\text { a la organización en su } \\
\text { contexto actual }\end{array}$} \\
\hline & & $X$ & $X$ & $\mathrm{X}$ & & \\
\hline & & & $x$ & $X$ & & \\
\hline $\begin{array}{c}\text { Sistema de gestión de } \\
\text { calidad }\end{array}$ & $X$ & $X$ & $X$ & $X$ & $X$ & $\begin{array}{l}\text { Conocer la planificación y } \\
\text { mejora de la } \\
\text { organización, y el } \\
\text { impacto en los criterios y } \\
\text { el desarrollo de los } \\
\text { principios fundamentales } \\
\text { de la excelencia }\end{array}$ \\
\hline \multirow{4}{*}{$\begin{array}{l}\text { Relación con la } \\
\text { sostenibilidad: } \\
\text { - Necesidades de } \\
\text { Pacientes } \\
\text { - Necesidades de } \\
\text { Personas } \\
\text { - Necesidades } \\
\text { Sociedad } \\
\text { - Necesidades Aliados } \\
\text { y Proveedores }\end{array}$} & $X$ & & $X$ & & $X$ & \multirow{4}{*}{$\begin{array}{l}\text { Búsqueda de evidencias } \\
\text { de sostenibilidad y como } \\
\text { se ha desarrollado e } \\
\text { implantado. } \\
\text { Factores potenciadores } \\
\text { e inhibidores }\end{array}$} \\
\hline & $x$ & $x$ & $\mathrm{X}$ & $\mathrm{X}$ & $X$ & \\
\hline & & & $X$ & & & \\
\hline & $X$ & & $X$ & $X$ & $X$ & \\
\hline
\end{tabular}

Fuente: Elaboración propia basada en Suarez 2007

Cada uno de los pasos de la planificación de la recolección de datos se explica por separado a continuación. 


\subsubsection{Búsqueda bibliográfica}

El análisis bibliográfico se realizó a partir de la lectura selectiva, comprensiva y crítica de libros, revistas y artículos científicos con el fin de conocer conceptos teóricos previos sobre la metodología propia del trabajo de investigación y sobre el propio modelo EFQM y su relación con la sostenibilidad de las organizaciones sanitarias públicas.

La revisión de literatura en esta investigación se realizó en momentos diferenciados:

1 Búsqueda previa. La búsqueda bibliográfica fue el primer paso del proceso de investigación. La revisión de la literatura sirvió para generar ideas, comprobar el estado actual de los conocimientos sobre el tema, contextualizar el tema a investigar en un marco teórico actualizado y comparar diferentes abordajes metodológicos para su resolución.

2o Búsqueda paralela al proceso de recolección de datos y a los análisis preliminares. Se empleó para los hallazgos que fueron surgiendo al realizar el análisis de la información generada y recogida en el proceso de investigación.

La búsqueda de nuevas fuentes de información y de investigaciones publicadas se orientó por los propios hallazgos que se fueron haciendo con el avance de la investigación.

La revisión bibliográfica trató de elaborar un referente que sirviese de guía indicativa y provisional que apoyase la construcción de teorías sin pretender validar el conocimiento ya existente. Desde este punto de vista se revisó la literatura y se realizaron dos temáticas diferenciadas de búsqueda: relativa a la metodología propia de la investigación y relativa al objeto de estudio de la misma

Para establecer el ámbito de la investigación y definir la metodología a seguir en el estudio se analizó información de los sistemas de salud y las organizaciones objeto del estudio. Se revisó toda la documentación existente y disponible sobre la OSI BilbaoBasurto y el Servicio Vasco de Salud-Osakidetza, y el Hospital de San Pedro y el Servicio Riojano de Salud (SERIS). Esta documentación incluyó memorias, informes, planes y otras publicaciones proporcionadas por las propias organizaciones 0 disponibles en la red.

Por otro lado, y para trabajar la parte cuantitativa del estudio que complementa el estudio cualitativo, se recogieron datos de fuentes relevantes, como por ejemplo los indicadores clave del Sistema Nacional de Salud de la página web del Ministerio de Sanidad, Servicios Sociales e Igualdad. Los datos utilizados en este estudio se encontraron en lugares de acceso público en línea con la idea de transparencia de las organizaciones. La disponibilidad o no de los datos es indicativa del grado de compromiso social y ético de las organizaciones como elemento principal de la sostenibilidad social.

Los indicadores con los que se trabajó en este estudio están respaldados en la literatura encontrada:

- Indicadores de eficiencia (García, 2014)

- Indicadores de efectividad clínica (Barrasa, JI 2013). 
- Herramientas para medir la sostenibilidad corporativa (Paternoster, 2011).

- Indicadores sobre determinantes sociales (Álvarez, 2009).

\section{Metodología de búsqueda}

Se realizó una revisión sistemática. Para la búsqueda en las diferentes bases de datos y buscadores académicos se emplearon diversas combinaciones de palabras adaptadas a cada buscador. Los términos específicos de búsqueda tanto en español como en lengua inglesa que fueron empleados para la búsqueda bibliográfica relacionados con el tema fueron: Sostenibilidad, EFQM, sistema sanitario público, sistema de gestión, etc.

También se realizaron búsquedas con otros términos menos específicos para conseguir información relevante para la metodología: investigación cualitativa, método de caso, entrevistas, investigación cualitativa, comparación, iterativo deductivo, etc.

No obstante y como consecuencia del método iterativo deductivo empleada en esta investigación se realizaron búsquedas específicas sobre apartados que requerían mayor información en determinados momentos.

En cuanto a los criterios de inclusión y exclusión, se comenzó la búsqueda con el filtro "full text" o "texto completo", para así poder optar a los artículos, documentos y revistas que se encuentran en internet de manera completa. Se revisaron publicaciones relacionadas con la calidad y la sostenibilidad desde 2008 hasta la actualidad y relacionadas con la metodología desde la misma fecha siendo insuficientes los datos encontrados por lo que amplió la búsqueda sin filtro de fechas. Se emplearon artículos anteriores a 2008, dado a la imposibilidad de eliminarlos por contener información relevante para el estudio de investigación y la metodología de la misma.

Como criterio de inclusión en las búsquedas relacionadas con el tema de investigación se tomó como prioritario el que fuesen artículos o revistas de ámbito sanitario público español, pero sin excluir cualquier otra temática de artículo o revista que pudiese aportar información relevante.

\section{Bases de datos, buscadores académicos y otros buscadores empleados}

Aunque la estrategia de búsqueda bibliográfica empleada en este estudio hace uso principal de los recursos accesibles desde internet, se han utilizado recursos tales como las bibliotecas físicas y documentación aportada por los participantes en el trabajo

Las fuentes de información consultadas son las siguientes:

- OVID. Plataforma de investigación médica con información sobre calidad y sistema sanitario. Permite el acceso a bases de datos como Pub-med/Medline, base de datos bibliográfica producida por la National Library of Medicine (Biblioteca Nacional de Medicina) de los Estados Unidos, que recopila millones de referencias bibliográficas de artículos publicados desde 1960, provenientes de unas 4800 revistas médicas desde 1966. Abarca los campos de la enfermería, 
medicina, oncología, odontología, veterinaria, salud pública y ciencias preclínicas.

- Ed. Elsevier. http://www.elsevier.es. Página web que permite el acceso a publicaciones relacionadas con el estudio: revista de calidad asistencial, ciencias sociales

- Bazar. Fundación Signo. Es un sitio web dependiente de la Fundación Signo cuyo fin es hacer llegar a los profesionales y a la sociedad las herramientas necesarias para evaluar y mejorar la gestión sanitaria encontrando ejemplos de cómo otros están haciendo las cosas.

- Cuiden. Base de datos en español. Pertenece a la Fundación Index, la cual incluye producción científica sobre Cuidados de Salud en el espacio científico Iberoamericano, tanto de contenido clínico-asistencial y promoción de la salud en todas sus especialidades, como con sus enfoques metodológicos, históricos, sociales o culturales. Contiene artículos de revistas científicas, libros, monografías y otros documentos, incluso materiales no publicados, cuyos contenidos han sido evaluados previamente por un comité de expertos. Permite recuperar referencias bibliográficas con el resumen de autor y acceder al texto completo de los documentos.

- IBECS (Índice bibliográfico español en ciencias de la salud). base de datos en español y de acceso gratuito. Elaborada por la Biblioteca Virtual en Salud (BVS). Contiene referencias de artículos de revistas científico-sanitarias editadas en España, e incluye contenidos de las diferentes ramas de las ciencias de la salud tales como: enfermería y medicina (incluyendo salud pública, epidemiología y administración aanitaria), farmacia, veterinaria, psicología y odontología.

- Biblioteca Cochrane Plus. Base de datos en español e inglés, con acceso gratuito gracias a la suscripción realizada por el Ministerio de Sanidad, Servicios Sociales e lgualdad para todo el territorio español. Contiene la traducción al español de revisiones sistemáticas completas y otros documentos relevantes, y las referencias bibliográficas de otros documentos de interés, como ensayos clínicos, artículos científicos, etc.

- SCIELO (Scientific Electronic Library Online). Biblioteca electrónica, iniciativa de la Fundación para el Apoyo a la Investigación del estado de São Paulo, Brasil y del Centro Latinoamericano y del Caribe de Información en Ciencias de la Salud, que posibilita el acceso a través de distintos mecanismos, incluyendo listas de títulos y por materia, índices de autores y materias y motor de búsqueda. Cuenta con el apoyo de diversas instituciones nacionales e internacionales vinculadas a la edición y divulgación científica.

- Dialnet. Es uno de los mayores portales bibliográficos del mundo, cuyo principal cometido es dar mayor visibilidad a la literatura científica hispana. Centrado fundamentalmente en los ámbitos de las Ciencias Humanas, Jurídicas y Sociales. Se pueden encontrar en Dialnet artículos de revista, libros y artículos de libros colectivos, actas de congresos, tesis doctorales, reseñas de otras publicaciones, etc. 
- Google académico. Forma sencilla de buscar bibliografía académica. Permite buscar a través de muchas disciplinas y fuentes: artículos, tesis, libros, resúmenes y opiniones de las editoriales académicas, sociedades profesionales, universidades y otros sitios web.

- Biblioteca Central del Ministerio de Sanidad, Servicios Sociales e lgualdad. Gran cantidad de fondos relacionados con el tema estudiado. Fondos documentales y bibliográficos: 22.500 Libros, 753 títulos de revistas, bancos de datos sanitarios, bancos de datos de carácter legal, colecciones de carácter jurídico, sanitario, normativo y estadísticas.

Para organizar toda la documentación y las referencias bibliográficas previas como la que fue surgiendo a lo largo del proceso de investigación se usó una herramienta de acceso libre (Zotero Standalone) que funciona como extensión o complemento del navegador de internet y permite también incluir referencias manualmente.

\subsubsection{Contacto y primeras visitas a las organizaciones seleccionadas}

Como ya se ha citado anteriormente, se realizaron contactos previos con las organizaciones para seleccionar las que finalmente serían objetos de estudio. El primer contacto con la OSI Basurto- Bilbao se realizó vía telefónica, previa llamada de presentación de Osakidetza, al Coordinador de Calidad del centro citado. Con el que se programó y realizó una reunión (efectuada el 17 de agosto de 2015) en la que se presentó el objetivo del proyecto investigación, el alcance y los aspectos necesarios para la recolección de los datos, con el fin de tener acceso a esta institución pública. En esta reunión también se recogió documentación proporcionada por el centro para su estudio y se realizó una visita al centro y fotografías de algunas de las instalaciones de acceso público.

Lo más importante, fue el hecho de que se estableció un vínculo de confianza con el responsable de calidad del centro, que permitió a la postre una eficaz recolección de datos e intercambio de información. A ello contribuyó que el investigador se formó y trabajó en el centro, lo cual introduce elementos de pertenencia y confianza, elemento necesario en los estudios longitudinales (Pettigrew, 1990).

Se solicitó la disponibilidad para mantener comunicación vía mail y telefónica para aclaración de dudas, confirmación de hallazgos, y solicitud y envío de información documental adicional.

Paralelamente al SERIS se escribió una carta de presentación y solicitud de colaboración al Director Gerente del Servicio Riojano de salud y al Director del Área de Salud. Tras la respuesta positiva se estableció un contacto permanente mediante correos electrónicos en el que se informaba de cada uno de los pasos que se realizaban y las personas con las que se contactó para el estudio quedando en todo momento a disponibilidad de la dirección para ampliar la información que considerase necesaria 


\subsubsection{Observación directa y fotografías}

La observación directa en el ámbito natural es una herramienta importante para las ciencias sociales y esta investigación no quería ser una excepción y remarcar su carácter eminentemente social. La observación directa consistió en la realización de visitas a los lugares donde se verifica la implantación del sistema. Como procedimiento de observación se hizo énfasis en los procesos asistenciales, de apoyo y de gestión identificando aspectos relacionados con el modelo. En este sentido, se recorrieron los puntos por dónde pasan los principales grupos de interés:

- Pacientes y acompañantes. Puntos de atención al paciente, consultas externas, salas de urgencias, salas de espera, salas de hospitalización, etc.

- Personal. laboratorios, oficinas, áreas de trabajo, talleres de mantenimiento, almacenes,

Además, se recorrieron los lugares físicos en donde se habían implantado actividades de mejora surgidas de la implantación del modelo y detectadas a través de la literatura o de las entrevistas. .

Se realizaron algunas fotografías que sirvieron como complemento de este método de recolección de datos (Suarez, 2007). De hecho, la documentación vía fotográfica ayudó a capturar datos que no pudieran ser mostrados mediante las entrevistas o la observación directa. Por ejemplo, cartelería informativa. Cada una de las fotografías presentadas en esta memoria de tesis, se sometió a autorización por parte de los responsables de las organizaciones objeto de estudio.

\subsubsection{Análisis documental}

Antes de realizar el "aterrizaje" en las organizaciones fue importante conocer las características, el entorno y la historia de la organización, porque esto permitía una mejor comprensión del presente (Merriam, 1998). Para ello, se recolectó en los centros seleccionados el material documental necesario para la integración del caso y a través de internet se realizó una búsqueda exhaustiva de información relacionada con estos centros y toda aquella información que proporcionase una visión completa de los mismos.

Se recolectaron para su análisis documentos internos y memorias y publicaciones de carácter público de los centros del estudio. Durante la recolección de los mismos se realizó una especial atención en obtener evidencias de diferentes fuentes, referentes a un conjunto similar de hechos (Ritchie, 2013).

El análisis documental de las organizaciones también permitió recolectar datos cuantitativos estadísticos útiles para conocer los casos a través de la combinación con los datos cualitativos (Yin, 2009). Además de funcionar como una fuente de conocimiento inicial, también sirvió como fuente de confirmación y validación de los datos después de terminar el proceso de recolección de datos (al momento de redactar los casos). 
Los datos objetivos (documentos oficiales) presentan la ventaja de cuantificar el ser y proteger frente a las percepciones individuales, a su vez representan la posición oficial de la organización (Alonso, 2004).

Por otra parte, los estudios hemerográficos (Escobar, 2016) complementaron toda la información recogida y permitieron disponer siempre de la última información relacionada con la sostenibilidad, la calidad y los centros al objeto de mantener una relación actualizada con el entorno. Esta fuente de información también aportaba datos sobre la visión que la sociedad tiene de cada uno de los centros y de la problemática de la sostenibilidad y el sistema sanitario público.

Se realizó consultando publicaciones periódicas que aportasen información relevante para el estudio. Se eligieron como fuentes de información:

- Periódicos generales: El País, La Rioja, El Correo y El Mundo

- Revistas Especializadas: Calidad Asistencial, Fundación Signo

- Newsletter: Fundación Signo, Asociación Española de Calidad Asistencial, Responsabilidad/i+ (Club de Excelencia en Sostenibilidad), Vision (Club de Excelencia en Gestión), Asociación Española para la Calidad, Globalización, Competitividad y Gobernabilidad de Georgetown/Universia, Federación de Empresarios de La Rioja, Research Centre of Governance, Sustainability and Reputation

Finalmente, se acordó con las organizaciones estudiadas la no publicación de información que no estuviese previamente revisada por su parte.

\subsubsection{Observación participativa no intrusiva}

Para no influir en la normalidad de las actividades del centro (Ritchie et al, 2013), la participación se limitó a aspectos de relaciones humanas en la OSI Bilbao-Basurto para permitir una entrada más fácil al campo de estudio (por ejemplo, explicar la presencia del investigador a los observados), así como también, para preguntar e indagar por aquellas actuaciones relacionadas con el uso de técnicas y herramientas que formen parte de la sostenibilidad de la Organización, las cuales posteriormente fueran validadas en las entrevistas. En todo momento se mantuvo una postura periférica tratando de minimizar al máximo la influencia y evitando también en todo lo posible, los prejuicios y percepciones engañosas que pudiese limitar la correcta interpretación de los datos (Angrosino, 2012).

En el Servicio Riojano de Salud, con el objetivo de profundizar más en el conocimiento del mismo y dada la facilidad para participar y al dificultad que añadía a las entrevistas conocer al entrevistador, se optó por participar en reuniones de evaluación y planificación de temas relacionados con la calidad y el modelo EFQM.

En la presente investigación se observaron reuniones con el equipo directivo y los miembros del comité de calidad (centrada específicamente en el Hospital San Pedro de Logroño), así como reuniones con los coordinadores de calidad. Las sesiones de trabajo y sesiones no se grabaron por propia solicitud de los equipos, sólo se tomaron notas en el diario del investigador debido a la naturaleza confidencial del trabajo de planificación, gestión y coordinación realizado. 
Las notas de la investigación de campo obtenidas en esta observación participativa se separaron en observaciones directas (temas tratados en la reunión) y en las reflexiones (análisis) posteriores de la mismas. En algunas ocasiones también se mantuvieron conversaciones informales que permitieron aclarar cuestiones (Leonard-Barton, 1990).

\subsubsection{Entrevista abierta}

Para esta investigación, como ya se ha señalado anteriormente, se optó por una entrevista semiestructurada o focalizada (tabla 22) para profundizar en el conocimiento de las organizaciones y disponer de una visión holística de las mismas. (Suarez, 2007).

Tabla 22. Preparación de las entrevistas

\begin{tabular}{|c|c|}
\hline $\begin{array}{l}\text { A. Preparación de la } \\
\text { entrevista }\end{array}$ & $\begin{array}{l}\text { - Elección del lugar: En el centro. Sala a elegir por el entrevistado } \\
\text { (para que se sienta cómodo y no sienta que está organizado por el } \\
\text { hospital y así disminuir su influencia a la hora de responder). } \\
\text { - Cita y contacto: A través del Responsable de Calidad }\end{array}$ \\
\hline $\begin{array}{l}\text { B. Desarrollo de la } \\
\text { entrevista }\end{array}$ & $\begin{array}{l}\text { - Fase de presentación: datos de la investigación y otros datos que } \\
\text { se precisen } \\
\text { - Fase inicial: temas generales, fáciles, "romper el hielo" pero sin } \\
\text { trivialidades } \\
\text { - Fase intermedia: temas más complicados y vinculados los objetivos } \\
\text { de la investigación } \\
\text { - Fase final: recapitulación. Procurar que la entrevista termine con } \\
\text { sensación de bienestar. } \\
\text { - Después de la entrevista: Información adicional, comentarios. }\end{array}$ \\
\hline C. Registro & $\begin{array}{l}\text { - Grabación del audio } \\
\text { - Anotaciones a lo largo de la entrevista }\end{array}$ \\
\hline $\begin{array}{l}\text { D. Ficha de la } \\
\text { entrevista }\end{array}$ & $\begin{array}{l}\text { - Información técnica } \\
\text { - Datos de localización } \\
\text { - Datos contextuales } \\
\text { - Resumen de la entrevista } \\
\end{array}$ \\
\hline $\begin{array}{l}\text { E. Transcripción de } \\
\text { la entrevista }\end{array}$ & - Literal \\
\hline \multicolumn{2}{|c|}{$\begin{array}{l}\text { Pautas seguidas por el entrevistador durante la entrevista: } \\
\text { Escuchar sin interrumpir, reconducir la conversación a la temática, no preocuparse por los } \\
\text { silencios (tienen significados y permiten al entrevistado la reflexión, a la vez que abren el } \\
\text { discurso), prestar atención a lo latente e intentar parecer neutral ante opiniones y } \\
\text { valoraciones del entrevistado. }\end{array}$} \\
\hline
\end{tabular}

Elaboración propia. Tomada de Vallés 2014

Con la ayuda de un facilitador interno se seleccionaron para ser entrevistados a informantes cualificados (observadores privilegiados) que, previa información, quisieron participar en el estudio de forma voluntaria. Estas personas fueron seleccionadas porque cumplían un rol fundamental en la investigación como conocedores expertos de la gestión y la sostenibilidad de la organización investigada (Batthyany, 2011) (tabla23). 
Tabla 23. Personas entrevistadas en cada organización

\begin{tabular}{|c|c|c|c|}
\hline \multicolumn{2}{|r|}{ OSI Bilbao Basurto (OSI) } & \multicolumn{2}{|r|}{ SERIS (SRS) } \\
\hline 1 & Jefe de servicio de calidad & 1 & $\begin{array}{c}\text { Responsable de calidad del servicio de } \\
\text { alimentación }\end{array}$ \\
\hline 2 & Subdirector económica & 3 & Directora económica \\
\hline 3 & Director de mantenimiento & 7 & Subdirector de mantenimiento \\
\hline 4 & Técnico de gestión medioambiental & & \\
\hline 5 & $\begin{array}{c}\text { Responsable de unidad de gestión } \\
\text { sanitaria }\end{array}$ & 2 & Jefe de servicio de admisión \\
\hline 6 & Jefe de oncología & 5 & Jefe de hospitalización a domicilio \\
\hline 7 & Jefe de estudios & 8 & Jefe de estudios \\
\hline 8 & Responsable de formación & & Jefa de servicio de formación \\
\hline 9 & $\begin{array}{l}\text { Supervisora de hospital de día } \\
\text { quirúrgico }\end{array}$ & 6 & Supervisora de hospital de día \\
\hline 10 & Directora médica & 9 & Director médico \\
\hline 11 & Supervisora de atención al paciente & 10 & $\begin{array}{l}\text { Jefe de servicio de atención } \\
\text { sociosanitaria }\end{array}$ \\
\hline 12 & Directora de enfermería & 4 & Subdirectora de enfermería \\
\hline
\end{tabular}

Se realizaron un total de 23 entrevistas con un tiempo promedio por entrevista de noventa minutos, comunicando a los entrevistados que los datos generados serían confidenciales mediante codificación de sus identidades. A este número de entrevistados se llegó mediante un proceso iterativo, en el cual el investigador seleccionó una serie de cargos relevantes, analizó los datos, y posteriormente se dirigió a otros cargos que ayudaron a refinar los resultados encontrados. Este proceso continuó hasta que se alcanzó la saturación y no se encontraban más resultados aunque se siguiese el muestreo (Ritchie, 2013).

Se trató de establecer un diálogo cuyo orden facilitar el hilo de una conversación natural. Existió la posibilidad de ir de un tema a otro conforme aparecen para facilitar la comodidad de los entrevistados. Para facilitarlo se determinaron una serie de puntos de referencia de paso obligatorio para recoger la información de una forma controlada. La conversación y los temas a tratar se prepararon en función de la bibliografía consultada 
y estudiada previamente. Se elaboró el guion de la entrevista (tabla 24) basándose en el concepto fundamental de la excelencia "crear un futuro sostenible" (CEG, 2014). Como ya se ha indicado, este guion inicial se validó realizando una investigación piloto con el Servicio de Alimentación del Hospital San Pedro.

Tabla 24. Esquema de la entrevista

\section{Entrevista}

Duración: sesiones de 60 minutos (máx. 90minutos)

Lugar: Centro. Sala a elegir por el entrevistado (para hacerle sentir cómodo y no crea que está organizado por el hospital y así disminuir su influencia a la hora de responder).

\section{Presentación}

Para lograr confianza y participación de los entrevistados se comienza con una breve explicación a los entrevistados sobre el entrevistador y el trabajo de investigación (Objetivos, ámbito,

metodología...)

El estudio es una investigación personal en la que el centro no está involucrado (sólo participa),

Solicitar autorización para tomar notas, grabar la conversación y para posteriormente elaborar los datos de forma objetiva. Asegurar la confidencialidad y la imparcialidad

Solicitar la posibilidad de futuros contactos si es necesario. Compromiso de Información de resultados Fase inicial

Temas generales, fáciles, "romper el hielo" pero sin trivialidades, dejar hablar al sujeto, que se explaye, para que se sienta importante porque cuenta lo que hace y demostrar interés: ¿Cuánto tiempo llevas en este hospital? ¿Has estado en otros? ¿Hay diferencia con otros hospitales? ¿Este tiene algo especial? ¿Cuáles son tus tareas?

\section{Temas entrevista}

\begin{tabular}{c|l|c|}
$\begin{array}{c}\text { Tema } \\
\text { Principal } \\
\text { (criterios) }\end{array}$ & Sub-Tema (subcriterios) & \multicolumn{1}{c}{ Guion entrevista } \\
& 0.1 Definición de & ¿Qué tipo de obstáculos encontráis (de donde vienen los \\
\hline
\end{tabular}

0.1 Definición de

\begin{tabular}{l|l} 
General & sostenibilidad \\
0.2 Sostenibilidad de la
\end{tabular} organización en su conjunto 0.3 Obstáculos a la Sostenibilidad

Estrategia 2.c La estrategia y sus

(criterio2) políticas de apoyo se desarrollan, revisan y actualizan

Procesos, 5.b Los productos y productos servicios se desarrollan para servicios dar un valor óptimo a los

(criterio5) clientes

4.b Gestión de los recursos económicos y financieros

Alianzas y para asegurar un éxito

Recursos sostenido

(criterio4) $4 . c$ Gestión sostenible de edificios, equipos,

materiales y recursos naturales

1.a Los líderes desarrollan la misión, visión y valores y principios éticos y actúan como modelo de referencia 1.c Los líderes se implican con los grupos de interés Liderazgo externo (criterio1)

1.e Los líderes se aseguran de que la organización sea flexible y gestionan el cambio de manera eficaz obstáculos, qué motivan los obstáculos, qué hacéis para minimizarlos, qué impacto tienen... habéis tenido que renunciar a algo por los obstáculos...?? (0.3)

$¿$ Crees que el centro da respuesta a las necesidades de los pacientes, usuarios, sociedad...? ¿Por qué? ¿Qué debería hacer? (5.b)

¿Sabes si existen políticas, planes, ideas, estrategias para el buen funcionamiento del centro? ¿Las conoces? ¿Sabes si se revisan y actualizan? (2.c)

¿Crees que el centro es flexible y capaz de adaptarse a los cambios de manera eficaz? ¿Conoces algún ejemplo? Si no es así porqué y qué debería hacer el centro.(1.e)

¿Qué hace el hospital para asegurar la sostenibilidad?.... ¿hay medidas económicas? ¿financieras....? (4.b)

¿Existe una gestión sostenible/adecuada de edificios, equipos, materiales y recursos naturales?¿Qué hacéis al respecto?¿Qué más podría hacerse? (4.c)

¿El centro se implica con los grupos de interés externo (pacientes, asociaciones profesionales....) y con la sociedad (asociaciones de vecinos, municipio.....)? ¿Y los jefes o directivos? (1.c)

¿Los directivos o los jefes son modelo de referencia en cuanto a calidad y principios éticos? (1.a)

Para finalizar podrías decirme ¿qué es para ti un centro sanitario sostenible? ¿Crees que este lo es? ¿Por qué? (0.1 y 0.2 )

Recapitulación. Procurar que la entrevista termine con sensación de bienestar.

Después de la entrevista: Información adicional, comentarios. 


\subsubsection{Diario del investigador}

En el diario del investigador se anotó toda la información recogida en cada contacto durante el proceso de investigación. Este diario ha sido una fuente para guiar y ajustar la investigación cuando fue necesario, por ejemplo, durante las entrevistas que no pudieron ser grabadas.

El diario representó un instrumento útil para realizar observaciones y anotar cualquier dato relevante, además, de todo el material grabado de las entrevistas en profundidad y de la observación participativa no intrusiva, el diario de investigador sirvió de referencia al momento de las transcripciones y análisis.

Por otro lado, su utilidad como método de reflexión resultó importante porque permitió anotar ideas surgidas en diferentes momentos del proceso de investigación y ayudó a guiar el ciclo iterativo deductivo e inductivo planteado en el diseño de la metodología.

El diario del investigador se organizó en cuatro tipos de anotaciones principales:

1. Notas de las reuniones: participantes, tiempo, responsabilidades, etc.

2. Notas en forma de guía de las entrevistas en profundidad semi-estructuradas;

3. La elaboración de distribuciones físicas, aulas de formación, puntos de atención al ciudadano, etc. producto de la observación directa

4. La elaboración de pequeños resúmenes y cuadros sinópticos a manera de reflexión al concluir las observaciones, las entrevistas, la revisión de documentos e incluso ideas que surgían en cualquier momento relacionadas con el tema de investigación.

\subsection{Diseño de la investigación cuantitativa}

En 2005 la Universidad de Leicester se realizó un trabajo de investigación para valorar la relación entre la excelencia y el rendimiento organizativo (Boulder 2005).Tomando este estudio como referencia y dando la vuelta al argumento se planteó dotar a nuestro trabajo de la objetividad que aporta el estudio cuantitativo de datos para complementar el estudio cualitativo pretendiendo ampliar y profundizar en el conocimiento sobre las formas organizativas que determinan un determinado resultado en términos de eficacia/eficiencia.

El estudio de datos cuantitativos no se centró en indicadores de las organizaciones estudiadas, sino que se amplió a todo el sistema público de salud de cada comunidad autónoma por entenderse que las organizaciones estudiadas forman parte de un sistema con el que interactúan, del que forman parte y que determina aspectos tan importantes como la cartera de servicios, las inversiones y los presupuestos la política estratégica sanitaria e incluso los recursos humanos. 
Respecto a la integración de los datos cualitativos de los centros sanitarios y cuantitativos de las comunidades autónomas son necesarias las siguientes consideraciones:

- En La Rioja, el Hospital San Pedro es el único hospital general existente. Por tanto, los datos de la Comunidad Autónoma son fácilmente asimilables a los propios del centro.

- Respecto a Osakidetza, dispone de una política estratégica común para todos los centros. El estudio cualitativo de la OSI Bilbao-Basurto se considera un muestreo de lo que ocurre en los centros de Osakidetza (Osteba, 2016).

Se valoró la accesibilidad de los datos y se decidió estudiar aquellos datos que fuesen de fácil acceso y estuviesen respaldados por la literatura científica.

Los Indicadores Clave del Sistema Nacional de Salud son una lista de indicadores seleccionados de entre los miles de datos disponibles en las fuentes rutinarias que constituyen el sistema de información del Sistema Nacional de Salud y de fuentes de datos gestionadas por otros organismos oficiales. Son los indicadores que se consideran más relevantes para entender la salud de los ciudadanos, el funcionamiento del sistema sanitario público y los factores que influyen en la salud. Permiten observar cambios y tendencias y los datos están segmentados por comunidades autónomas. La lista está compuesta por 247 Indicadores clasificados en diversos campos (dominios y subdominios). De toda la lista el Ministerio identifica 50 como esenciales (Lista Corta).

Según el documento de interpretación de la versión 2013 del modelo EFQM para las administraciones públicas, resultados clave son aquellos que las organizaciones excelentes alcanzan y mantienen en el tiempo que satisfacen o exceden las necesidades y expectativas de los grupos de interés.

La taxonomía clásica de indicadores de desarrollo sostenible diferencia entre indicadores ambientales, sociales (o socio-políticos) y económicos (Hanley, Moffat, Faichney, \& Wilson. 1999) por lo que también se han añadido aquellos que no se encontraban en esta lista corta (esenciales) pero que aportaban información sobre aspectos de sostenibilidad tales como:

- Social. Eficacia y Satisfacción de pacientes

- Económico. Eficiencia y gasto

Diferenciando entre indicadores de resultados obtenidos por el sistema de salud y los indicadores de criterios agentes relacionados con los condicionantes o determinantes de salud entendiendo estos como las circunstancias en que las personas nacen, crecen, viven, trabajan y envejecen, incluido el propio sistema de salud (OMS 2005) se seleccionaron (tablas 25,26 y 27 ). 
Tabla 25. Indicadores seleccionados

\begin{tabular}{|c|c|c|}
\hline INDICADOR & DOMINIOS & $\begin{array}{c}\text { Dimensión } \\
\text { Sostenibilidad }\end{array}$ \\
\hline Esperanza de vida al nacer & Bienestar & \multirow{25}{*}{$\begin{array}{l}\text { Social: } \\
\text { Resultados } \\
\text { Clave en } \\
\text { Salud }\end{array}$} \\
\hline Esperanza de vida en buena salud al nacer & Bienestar & \\
\hline Años de vida saludable a los 65 años & Bienestar & \\
\hline $\begin{array}{l}\text { Porcentaje de población con valoración positiva de su } \\
\text { estado de salud }\end{array}$ & Bienestar & \\
\hline $\begin{array}{l}\text { Porcentaje de población de } 65 \text { años y más años con } \\
\text { valoración positiva de su estado de salud }\end{array}$ & Bienestar & \\
\hline $\begin{array}{l}\text { Tasa de mortalidad prematura por Cáncer, ajustada } \\
\text { por edad, por } 100000 \text { hab }\end{array}$ & Mortalidad & \\
\hline $\begin{array}{l}\text { Tasa de mortalidad prematura por Cardiopatía } \\
\text { isquémica, ajustada por edad, por } 100000 \text { hab. }\end{array}$ & Mortalidad & \\
\hline $\begin{array}{l}\text { Tasa de mortalidad prematura por Diabetes mellitus, } \\
\text { ajustada por edad, por } 100000 \text { hab. }\end{array}$ & Mortalidad & \\
\hline $\begin{array}{l}\text { Tasa de mortalidad prematura por Enfermedad } \\
\text { vascular cerebral, ajustada por edad, por } 100000 \text { hab. }\end{array}$ & Mortalidad & \\
\hline $\begin{array}{l}\text { Tasa de mortalidad prematura enfermedades crónicas } \\
\text { de vías respiratorias inferiores por } 100000 \text { hab. }\end{array}$ & Mortalidad & \\
\hline Tasa de mortalidad infantil por 1000 nacidos vivos & Mortalidad & \\
\hline $\begin{array}{l}\text { Tasa de mortalidad perinatal por cada } 1000 \text { nacidos } \\
\text { vivos }\end{array}$ & Mortalidad & \\
\hline Incidencia de tuberculosis por 100000 hab. & Morbilidad & \\
\hline $\begin{array}{l}\text { Prevalencia declarada de diabetes mellitus en } \\
\text { población adulta. Ver definición }\end{array}$ & Morbilidad & \\
\hline $\begin{array}{l}\text { Prevalencia declarada de trastornos mentales en } \\
\text { población adulta. Ver definición }\end{array}$ & Morbilidad & \\
\hline $\begin{array}{l}\text { Tasa ajustada de hospitalización por infarto agudo de } \\
\text { miocardio por } 10000 \text { hab. }\end{array}$ & Morbilidad & \\
\hline $\begin{array}{l}\text { Tasa de mortalidad ajustada por edad por cardiopatía } \\
\text { isquémica por } 100000 \text { hab. }\end{array}$ & Eficacia & \\
\hline $\begin{array}{l}\text { Tasa de mortalidad ajustada por edad, por enfermedad } \\
\text { cerebrovascular por } 100000 \text { hab. }\end{array}$ & Eficacia & \\
\hline Tasa de mortalidad perinatal & Eficacia & \\
\hline Tasa de infección hospitalaria. & Eficacia & \\
\hline Tasa de fracturas de cadera en pacientes ingresados. & Eficacia & \\
\hline $\begin{array}{l}\text { Tasa de notificación de reacciones adversas a } \\
\text { medicamentos (total) }\end{array}$ & Eficacia & \\
\hline $\begin{array}{l}\text { Mortalidad intrahospitalaria global por cada } 100 \text { altas } \\
\text { hospitalarias }\end{array}$ & Eficacia & \\
\hline $\begin{array}{l}\text { Mortalidad intrahospitalaria tras intervención quirúrgica } \\
\text { por cada } 100 \text { altas quirúrgicas }\end{array}$ & Eficacia & \\
\hline $\begin{array}{l}\text { Mortalidad intrahospitalaria de pacientes con } \\
\text { neumonía por cada } 100 \text { altas por neumonía }\end{array}$ & Eficacia & \\
\hline
\end{tabular}




\begin{tabular}{|c|c|c|}
\hline INDICADOR & DOMINIOS & $\begin{array}{l}\text { Dimensión } \\
\text { Sostenibilidad }\end{array}$ \\
\hline Índice de dependencia & Sociodemográfico & \multirow{9}{*}{$\begin{array}{l}\text { Social: } \\
\text { Determinantes } \\
\text { de la Salud }\end{array}$} \\
\hline $\begin{array}{l}\text { Prevalencia de consumo de tabaco en población } \\
\text { adulta. Ver definición }\end{array}$ & Estilos de vida & \\
\hline $\begin{array}{l}\text { Prevalencia de obesidad en población de } 18 \text { y más } \\
\text { años }\end{array}$ & $\begin{array}{l}\text { Determinantes } \\
\text { biológicos }\end{array}$ & \\
\hline Prevalencia de obesidad en población de 2 a 17 años & $\begin{array}{l}\text { Determinantes } \\
\text { biológicos }\end{array}$ & \\
\hline $\begin{array}{l}\text { Proporción de población de } 25 \text { a } 64 \text { años con nivel de } \\
\text { estudios de 1ํ Etapa de educación secundaria o } \\
\text { inferior }\end{array}$ & $\begin{array}{l}\text { Determinantes } \\
\text { sociales }\end{array}$ & \\
\hline $\begin{array}{l}\text { Cobertura (\%) de personas mayores de } 65 \text { años } \\
\text { vacunadas frente a la gripe }\end{array}$ & Accesibilidad & \\
\hline $\begin{array}{l}\text { Cobertura (\%) de vacunación frente a la poliomielitis } \\
\text { (primovacunación 0-1 años) }\end{array}$ & Accesibilidad & \\
\hline $\begin{array}{l}\text { Cobertura (\%) de vacunación frente a sarampión- } \\
\text { rubéola-parotiditis (primovacunación 1-2 años) }\end{array}$ & Accesibilidad & \\
\hline $\begin{array}{l}\text { Porcentaje de mujeres de } 50 \text { a } 69 \text { años con } \\
\text { mamografía realizada con la frecuencia recomendada }\end{array}$ & Accesibilidad & \\
\hline $\begin{array}{l}\text { Notificación de reacciones adversas graves a } \\
\text { medicamentos (Tasa por } 1000 \text { 000) }\end{array}$ & Seguridad & \multirow{7}{*}{$\begin{array}{l}\text { Social: Ética } \\
\text { Sanitaria. } \\
\text { Seguridad y } \\
\text { cobertura }\end{array}$} \\
\hline $\begin{array}{l}\text { Mortalidad intrahospitalaria postinfarto por cada } 100 \\
\text { altas por infarto }\end{array}$ & Seguridad & \\
\hline $\begin{array}{l}\text { Tasa de amputaciones miembro inferior en pacientes } \\
\text { diabéticos }\end{array}$ & Seguridad & \\
\hline Incidencia de hepatitis B por cada 100000 hab. & & \\
\hline $\begin{array}{l}\text { Porcentaje de población cubierta por el sistema } \\
\text { sanitario publico }\end{array}$ & Accesibilidad & \\
\hline $\begin{array}{l}\text { Tiempos de espera para intervenciones quirúrgicas no } \\
\text { urgentes }\end{array}$ & Accesibilidad & \\
\hline Tiempos de espera para consultas especializadas & Accesibilidad & \\
\hline $\begin{array}{l}\text { Grado de satisfacción de los ciudadanos con el } \\
\text { funcionamiento del sistema sanitario público }\end{array}$ & $\begin{array}{l}\text { Satisfacción } \\
\text { Ciudadanos }\end{array}$ & \multirow{3}{*}{$\begin{array}{l}\text { Social: } \\
\text { Satisfacción } \\
\text { ciudadano }\end{array}$} \\
\hline $\begin{array}{l}\text { Grado de satisfacción del ciudadano con el } \\
\text { conocimiento del historial y el seguimiento de sus } \\
\text { problemas de salud por el médico de familia y el } \\
\text { pediatra }\end{array}$ & $\begin{array}{l}\text { Satisfacción } \\
\text { Ciudadanos }\end{array}$ & \\
\hline $\begin{array}{l}\text { Grado de satisfacción del ciudadano con la } \\
\text { información recibida en la consulta del médico } \\
\text { especialista sobre su problema de salud }\end{array}$ & $\begin{array}{l}\text { Satisfacción } \\
\text { Ciudadanos }\end{array}$ & \\
\hline
\end{tabular}




\begin{tabular}{|c|c|c|}
\hline INDICADOR & DOMINIOS & $\begin{array}{c}\text { Dimensión } \\
\text { Sostenibilidad }\end{array}$ \\
\hline Personal médico AP por 1000 personas asignadas & Recursos & \multirow{12}{*}{$\begin{array}{l}\text { Determinantes } \\
\text { Económicos: } \\
\text { Recursos } \\
\text { utilizados }\end{array}$} \\
\hline Camas hospitalarias en funcionamiento por $1000 \mathrm{~h}$. & Recursos & \\
\hline Puestos en hospitales de día por 1000 hab. & Recursos & \\
\hline Equipos de hemodinámica por 100000 hab. & Recursos & \\
\hline $\begin{array}{l}\text { Frecuentación en medicina de AP por persona } \\
\text { asignada/año }\end{array}$ & Uso & \\
\hline $\begin{array}{l}\text { Tasas de uso de resonancia magnética por } 1000 \\
\text { hab./año }\end{array}$ & Uso & \\
\hline Índice de la estancia media ajustada (IEMA) & Uso & \\
\hline Porcentaje de cirugía ambulatoria en el SNS & Uso & \\
\hline DHD de antibióticos & Uso & \\
\hline Tasa de cesáreas & Pertinencia & \\
\hline $\begin{array}{l}\text { Porcentaje de cirugía conservadora en cáncer de } \\
\text { mama }\end{array}$ & Pertinencia & \\
\hline $\begin{array}{l}\text { Porcentaje de pacientes con fractura de cadera } \\
\text { intervenidos en las primeras } 48 \text { horas }\end{array}$ & Pertinencia & \\
\hline $\begin{array}{l}\text { Gasto sanitario público territorializado, por habitante } \\
\text { protegido }\end{array}$ & Económico & \multirow{10}{*}{$\begin{array}{c}\text { Determinantes } \\
\text { Económicos: } \\
\text { Gasto }\end{array}$} \\
\hline Porcentaje del gasto sanitario en atención primaria & Económico & \\
\hline \% del gasto de los servicios de atención especializada & Económico & \\
\hline$\%$ del gasto en farmacia & Económico & \\
\hline \% del gasto en remuneración de personal & Económico & \\
\hline$\%$ del gasto en consumos intermedios & Económico & \\
\hline$\%$ del gasto dedicado a conciertos & Económico & \\
\hline Estancia media ajustada por la casuística (EMAC) & Eficiencia & \\
\hline Porcentaje de cirugía ambulatoria & Eficiencia & \\
\hline Porcentaje global de reingresos & Eficiencia & \\
\hline
\end{tabular}

Para su presentación en el capítulo 5 se sigue la nomenclatura establecida en el propio cuadro:

1. Indicadores de resultados clave en salud (Social). Relacionados con la respuesta a las necesidades de todos los grupos de interés y al cumplimiento de la misión del sistema sanitario. Hacen referencia a lo esencial. Son los resultados clave económicos y no económicos que demuestran el éxito alcanzado en la implantación de la estrategia (CEG, 2014) y las políticas de salud definidas junto a las partes interesadas. Estos indicadores incluyen información sobre bienestar, mortalidad, morbilidad y eficacia.

2. Indicadores de satisfacción de los ciudadanos. Muestran los resultados de la percepción de los ciudadanos como clientes (pacientes) de las organizaciones sanitarias. Además, desde su posición de ciudadanos tienen la capacidad de influir sobre los políticos y las instituciones para mantener las políticas sanitarias 
o modificarlas y los recursos que se destinan al sistema sanitario público. Con estos indicadores se mide el grado de satisfacción de las expectativas de los ciudadanos respecto al sistema público de salud.

3. Indicadores de seguridad y cobertura (Social). Muestran el cumplimiento de la legislación y aspectos de ética sanitaria.

4. Indicadores de recursos utilizados (Determinantes económicos). Muestran los recursos no económicos que se han utilizado para alcanzar los resultados. Dan idea de la capacidad de optimización de los recursos y permiten la comparación y dimensionamiento de los resultados clave obtenidos

5. Indicadores de gasto (Determinantes económicos). Muestran los recursos económicos que se han utilizado para alcanzar los resultados. Dan idea de la capacidad de optimización del presupuesto empleado y permiten la comparación y dimensionamiento de los resultados clave obtenidos.

6. Indicadores de determinantes de la salud (Social). Recogen las condiciones sociales y económicas que influyen en las diferencias individuales y colectivas en el estado de salud. Sirven para valorar los factores externos al sistema sanitario que pueden condicionar y diferenciar los resultados en salud.

Los indicadores del ministerio analizados indican los resultados del sistema de salud para cubrir las necesidades de la sociedad y los ciudadanos, respondiendo así a su responsabilidad social (ilustración 20 ) donde la organización contribuye al bienestar económico y social (Huckle y Sterling, 1996).

Por tanto, según la teoría de la sostenibilidad de los grupos de Interés, la sociedad a través de los gestores políticos invierte en el sistema de salud porque lo considera necesario y obtiene resultados favoreciendo así su perdurabilidad en el tiempo.

Ilustración 20. Marco conceptual de los Indicadores Clave del SNS
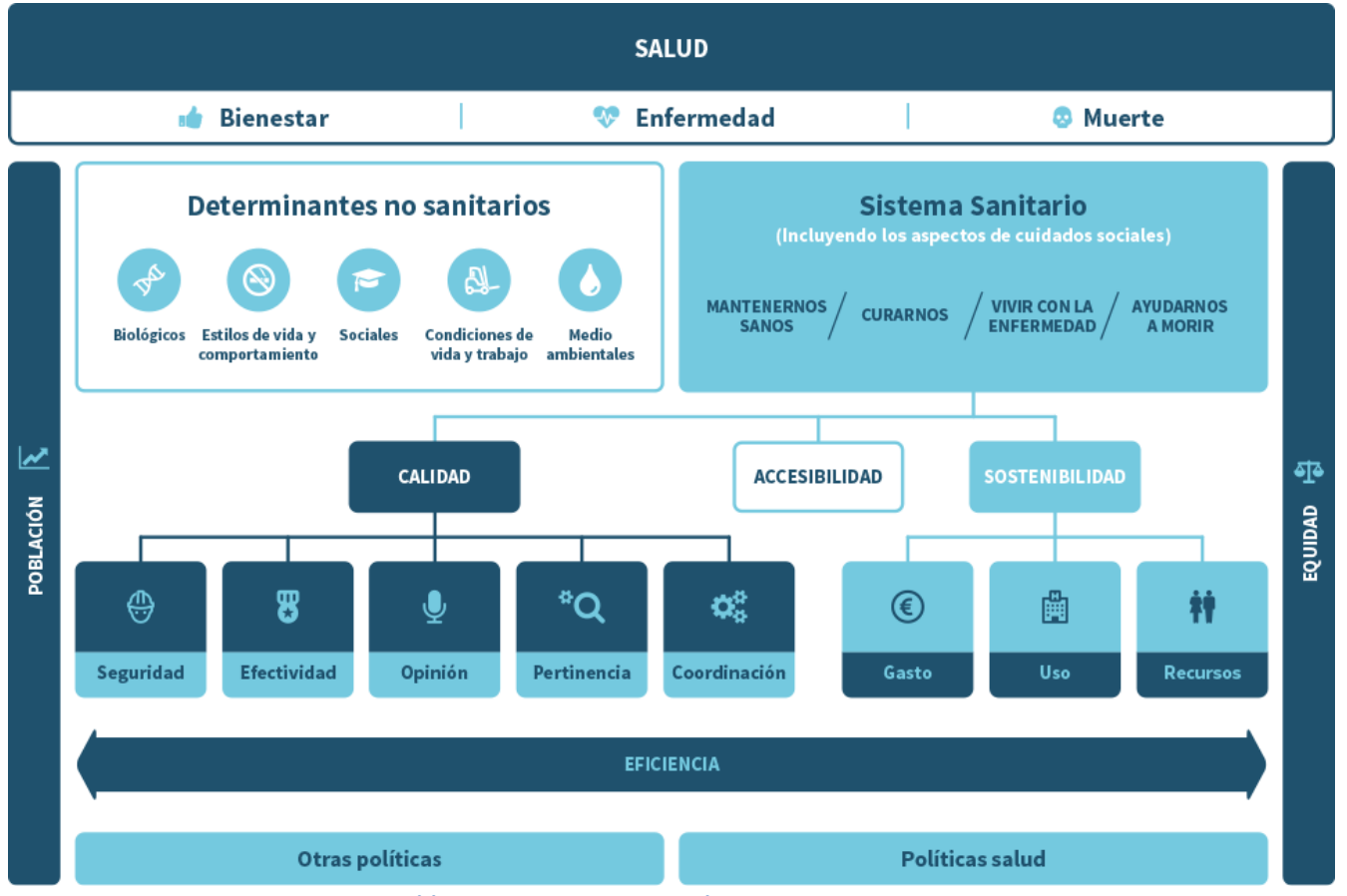

Fuente: MSSSI. Tomado de http://inclasns.msssi.es/doc. Acceso 21/08/2017 


\section{Validez de los indicadores}

Según el propio ministerio, para la selección de indicadores en su base de datos, se han usado los siguientes criterios:

- Existencia de una fuente oficial, estable y sostenible de datos

- Recogida del dato de forma homogénea en cuanto a calidad y cobertura en los distintos niveles de desagregación

- Adecuado balance en la representación de los distintos Dominios (población, estado de salud, determinantes y sistema sanitario)

- Inclusión de las perspectivas de Salud Pública, Asistencia Sanitaria y Otras Políticas, como la equidad.

- Referencia a un aspecto de salud importante desde el punto de vista de las políticas sanitarias y estrategias de intervención

- Posibilidad de evaluar tendencias y comparación entre ámbitos geográficos

- Cumplir las características básicas de indicador (validez, fiabilidad, etc.)

El modelo conceptual en el que se basan es el sugerido por los Indicadores Europeos de Salud (ECHI3 por sus siglas en inglés). Este modelo se ha adaptado a las características del SNS y de su sistema de información así como a las necesidades y prioridades estratégicas. También se han tenido en cuenta otros modelos tanto nacionales (OBSA, Andalucía) como internacionales (OCDE, OMS). Todo ello aporta un grado de fiabilidad que se ha considerado suficiente para este estudio.

Asimismo, los indicadores de Eficiencia en hospitales (García 2014) y los de efectividad clínica (Barrasa, 2013) están Validados por los coordinadores de calidad de centros e institucionales sanitarias de todo el país y representantes de sociedades autonómicas de calidad coordinados por la Sociedad Española de Calidad Asistencial.

\subsection{Metodología del análisis de datos}

Aunque este apartado se presente como un proceso separado, solamente lo es con un fin didáctico. En el trabajo de campo la recolección y el análisis de los datos siguió el ciclo iterativo deductivo e inductivo propuesto, es decir, la obtención y el análisis de datos se llevó a cabo al mismo tiempo (Marshall y Rossman, 1989 citados por Kawulich 2005), debido a que los datos se iban reflexionando en la medida que se generaban con el fin de ir orientando la investigación de acuerdo a lo que los mismos datos indicaban (Merriam, 1998).

Siguiendo a Huberman y Miles (1994) y el diseño de investigación establecido para el análisis de los datos de manera general, se llevaron a cabo tres actividades principales que se describen a continuación.

\subsubsection{Reducción de datos}

Seleccionar, abstraer, enfocar y transformar los datos en notas y transcripciones de campo que permitieron sentar las bases para el análisis de los datos generados. 


\subsubsection{Análisis de las entrevistas}

Todas las entrevistas fueron transcritas literalmente y anonimizadas mediante la asignación de un código identificativos de organización y un número correlativo. Para su análisis se utilizó el programa Atlas ti. El análisis de la información procedente de las entrevistas realizadas en la investigación se basó en el análisis de discurso (Casamiglia, 1999) para profundizar en el conocimiento de las organizaciones y disponer de una visión holística de las mismas. (Suarez, 2007).

Partiendo de los textos de las entrevistas se extrajo la información relevante de lo referido por los entrevistados y que estuviese relacionado con los objetivos de la investigación. La lectura de las entrevistas se realizó en fases interrelacionadas (Francés, 2015):

a. Lectura intuitiva. Se comenzó el análisis leyendo independientemente cada entrevista una o dos veces. En un segundo paso se leyeron de nuevo extrayendo aquellas frases que en un primer golpe de vista llamaron la atención. Se trató de buscar "titulares de prensa" en los discursos. Se trató de facilitar un primer acercamiento al discurso en su conjunto (lo que se dice y cómo se dice)

b. Lectura temática. Posteriormente, se seccionó el discurso según los diversos bloques temáticos. Se sacaron aquellos párrafos que tenían alguna relación con el tema de investigación o que nos mostraban claves útiles para la misma. Primero los grandes temas y después los subtemas de estos primeros. Para esta labor se han usado el programa informáticos de asistencia en el análisis de discurso, Atlas-ti.

c. Lectura relacional. Se trató de juntar los distintos mapas conceptuales o de redes de cada entrevista para construir el esquema general conceptual, que mostrase los principales posicionamientos y los puntos de coincidencia que definían la cultura de la organización.

\subsubsection{Análisis de Indicadores}

Para realizar el análisis de los datos recopilados se compararon las series de indicadores de La Rioja y del País Vasco buscando si existían diferencias significativas y analizando su significado y relevancia. En una primera aproximación se analizan el incremento o descenso de los valores en cada uno de los indicadores de los diferentes grupos a lo largo del periodo estudiado comparando el primer valor de la serie con el de fecha más reciente.

Posteriormente, se trató de evidenciar si existían diferencias significativas entre los resultados clave, en salud y en satisfacción, obtenidos entre las Comunidades Autónomas del País Vasco y de La Rioja por un lado, y si existían diferencias significativas entre los datos de gastos, recursos y determinantes de la salud en ambas comunidades.

Ante el gran número de indicadores disponibles se seleccionaron aquellos de los que se disponían datos de todos los años del periodo estudiado (2007-2015) y solo uno de los que se repetían en la misma área temática. 
Para realizar este análisis se utilizó el Programa de Regresión Joinpoint, versión 4.4.0.0- enero 2017 de metodología estadística y aplicaciones desarrollado por el Programa de Investigación de Vigilancia del Instituto Nacional del Cáncer.

Jointpoint es un paquete de software estadístico basado en Windows que analiza modelos de punto de unión y que comparar series y probar si un cambio aparente en la tendencia es estadísticamente significativo.

Joinpoint se ajustaba a los datos de tendencia seleccionados (por ejemplo, las tasas de cáncer) en el modelo de punto de unión más simple que permiten los datos. La ilustración resultante muestra las líneas de tendencia y permite ver si sus diferencias son significativas o no. El modelo de regresión Joinpoint y las pruebas de permutación para identificar cambios en la tendencia fueron descritos por Kim, Fay, Feuer y Midthune (2000).

Para la realización de los cálculos, en el caso de las tasas ajustadas a la edad, al no disponer del número de casos, pero sí de las poblaciones, el error estándar se calculó como si la tasa ajustada fuese una tasa cruda (Davies, 1998).

Las gráficas de los resultados obtenidos mediante este programa están recogidas en el anexo II.

\subsubsection{Despliegue de los datos}

La organización y estructuración de la información se llevó a cabo a través borradores, en las cuales se transcribieron y organizaron los datos con el fin de facilitar la comprensión de los resultados que se iban obteniendo. Además, de manera complementaria, se utilizaron los resúmenes realizados durante las observaciones participativas y las entrevistas en profundidad recogidos en el diario del investigador.

\subsubsection{Análisis final de los mismos}

Esquematización de la conclusión y la verificación mediante, la elaboración de matrices y la obtención de los patrones y regularidades observadas para probar un grado mínimo de validez. Se realizaron segundas o terceras reflexiones, cruce de datos de las dos organizaciones sobre los patrones encontrados, y vuelta a empezar.

Para realizar la interpretación de los resultados obtenidos se platearon diferentes hipótesis que se recogen en la tabla 28. 


\begin{tabular}{|c|c|c|c|c|c|}
\hline & & \multicolumn{2}{|c|}{$\begin{array}{c}\text { ¿Existen diferencias significativas en } \\
\text { resultados clave? }\end{array}$} & \multicolumn{2}{|c|}{$\begin{array}{c}\text { ¿Existen diferencias significativas } \\
\text { en satisfacción? }\end{array}$} \\
\hline & & SI & NO & SI & NO \\
\hline \multirow{2}{*}{$\begin{array}{c}\text { ¿Existen } \\
\text { diferencias } \\
\text { significativas } \\
\text { entre } \\
\text { recursos } \\
\text { empleados? }\end{array}$} & SI & $\begin{array}{l}\text { El empleo de diferentes } \\
\text { recursos podría justificar } \\
\text { las diferencias en } \\
\text { resultados clave }\end{array}$ & \begin{tabular}{|lr||} 
La implantación del \\
modelorr & EFQM \\
podría & ser la causa \\
que & permita \\
alcanzar & resultados \\
similares a pesar de \\
la diferencia en \\
recursos
\end{tabular} & $\mid \begin{array}{lrr}\text { El empleo } & \text { de } \\
\text { diferentes recursos } \\
\text { podría justificar las } \\
\text { diferencias } & \text { en } \\
\text { satisfacción } & \end{array}$ & $\begin{array}{l}\text { La implantación del } \\
\text { modelo EFQM podría } \\
\text { ser la causa que } \\
\text { permita alcanzar } \\
\text { resultados similares a } \\
\text { pesar de la diferencia } \\
\text { en agentes.. }\end{array}$ \\
\hline & NO & $\begin{array}{l}\text { La implantación del } \\
\text { modelo EFQM podría } \\
\text { justificar las diferencias } \\
\text { en resultados porque se } \\
\text { descartan } \\
\text { factores. otros }\end{array}$ & \begin{tabular}{|l||} 
La implantación del| \\
modelo EFQM no \\
lograrangún ningún \\
impacto medible en \\
términos \\
cuantitativos en la \\
organización
\end{tabular} & $\begin{array}{|lr|}\text { La implantación } \\
\text { del modelo EFQM } \\
\text { podría justificar las } \\
\text { diferencias } \text { en } \\
\text { resultados porque } \\
\text { se descartan otros } \\
\text { factores }\end{array}$ & $\begin{array}{l}\text { La implantación del } \\
\text { modelo EFQM no } \\
\text { logra ningún impacto } \\
\text { medible en términos } \\
\text { cuantitativos en la } \\
\text { organización }\end{array}$ \\
\hline \multirow{2}{*}{$\begin{array}{c}\text { ¿Existen } \\
\text { diferencias } \\
\text { significativas } \\
\text { entre el } \\
\text { gasto } \\
\text { realizado? }\end{array}$} & SI & 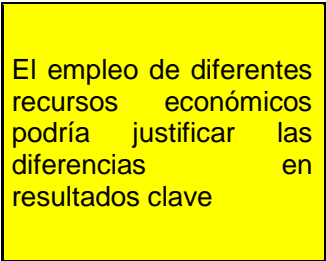 & \begin{tabular}{|lr||} 
La implantación del \\
modelorr & EFQM \\
podría & ser la causa \\
que & permita \\
alcanzar & resultados \\
similares a pesar de \\
la diferencia & en el \\
gasto
\end{tabular} & $\mid \begin{array}{lrr}\text { El } & \text { empleo } & \text { de } \\
\text { diferentes recursos } \\
\text { económicos } & \text { podría } \\
\text { justificar } & \text { las } \\
\text { diferencias } & \text { en } \\
\text { satisfacción } & \end{array}$ & $\begin{array}{l}\text { La implantación del } \\
\text { modelo EFQM podría } \\
\text { ser la causa que } \\
\text { permita alcanzar } \\
\text { resultados similares a } \\
\text { pesar de la diferencia } \\
\text { en agentes. }\end{array}$ \\
\hline & NO & $\begin{array}{l}\text { La implantación del } \\
\text { modelo EFQM podría } \\
\text { justificar las diferencias } \\
\text { en resultados porque se } \\
\text { descartan } \\
\text { factores. }\end{array}$ & \begin{tabular}{|l||} 
La implantación del \\
modelo EFQM no \\
logra ningún \\
impacto medible en \\
términos \\
cuantitativos en la \\
organización \\
\end{tabular} & \begin{tabular}{||lr|} 
La & implantación \\
del modelo & EFQM \\
podría justificar las \\
diferencias $r$ \\
resultados porque \\
se descartan otros \\
factores. \\
\end{tabular} & $\begin{array}{l}\text { La implantación del } \\
\text { modelo EFQM no } \\
\text { logra ningún impacto } \\
\text { medible en términos } \\
\text { cuantitativos en la } \\
\text { organización }\end{array}$ \\
\hline \multirow{2}{*}{$\begin{array}{c}\text { ¿Existen } \\
\text { diferencias } \\
\text { significativas } \\
\text { entre } \\
\text { determinant } \\
\text { es de la } \\
\text { salud? }\end{array}$} & SI & $\begin{array}{l}\text { Las diferencias en } \\
\text { determinantes de la } \\
\text { salud podría justificar las } \\
\text { diferencias } \\
\text { resultados clave }\end{array}$ & \begin{tabular}{|l||} 
La implantación del \\
modelorrafaM \\
podría ser la causa \\
querrarmita \\
alcanzar resultados \\
similares a pesar de \\
la diferencia en \\
determinantes \\
\end{tabular} & $\mid \begin{array}{|rr|}\text { Las diferencias en } \\
\text { determinantes de la } \\
\text { salud } & \text { podría } \\
\text { justificar } & \text { las } \\
\text { diferencias } & \text { en } \\
\text { satisfacción } & \\
& \end{array}$ & $\begin{array}{l}\text { La implantación del } \\
\text { modelo EFQM podría } \\
\text { ser la causa que } \\
\text { permita alcanzar } \\
\text { resultados similares a } \\
\text { pesar de la diferencia } \\
\text { en agentes. }\end{array}$ \\
\hline & NO & $\begin{array}{l}\text { La implantación del } \\
\text { modelo EFQM podría } \\
\text { justificar las diferencias } \\
\text { en resultados porque se } \\
\text { descartan } \\
\text { factores. otros }\end{array}$ & \begin{tabular}{|l||} 
La implantación del \\
modelo \\
logra ra no no \\
limpacto medible en \\
términos \\
cuantitativos en la \\
organización
\end{tabular} & \begin{tabular}{||lr|} 
La implantación \\
del modelo \\
podría justificar las \\
diferencias $r$ en \\
resultados porque \\
se descartan otros \\
factores.
\end{tabular} & $\begin{array}{l}\text { La implantación del } \\
\text { modelo EFQM no } \\
\text { logra ningún impacto } \\
\text { medible en términos } \\
\text { cuantitativos en la } \\
\text { organización }\end{array}$ \\
\hline \multicolumn{6}{|c|}{$\begin{array}{l}\text { Cuadros verdes respaldan el impacto de la implantación del modelo EFQM en los resultados clave y la } \\
\text { satisfacción } \\
\text { Cuadros amarillos es necesario realizar más pruebas para poder descartar la relación entre agentes y } \\
\text { resultados } \\
\text { Cuadros blancos descartan el impacto de la implantación del modelo EFQM }\end{array}$} \\
\hline
\end{tabular}

Elaboración propia

Todo ello haciendo una triangulación cruzada entre los diferentes métodos de recolección (Eisenhardt y Graebner, 2007).

El proceso de análisis puede clasificarse para su explicación didáctica en dos etapas básicas, el análisis efectuado para cada caso y el análisis cruzado entre los casos. 


\subsubsection{Cada caso}

Como se ha descrito anteriormente, se realizó la recogida de la información mediante los diferentes métodos reflejándola en transcripciones, resúmenes y datos recogidos en el diario del investigador.

Se elaboró un documento que organizó, concentró y presentó los datos obtenidos de cada caso. Se realizó la primera codificación. Siguiendo el ciclo iterativo adoptado para este trabajo, se redactó una primera aproximación de cada caso utilizando como fuente la información previa recogida a través de la documentación, las entrevistas y el diario del investigador. La primera redacción de los casos se envió a los responsables de cada centro para confirmar los datos encontrados y recibir nuevo feedback de los mismos.

Con los comentarios del feedback de las organizaciones, se realizó otro proceso de reflexión con el fin de realizar un análisis más detallado y una segunda codificación de la información que permitió triangular o comparar nuevamente todas las fuentes de datos.

Finalmente se realizó la redacción final del caso en base a todo el proceso iterativo anterior, buscando cumplir con el objetivo de la investigación y el diseño metodológico

Para buscar indicios sobre la sostenibilidad de las organizaciones, se orientó la búsqueda mediante las teorías de la sostenibilidad citadas en el capítulo 2.2.

- Tres cuentas de resultados (Elkington, 1994). Se buscaron indicios de cada una de las tres cuentas (Medioambiente, social, económica)

- Teoría de los grupos de Interés (Portales, 2009). Se buscaron indicios que permitiesen identificar estrategias y políticas que garantizasen el desarrollo de los procesos de forma sostenible y que no impactasen contra los derechos sociales y ambientales de los grupos de interés implicados logrando un equilibrio entre los intereses de todos Identificación, clasificación y priorización de los grupos de interés, identificación de necesidades de grupos de interés, equilibrio entre los intereses y compromiso con los grupos de interés)

- Teoría de la rueda de cambio (Doppelt, 2003). Se utilizó como referencia el conjunto de los siete principios que debe cumplir toda organización que quiera triunfar a la hora de incorporar la sostenibilidad en su estrategia (tabla 29). Tomando esto como referencia y con la información recogida se trató de identificar en qué parte del camino se encuentra cada una de las organizaciones, 


\begin{tabular}{|c|c|}
\hline Organización no sostenible & Cambios hacia la sostenibilidad \\
\hline $\begin{array}{c}\text { Organización patriarcal que lleva a } \\
\text { un falso sentimiento de seguridad }\end{array}$ & $\begin{array}{c}\text { Cambiar la mentalidad hacia la } \\
\text { sostenibilidad }\end{array}$ \\
\hline $\begin{array}{c}\text { Los temas medioambientales y } \\
\text { socioeconómicos se aíslan, no hay } \\
\text { relación entre ellos. }\end{array}$ & $\begin{array}{c}\text { Reordenar las partes del sistema } \\
\text { mediante grupos de transición }\end{array}$ \\
\hline $\begin{array}{c}\text { No hay una visión clara de la } \\
\text { sostenibilidad }\end{array}$ & $\begin{array}{c}\text { Alterar las metas del sistema creando } \\
\text { una visión hacia la sostenibilidad }\end{array}$ \\
\hline $\begin{array}{c}\text { Confusión sobre causa efecto } \\
\text { Reestructurar las reglas de compromiso } \\
\text { del sistema }\end{array}$ \\
\hline $\begin{array}{c}\text { Falta de información } \\
\text { Mecanismos de aprendizaje } \\
\text { insuficiente }\end{array}$ & $\begin{array}{c}\text { Comunicación continua de la necesidad, } \\
\text { la visión y las estrategias para alcanzar la } \\
\text { sostenibilidad }\end{array}$ \\
\hline $\begin{array}{c}\text { Fallo de la institucionalización de } \\
\text { la sostenibilidad }\end{array}$ & $\begin{array}{c}\text { Alinear sistema, estructuras, políticas y } \\
\text { procedimientos con sostenibilidad. }\end{array}$ \\
\hline
\end{tabular}

Para Doppelt (2012), la sostenibilidad da lugar a un conjunto compartido de creencias y de imágenes mentales comunes, y debería "mostrar una imagen positiva del futuro".

La cultura es absolutamente fundamental para que las organizaciones de servicios orienten sus actividades hacia la sostenibilidad. Es uno de los factores clave para el éxito de un proceso de cambio hacia la sostenibilidad (Arenas, 2010).

Puesto que la adopción del modelo EFQM implica centrar la atención en una serie de dimensiones críticas, se buscaron evidencias que mostrasen aquellos aspectos que según Powell (1995) citado por Zardoya (2007) caracterizan a las organizaciones cuya filosofía de trabajo da lugar a un proceso de mejora continua buscando la eficacia y la eficiencia y respondiendo a las necesidades de todos sus grupos de interés.

La adopción del modelo EFQM puede generar ventajas competitivas sostenibles para aquellas organizaciones que logran implantarlo con éxito (Zardoya 2007).

Para EFQM los conceptos fundamentales son atributos de una cultura orientada a la excelencia que forman parte del conjunto de normas y valores específicos (tabla 30) que comparten las personas de cada organización. 
Tabla 30. Cultura de la organización: Valores que aporta EFQM

\begin{tabular}{|c|c|}
\hline Valores & Definición \\
\hline $\begin{array}{l}\text { Añadir valor para } \\
\text { los clientes }\end{array}$ & $\begin{array}{l}\text { Las organizaciones excelentes añaden constantemente valor para los } \\
\text { clientes comprendiendo, anticipando y satisfaciendo necesidades, } \\
\text { expectativas y oportunidades. }\end{array}$ \\
\hline $\begin{array}{l}\text { Crear un futuro } \\
\text { sostenible }\end{array}$ & $\begin{array}{l}\text { Las organizaciones excelentes producen un impacto positivo en el } \\
\text { mundo que les rodea porque incrementan su propio rendimiento al } \\
\text { tiempo que mejoran las condiciones económicas, ambientales y } \\
\text { sociales de las comunidades con las que tienen contacto. }\end{array}$ \\
\hline $\begin{array}{l}\text { Desarrollar la } \\
\text { capacidad de la } \\
\text { organización }\end{array}$ & $\begin{array}{l}\text { Las organizaciones excelentes incrementan sus capacidades } \\
\text { gestionando el cambio de manera eficaz dentro y fuera de ellas. }\end{array}$ \\
\hline $\begin{array}{l}\text { Aprovechar la } \\
\text { creatividad y la } \\
\text { innovación }\end{array}$ & $\begin{array}{l}\text { Las organizaciones excelentes generan mayor valor y mejores } \\
\text { resultados a través de la mejora continua y la innovación sistemática, } \\
\text { aprovechando la creatividad de sus grupos de interés. }\end{array}$ \\
\hline $\begin{array}{l}\text { Liderar con } \\
\text { visión, } \\
\text { inspiración e } \\
\text { integridad }\end{array}$ & $\begin{array}{l}\text { Las organizaciones excelentes tienen líderes que dan forma al futuro y } \\
\text { lo hacen realidad, actuando como modelo de referencia de sus valores } \\
\text { y principios éticos. }\end{array}$ \\
\hline $\begin{array}{l}\text { Gestionar con } \\
\text { agilidad }\end{array}$ & $\begin{array}{l}\text { Las organizaciones excelentes se reconocen de manera generalizada } \\
\text { por su habilidad para identificar y responder de forma eficaz y eficiente } \\
\text { a oportunidades y amenazas }\end{array}$ \\
\hline $\begin{array}{l}\text { Alcanzar el éxito } \\
\text { mediante el } \\
\text { talento de las } \\
\text { personas }\end{array}$ & $\begin{array}{l}\text { Las organizaciones excelentes valoran a las personas que las integran } \\
\text { y crean una cultura de delegación y asunción de responsabilidades que } \\
\text { permite alcanzar tanto los objetivos personales como los de la } \\
\text { organización. }\end{array}$ \\
\hline $\begin{array}{l}\text { Mantener en el } \\
\text { tiempo } \\
\text { resultados } \\
\text { sobresalientes }\end{array}$ & $\begin{array}{l}\text { Las organizaciones excelentes alcanzan resultados sobresalientes que } \\
\text { se mantienen en el tiempo y satisfacen las necesidades a corto y largo } \\
\text { plazo de todos sus grupos de interés, en el contexto de su entorno } \\
\text { operativo }\end{array}$ \\
\hline
\end{tabular}

Sin embargo, durante el proceso de análisis la codificación se fue modificando con el análisis de los datos obtenidos y se realizó también codificación libre, que permitió la posibilidad de estudiar nuevos temas como, por ejemplo, si las organizaciones habían implementado alguna de las acciones propuestas por la Federación de Asociaciones para la Defensa de la Sanidad Pública (2011) para la sostenibilidad del sistema sanitario público o el nivel alcanzado por las organizaciones en su camino hacia la sostenibilidad medioambiental (Sloan, Klingenberg y Rider 2013)

Todo ello buscando la mejor comprensión del fenómeno estudiado y cumplir con los objetivos de la investigación.

La codificación se realizó, a partir de los textos trascritos de las entrevistas en profundidad, con la ayuda del programa Atlas Ti. Sin embargo, como ya se indicó, esto nunca limitó la apertura al surgimiento de más temas o códigos. Posteriormente, se realizó una segunda codificación con el fin de facilitar análisis posteriores y para simplificar el momento de elaborar las bases de datos electrónicas de los temas y códigos.

Una vez que se realizó el análisis de los datos a través de esquemas tipo red, que permitió dar claridad a las interrelaciones de cada tema, categoría y subcategoría, ayudando a la triangulación de los datos y a las redacciones preliminares de cada caso, se determinó la lista de temas o códigos finales que constituyó la base para construir los esquemas conceptuales de esta investigación. 
Cada vez que se completaba la codificación de cada caso de estudio se presentaba la misma a las personas de contacto de cada centro. El objetivo de este feedback era presentar los resultados preliminares para verificar los hallazgos desde el punto de vista de los profesionales y gestores de los centros.

Para la presentación de los resultados se siguió el esquema EFQM de criterios agentes (Liderazgo, estrategia, personas, Alianzas y recursos, procesos, productos y servicios) en el que se describe qué han hecho las organizaciones en el camino de la sostenibilidad. También se expone su relación con las diferentes teorías de la sostenibilidad.

\subsubsection{Entre casos}

Siguiendo el diseño de la investigación establecido se procedió a la comparación entre los casos cruzando contextos con el fin de encontrar coincidencias en los conceptos determinados individualmente o diferencias que se puedan explicar lógicamente (Yin, 2009)

El cruce entre los casos se realizó fundamentalmente a través de matrices y tablas comparativas, lo cual permitió establecer ciertos patrones que permitieron comprender el fenómeno y presentarlo de una manera que integraba lo encontrado en los dos casos (Eisenhardt y Graebner, 2007).

Como resultado del análisis del cruce entre los casos se obtuvo un esquema, en forma de fotografía fija, que describe y explica el fenómeno de la sostenibilidad en los centros sanitarios, resultado del análisis de contexto, es decir, las interrelaciones de los elementos básicos o drivers (factores económicos, sociales), potenciadores (sistema de gestión), de resultados (indicadores de resultados), inhibidores (políticas), y actividades de mejora (el espacio de sostenibilidad).

Como ya se planteaba desde el inicio de la investigación se investigaron dos formas de abordar la sostenibilidad que se generaron durante los años de la crisis a partir del sistema de gestión implantado en cada una de las organizaciones al inicio del periodo 2008-2015.

Los productos de la investigación, resultado del análisis del cruce de casos, fueron nuevamente comparados con la literatura (teorías, modelos y marcos de referencias) existente al respecto, tanto desde la perspectiva de la implantación de EFQM en el sector sanitario público, como la de los modelos de sostenibilidad. Se trató de proporcionar credibilidad a la investigación con el fin de establecer un marco teórico y práctico que realmente aportará al campo de la sostenibilidad en el ámbito sanitario público.

Los resultados encontrados se presentaron y discutieron con la directora de tesis y otros investigadores del tema con el objeto incrementar la validez de los mismos (triangulación de investigadores) (Huberman y Miles, 1994). 


\subsection{Validez y fiabilidad de la investigación}

Para determinar la calidad de una investigación se valora su rigor científico, adecuación metodológica, fiabilidad, validez, credibilidad, etc.

La fiabilidad es el grado en que los hallazgos del estudio son independientes de circunstancias accidentales, mientras que la validez significa el grado en que los hallazgos son interpretados en forma correcta (Ritchie 2013). Si la investigación no es válida, no es verdadera. El mal trabajo de investigación no tiene credibilidad (Sandín, 2000).

Si el estudio realizado no puede ofrecer resultados válidos, las decisiones organizativas, políticas, sanitarias, estratégicas que pudiesen derivarse del mismo no pueden basarse en ellos y por tanto lo aportado por esta tesis no sería relevante ni cumpliría el fin último de toda investigación.

En la investigación cualitativa los datos dependen en gran medida de las habilidades metodológicas, de la sensibilidad e integridad del investigador, y de que las técnicas de recolección y análisis de los datos sean de alta calidad y se realicen de forma rigurosa. Al respecto Patton (2002) indica "la observación sistemática implica más allá de estar presentes y mirar alrededor. Las habilidades para entrevistar, implica mucho más allá de solamente hacer preguntas. El análisis de los contenidos requiere considerablemente mucho más allá que solamente leer lo que está pasando ahí. Generar un hallazgo cualitativo útil y creíble a través de la observación, las entrevistas y el análisis de contenidos requieren disciplina, conocimiento, entrenamiento, práctica, creatividad y un trabajo arduo".

Al respecto de los requisitos citados por Patton es destacable el conocimiento y la experiencia sobre el modelo EFQM y la gestión sanitaria en general que da la experiencia del investigador en puestos relacionados con esta temática desde 2001 y el conocimiento de las organizaciones estudiadas, una por ser el lugar donde desarrolla su actividad profesional en la actualidad y la otra por ser la organización en la que inició su formación universitaria.

Algunos de los procedimientos más utilizados para verificar los criterios de validez de los trabajos de investigación según Creswell (1998), citado por Sandín (2000), se han empleado en este trabajo.

\subsubsection{Trabajo prolongado y observación persistente}

La fiabilidad de este estudio se basa en la documentación de los datos y los procedimientos que utilizó el investigador durante todo el proceso de estudio (Yin, 2009). Por otro lado, el mismo diseño de la investigación y la utilización de diferentes métodos y diversas fuentes de evidencia, produjo un proceso de comparación constante en el análisis de los datos obtenidos de forma rigurosa. El proceso de investigación realizado mediante herramientas informáticas (Atlas Ti, Zotero, bases de datos) se mantuvo durante todo el estudio y junto a una actitud crítica e integra del investigador proporciona indicios razonables de fiabilidad. 


\subsubsection{Triangulación}

La triangulación es una de las formas más sólidas para dar validez y fiabilidad a cualquier estudio (Patton, 2002). De hecho, representó la base para potenciar la validez interna de la investigación, además del diseño. Para la interpretación de la información obtenida mediante las entrevistas se usaron como referencia todos los conocimientos adquiridos en la fase previa de documentación y en la continua colaboración y conocimientos aportados en sucesivas consultas por los entrevistados. Se trató de reconocer todo aquello que aportaba sentido. La posible subjetividad inherente al estudio se intentó limitar con el estudio cuantitativo desarrollado en paralelo (Escobar, 2016) haciendo una triangulación cruzada entre los métodos de recolección de la información (Eisenhardt y Graebner, 2007).

De esta manera, en la presente investigación se trató de reducir al máximo las desviaciones que se pudieran presentar al momento de recolectar los datos, especialmente este estudio se centró en cuidar la validez del constructo a través de la triangulación de los datos que se explicaron ampliamente en los subíndices anteriores. Haciendo en todo momento, una iteración de los múltiples métodos de recolección de datos, especialmente reforzando las posibles desviaciones que se pudieron obtener en las entrevistas individuales. Para ello, se realizó una comparación constante con la observación directa de los entrevistados durante sus jornadas laborales cotidianas 0 haciendo una observación participativa no intrusiva en las reuniones de trabajo de los entrevistados, todo ello, en la medida que fue posible hacerlo.

La triangulación puede ser de cuatro tipos (Patton, 2002):

a) Triangulación de datos. Utilización de diferentes fuentes para obtener los datos: observación participativa no intrusiva, análisis documental, entrevistas, diario del investigador

b) Triangulación del investigador. Participación de diferentes investigadores 0 evaluadores: directora de tesis, responsables de calidad, gestores.

c) Triangulación de la teoría. Uso de múltiples perspectivas para interpretar un mismo conjunto de datos.

d) Triangulación metodológica. Uso de múltiples métodos de estudio de un mismo problema. En este caso, metodología cualitativa complementada con estudio cuantitativo.

Por otro lado, la triangulación desde el principio de complementariedad (Murcia y Jaramillo 2001) debe tener en cuenta que:

1. Los diferentes sujetos informantes que tengan relación con el fenómeno en la observación de este (validación interna). Para ello se seleccionó a personas referentes y representativas de diferentes ámbitos de cada organización

2. Las observaciones del fenómeno desde diferentes ángulos geográficas e históricas. Para ello se planteó la comparación entre dos comunidades autónomas diferentes con una serie de características comunes pero otras diferenciadas y un periodo de tiempo que permitiese evidenciar el efecto sobre la sostenibilidad de la implantación del modelo EFQM 
3. Los diferentes contextos internos y externos que intervienen en el fenómeno a estudiar. Se ha realizado un estudio del contexto social sanitario y estratégico.

4. Comprender la realidad desde la confrontación entre los sujetos protagonistas, la interpretación del investigador y las teorías formales desarrolladas sobre el fenómeno mediante ciclo iterativo deductivo e inductivo.

\subsubsection{Revisión Jueces}

Se realizó una triangulación de investigadores, que aunque no incluyó un grupo numeroso de expertos, se apoyó en el papel evaluador y crítico del director de tesis, así como, en el apoyo y el feedback obtenido en las presentaciones a expertos del Hospital de Cruces, la Universidad de La Rioja, la presentación del proyecto de tesis en el seminario de doctorado, la Unidad de Apoyo a la Investigación del SERIS y a la validación de la información y los datos por los responsables de los centros estudiados.

\subsubsection{Confirmación con los participantes}

Se realizó con los coordinadores de calidad y gestores de los centros, así como, la validación de las primeras redacciones de los casos por parte de los mismos participantes. Por lo tanto, la validez de constructo fue reforzada a través de dichos informantes claves en la revisión de los primeros documentos elaborados sobre las organizaciones estudiadas (Suarez 2007) y en las sucesivas revisiones.

\subsubsection{Clarificación de los sesgos del investigador}

La validez de los hallazgos en un estudio cualitativo puede ser mayor si el investigador mantiene durante el análisis una actitud crítica (Silverman, 2000) en la búsqueda del núcleo del conocimiento. En este sentido, para realizar esta investigación se ha trabajado con una actitud crítica durante todo el proceso, en ello la directora de la tesis ha jugado un papel central para motivar y mantener esta actitud, además de que el propio tema de la sostenibilidad del sector sanitario público, por su importante carácter social, lo requería.

No obstante, existen factores que influyen en la percepción del investigador y que han sido expuestos en el apartado 1.4 de esta tesis. Al respecto estos factores pueden haber supuesto un riesgo en el mantenimiento de la objetividad, pero también han facilitado el conocimiento en profundidad del tema y los casos estudiados.

Por otro lado, Calderón (2002) también propone como criterio la relevancia las repercusiones que el trabajo de investigación tiene para un mejor conocimiento del fenómeno y de la práctica a quienes la investigación va dirigida. Para ello se ha expuesto en el apartado 3.3 de este trabajo la finalidad de la investigación, y se ha realizado la descripción de la situación de partida a través de la descripción histórica de los centros estudiados.

Esta investigación también pretende ser relevante para las organizaciones estudiadas porque puede suponer un reconocimiento a su trayectoria o una guía para iniciar una nueva andadura, en todo caso pretende completar el ciclo de mejora continua o PDCA 
analizando la situación y valorado en qué medida el modelo después de haber sido implantado y trabajado durante este periodo de tiempo ha contribuido a la sostenibilidad de las organizaciones estudiadas. Todo ello enmarcado en un ámbito socialmente relevante como es la Sanidad Pública. 


\section{ESTUDIOS DE CASO}

\subsection{El caso retrospectivo del Servicio Riojano de Salud (SERIS)}

\subsubsection{Descripción del contexto}

\subsubsection{Situación sociodemográfica}

La Rioja es una Comunidad Autónoma pequeña $(5.045 \mathrm{~km} 2)$ con una cabecera urbana principal (Logroño). Existe un eje de comunicaciones principal paralelo al río Ebro que organiza la región. Otros ejes secundarios dan acceso a las montañas, pero no existe un eje que comunique las comarcas montañosas entre sí.

En La Rioja la estructura urbana está muy jerarquizada y, en cierto sentido, equilibrada. Su área de influencia tiene un alcance extra regional, adentrándose en Álava y Navarra. La población rural riojana presenta una tendencia muy fuerte al núcleo concentrado. La Rioja se caracteriza por contar con un número elevado de pequeños municipios. El $76,13 \%$ de los habitantes se concentra en nueve municipios; y casi la mitad de la población riojana reside en su capital, Logroño $(47,5 \%)$.

La Rioja tiene una baja densidad de población con una cifra de 64 habitantes $/ \mathrm{Km}^{2}$, por debajo de la de España de 93,4 habitantes/ $/ \mathrm{Km}^{2}$. La densidad de población en la capital, Logroño, es de 1.928,3 habitantes/ $\mathrm{Km}^{2}$.

La población en La Rioja experimentó un crecimiento progresivo en los primeros años de este siglo, pasando de 267.911 habitantes en 2000 al máximo alcanzado en 2012 con 320.951 habitantes. A uno de enero de 2016 la población de La Rioja era de 312.815 habitantes continuando con el descenso demográfico ocurrido desde 2012 (tabla 31).

Tabla 31. Población de La Rioja

\begin{tabular}{|c|c|c|c|c|}
\hline & 1 enero 2013 & 1 enero 2014 & 1 enero 2015 & 1 enero 2016 \\
\hline Población & 318.639 & 315.223 & 313.569 & 312.815 \\
\hline
\end{tabular}

En cuanto a los datos demográficos de La Rioja (tabla 32), la proyección de población a corto plazo para el periodo 2013-2023 (INE) indican un retroceso progresivo de la población de La Rioja, ya que en el periodo 2013-2023 la población residente disminuiría en 26.403 personas (un -8,28\%), el porcentaje de variación anual se retraerá entorno a un $0,83 \%$ cada año.

En el periodo 2008-2015 las variaciones de población en La Rioja se debieron principalmente a:

- Un aumento de la población infantil, debido a la mayor natalidad entre el colectivo inmigrante.

- Un importante descenso en la población entre 15 y 34 años como consecuencia del descenso de la inmigración.

- Un incremento de la población adulta, especialmente en el grupo de 85 y más años.

Como consecuencia de todo esto La Rioja presenta una población más envejecida que la de la media nacional. El $19,07 \%$ de la población riojana tiene 65 años o más $(21,34 \%$ 
de mujeres y 16,79\% de hombres). El INE estima que en 2023 los riojanos mayores de 64 años serán casi el $24 \%$ de población. El incremento será mayor para los hombres (6 puntos porcentuales) y será menor en las mujeres, reduciéndose el desequilibrio en dos puntos por encima a favor de las mujeres.

La Tasa de Dependencia (relación entre la población menor de 16 años o mayor de 64 y la población de 16 a 64 años) pasará del 53,5\% en 2013 al 64,4\% una década después. La previsión para la población entre 16 y 44 años disminuirá en La Rioja alrededor de 4 puntos porcentuales, supuesto que no le impedirá continuar siendo el intervalo de edad más numeroso $(60,82 \%)$.

Tabla 32 Indicadores demográficos de La Rioja

\begin{tabular}{|l|c|c|}
\hline \multicolumn{1}{|c|}{ La Rioja } & $\mathbf{2 0 0 8}$ & $\mathbf{2 0 1 5}$ \\
\hline Esperanza de Vida Hombres & 79.04 & 80.65 \\
\hline Esperanza de Vida Mujeres & 84.95 & 86.19 \\
\hline Saldo vegetativo por mil habitantes & 2.06 & -1.15 \\
\hline Edad Media de la Población & 41.65 & 43.48 \\
\hline \% de población extranjera & $13.87 \%$ & $10.61 \%$ \\
\hline \% personas mayores de 64 años & $17.89 \%$ & $20.30 \%$ \\
\hline Tasa de dependencia & 55.93 & 48.64 \\
\hline
\end{tabular}

Por otra parte la tasa de paro, después de haber repuntado durante la crisis, parece que ha cambiado de tendencia y mejora sus resultados (tabla 33). No obstante, la tasa de paro en La Rioja siempre ha estado entre las más bajas del conjunto del País.

Tabla 33. Histórico de la Tasa de Paro en La Rioja

\begin{tabular}{|c|c|c|c|c|c|c|c|c|}
\hline & 2008 & 2009 & 2010 & $\mathbf{2 0 1 1}$ & $\mathbf{2 0 1 2}$ & $\mathbf{2 0 1 3}$ & $\mathbf{2 0 1 4}$ & $\mathbf{2 0 1 5}$ \\
\hline $\begin{array}{c}\text { Tasa } \\
\text { de } \\
\text { Paro }\end{array}$ & 9.8 & 13.76 & 15.58 & 18.61 & 18.82 & 20.24 & 17.17 & 13.97 \\
\hline
\end{tabular}

Fuente: 2016 - Informe del Mercado de Trabajo de la provincia de La Rioja. Datos 2015

La economía riojana evoluciona de forma similar a la española, con un crecimiento del 2,8\% en 2015, y en los resultados de 2016 se espera una mejora del PIB regional similar al del conjunto de España. El gran peso que representa la industria riojana, un 30,33\% del PIB, y la cada vez mayor diversificación de su sector exportador, ha contribuido a que el impulso económico tenga más vigor y que la tasa de paro de la Comunidad Autónoma sea una de las más bajas de España.

Los puntos fuertes de la economía riojana son la agricultura, por la calidad de sus productos, y el peso que supone el sector industrial respecto al PIB, especialmente la industria agroalimentaria y la industria del calzado.

La diversificación de la economía (tabla 34), la apuesta por la innovación y el comercio exterior presenta una evolución muy favorable según el Gobierno de La Rioja. 
Tabla 34. Distribución de la actividad por sectores y PIB per cápita (2015)

\begin{tabular}{|c|c|c|c|}
\hline & País Vasco & La Rioja & España \\
\hline Agricultura & 0,78 & 5,4 & 2,52 \\
\hline Industria & 27,03 & 30,33 & 16,99 \\
\hline Construcción & 6,29 & 5,59 & 5,42 \\
\hline Servicios & 65,9 & 58,68 & 75,07 \\
\hline PIB per cápita & 30.459 & 25.507 & 23.200 \\
\hline
\end{tabular}

Fuente: INE y 2016 - Informe del Mercado de Trabajo de la provincia de La Rioja y Bizkaia (Servicio Público de Empleo).

En cuanto al salario medio, con los últimos datos disponibles (2014) en el País Vasco se registró el salario medio anual más alto, con $27.786,57$ euros anuales por trabajador y en Extremadura el más bajo, con 19.180,57 euros. La Rioja se situó en una posición intermedia con 21.954,10 euros anuales por trabajador. Atendiendo al crecimiento respecto al año anterior, La Rioja presentó el mayor aumento con un 6,4\%. (Fuente: Encuesta Anual de Estructura Salarial año 2016).

Otro factor a tener en cuenta es que, incluso a pesar de tener un salario, hay personas en riesgo de pobreza y exclusión social (tabla 35).

Tabla 35. Riesgo de pobreza o exclusión social en La Rioja

\begin{tabular}{|l|c|c|c|c|c|c|c|c|}
\hline & $\mathbf{2 0 1 5}$ & $\mathbf{2 0 1 4}$ & $\mathbf{2 0 1 3}$ & $\mathbf{2 0 1 2}$ & $\mathbf{2 0 1 1}$ & $\mathbf{2 0 1 0}$ & $\mathbf{2 0 0 9}$ & $\mathbf{2 0 0 8}$ \\
\hline La Rioja & 22,1 & 20,1 & 22,2 & 22,6 & 26,1 & 27,3 & 19,5 & 19,6 \\
\hline España & 28.6 & 29.2 & 27.3 & 27.2 & 26.7 & 26.10 & 24.7 & 23.8 \\
\hline
\end{tabular}

Fuente: INE

También es interesante conocer los determinantes de la salud (tabla 36), factores externos al sistema sanitario, que influyen en la salud de los ciudadanos de los riojanos. Se toman como referencia 2009 y 2014 por ser años del periodo estudiado de los que se disponen todos los indicadores de la serie seleccionada.

Tabla 36. Indicadores de determinantes de salud en La Rioja

\begin{tabular}{|c|c|c|c|c|c|}
\hline \multirow{2}{*}{ Dominio } & \multirow{2}{*}{ Indicador } & \multicolumn{2}{|c|}{2009} & \multicolumn{2}{|c|}{2014} \\
\hline & & España & La Rioja & España & La Rioja \\
\hline Estilos de vida & $\begin{array}{l}\text { Prevalencia de consumo de tabaco en } \\
\text { población adulta. }\end{array}$ & 26,16 & 29,43 & 22.98 & 21,76 \\
\hline $\begin{array}{l}\text { Determinantes } \\
\text { biológicos }\end{array}$ & Prevalencia de obesidad (más de 18) & 16 & 14,66 & 16.91 & 14,37 \\
\hline $\begin{array}{l}\text { Determinantes } \\
\text { sociales }\end{array}$ & $\begin{array}{l}\text { \% población de } 25 \text { a } 64 \text { con nivel de } \\
\text { estudios inferior a secundaria }\end{array}$ & 48.50 & 43,00 & 43.40 & 38,90 \\
\hline Sociodemográfico & Índice de dependencia & 46.01 & 47,63 & 50.37 & 53,19 \\
\hline Accesibilidad & $\begin{array}{l}\text { (\% de personas mayores de } 65 \text { años } \\
\text { vacunadas frente a la gripe }\end{array}$ & 65.67 & 72,72 & 56.20 & 66,50 \\
\hline Accesibilidad & $\begin{array}{l}\text { \% de vacunación frente a la } \\
\text { poliomielitis ( } 1{ }^{a} \text { vacunación } 0-1 \text { años) }\end{array}$ & 95.88 & 98,11 & 96.60 & 98,70 \\
\hline Accesibilidad & $\begin{array}{l}\text { \% de vacunación triple } \\
\text { vírica(1ª̂nacunación } 1-2 \text { años) }\end{array}$ & 97.42 & 97,75 & 96.10 & 98,30 \\
\hline Accesibilidad & $\begin{array}{l}\% \text { de mujeres de } 50 \text { a } 69 \text { años con } \\
\text { mamografía periódica }\end{array}$ & 71.99 & 86,78 & 79.79 & 85,21 \\
\hline
\end{tabular}

Fuente: INCLASS 2016 
Los factores que pueden afectar a la salud de los riojanos no han sufrido una gran variación en este periodo de tiempo. Ha disminuido el tabaquismo y la obesidad y ha aumentado la cobertura en primovacunación y frente a la poliomielitis como aspectos positivos. Los aspectos negativos tienen que ver con la disminución de cobertura del plan de detección precoz del cáncer de mama y de la vacunación contra la gripe en el colectivo de personas mayores. Como aspectos sociales se aprecia una mejora en la formación de los riojanos y un aumento de la tasa de dependencia en línea con lo que se observa en otras comunidades.

\subsubsection{Determinantes de la salud}

Los determinantes de la salud (tabla 37) son aquellos factores que condicionan el nivel de salud de la población. Se trata de condicionantes sociales, políticos, demográficos, económicos, etc.

Tabla 37. Indicadores de determinante de la salud (La Rioja/España)

\begin{tabular}{|c|c|c|c|c|c|c|c|c|c|c|c|c|c|c|c|c|c|}
\hline \multirow[b]{2}{*}{ Dominio } & \multirow[b]{2}{*}{ Indicador } & \multicolumn{2}{|c|}{2008} & \multicolumn{2}{|c|}{2009} & \multicolumn{2}{|c|}{2010} & \multicolumn{2}{|c|}{2011} & \multicolumn{2}{|c|}{2012} & \multicolumn{2}{|c|}{2013} & \multicolumn{2}{|c|}{2014} & \multicolumn{2}{|c|}{ Periodo } \\
\hline & & LR & $\bar{E}$ & LR & $\bar{E}$ & LR & $\mathrm{E}$ & LR & 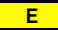 & LR & $\bar{E}$ & LR & $\mathrm{E}$ & LR & $\mathrm{E}$ & LR & $E$ \\
\hline Estilos de vida & $\begin{array}{l}\text { Prevalencia de consumo de tabaco } \\
\text { en población adulta. }\end{array}$ & & $\cdots$ & 29,43 & 26,16 & $\ldots$ & $\ldots$ & 24,43 & 23,95 & ... & ... & $\ldots$ & $\ldots$ & 21,76 & 22,98 & 6,32 & 5,07 \\
\hline $\begin{array}{l}\text { Detreminantes } \\
\text { biológicos }\end{array}$ & \begin{tabular}{|l|} 
Prevalencia de obesidad en \\
población de 18 y más años
\end{tabular} & $\ldots$ & $\ldots$ & 14,66 & 16,00 & $\ldots$ & $\ldots$ & 14,88 & 17,03 & $\ldots$ & $\ldots$ & $\ldots$ & $\ldots$ & 14,37 & 16,91 & $-7,67$ & $-3,18$ \\
\hline $\begin{array}{l}\text { Determinantes } \\
\text { sociales }\end{array}$ & $\begin{array}{l}\text { Proporción de población de } 25 \text { a } \\
64 \text { años con nivel de estudios de } \\
\text { 10 Etapa de educación secundaria } \\
\text { o inferior }\end{array}$ & 45,80 & 49,00 & 43,00 & 48,50 & 45,10 & 47,40 & 43,80 & 46,20 & 40,60 & 45,60 & 41,30 & 44,50 & 38,90 & 43,40 & $-0,29$ & 0,91 \\
\hline Sociodemográfico & İ́ndice de dependencia & 46,87 & 45,30 & 47,63 & 46,01 & 49,08 & 46,86 & 50,46 & 47,69 & 51,59 & 48,44 & 52,11 & 49,45 & 53,19 & 50,37 & $-8,8$ & $-6,4$ \\
\hline Accesibilidad & $\begin{array}{l}\text { Cobertura }(\%) \text { de personas } \\
\text { mayores de } 65 \text { años vacunadas } \\
\text { frente a la gripe }\end{array}$ & 72,00 & 65,41 & 72,72 & 65,67 & 69,68 & 56,87 & 69,20 & 57,70 & 67,20 & 57,00 & 66,40 & 56,40 & 66,50 & 56,20 & $-6,5$ & $-9,31$ \\
\hline Accesibilidad & $\begin{array}{l}\text { Cobertura }(\%) \text { de vacunación } \\
\text { frente a la poliomielitis } \\
\text { (primovacunación } 0-1 \text { años) }\end{array}$ & 98,10 & 96,71 & 98,11 & 95,88 & 98,48 & 96,56 & 98,10 & 97,10 & 98,30 & 96,30 & 98,10 & 95,60 & 98,70 & 96,60 & 0,9 & $-0,11$ \\
\hline Accesibilidad & $\begin{array}{l}\text { Cobertura (\%) de vacunación } \\
\text { frente a sarampión-rubéola- } \\
\text { parotiditis (primovacunación 1-2 } \\
\text { años) }\end{array}$ & 97,81 & 97,65 & 97,75 & 97,42 & 98,14 & 95,52 & 97,80 & 96,80 & 97,50 & 97,10 & 97,20 & 95,30 & 98,30 & 96,10 & 1,29 & $-1,45$ \\
\hline Accesibilidad & $\begin{array}{l}\text { Porcentaje de mujeres de } 50 \text { a } 69 \\
\text { años con mamografía realizada } \\
\text { con la frecuencia recomendada }\end{array}$ & $\ldots$ & & 86,78 & 71,99 & $\ldots$ & & 69,69 & 77,05 & $\ldots$ & & $\ldots$ & & 85,21 & 79,79 & $-1,57$ & 7,8 \\
\hline
\end{tabular}

Elaboración propia. Datos del http://inclasns.msssi.es

La Rioja, a pesar de tener aún un alta prevalencia de hábitos no saludables como el tabaco o la obesidad, se encuentra en una situación mejor que la media española. La accesibilidad al sistema sanitario también es mejor para los riojanos. No obstante, La Rioja presenta un mayor índice de dependencia que señala hacia al mayor envejecimiento de la población riojana respecto a la media española.

\subsubsection{Resultados en salud}

La causa más importante de mortalidad en los riojanos es la isquemia cardiaca mientras que en el caso de las riojanas es la enfermedad cerebrovascular.

Las 12 causas específicas de mortalidad más importantes suponen el $56,28 \%$ de las muertes en los hombres. Las causas de mortalidad más significativas por tumores en los hombres (tabla 38) son el cáncer de pulmón, cáncer colorrectal, cáncer de próstata, y cáncer de estómago. 
Las 12 causas específicas de mortalidad más importantes suponen el $57,46 \%$ de las muertes en las mujeres. Las causas de mortalidad más significativas por tumor (tabla 38) es en las mujeres son el cáncer colorrectal, cáncer de mama y cáncer de estómago.

Tabla 38. Tasas de mortalidad por 100000 hab. La Rioja (2014).

\begin{tabular}{|c|c|c|}
\hline & Hombres & Mujeres \\
\hline Total & 547,88 & 296,11 \\
\hline & \multicolumn{2}{|c|}{ Por Causa: } \\
\hline Cáncer & 188,99 & 88,03 \\
\hline Cardiopatía isquémica & 51,48 & 20,41 \\
\hline $\begin{array}{c}\text { Enfermedad } \\
\text { cerebrovascular }\end{array}$ & 33,76 & 18,45 \\
\hline EPOC & 26,52 & 6,28 \\
\hline Accidentes & 19,41 & 6,77 \\
\hline Alzheimer & 12,04 & 16,57 \\
\cline { 2 - 4 } & $\begin{array}{c}2 \\
\text { Mortalidad infantil por } 1000 \text { nacidos }\end{array}$ \\
\hline
\end{tabular}

Fuente: INCLASNS

La tasa de morbilidad (tabla 39 y 40) por 100 de hospitalización (altas por 100.000 habitantes) fue en 2015 de 11.187 en La Rioja mientras que en España fue de 10.228 y en el País Vasco de 11.385

Tabla 39. Distribución de altas de hospitalización y tipo de hospital (2015)

Fuente: INE

\begin{tabular}{|c|c|c|}
\hline & Público & Privado \\
\hline La Rioja & $87.1 \%$ & $12.9 \%$ \\
\hline
\end{tabular}

Tabla 40. Tasas de morbilidad por 10000 hab en La Rioja (2014)

\begin{tabular}{|l|c|c|}
\hline & Hombres & Mujeres \\
\hline VIH & 5,79 & 2,52 \\
\hline Diabetes & 8,92 & 2,73 \\
\hline Trastornos mentales & 4,17 & 13,67 \\
\hline Asma & 4,77 & 2,9 \\
\hline $\begin{array}{l}\text { Enfermedad } \\
\text { respiratoria crónica }\end{array}$ & 2,89 & 1,69 \\
\hline $\begin{array}{l}\text { Infarto agudo } \\
\text { miocardio }\end{array}$ & 12,71 & 3,95 \\
\hline $\begin{array}{l}\text { Enfermedades } \\
\text { cerebrovasculares }\end{array}$ & 19,75 & 10,68 \\
\hline $\begin{array}{l}\text { Enfermedad } \\
\text { hipertensiva }\end{array}$ & 5,97 & 3,81 \\
\hline $\begin{array}{l}\text { Insuficiencia } \\
\text { Cardiaca Congestiva }\end{array}$ & 15,33 & 11,42 \\
\hline Tuberculosis & & 10,19 \\
\hline Accidentes de trabajo & \multicolumn{2}{|c|}{} \\
\hline
\end{tabular}


Los indicadores clave (tabla 41) del Ministerio de Sanidad, Servicios Sociales e Igualdad que muestran el estado de la salud de los riojanos en aspectos clave en el periodo de estudio de este trabajo y la media española.

Tabla 41. Indicadores de salud (La Rioja/España)

\begin{tabular}{|c|c|c|c|c|c|c|c|c|c|c|c|c|c|c|c|c|c|}
\hline \multirow{2}{*}{ Dominios } & \multirow[b]{2}{*}{ Indicador } & \multicolumn{2}{|c|}{2008} & \multicolumn{2}{|c|}{2009} & \multicolumn{2}{|c|}{2010} & \multicolumn{2}{|c|}{2011} & \multicolumn{2}{|c|}{2012} & \multicolumn{2}{|c|}{2013} & \multicolumn{2}{|c|}{2014} & \multicolumn{2}{|c|}{ Periodo } \\
\hline & & LR & $E$ & LR & $E$ & LR & $E$ & LR & $E$ & LR & $E$ & LR & $E$ & LR & $E$ & LR & $E$ \\
\hline Bienestar & Esperanza de vida al nacer & 81,80 & 81,42 & 82,90 & 81,85 & 83,23 & 82,32 & 83,11 & 82,52 & $\ldots$ & 82,75 & 83,97 & 83,10 & 84,14 & 83,22 & 2,34 & 1,80 \\
\hline Bienestar & $\begin{array}{l}\text { Esperanza de vida en buena } \\
\text { salud al nacer }\end{array}$ & $\ldots$ & 63,15 & 63,50 & 61,96 & $\ldots$ & 62,15 & 64,19 & 66,51 & $\ldots$ & 66,60 & 67,40 & 66,83 & 67,51 & 66,88 & 4,01 & 4,92 \\
\hline Bienestar & $\begin{array}{l}\text { Años de vida saludable a los } \\
65 \text { años }\end{array}$ & $\cdots$ & 11,51 & 10,28 & 9,09 & & 9,16 & 12,20 & 12,19 & $\ldots$ & 12,28 & 12,58 & 12,36 & 12,60 & 12,39 & 2,32 & 3,30 \\
\hline Bienestar & \begin{tabular}{|l|} 
Porcentaje de población con \\
valoración positiva de su \\
estado de salud
\end{tabular} & $\ldots$ & $\ldots$ & 75,37 & 70,86 & $\ldots$ & $\ldots$ & 78,50 & 75,27 & $\ldots$ & $\ldots$ & & $\ldots$ & & & 3,13 & 4,41 \\
\hline Bienestar & $\begin{array}{l}\text { Porcentaje de población de } 65 \\
\text { años y más años con } \\
\text { valoración positiva de su } \\
\text { estado de salud }\end{array}$ & $\ldots$ & $\ldots$ & 46,40 & 44,15 & $\ldots$ & $\ldots$ & 53,45 & 44,15 & $\ldots$ & $\ldots$ & $\ldots$ & $\ldots$ & 48,49 & 43,58 & 2,09 & $-0,57$ \\
\hline Mortalidad & \begin{tabular}{|l|} 
Tasa de mortalidad prematura \\
por Cáncer, ajustada por \\
edad, por 100000 hab \\
\end{tabular} & 105,77 & 106,51 & 99,30 & 105,11 & 96,33 & 104,08 & 100,19 & 103,44 & $\ldots$ & 102,64 & 87,14 & 100,74 & 91,42 & 97,99 & $\mid-14,35$ & $-8,52$ \\
\hline Mortalidad & $\begin{array}{l}\text { Tasa de mortalidad prematura } \\
\text { por Cardiopatía isquémica, } \\
\text { ajustada por edad, por } 100 \\
000 \text { hab. }\end{array}$ & 16,89 & 22,20 & 17,70 & 20,78 & 16,63 & 20,00 & $\mid 18,04$ & 18,78 & $\ldots$ & 18,44 & 16,58 & 18,04 & 19,09 & 17,53 & 2,20 & $-4,67$ \\
\hline Mortalidad & $\begin{array}{l}\text { Tasa de mortalidad prematura } \\
\text { por Diabetes mellitus, ajustada } \\
\text { por edad, por } 100000 \text { hab. }\end{array}$ & 3,74 & 4,20 & 3,20 & 3,96 & 3,31 & 3,68 & 1,42 & 3,48 & $\ldots$ & 3,22 & 2,88 & 2,98 & 2,35 & 3,12 & $-1,39$ & $-1,08$ \\
\hline Mortalidad & \begin{tabular}{|l|} 
Tasa de mortalidad prematura \\
por Enfermedad vascular \\
cerebral, ajustada por edad, \\
por 100000 hab.
\end{tabular} & 12,90 & 12,10 & 10,40 & 10,25 & 6,37 & 10,07 & 10,26 & 9,48 & $\ldots$ & 9,25 & 6,56 & 8,70 & 6,32 & 8,57 & $-6,58$ & $-3,53$ \\
\hline Mortalidad & \begin{tabular}{|l|} 
Tasa de mortalidad prematura \\
enfermedades crónicas de \\
vías respiratorias inferiores \\
por 100000 hab.
\end{tabular} & 5,42 & 6,28 & 3,93 & 6,29 & 4,37 & 5,85 & 3,68 & 5,69 & $\ldots$ & 5,67 & 4,04 & 5,32 & 4,21 & 5,10 & $-1,21$ & $-1,18$ \\
\hline Mortalidad & $\begin{array}{l}\text { Tasa de mortalidad infantil por } \\
1000 \text { nacidos vivos }\end{array}$ & 5,40 & 3,30 & 5,40 & 3,30 & 1,78 & 3,19 & 4,73 & 3,19 & $\ldots$ & 3,09 & 3,10 & 2,73 & 2,12 & 2,88 & $-3,28$ & $-0,42$ \\
\hline Mortalidad & \begin{tabular}{|l|} 
Tasa de mortalidad perinatal \\
por cada 1000 nacidos vivos
\end{tabular} & 6,25 & 4,38 & 9,30 & 4,50 & 7,41 & 4,43 & 7,83 & 4,59 & $\ldots$ & 4,63 & 6,17 & 4,58 & 5,27 & 4,38 & $-0,98$ & 0,00 \\
\hline Morbilidad & $\begin{array}{l}\text { Incidencia de tuberculosis por } \\
100000 \text { hab. }\end{array}$ & 29,32 & 18,02 & 23,39 & 16,81 & 17,47 & 15,71 & 18,23 & 14,63 & 13,80 & 13,11 & 15,48 & 11,87 & 10,19 & 10,80 & $-19,13$ & $|-7,22|$ \\
\hline Morbilidad & $\begin{array}{l}\text { Prevalencia declarada de } \\
\text { diabetes mellitus en población } \\
\text { adulta. Ver definición }\end{array}$ & $\ldots$ & $\ldots$ & 6,30 & 5,90 & $\ldots$ & $\ldots$ & 6,16 & 6,96 & $\ldots$ & $\ldots$ & $\ldots$ & $\ldots$ & 5,78 & 6,82 & $-0,52$ & 0,92 \\
\hline Morbilidad & \begin{tabular}{|l|} 
Prevalencia declarada de \\
trastornos mentales en \\
población adulta. Ver \\
definición
\end{tabular} & $\ldots$ & $\ldots$ & 8,06 & 9,58 & $\ldots$ & $\ldots$ & 4,53 & 9,61 & $\ldots$ & $\ldots$ & $\ldots$ & $\ldots$ & 8,99 & 10,65 & 0,93 & 1,07 \\
\hline Morbilidad & $\begin{array}{l}\text { Tasa ajustada de } \\
\text { hospitalización por infarto } \\
\text { agudo de miocardio por } 10 \\
000 \text { hab. } \\
\end{array}$ & $\ldots$ & $\ldots$ & $\ldots$ & $\ldots$ & 7,60 & 8,72 & 8,01 & 8,44 & $\ldots$ & 8,57 & 9,59 & 8,51 & 8,25 & 8,21 & 0,65 & $-0,51$ \\
\hline Eficacia & $\begin{array}{l}\text { Tasa de mortalidad ajustada } \\
\text { por edad por cardiopatía } \\
\text { isquémica por } 100000 \text { hab. } \\
\end{array}$ & 39,55 & 47,31 & 37,91 & 45,17 & 33,93 & 43,34 & 33,86 & 41,26 & 36,98 & 40,24 & 34,56 & 38,13 & 34,88 & 36,44 & $-4,67$ & $-10,87$ \\
\hline Eficacia & $\begin{array}{l}\text { Tasa de mortalidad ajustada } \\
\text { por edad, por enfermedad } \\
\text { cerebrovascular por } 100000 \\
\text { hab. } \\
\end{array}$ & 38,18 & 38,24 & 34,78 & 36,01 & 34,31 & 33,42 & 32,61 & 30,88 & 30,95 & 30,66 & 24,78 & 28,17 & 24,81 & 27,19 & $-13,37$ & $-11,05$ \\
\hline Eficacia & Tasa de mortalidad perinatal & 6,25 & 4,38 & 9,30 & 4,50 & 7,41 & 4,43 & 7,83 & 4,59 & 6,86 & 4,63 & 6,17 & 4,58 & 5,27 & 4,56 & $-0,98$ & 0,18 \\
\hline Eficacia & Tasa de infección hospitalaria. & 1,08 & 1,25 & 0,93 & 1,27 & 0,90 & 1,29 & 0,93 & 1,26 & 1,11 & 1,29 & 1,26 & 1,32 & 1,00 & 1,24 & $-0,08$ & $-0,01$ \\
\hline Eficacia & $\begin{array}{l}\text { Tasa de fracturas de cadera } \\
\text { en pacientes ingresados. }\end{array}$ & 0,05 & 0,06 & 0,03 & 0,06 & 0,06 & 0,07 & 0,06 & 0,06 & 0,05 & 0,05 & 0,05 & 0,06 & 0,05 & 0,05 & 0,00 & $-0,01$ \\
\hline Eficacia & \begin{tabular}{|l|} 
Tasa de notificación de \\
reacciones adversas a \\
medicamentos (total)
\end{tabular} & 280,00 & $220,00 \mid$ & $330,00 \mid$ & 320,00 & 300,00 & 310,00 & 280,00 & 310,00 & $|350,00|$ & 330,00 & 313,64 & 381,58 & $|247,65|$ & 368,84 & $-32,35$ & 148,84 \\
\hline Eficacia & $\begin{array}{l}\text { Mortalidad intrahospitalaria } \\
\text { global por cada } 100 \text { altas } \\
\text { hospitalarias }\end{array}$ & 3,41 & 4,09 & 3,36 & 4,12 & 3,45 & 4,18 & 3,47 & 4,26 & 3,50 & 4,36 & 3,35 & 4,21 & 3,27 & 4,24 & $-0,14$ & 0,15 \\
\hline Eficacia & \begin{tabular}{|l|} 
Mortalidad intrahos pitalaria \\
tras intervención quirúrgica \\
por cada 100 altas quirúrgicas
\end{tabular} & 1,12 & 1,73 & 1,00 & 1,71 & 1,20 & 1,67 & 1,05 & 1,69 & 1,14 & 1,62 & 0,93 & 1,55 & 0,95 & 1,53 & $-0,17$ & $-0,20$ \\
\hline Eficacia & $\begin{array}{l}\text { Mortalidad intrahospitalaria de } \\
\text { pacientes con neumonía por } \\
\text { cada } 100 \text { altas por neumonía }\end{array}$ & 6,70 & 8,69 & 6,10 & 8,50 & 5,09 & 8,38 & 6,32 & 8,80 & 5,46 & 9,80 & 6,97 & 8,93 & 6,73 & 8,44 & 0,03 & $-0,25$ \\
\hline
\end{tabular}

Elaboración propia. Datos del http://inclasns.msssi.es 


\subsubsection{Política sanitaria}

La Ley 2/2002 de 17 de abril, de Salud de La Rioja, organiza funcionalmente la asistencia sanitaria en dos niveles asistenciales, atención primaria y atención especializada. Participando de ambos niveles de atención se presta la atención a las urgencias y emergencias sanitarias, y a la Salud Mental y drogodependencias.

Los puntos de referencia básicos en los que se desarrolla la actividad de urgencias son los Puntos de Atención Continuada en coordinación con los centros hospitalarios y los servicios de urgencias y emergencias, en su caso.

La Ley de Salud de La Rioja también hace referencia a la atención sociosanitaria que se desarrolla con el Decreto 24/2004, de 16 de abril, sobre centros sociosanitarios de convalecencia.

El Decreto 121/2007, de 5 de octubre, organiza el sistema público de salud de La Rioja en una demarcación territorial, denominada Área de Salud Única de La Rioja, que comprende la totalidad del ámbito territorial de la misma.

El III Plan de Salud de La Rioja 2015-2019 establece los fundamentos de la planificación de las políticas sanitarias de La Rioja a lo largo de los próximos años. Es el referente a la hora de establecer objetivos y el medidor y orientador de las políticas de salud. En la presentación del Plan, el Consejero de Salud afirmó que el paciente es el eje de este Plan y en el fondo de toda la política sanitaria de La Rioja.

EI III Plan de Salud se fundamenta en los siguientes principios orientadores: respeto, centralidad, participación, integración y coordinación; calidad; sostenibilidad; adaptabilidad e innovación; y coordinación entre políticas.

El seguimiento de la implantación del III Plan de Salud de La Rioja se realiza mediante 401 indicadores que valoran los logros alcanzados agrupados en cada una de las 14 líneas prioritarias de trabajo:

1. Hábitos, estilos de vida y protección de la salud. Influyen de manera importante en las tasas de morbilidad y mortalidad.

2. Cáncer. Alta prevalencia. La mitad de muertes por cáncer en Europa podrían evitarse siguiendo sencillas recomendaciones.

3. Cronicidad y calidad de vida. En La Rioja, uno de cada 3 habitantes.

4. Demencias. Es la enfermedad que provoca mayor dependencia.

5. Diabetes. Patología en alza por el incremento de la obesidad y la vida sedentaria.

6. Discapacidad. Fenómeno complejo que requiere gran coordinación.

7. Enfermedades cardiovasculares. Suponen la principal causa de muerte en La Rioja (30.3\%).

8. Enfermedades cerebrovasculares. Es la principal causa de discapacidad en adultos y la segunda causa de demencias.

9. Envejecimiento. El aumento de la esperanza de vida incrementa a su vez la prevalencia de enfermedades crónicas, que están vinculadas a mayor fragilidad, discapacidad y dependencia.

10. Salud mental.

11. Fortalecimiento del sistema de salud público de La Rioja. Tras una fase marcada por la mejora de las infraestructuras, en este Plan se señala que se sigue 
apostando por potenciar la calidad asistencial, la formación de los profesionales y desarrollar una red biotecnológica que contribuya el crecimiento económico regional.

12. Enfermedades emergentes y reemergentes. Aboga por prevenir a través de la inmunización y fortalecer el funcionamiento de la Red de Vigilancia Epidemiológica.

13. Enfermedades infecciosas. Se aspira a reducir la morbimortalidad y la mortalidad en casos muy concretos (sepsis grave, VIH-SIDA, VHC, infecciones microorganismos multirresistentes e infecciones en viajeros).

14. Enfermedades raras. Se pretende desarrollar un modelo de atención integral y fomentar la formación e investigación entre los profesionales sanitarios riojanos.

Asimismo, incluye la identificación de las necesidades de formación de los profesionales con el objetivo de adecuar su actuación profesional al estado del conocimiento y desarrollo científico-técnico de mayor evidencia; la definición de las líneas de investigación que redunden en una mejora de la situación; y las fuentes de financiación.

En el año 2007 se puso en marcha el nuevo Hospital San Pedro, como hospital de referencia de la Comunidad Autónoma de La Rioja. A lo largo del periodo 2007-2015, La Rioja dio un importante impulso a la estructura sanitaria de La Rioja con la construcción de nuevos centros e infraestructuras:

- Centro de Alta Resolución de Procesos Asistenciales (CARPA).Trabaja con procesos de alta resolución que suponen una atención más ágil y completa para el paciente.

- Nuevos accesos al Hospital San Pedro.

- Ampliación de la Fundación Hospital Calahorra.

- Nuevos centros de salud de La Guindalera, Arnedo, Nájera y Santo Domingo

- Remodelación del centro de salud de Calahorra

- Nuevo centro de salud mental de Albelda.

- Hospital de día para trastornos de conducta alimentaria.

Además de la construcción de infraestructuras sanitarias de La Rioja, la cartera de servicios del sistema público de La Rioja ha ido creciendo. La Consejería de Salud ha incorporado, en el periodo estudiado, nuevos servicios, tratamientos y técnicas, tanto en atención especializada como en atención primaria:

- Ampliación de área de cobertura y cartera de servicios del servicio de hospitalización a domicilio.

- Inicio de la cirugía laparoscópica en urología y en ginecología.

- Cirugía láser en otorrinolaringología y en oftalmología.

- Incorporación de la vacuna del papiloma humano para las niñas de entre 11 y 14 años, con el fin de prevenir el cáncer de cérvix.

- Nuevo servicio de pediatría en el centro de salud de Murillo.

- Incorporación de nuevas técnicas en digestivo, cardiología, neurología, ginecología, oncología, hematología, etc.

- Nueva sala de cuentos para niños hospitalizados en el Hospital San Pedro.

- Nueva consulta de cáncer hereditario.

- Banco de tumores (biobanco) de la comunidad autónoma destinado a la investigación biomédica. 
- El Hospital San Pedro se convierte en hospital universitario.

- Nuevos programas de salud para la mujer.

- Nuevas tecnologías: telemedicinas, historia electrónica, receta electrónica, cita multicanal y aplicaciones de todos los servicios centrales.

También se ha desarrollado nueva normativa:

- Decreto de garantía de tiempos máximos de espera y el sistema de información sanitaria en el sistema público de salud de La Rioja.

- Decreto por el que se determinan los requisitos y condiciones para que los ciudadanos puedan ejercer su derecho a solicitar una segunda opinión médica.

- III Plan de Salud de La Rioja

La última actualización del mapa sanitario de La Rioja (Orden 6/2013, de 28 de octubre, de la Consejería de Salud y Servicios Sociales) constituye la zona básica de salud como el marco territorial elemental para la prestación de la atención primaria de salud, de acceso directo de la población, con capacidad para proporcionar una asistencia continuada, integral, permanente y accesible. El área única de salud comprende 20 zonas básicas de salud.

En atención primaria (AP), hay en funcionamiento 20 centros de salud y 169 consultorios rurales. En Logroño la atención continuada en AP se realiza en el Centro de Alta Resolución de Procesos Asistenciales (CARPA).

En cuanto a los recursos hospitalarios, a 31 de diciembre de 2016, el sistema público de salud de La Rioja (SRS) dispone de 717 camas instaladas de un total de 1.034, lo que representa el 69,34 \% de las camas de hospitalización general junto con las de psiquiatría (tabla 42). La dotación de equipos de alta tecnología se concentra fundamentalmente en el Hospital San Pedro, que es el centro de referencia en La Rioja.

Tabla 42. Recursos sanitarios Atención Especializada en La Rioja a 31/12/2015.

\begin{tabular}{|l|c|c|c|}
\hline \multicolumn{1}{|c|}{ Recurso } & Camas & Tipo & Financiación \\
\hline Hospital San Pedro. & 522 & General & Público (SRS) \\
\hline Hospital General de La Rioja & 55 & General & Público (SRS) \\
\hline Centro Asistencial de Albelda de Iregua & 140 & Psiquiátrico & Público (SRS) \\
\hline Fundación Hospital Calahorra & 90 & General & Fundación Pública \\
\hline Clínica Los Manzanos & 50 & $\begin{array}{c}\text { Médico- } \\
\text { Quirúrgico }\end{array}$ & $\begin{array}{c}\text { Privado no benéfico/ } \\
\text { concierto }\end{array}$ \\
\hline $\begin{array}{l}\text { Centro de investigación Biomédica de } \\
\text { La Rioja (CIBIR) Fundación Rioja Salud }\end{array}$ & -- & $\begin{array}{c}\text { Investigación } \\
\text { ytratamiento } \\
\text { oncológico }\end{array}$ & Fundación Pública \\
\hline $\begin{array}{l}\text { Centro de Alta Resolución de Procesos } \\
\text { Asistenciales (CARPA) }\end{array}$ & - & $\begin{array}{c}\text { Centro de } \\
\text { diagnóstico }\end{array}$ & Público (SRS) \\
\hline Centros Media y Larga estancia & 177 & General & Privados/concierto \\
\hline
\end{tabular}

Fuente: Elaboración propia a partir de datos de III Plan de Salud de La Rioja

No obstante, y a pesar de las inversiones realizadas, según Bacigalupe (2015), en este periodo La Rioja destaca entre el resto de comunidades autónomas por haber aplicado una intensa política de austeridad y por haber aumentado su gasto sanitario en contratación con centros privados. 
Actualmente, las prestaciones y la cartera de servicios del sistema público de salud de La Rioja está constituida por la cartera de servicios comunes del sistema nacional de salud, cuyo contenido viene recogido en la Ley 16/2003, de 28 de mayo, de cohesión y calidad del Sistema Nacional de Salud, el real decreto 1030/2006, del 15 de septiembre, por el que se establece la cartera de servicios comunes del Sistema Nacional de Salud y el procedimiento para su actualización, desarrollado en lao SCO/33422/2007, de 21 de noviembre.

Las prestaciones se recogen en la cartera de servicios del Hospital San Pedro (ilustración 21), referencia en la Comunidad Autónoma de La Rioja (tabla 43).

Ilustración 21.Hospital San Pedro de La Rioja
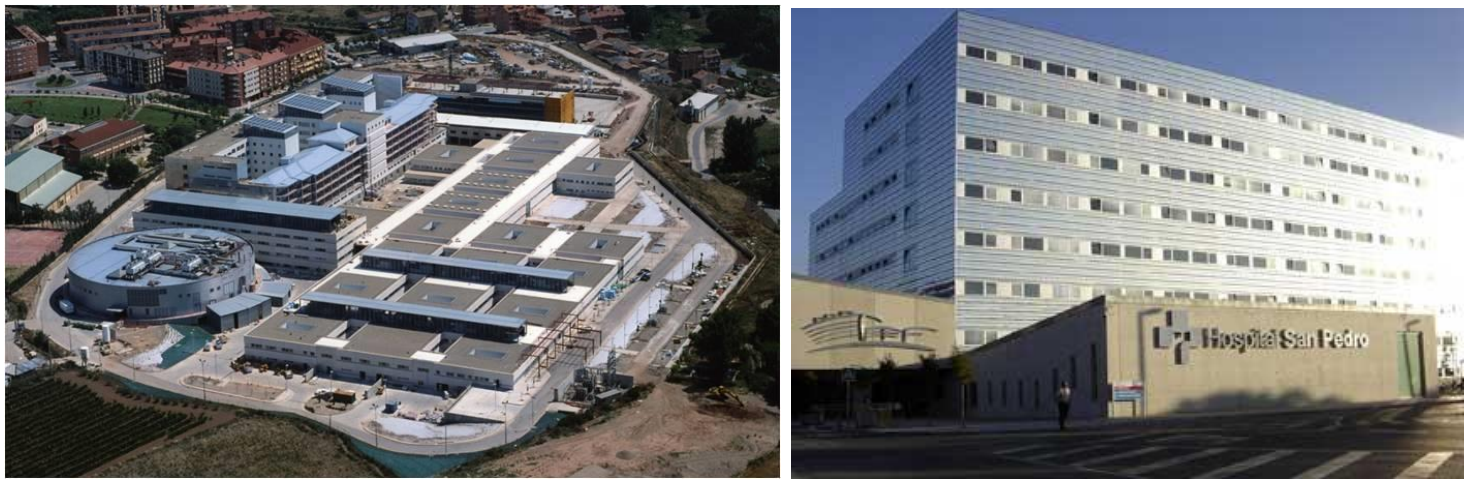

Fuente: Página web de Riojasalud

Tabla 43. Equipamiento y cartera de servicios Hospital San Pedro

\begin{tabular}{|l|l|}
\hline Infraestructura & 522 \\
\hline Camas Instaladas & 501 \\
\hline Camas Funcionantes & 22 \\
\hline № de quirófanos & 4 \\
\hline Paritorios & 24 \\
\hline Oncohematológico: puesto hospital día & 20 \\
\hline C M A & 1 \\
\hline Otros: puesto hospital de día & 187 \\
\hline Locales de consulta y gabinetes (CARPA, H.S. Pedro-La Rioja) & 11 \\
\hline № de centros de salud a los que se desplazan especialistas & \\
\hline Cartera de servicios & $\begin{array}{l}\text { Alergología, cardiología, cirugía vascular y angiología, cirugía general de aparato digestivo } \\
\text { y plástica, cirugía maxilo-facial, cirugía torácica, dermatología, digestivo, endocrinología, } \\
\text { ginecología, hematología/hemoterapia, hospitalización domicilio, enfermedades } \\
\text { infecciosas, medicina intensiva, medicina interna, nefrología, neonatología, neumología, } \\
\text { neurología, obstetricia, oftalmología, oncología, otorrinolaringología, pediatría, psiquiatría, } \\
\text { rehabilitación, reumatología, traumatología y ortopedia, unidad del dolor, urgencias, unidad } \\
\text { de corta estancia, servicios centrales y unidades de apoyo. formación pregrado (FP y } \\
\text { enfermería) y postgrado (especialistas sanitarios) }\end{array}$ \\
\hline
\end{tabular}

Fuente: Memoria del Servicio Riojano de Salud, 2015

En cuanto a los recursos empleados por el Servicio Riojano de Salud (tablas 44 y 45), el recurso humano, concretamente el ratio de personal por mil habitantes en La Rioja está por debajo de la media de España en personal sanitario (médicos, enfermeras y 
matronas) y MIR, y por encima en auxiliar de enfermería y personal no sanitario según los datos del Ministerio.

Tabla 44. Personal vinculado al sistema sanitario. La Rioja y España.

\begin{tabular}{|l|c|c|c|c|c|c|}
\hline & $\begin{array}{c}\text { Médicos } \\
\text { por 1.000 } \\
\text { habitantes }\end{array}$ & $\begin{array}{c}\text { Enfermeras } \\
\text { por 1.000 } \\
\text { habitantes }\end{array}$ & $\begin{array}{c}\text { Matronas } \\
\text { por 1.000 } \\
\text { habitantes }\end{array}$ & $\begin{array}{c}\text { Auxiliares } \\
\text { enferm por } \\
\mathbf{1 . 0 0 0} \text { hab }\end{array}$ & $\begin{array}{c}\text { Perso. no } \\
\text { sanitario } \\
\mathbf{1 . 0 0 0} \text { hab }\end{array}$ & $\begin{array}{c}\text { MIR por } \\
\mathbf{1 . 0 0 0} \\
\text { habitantes }\end{array}$ \\
\hline La Rioja & 1.7 & 2.99 & 0.36 & 2.47 & 2.80 & 0.32 \\
\hline España & 1.81 & 3.08 & 0.39 & 2.42 & 2.83 & 0.46 \\
\hline
\end{tabular}

Fuente: MSSSI. 2012

Tabla 45. Indicadores de recursos, uso y pertinencia (La Rioja/España)

\begin{tabular}{|c|c|c|c|c|c|c|c|c|c|c|c|c|c|c|c|c|c|}
\hline \multirow[b]{2}{*}{ DOMINOS } & \multirow[b]{2}{*}{ INDICADOR } & \multicolumn{2}{|c|}{2008} & \multicolumn{2}{|c|}{2009} & \multicolumn{2}{|c|}{2010} & \multicolumn{2}{|c|}{2011} & \multicolumn{2}{|c|}{2012} & \multicolumn{2}{|c|}{2013} & \multicolumn{2}{|c|}{2014} & \multicolumn{2}{|c|}{ Periodo } \\
\hline & & LR & E & IR & E & IR & E & LR & $E$ & LR & $E$ & IR & $E$ & IR & $E$ & $\mathbb{R}$ & E \\
\hline Recursos & $\begin{array}{l}\text { Personal médico APpor } 1000 \\
\text { personas asignadas }\end{array}$ & 0,83 & 0,75 & 0,83 & 0,74 & 0,88 & 0,75 & 0,83 & 0,76 & 0,83 & 0,77 & 0,83 & 0,76 & 0,83 & 0,76 & 0,00 & 0,01 \\
\hline Recursos & $\begin{array}{l}\text { Camas hospitalarias en funcionamiento } \\
\text { por } 1000 \text { hab. }\end{array}$ & 3,00 & 3,22 & 2,81 & 3,19 & 2,97 & 3,15 & 2,98 & 3,09 & $\ldots$ & 3,03 & 3,13 & 2,97 & 3,20 & 2,97 & 0,20 & $-0,25$ \\
\hline Recursos & $\begin{array}{l}\text { Puestos en hospitales de día por } 1000 \\
\text { hab. }\end{array}$ & 0,10 & 0,24 & 0,10 & 0,26 & 0,20 & 0,35 & 0,22 & 0,37 & $\ldots$ & 0,40 & 0,22 & 0,40 & 0,22 & 0,41 & 0,12 & 0,17 \\
\hline Recursos & $\begin{array}{l}\text { Equipos de hemodinámica por } 100000 \\
\text { hab. }\end{array}$ & 0,32 & 0,49 & 0,32 & 0,48 & 0,32 & 0,53 & 0,64 & 0,55 & .". & 0,57 & 0,63 & 0,58 & 0,64 & 0,57 & 0,32 & 0,08 \\
\hline Uso & $\begin{array}{l}\text { Frecuentación en medicina de APpor } \\
\text { persona asignadalaño }\end{array}$ & 4,50 & 6,10 & 5,16 & 5,56 & 3,24 & 5,43 & 5,93 & 5,51 & 6,33 & 5,31 & 6,77 & 5,30 & 6,35 & 5,24 & 1,85 & $-0,86$ \\
\hline Uso & $\begin{array}{l}\text { Tasas de uso de resonancia } \\
\text { magnética por } 1000 \text { hab./año }\end{array}$ & 19,96 & 38,92 & 23,75 & 43,06 & 47,69 & 48,25 & 47,99 & 50,67 & $\ldots$ & 50,96 & 50,43 & 54,86 & 72,54 & 60,28 & 52,58 & 21,36 \\
\hline Uso & $\begin{array}{l}\text { Índice de la estancia media ajustada } \\
\text { (EEMA) }\end{array}$ & 0,96 & 1,00 & 0,95 & 1,00 & 0,96 & 1,00 & 0,96 & 1,00 & .'. & 1,00 & 0,99 & 1,00 & 0,98 & 1,00 & 0,02 & 0,00 \\
\hline Uso & $\begin{array}{l}\text { Porcentaje de cirugía ambulatoria en el } \\
\text { SNS }\end{array}$ & 56,75 & 40,45 & 58,18 & 42,33 & 58,04 & 43,04 & 57,60 & 43,93 & $\ldots$ & 45,19 & 55,96 & 46,50 & 53,96 & 46,86 & $-2,79$ & 6,41 \\
\hline Uso & DHD de antibióticos & ... & & ... & & "' & & $\ldots$ & & 22,63 & 19,14 & 19,81 & 19,47 & 21,48 & 20,86 & $-1,15$ & 1,72 \\
\hline Pertinencia & $\begin{array}{l}\text { Porcentaje de cirugía conservadora en } \\
\text { cáncer de mama }\end{array}$ & 56,60 & 61,49 & 48,14 & 62,43 & 61,94 & 62,98 & 61,29 & 63,33 & ... & 64,67 & 58,12 & 63,80 & 61,46 & 65,27 & 4,86 & 3,78 \\
\hline Pertinencia & $\begin{array}{l}\text { Porcentaje de pacientes con fractura } \\
\text { de cadera intervenidos en las primeras } \\
48 \text { horas }\end{array}$ & 45,19 & 36,74 & 46,47 & 37,13 & 47,11 & 40,49 & 48,00 & 41,42 & .". & 40,47 & 49,29 & 42,03 & 56,52 & 42,03 & 11,33 & 5,29 \\
\hline
\end{tabular}

Elaboración propia. Datos del http://inclasns.msssi.es

Mantener el sistema sanitario riojano supone gran parte del presupuesto de la Comunidad Autónoma, siendo mayor el gasto por habitante en salud en La Rioja que la media española (tabla 46), a pesar de que durante el periodo estudiado el porcentaje de disminución del mismo es mayor en La Rioja. 


\begin{tabular}{|c|c|c|c|c|c|c|c|c|c|c|c|c|c|c|c|c|c|}
\hline \multirow[b]{2}{*}{ DOMINOS } & \multirow[b]{2}{*}{ INDICADOR } & \multicolumn{2}{|c|}{2008} & \multicolumn{2}{|c|}{2009} & \multicolumn{2}{|c|}{2010} & \multicolumn{2}{|c|}{2011} & \multicolumn{2}{|c|}{2012} & \multicolumn{2}{|c|}{2013} & \multicolumn{2}{|c|}{2014} & \multicolumn{2}{|c|}{ Periodo } \\
\hline & & LR & E & LR & E & LR & E & LR & E & LR & E & LR & E & LR & E & LR & E \\
\hline Econónico & $\begin{array}{l}\text { Gasto sanilario púbico terithorializado, } \\
\text { por habitante protegido }\end{array}$ & 1548,71 & 1389,88 & 1514,99 & 1447,39 & 1516,94 & 1423,51 & 1490,10 & 1392,31 & 1342,34 & 1339,49 & 1331,31 & 1296,38 & 1353,42 & 1289,24 & $.195,29$ & $\cdot 100,64$ \\
\hline Econónico & $\begin{array}{l}\text { Porcentiajedel gasio santario en } \\
\text { atención pirmaria }\end{array}$ & 14,12 & 14,52 & 14,07 & 14,34 & 13,11 & 14,19 & 12,88 & 13,77 & 13,13 & 13,55 & 13,82 & 12,95 & 14,37 & 13,40 & 0,25 & $-1,12$ \\
\hline Econónico & $\begin{array}{l}\text { \% del gassio de los servicios de } \\
\text { atención especializada }\end{array}$ & 57,21 & 50,85 & 55,28 & 51,50 & 55,12 & 51,55 & 56,49 & 53,33 & 57,12 & 54,93 & 56,79 & 54,70 & 57,12 & 55,80 & $-0,09$ & 4,95 \\
\hline Econónico & $\%$ del gastion tarmacia & 18,52 & 20,67 & 19,36 & 20,59 & 19,22 & 20,78 & 18,15 & 19,27 & 17,09 & 17,55 & 16,27 & 17,81 & 16,65 & 17,55 & $-1,87$ & $-3,12$ \\
\hline Econónico & $\begin{array}{l}\text { \% del gasio en remuneración de } \\
\text { personal }\end{array}$ & 49,26 & 44,69 & 49,49 & 45,63 & 48,22 & 45,66 & 46,91 & 45,62 & 47,35 & 44,52 & 48,19 & 46,09 & 48,79 & 45,97 & 0,47 & 1,28 \\
\hline Econónico & $\%$ del lassto en consumos intermedios & 21,24 & 20,91 & 21,45 & 21,02 & 23,16 & 20,84 & 24,37 & 22,88 & 25,41 & 25,77 & 25,11 & 24,20 & 24,74 & 24,52 & 3,50 & 3,61 \\
\hline Econónico & $\%$ del gasio dedicado a conciertos & 6,01 & 9,45 & 6,99 & 8,98 & 7,31 & 9,03 & 7,46 & 9,26 & 8,08 & 9,57 & 8,78 & 9,52 & 8,66 & 9,56 & 2,65 & 0,11 \\
\hline Eiciencia & $\begin{array}{l}\text { Estancia media ausistada por la } \\
\text { casusisica (EMAC) }\end{array}$ & 5,70 & 6,17 & 5,64 & 6,04 & 5,55 & 6,01 & 5,44 & 5,89 & 5,41 & 5,75 & 5,47 & 5,68 & 5,40 & 5,77 & $-0,30$ & $\cdot 0,40$ \\
\hline Eiciencia & Porcentajeje de cirugua ambulatoria & 56,75 & 40,45 & 58,18 & 42,33 & 58,04 & 43,04 & 57,60 & 43,93 & 57,26 & 45,19 & 55,96 & 46,50 & 53,96 & 46,86 & $-2,79$ & 6,41 \\
\hline Eiciencia & Porcentaje global de réngyesos & 6,96 & 7,08 & 7,35 & 7,16 & 7,21 & 7,08 & 7,77 & 7,31 & 8,10 & 7,43 & 7,60 & 7,56 & 7,69 & 7,73 & 0,73 & 0,05 \\
\hline
\end{tabular}

Elaboración propia. Datos del http://inclasns.msssi.es

\subsubsection{Gestión de la calidad}

Durante el periodo de tiempo estudiado en este trabajo La Rioja ha pasado por varias fases respecto al apoyo dado desde la Consejería de Salud a la implantación de sistemas de gestión de la calidad.

\section{Situación anterior a 2007}

En este periodo se desarrollan en La Rioja algunas iniciativas encaminadas a implantar un modelo de calidad en línea con lo que se está realizando en otras partes de España.

El I Plan Estratégico para la Calidad del Gobierno de La Rioja dispuso en 2004, como prioridades del Gobierno de La Rioja, las siguientes líneas estratégicas:

- La consolidación y evolución del sistema de atención al ciudadano.

- La calidad en la gestión.

- La calidad en la toma de decisiones.

Para contribuir al desarrollo de la coordinación entre las diferentes estructuras sanitarias de la Comunidad Autónoma, desde la Consejería de Salud de La Rioja se detectó la necesidad de crear un órgano que proporcionase soporte de gestión y operativo para la implementación de políticas de calidad integrada, así como actuaciones para potenciar mecanismos de coordinación entre programas e instituciones. Se creó la Unidad para la gestión integrada de la calidad, evaluación y mejora de la eficiencia de la atención sanitaria de La Rioja (Corcuera, 2004). Esta unidad dependía funcionalmente de la Secretaría General Técnica de la Consejería de Salud, y orgánicamente de la Fundación Rioja Salud, que en sus estatutos recogía la posibilidad de "poner a disposición del Gobierno de La Rioja y la Consejería de Salud los medios disponibles de la Fundación 
para la implantación de sistemas de calidad, de evaluación y eficiencia de todos los dispositivos del sistema público de La Rioja".

La Unidad disponía de una dirección y 4 áreas funcionales que trabajaban en la gestión de calidad integrada, el desarrollo de nuevas tecnologías, la mejora de la eficiencia y la mejora de la satisfacción

En esta etapa se diseñó para el SERIS una estructura de tres áreas de salud y direcciones de procesos.

Ilustración 22. Organigrama del Servicio Rojano de Salud (2005)

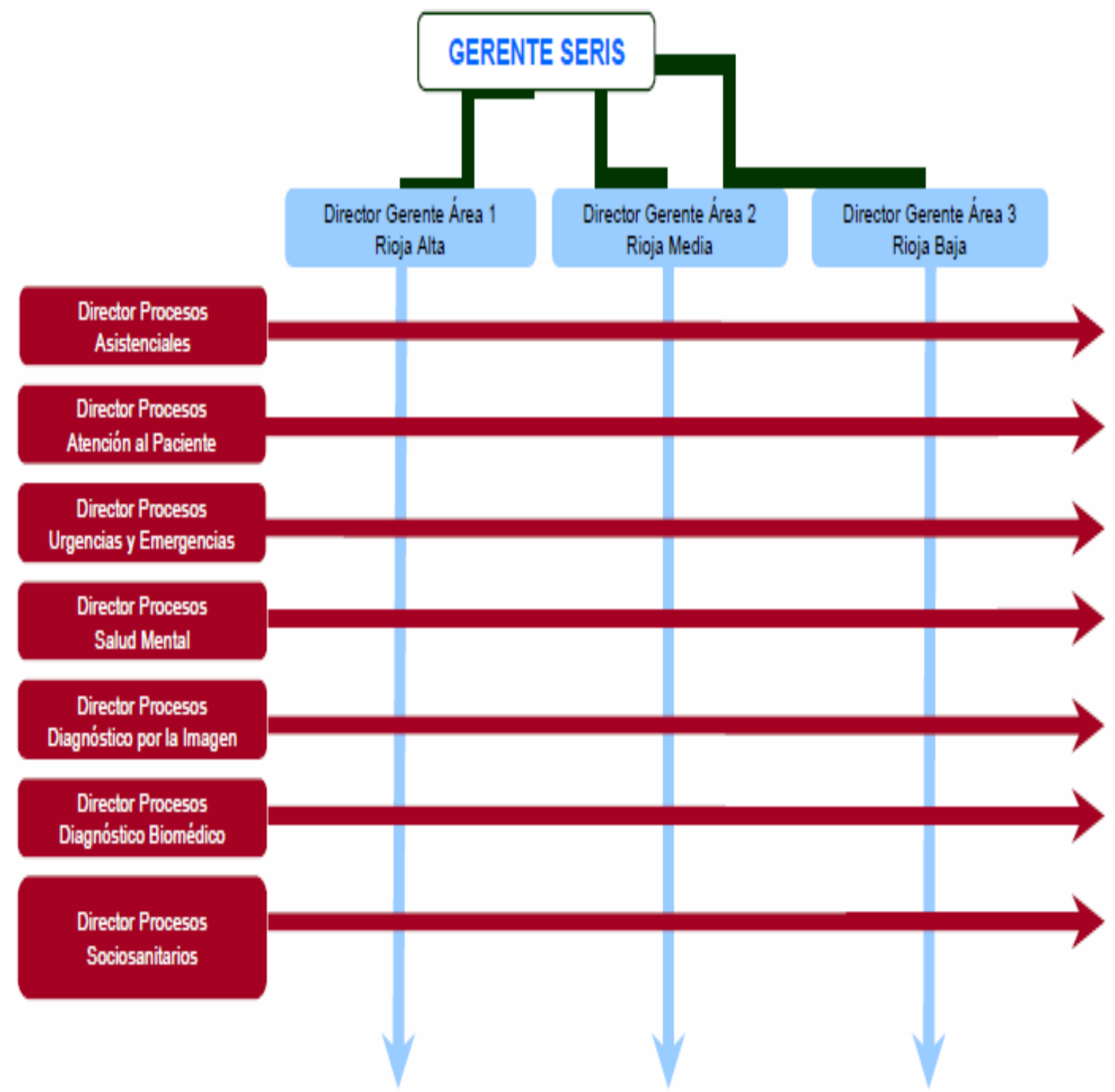

Fuente: Riojasalud 2006

El Equipo Directivo definió la política de calidad (tabla 47) y el mapa de procesos que conformaban el SERIS (ilustración 23). 


\section{Misión}

EI SERIS, es el organismo autónomo del sistema de salud de La Rioja principal proveedor de servicios sanitarios públicos de la comunidad, su misión es elevar el nivel de salud de la población y de sus usuarios satisfaciendo sus necesidades sanitarias a través de la prestación de servicios para la promoción, prevención, diagnóstico, tratamiento, rehabilitación y cuidados a las personas aplicando criterios de equidad, eficacia, eficiencia, accesibilidad y calidad.

\section{Valores}

Para conseguirlo asumimos:

- El ciudadano es el eje principal sobre el que orientamos la actuación considerando su satisfacción como nuestro objetivo básico.

- Los trabajadores son los artífices de esta tarea, orientando nuestra gestión a disponer de personas altamente competentes integradas y satisfechas.

- La innovación y la mejora continua son la herramienta clave para la optimización de nuestros servicios y nuestro funcionamiento.

- La coordinación y la integración de los diferentes unidades/centros/dispositivos del sistema es un requisito fundamental para la calidad y la efectividad de nuestros servicios.

- El impacto en nuestra comunidad se basa en la sostenibilidad social y medioambiental

Fuente: Riojasalud 2006

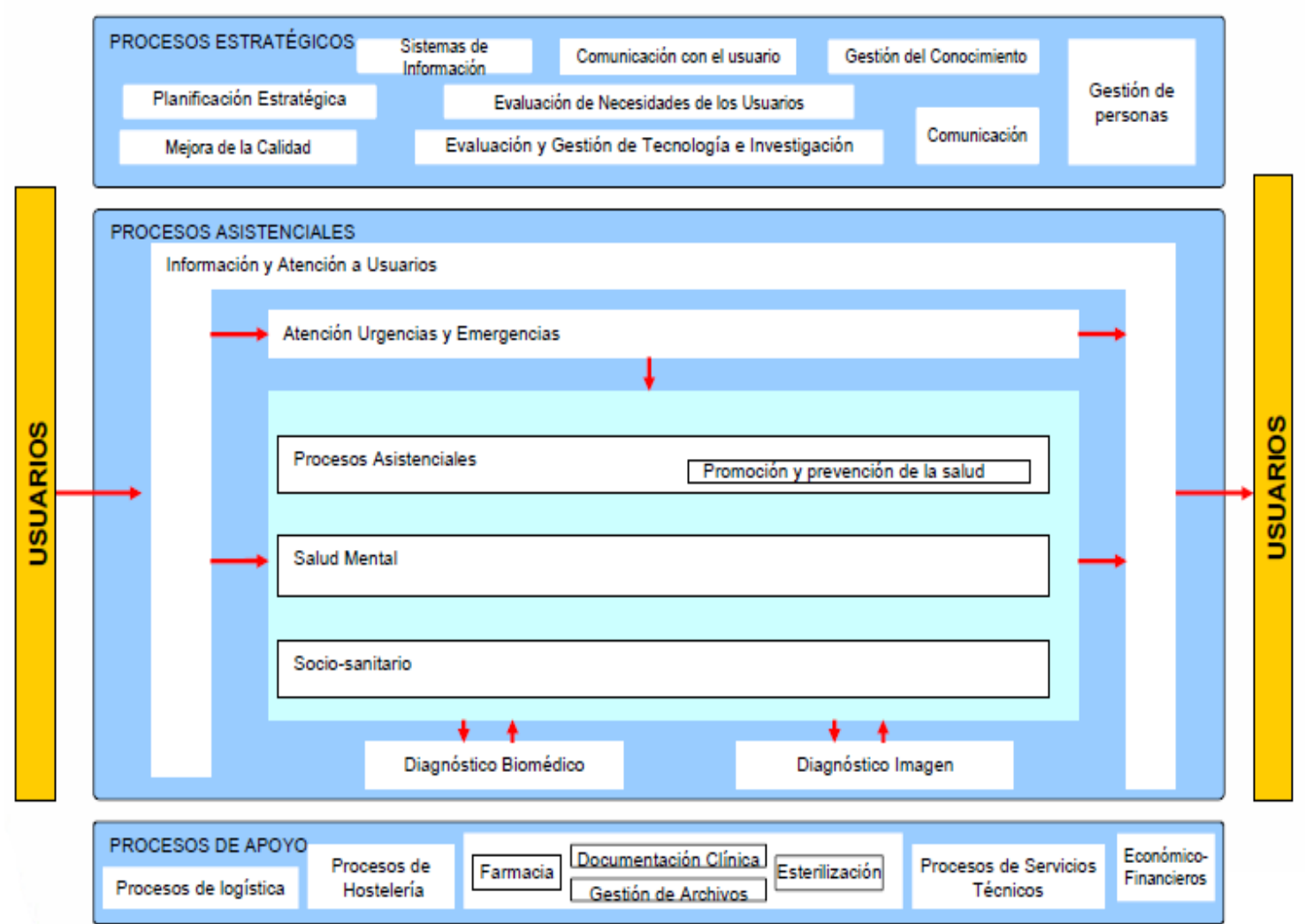

Fuente: Riojasalud 2006 


\section{Situación durante el periodo 2007-2014}

Con la apertura del nuevo hospital San Pedro se propició la implantación de algunas unidades de sistemas de gestión de calidad (tabla 48) con la colaboración de proveedores.

El cambio de consejero de salud propicia un cambio en la política de calidad en la organización y se reestructura la misma volviendo al área única y eliminándose las direcciones y la Gestión por Procesos como sistema de gestión de la organización.

También se elimina la Agencia de Calidad. Durante este periodo se desarrolla en la organización algunas iniciativas lideradas por jefes/responsables de unidades sin existir una estrategia más allá de la apuesta por el ahorro (tabla 48).

Tabla 48. Situación de la gestión de la calidad en el SERIS en 2014

\begin{tabular}{|c|c|c|}
\hline Organización / Servicio & Sistema / Modelo & Situación \\
\hline \multirow{3}{*}{ Servicio de Alimentación } & ISO 9001 & Certificado \\
\hline & $\begin{array}{c}\text { ISO } 22.000 \text { (seguridad } \\
\text { alimentaria) }\end{array}$ & Implantado sin certificar \\
\hline & EFQM & Reconocimiento $\mathrm{Q}$ bronce \\
\hline Central de Esterilización & ISO 9001 & Certificado \\
\hline Hospitalización a Domicilio & ISO 9001 & Certificado \\
\hline $\begin{array}{l}\text { Sistema Docente Sanitario } \\
\text { Postgrado Especializado }\end{array}$ & EFQM & Reconocimiento $Q$ bronce \\
\hline Hospital San Pedro & Carta de Compromiso & Publicada \\
\hline $\begin{array}{l}\text { Servicio de Prevención de } \\
\text { Riesgos Laborales }\end{array}$ & EFQM & Reconocimiento $Q$ bronce \\
\hline
\end{tabular}

Fuente: Elaboración propia. Actualización a partir del Informe de Situación: Servicio de Planificación, Evaluación y Calidad (2011)

El Ministerio de Sanidad, Servicios Sociales e Igualdad, a través de la Agencia de Calidad y dentro del Plan de Calidad para el Sistema Nacional de Salud ha impulsado la elaboración de estrategias en salud para las patologías más prevalentes. Los profesionales de la administración sanitaria de La Rioja han participado en todas ellas, tanto en su elaboración en unos casos como en su desarrollo e implementación en otros. La potenciación de relaciones para la mejora del sistema de salud constituía uno de los objetivos del II Plan de Salud, que se alcanzó satisfactoriamente según los responsables del mismo.

El II Plan de Salud de La Rioja planteaba también que, tras una fase marcada por la mejora de las infraestructuras, debía emprenderse la optimización de las mismas y de la utilización del capital humano, potenciando el trabajo en calidad, la búsqueda de la mejora continua y la difusión de las buenas prácticas. El objetivo básico del sistema es la satisfacción de las necesidades reales del usuario, que deben ser conocidas de la manera más directa posible. 
Por otro lado, en ese mismo Plan, se señala que los profesionales sanitarios deben estar adecuadamente formados, participar en el funcionamiento del sistema y sentirse satisfechos con el mismo, para prestar la asistencia que se les demanda. En este sentido se planteó establecer canales de comunicación interna, fomentar la participación en Comisiones y Grupos de Trabajo e impulsar la implantación de un Plan de Acogida al trabajador. La realización de encuestas, también propuesta, permitiría evaluar la eficacia de estas medidas.

Estos objetivos no fueron alcanzados en su totalidad por lo que se revisaron y redefinieron para el III Plan de Salud de La Rioja, actualmente en vigor.

Durante este periodo el Servicio Riojano de Salud ha sido galardonado con los premios TOP20 Hospitalarios por su elevado nivel de calidad asistencial en un proceso asistencial concreto y por su eficiente gestión económica.

No obstante, y a pesar de los reconocimientos, no ha existido una política de calidad común desplegada en todo el Servicio Riojano de Salud, aunque existan unidades/servicios que por propia iniciativa han desarrollado sus propios sistemas de calidad.

Durante este periodo, y continua actualmente, ha existido un servicio de referencia en la Consejería de Salud, el Servicio de Planificación, Evaluación y Calidad que marca las directrices a seguir a través del diseño y el seguimiento de las acciones e indicadores contemplados en los planes de salud de La Rioja. En el SERIS no existe una estructura formal de calidad, el Responsable de Calidad y Apoyo a las Unidades Docentes y a la Investigación es la persona que asume en ciertos aspectos el liderazgo de los temas relacionados con la gestión de la calidad.

\section{Situación desde 2014}

El III Plan de Salud de La Rioja 2015-2019 es el eje sobre el que va a girar la planificación de las políticas sanitarias de la Comunidad Autónoma a lo largo de los próximos años. Debe ser el referente a la hora de establecer objetivos y como medidor y orientador de las políticas de salud que se establezcan en el periodo en el que va a estar vigente.

En el III Plan de Salud de La Rioja se reconoce que las herramientas de gestión de la calidad, en concreto la potenciación de la participación en Comisiones Clínicas y Grupos de Trabajo como excelentes herramientas de participación de los profesionales que permiten llevar a la práctica clínica a los niveles de efectividad y eficiencia que son deseables.

Las herramientas de gestión de calidad deben contemplarse en los distintos planes de formación e iniciarse su implantación en los distintos servicios y unidades. Así mismo, el III Plan plantea como necesario continuar extendiendo la cultura de la calidad en el sistema público de salud de La Rioja.

Esta estrategia, esbozada ya en documentos inmediatamente anteriores al III Plan de Salud (ilustración24), como la estrategia de atención al paciente crónico en La Rioja de 2014, muestra el camino a seguir e identifica que resultados se pretenden obtener con 
la transformación del modelo asistencial del SERIS (tabla 49) de cara al futuro inmediato.

Tabla 49. Beneficios esperados de la transformación del modelo asistencial del SERIS

\begin{tabular}{|c|c|c|c|}
\hline Beneficios & Pacientes y cuidadores & Profesionales & Organización \\
\hline $\begin{array}{l}\text { Calidad de } \\
\text { la prestación }\end{array}$ & $\begin{array}{l}\text { Asistencia centrada en el } \\
\text { Paciente } \\
\text { Adaptación a las } \\
\text { necesidades } \\
\text { del paciente evitando } \\
\text { la fragmentación de la } \\
\text { atención } \\
\text { Paciente activo con } \\
\text { mayor } \\
\text { protagonismo y } \\
\text { corresponsabilidad } \\
\text { en el proceso de } \\
\text { su enfermedad }\end{array}$ & $\begin{array}{l}\text { Mejora del acceso a } \\
\text { información } \\
\text { del paciente en } \\
\text { todos los niveles asistenciales } \\
\text { y a nivel social } \\
\text { Mejora del nivel de } \\
\text { competencia } \\
\text { y capacidad en la } \\
\text { gestión en todos los niveles } \\
\text { de organización y en } \\
\text { enfermería } \\
\text { Mejora de la coordinación } \\
\text { intersectorial y del acceso a } \\
\text { los recursos de la red. }\end{array}$ & $\begin{array}{l}\text { Evolución hacia un } \\
\text { sistema } \\
\text { más proactivo } \\
\text { Adecuación } \\
\text { a las necesidades } \\
\text { del paciente a partir } \\
\text { de } \\
\text { actuación } \\
\text { multidisciplinar } \\
\text { coordinada } \\
\text { Disminución de la } \\
\text { variabilidad por la } \\
\text { utilización común de } \\
\text { protocolos, vías y } \\
\text { guías clínicas } \\
\text { homogéneas. }\end{array}$ \\
\hline $\begin{array}{l}\text { Gestión y } \\
\text { sostenibilidad }\end{array}$ & $\begin{array}{l}\text { Mayor autonomía del } \\
\text { paciente y familiar en el } \\
\text { autocuidado y en la } \\
\text { gestión } \\
\text { de su enfermedad } \\
\text { Acceso a Consejo clínico } \\
\text { información sobre su } \\
\text { enfermedad } \\
\text { sin desplazamientos, } \\
\text { evitando saturación }\end{array}$ & $\begin{array}{l}\text { Uso adecuado de } \\
\text { Recursos y agilidad en la } \\
\text { gestión pacientes } \\
\text { Disminución de la demanda } \\
\text { (evitar asistencias } \\
\text { innecesarias) } \\
\text { Colaboración con pacientes y } \\
\text { familiares en la atención para } \\
\text { conseguir una mayor } \\
\text { autonomía } \\
\text { del paciente }\end{array}$ & $\begin{array}{l}\text { Optimización por el } \\
\text { uso } \\
\text { racional de los } \\
\text { recursos a } \\
\text { nivel de dispositivos y } \\
\text { tecnologías } \\
\text { y otros medicamentos } \\
\text { Mejora de la eficiencia } \\
\text { del sistema } \\
\text { Cultura de evaluación } \\
\text { y } \\
\text { mejora continua }\end{array}$ \\
\hline $\begin{array}{l}\text { Resultados } \\
\text { en salud }\end{array}$ & \multicolumn{3}{|c|}{$\begin{array}{l}\text { Disminución de la morbilidad: reagudizaciones o aparición de nuevas patologías } \\
\text { Mejora de la calidad de vida y mayor satisfacción de los pacientes, familia y } \\
\text { cuidadores } \\
\text { Disminución de la mortalidad evitable por enfermedades crónicas }\end{array}$} \\
\hline
\end{tabular}

Fuente: Estrategia de atención al paciente crónico en La Rioja. Documento general (2014)

La Estrategia de Atención al Paciente Crónico de La Rioja (Riojasalud, 2014) supone un ejemplo de la propuesta de nueva cultura en la organización, que focaliza los esfuerzos y asigna recursos para mejorar la atención a los pacientes crónicos, pero a la vez, propone la creación de una nueva cultura global en todo el SERIS. Este nuevo paradigma de atención colaborativa está enfocado a:

- Orientación poblacional, haciendo del paciente el eje del sistema

- Apuesta decidida por un modelo colaborativo de atención

- Mejora de la capacidad de resolución de AP 
- Nueva cultura de relación entre niveles asistenciales, de manera que tanto la $\mathrm{AE}$, como Servicios Sociales presten el apoyo requerido a AP para garantizar la eficacia global del sistema

- Orientación al logro de resultados, mediante la innovación organizativa, la autoevaluación y mejora continua del proceso integral de atención al paciente crónico

- Responsabilidad e implicación activa del personal asistencial en la trasformación de la práctica clínica

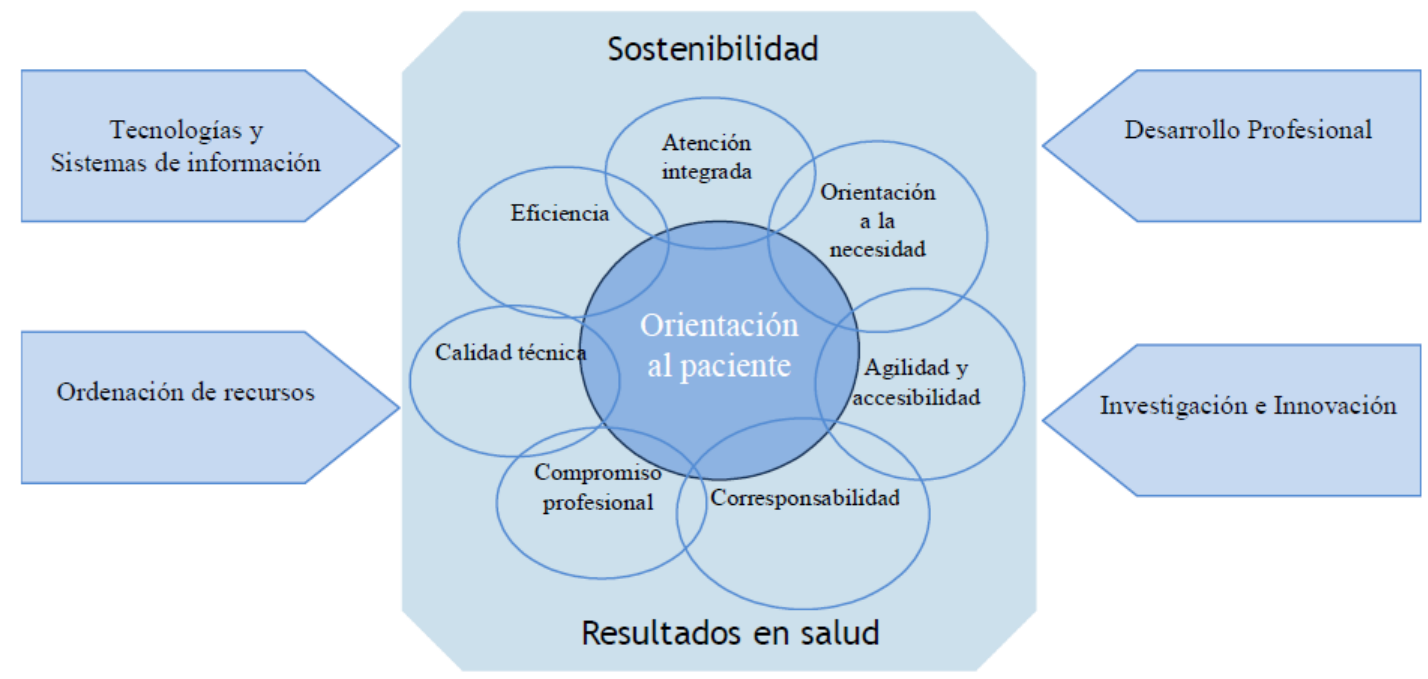

Fuente: Estrategia de atención al paciente crónico en La Rioja. Documento general (2014)

En esta línea de introducción de conceptos relacionados con la calidad y siguiendo los pasos expuestos en el III Plan de Salud, en Diciembre de 2016 se creó el comité de calidad formado por los presidentes de otras comisiones clínicas del Hospital san Pedro. La dirección encargó a este grupo realizar una autoevaluación con el modelo EFQM para poder disponer de una imagen lo más objetiva posible de la organización identificando sus puntos fuertes y sus áreas de mejora.

Las puntuaciones obtenidas (tabla 50) reflejan aquellos criterios en los que la mayoría de los evaluadores creían que se necesitaba un mayor esfuerzo por parte de la organización.

Tabla 50. Resultados autoevaluación EFQM. SERIS 2016

\begin{tabular}{|c|c|c|c|c|c|c|c|c|}
\hline \multicolumn{9}{|c|}{ Criterios Agentes } \\
\hline \multirow{3}{*}{$\begin{array}{c}\text { Criterio peor } \\
\text { valorado }\end{array}$} & \multirow{2}{*}{ Resultado Global } & \multicolumn{7}{|c|}{ Resultados para cada evaluador } \\
\hline & & 1 & 2 & 3 & 4 & 5 & 6 & 7 \\
\hline & $\begin{array}{c}\text { Criterio 4. Alianzas y } \\
\text { recursos }\end{array}$ & 4 & 4 & $4,5,1$ & 3 & 4 & 4 & 4 \\
\hline & Criterio3. Personas & 1 & 3 & & 5 & 3 & 3 & 5 \\
\hline & Criterio 5. Procesos & 3 & 2 & & 4 & 5 & 5 & 3 \\
\hline & Criterio1. Liderazgo & 2 & 1 & 3 & 1,2 & 1 & 2 & 2 \\
\hline valorado & Criterio 2. Estrategia & 5 & 5 & 2 & & 2 & 1 & 1 \\
\hline
\end{tabular}


En estos momentos también se están elaborando el plan de calidad y el plan director de Infraestructuras que identifica cuáles serán las necesidades de recursos para los próximos diez años para que el SERIS responda a las necesidades de salud de los riojanos y a sus expectativas de satisfacción de sus expectativas y seguridad en la práctica clínica.(tabla 51)

Tabla 51. Indicadores de resultados en calidad (La Rioja/España)

\begin{tabular}{|c|c|c|c|c|c|c|c|c|c|c|c|c|c|c|c|c|c|}
\hline \multirow[b]{2}{*}{ DOMINIOS } & \multirow[b]{2}{*}{ INDICADOR } & \multicolumn{2}{|c|}{2008} & \multicolumn{2}{|c|}{2009} & \multicolumn{2}{|c|}{2010} & \multicolumn{2}{|c|}{2011} & \multicolumn{2}{|c|}{2012} & \multicolumn{2}{|c|}{2013} & \multicolumn{2}{|c|}{2014} & \multicolumn{2}{|c|}{ Periodo } \\
\hline & & LR & E & LR & E & LR & $E$ & LR & E & LR & E & LR & $E$ & LR & E & LR & E \\
\hline Seguridad & $\begin{array}{l}\text { Notificación de reacciones adversas } \\
\text { graves a medicamentos }\end{array}$ & 90,00 & 100,00 & 130,00 & 150,00 & 90,00 & 150,00 & 120,00 & 160,00 & 210,00 & 210,00 & 167,69 & 217,42 & 178,68 & 213,78 & 88,68 & 113,78 \\
\hline Seguridad & $\begin{array}{l}\text { Mortalidad intrahospitalaria postinfarto } \\
\text { por cada } 100 \text { altas por infarto }\end{array}$ & 9,09 & 9,04 & 10,40 & 8,47 & 8,05 & 8,35 & 7,50 & 8,03 & $\ldots$ & 7,51 & 8,69 & 7,28 & 8,16 & 7,16 & $-0,93$ & $-1,88$ \\
\hline Seguridad & $\begin{array}{l}\text { Tasa de amputaciones miembro inferior } \\
\text { en pacientes diabéticos }\end{array}$ & 0,04 & 0,11 & 0,10 & 0,11 & 0,07 & 0,10 & 0,05 & 0,10 & ... & 0,10 & 0,04 & 0,10 & 0,05 & 0,10 & 0,01 & $-0,01$ \\
\hline Efectividad & Incidencia de hepatitis B por $100000 \mathrm{~h}$. & 1,27 & 2,12 & 0,32 & 1,85 & 1,91 & 1,86 & 0,00 & 1,65 & 2,25 & 1,27 & 0,63 & 1,53 & 1,27 & 1,43 & 0,00 & $-0,69$ \\
\hline $\begin{array}{l}\text { Satisfacción } \\
\text { Ciudadanos }\end{array}$ & $\begin{array}{l}\text { Grado de satisfacción de los } \\
\text { ciudadanos con el funcionamiento del } \\
\text { sistema sanitario público }\end{array}$ & 6,93 & 6,36 & 6,97 & 6,45 & 7,10 & 6,58 & 7,10 & 6,53 & 6,89 & 6,57 & 6,77 & 6,47 & 6,88 & 6,38 & $-0,05$ & 0,02 \\
\hline $\begin{array}{l}\text { Satisfacción } \\
\text { Ciudadanos }\end{array}$ & $\begin{array}{l}\text { Grado de satisfacción del ciudadano } \\
\text { con el conocimiento del historial y el } \\
\text { seguimiento por el médico de familia y } \\
\text { el pediatra }\end{array}$ & 7,26 & 6,95 & 7,03 & 7,05 & 7,66 & 7,26 & 7,89 & 7,52 & 7,97 & 7,52 & 8,04 & 7,56 & 7,90 & 7,50 & 0,64 & 0,55 \\
\hline $\begin{array}{l}\text { Satisfacción } \\
\text { Ciudadanos }\end{array}$ & $\begin{array}{l}\text { Grado de satisfacción del ciudadano } \\
\text { con la información recibida en la } \\
\text { consulta del médico especialista sobre } \\
\text { su problema de salud }\end{array}$ & 7,27 & 6,94 & 7,29 & 7,03 & 7,74 & 7,12 & 7,65 & 7,24 & 7,70 & 7,30 & 7,42 & 7,35 & 7,03 & 7,13 & $-0,24$ & 0,19 \\
\hline
\end{tabular}

Elaboración propia. Datos del http://inclasns.msssi.es

\subsubsection{Resultados cualitativos}

Los conceptos fundamentales de la excelencia muestran valores comunes que pueden considerarse parte de la "cultura de la organización" (CEG, 2014), aparecen en algunas ocasiones en el discurso de las personas entrevistadas (tabla 52),

Tabla 52. Verbatines correspondientes a conceptos fundamentales de la excelencia

Añadir valor para los clientes. "Dentro de que nuestra obligación es un sistema público 100\%, tenemos que asistir a la población primero y después veremos..." (SRS10)

Liderar con visión, inspiración e integridad. "La anterior gestión era eficaz, el hospital hacía cosas y tal. No era una mala gestión pero era un estilo de gestión que no estaba alineado con lo que se pretende" (SRS5)

Crear un futuro sostenible; "En sostenibilidad nosotros miramos euro a euro....el gobierno no nos puede financiar sin límite y hay que tener en cuenta que es dinero público" (SRS3).

Mantener en el tiempo resultados sobresalientes. "Se necesita más dinero para mantener buenos resultados, conseguirlo a través de proveedores, buscar en otros hospitales otras medidas semejantes que se hayan podido poner en marcha, buscar otras salidas, no quedarnos estancadas" (SRS1).

Transcripciones literales de las entrevistas. Análisis mediante Atlas Ti 
Respecto a los conceptos fundamentales de "alcanzar el éxito mediante el talento de las personas" no se han encontrado verbatines que reflejen este concepto, aunque si se han encontrado otros que manifiestan el malestar de las personas y la falta de orgullo de pertenencia.

"Teniendo objetivamente razones para estar orgullosos luego...es como un negativismo, un pesimismo, un complejo de inferioridad, un autodesprecio..."(SRS5)

"Debería haber un plan en ese sentido de concienciación por una parte que la gente se sintiese orgullosa de trabajar dónde trabaja y hacer equipo" (SRS4)

Otros valores que tampoco aparecen en las entrevistas son "aprovechar la creatividad y la innovación" y "desarrollar la capacidad de la organización”.

Respecto a la presencia de valores fundamentales como "crear un futuro sostenible" solo se han podido recoger opiniones relacionadas con la sostenibilidad económica de la organización. Otros aspectos de la sostenibilidad expuestos en este trabajo, como la sostenibilidad medioambiental o los aspectos relacionados con la ética o la sociedad, no han surgido de forma espontánea durante las entrevistas, no han tenido cabida en el discurso de las personas del Servicio Riojano de Salud. Aunque si reconocían su existencia cuando eran preguntados por ellos como se puede observar en la ilustración 25.

El pensamiento del personal del SERIS en relación a la sostenibilidad de la organización se explica en el mapa conceptual (ilustración25) obtenido a partir de las entrevistas realizadas.

\section{Ilustración 25. Entrevistas SERIS Sostenibilidad}

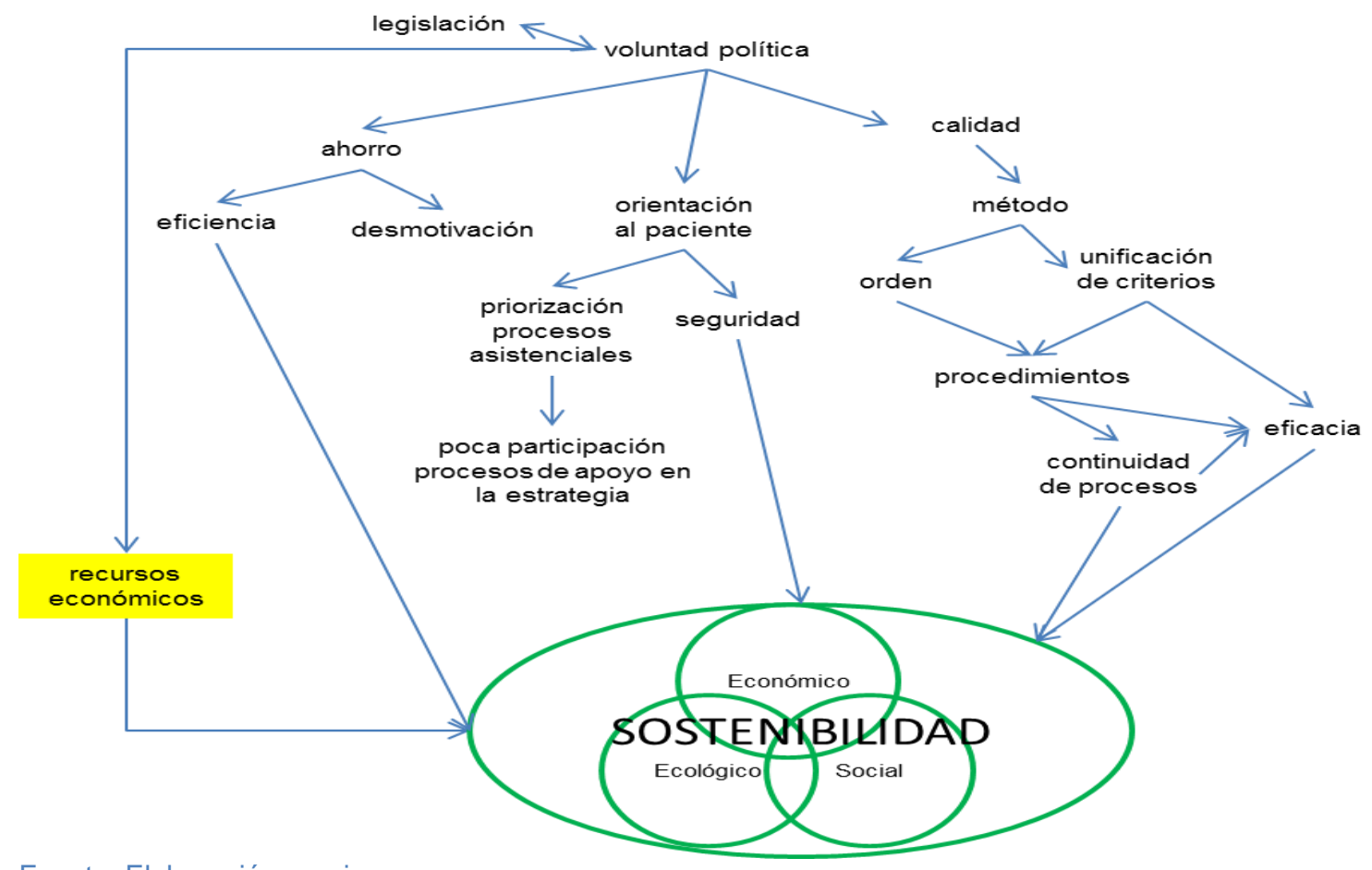

Fuente: Elaboración propia 
Las personas entrevistadas del Servicio Riojano de Salud tenían en común que el concepto de sostenibilidad de su organización debía abarcar las tres cuentas de resultados (social, económico y medioambiental) descritas por Elkington (1994) (ilustración 25). No obstante, cuando se les preguntó por la sostenibilidad de su organización, como ya se ha indicado en la identificación de los conceptos fundamentales, todos hicieron referencia al aspecto económico en mayor medida y a la financiación condicionada por las políticas públicas.

"Los hospitales sí que pueden ser sostenibles, por ejemplo existen hospitales privados que, no conozco mucho y a lo mejor tampoco comulgo mucho con este modelo que es cuestión de ideología, hay hacen la gestión más estricta en este aspecto, cuidan muy mucho las herramientas con las que están trabajando, no hacen esas renovaciones tan frecuentemente, están persiguiendo...ya estamos entrando a lo mejor en cuestiones de metafísica. Los propios políticos hacen sus ventas en continua aportación de mejoras...y todo depende de lo que ellos prometan" (SRS7)

Según la senadora de La Rioja, Francisca Mendiola, "la reforma del Partido Popular ha logrado un sistema sanitario sostenible y viable para garantizar una asistencia pública, gratuita, universal y de calidad que cada día ofrece mejores prestaciones a los riojanos" (La Rioja, 26 agosto 2015)

No obstante, en la actualidad, no existe unanimidad en la organización sobre su sostenibilidad. Hay quienes cuestionan la sostenibilidad porque la medicina va cambiando y evolucionando a un ritmo tremendo. El gasto es elevado y de crecimiento geométrico y algunas veces no están demostrados los beneficios que aporta.

"Lo que pasa es que el gasto más grande no es por lo que pidan los usuarios sino por lo que va avanzando la medicina." (SRS2)

"yo no creo que dependa del dinero que haya de presupuesto, yo o que creo que depende es de la organización, de uso adecuado de los recursos de este centro y de la sanidad en general" (SRS4)

"La competitividad del centro cada vez requiere más recursos y los equipamientos tienen unos precios elevadísimos. Las organizaciones sanitarias si quieren ser sostenibles deben hacer la gestión más estricta y cuidar muy mucho las herramientas con las que están trabajando, no hacen esas renovaciones tan frecuentemente salvo que se demuestren los beneficios" (SRS7)

Aunque para personas que participan en procesos relacionados con la capacidad hostelera del centro, este si es competitivo y sostenible.

"...incluso se ha hecho un estudio para privatizar la cocina y los datos a nivel económico son mejores" (SRS1).

"Si, hombre este hospital tiene una ventaja tremenda que es la hostelería, que eso no tienen otros hospitales.... lo que eso supone de mejor trato, de más privacidad y tal no lo tiene ningún hospital y eso es una ventaja muy grande. Y luego yo creo que es un hospital poco saturado, salvo momentos muy puntuales... Técnicamente seguro que hay áreas en las que podrían llevarse gente, pero en cuanto a atención, a calidad percibida y demás es un hospital con muchas ventajas" (SRS9) 
Según los entrevistados la situación actual del SERIS es un momento de cambio cuyo máximo objetivo es el ahorro y el control presupuestario. De un año para otro cambia (disminuye) mucho el presupuesto y es necesario ajustar para que el paciente no lo llegue a notar.

"Como yo siempre les he dicho a Hacienda aquí no se puede decir le atenderé al año que viene, aquí en Sanidad no puedes decir al paciente venga usted al tratamiento el año que viene (SRS3)

"El factor económico tiene su importancia en los criterios de valoración pero hay criterios técnicos en un porcentaje importante. Como ya se ha señalado se trata fundamentalmente de no bajar demasiado la calidad ni la asistencia" (SRS3).

"Esta etapa en la que estamos pasando tenemos una revisión de una serie de indicadores económicos que además nos los mandan los directivos para ir poniendo mejoras porque si no es imposible. De un año para otro te cambia mucho el presupuesto y tienes que ajustarte para que el paciente no lo llegue a notar" (SRS1)

Los directivos gestionan en base a una serie de datos de indicadores para identificar mejoras, principalmente, de carácter económico. Los trabajadores reconocen que hay otro tipo de sostenibilidad pero ahora solo se trabaja la económica, en la eficiencia.

"Bajar precios pero sin llegar a pasar un límite en el cual a las empresas no les sea rentable trabajar con la organización. No rebajar la calidad a cualquier precio de ninguna manera...la calidad de los suministros, de los servicios" (SRS3)

"Dar la misma asistencia buena e incluso se han abierto nuevos servicios incrementando la cartera de servicios ajustando todo lo que han podido (SRS2).

"El hospital, hace diez años cuando se abrió, era todo nuevo pero ahora tanto en aparatos por su obsolescencia y en las instalaciones por lo mismo va a requerir más inversión en el futuro y será necesario hacerla. Pero estos años han enseñado que se debe hacer con unos criterios de eficiencia y eficacia" (SRS7)

Por otro lado también hablan de que durante este periodo se ha recortado en personal y se ha pedido un esfuerzo extra a los trabajadores, que aunque parece que entendido en un principio ha creado malestar.

"Los trabajadores sienten que el personal verdaderamente ha trabajado y ha tenido menos sueldo y más horas y la gente ha cumplido en general salvo raras excepciones. Se ha cumplido, unos de mejor grado que otros, pero ahora ha llegado un momento en que es necesario reconocer y premiar el esfuerzo...." (SRS3)

"La anterior gestión era eficaz, el hospital hacía cosas. No era una mala gestión pero era un estilo de gestión que no estaba alineado con los objetivos. Era eficaz pero por otro lado rompía con otras cosas también necesarias... no es solo lo económico que hay otras cosas importantes. Era un poco el despreciar a las personas..." (SRS5)

Aunque se han puesto en marcha servicios importantes y con repercusión social, pero según expresan los entrevistados falta un poco el sentido de que son un hospital y de que estos eran logros de todos. El personal no siente orgullo de su organización. 
"Teniendo objetivamente razones para poder estar orgullosos existe entre el personal un sentimiento de negativismo, un pesimismo, un complejo de inferioridad, un autodesprecio..." (SRS5)

"Debería haber un plan en ese sentido de concienciación por una parte que la gente se sintiese orgullosa de trabajar dónde trabaja y hacer equipo" (SRS4)

"Yo creo que hay una conciencia de que es un mal hospital, de que es un desastre y demás, cosa que es falsa según me parece a mí. Yo creo que hay que salir y ver otros hospitales" (SRS5)

Para los entrevistados el reto de la dirección es revertir la situación del personal y crear el espíritu de equipo, de orgullo, de pertenencia.

"Hay cosas mejorables, e incluso creo que ahora en gestión están cambiando las cosas, está habiendo un tipo de gestión más participativa y más conocida y eso es muy bueno. $Y$ que a lo mejor falta eso, faltan criterios arriba y en los servicios de organización, de gestión" (SRS5)

En esta línea se percibe entre el personal la sensación de que se está comenzando a producir un cambio en la organización (ilustración 25).

Sería necesario concienciar al personal también de su importancia en la sostenibilidad de la organización y de implicarlo en la gestión.

“El problema del personal es algo que está ahí, está claro."(SRS2)

"El mayor activo en un hospital es el recurso humano y en función de cómo está orientada la mente de la gente que está trabajando es más sostenible o menos sostenible. Como todo es de todos es como si no fuese de nadie. Las roturas pueden ser porque se caen las cosas a veces justificadamente, pero otras muchas por falta de cuidado. $Y$ eso es lo que se está cuidando en el sector privado por miedo, por objetivos o por lo que sea" (SRS7).

"Dentro de la obligación de un sistema público 100\%, hay que dar respuesta a toda la población. El personal asistencial no tiene como principal criterio los criterios económicos a la hora de planificar su actividad asistencial" (SRS4).

No obstante, los profesionales de la salud consideran que el servicio ofrecido es muy bueno, aunque preocupa el aspecto económico. La percepción de la capacidad asistencial y de los cuidados dispensados es muy buena. También se aprecia diferencia entre las personas que forman parte de personal sanitario asistencial y las que pertenecen a procesos de apoyo.

"En la administración pública hay muchísimos factores que impiden hacer una gestión más adecuada, pero la medicina pública es bastante más avanzada que la privada porque el sector privado no puede hacer una cobertura tan amplia. Sin inversiones públicas es imposible. Si recortas los flecos la sanidad pública es sostenible."(SRS8)

"La organización actualmente tiene un personal muy preparado aunque el riesgo en breve es que se jubila gran parte de la plantilla y puede ser difícil atraer a este centro a personal cualificado" (SRS2) 
"Por cultura de los médicos o por la ilusión sí que vemos que en general los pacientes están muy contentos con el centro. La relación médico paciente sobre todo en consulta es la satisfacción por todo esto... la seguridad de los pacientes, la habitación individual y esas cosas es importante pero luego tienen que estar contentos con el trato" (SRS3)

Por otra parte, respecto a la implantación de sistemas o herramientas de calidad, las personas reconocen su poco conocimiento, aun así manifiestan una visión positiva de los mismos.

"La verdad es que hemos echado pestes de la lso y de todo eso pero ahora lo tengo todo ordenado, que me sirve y que desde luego no prescindiría de ello. Lógicamente tampoco veo mucho sentido a que esté acreditado un servicio por separado, lo lógico es que se acredite un hospital" (SRS6)

"Prácticamente cualquier sistema. No soy capaz de juzgar si uno es mejor que otro, pero creo que prácticamente cualquier sistema que intente poner orden y medir las cosas es esencial. Es un poco analizar qué haces, para qué lo haces, cómo lo haces, ver o que tienes y me da igual un sistema que otro. Yo creo que para unidades individuales ISO 9001 muy bien y la EFQM yo lo veo más para el hospital en su conjunto. Yo creo que el hospital debería plantearse como hospital adoptar el modelo EFQM y trabajar en sus unidades con la ISO u propios sistemas propios de certificación" (SRS5)

\subsubsection{Interpretación del investigador}

No existe unanimidad sobre la sostenibilidad de la organización. También se aprecia diferencia entre las personas que forman parte de personal sanitario asistencial y las que pertenecen a procesos de apoyo. Los profesionales de la salud consideran que el servicio ofrecido es muy bueno, aunque preocupa el aspecto económico. La percepción de la capacidad asistencial y de los cuidados dispensados es muy buena.

Para algunos entrevistados, el sistema actual no es sostenible. Los recursos son finitos. El sistema es sostenible siempre y cuando el que da el dinero, la consejería, tenga dinero para hacerlo. Si este recauda menos es difícil. El sistema no es sostenible y los hospitales serán sostenibles en la medida en que la administración, que es la que tiene el dinero, pueda dar ese dinero. Todo depende de la prioridad política y de la legislación vigente en cada momento.

También depende de la voluntad política la implantación de un modelo de calidad, y la priorización de la actividad del centro en función de la disponibilidad de recursos económicos, pero siempre sin perder la referencia del paciente. Esta apuesta por priorizar el ahorro mejora la eficiencia de la organización, pero por otro lado provoca en las personas de la organización un sentimiento de falta de sensibilidad por el equipo directivo y en consecuencia un desapego de la organización.

En todo caso, la implantación de sistemas de gestión de calidad introduce en la organización un método de trabajo. Ordena los procedimientos dotándolos de continuidad y mejorando su eficacia. Por otro lado, proporciona a los profesionales la unificación de criterios. 
Toda la organización reconoce al paciente como su principal cliente. Esto hace que se priorice lo asistencial sobre todo lo demás y que exista la sensación de poca implicación o poco reconocimiento de la importancia y la participación de los procesos de apoyo en el logo de la misión de la organización. Esta orientación al paciente busca no solo la satisfacción sino que también favorece que se mejoren aspectos como la seguridad.

Otro aspecto importante que surge del análisis del discurso de las personas de la organización es la importancia que se le concede al colectivo de enfermería. Según los entrevistados la enfermería es una pieza clave del futuro de la sostenibilidad sanitaria. La situación social y económica de La Rioja es similar a la del resto de España, puede que en algunos indicadores económicos como tasa de desempleo o renta per cápita sea ligeramente mejor, aunque sin alcanzar los niveles de País Vasco.

La Rioja es una comunidad pequeña, y no puede tener centros ubicados a lo largo del territorio e intenta dar respuestas con los recursos de los que dispone. Se ha optado por la cercanía al territorio y a la población, y no se optó por unidades súper especializadas porque tendrían que estar cerca de los hospitales con lo cual estarían lejos de los pueblos.

Con el II Plan de salud de La Rioja se consiguió elaborar un sistema de información de indicadores de calidad cuya evaluación permite la mejora continua. Quedaron pendientes de completar dentro de este objetivo específico el elaborar un plan de calidad común para todo el sistema riojano de salud y el impulsar la figura del coordinador de calidad en los distintos centros sanitarios.

Para mejorar la satisfacción del paciente con el sistema se propuso la realización de encuestas de satisfacción, llevadas a cabo en distintos ámbitos, con el establecimiento de planes de mejora a partir de las mismas se consideró necesario actualizar e impulsar el plan de acogida al paciente, objetivo ya alcanzado. No obstante no es hasta principios de 2017 cuando se empiezan a realizar las encuestas de satisfacción de pacientes de forma general en el SERIS por lo que la medida de la percepción de estos durante los pasados años resulta cuanto menos cuestionable, ya que la única fuente de información al respecto eran las encuestas realizadas dentro del barómetro sanitario realizado por el ministerio. Estas encuestas se realizan mediante muestreo en relación a proporcionar a la población de todas las comunidades autónomas correspondiéndole a La Rioja un número de encuestas muy pequeño que pone en cuestión su representatividad.

No se ha trabajado con el modelo EFQM durante los años de la crisis la organización y la percepción de los trabajadores fue que la dirección priorizaba el ahorro económico en detrimento de los demás criterios.

No obstante a partir de 2014 se comienzan a ver en la organización signos de cambio. Por un lado se define una nueva estrategia de crónicos que muestra en sus documentos una planificación orientada a la mejora continua y a la sostenibilidad.

Además en 2016 se comienzan a realizar encuestas de satisfacción a pacientes, se crea el Código de Buenas Prácticas con la participación de los profesionales y se realiza la primera autoevaluación del Hospital San Pedro con el modelo EFQM. En 2017 se comienza la elaboración de plan de calidad y del plan director. 


\subsection{El caso retrospectivo de la OSI Bilbao-Basurto}

La OSI Bilbao-Basurto (OSIBB) es una organización de servicios sanitarios formada por la antigua comarca de Atención Primaria de Bilbao y el Hospital Universitario Basurto. Se trata de una organización surgida al amparo de la política sanitaria de Osakidetza en 2014. Aún es pronto para saber si esta unión sumará, multiplicará o restará a la organización o a sus grupos de interés. No obstante, el objetivo de esta integración es ofertar una prestación integrada de servicios de atención primaria y hospitalaria destinados a la promoción de la salud, así como a la prevención, cuidado, mejora y curación de la enfermedad en coordinación con otras estructuras asistenciales de Osakidetza y de otras organizaciones, así como con los agentes sociales e institucionales implicados (OSIBB, 2015).

\subsubsection{Descripción del contexto}

\subsubsection{Situación sociodemográfica}

En la actualidad la OSI Bilbao- Basurto asume la provisión de servicios sanitarios del área de Bilbao, siendo referencia para unos 370.000 habitantes.

La OSI Bilbao-Basurto es una organización sanitaria que desarrolla su labor en el País Vasco, cuyas características demográficas se exponen en la siguiente tabla (tabla 53).

Tabla 53. Indicadores demográficos del País Vasco

\begin{tabular}{|l|c|c|}
\hline \multicolumn{1}{|c|}{ País Vasco } & $\mathbf{2 0 0 8}$ & $\mathbf{2 0 1 5}$ \\
\hline Esperanza de Vida Hombres & 78.367518 & 80.129739 \\
\hline Esperanza de Vida Mujeres & 85.099707 & 85.996982 \\
\hline Saldo vegetativo por mil habitantes & 0.866255 & $-1,230706$ \\
\hline Edad Media de la Población & 42.989701 & 44.652625 \\
\hline \% de población extranjera & 5.794410 & 4.962357 \\
\hline \% personas mayores de 64 años & 18.498483 & 21.713589 \\
\hline Tasa de dependencia & 57.319831 & 47.220147 \\
\hline
\end{tabular}

Fuente: INE

La recuperación en la actividad y en el empleo se mantuvo durante 2016. EI PIB de la economía del País Vasco creció un 3,1\% a lo largo del año 2016, dos décimas más que en el año anterior y casi el doble que en $2014(1,6 \%)$. Los cuatro grandes sectores de actividad registran variaciones positivas, destacando los sectores de la Industria $(3,3 \%)$ y el sector Servicios (3,2\%). Tanto la rama de Construcción como el sector Primario registraron variaciones positivas pero más moderadas, del 1,6\%. Según la Encuesta de Población en Relación con la Actividad (PRA) del Eustat, la población ocupada creció durante 2016 en 8.100 personas. Este aumento se concentró fundamentalmente en las mujeres, con 5.500 ocupadas más, en tanto que los hombres ocupados aumentaron en 2.600. La tasa de ocupación, porcentaje de personas ocupadas de 16 a 24 años sobre el total de esas edades, se situó en el $65,9 \%$.

Durante 2016 la tasa de paro disminuyó en 2,2 puntos porcentuales (del 14,7\% al $12,5 \%$ ). Esta tasa de paro del $12.5 \%$ en el País Vasco es menor que la registrada en España $(19,2 \%)$ pero superior a la tasa del conjunto de la Unión Europea-28 (8,3\%, 
según EUROSTAT en noviembre de 2016). Por grupos de edad la tasa de paro juvenil $(24,8 \%)$ sigue siendo la más alta y casi duplica la media de la población.

El salario medio bruto anual por persona trabajadora en el año 2014, según la Encuesta de Estructura Salarial realizada por el INE, ascendía a 27.787 euros, siendo la Comunidad con los salarios más altos. El salario medio a nivel estatal se sitúa en $22.858,17$ euros.

También es una de las regiones españolas con menor riesgo de pobreza (tabla 54)

Tabla 54. Riesgo de pobreza o exclusión social en País Vasco

\begin{tabular}{|c|c|c|c|c|c|c|c|c|}
\hline $\begin{array}{c}\text { Tasa de riesgo de pobreza o } \\
\text { exclusión social (indicador } \\
\text { AROPE) }\end{array}$ & $\mathbf{2 0 1 5}$ & $\mathbf{2 0 1 4}$ & $\mathbf{2 0 1 3}$ & $\mathbf{2 0 1 2}$ & $\mathbf{2 0 1 1}$ & $\mathbf{2 0 1 0}$ & $\mathbf{2 0 0 9}$ & $\mathbf{2 0 0 8}$ \\
\hline País Vasco & 17,6 & 15,3 & 16,8 & 17,7 & 18,9 & 16,3 & 14,8 & 13,9 \\
\hline España & 28.6 & 29.2 & 27.3 & 27.2 & 26.7 & 26.10 & 24.7 & 23.8 \\
\hline
\end{tabular}

El fenómeno del envejecimiento demográfico afecta al País Vasco, al igual que al conjunto de las sociedades occidentales, con previsiones de duplicación del porcentaje de personas de 60 o más años para el año 2050. Esta evolución responde por un lado al notable aumento de la esperanza de vida a lo largo de las últimas décadas, y por otro a la caída de las tasas de natalidad. El efecto combinado de ambas causas hace que aumente el peso relativo de las personas mayores en el conjunto de la población. En el País Vasco este fenómeno es incluso más evidente y acelerado. La esperanza de vida es más alta que la media europea y la tasa de natalidad es más baja que la media europea. La proporción de población de 65 y más años en esta comunidad es del 21,4\%, superior a la que se da en España (18,5\%) y en Europa (18,9\%). Respecto a hace 10 años la proporción ha subido en 3 puntos porcentuales.

Si se tienen en cuenta las edades más avanzadas, las personas de 85 y más años, han pasado de ser el $2 \%$ en 2006 al 3,4\% en 2016. En la población de 100 y más años la prueba del envejecimiento de la población es más evidente, de 308 personas de estas edades en 2006 se ha pasado a 576 en 2016, lo que supone un aumento del $87 \%$. En 2026 se estima que este grupo en el País Vasco alcanzará las 2.182 personas.

En 2015 se registraron 18.851 nacimientos, lo que supone un descenso del 2,8\% con respecto al año anterior. La tasa de natalidad de Bizkaia y del País Vasco es baja. Fue del 8,7 por 1.000 habitantes en 2015 , por debajo de la media estatal $(9,0)$ y de la Unión Europa $(10,0)$.

Según las Proyecciones Demográficas para 2026 realizadas por Eustat, el País Vasco en 10 años contará con 2.077.000 habitantes, con lo que disminuirá en más de 100.000 personas entre 2013 y 2026. Se prevé que al crecimiento vegetativo negativo de la población, con un aumento de las defunciones y la disminución de los nacimientos, se sumará un saldo migratorio negativo en los próximos años. 


\subsubsection{Determinantes de la salud}

Los determinantes de la salud (tabla 55) condicionan el nivel de salud de los ciudadanos del País Vasco

Tabla 55. Indicadores de determinante de la salud (País Vasco/España)

\begin{tabular}{|c|c|c|c|c|c|c|c|c|c|c|c|c|c|c|c|c|c|}
\hline \multirow[b]{2}{*}{ Dominio } & \multirow[b]{2}{*}{ Indicador } & \multicolumn{2}{|c|}{2008} & \multicolumn{2}{|c|}{2009} & \multicolumn{2}{|c|}{2010} & \multicolumn{2}{|c|}{2011} & \multicolumn{2}{|c|}{2012} & \multicolumn{2}{|c|}{2013} & \multicolumn{2}{|c|}{2014} & \multicolumn{2}{|c|}{ Periodo } \\
\hline & & PV & $E$ & PV & $E$ & PV & $E$ & PV & $E$ & PV & $E$ & PV & $E$ & PV & $E$ & PV & $E$ \\
\hline Estilos de vida & $\begin{array}{l}\text { Prevalencia de consumo de tabaco } \\
\text { en población adulta. Ver definición }\end{array}$ & & $\ldots$ & 27,24 & 26,16 & .. & ... & 23,31 & 23,95 & $\ldots$ & $\ldots$ & & $\ldots$ & 22,75 & 22,98 & 8,54 & 5,07 \\
\hline $\begin{array}{l}\text { Detreminantes } \\
\text { biológicos }\end{array}$ & $\begin{array}{l}\text { Prevalencia de obesidad en } \\
\text { población de } 18 \text { y más años }\end{array}$ & .. & $\ldots$ & 14,06 & 16,00 & .. & $\ldots$ & 15,26 & 17,03 & $\ldots$ & $\ldots$ & $\ldots$ & $\ldots$ & 12,99 & 16,91 & $-4,49$ & $-3,18$ \\
\hline $\begin{array}{l}\text { Determinantes } \\
\text { sociales }\end{array}$ & $\begin{array}{l}\text { Proporción de población de } 25 \text { a } \\
64 \text { años con nivel de estudios de } \\
\text { 10 Etapa de educación secundaria } \\
\text { o inferior }\end{array}$ & 36,40 & 49,00 & 35,50 & 48,50 & 33,50 & 47,40 & 33,00 & 46,20 & 31,90 & 45,60 & 31,90 & 44,50 & 31,60 & 43,40 & $-1,07$ & 0,91 \\
\hline Sociodemográf & id índice de dependencia & 46,01 & 45,30 & 47,10 & 46,01 & 48,58 & 46,86 & 50,04 & 47,69 & 51,43 & 48,44 & 53,05 & 49,45 & 54,55 & 50,37 & $-6,3$ & $-6,4$ \\
\hline Accesibilidad & $\begin{array}{l}\text { Cobertura }(\%) \text { de personas } \\
\text { mayores de } 65 \text { años vacunadas } \\
\text { frente a la gripe }\end{array}$ & 70,08 & 65,41 & 70,56 & 65,67 & & 56,87 & 68,10 & 57,70 & 60,60 & 57,00 & 59,80 & 56,40 & 60,30 & 56,20 & $-9,58$ & $-9,31$ \\
\hline Accesibilidad & $\begin{array}{l}\text { Cobertura }(\%) \text { de vacunación } \\
\text { frente a la poliomielitis } \\
\text { (primovacunación 0-1 años) }\end{array}$ & 92,97 & 96,71 & 94,77 & 95,88 & .. & 96,56 & 95,50 & 97,10 & 95,10 & 96,30 & 95,20 & 95,60 & 95,20 & 96,60 & 0,43 & $-0,11$ \\
\hline Accesibilidad & $\begin{array}{l}\text { Cobertura (\%) de vacunación } \\
\text { frente a sarampión-rubéola- } \\
\text { parotiditits (primovacunación 1-2 } \\
\text { años) }\end{array}$ & 95,32 & 97,65 & 96,80 & 97,42 & .. & 95,52 & 94,30 & 96,80 & 94,30 & 97,10 & 92,20 & 95,30 & 92,20 & 96,10 & $-1,42$ & $-1,45$ \\
\hline Accesibilidad & $\begin{array}{l}\text { Porcentaje de mujeres de } 50 \text { a } 69 \\
\text { años con mamografía realizada } \\
\text { con la frecuencia recomendada }\end{array}$ & & & 73,46 & 71,99 & & & 86,52 & 77,05 & & & & & 83,07 & 79,79 & 9,61 & 7,8 \\
\hline
\end{tabular}

Elaboración propia. Datos del http://inclasns.msssi.es

\subsubsection{Resultados en salud}

El número de defunciones en el País Vasco en 2015 fue de 21.509, lo que supone un incremento del 6,7\% respecto a 2014. La edad media de las mujeres fallecidas fue de 83,2 años y la de los hombres 76,6 años. Por causas, el $29,7 \%$ de las defunciones ocurridas en 2015 (6.379 muertes) se debió a tumores; a continuación se situaron las enfermedades del aparato circulatorio con un $26,9 \%$ (5.788 defunciones) y en tercer lugar las enfermedades respiratorias, que supusieron el 9,9\% (2.119).

La esperanza de vida al nacer en 2015 fue de 85,82 en las mujeres y de 79,97 en los hombres, y es una de las más altas de Europa. La tendencia ascendente en esperanza de vida se mantiene en los últimos años (ilustración26) pero esta progresión parece haberse frenado algo, particularmente en el caso de las mujeres, donde se ha incrementado 1,7 años en el periodo 2001-2015. En los hombres, y durante ese mismo periodo, la esperanza de vida ha incrementado 3,4años. El diferencial mujeres-hombres, que llegó a alcanzar los 8 años durante la década de los 90 se ha acortado hasta los 5,9 años. 


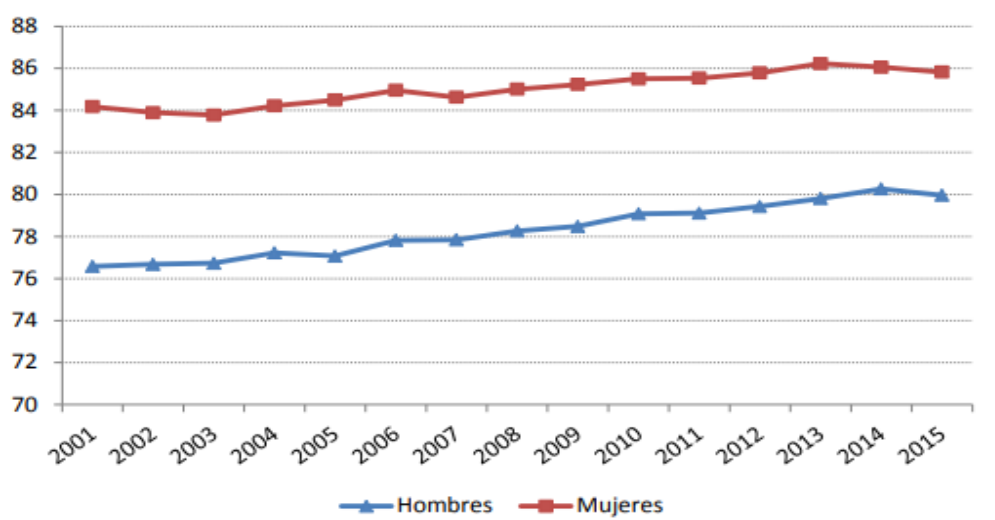

Fuente: Dirección de Planificación, Ordenación y Evaluación Sanitaria. Departamento de Salud. Informe Salud pública. 2016

La tasa bruta de mortalidad es de 965,2 por 100.000 habitantes (un 6,1\% más que en el 2014), 941,0 para las mujeres y 990,7 para los hombres. La tasa de mortalidad ajustada por edad a la población europea estándar de 1976, es de 437,8 por 100.000 habitantes, 324,3 para las mujeres y 583,7 para los hombres. La tasa de mortalidad ajustada por edad a la población europea estándar de 2013 , es de 838,8 por 100.000 habitantes, 641,4 para las mujeres y 1.126,6 para los hombres.

Los tumores (30\%) son la primera causa de muerte entre la población del País Vasco en el 2015, en segundo lugar se encuentran las enfermedades del sistema circulatorio $(27 \%)$. En orden de frecuencia le siguen las enfermedades del sistema respiratorio $(10 \%)$, las enfermedades del sistema nervioso (7\%) y los trastornos mentales $(6 \%)$.

Por sexos, en las mujeres la primera causa de muerte son las enfermedades del sistema circulatorio (29\%), seguidas de los tumores (24\%), a continuación se encuentran las enfermedades del sistema respiratorio ( $9 \%)$, las enfermedades del sistema nervioso y los trastornos mentales ambos con un $8 \%$.

En los hombres, los tumores (36\%) son la primera causa de muerte, seguidos de las enfermedades del sistema circulatorio (25\%) y de las enfermedades del sistema respiratorio (11\%), del sistema nervioso $(5 \%)$, las enfermedades del sistema digestivo los trastornos mentales y las causas externas con un $4 \%$ cada una

Los fallecimientos hospitalarios aumentaron un $8,3 \%$ en 2015 , hasta los 7.949 . Las principales causas de defunción fueron las enfermedades circulatorias y los tumores, que supusieron el $43 \%$ de las defunciones, seguidas por las enfermedades respiratorias, que experimentaron un aumento del $16,7 \%$ respecto al año anterior

La esperanza de vida libre de discapacidad es un indicador que combina la visión aportada por los datos de la mortalidad con los de la discapacidad. Según la Encuesta de Salud del País Vasco de 2013 la esperanza de vida libre de discapacidad es de 69,8 años en hombres y 73,6 en mujeres. Respecto a la encuesta de 2007, la esperanza de vida libre de discapacidad ha disminuido 0,3 años en los hombres y 1,8 años en las mujeres. Los años vividos con discapacidad han aumentado, tanto en hombres como en mujeres. 
Los indicadores clave (tabla 56) identificados por el ministerio reflejan los niveles de salud en el País Vasco.

Tabla 56. Indicadores de salud (País Vasco/España)

\begin{tabular}{|c|c|c|c|c|c|c|c|c|c|c|c|c|c|c|c|c|c|}
\hline \multirow{2}{*}{ Dominios } & \multirow[b]{2}{*}{ Indicador } & \multicolumn{2}{|c|}{2008} & \multicolumn{2}{|c|}{2009} & \multicolumn{2}{|c|}{2010} & \multicolumn{2}{|c|}{2011} & \multicolumn{2}{|c|}{2012} & \multicolumn{2}{|c|}{2013} & \multicolumn{2}{|c|}{2014} & \multicolumn{2}{|c|}{ Periodo } \\
\hline & & PV & $E$ & PV & E & PV & $\mathrm{E}$ & PV & $E$ & PV & E & PV & E & PV & $E$ & PV & $E$ \\
\hline Bienestar & Esperanza de vida al nacer & 82,05 & 81,42 & 82,31 & 81,85 & 82,85 & 82,32 & 82,95 & 82,52 & 83,21 & 82,75 & 83,73 & 83,10 & 83,88 & 83,22 & 1,83 & 1,80 \\
\hline Bienestar & $\begin{array}{l}\text { Esperanza de vida en buena } \\
\text { salud al nacer }\end{array}$ & 63,57 & 63,15 & 65,77 & 61,96 & 65,99 & 62,15 & 68,07 & 66,51 & 68,19 & 66,60 & 68,54 & 66,83 & 68,66 & 66,88 & 2,89 & 4,92 \\
\hline Bienestar & $\begin{array}{l}\text { Años de vida saludable a los } \\
65 \text { años }\end{array}$ & 11,96 & 11,51 & 10,79 & 9,09 & 10,92 & 9,16 & 15,52 & 12,19 & 15,65 & 12,28 & 15,80 & 12,36 & 15,78 & 12,39 & 4,99 & 3,30 \\
\hline Bienestar & $\begin{array}{l}\text { Porcentaje de población con } \\
\text { valoración positiva de su } \\
\text { estado de salud }\end{array}$ & $\ldots$ & $\ldots$ & 70,89 & 70,86 & $\ldots$ & $\ldots$ & 75,34 & 75,27 & $\ldots$ & $\ldots$ & $\ldots$ & $\ldots$ & & & 4,45 & 4,41 \\
\hline Bienestar & $\begin{array}{l}\text { Porcentaje de población de } 65 \\
\text { años y más años con } \\
\text { valoración positiva de su } \\
\text { estado de salud }\end{array}$ & $\ldots$ & $\ldots$ & 41,60 & 44,15 & $\ldots$ & $\ldots$ & 52,67 & 44,15 & ... & $\ldots$ & $\ldots$ & $\ldots$ & 50,51 & 43,58 & 8,91 & $-0,57$ \\
\hline Mortalidad & $\begin{array}{l}\text { Tasa de mortalidad prematura } \\
\text { por Cáncer, ajustada por } \\
\text { edad, por } 100000 \text { hab }\end{array}$ & 116,58 & 106,51 & 116,92 & 105,11 & 11,89 & 104,08 & 114,32 & 103,44 & $\mid 107,29$ & $\mid 102,64$ & $\mid 107,49$ & 100,74 & $\mid 109,81$ & 97,99 & $-6,77$ & $-8,52$ \\
\hline Mortalidad & $\begin{array}{l}\text { Tasa de mortalidad prematura } \\
\text { por Cardiopatía isquémica, } \\
\text { ajustada por edad, por } 100 \\
000 \text { hab. }\end{array}$ & 17,23 & 22,20 & 17,18 & 20,78 & 16,16 & 20,00 & $\mid 16,50$ & 18,78 & 15,31 & 18,44 & 15,86 & 18,04 & 14,36 & 17,53 & $-2,87$ & $-4,67$ \\
\hline Mortalidad & $\begin{array}{l}\text { Tasa de mortalidad prematura } \\
\text { por Diabetes mellitus, ajustada } \\
\text { por edad, por } 100000 \text { hab. }\end{array}$ & 2,79 & 4,20 & 2,38 & 3,96 & 2,67 & 3,68 & 3,11 & 3,48 & 2,38 & 3,22 & 3,21 & 2,98 & 2,51 & 3,12 & $-0,28$ & $-1,08$ \\
\hline Mortalidad & $\begin{array}{l}\text { Tasa de mortalidad prematura } \\
\text { por Enfermedad vascular } \\
\text { cerebral, ajustada por edad, } \\
\text { por } 100000 \text { hab. } \\
\end{array}$ & 10,33 & 12,10 & 10,14 & 10,25 & 9,23 & 10,07 & 9,22 & 9,48 & 8,46 & 9,25 & 7,83 & 8,70 & 7,85 & 8,57 & $-2,48$ & $-3,53$ \\
\hline Mortalidad & $\begin{array}{l}\text { Tasa de mortalidad prematura } \\
\text { enfermedades crónicas de } \\
\text { vías respiratorias inferiores } \\
\text { por } 100000 \text { hab. }\end{array}$ & 5,17 & 6,28 & 4,92 & 6,29 & 5,67 & 5,85 & 4,35 & 5,69 & 4,55 & 5,67 & 4,23 & 5,32 & 4,20 & 5,10 & $-0,97$ & $-1,18$ \\
\hline Mortalidad & $\begin{array}{l}\text { Tasa de mortalidad infantil por } \\
1000 \text { nacidos vivos }\end{array}$ & 2,91 & 3,30 & 3,10 & 3,30 & 2,60 & 3,19 & 2,74 & 3,19 & 2,58 & 3,09 & 2,30 & 2,73 & 2,22 & 2,88 & $-0,69$ & $-0,42$ \\
\hline Mortalidad & $\begin{array}{l}\text { Tasa de mortalidad perinatal } \\
\text { por cada } 1000 \text { nacidos vivos }\end{array}$ & 5,07 & 4,38 & 5,90 & 4,50 & 5,48 & 4,43 & 4,38 & 4,59 & 5,43 & 4,63 & 4,80 & 4,58 & 4,22 & 4,38 & $-0,85$ & 0,00 \\
\hline Morbilidad & $\begin{array}{l}\text { Incidencia de tuberculosis por } \\
100000 \text { hab. }\end{array}$ & 18,99 & 18,02 & 18,88 & 16,81 & 18,48 & 15,71 & 18,56 & 14,63 & 16,30 & 13,11 & 14,79 & 11,87 & 14,87 & 10,80 & $-4,12$ & $-7,22$ \\
\hline Morbilidad & \begin{tabular}{|l|} 
Prevalencia declarada de \\
diabetes mellitus en población \\
adulta. Ver definición
\end{tabular} & $\ldots$ & $\ldots$ & 6,50 & 5,90 & $\ldots$ & $\ldots$ & 5,66 & 6,96 & $\ldots$ & $\ldots$ & $\ldots$ & $\ldots$ & 5,82 & 6,82 & $-0,68$ & 0,92 \\
\hline Morbilidad & \begin{tabular}{|l|} 
Prevalencia declarada de \\
trastornos mentales en \\
población adulta. Ver \\
definición
\end{tabular} & $\ldots$ & $\ldots$ & 7,25 & 9,58 & $\ldots$ & $\ldots$ & 8,17 & 9,61 & $\ldots$ & $\ldots$ & $\ldots$ & $\ldots$ & 9,22 & 10,65 & 1,97 & 1,07 \\
\hline Morbilidad & $\begin{array}{l}\text { Tasa ajustada de } \\
\text { hospitalización por infarto } \\
\text { agudo de miocardio por } 10 \\
000 \text { hab. }\end{array}$ & $\ldots$ & $\ldots$ & $\ldots$ & $\ldots$ & 7,22 & 8,72 & 6,25 & 8,44 & 6,33 & 8,57 & 6,53 & 8,51 & 5,95 & 8,21 & $-1,27$ & $-0,51$ \\
\hline Eficacia & $\begin{array}{l}\text { Tasa de mortalidad ajustada } \\
\text { por edad por cardiopatía } \\
\text { isquémica por } 100000 \text { hab. }\end{array}$ & 34,72 & 47,31 & 36,29 & 45,17 & 34,19 & 43,34 & 32,62 & 41,26 & 31,04 & 40,24 & 30,64 & 38,13 & 27,55 & 36,44 & $-7,17$ & $-10,87$ \\
\hline Eficacia & $\begin{array}{l}\text { Tasa de mortalidad ajustada } \\
\text { por edad, por enfermedad } \\
\text { cerebrovascular por } 100000 \\
\text { hab. } \\
\end{array}$ & 33,73 & 38,24 & 33,28 & 36,01 & 28,91 & 33,42 & 29,28 & 30,88 & 27,72 & 30,66 & 24,58 & 28,17 & 24,04 & 27,19 & $-9,69$ & $\mid-11,05$ \\
\hline Eficacia & Tasa de mortalidad perinatal & 5,07 & 4,38 & 5,90 & 4,50 & 5,48 & 4,43 & 4,38 & 4,59 & 5,43 & 4,63 & 4,80 & 4,58 & 4,22 & 4,56 & $-0,85$ & 0,18 \\
\hline Eficacia & Tasa de infección hospitalaria. & 1,25 & 1,25 & 1,24 & 1,27 & 1,26 & 1,29 & 1,16 & 1,26 & 1,16 & 1,29 & 1,24 & 1,32 & 1,17 & 1,24 & $-0,08$ & $-0,01$ \\
\hline Eficacia & $\begin{array}{l}\text { Tasa de fracturas de cadera } \\
\text { en pacientes ingresados. }\end{array}$ & 0,16 & 0,06 & 0,16 & 0,06 & 0,16 & 0,07 & 0,17 & 0,06 & 0,15 & 0,05 & 0,14 & 0,06 & 0,05 & 0,05 & $-0,11$ & $-0,01$ \\
\hline Eficacia & \begin{tabular}{|l|} 
Tasa de notificación de \\
reacciones adversas a \\
medicamentos (total)
\end{tabular} & 340,00 & 220,00 & 550,00 & 320,00 & 510,00 & 310,00 & 390,00 & 310,00 & 490,00 & 330,00 & 519,24 & 381,58 & 442,21 & 368,84 & 102,21 & 148,84 \\
\hline Eficacia & $\begin{array}{l}\text { Mortalidad intrahospitalaria } \\
\text { global por cada } 100 \text { altas } \\
\text { hospitalarias }\end{array}$ & 4,05 & 4,09 & 4,23 & 4,12 & 4,25 & 4,18 & 4,35 & 4,26 & 4,30 & 4,36 & 4,04 & 4,21 & 4,05 & 4,24 & 0,00 & 0,15 \\
\hline Eficacia & $\begin{array}{l}\text { Mortalidad intrahospitalaria } \\
\text { tras intervención quirúrgica } \\
\text { por cada } 100 \text { altas quirúrgicas }\end{array}$ & 1,64 & 1,73 & 1,74 & 1,71 & 1,50 & 1,67 & 1,59 & 1,69 & 1,42 & 1,62 & 1,39 & 1,55 & 1,16 & 1,53 & $-0,48$ & $-0,20$ \\
\hline Eficacia & $\begin{array}{l}\text { Mortalidad intrahospitalaria de } \\
\text { pacientes con neumonía por } \\
\text { cada } 100 \text { altas por neumonía }\end{array}$ & 7,12 & 8,69 & 7,81 & 8,50 & 8,06 & 8,38 & 7,48 & 8,80 & 7,79 & 9,80 & 7,59 & 8,93 & 6,88 & 8,44 & $-0,24$ & $-0,25$ \\
\hline
\end{tabular}

Elaboración propia. Datos del http://inclasns.msssi.es 


\subsubsection{Política sanitaria}

La Constitución Española de 1978 y el Estatuto de Autonomía del País Vasco de 1979 marcan las funciones que desempeña la Comunidad Autónoma del País Vasco en el campo de la sanidad.

Osakidetza-Servicio Vasco de Salud es el organismo creado en 1984 encargado del sistema de prestaciones sanitarias públicas en la comunidad autónoma del País Vasco, perteneciente al Sistema Nacional de Salud, creado en 1986 y que sustituyó al INSALUD.

El Departamento de Sanidad y Osakidetza, como organismos provisor, son los responsables de que los ciudadanos vascos tengan acceso a la atención sanitaria con la mayor calidad posible.

En 1993 se publicó Osasuna Zainduz, plan estratégico para la sanidad vasca. Este plan se formuló bajo la premisa de que los cambios sobre los factores endógenos del propio modelo de organización y gestión permitirían el reforzamiento de los fundamentos ideológicos de un modelo sanitario público y con unos niveles de autonomía que facilitasen una mayor eficiencia en el empleo de los recursos públicos. (Osakidetza, 2014)

En 1994 se redactó el primer Plan de Salud del Gobierno Vasco. Este Plan establecía el protagonismo del ciudadano como eje central en la fijación de metas y objetivos y de él se derivaban las directrices principales de actuación y el establecimiento de las estrategias a seguir en Osakidetza y después, en cada uno de sus organizaciones (despliegue vertical), para garantizar una adecuada cobertura para satisfacer las necesidades de los grupos de interés.

El Gobierno Vasco siempre ha mostrado apoyo a las políticas de calidad y una apuesta continuada por la creación en todos los ámbitos de la CAPAIS VASCO, incluida la salud, de una cultura de la excelencia. Para desarrollar esta política se creó en 1992 Euskalit, Fundación Vasca para la Calidad. Euskalit tiene como misión propiciar la mejora y la innovación de la gestión mediante la promoción de la cultura de la calidad total en todos los ámbitos de la sociedad. Su objetivo es contribuir al desarrollo, competitividad y bienestar del País Vasco. En 1995, dentro del marco de esta apuesta por la excelencia y con el apoyo de Euskalit, Osakidetza adopta el modelo EFQM.

En 1997 se aprobó la Ley de Ordenación Sanitaria de Euskadi, que establecía la estructura y la organización de todo el sistema sanitario público vasco. En esta Ley, se otorga el papel central a los ciudadanos en el sistema sanitario insistiendo en su carácter participativo. También se destaca la garantía de la protección legal de la salud con el respeto a la intimidad y dignidad de la persona, la práctica del consentimiento informado y el reconocimiento de la capacidad de elección.

La mejor manera de presentar el contexto estratégico en el que se encuentra inmerso Osakidetza es a través de las palabras expresadas por el consejero de salud del gobierno vasco, Jon Darpón Sierra (2014): "nuestro Objetivo es mantener el sistema de salud vasco, como público y universal, y trabajar para garantizar su futuro". En esta entrevista el consejero expresa el compromiso del sistema público de salud con los 
principios esenciales de universalidad, solidaridad, equidad, participación, calidad y sostenibilidad. La apuesta por el sistema público se refleja en el porcentaje de altas hospitalarias (tabla 57).

Tabla 57. Distribución de altas de hospitalización y tipo de hospital (2015).

\begin{tabular}{|c|c|c|}
\hline & Público & Privado \\
\hline País Vasco & $82.4 \%$ & $17.6 \%$ \\
\hline La Rioja & $87.1 \%$ & $12.9 \%$ \\
\hline España & $\mathbf{7 2 . 4 \%}$ & $\mathbf{2 7 . 6 \%}$ \\
\hline
\end{tabular}

El Gobierno Vasco señala que su objetivo es que la cultura de la promoción y prevención de la salud gane espacio frente a la cultura de la asistencia sanitaria y supone la espina dorsal del Plan de Salud 2013-2020 (Darpón, 2014). Darpón señala que el actual Plan de salud se elaboró tomando como referencia las políticas sanitarias de los países noreuropeos. A partir de la idea de la salud como un derecho y una responsabilidad de todas las personas, el plan propone lograr un sistema sanitario vasco equitativo y de calidad, priorizando la promoción de la salud, los entornos y estilos de vida saludables, y haciendo énfasis en los colectivos más vulnerables, es decir, mayores, infancia y juventud, y crónicos (Darpón, 2014). Este plan se entiende como un contrato social con los ciudadanos, liderado por el propio Lehendakari e incorporando una visión transversal, interinstitucional e intersectorial, para poder hacer salud también desde el resto de las políticas.

El actual Plan de Salud del Gobierno Vasco pretende, en palabras del consejero de salud, priorizar, racionalizar servicios, evitar duplicidades, comprar mejor, reorganizar, evaluar con rigor y actuar en consecuencia. Para ello se ha apostado por la creación de las OSIs integrando los niveles asistenciales de AP y AE e incorporando los Servicios Sociales. Todo ello con el objetivo de mejorar la respuesta y la continuidad de los cuidados a una población cada vez más envejecida y con enfermedades crónicas. El Plan trata de organizar la asistencia sanitaria desplazándola hacia la comunidad y el domicilio mediante el cambio de rol de los profesionales y el desarrollo de modalidades de atención sanitaria no presenciales (TICS, telemedicina). Para ello es preciso acompañarlo de una reorientación de las políticas de RRHH y favorecer la participación e implicación de los profesionales

Por su parte Osakidetza edita las Líneas Estratégicas y Planes de Acción para el periodo 2013-2016

Con este Plan se plantean y transmiten las directrices y las acciones a desarrollar para alcanzar los objetivos señalados en las Líneas Generales de las Políticas de Salud del Gobierno Vasco. En este documento se reconocen a la crisis económica y al progresivo envejecimiento poblacional, con un incremento paralelo de pacientes con pluripatología y dependencia, como los condicionantes sobre los que deben desarrollarse las acciones a desplegar en los próximos años. También expresa el compromiso de Osakidetza de ser un servicio público, universal y de calidad.

Siguiendo en esta línea el plan reconoce que los valores y logros en los que Osakidetza ha trabajado prácticamente desde sus orígenes no deben ser abandonados, sino que apoyándose en ellos, deberían ayudar a superar los problemas actuales. Uno de estos 
elementos es la calidad del servicio (ilustración 27). Calidad que siguen planteando como un elemento distintivo de valor de la organización tomando como centro y referencia de la misma al paciente. Pero también inciden en la calidad como eficiencia, como elemento esencial de la gestión.

Ilustración 27. Organizaciones con reconocimientos de calidad en Osakidetza

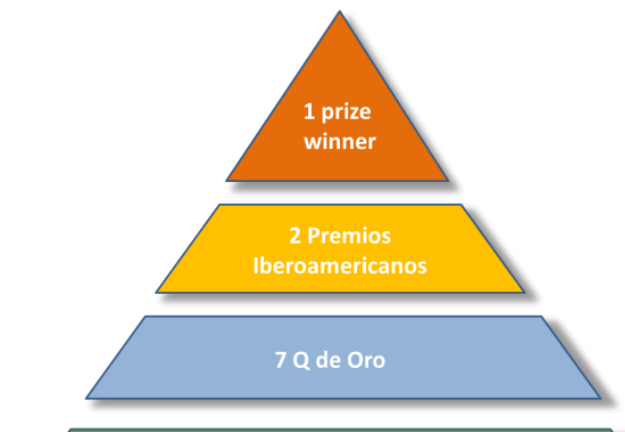

21 Q de plata

Fuente: Apezetxea, 2017

En este documento se señala que, en la actual situación, es necesario lograr el equilibrio de mantener y mejorar las prestaciones sanitarias con las limitaciones del presupuesto (tabla 58)

Tabla 58.Gasto sanitario público territorializado, por habitante protegido (euros)

\begin{tabular}{|l|c|c|c|c|c|c|c|c|}
\hline & $\mathbf{2 0 0 7}$ & $\mathbf{2 0 0 8}$ & $\mathbf{2 0 0 9}$ & $\mathbf{2 0 1 0}$ & $\mathbf{2 0 1 1}$ & $\mathbf{2 0 1 2}$ & $\mathbf{2 0 1 3}$ & $\mathbf{2 0 1 4}$ \\
\hline País Vasco & 1440 & 1579,7 & 1692,06 & 1687,53 & 1661,47 & 1561,5 & 1570,41 & 1583,12 \\
\hline La Rioja & 1884 & 1548,7 & 1514,99 & 1516,94 & 1490,1 & 1342,3 & 1331,31 & 1353,42 \\
\hline España & 1275 & 1389,9 & 1447,39 & 1423,51 & 1392,31 & 1339,5 & 1296,38 & 1289,24 \\
\hline
\end{tabular}

Fuente: INE

Así mismo afirma que es necesario gestionar con criterios de sostenibilidad. No solo siendo escrupulosos con los gastos, sino que es necesario ser transparentes y hablar de Buen Gobierno. Por todo ello propone como una necesidad propiciar cambios en las organizaciones, que deben ser entendidos como un reto de continua mejora y una apuesta por su propia supervivencia.

Los objetivos y planes de acción propuestos como objetivo general son (ilustración 28) en el Plan de Acción para el periodo 2013-2016 de Osakidetza:

- Preservar un sistema sanitario vasco, público, universal y de calidad

- Centrado en las personas-pacientes a los que se oferta servicios para mejorar y proteger su salud

- Con el concurso de sus profesionales y de los pacientes-clientes activos y comprometidos

- Bajo la premisa de que necesitamos un sistema sostenible

- Y para ello, nos apoyamos en la investigación e innovación y siendo uno de los pilares la integración, como modelo de atención y gestión 


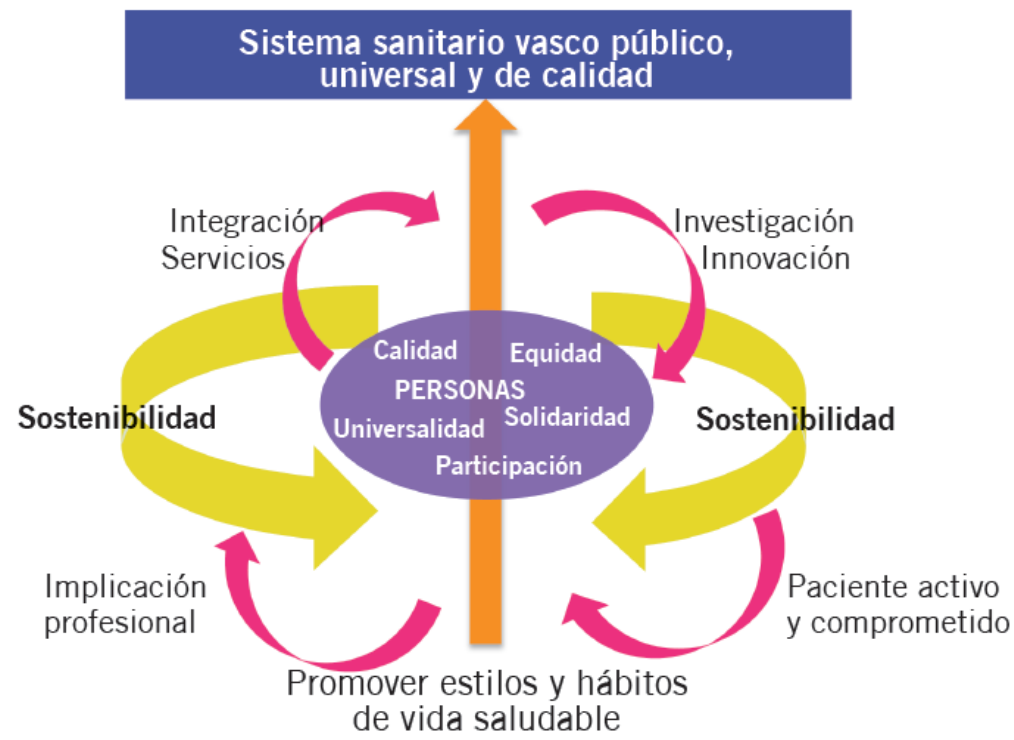

Fuente: Líneas Estratégicas Osakidetza 2013-2016.

Como se puede apreciar en la ilustración 28, el actual Plan Contiene las siguientes líneas estratégicas:

- Las personas son el eje central del sistema de salud

- Respuesta integrada a la cronicidad, vejez y dependencia

- Garantizar la sostenibilidad del sistema

- Protagonismo e implicación profesional

- Potencial la investigación y la innovación

Siguiendo el objeto de este trabajo, se expone a continuación la línea estratégica del Sistema Vasco de Salud-Osakidetza relacionada con la sostenibilidad del sistema. En ella se indica que todas las actuaciones (tabla 59) deben contribuir a preservar el sistema sanitario público y de calidad y su sostenibilidad presente y futura.

En los objetivos se cita la necesidad de impulsar un sistema de atención integral del paciente que evite duplicidades y aproveche sinergias adecuando estructuras administrativas y de gestión. Para lograrlo se plantea la necesidad de integrar estructuras que favorezcan la continuidad asistencial y la eficiencia.

Las Organizaciones Sanitarias Integradas (OSIs) son modelos organizativos que se adoptan para mejorar la atención sanitaria prestada a los ciudadanos potenciando el "enfoque poblacional" asumiendo la responsabilidad de la salud de toda la población de un área geográfica determinada.

Esto supone que se mejora la coordinación entre los diferentes niveles asistenciales por un lado y con los agentes sociales y de salud pública por otro lado. Es decir, se trabaja en el diseño de estrategias (tabla 59) y planes de acción para los pacientes atendidos, y para la población sana con el fin de desarrollar actividades de promoción de la salud y prevención. 
Tabla 59. Objetivos relacionados con la sostenibilidad del sistema (Osakidetza).

\begin{tabular}{|c|c|}
\hline Objetivo & Acciones \\
\hline $\begin{array}{l}\text { Impulsar un sistema de } \\
\text { atención integral del } \\
\text { paciente que evite } \\
\text { duplicidades y aproveche } \\
\text { sinergias adecuando } \\
\text { estructuras administrativas } \\
\text { y de gestión }\end{array}$ & $\begin{array}{l}\text { - Integrar estructuras favoreciendo la continuidad } \\
\text { - } \quad \text { Mejistencial y la eficiencia } \\
\text { - } \quad \text { Reforzar el papacidad resolutiva de la atención primaria } \\
\text { - } \quad \text { Facilitar la comunicación entre profesionales } \\
\text { - Elaborar un plan colaborativo entre diversas } \\
\text { organizaciones de servicios centrada en el paciente }\end{array}$ \\
\hline $\begin{array}{l}\text { Incluir en el sistema de } \\
\text { salud una política de } \\
\text { responsabilidad social } \\
\text { corporativa }\end{array}$ & 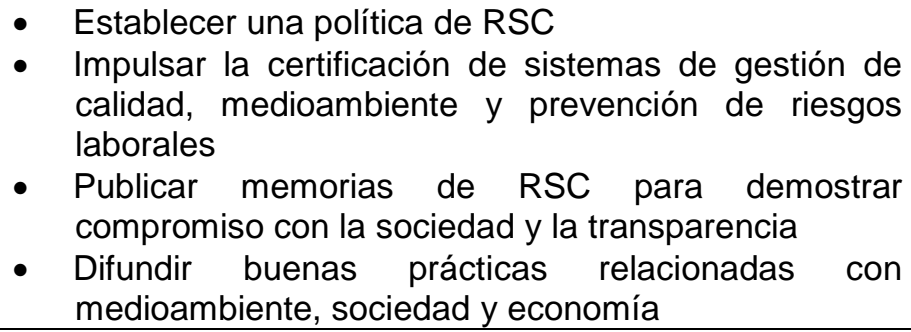 \\
\hline $\begin{array}{l}\text { Garantizar que el sistema } \\
\text { de salud cuente con las } \\
\text { infraestructuras } \\
\text { tecnologías adecuadas a } \\
\text { las necesidades de los } \\
\text { pacientes }\end{array}$ & $\begin{array}{l}\text { - } \quad \text { Elaborar un plan de infraestructuras y equipamientos } \\
\text { con criterios de sostenibilidad } \\
\text { - } \quad \text { Desarrollar unidades de referencia } \\
\text { - } \quad \text { Concentrar servicios hospitalarios } \\
\text { - } \quad \text { Desplegar un plan director de laboratorios } \\
\text { - Implantar acciones de gestión clínica para mejorar la } \\
\quad \text { eficiencia de los procesos }\end{array}$ \\
\hline $\begin{array}{l}\text { Desarrollar políticas de } \\
\text { eficiencia para garantizar la } \\
\text { sostenibilidad del sistema } \\
\text { de salud, reorientando la } \\
\text { contratación sanitaria hacia } \\
\text { resultados en salud }\end{array}$ & 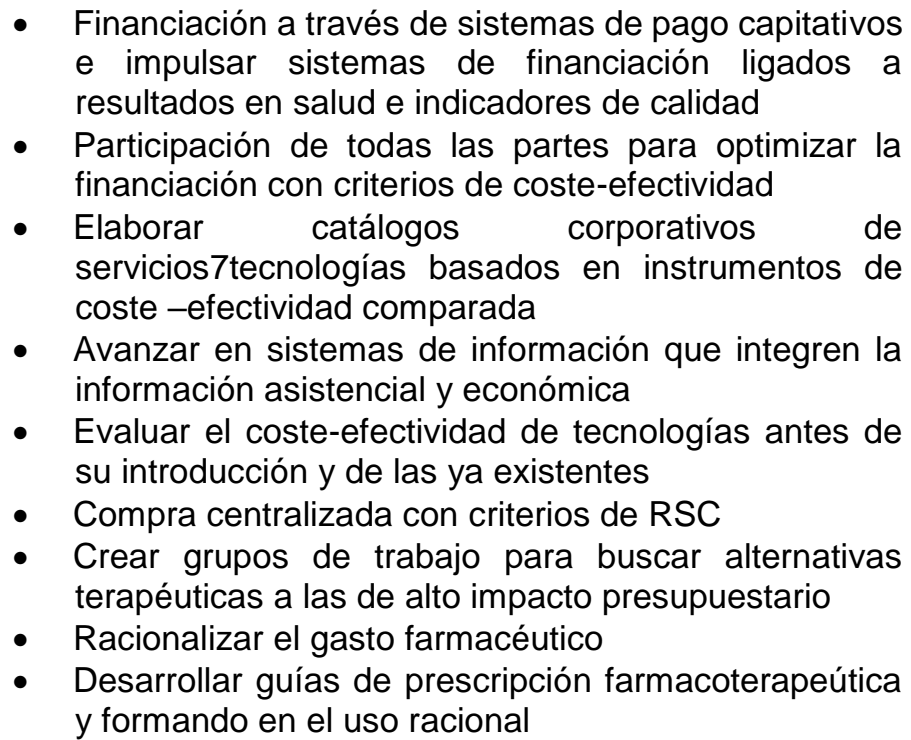 \\
\hline
\end{tabular}

Fuente: Líneas Estratégicas y Planes de Acción para el periodo 2013-2016 (disponible en Internet: http,//www.osakidetza.euskadi.net (2013)

Actualmente se está trabajando en este proyecto y existen varios procesos y líneas de trabajo que precisan de la implicación de todas las personas que forman parte de la OSIBB.

Según se expresa en la primera revista publicada de la OSI Bilbao -Basurto: "estamos convencidos de que la creación de la OSI supone un paso más para hacer frente, con garantía y calidad, a la sostenibilidad de nuestro sistema sanitario y mejorar e innovar, aún más si cabe, el servicio prestado a los ciudadanos". (BIBA 2014) 
También es necesario conocer los recursos humanos, el uso del sistema y la pertinencia de actividades clave (tabla 60), y los recursos económicos (tabla 61) que ha puesto el País Vasco para hacer efectiva su estrategia y poder establecer la eficacia y eficiencia del sistema

Tabla 60. Indicadores de recursos (País Vasco/España)

\begin{tabular}{|c|c|c|c|c|c|c|c|c|c|c|c|c|c|c|c|c|c|}
\hline \multirow[b]{2}{*}{ DOMINIOS } & \multirow[b]{2}{*}{ INDICADOR } & \multicolumn{2}{|c|}{2008} & \multicolumn{2}{|c|}{2009} & \multicolumn{2}{|c|}{2010} & \multicolumn{2}{|c|}{2011} & \multicolumn{2}{|c|}{2012} & \multicolumn{2}{|c|}{2013} & \multicolumn{2}{|c|}{2014} & \multicolumn{2}{|c|}{ Periodo } \\
\hline & & PV & E & PV & E & PV & E & PV & E & PV & E & PV & E & PV & E & PV & E \\
\hline Recursos & $\begin{array}{l}\text { Personal médico AP por } 1000 \\
\text { personas asignadas }\end{array}$ & 0,69 & 0,75 & 0,61 & 0,74 & 0,62 & 0,75 & 0,78 & 0,76 & 0,78 & 0,77 & 0,73 & 0,76 & 0,78 & 0,76 & 0,09 & 0,01 \\
\hline Recursos & $\begin{array}{l}\text { Camas hospitalarias en funcionamiento } \\
\text { por } 1000 \text { hab. }\end{array}$ & 3,75 & 3,22 & 3,71 & 3,19 & 3,69 & 3,15 & 3,63 & 3,09 & 3,60 & 3,03 & 3,40 & 2,97 & 3,37 & 2,97 & $-0,38$ & $-0,25$ \\
\hline Recursos & $\begin{array}{l}\text { Puestos en hospitales de día por } 1000 \\
\text { hab. }\end{array}$ & 0,27 & 0,24 & 0,28 & 0,26 & 0,24 & 0,35 & 0,28 & 0,37 & 0,56 & 0,40 & 0,59 & 0,40 & 0,59 & 0,41 & 0,32 & 0,17 \\
\hline Recursos & $\begin{array}{l}\text { Equipos de hemodinámica por } 100000 \\
\text { hab. }\end{array}$ & 0,47 & 0,49 & 0,47 & 0,48 & 0,56 & 0,53 & 0,47 & 0,55 & 0,66 & 0,57 & 0,69 & 0,58 & 0,74 & 0,57 & 0,27 & 0,08 \\
\hline Uso & $\begin{array}{l}\text { Frecuentación en medicina de AP por } \\
\text { persona asignada/año }\end{array}$ & 4,68 & 6,10 & 3,92 & 5,56 & 3,87 & 5,43 & 4,17 & 5,51 & 4,77 & 5,31 & 4,84 & 5,30 & 4,83 & 5,24 & 0,15 & $-0,86$ \\
\hline Uso & $\begin{array}{l}\text { Tasas de uso de resonancia } \\
\text { magnética por } 1000 \text { hab./año }\end{array}$ & 33,32 & 38,92 & 32,27 & 43,06 & 29,49 & 48,25 & 29,52 & 50,67 & 33,23 & 50,96 & 32,00 & 54,86 & 49,23 & 60,28 & 15,91 & 21,36 \\
\hline Uso & $\begin{array}{l}\text { Índice de la estancia media ajustada } \\
\text { (IEMA) }\end{array}$ & 0,99 & 1,00 & 0,98 & 1,00 & 0,98 & 1,00 & 0,99 & 1,00 & 0,98 & 1,00 & 0,98 & 1,00 & 0,97 & 1,00 & $-0,02$ & 0,00 \\
\hline Uso & $\begin{array}{l}\text { Porcentaje de cirugía ambulatoria en el } \\
\text { SNS }\end{array}$ & 37,74 & 40,45 & 38,64 & 42,33 & 39,09 & 43,04 & 40,39 & 43,93 & 39,18 & 45,19 & 40,83 & 46,50 & 42,75 & 46,86 & 5,01 & 6,41 \\
\hline Uso & DHD de antibióticos & & & & & & & & & 19,16 & 19,14 & 22,06 & 19,47 & 23,35 & 20,86 & 4,19 & 1,72 \\
\hline Pertinencia & $\begin{array}{l}\text { Porcentaje de cirugía conservadora en } \\
\text { cáncer de mama }\end{array}$ & 69,78 & 61,49 & 67,65 & 62,43 & 66,49 & 62,98 & 68,76 & 63,33 & 72,02 & 64,67 & 69,58 & 63,80 & 71,15 & 65,27 & 1,37 & 3,78 \\
\hline Pertinencia & $\begin{array}{l}\text { Porcentaje de pacientes con fractura } \\
\text { de cadera intervenidos en las primeras } \\
48 \text { horas }\end{array}$ & 44,91 & 36,74 & 46,18 & 37,13 & 57,16 & 40,49 & 52,00 & 41,42 & 54,35 & 40,47 & ... & 42,03 & 53,55 & 42,03 & 8,64 & 5,29 \\
\hline
\end{tabular}

Elaboración propia. Datos del http://inclasns.msssi.es

Tabla 61. Indicadores de recursos económicos (País Vasco/España)

\begin{tabular}{|c|c|c|c|c|c|c|c|c|c|c|c|c|c|c|c|c|c|}
\hline \multirow[b]{2}{*}{ DOMNNOS } & \multirow[b]{2}{*}{ INDCADOR } & \multicolumn{2}{|c|}{2008} & \multicolumn{2}{|c|}{2009} & \multicolumn{2}{|c|}{2010} & \multicolumn{2}{|c|}{2011} & \multicolumn{2}{|c|}{2012} & \multicolumn{2}{|c|}{2013} & \multicolumn{2}{|c|}{2014} & \multicolumn{2}{|c|}{ Periodo } \\
\hline & & PV & E & PV & E & PV & E & PV & E & PV & E & PV & E & PV & E & PV & E \\
\hline Económico & $\begin{array}{l}\text { Gasto sanitario público territorializado, } \\
\text { por habilante protegido }\end{array}$ & 1579,69 & 1389,88 & 1692,06 & 1447,39 & 1687,53 & 1423,51 & 1661,47 & 1392,31 & 1561,50 & 1339,49 & 1570,41 & 1296,38 & 1583,12 & 1289,24 & 3,43 & $-100,64$ \\
\hline Econónico & $\begin{array}{l}\text { Porcentiaje del lassio santariorio en } \\
\text { atención pimarila }\end{array}$ & 14,64 & 14,52 & 14,82 & 14,34 & 14,81 & 14,19 & 14,64 & 13,77 & 14,73 & 13,55 & 14,30 & 12,95 & 14,36 & 13,40 & 0,28 & $-1,12$ \\
\hline Econónico & $\begin{array}{l}\text { \% del gasto de los servicios de } \\
\text { atención especializada }\end{array}$ & 54,28 & 50,85 & 54,77 & 51,50 & 55,28 & 51,55 & 56,44 & 53,33 & 57,01 & 54,93 & 58,35 & 54,70 & 59,84 & 55,80 & 5,56 & 4,95 \\
\hline Econónico & $\%$ dol gastion en farmacia & 18,75 & 20,67 & 18,02 & 20,59 & 17,76 & 20,78 & 16,75 & 19,27 & 15,86 & 17,55 & 15,18 & 17,81 & 14,48 & 17,55 & 4,27 & $-3,12$ \\
\hline Econónico & $\begin{array}{l}\% \text { dol gasito en remuneración de } \\
\text { personal }\end{array}$ & 49,56 & 44,69 & 50,09 & 45,63 & 50,45 & 45,66 & 50,80 & 45,62 & 50,21 & 44,52 & 51,36 & 46,09 & 52,18 & 45,97 & 2,62 & 1,28 \\
\hline Econónico & $\%$ del lasasto en consumos intermedios & 1898 & 20,91 & 19,63 & 21,02 & 19,90 & 20,84 & 20,35 & 22,88 & 22,25 & 25,77 & 22,81 & 24,20 & 22,67 & 24,52 & 3,69 & 3,61 \\
\hline Econónico & $\%$ del lasio dedicado a conciertos & 7,18 & 9,45 & 7,06 & 8,98 & 6,96 & 9,03 & 6,96 & 9,26 & 7,19 & 9,57 & 7,05 & 9,52 & 6,96 & 9,56 & 0,22 & 0,11 \\
\hline Eiciencia & $\begin{array}{l}\text { Estancia media aujsistala por la } \\
\text { casuisicica (BARC) }\end{array}$ & 6,13 & 6,17 & 6,03 & 6,04 & 5,96 & 6,01 & 5,86 & 5,89 & 5,74 & 5,75 & 5,63 & 5,68 & 5,57 & 5,77 & $\cdot 0,56$ & $\cdot 0,40$ \\
\hline Eiciencia & Porcentaje de cirugáa ambulatoria & 37,74 & 40,45 & 38,64 & 42,33 & 39,09 & 43,04 & 40,39 & 43,93 & 39,18 & 45,19 & 40,83 & 46,50 & 42,75 & 46,86 & 5,01 & 6,41 \\
\hline Eicicincia & Porcentiaje gobal de rengieresos & 7,59 & 7,08 & 7,69 & 7,16 & 6,90 & 7,08 & 6,95 & 7,31 & 7,54 & 7,43 & 7,53 & 7,56 & 7,71 & 7,73 & 0,12 & 0,65 \\
\hline
\end{tabular}

Elaboración propia. Datos del http://inclasns.msssi.es 


\subsubsection{Gestión de la calidad}

\section{Situación anterior a 2007}

El Hospital de Basurto fue edificado, gracias a donaciones, entre los años 1898 y 1908 para responder a las necesidades sanitarias de la población de Bizkaia siguiendo los criterios de modernidad de la época. El hospital fue construido en el barrio de Basurto, del que tomó su nombre. Los edificios del hospital han sido declarados bien de interés cultural por lo que su aspecto externo no ha sufrido grandes modificaciones (ilustración 29). No obstante, para adecuarlo a las necesidades sanitarias actuales se ha ido actualizando y remodelando (ilustración 30 ).

Ilustración 29. Hospital Universitario Basurto (Bilbao)
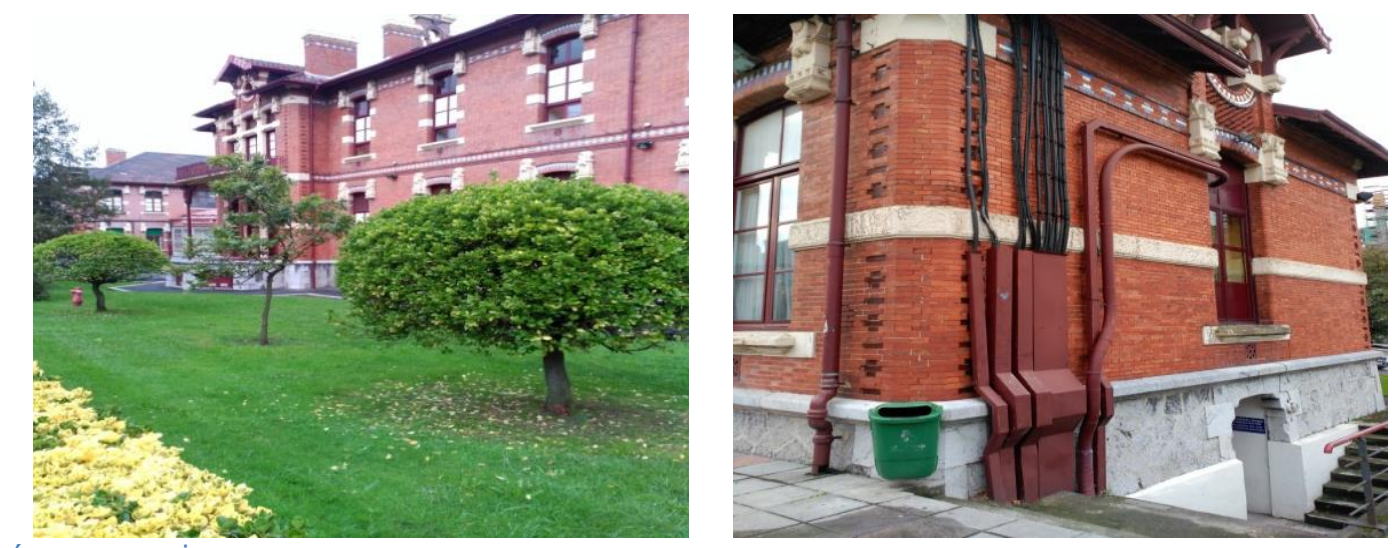

Imágenes propias

El Hospital de Basurto perteneció hasta la década de los 80 del siglo XX a la Diputación Foral de Vizcaya. Tras la creación de Osakidetza, esta asumió la gestión de todos los centros sanitarios públicos de la Comunidad Autónoma del País Vasco, y en 1992 el Hospital de Basurto se integró definitivamente en la red sanitaria pública vasca y se incorporó al primer plan integral de calidad de Osakidetza.

Ilustración 30. Mapa del Hospital de Basurto

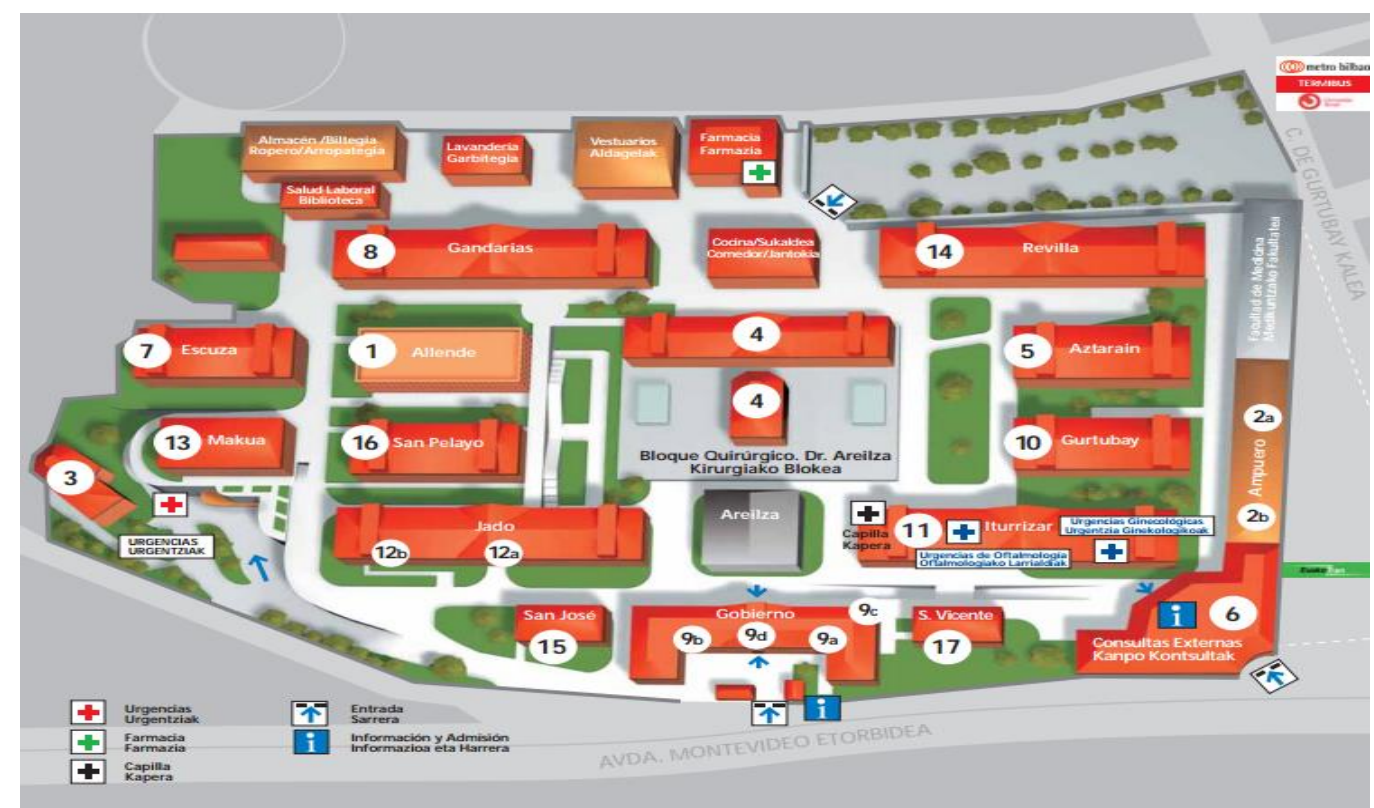

Fuente: http://www.osakidetza.euskadi.eus 
Por su parte, la otra organización que pasó a formar parte de la OSI Bilbao-Basurto, la Comarca Bilbao, inició su andadura en 1989 como responsable de la asistencia sanitaria extrahospitalaria del municipio de Bilbao incluyendo atención primaria, atención especializada ambulatoria y salud mental. A partir de 1997, la atención especializada se integra en el Hospital de Basurto y la Comarca Bilbao pasa a ser una organización exclusivamente de servicios de Atención Primaria de Salud.

El Servicio Vasco de Salud-Osakidetza comienza con la elaboración en 1992 del primer Plan Integral de Calidad de Osakidetza, la aplicación de modelo y herramientas de calidad.

En el año 1994, Osakidetza se vincula como miembro de la Fundación Vasca para el Fomento de la Calidad (FVFC) "Euskalit", la cual opta por el modelo europeo de gestión de la calidad total como modelo de referencia.

Este compromiso con la calidad total, que ya tenía un precedente en el documento Osasuna Zainduz (estrategias de cambio para la sanidad vasca) aprobado por el Parlamento Vasco hace que, en el año siguiente (1995), Osakidetza se plantee como objetivo que las estructuras directivas de la organización se sensibilicen y se identifiquen con los principios de la calidad total y apliquen a los sistemas de gestión de sus organizaciones mediante un método estructurado para la mejora continua de la calidad de la gestión. En este momento se selecciona el modelo de gestión de la calidad total de la EFQM y el ciclo de mejora continua PDCA como herramientas útiles para conseguirlo. Para ello se inicia un proceso de formación para conseguir la implantación del modelo de la EFQM en todas las organizaciones de servicios de Osakidetza. El proceso comienza con un programa de sensibilización y formación sobre el contenido y aplicabilidad del modelo, dirigido en un principio a directivos y metodólogos de calidad con la asesoría y apoyo de "Euskalit". Ya entonces existían experiencias en la comunidad autónoma vasca que demostraban la utilidad del modelo en la gestión empresarial.

La primera autoevaluación en todos los centros sanitarios de la red, se realiza en el año 1996. Resultan de la misma una serie de áreas de mejora en cada centro que, priorizadas, se convierten en objetivos estratégicos y planes de acción. Era la primera experiencia de aplicación del modelo europeo a todos los centros de una red sanitaria en Europa.

En 1998, Osakidetza elabora un nuevo Plan Estratégico (1998-2002) planteando sus objetivos estratégicos como resultado de las exigencias derivadas de la misión a cumplir, de los valores a desarrollar y de las variables que provienen del entorno y de su propia realidad interna. Este Plan Estratégico, explicita y asume la calidad total como uno de sus cinco objetivos estratégicos generales y el modelo de gestión de la EFQM como referente de mejora de la gestión de la red sanitaria vasca.

EI SVS- Osakidetza en su informe sobre la situación de la sanidad pública vasca (2006) presentó el Plan de Calidad 2003-2007 como vehículo para mejorar la calidad de los servicios sanitarios públicos y también de su gestión, cuyos grandes objetivos eran mejorar la calidad del servicio sanitario y mejorar la calidad de la gestión. 
Cada uno de estos objetivos específicos contaba con diferentes líneas de actuación para su consecución y con indicadores que permitían conocer su evolución y medir su grado de alcance. En conjunto, se trataba de 12 objetivos específicos, 73 líneas de actuación y 89 indicadores cuantificables.

Según los datos de la evaluación correspondiente al año 2005, en relación al objetivo de mejora de la calidad del servicio sanitario, la mejora alcanzada en la eficacia y efectividad de las prestaciones sanitarias y en la mejora de la adecuación en el uso de las prestaciones sanitarias, se logró:

Mejorar la eficacia y efectividad de las prestaciones sanitarias.

a. El $66,7 \%$ de servicios/unidades asistenciales realizaban actividades regulares de autoevaluación y mejora de la eficacia y efectividad de los procesos asistenciales.

b. El $30,5 \%$ de personas que realizaban actividad clínica en una unidad/servicio que había implantado un sistema de gestión de la calidad tipo ISO o de gestión por procesos.

c. Evaluación positiva del proceso de atención de enfermería

En relación a la mejora de la adecuación en el uso de las prestaciones sanitarias.

a. El 11,8\% de prescripciones eran envases EFG (especialidad genérica farmacéutica) en atención primaria.

b. El 50,1\%, de unidades y servicios asistenciales evaluaban de forma regular la adecuación de la indicación de uno o más procedimientos, tecnologías médicas o quirúrgicas, o derivaciones.

Por otro lado, en relación al sistema de organización de los centros.

a. El $66 \%$ de las organizaciones tenían un sistema de gestión por procesos implantado.

b. El 56,2\%, de unidades y servicios disponían de planes de gestión

c. El $41,2 \%$ de personas participaba en proyectos de mejora: gestión de procesos, certificación ISO, 5S, otras metodologías de mejora, grupos de mejora, comisiones, procesos en vías de certificación....

En el Hospital de Basurto la reflexión estratégica de 1996 y la adopción del modelo EFQM constituyeron el arranque y el eje para los cambios en la gestión de la organización y su orientación hacia la excelencia. El centro pasó de trabajar únicamente en Dirección Participativa por Objetivos, a implantar un sistema de gestión por procesos, y con un sistema de aseguramiento de la calidad certificado según la Norma ISO 9001 en diferentes unidades. Ambos cambios, organizativo y metodológico supusieron un cambio orientado a la mejora de la satisfacción de los grupos de interés.

Ese mismo año se realizó la primera autoevaluación del que surgió el primer plan estratégico en 1997. Según consta en su memoria de evaluación EFQM de 2005 la razón para la adopción del modelo EFQM fue que este sistema de gestión entiende que un sistema de calidad no debe ser un elemento de control sino una filosofía organizativa que permita satisfacer las necesidades de los clientes y conseguir resultados más sobresalientes. 
En la Comarca Bilbao, la puesta en marcha en 2004 de la estrategia de mejora Hobekuntza con la adopción del modelo EFQM constituyó el inicio del cambio de una Comarca gestionada de manera tradicional a una gestionada por procesos. Esto supuso la certificación de su sistema de gestión en base a numerosos estándares internacionales. Además, el enfoque estratégico orientado hacia la sostenibilidad impulsado por la propia sociedad (Comarca Bilbao, 2012) supuso el cambio en la forma de hacer, tanto en lo referido a la Política Medioambiental con la certificación EMAS III como a la prevención de riesgos con OHSAS y la gestión socialmente responsable con la norma RS10.

En esta etapa (2005) comienza la adopción del modelo EFQM según los datos disponibles en la memoria del Hospital de Basurto se mantuvo el equilibrio presupuestario contribuyendo a la sostenibilidad del sistema. Los gastos de farmacia y material sanitario se incrementaron un $10,9 \%$ en 2006 y un $7,4 \%$ en 2007 fruto del aumento de actividad y de la implantación de nuevos fármacos y programas (digitalización de la imagen, incremento de laparoscopia...).

El hospital realizó obras dentro del plan de remodelación que supuso obras en varios pabellones y en la urgencia, así como obras para instalar el tercer acelerador y la ampliación del bloque quirúrgico y reanimación.

Con respecto al sistema de gestión, se continuó con el despliegue de la gestión de procesos y la implantación de la ISO 9001 y la certificación en la ISO 14001 gracias a una gestión medioambiental responsable en línea con el compromiso con la sociedad

\section{Situación durante el periodo 2007-2014}

En lo referente a certificaciones ISO 9001, el Hospital de Basurto, en el ejercicio 2008, se certificó el Proceso de Gestión Retributiva de Personal - Nóminas y Seguridad Social en la Corporación (Organización Central y resto de organizaciones de servicios de Osakidetza), revalidando así mismo las certificaciones obtenidas en 2006 y 2007 de los Subprocesos de Gestión y Desarrollo de Personas y Gestión de la Formación Continua. En cuanto a la Unidad Básica de Seguridad / Prevención, se implantaron nuevos procedimientos y protocolos actualizados desde los servicios centrales y del propio hospital. Además se comenzó a trabajar en la certificación del sistema de gestión de la seguridad y salud laboral según especificaciones OHSAS 18.001.

Además, en el año 2008, el Hospital de Basurto elabora su nuevo plan estratégico 20082012. En ese momento es director gerente Jon Darpón, quien fue nombrado Consejero de Salud del Gobierno Vasco en diciembre de 2012.

El Plan Estratégico 2008-2012 del Hospital de Basurto recogía los objetivos a los que el Hospital aspiraba, las metas y las pautas de actuación que se consideraban necesarias para lograr dichos objetivos. 


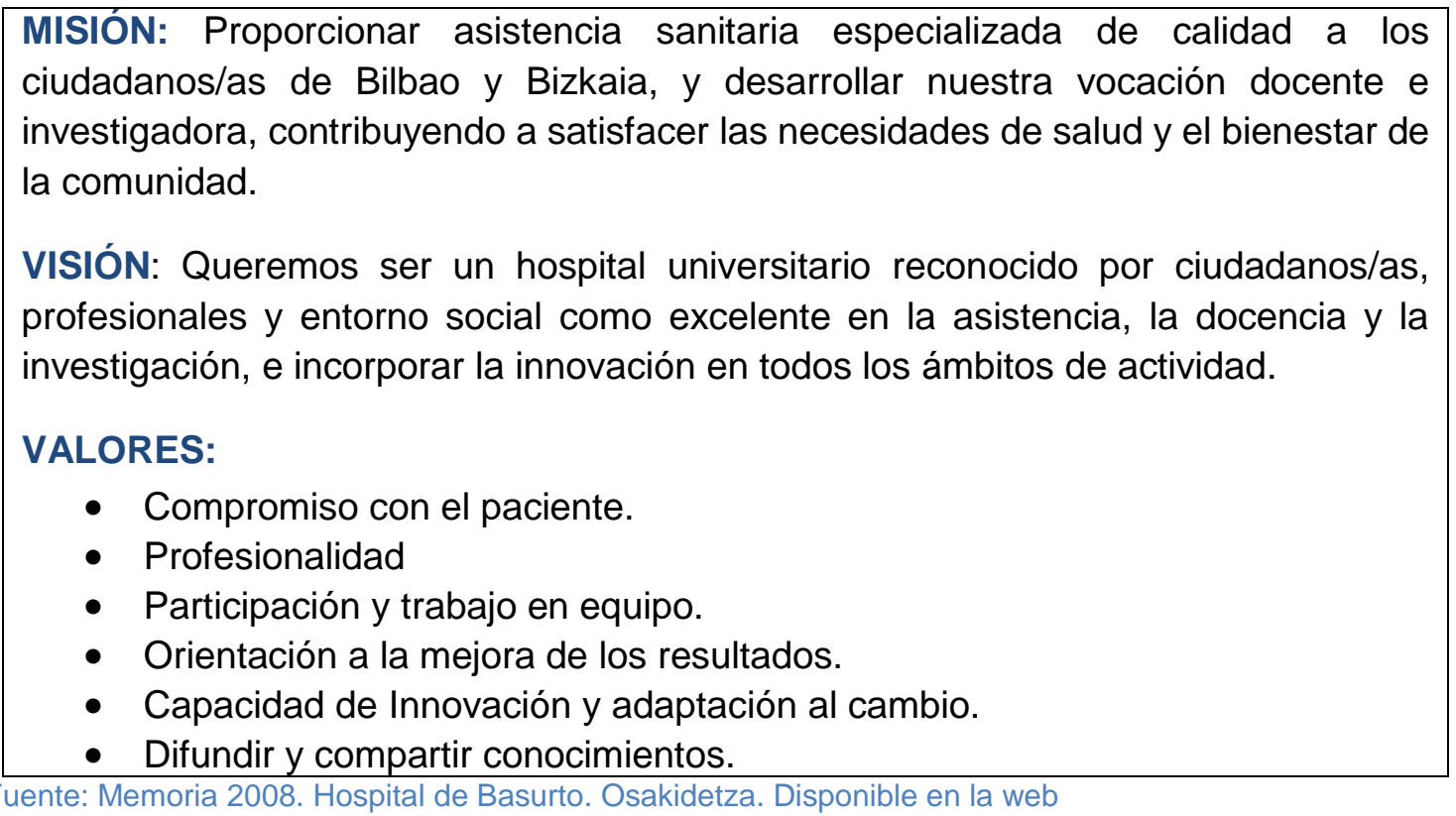

En línea con la Misión y Visión (tabla 63), que se definieron en 2008 el compromiso del Hospital se materializó en un reto estratégico de "Sostenibilidad y Compromiso con la Sociedad"

En cuanto a la Comarca, a finales de 2006 incorporó como objetivo permanente la respuesta a los nuevos retos de la sociedad; esta idea se plasmó en los PE 2007 - 2012 y 2013 - 2017 en los siguientes ejes principales:

- La apuesta por la participación de los profesionales en la mejora de la gestión

- Una nueva forma de entender el modelo sanitario público para los ciudadanos y profesionales, reformulando las funciones de estos últimos hacia aspectos más relacionados con la prevención y promoción de la salud y haciendo copartícipes a los ciudadanos en la mejora de su salud.

- La innovación, basada en la implantación de las TICs como herramientas para la mejora de la gestión de la información y conocimiento, el desarrollo de nuevas herramientas de gestión y la utilización de tecnologías diagnósticas que permitan el cuidado y monitorización a distancia.

- Impulso a la gestión ética y socialmente responsable bajo criterios de transparencia.

- El desarrollo del espacio sociosanitario, donde se incluyen aquellas personas que por causa de graves problemas de salud o limitaciones funcionales $y / 0$ de riesgo de exclusión social, necesitan una atención sanitaria y social simultánea, coordinada y estable

- El enfoque de la actividad hacia el paciente crónico

- El desarrollo de criterios de Buen Gobierno en la gestión de las organizaciones

En 2007, la Comarca tras realizar actividad de benchmarking con el Hospital de Zumárraga y la Comarca Ekialde, apostó por la gestión ambiental de su actividad, logrando la certificación ISO 14001 para el sistema de gestión ambiental que engloba a 
los 25 centros de trabajo de la Comarca y siendo la primera comarca de AP en el estado en lograr la certificación EMAS.

Ya en la memoria de la Comarca (2012) se aseguraba que son modelo de referencia en sostenibilidad. La organización promocionaba los valores compartidos, el comportamiento ético y responsable y la transparencia. La organización se aseguraba que las personas de la Organización actuaban con integridad.

Además de impulsar los enfoques y herramientas antes descritos, el 100\% de los líderes participaban activamente en el despliegue de los mismos ejerciendo de ejemplo y por lo tanto, fomentando los valores y el desarrollo de una cultura de gestión ética y responsable en el resto de profesionales y Gl. Ejemplo de ello, la realización de auditorías, verificaciones y evaluaciones externas de manera voluntaria en base a modelos de excelencia y otros estándares con aplicación a todo el sistema de gestión., que complementaban los controles realizados por el Departamento de Hacienda y Administración Pública del Gobierno Vasco y el Departamento de Salud. Además también estaban sometidos al control por diferentes organismos de la actividad contratada y de la utilización de las dotaciones económicas. Todo esto quedaba reflejado, ya en aquella época, en las memorias de responsabilidad social corporativa que de forma voluntaria realizaba la organización.

Por otra parte, la actuación integra de los profesionales estaba garantizada por el decreto 175/1989 "Derechos y Obligaciones de los pacientes" que garantizaba los derechos de los clientes en la relación con la organización sanitaria, la ley de ordenación sanitaria que regula la actuación de los profesionales como trabajadores de la administración pública, los principios en la prestación de la asistencia sanitaria de universalidad, solidaridad, equidad, eficiencia, sostenibilidad y calidad recogidos en la Misión y los códigos deontológicos de los respectivos colegios profesionales de los profesionales sanitarios.

En 2010, la Comarca dio un importante salto cualitativo en este aspecto, siendo la primera organización sanitaria pública del estado en certificar su sistema de gestión como "ético y socialmente responsable" en base a la Norma RSC10. Esta Norma es la primera norma internacional que establece los requisitos que debe cumplir una organización para integrar voluntariamente en su estrategia y gestión las preocupaciones sociales y medioambientales en la actividad y en las relaciones con sus grupos de interés. Para ello, la Comarca fue la primera organización sanitaria que definió un código ético propio, que complementaba a los anteriores.

Los años que ya habían transcurrido en esta época desde el inicio de esta política de calidad, dan una perspectiva global sobre el camino que ya se había recorrido. En estos momentos podía decirse que la calidad total y el modelo europeo habían calado en Osakidetza y en la OSI Bilbao-Basurto. Esto se manifestaba fundamentalmente en dos aspectos, por un lado la existencia de un compromiso visible con la calidad por parte de los equipos directivos de las organizaciones de servicios y por otro lado, la visión integrada de todas las actividades de la organización, conseguida a través de la utilización del modelo (Ladrón de Guevara, 2003).

Todo ello se concretó en la OSI Bilbao-Basurto en diferentes reconocimientos (tabla 63) y premios (tabla 64) durante este periodo. 


\section{Reconocimientos EFQM}

\section{Comarca Bilbao}

2006. Reconocimiento Q de Plata (Más de 400 puntos). Euskalit

2008. Reconocimiento $Q$ de Oro (Más de 500 puntos). Euskalit

2011. Finalista de los Premios de Excelencia EFQM Europa

\section{Hospital de Basurto}

2005. Reconocimientos Q de Plata (Más de 400 puntos). Euskalit

Fuente: Elaboración propia a partir de datos de http://www.osakidetza.euskadi.eus/r85-

skorga03/es/contenidos/informacion/osk_organizacion_todo/es_org_osk/reconocimientos_c.html. Acceso 06/08/2015

Tabla 64. Premios relacionados con la calidad de las organizaciones de la OSIBB

\begin{tabular}{|l|l|l|}
\hline Organización & Año & Reconocimiento \\
\hline Comarca Bilbao & 2013 & Premio Avedis Donabedian - Calidad en Atención Primaria \\
\hline Comarca Bilbao & 2013 & $\begin{array}{l}\text { Premio ESTEVE a la mejor iniciativa en atención al paciente en } \\
\text { el Área de Enfermería, por el proyecto "Nuevos roles de } \\
\text { enfermería: enfermera gestora de competencias avanzadas" }\end{array}$ \\
\hline Comarca Bilbao & 2013 & $\begin{array}{l}\text { AEVAL a la Excelencia en la Administración Pública. Premio } \\
\text { concedido por el Ministerio de Administraciones Públicas }\end{array}$ \\
\hline Comarca Bilbao & 2013 & $\begin{array}{l}\text { Premio Best in Class a la mejor Organización de Atención } \\
\text { Primaria }\end{array}$ \\
\hline Comarca Bilbao & 2012 & EFQM-Good Practice Competition 2012 - Mención Especial \\
\hline Comarca Bilbao & 2012 & Premio Best in Class al Mejor Servicio de Atención Primaria \\
\hline Hospital Basurto & 2012 & Premio Best in Class al Mejor Servicio de Reumatología \\
\hline Hospital Basurto & 2012 & Premio Best in Class al Mejor Servicio de Cardiología \\
\hline Hospital Basurto & 2012 & Premio Best in Class al Mejor Servicio de Oncología \\
\hline Comarca Bilbao & 2011 & Premio Best in Class al Mejor Servicio de Atención Primaria \\
\hline Hospital Basurto & 2011 & Premio Best in Class al Mejor Servicio de Psiquiatría \\
\hline Comarca Bilbao & 2011 & Certificación RS10-Responsabilidad Social \\
\hline Comarca Bilbao & 2011 & $\begin{array}{l}\text { Premio Europeo de Medio Ambiente a la Empresa en el País } \\
\text { Vasco }\end{array}$ \\
\hline Hospital Basurto & 2010 & Premio Best in Class al Mejor Servicio de Pediatría \\
\hline Hospital Basurto & 2009 & $\begin{array}{l}\text { Premio Best in Class al Mejor Servicio de Enfermedades } \\
\text { Infecciosas }\end{array}$ \\
\hline Hospital Basurto & 2009 & $\begin{array}{l}\text { Premio Best in Class al Mejor Servicio de Obstetricia y } \\
\text { Ginecología }\end{array}$ \\
\hline Hospital Basurto & 2008 & $\begin{array}{l}\text { Ganador del III Premio Best in Class al Mejor Hospital en } \\
\text { Atención al Paciente }\end{array}$ \\
\hline Comarca Bilbao & 2007 & $\begin{array}{l}\text { Premio a la Innovación en la mejora global de la calidad } \\
\text { asistencial }\end{array}$ \\
\hline & Prom \\
\hline
\end{tabular}

Fuente: Elaboración propia a partir de datos de http://www.osakidetza.euskadi.eus/r85-

skorga03/es/contenidos/informacion/osk_organizacion_todo/es_org_osk/reconocimientos_c.html. Acceso 06/08/2015 
Al final de este periodo la OSI Bilbao-Basurto cuenta con diversos reconocimientos externos (tabla 65) en forma de implantación de normas y estándares.

Tabla 65. Reconocimientos externos. Certificaciones (octubre 2013)

\begin{tabular}{|c|c|c|c|}
\hline Organización & Alcance & & Norma \\
\hline \multirow[b]{4}{*}{ HU Basurto } & Certificación alcance global & ISO 14001 & $\begin{array}{l}\text { Gestión } \\
\text { Medioambiental }\end{array}$ \\
\hline & Certificación alcance global & ISO 9001 & Gestión de la Calidad \\
\hline & Certificación alcance global & UNE 166002 & Gestión de I+D+i \\
\hline & Certificación alcance global & UNE 179006 & $\begin{array}{l}\text { Sistema para la } \\
\text { vigilancia, prevención } \\
\text { y control de las } \\
\text { infecciones } \\
\text { relacionadas con la } \\
\text { atención sanitaria en } \\
\text { los hospitales }\end{array}$ \\
\hline $\begin{array}{l}\text { HU Basurto + } \\
\text { Comarca Bilbao }\end{array}$ & $\begin{array}{l}\text { Proceso Embarazo- Parto- } \\
\text { Puerperio }\end{array}$ & ISO 9001 & Gestión de la Calidad \\
\hline $\begin{array}{l}\text { HU Basurto + } \\
\text { Comarca Bilbao }\end{array}$ & $\begin{array}{l}\text { Gestión de muestras } \\
\text { biológicas }\end{array}$ & ISO 9001 & Gestión de la Calidad \\
\hline \multirow{8}{*}{ Comarca Bilbao } & Certificación alcance global & $\begin{array}{l}\text { GRI checked } \\
\mathrm{A}_{+}\end{array}$ & $\begin{array}{l}\text { RSC Validación anual } \\
\text { desde } 2006\end{array}$ \\
\hline & Certificación alcance global & ISO 27001 & $\begin{array}{l}\text { Seguridad de la } \\
\text { información }\end{array}$ \\
\hline & Certificación alcance global & Bikain & $\begin{array}{l}\text { Calidad de la Gestión } \\
\text { Lingüística }\end{array}$ \\
\hline & Certificación alcance global & EMAS III & $\begin{array}{l}\text { Gestión } \\
\text { Medioambiental }\end{array}$ \\
\hline & $\begin{array}{l}\text { Servicios de Atención Primaria } \\
\text { (gestión administrativa y } \\
\text { asistencia sanitaria) }\end{array}$ & ISO 14001 & $\begin{array}{l}\text { Gestión } \\
\text { Medioambiental }\end{array}$ \\
\hline & $\begin{array}{l}\text { Servicios de Atención Primaria } \\
\text { (gestión administrativa y } \\
\text { asistencia sanitaria) }\end{array}$ & IQNET RS10 & $\begin{array}{l}\text { Sistema de Gestión } \\
\text { Socialmente } \\
\text { Responsable }\end{array}$ \\
\hline & Toda la cartera de servicios & $\begin{array}{l}\text { AENOR } \\
\text { Carta de } \\
\text { Servicios }\end{array}$ & Carta de Servicios \\
\hline & Toda la Comarca & $\begin{array}{l}\text { OHSAS } \\
18001\end{array}$ & $\begin{array}{l}\text { Prevención de } \\
\text { Riesgos Laborales }\end{array}$ \\
\hline
\end{tabular}

Fuente: Memoria Osakidetza 2013

\section{Situación desde 2014}

En 2014 se decide la integración de ambas organizaciones en una sola estructura denominada Organización Sanitaria Integrada (OSI), creándose la OSI Bilbao-Basurto (OSIBB)

Con la creación de la OSIBB se busca facilitar la optimización de recursos y la continuidad de los cuidados. Su pertenencia a Osakidetza ofrece ventajas importantes al poder compartir estrategias comunes y la utilización de herramientas conjuntas. La 
transmisión de conocimientos y la posibilidad de aprendizaje de otros grupos, procesos o centros del sistema público vasco de salud constituyen también una fuente continua de aprendizaje y posibilidad de mejora para la organización.

EL Servicio Vasco de Salud (Osakidetza) y por añadidura la OSI Bilbao-Basurto son un referente a nivel estatal y un servicio muy bien valorado entre la población vasca según los datos del barómetro sanitario presentados en las tablas de indicadores (tabla 63). Además, como reconocimientos de carácter asistencial, el Hospital de Basurto figura como referente en la relación de centros, servicios y unidades de referencia (CSUR) del Sistema Nacional de Salud designados por el Ministerio de Sanidad, Servicios Sociales e Igualdad, para la atención a pacientes diagnosticados de esclerosis múltiple (MSSSI, 2014)

La OSI Bilbao Basurto desarrolla actividades relacionadas con la atención primaria y la atención hospitalaria, actividades que se reflejan de manera general en el actual mapa de procesos que se muestra a continuación (ilustración 31).

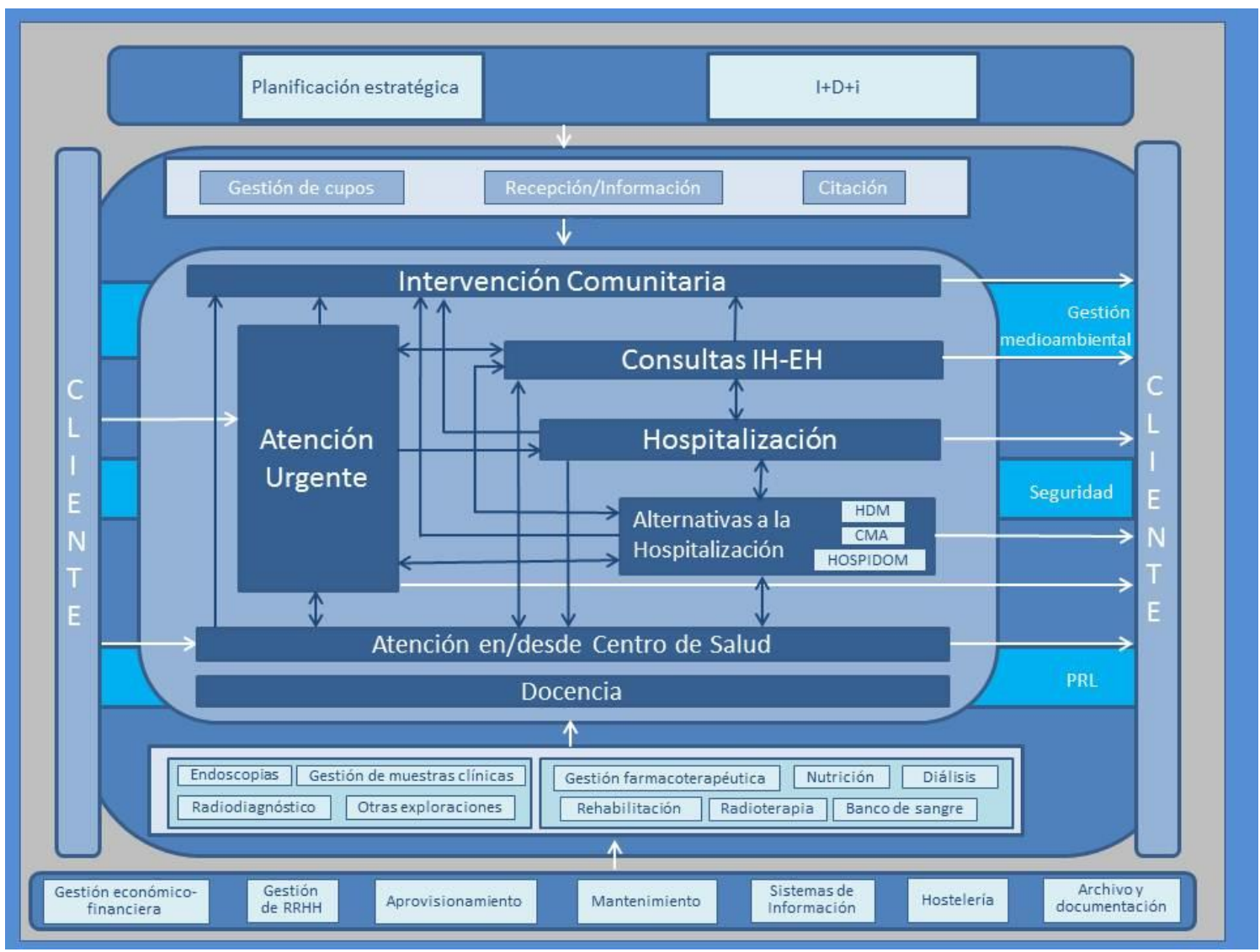

Fuente: http://www.osakidetza.euskadi.eus/

De manera general, los centros de trabajo que componen la OSI Bilbao Basurto son los siguientes:

- Hospital Universitario Basurto (37 Servicios con 683 camas).

- 22 Unidades de atención primaria (UAP) con 25 centros de salud. En 5 de estas UAPs se prestan también determinados servicios de la atención hospitalaria.

- Centro penitenciario Urbi Basauri. 
- 3 Puntos de atención continuada.

- 1 Call center

La OSIBB nació integrando a las personas provenientes de la Comarca y del Hospital creando una sola estructura y un organigrama con un equipo directivo común para facilitar esa integración.

También ha definido su política de calidad (tabla 66) en la que se apuesta por la continuidad en la mejora continua y la excelencia, y en la participación e implicación de todos los grupos de interés.

Tabla 66. Misión, Visión y Valores de la OSI Bilbao Basurto

Misión: Satisfacer las necesidades de salud de nuestros usuarios de una manera segura, eficiente y de calidad, estando comprometidos con la formación de profesionales excelentes y con la investigación.

Visión: Ser una Organización Sanitaria Integrada, que en un contexto de crisis ha sabido innovar y modernizarse, siendo una referencia reconocida por los profesionales, usuarios y entorno social por:

- La calidad y seguridad de sus servicios

- Capacitar e implicar al ciudadano en la gestión de su salud.

- La investigación y la innovación en procesos, modelos y tecnologías que contribuyan a la mejora en resultados de salud.

- Una gestión ética, transparente y eficiente en el uso de los recursos.

- Integrar a sus profesionales en la gestión y la mejora, desarrollando sus capacidades en un entorno motivador y seguro.

- Una actitud colaborativa con instituciones y otros representantes de la sociedad.

Valores:

- Actitud positiva, abierta e innovadora.

- Orientación a la mejora.

- Comportamiento profesional, ético, y responsable.

- Compromiso con la respuesta adecuada, con una actitud personalizada, cercana y respetuosa.

- Trabajo en equipo.

- Cultura participativa con otras instituciones/organizaciones.

- Satisfacción por el trabajo bien hecho y por la pertenencia a la Organización.

Fuente: http://www.osakidetza.euskadi.eus

En línea con la política expuesta, la OSIBB manifiesta en su página web (OSIBB, 2015) que la Responsabilidad Social Corporativa forma parte de su razón de ser como organización pública sanitaria. Señalan que su actividad diaria implica una dimensión social esencial, entendiendo por tanto que las actividades con las que de forma natural se identifican constituyen de por sí una actividad de responsabilidad social, pero que además trascienden más allá de la asistencia sanitaria, lo que debe colocar a la organización en una posición de liderazgo, compromiso e impacto positivo en su entorno.

En este mismo documento la Dirección de la OSI Bilbao-Basurto manifiesta que impulsará todas las iniciativas que conduzcan el cumplimiento de los objetivos 
estableciendo los cauces de colaboración necesarios con sus grupos de interés comprometiéndose a:

- Comunicar el significado de la política para que sea comprendida por todas las partes.

- Definir e implantar un sistema de gestión y mejorar continuamente su eficacia

- Facilitar un marco de referencia para el establecimiento de los objetivos de los diferentes sistemas.

- Garantizar el cumplimiento de las normas y legislación vigente así como cualquier compromiso que la organización suscriba.

- Encaminar los recursos humanos y materiales para cumplir con los requisitos establecidos y conseguir la satisfacción de los clientes y partes interesadas.

- Asignar los recursos suficientes para que el sistema de gestión sea eficiente.

- Garantizar la información y participación de todos los trabajadores.

- Delegar en las personas responsables de los procesos la autoridad necesaria para asegurar el mantenimiento del sistema de gestión.

- Fomentar el impulso de la responsabilidad social corporativa.

- Disminuir el impacto medioambiental generado.

- Convertir la seguridad del paciente en un pilar básico, contribuyendo al mantenimiento de la cultura de seguridad.

- Garantizar la seguridad y salud de los trabajadores de la organización.

- Apostar por un modelo de I+D+i basado en las personas que genere una cultura de creatividad y espacios de conversación.

Para adaptarse a los requerimientos del entorno, los objetivos de la OSIBB tratan de ser flexibles y se revisan anualmente para establecer las prioridades en materia de calidad en cada momento (OSIBB, 2015).

La OSIBB publica anualmente su memoria de responsabilidad social corporativa para hacer públicas sus actuaciones y resultados potenciando de esta forma su transparencia con los diferentes grupos de interés.

Por otra parte, además de las mejoras en el sistema de gestión y los reconocimientos obtenidos, los líderes de la organización participaron en diferentes foros para difundir la cultura de la excelencia y el desarrollo sostenible, por ejemplo como miembros del Club de Evaluadores de Euskalit, participando de manera activa en evaluaciones externas y contrastes.

Con todo ello la OSI Bilbao-Basurto ha trabajado y alcanzado diferentes resultados en sostenibilidad como los que se presentan a continuación (tabla 67). 
Tabla 67. Hitos sostenibilidad alcanzados por la OSI Bilbao-Basurto

\begin{tabular}{|c|c|}
\hline Año & Mejoras \\
\hline 2004 & Creación de la Comisión Medioambiental \\
\hline 2004 & $\begin{array}{l}\text { Apuesta por la GPP como modelo para gestionar la organización de una manera más } \\
\text { eficiente: Definición y revisión del Mapa de Procesos comarcal. Identificación y mejora de los } \\
\text { flujos de trabajo e interfases. Rediseño de los indica- dores de rendimiento interno. } \\
\text { Implantación de las reuniones de equipos de proceso }\end{array}$ \\
\hline 2005 & Certificado Ekoscan (HU Basurto) del sistema de gestión medioambiental \\
\hline 2006 & $\begin{array}{l}\text { Consolidación del "desayuno con Proveedores" para la mejora de la relación y la mejora del } \\
\text { proceso de Gestión Económica Financiera y Aprovisionamiento }\end{array}$ \\
\hline 2006 & Diseño de la Estrategia de Sociedad y Proveedores \\
\hline 2006 & Adopción de la Norma Ekoscan en 7 Unidades como referencia \\
\hline 2007 & $\begin{array}{l}\text { Implantación de sistemas de cogeneración térmica en dos unidades para aprovechamiento } \\
\text { de energía y disminución de impacto ambiental. }\end{array}$ \\
\hline 2007 & $\begin{array}{l}\text { Ampliación a todos los centros de salud de la Gestión ambiental. Se toma como referencia la } \\
\text { ISO } 14001 \text { y el reglamento EMAS. }\end{array}$ \\
\hline 2007 & Diseño de indicadores de Gestión Ambiental (consumos, reciclaje....) \\
\hline 2007 & Elaboración de memoria pública RSC que recoge los objetivos y resultados del año \\
\hline 2008 & Asunción de la transparencia como un eje de gestión en el ámbito del Buen Gobierno \\
\hline 2008 & $\begin{array}{l}\text { Formación a profesionales sanitarios de las residencias Gestión más eficaz de los recursos. } \\
\text { Mejora de la atención a los pacientes }\end{array}$ \\
\hline 2008 & $\begin{array}{l}\text { Ampliación de la estrategia ambiental a los ciudadanos: Se implanta en todos los centros el } \\
\text { Punto Verde de recogida de Medicamentos caducados, pilas y radiografías. }\end{array}$ \\
\hline 2008 & Certificación ISO 14001 Hospital Basurto \\
\hline 2008 & Valoración del impacto ambiental en la elección de tecnologías \\
\hline 2009 & Ponencia "Modelo Éticos de gestión sanitaria: modelo EFQM" \\
\hline 2009 & $\begin{array}{l}\text { Asunción de compromisos públicos y objetivables para nuestra cartera de servicios - } \\
\text { certificación de la carta de servicios }\end{array}$ \\
\hline 2009 & $\begin{array}{l}\text { Se inicia la colaboración la oficina contra el cambio climático de Bilbao y con AAVV para } \\
\text { mejorar la concienciación ambiental del ciudadano. }\end{array}$ \\
\hline 2009 & Contratación de proveedores medioambientales “Compra verde” Hospital Basurto \\
\hline 2010 & Impulso a la gestión ética como eje transversal a la gestión de BiE por parte del CGGE \\
\hline 2010 & $\begin{array}{l}\text { Impulso a la sistematización en la gestión de la seguridad de la información : enfoque de las } \\
\text { actividades bajo la Norma ISO } 27001\end{array}$ \\
\hline 2010 & $\begin{array}{l}\text { Protocolo atención social urgente en coordinación Ayto. Bilbao Mayor facilidad profesionales } \\
\text { para derivación servicios sociales Captación necesidades sociales urgentes más eficiente }\end{array}$ \\
\hline 2010 & $\begin{array}{l}\text { En colaboración con la empresa de limpieza IMPACTO se sustituyen los productos de mayor } \\
\text { impacto ambiental por productos biodegradables }\end{array}$ \\
\hline 2011 & $\begin{array}{l}\text { Revisión de LIDERBiE: Inclusión del ámbito competencial "Gestión Ética" y redefinición de } \\
\text { "Orientación al ciudadanos" y "gestión de Redes" }\end{array}$ \\
\hline 2011 & Diseño e implementación de criterios de Compra Pública \\
\hline 2011 & Identificación de impactos en sostenibilidad para la priorización de objetivos \\
\hline 2011 & $\begin{array}{l}\text { Envío individualizado a los representantes de la sociedad de información relacionada con la } \\
\text { estrategia segmentada en base a su tipología }\end{array}$ \\
\hline 2011 & $\begin{array}{l}\text { Colaboración con la ONG ALBOAN en el programa "Dona tu móvil", que promueve la } \\
\text { donación de móviles para la obtención de fondos destinados a proyectos de medioambiente, } \\
\text { educación y desarrollo, mediante la reutilización y reciclado de los terminales }\end{array}$ \\
\hline 2011 & $\begin{array}{l}\text { Estudio de eficiencia energética en } 3 \text { centros: Deusto, Altamira y Otxarkoaga y obras } \\
\text { relacionadas con este estudio }\end{array}$ \\
\hline 2012 & Reconocimiento a los profesionales de las Unidades en la mejora de la Gestión Ambiental \\
\hline 2012 & $\begin{array}{l}\text { Establecimiento de sistemática para la recogida de agujas y punzantes de los domicilios de } \\
\text { usuarios derivados de su tratamiento de salud. }\end{array}$ \\
\hline 2012 & $\begin{array}{l}\text { Interconsulta a través de Osabide AP mejora la interrelación con el Hospital, disminuyendo } \\
\text { los tiempos de respuesta a las consultas realizadas por los Sanitarios al especialista. }\end{array}$ \\
\hline 2013 & Inclusión de parámetros de Seguridad de la Información en la elección de TICs \\
\hline
\end{tabular}


Los cambios que se han ido realizando a lo largo de estos años han producido un cambio organizativo, clarificación de los alcances e interacciones entre los procesos y un aseguramiento y mejora de la continuidad asistencial del paciente.

El propio hecho de la integración en la OSIBB proporciona una mejor interacción de los especialistas con la sociedad facilitando su comunicación y su accesibilidad. EI HUB se integra, se relaciona más con la comunidad en la que desarrolla su actividad y la OSIBB facilita la accesibilidad de sus clientes a los servicios de atención especializada, la continuidad de los cuidados y la formación de sus profesionales.

Actualmente en la organización existen varios niveles de comunicación interna para difundir las estrategias y la política del centro. La propia gerente anualmente hace, al menos, una sesión para todo el personal, incluso repetida para que llegue a los más de 4500 trabajadores. Comunica cuáles son los objetivos, cuál es la estrategia del año, el cierre del año, si se han alcanzado los objetivos. Por otro lado, la OSIBB ha editado el Plan Estratégico en formato folleto, que está disponible en su página web, y que se notifica vía correo electrónico a los trabajadores.

El problema de esta comunicación interna es que no es posible valorar actualmente su eficacia, puesto que desde el año 2010 se tomó la decisión corporativa de no hacer encuestas de satisfacción al personal. El centro reconoce que tiene ahí un área de mejora evidente, que aunque Osakidetza ya no realice encuestas a su personal, reconocen que deberían potenciar otras vías de captar la información de los trabajadores mediante grupos focales o indicadores indirectos.

No obstante, y relacionados con el contrato programa, se están realizando cuestionarios a los trabajadores para medir el grado de integración asistencial.

La gestión de la calidad no ha sufrido recortes y continua siendo un área prioritaria para Osakidetza y para la OSIBB. A la plantilla de la subdirección de calidad del Hospital se han incorporado personas que estaban en la Comarca y dan soporte a toda la OSIBB. Su trabajo consiste en dar apoyo metodológico para el mantenimiento de las certificaciones ya existentes y el desarrollo de nuevas iniciativas relacionadas con la calidad, ya sean de calidad asistencial, seguridad del paciente, RSC, gestión medioambiental o gestión de personas.

A nivel de sostenibilidad medioambiental, cuando comenzó a funcionar la OSIBB, la Comarca estaba más avanzada que el Hospital. La Comarca tenía los reconocimientos ISO 14001 y EMAS. A la hora de la integración, han existido dificultades para que el alcance de la ISO14001 incluyese al Hospital también, y se decidió que desde el hospital revisase todo el sistema y se trabajase para adaptar el sistema a la norma 14001. Tras la auditoría celebrada en 2016, el HUB también se certificó con la Norma 14001:2015, siendo por lo tanto el alcance de toda la OSIBB. El año 2018 está previsto que el Hospital se integre también en el Reglamento EMAS.

A partir de las fotografías obtenidas (ilustración 32) se pueden evidenciar algunos aspectos de la sostenibilidad del Hospital de Basurto tales como la segregación de residuos en colaboración con el Ayuntamiento de Bilbao, la apuesta por el mantenimiento de espacios verdes para pacientes y usuarios y los problemas de mantenimiento de infraestructuras que supone la antigüedad de los edificios. Este último 
término corroborado por las opiniones vertidas por el responsable de mantenimiento del propio hospital.

Ilustración 32. Fotografías. HUB. Aspectos sostenibles.
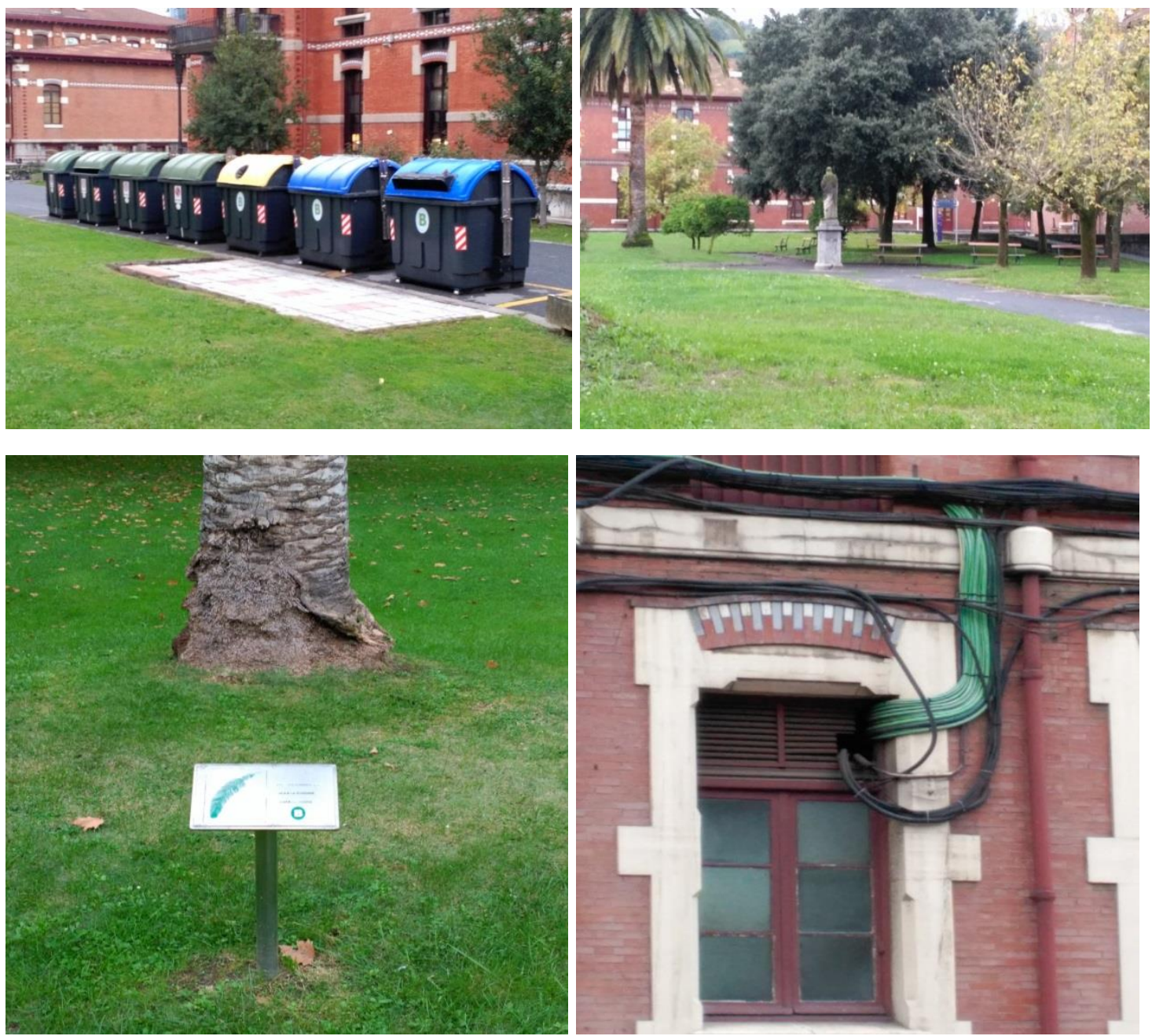

Fuente: Imágenes propias. Tomadas en marzo 2015
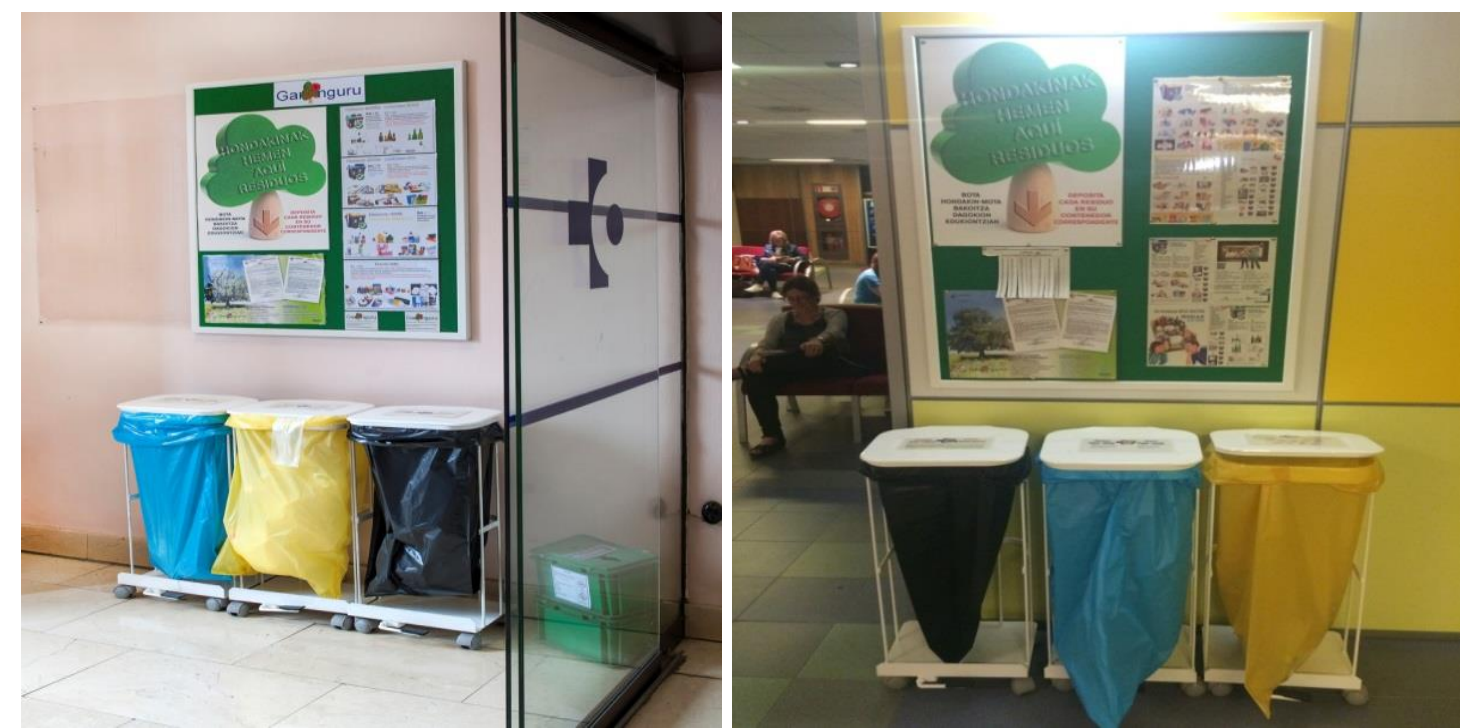

Fuente: Imágenes Antxón Apezetxea (2017) 
Para dar respuesta a los retos que plantean a la OSIBB los pacientes, sus asociaciones o a la Sociedad en su conjunto, se creó la dirección de integración asistencial. Entre sus objetivos está potenciar la integración con el área sociosanitaria, trabajando conjuntamente con residencias, con el área social del ayuntamiento, con los servicios educativos, etc.

Por otro lado, la OSIBB también establece colaboraciones con sociedades, tanto de pacientes como de vecinos, familiares de pacientes, etc., en algunos casos puntuales aunque periódicas y en otras colaboraciones formales, documentadas, etc. Además, algunos servicios mantienen, desde hace años, relaciones estables de colaboración con asociaciones de pacientes relacionadas con las patologías que entran en el ámbito de su especialidad. No obstante, la evaluación llevada a cabo en 2015 con el modelo de gestión avanzada identificó como una de las áreas de mejora en el tema de sociedad, la necesidad de sistematizar esta relación con la sociedad, con las diferentes asociaciones para tener identificados los objetivos que se persiguen con cada uno de ellos, incluso yendo más allá con algún tipo de acción que permita a la OSIBB implicarse con los barrios más allá de lo que es el propio cuidado de la salud como mejorar las condiciones de vida de un barrio mediante la actuación que pueda hacer la propia OSIBB. La OSIBB se planteó ser más proactiva en este sentido e involucrarse con la sociedad.

Como muestra de la integración de la OSIBB en la sociedad, el ayuntamiento de Bilbao reconoció al Hospital de Basurto con una medalla, con un reconocimiento de hijo predilecto como homenaje a tantos años de trabajo realizado en favor de la sociedad bilbaína.

En cuanto a la Gestión de los recursos económicos y financieros, se han desarrollado e implantado estrategias, políticas y procesos económicos y financieros para apoyar la estrategia global de la organización. Para ello se han diseñado procesos de planificación, control, de informes y de revisión económico-financieros para optimizar el uso eficiente y eficaz de los recursos y se han establecido e implantado procesos de gobierno económico-financiero a medida de todos los niveles adecuados de la organización.

En una entrevista a Aránzazu Gonzalo (BIBA, 2014), Directora de integración asistencial OSI Bilbao-Basurto, ésta señaló que para poder garantizar la sostenibilidad del sistema sanitario, es necesario trabajar como un único equipo asistencial. Es preciso desarrollar una actuación integral de cara a los ciudadanos de los ámbitos sanitario y social, con una utilización más ágil, rápida y eficiente de los recursos. Para ello, según A. Gonzalo (BIBA, 2014) de cara a los profesionales es también un importante reto, que supone un cambio de en la forma de actuación, aunque puede suponer, que esta integración creará más satisfacción en los profesionales porque los resultados serán más satisfactorios, con un enfoque más amplio y global con cada uno de los pacientes.

Después de años de trabajar con el modelo EFQM, Euskalit apostó por desarrollar un nuevo modelo, el Modelo de Gestión Avanzada 2015. Las razones para este cambio fueron cierto agotamiento de las organizaciones que habían trabajado en el modelo y la necesidad de incorporar a otras, para revitalizar el sistema buscando aportar mayor valor añadido mediante una herramienta más sencilla, ágil y simple (Apezetxea, 2017). 
Para Euskalit (2014) se puede calificar como gestión avanzada (ilustración 33) a aquella que genera mejores resultados para todos los grupos de interés que otras formas de gestión. Este modelo pretende superar los estilos tradicionales de gestión, basados en una estructura que distribuye instrucciones de manera escalonada, por un estilo de gestión más participativo que logre un mayor compromiso de las personas y también relaciones más sólidas con los clientes y otros grupos de interés y con ello, finalmente, lograr mejores y más satisfactorios resultados.

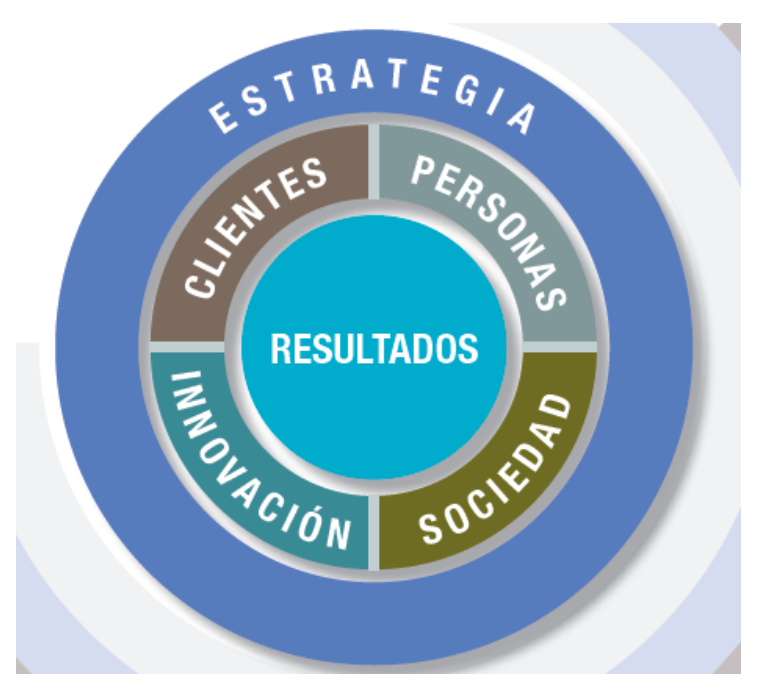

La elaboración de este modelo es fruto de la participación y del consenso de personas expertas en gestión, pertenecientes a organizaciones e instituciones relevantes coordinados por Euskalit. Su propósito es orientar a las organizaciones en la búsqueda de mejoras de competitividad, integrando conceptos de gestión aportados desde diferentes ámbitos en las últimas décadas de experiencia con el modelo EFQM: gestión del conocimiento, calidad total, excelencia en la gestión, innovación, y responsabilidad social empresarial entre otras.

Los elementos contemplados en el modelo (tabla 68), son la base para el desarrollo del sistema de gestión. Su objetivo es:

- Generar en las personas un sentimiento de pertenencia a un proyecto compartido.

- Orientar la organización hacia los clientes realizando una aportación diferencial de valor.

- Aplicar la innovación en todos los ámbitos de la organización.

- Potenciar el compromiso con la sociedad, importante suministrador de capacidades competitivas relevantes.

- Generar una visión de largo plazo que se materialice mediante una estrategia claramente definida.

- Alcanzar resultados satisfactorios para los diferentes grupos de interés de manera sostenida y equilibrada. 


\section{Elemento 1. Estrategia \\ E.1 Cómo se gestiona la información necesaria para definir la estrategia \\ E.2 Cómo se reflexiona y se establece la estrategia \\ E.3 Cómo desplegamos la estrategia \\ E.4 Cómo comunicamos, revisamos y actualizamos la estrategia}

\section{Elemento 2. Clientes}

C.1 Cómo gestionamos las relaciones con clientes

C.2 Cómo se desarrollan y comercializan productos y servicios orientados hacia los clientes

C. 3 Cómo se producen y distribuyen nuestros productos y se prestan nuestros servicios

C.4 Cómo gestionamos las relaciones con proveedores

\section{Elemento 3. personas}

P.1 Cómo seleccionamos, retribuimos y atendemos a las personas

P.2 Cómo desarrollamos el conocimiento y competencias de las personas

P.3 Cómo comprometemos a las personas con la organización

P.4 Cómo ampliamos la capacidad de liderazgo de las personas

Elemento 4. sociedad

S.1 Cómo gestionamos el compromiso con nuestro entorno social

S.2 Cómo impulsamos la sostenibilidad medioambiental

Elemento 5. innovación

I.1 Cómo definimos nuestros objetivos y estrategia para innovar

I.2 Cómo creamos el contexto interno para innovar

I.3 Como aprovechamos el potencial de nuestro entorno

I.4 Cómo gestionamos las ideas y proyectos innovadores

Elemento 6. resultados

R.1 Resultados estratégicos

R.2 Resultados en clientes

R.3 Resultados en personas

R.4 Resultados en la sociedad

R.5 Resultados de la innovación

El Modelo de Gestión Avanzada, después de tres años de andadura, había sido adoptado por 600 organizaciones de diferentes ámbitos, se han realizado 45 evaluaciones externas (Apezetxea, 2017).

Para las organizaciones es un modelo más fácil de entender, más amigable y más claro (Apezetxea, 2017). No obstante, es una herramienta que tiene una estructura y una finalidad común con el modelo EFQM, realizar un diagnóstico de las organizaciones y orientarlas en su mejora continua.

En cuanto a los resultados obtenidos por el sistema sanitario respecto a la calidad obtenida (tabla 69) se muestran en la siguiente tabla resultados de efectividad y percepción (satisfacción) de pacientes, así como resultados respecto a las seguridad de estos, que es un aspecto que los sistemas de calidad han trabajado intensamente en los últimos años. 
Tabla 69. Indicadores de resultados en calidad (La Rioja/España)

\begin{tabular}{|c|c|c|c|c|c|c|c|c|c|c|c|c|c|c|c|c|c|}
\hline \multirow[b]{2}{*}{ DOMINIOS } & \multirow[b]{2}{*}{ INDICADOR } & \multicolumn{2}{|c|}{2008} & \multicolumn{2}{|c|}{2009} & \multicolumn{2}{|c|}{2010} & \multicolumn{2}{|c|}{2011} & \multicolumn{2}{|c|}{2012} & \multicolumn{2}{|c|}{2013} & \multicolumn{2}{|c|}{2014} & \multicolumn{2}{|c|}{ Periodo } \\
\hline & & PV & E & PV & $E$ & PV & $E$ & PV & $E$ & PV & E & PV & $E$ & PV & $E$ & PV & E \\
\hline Seguridad & $\begin{array}{l}\text { Notificación de reacciones adversas } \\
\text { graves a medicamentos }\end{array}$ & 130,00 & 100,00 & 210,00 & 150,00 & 180,00 & 150,00 & 140,00 & 160,00 & 250,00 & 210,00 & 268,29 & 217,42 & 246,23 & 213,78 & 116,23 & 113,78 \\
\hline Seguridad & $\begin{array}{l}\text { Mortalidad intrahospitalaria postinfarto } \\
\text { por cada } 100 \text { altas por infarto }\end{array}$ & 7,74 & 9,04 & 8,67 & 8,47 & 7,84 & 8,35 & 8,76 & 8,03 & 7,68 & 7,51 & 6,44 & 7,28 & 6,68 & 7,16 & $-1,06$ & $-1,88$ \\
\hline Seguridad & $\begin{array}{l}\text { Tasa de amputaciones miembro inferior } \\
\text { en pacientes diabéticos }\end{array}$ & 0,08 & 0,11 & 0,09 & 0,11 & 0,09 & 0,10 & 0,08 & 0,10 & 0,10 & 0,10 & 0,08 & 0,10 & 0,08 & 0,10 & 0,00 & $-0,01$ \\
\hline Efectividad & Incidencia de hepatitis B por $100000 \mathrm{~h}$. & 2,10 & 2,12 & 1,36 & 1,85 & 1,64 & 1,86 & 1,08 & 1,65 & 0,94 & 1,27 & 1,06 & 1,53 & 1,06 & 1,43 & $-1,04$ & $-0,69$ \\
\hline $\begin{array}{l}\text { Satisfacción } \\
\text { Ciudadanos }\end{array}$ & $\begin{array}{l}\text { Grado de satisfacción de los } \\
\text { ciudadanos con el funcionamiento del } \\
\text { sistema sanitario público }\end{array}$ & 6,72 & 6,36 & 6,74 & 6,45 & 6,86 & 6,58 & 6,67 & 6,53 & 6,76 & 6,57 & 6,84 & 6,47 & 6,96 & 6,38 & 0,24 & 0,02 \\
\hline $\begin{array}{l}\text { Satisfacción } \\
\text { Ciudadanos }\end{array}$ & $\begin{array}{l}\text { Grado de satisfacción del ciudadano } \\
\text { con el conocimiento del historial y el } \\
\text { seguimiento por el médico de familia y } \\
\text { el pediatra }\end{array}$ & 6,82 & 6,95 & 7,12 & 7,05 & 7,33 & 7,26 & 7,49 & 7,52 & 7,35 & 7,52 & 7,55 & 7,56 & 7,51 & 7,50 & 0,69 & 0,55 \\
\hline $\begin{array}{l}\text { Satisfacción } \\
\text { Ciudadanos }\end{array}$ & $\begin{array}{l}\text { Grado de satisfacción del ciudadano } \\
\text { con la información recibida en la } \\
\text { consulta del médico especialista sobre } \\
\text { su problema de salud }\end{array}$ & 7,11 & 6,94 & 7,30 & 7,03 & 7,36 & 7,12 & 7,62 & 7,24 & 7,52 & 7,30 & 7,28 & 7,35 & 7,34 & 7,13 & 0,23 & 0,19 \\
\hline
\end{tabular}

Elaboración propia. Datos del http://inclasns.msssi.es

\subsubsection{Resultados cualitativos}

Los conceptos fundamentales de la excelencia aparecen en reiteradas ocasiones en el discurso de las personas entrevistadas (tabla 70), mostrando valores comunes que pueden considerarse "cultura de la organización" (CEG, 2014)

Tabla 70. Verbatines correspondientes con conceptos fundamentales de la excelencia

Alcanzar el éxito mediante el talento de las personas. "El empoderamiento de la enfermería es vital para el sostenimiento del sistema sanitario" (OS/12).

Añadir valor para los clientes. "El paciente es el elemento fundamental. El enfoque es al paciente y a mejorar continuamente su atención" (OSI8)

Aprovechar la creatividad y la innovación." Hay que aplicar las nuevas tecnologías para que el paciente esté comunicado con el hospital sin tener que acudir, de forma no presencial. Hay que innovar si no el sistema no se sostiene". (OS/3)

Liderar con visión, inspiración e integridad. "Un líder te ayuda a echar para adelante miles de historias y moverte a la gente, motivar y crear buen ambiente, ser capaz de encabezar proyecto" (OSI5)

Crear un futuro sostenible; "La competitividad siempre va un poco de la mano del dinero.. Pero si creo que podemos ser sostenibles por competitivos" (OSI10)

Mantener en el tiempo resultados sobresalientes. "Puede ser sostenible desde el punto de vista de resultados asistenciales, somos buenos. Este es un centro de más de cien años que ha pasado muchas vicisitudes y no se ha hundido con lo cual yo creo que el futuro del hospital como organización está asegurado" (OSI7)

Desarrollar la capacidad de la organización. "Este es un hospital que trabaja en equipo, todos ponen de su parte, no hay nadie más que nadie. Todos somos iguales".(OSI4)

Transcripciones literales de las entrevistas. Análisis mediante Atlas Ti 
A partir de las respuestas de los entrevistados se elaboró el mapa conceptual (ilustración 34) que recoge las ideas expresadas por las personas de la organización y que muestra valores o contenidos de su cultura común.

Ilustración 34. Interpretación entrevistas OSIBB

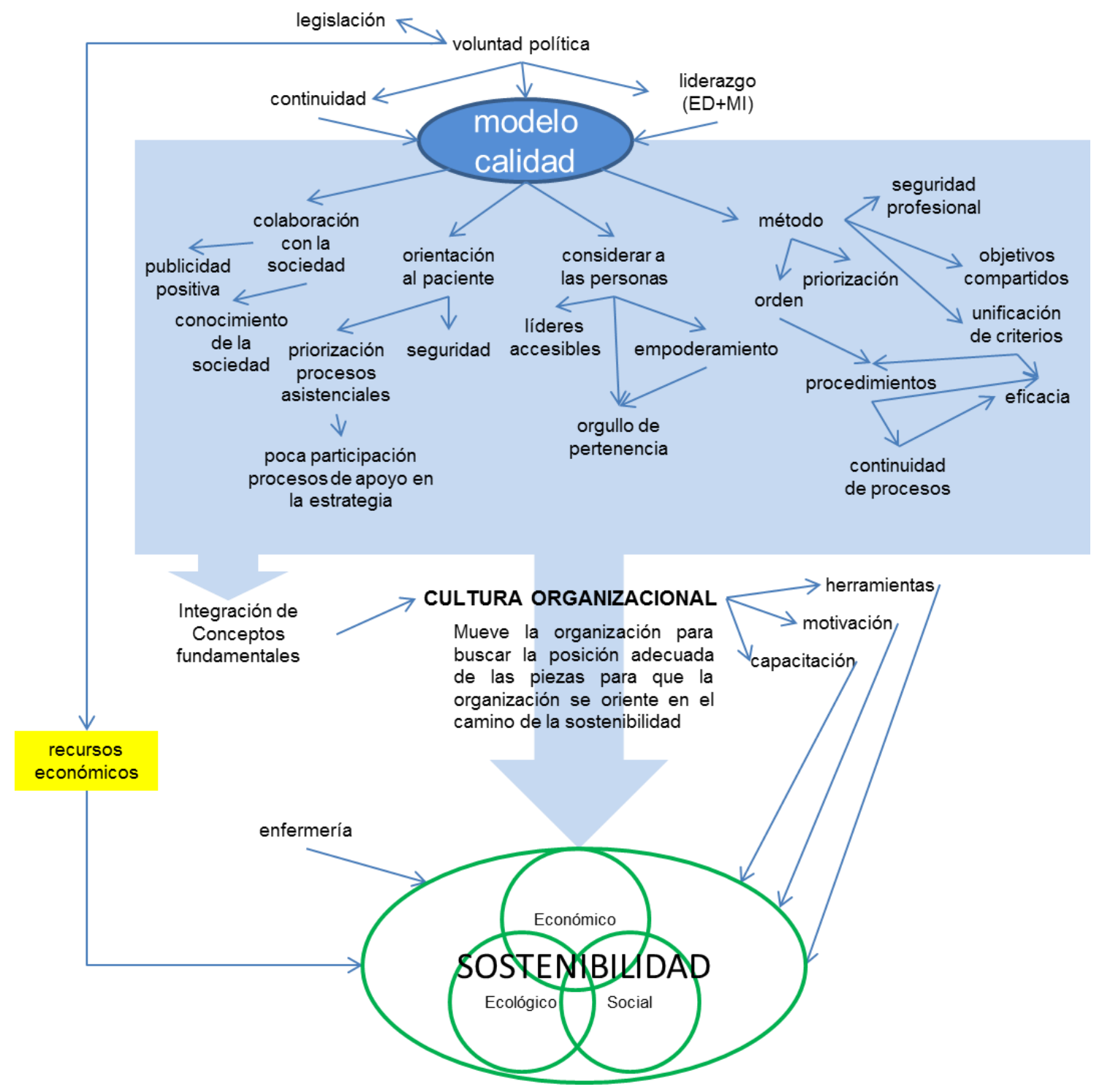

Fuente: Elaboración Propia

Aunque para los entrevistados el concepto de sostenibilidad abarca los aspectos sociales, económicos y medioambientales (ilustración 34), cuando se les preguntó por la sostenibilidad de su organización todos respondieron haciendo referencia al aspecto económico exclusivamente.

Para las personas de la OSI, la organización por sí misma es insostenible. Los recursos son finitos. Para el Responsable de Calidad la organización debe trabajar en conseguir ser más eficiente para que el aumento de la actividad no implique necesariamente un aumento paralelo en el consumo de recursos. 
"La sanidad tal como la vivimos es complicada porque el envejecimiento, la cronicidad, la renovación tecnológica, el tema de farmacia con cada vez nuevos fármacos que alargan la vida de las personas y mejoran la calidad de vida pero a un coste económico importante..." (OSI1).

Según el responsable de calidad la crisis presupuestaria no ha repercutido en los resultados de la OSIBB. También añade que los índices de satisfacción de los clientes son los mismos, e incluso la lista de espera va bajando, aunque es cierto que, a nivel interno, hay muchas cosas que están en precario, por ejemplo los aparatajes, y hubo que buscar alternativas para mejorar la eficiencia del resto del material.

El sistema sanitario es sostenible siempre y cuando el que da el dinero, la administración pública, tenga dinero para hacerlo. Depende de la prioridad política y de la legislación vigente en cada momento (ilustración 34). También depende de la voluntad política la implantación de un modelo de calidad, el nombramiento y el apoyo a un equipo directivo, así como la continuidad en el tiempo de este apoyo (ilustración 34).

"El sistema no es sostenible y yo creo que los hospitales serán sostenibles en la medida en que la administración que es la que tiene el dinero pueda dar ese dinero" (OSI6).

Para los entrevistados, la implantación del modelo EFQM en el caso de la OSI, potenció en la organización una serie de elementos (señalados en azul en la ilustración 34):

- Método de trabajo. Ordena y prioriza los procedimientos dotándolos de continuidad y mejorando su eficacia. Proporciona a los profesionales seguridad en la realización de su trabajo, unos objetivos comunes y la unificación de criterios. Todo ello refuerza también la eficacia de los procesos asistenciales.

"EI EFQM te permite trabajar de una forma mucho más organizada, básicamente tienes que tener la política y la estrategia". (OSI10)

"EI EFQM vino muy bien porque me dio una herramienta de trabajo, me ayudó a ordenar, a elaborar protocolos, a saber que eso era bueno" (OSI9)

- Consideración de las personas. Se pone de relieve la necesidad de empoderar a las personas haciéndolas líderes de los procesos y potenciando la labor de los líderes intermedios. Se reconoce la accesibilidad de los líderes y la necesidad de trabajar la satisfacción de las personas.

"Los logros que hemos conseguido son gracias a todos, a los equipos que tienen que estar formados por personas con potencialidades, con conocimientos, con ganas, con inquietudes. Tener capacidad de liderazgo visionario y no encasquetarte en lo que trabajas en el día a día e ir más allá”. (OS/10)

- Orientación al paciente. Las personas reconocen al paciente como su cliente principal. Se prioriza lo asistencial sobre todo lo demás. La orientación al paciente busca no solo la satisfacción sino que también favorece que se mejoren aspectos como la seguridad. Por contra se concede poca importancia a la participación de los procesos de apoyo.

"Lo primero son los pacientes, lo importante es cumplir los resultados en todo lo que tiene que ver con lo asistencial" (OSIO8) 
- Colaboración con la sociedad. El modelo introduce en la organización la idea de pertenencia a un entorno social con el que continuamente está interactuando y al que hay que considerar como factor importante en su sostenibilidad.

"El hospital tiene un reconocimiento de hijo predilecto. El ayuntamiento de Bilbao ha reconocido al hospital con una medalla hace unos años. Es una de las cosas de Bilbao además del Athletic, la Virgen de Begoña, la ría y los bollos de mantequilla..." (OS/1)

"Es un referente y forma parte de la cultura y de la esencia de los bilbaínos...y es muy querido por estos" (OSI4)

Las ideas describen los atributos de una cultura orientada a la excelencia. Facilitan la creación de una visión compartida y un lenguaje común que conforman una cultura de Excelencia. Esta cultura proporciona a su vez motivación a las personas y herramientas para la mejora continua, la adaptabilidad y la capacitación (ilustración 34)

En línea con lo anterior, durante el análisis se identificó un término, "espíritu basurtiano", común en el discurso, que para personas con larga trayectoria en el hospital implica disciplina, compañerismo, profesionalidad, orientación al paciente, mejora continua e innovación. También manifiestan orgullo de pertenencia y el convencimiento de que la capacidad asistencial y los cuidados dispensados son excelentes.

"Hay un espíritu muy constructivo, somos un grupo de gente que está haciendo el trabajo por el paciente. No hay una pelea de una especialidad con otra, el espíritu es muy simple, siempre ser educado" (OSI7).

“La gente es muy de aquí, muy de Basurto, siente la marca” (OSI7).

"Este hospital tiene una idiosincrasia propia que hace que la gente tenga mucho sentimiento de pertenencia". (OSI8)

"Creo que el entorno influye y luego la cultura se va transmitiendo de unos a otros" (OSI5)

No obstante, y a pesar de que la mayoría de las personas entrevistadas en la OSI BilbaoBasurto sean defensoras del modelo EFQJM, también reconocen que existen aspectos negativos en el modelo. Se han identificado algunos inconvenientes en la implantación del modelo EFQM en la OSI Bilbao-Basurto.

"Yo no soy enemigo de la calidad. No habrá nadie más convencido que yo que los sistemas de gestión de la calidad son necesarios y bien aplicados funcionan. Pero lo que no voy a participar es en la calidad enmascarada, en la foto, en el diploma, en el no sequé" (OSI3)

Para algunas personas de la OSI, el modelo puede ser usado solo como herramienta de propaganda, como elemento de buena imagen del que se aprovechen los líderes o los políticos. 
"Las cosas son así, que no hay dinero, que es muy difícil asignar recursos" bien pues no hagas, no asignes, no...pero luego no salgas hay a la palestra a decir que aquí EFQM, modelos de gestión de tal y cuál .Absoluta patraña y mentita todo" (OSI3)

"Esta voracidad que tienen las direcciones de los organismos sanitarios públicos de salir en la prensa porque somos los EFQM y somos los 14000, EMAS, RSC, tal y tal y una colección del copón de la baraja cuando tenemos un montón de gente trabajando en ello para disfrazarnos un poco de toda esa historia" (OSI3)

El sistema de gestión es una especie de decorado y solo se trabaja en él cuando van a venir los auditores o los evaluadores.

"Dedicar recursos, personas y tiempo a cosas que no están funcionando, porque cada vez que viene una auditoría el hospital todo dios se tira un mes nada más que contando mentiras para poner en los papeles para enseñarles a os auditores. ES que esto es así y el que diga lo contrario miente como un bellaco. Estoy seguro que a calzón quitado nadie me lo niega porque es así, sé que es así" (OSI3)

Algunas personas no se sienten participes del sistema e incluso sienten que cuando alguien se sale de la estructura preestablecida, del organigrama formal, se corta y se evita ese liderazgo natural.

"Tampoco despierta ningún interés, sobre todo entre los trabajadores, ningún interés" (OSI3)

"Yo tengo admiración porque conseguir hacer lo que hacen y que para mí es absolutamente artificial tiene mucho mérito. La gestión por procesos para mí no existe, yo no la veo en ningún ámbito del hospital. Aquí se coartan los liderazgos, se cercenan por la base inmediatamente" (OS/3)

En el liderazgo del sistema las personas que más participan son los profesionales asistenciales, en especial los médicos, y los profesionales de los procesos de apoyo no se sienten valorados, ni participan en la planificación, ni en la toma de decisiones.

"En cierta medida "La fuerza que tienen los médicos para exigir equipamiento hospitalario está a años luz de la importancia que se le concede al envoltorio, al resto, a la caja donde van esos equipos" (OS/3)

"No manejo ningún tipo de información. Aquí somos expertos en improvisar y luego cuando pasa una desgracia aprovechamos ahí para intentar meter la cuña" (OS/3)

La participación de todas las personas de la organización y el encaje en las políticas de calidad es difícil y se realiza con estructuras verticales rígidas y el predominio de los médicos. La organización prioriza las necesidades del colectivo médico y los colectivos de personal de procesos de apoyo sienten que no son tenidos en consideración suficientemente.

En definitiva lo que se reconoce es que lo primero que debe hacer cualquier organización sanitaria es cumplir con la normativa vigente. Lo que aportan las normas y 
sistemas de calidad es un plus de reconocimiento, en línea con lo expresado en párrafos anteriores.

"Lo que pasa que supongo que todos los hospitales la cumplen pero no tienen esa calificación o esos reconocimientos oficiales pero estoy seguro que se cumplen las normas. Pero supongo que para presentarse a la iso y estas cosas todo es dinero. Yo creo que lo que da esto es prestigio" (OSI6)

"Te obliga a, lo mismo la iso que cualquier otra norma a la que te presentas, te obligas a ver que estás dentro de unos niveles estándares que son los adecuados o que son los que tú quieres." (OSI6)

"Los reconocimientos se venden como medallas para la organización. Hay que venderlos no como medallas sino para ver los aspectos positivos de todo ello, como por ejemplo: el aumento de la seguridad laboral, la disminución de residuos, etc. "(OS/4)

No obstante también se ve como una oportunidad, no solo de cumplir la normativa, si no de mejorar más allá del estricto cumplimiento y buscar la excelencia en aspectos como la seguridad laboral, la ecoeficiencia, etc.

A pesar de todo, las personas entrevistadas reconocen que el modelo ha introducido la calidad y la mejora continua en su organización de forma inconsciente. La ha incorporado a su ADN, a su cultura.

"El modelo EFQM basado en la calidad que a pesar de que no somos conscientes de que funciona la verdad es que ha calado hondo en la forma de trabajar y de funcionar. Casi todo el mundo utiliza estándares de calidad. Es una cosa que es bueno en el sentido de que nadie entiende que trabaja en ello, nadie es consciente de que lo trabaja pero sí que es cierto que ha influido mucho en nuestra forma de funcionar. El proceso de mejora continua forma parte del ADN de los sistemas de calidad es lo que nosotros continuamente hacemos" (OSI7)

"Todo lo que nosotros somos viene del EFQM. Yo en su momento me lo creí. Igual que me dieron la ISO. Pero en tu día normal, a diario, no lo tienes en cuenta" (OSI6)

Aunque hay quienes aseguran que primero fue la cultura de calidad y después vino EFQM a ordenarlo o consolidarlo.

"Yo creo que no vino nada más que a ordenar y a darle nombre a algo que de forma inherente, innata, ya se estaba haciendo en el hospital" (OS/9)

Otro aspecto importante que surge del análisis del discurso es la importancia que se conceden a la enfermería (ilustración 34). Según los entrevistados, la enfermería es una pieza clave del futuro. Para ser sostenibles las organizaciones deben adaptarse a los retos que plantean el envejecimiento y el aumento de crónicos para lo que se precisarán profesionales capaces de responder a las necesidades de estos pacientes de forma integral y holística. El profesional adecuado para responder a este reto es la enfermera. "La gran apuesta de los próximos años tiene que ser por enfermería...se está trabajando en dos cuestiones: establecer claramente que las competencias de enfermería tienen que vincularse al seguimiento del crónico, algo propio de enfermería y que la atención tiene que realizarse en su entorno". (OSI10) 


\subsubsection{Interpretación del investigador}

Los líderes de la OSI Bilbao-Basurto (OSIBB) han asumido la transparencia, la mejora continua y la innovación como mecanismos de gestión de las tres dimensiones de la sostenibilidad.

- Económica. Implica gestión eficiente de los recursos económicos de la organización

- Social. Incluye todas las actividades, objetivos, etc. relacionados con los GI

- Ambiental. Impacto de las actividades de la organización en el medioambiente

Para ello, han diseñado e implantado diferentes enfoques, entre los que podemos destacar los siguientes:

- Desarrollo del sistema de gestión. La OSIBB ha asumido la Gestión por Procesos y el Modelo Avanzado de Gestión como modelo de gestión, y el papel de los líderes ha sido relevante.

- Compromiso con la innovación. Los líderes de la OSIBB participan en el diseño e implantación de proyectos innovadores, ya sea participando activamente como miembro del equipo responsable de su diseño como aportando los recursos necesarios.

- Impulso a los estándares de calidad y gestión como referencias voluntarias y auditables de manera externa como compromiso con la mejora continua hacia los GI.

- Participación activa con los Gl. los líderes asumen el protagonismo principal en estas relaciones

- Transparencia en la gestión. Esto se ha plasmado, entre otros aspectos, en la elaboración de memorias de RSC, que están disponibles para todos los GI.

- Adopción de compromisos más allá de lo legalmente exigible.

En sus memorias reconocen que, si bien la propia razón de ser de la OSIBB hace que su actividad tenga un impacto directo en la mejora de la salud, el hecho de ser una administración pública la obliga también a ser referentes en las dimensiones económicas, sociales y ambientales que definen la sostenibilidad. Bajo esta premisa, para la OSIBB la relación entre el concepto de sostenibilidad y el equilibrio de sus necesidades con las de sus Gl es unívoca. Esta relación queda explicitada en su Misión y en la Visión.

De esta manera, desde 2008, la Comarca por un lado y el Hospital por otro y desde 2014 de forma integrada, han estado trabajando en impulsar su adaptación para afrontar los cambios en la sociedad y fomentar la sostenibilidad de la organización a través de la orientación del modelo sanitario público hacia los ciudadanos y profesionales, reformulando las funciones de estos últimos hacia aspectos más relacionados con la prevención y promoción de la salud y haciendo copartícipes a los ciudadanos en la mejora de su salud. Con este objetivo, se han llevado a cabo diferentes estrategias:

- Desarrollo del espacio sociosanitario, donde se incluyen aquellas personas que por causa de graves problemas de salud o limitaciones funcionales y/o de riesgo de exclusión social, necesitan una atención sanitaria y social simultánea, coordinada y estable

- Enfoque de la actividad hacia el paciente crónico 
- Fomento de la corresponsabilidad en el tratamiento y autocuidados de los pacientes

- Utilización de tecnologías que permitan el cuidado y monitorización a distancia sin necesidad de hacer ir a los pacientes a los centros de salud y que fomenten la eficiencia en la relación entre la Atención Primaria y el resto de niveles asistenciales (Hospitales, emergencias) en el envío de información y ahorro de tiempos

- Utilización de la web 2.0 como oportunidad para una nueva relación más cercana entre la sanidad y la ciudadanía por la otra

El impacto ambiental de la propia actividad diaria en el entorno en forma de residuos, emisión CO2, consumo de papel, etc. se está trabajando desde hace varios años. Tras la constitución de la OSIBB la certificación ISO 14001 alcanza a toda la organización.

La OSIBB dispone de una batería de indicadores para medir el impacto de su estrategia en el conjunto de la Sociedad. Esta información se complementa con el resto de indicadores recogidos en las Memorias de RSC. Hacen referencia a los siguientes ámbitos:

- Sostenibilidad Medioambiental

- Igualdad de oportunidades

- Compromiso con la educación y la gestión del conocimiento

- Gestión Responsable

- Compromiso con desarrollo económico

Respecto a la pregunta de si la organización es competitiva las personas de la OSIBB manifiestan la sostenibilidad depende de los objetivos. La exigencia de la pública es diferente. La diferencia entre la pública y la privada está en la gestión de los trabajadores. En la pública faltan incentivos.

"La diferencia probablemente sean los tiempos En general tenemos servicios que son competitivos, muy competitivos y que hacen fenomenal las cosas. La gente va más a la privada por temas de hostelería. La gente sana va a la privada pero cuando tienen un problema cada vez más recurren a Osakidetza". (OSI8).

En el caso de un mercado libre y abierto la organización tendría que redimensionar el hospital y hacer organizaciones por especialidades en torno a las especialidades de referencia que cuentan con excelentes profesionales.

Para los entrevistados la organización goza de prestigio por un lado, pero es percibido como cercano y familiar por otro luego está el tema del oncológico que lo tratamos de maravilla e intentas buscar todas las posibilidades y cuando no tienes posibilidades en un sitio te mueves al mundo mundial, pero al final yo creo que la sanidad pública en general está muy bien y nuestro hospital como parte de ello tiene mucho.

"El hospital es competitivo sin duda y sin duda con la integración ha ganado" (OSI2)

En el tema económico (OSI1) si la organización se privatizara la política económica debería ser diferente porque se están produciendo unas desviaciones sobre lo presupuestado que no serían asumibles, con lo cual primaría ajustar más a los objetivos económicos que a los asistenciales. Hoy día en la organización es al revés se priman 
más los asistenciales que los económicos. No obstante, el tema económico tiene una gran importancia también y se tiene en cuenta el impacto económico de la actividad general de la organización. Mensualmente se realiza un seguimiento tanto de la actividad asistencial como del gasto y en ocasiones es necesario ajustar la actividad asistencial para que en el balance económico anual no presente un gran desequilibrio económico.

La organización debe dar un servicio a una población con unos mínimos criterios de calidad y eso, en ocasiones, cuesta más de lo que estaba presupuestado. Esto hasta cierto punto es asumible porque luego a nivel de gobierno destinan partidas.

Por tanto, la competitividad siempre va de la mano de la financiación. La OSI es ambiciosa y según los profesionales va por buen camino. La organización tiene capacidad de adaptación a las circunstancias cambiantes.

Aunque las circunstancias sean difíciles porque existe mucha dependencia de la tecnología y es cara, y cuando los equipamientos se van quedando obsoletos cada vez es más deprisa, la organización tiene que adaptarse a las circunstancias. En las "vacas gordas" se ha dispuesto de un presupuesto más holgado, quizás se llegó a derrochar, y en ese momento nadie se preocupó de reparar en gastos. En estos momentos sin embargo parece necesario trabajar con guías clínicas, con medicina basada en la evidencia, con todas sus ventajas y desventajas.

En general, la OSIBB es muy ágil, aunque su pertenencia a Osakidetza hace difícil introducir cambios. En aquellos problemas en los que la toma de decisiones se hace en el hospital es muy ágil, funciona muy bien y es muy activo y es un hospital muy actual. Además los profesionales del hospital y de la OSIBB tienen una capacidad de adaptación brutal. Según los profesionales la organización tiene una gran capacidad de improvisación 'de adaptación y se van engarzando formando en sí mismos un equipo de mejora al unirse. Se han formado, por ejemplo, grupos de trabajo con gente de almacén del hospital y de Atención Primaria en el que participa la dirección, y esto al director le gusta y al almacenero le hace sentirse escuchado y reconocido.

En estos momentos, la organización se encuentra en un proceso de cambio porque cada día se incorporan nuevas especialidades, nuevas técnicas y cada vez hay más pacientes y de mayor complejidad.

Tal y como se puede ver en el ilustración 34, las personas entrevistadas de la OSIBB tenían en común que el concepto de sostenibilidad de su organización debía abarcar las tres cuentas de resultados descritas por Elkington (1994). No obstante, cuando se les preguntó por la sostenibilidad de su organización todos hicieron referencia al aspecto económico en mayor medida.

"La sanidad tal como la vivimos es complicada porque el envejecimiento, la cronicidad, la renovación tecnológica que es carísima, el tema de farmacia con cada vez nuevos fármacos que alargan la vida de las personas y mejoran la calidad de vida pero a un coste económico importante" (OSI8)

No existe unanimidad sobre la sostenibilidad de la organización. También se aprecia diferencia entre las personas que forman parte de personal sanitario asistencial y las 
que pertenecen a procesos de apoyo. Los profesionales de la salud consideran que el servicio ofrecido es muy bueno, aunque preocupa el aspecto económico. La percepción de la capacidad asistencial y de los cuidados dispensados es muy buena.

El centro tiene necesidades de estructura y de mantenimiento que pueden ser mayores que otros centros por su antigüedad, pero al igual que los demás centros, necesitan que cada diez años se renueve todo el equipamiento y la tecnología. La idea general es que cada vez se consume más energía, más materiales, más recursos. Cada año más presupuesto.

El sistema como tal no es sostenible. Los recursos son finitos. El sistema es sostenible siempre y cuando el que da el dinero, la consejería, tenga dinero para hacerlo. Si este recauda menos es difícil. El sistema no es sostenible y los hospitales serán sostenibles en la medida en que la administración, que es la que tiene el dinero, pueda dar ese dinero. Todo depende de la prioridad política y de la legislación vigente en cada momento. El Responsable de Calidad añade un tercer factor, aparte de la actividad y los recursos, que es la eficiencia. Mediante iniciativas innovadoras la organización está trabajando en conseguir ser una más eficiente para que el aumento de la actividad no implique necesariamente un aumento paralelo en el consumo de recursos.

También depende de la voluntad política la implantación de un modelo de calidad, el nombramiento y el apoyo a un equipo directivo y su continuidad en el tiempo.

En todo caso, la implantación de un modelo de calidad, como el modelo EFQM en el caso de la OSIBB, introduce en la organización una serie de elementos.

- Método de trabajo. Ordena y prioriza los procedimientos dotándolos de continuidad y mejorando su eficacia. Por otro lado, proporciona a los profesionales seguridad en la realización de su trabajo, unos objetivos comunes compartidos y la unificación de criterios. Todo ello refuerza también la eficacia de los procesos asistenciales.

- Consideración de las personas. El modelo pone de relieve la necesidad de empoderar a las personas haciéndolas líderes de los procesos y potenciando la labor de los líderes intermedios. También facilita la accesibilidad a los líderes e introduce la necesidad de trabajar la satisfacción de las personas, el buen clima laboral y, en consecuencia, potencia el sentimiento de orgullo de pertenencia a la organización

- Orientación al paciente. Toda la organización reconoce al paciente como su principal cliente. Esto hace que se priorice lo asistencial sobre todo lo demás y que exista la sensación de poca implicación o poco reconocimiento de la importancia y la participación de los procesos de apoyo en el logo de la misión de la organización. Esta orientación al paciente busca no solo la satisfacción sino que también favorece que se mejoren aspectos como la seguridad.

- Colaboración con la sociedad. El modelo introduce en la organización la idea de pertenencia a un entorno social que está interactuando continuamente con la organización y al que hay que considerar como un factor importante en la sostenibilidad de la organización. El modelo EFQM refuerza esta idea proponiendo desde el criterio 8 que se mida el impacto de la organización en la sociedad. 
Los puntos anteriores parecen mostrar que entre las personas de la OSI Bilbao-Basurto se han interiorizado los conceptos fundamentales de la excelencia (ilustración 13).

Los conceptos fundamentales describen los atributos de una cultura orientada a la excelencia. Facilitan la creación de una visión compartida y un lenguaje común que forman una cultura de Excelencia (Foro de excelencia 2014).

La implantación del modelo EFQM ha introducido conceptos y valores relacionados con la excelencia en la organización que se manifiestan a través de las actitudes, comportamientos y expresiones utilizadas por el personal de la OSI tal y como demuestran los resultados obtenidos del análisis de sus discursos.

Los resultados obtenidos ayudan a comprender el fenómeno y dan respuestas sobre la experiencia social de los participantes. No se puede afirmar que el modelo EFQM sea el único elemento que apoye la sostenibilidad en las organizaciones sanitarias estudiadas. Las personas entrevistadas manifiestan preocupación por la sostenibilidad principalmente en términos económicos, aunque son conocedores de los demás ámbitos de la misma.

No obstante, sí se ha podido verificar la existencia de una cultura de la excelencia que trabaja por la sostenibilidad de forma cualitativa. Los resultados expuestos parecen mostrar que las personas de la OSI Bilbao-Basurto han interiorizado los conceptos fundamentales de la excelencia desarrollando valores compartidos que favorecen una actitud proactiva hacia la sostenibilidad. Se ha creado una cultura organizacional que las provee de motivación y herramientas metodológicas para buscar su adaptabilidad y su orientación en el camino de la sostenibilidad.

Los resultados están en sintonía con lo expresado en el informe sobre el impacto de la implantación de EFQM en Osakidetza publicado por Osalan que afirma que el modelo tuvo un impacto positivo en la percepción de las personas referida a elementos gestionables de forma diferenciada en cada organización, mientras que no se apreciaron diferencias en aquellos aspectos más homogéneos o centralizados. Además, se observó que cuanto mayor es el avance (Q-oro) mayor es la satisfacción de las personas respecto a las organizaciones menos avanzadas (sin reconocimiento). Esta idea respalda lo percibido en esta investigación respecto a la cultura propia de cada organización como elemento potenciado e influido por la implantación de EFQM

La cultura organizacional reforzada por el trabajo con el modelo EFQM les ha proporcionado un apoyo a la sostenibilidad manifestada a través de un conjunto compartido de creencias y de imágenes mentales comunes que muestra una imagen positiva de la organización, y confianza en el futuro.

Además, según los entrevistados (directivos de la OSIBB) la enfermería es una pieza clave del futuro de la organización sanitaria. Para ser sostenible las organizaciones deben adaptarse a los retos que plantean el envejecimiento y el aumento de crónicos para lo que se necesitarán profesionales de cuidados que sean capaces de responder a las necesidades de los pacientes de forma integral y desde una perspectiva holística. El profesional adecuado para responder a este reto es la enfermera. 


\section{DISCUSIÓN. ANÁLISIS COMPARADO DE CASOS}

A la hora de realizar la comparación entre las organizaciones, hay que destacar que tanto Osakidetza como el SERIS al inicio del periodo de crisis económica habían trabajado con el modelo EFQM y tenían ambas organizaciones contaban con reconocimientos de excelencia. Tanto en el HUB como en el Hospital San Pedro se trabajaba la gestión por procesos con una misión, visión y valores establecidos con el objetivo de, a través de la mejora continua, responder a las necesidades de todos los grupos de interés, es especial los pacientes. Todo ello apoyado desde sus respectivos Gobiernos Autonómicos.

Lo que realmente diferencia a ambas organizaciones fue la forma de afrontar esta prueba de estrés a las que les sometió la crisis. Osakidetza apostó por continuar trabajando en la calidad de las organizaciones llegando incluso a evolucionar el modelo. Como ya se ha citado, a partir de 1996, la dirección del HUB apostó por la implantación de un sistema de gestión basado en el modelo EFQM y la búsqueda de la excelencia trabajando un concepto de liderazgo compartido y la participación de las personas. En el año 2008, ayudados por una consultora externa, el hospital revisó su Misión, Visión y Valores, interviniendo en ello 220 líderes del hospital. Todos los datos indican que el HUB ha mantenido en todos estos años una política de calidad basada en el desarrollo del modelo EFQM implicando a sus personas y al resto de los grupos de interés.

Mientras tanto el SERIS optó por eliminar el sistema de gestión de la calidad en 2008 y apostar por una estructura vertical tradicional, eliminando órganos de participación de las personas (comisiones y comités), con el objetivo de minimizar los problemas derivados de los recortes por la priorización de la estrategia económico-financiera.

No obstante, y a pesar de las diferencias vividas por ambas organizaciones, los distintos discursos de los entrevistados recogidos en los apartados 4.1.2 y 4.2.2 en torno a la sostenibilidad y al modelo EFQM, reflejan unas ideas que muestran aspectos cualitativamente relevantes por su frecuencia e intensidad. Este discurso descubre un sistema de valores compartido y presidido por la orientación hacia las necesidades del paciente y la pervivencia de lo público en ambas organizaciones.

- Para los entrevistados de ambas organizaciones, la sostenibilidad abarca los campos de la economía, el medioambiente y el compromiso social. Aunque en su discurso predomine el componente económico sobre todos los demás. Estos últimos solo aparecen en el discurso si se pregunta explícitamente por ellos.

- En línea con el punto anterior, los entrevistados señalan que la sostenibilidad de las organizaciones sanitarias públicas depende de la financiación y en último término de la política o de los políticos que son quienes tienen la capacidad de gestionar los presupuestos.

- La implementación de políticas de calidad y de sistemas de gestión que las apoyen es vista como positivo en la sostenibilidad de las organizaciones con el 
objetivo de la mejora de las mismas, aunque a veces los trabajadores lo perciban como:

- Una apuesta de la dirección por mejorar su imagen o sus méritos.

- Un trabajo añadido al quehacer diario con un esfuerzo suplementario muy importante en todos los niveles de la organización.

- Una dificultad añadida a la hora de incorporar a todas las personas de la organización por las estructuras verticales rígidas y el predominio de los médicos

- Además, el lenguaje propio, es decir el "argot de la calidad" supone un problema en la comunicación, sobre todo a nivel de base, donde a la incomprensión se suma la percepción de exclusión. Esto se ha detectado principalmente entre los profesionales no sanitarios, como por ejemplo en los profesionales de mantenimiento.

- Existe la percepción de que los enfoques de calidad (EFQM, ISO...) son progresivamente convergentes en sus contenidos y propuestas. Que trabajar con un modelo u otro no es importante, lo importante es introducir la mejora continua en la organización. Por ejemplo, se señala que los modelos de calidad favorecen la coordinación Atención Primaria/Atención Hospitalaria y entre Servicios, lo que redunda en mejoras en la atención al paciente.

- El modelo EFQM aporta a las organizaciones aspectos positivos:

- Promueve la elaboración de objetivos comunes y fomenta el trabajo en equipo.

- Proporciona herramientas de trabajo que ayudan a ordenar y priorizar, a tener las ideas estructuradas, a saber que es lo bueno y darle nombre a algo que de forma inherente, innata, ya se está haciendo en los centros.

- Se valora el apoyo de la dirección y se considera como un factor clave de éxito su liderazgo e implicación.

- Los logros de la organización, relacionados con el reconocimiento y calidad, son vividos con protagonismo, orgullo y sensación de pertenencia

- En las organizaciones estudiadas también se han detectado aspectos mejorables:

- El liderazgo de los mandos intermedios (conocer el modelo, querer implantarlo y trabajarlo) es fundamental para que los modelos de calidad se implanten y se integren en la organización.

- La motivación, a través de la comunicación del modelo, es difícil, compleja y frecuentemente limitada al tiempo de auditorías 0 evaluaciones. La formación y el conocimiento del modelo EFQM, para establecer relaciones causa efecto con las mejoras propuestas y su identificación con el modelo podrían generar elementos motivadores.

- La obtención de reconocimiento externo a través de premios de excelencia, a veces es percibida como una perversión de los objetivos de la organización y no como un elemento motivador. Una suerte de publicidad o de venta de los políticos. 


\subsection{Contexto de las organizaciones}

Ambas organizaciones parten de una situación histórica de partida similar. Ya en 1999 el Insalud hablaba de impulsar la mejora continua en busca de la excelencia en el Plan de Calidad Total (INSALUD, 1999). Para ello proponía a las organizaciones definir una visión del modelo de referencia para la calidad a la que aproximarse. El plan de calidad de la organización debía proporcionar el método y la sistemática necesarios para desarrollar la evaluación y mejora continua de los procesos y los resultados de toda la organización.

Este objetivo constituía el soporte teórico y metodológico para la elaboración e implantación de muchas de las acciones operativas contenidas en el plan de calidad que debía contener los siguientes objetivos específicos:

a) Implantar el ciclo de la mejora continua de la calidad, como método de trabajo en toda la organización.

b) Los centros debían elaborar un plan de formación específica dirigido a la difusión de la cultura y el método de la mejora continua, de la calidad y la eficiencia.

c) Potenciar la implantación de la gestión de las actividades basadas en la calidad

d) Formar grupos de trabajo de mejora continua.

e) Autoevaluación, auditoría interna.

Las condiciones actuales de las organizaciones han cambiado y se han incorporado nuevas ideas, nuevos enfoques, diferentes y, en principio, más adecuados y apropiados para cada organización.

No obstante, ambas organizaciones sanitarias se enfrentan en la actualidad a un reto común sin precedentes, proporcionar la mejor asistencia a los ciudadanos en un entorno complejo y con unos costes muy altos.

La satisfacción de las necesidades del paciente es el objetivo principal manifestado por las personas de ambas organizaciones. El sistema de gestión de las organizaciones permite orientar todas las actividades sanitarias hacia la satisfacción de las necesidades y expectativas de los pacientes en primer término, aunque también tienen en cuenta a otros grupos de interés.

El entorno en el ámbito de las organizaciones proyecta hacia la misma un conjunto multifacético de tendencias económicas, políticas, ideológicas, culturales, religiosas, sociales, entre otras, marcadas por la evolución y el desarrollo histórico de la sociedad, Uno de los requisitos esenciales para el funcionamiento exitoso del sistema organizacional consiste en el conocimiento de las demandas del entorno y de sus principales tendencias que inciden en la organización en forma de impactos-positivos o negativos- denominados comúnmente oportunidades y amenazas.

La crisis económica, la inflación, las tendencias demográficas y las ambientales constituyen ejemplos concretos de macrotendencias. En este sentido son aspectos que se han analizado para evaluar la capacidad de adaptación externa de las organizaciones estudiadas. 
El análisis nos lleva a la reflexión en cuanto a que la cultura organizacional en su interacción con el entorno se va consolidando al intentar adaptarse a las sustanciales modificaciones que en él se operan, lo cual influye de forma importante en el proceso de formación, consolidación y cambio cultural.

\subsubsection{Determinantes de la salud}

Los determinantes sociales de la salud (tabla 71) son aquellos que condicionan la salud de los ciudadanos. Los determinantes sociales de la salud son las circunstancias en que las personas nacen, crecen, viven, trabajan y envejecen, incluido el sistema de salud.

Tabla 71. Tendencia de indicadores determinantes sociales de la salud

\begin{tabular}{|c|l|l|l|l|l|l|}
\hline $\begin{array}{c}\text { Gráfico } \\
\text { Anexo II }\end{array}$ & \multicolumn{2}{|r|}{ Indicador } & Valor de P & $\begin{array}{c}\text { Nivel de } \\
\text { significancia }\end{array}$ & $\begin{array}{l}\text { Resultados frente } \\
\text { hiópotesis de no } \\
\text { coincidencia }\end{array}$ & \multicolumn{1}{|c|}{ Conclusión } \\
\hline 1 & Indice dependencia & $\begin{array}{l}\text { Proporción de personas de menos } \\
\text { de 15 años+ número de personas } \\
\text { de más de } 64 \text { años, en un año } \\
\text { dependientes }\end{array}$ & 0.2284444 & 0.0500000 & $\begin{array}{l}\text { Failed to reject } \\
\text { Coincidence }\end{array}$ & Coincidencia \\
\hline 2 & Nivel de estudios & $\begin{array}{l}\text { Proporción de población de 25 a } \\
64 \text { años con nivel de estudios de } \\
1 \% \text { Etapa de educación secundaria } \\
\text { o inferior }\end{array}$ & 0.0024444 & 0.0500000 & Rejected \\
coincidence & $\begin{array}{l}\text { Diferencia } \\
\text { significativa }\end{array}$ \\
\hline 3 & Vacuna gripe & $\begin{array}{l}\text { Cobertura (\%) de personas } \\
\text { mayores de } 65 \text { años vacunadas } \\
\text { frente a la gripe }\end{array}$ & 0.0251111 & 0.0500000 & $\begin{array}{l}\text { Rejected } \\
\text { coincidence }\end{array}$ & $\begin{array}{l}\text { Diferencia } \\
\text { significativa }\end{array}$ \\
\hline 5 & Vacuna polio & $\begin{array}{l}\text { Cobertura (\%) de vacunación frente } \\
\text { a la poliomielitis (primovacunación } \\
0-1 \text { años) }\end{array}$ & 0.0002222 & 0.0500000 & $\begin{array}{l}\text { Rejected } \\
\text { coincidence }\end{array}$ & $\begin{array}{l}\text { Diferencia } \\
\text { significativa }\end{array}$ \\
\hline Vacuna triple vírica & $\begin{array}{l}\text { Cobertura (\%) de vacunación frente } \\
\text { a sarampión-rubéola-parotiditis } \\
\text { (primovacunación 1-2 años) }\end{array}$ & 0.0475556 & 0.0500000 & $\begin{array}{l}\text { Rejected } \\
\text { coincidence }\end{array}$ & $\begin{array}{l}\text { Diferencia } \\
\text { significativa }\end{array}$ \\
\hline
\end{tabular}

Resultados de análisis de tendencias con Programa Joint Point

\section{Análisis:}

- Sociodemográfico. El índice de dependencia implica que el número de personas de menos de 15 años más el número de personas de más de 64 años es mayor en el País Vasco. Además las pirámides de población observadas parecen indicar que existe un mayor número de personas mayores de 65 años con lo que eso supone de aumento de las enfermedades crónicas y del índice de morbilidad, así como del uso de recursos sanitarios y sociosanitarios.

- Estilos de vida. La prevalencia del consumo de tabaco donde más ha disminuido es en La Rioja

- Determinantes biológicos. La prevalencia de la obesidad en población adulta. La Rioja y sobre todo País Vasco han disminuido la tasa de obesos, no ocurre lo mismo en el conjunto del país 
- Determinantes sociales. Proporción de población de 25 a 64 años con nivel de estudios de $1^{\circ}$ Etapa de educación secundaria o inferior. En este periodo se observa una mejora en general de nivel de estudios. El País Vasco y La Rioja están por encima de la media nacional. Aunque el nivel de estudios más alto corresponde al País Vasco.

- Accesibilidad.

- Ha disminuido la cobertura (\%) de personas mayores de 65 años vacunadas frente a la gripe en los años de la crisis. Donde menos ha disminuido la cobertura ha sido en La Rioja

- La cobertura (\%) de vacunación frente a la poliomielitis (primovacunación 0-1 años) se encuentra en valores similares, aunque la tendencia en el conjunto de España es negativa. La tasa de cobertura es muy alta (99\%) en La Rioja.

- La cobertura (\%) de vacunación frente a sarampión-rubéola-parotiditis (primovacunación 1-2 años) en La Rioja ha aumentado En el resto del país ha empeorado.

- El porcentaje de mujeres de 50 a 69 años con mamografía realizada con la frecuencia ha empeorado en La Rioja aunque se mantiene en las tasas más altas

\subsubsection{Gasto sanitario}

Los indicadores de gastos (tabla 72) muestran los recursos económicos que ha empleado cada comunidad autónoma en las más importantes partidas de gasto. Por otro lado, se presentan datos de indicadores que miden la eficiencia de la actuación como la estancia media del paciente hospitalizado y el porcentaje de reingresos que cuanto menores sean sus valores, mejor uso hace el sistema de sus recursos. El indicador de cirugía mayor ambulatoria muestra el número de intervenciones quirúrgicas programadas que se realizan de forma ambulatoria facilitando la recuperación más rápida del paciente en su propio entorno, evitando el ingreso del mismo en el hospital y los gastos y las complicaciones que esto puede suponer.

Tabla 72. Tendencia de indicadores de gasto

\begin{tabular}{|c|l|c|c|c|}
\hline \multirow{2}{*}{ DomiNIOS } & \multicolumn{1}{|c|}{ INDICADOR } & \multicolumn{3}{|c|}{ Diferencia 2008-2014 } \\
\cline { 3 - 5 } & & $\begin{array}{c}\text { PAIS } \\
\text { VASCO }\end{array}$ & RIOJA & E \\
\hline Económico & $\begin{array}{l}\text { Gasto sanitario público territorializado, por habitante } \\
\text { protegido }\end{array}$ & 3,43 & $-195,3$ & $-100,64$ \\
\hline Económico & Porcentaje del gasto sanitario en atención primaria & $-0,28$ & 0,25 & $-1,12$ \\
\hline Económico & $\begin{array}{l}\text { \% del gasto de los servicios de atención } \\
\text { especializada }\end{array}$ & 5,56 & $-0,09$ & 4,95 \\
\hline Económico & $\%$ del gasto en farmacia & $-4,27$ & $-1,87$ & $-3,12$ \\
\hline Económico & $\%$ del gasto en remuneración de personal & 2,62 & $-0,47$ & 1,28 \\
\hline Económico & $\%$ del gasto en consumos intermedios & 3,69 & 3,5 & 3,61 \\
\hline Económico & $\%$ del gasto dedicado a conciertos & $-0,22$ & 2,65 & 0,11 \\
\hline Eficiencia & Estancia media ajustada por la casuística (EMAC) & $-0,56$ & $-0,3$ & $-0,4$ \\
\hline Eficiencia & Porcentaje de cirugía ambulatoria & 5,01 & $-2,79$ & 6,41 \\
\hline Eficiencia & Porcentaje global de reingresos & 0,12 & 0,73 & 0,65 \\
\hline
\end{tabular}




\section{Análisis}

- Económico:

- Mientras el gasto sanitario público (ilustración 35) se ha recortado mucho en La Rioja, (casi el doble que la media española), el sistema sanitario vasco no ha sufrido ajustes en su presupuesto.

- El porcentaje de gasto en especializada apenas ha cambiado en los últimos años en La Rioja, sin embargo ha tenido un pequeño repunte en el País Vasco y España. Según los expertos sería necesario potenciar la primaria y dotarla de más recursos.

- La reducción del gasto en farmacia es uno de los imprescindibles para lograr la sostenibilidad. Se ha comenzado a reducir, aunque en La Rioja aún es muy pequeña esa reducción.

- La Rioja es la única que ha rebajado el gasto en personal

- El porcentaje de gasto dedicado a conciertos ha subido en la Rioja como consecuencia del aumento de participación de la sanidad privada.

- Eficiencia:

- La estancia media ajustada es similar en toda España

- Otra de las recomendaciones para la sostenibilidad del sistema es la ambulatorización de procesos. En este sentido los datos demuestran que en el País Vasco y en España se ha trabajado para ello. Sin embargo, en La Rioja se muestra un recorte de este tipo de actividades.

- La tasa de reingresos en La Rioja es seis ves superior a la de País Vasco y se acerca a la media del resto de CCAA

Ilustración 35. Gasto sanitario por habitante

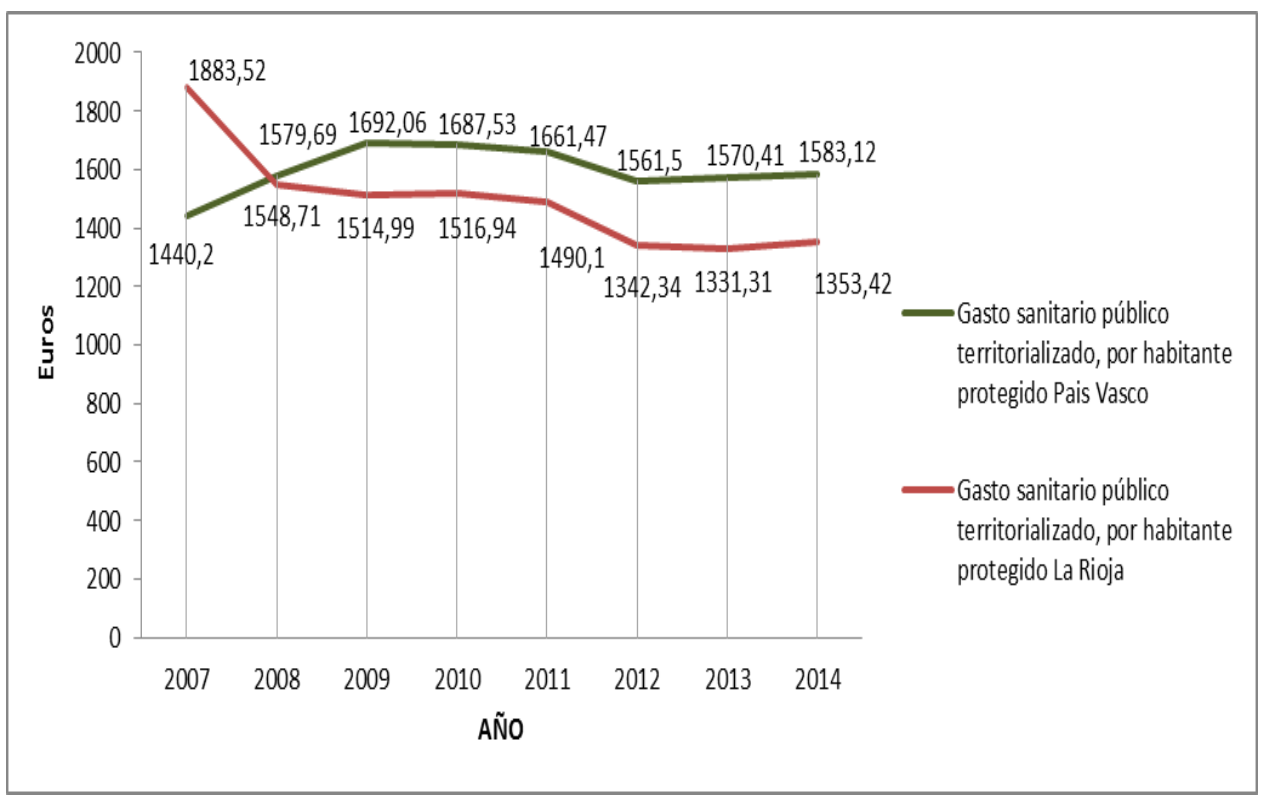

Y su distribución entre Atención Primaria y Especializada, muy parecida en ambas comunidades (ilustración 36). 


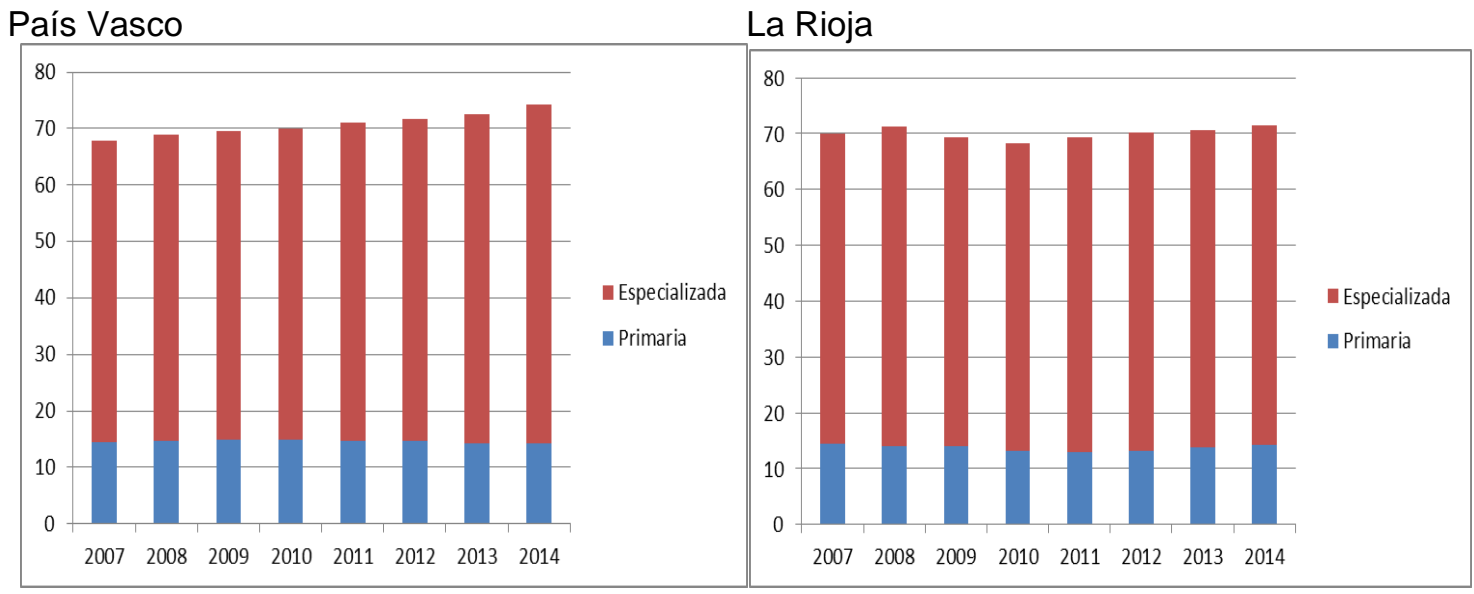

\subsubsection{Recursos sanitarios}

Los indicadores de recursos (tabla 73) muestran la cantidad de recursos humanos y materiales, el uso que se da por parte de los ciudadanos al sistema de salud y la pertinencia de algunos procedimientos tal y como los definen los expertos.

Tabla 73. Tendencia de indicadores de recursos

\begin{tabular}{|c|c|c|c|c|c|}
\hline $\begin{array}{l}\text { Gráfico } \\
\text { Anexo II }\end{array}$ & Indicador & Valor de P & $\begin{array}{l}\text { Nivel de } \\
\text { significancia }\end{array}$ & $\begin{array}{l}\text { Resultado frente a } \\
\text { hipótesis de no } \\
\text { coincidencia }\end{array}$ & Conclusión \\
\hline 6 & Indice de estancia media ajustada & 0.1517778 & 0.0500000 & Rejected coincidence & $\begin{array}{l}\text { Diferencia } \\
\text { significativa }\end{array}$ \\
\hline 7 & $\begin{array}{l}\text { Porcentaje de cirugía ambulatoria en el } \\
\text { SNS }\end{array}$ & 0.0044444 & 0.0500000 & Rejected coincidence & $\begin{array}{l}\text { Diferencia } \\
\text { significativa } \\
\end{array}$ \\
\hline 8 & $\begin{array}{l}\text { Personal médico en Atención Primaria } \\
\text { por } 1000 \text { personas asignadas }\end{array}$ & 0.0122222 & 0.0500000 & Rejected coincidence & $\begin{array}{l}\text { Diferencia } \\
\text { significativa } \\
\end{array}$ \\
\hline 9 & $\begin{array}{l}\text { Camas hospitalarias en funcionamiento } \\
\text { por } 1000 \text { habitantes }\end{array}$ & 0.0044444 & 0.0500000 & Rejected coincidence & $\begin{array}{l}\text { Diferencia } \\
\text { significativa } \\
\end{array}$ \\
\hline 10 & Porcentaje del gasto en farmacia & 0.0120000 & 0.0500000 & Rejected coincidence & $\begin{array}{l}\text { Diferencia } \\
\text { significativa } \\
\end{array}$ \\
\hline 11 & $\begin{array}{l}\text { Porcentaje de gsto en remuneración del } \\
\text { personal }\end{array}$ & 0.0002222 & 0.0500000 & Rejected coincidence & $\begin{array}{l}\text { Diferencia } \\
\text { significativa }\end{array}$ \\
\hline
\end{tabular}

Resultados de análisis de tendencias con Programa Joint Point 


\section{Análisis}

- Recursos:

- Las estadísticas generales del número de médicos en el primer nivel del sistema sanitario (atención primaria) señalan que no ha habido variación en el ratio (ligerísimo aumento), aunque si señalan que el número de médicos de atención primaria (AP) en La Rioja es menor

- El aumento de puestos en hospitales de día se debe al aumento de la ambulatorización de procesos. Más del doble en País Vasco que en La Rioja.

- Uso:

- En La Rioja ha aumentado la frecuentación en medicina de AP y está en valores absolutos por encima del resto de comunidades.

- En el uso de la resonancia magnética se ha producido un importante aumento del uso. Probablemente por el aumento de su uso como herramienta diagnóstica. Parece necesario replantearse su uso y buscar un consenso entre los profesionales sobre la eficiencia del uso de esta tipo de herramientas diagnósticas.

- En el índice de la estancia media ajustada (IEMA) no se dan diferencias relevantes entre CCAA.

- En el porcentaje de cirugía ambulatoria (CMA) La Rioja es la única que ha disminuido y está en los peores valores absolutos. Este dato es relevante porque la CMA está considerada una de las herramientas que han demostrado una mejora de los resultados de los procesos quirúrgicos en cuanto a la disminución de las listas de espera con buenos resultados, sin incremento de efectos iatrogénicos sobre los pacientes y disminuyendo los costes al evitar ingresos y disminuir los tiempos de convalecencia.

- Pertinencia. Tanto el porcentaje de cirugía conservadora en cáncer de mama como el porcentaje de pacientes con fractura de cadera intervenidos en las primeras 48 horas tienen en La Rioja sus mejores resultados.

\subsubsection{Resultados clave en salud}

Se han recogido los indicadores de País Vasco, La Rioja y la media de todas las comunidades autónomas de España. Como ya se ha expuesto en anteriores capítulos se trata de valorar la diferencia cuantitativa entre ambas comunidades autónomas y los posibles efectos de la política de calidad, y en concreto la implantación del modelo EFQM, como factor diferenciador entre ambas regiones durante el periodo de estudio.

En este estudio no hemos evaluado aspectos relacionados con el nivel de salud total en cada comunidad autónoma sino la evolución reflejada en el periodo estudiado en un contexto de crisis económicas. Los indicadores que se presentan en la tabla 74 exponen resultados considerados clave en salud por el Ministerio de Sanidad, Servicios Sociales e lgualdad que los considera representativos de la situación de la salud de los 
ciudadanos a través de los dominios de bienestar, mortalidad, morbilidad, y eficacia del sistema sanitario.

Tabla 74. Tendencia de indicadores de resultados clave

\begin{tabular}{|c|c|c|c|c|c|}
\hline $\begin{array}{l}\text { Gráfico } \\
\text { Anexo II }\end{array}$ & Indicador & Valor de $\mathbf{P}$ & $\begin{array}{l}\text { Nivel de } \\
\text { significancia }\end{array}$ & $\begin{array}{l}\text { Resultado frente a } \\
\text { hipótesis de no } \\
\text { coincidencia }\end{array}$ & Conclusión \\
\hline 12 & Años de vida saludable a los 65 años & 0.2360000 & 0.0500000 & \begin{tabular}{|l} 
Failed to reject \\
Coincidence
\end{tabular} & Coincidencia \\
\hline 13 & $\begin{array}{l}\text { Tasa de mortalidad ajustada por edad por } \\
\text { cardiopatía isquémica por } 100000 \text { hab. }\end{array}$ & 0.0297778 & 0.0500000 & Rejected coincidence & $\begin{array}{l}\text { Diferencia } \\
\text { significativa }\end{array}$ \\
\hline 14 & Esperanza de vida al nacer & 0.0573333 & 0.0500000 & \begin{tabular}{|l|}
$\begin{array}{l}\text { Failed to reject } \\
\text { Coincidence }\end{array}$ \\
\end{tabular} & Coincidencia \\
\hline 15 & Tasa de mortalidad infantil por 1000 nacidos vivos & 0.1137778 & 0.0500000 & $\begin{array}{l}\text { Failed to reject } \\
\text { Coincidence }\end{array}$ & Coincidencia \\
\hline 16 & $\begin{array}{l}\text { Tasa de mortalidad perinatal por cada 1000nacidos } \\
\text { vivos }\end{array}$ & 0.0100000 & 0.0500000 & Rejected coincidence & $\begin{array}{l}\text { Diferencia } \\
\text { significativa }\end{array}$ \\
\hline 17 & Incidencia de tuberculosis por 100000 hab & 0.4028889 & 0.0500000 & Rejected coincidence & $\begin{array}{l}\text { Diferencia } \\
\text { significativa }\end{array}$ \\
\hline 18 & $\begin{array}{l}\text { Tasa de mortalidad prematura por enfermedades } \\
\text { crónicas de vías respiratorias inferiores, ajustada } \\
\text { por edad, por } 100000 \text { hab. }\end{array}$ & 0.1213333 & 0.0500000 & Rejected coincidence & $\begin{array}{l}\text { Diferencia } \\
\text { significativa }\end{array}$ \\
\hline 19 & $\begin{array}{l}\text { Tasa de mortalidad prematura por enfermedad } \\
\text { vascular, ajustada por edad, por } 100.00 \text { hab. }\end{array}$ & 0.0988889 & 0.0500000 & Rejected coincidence & $\begin{array}{l}\text { Diferencia } \\
\text { significativa }\end{array}$ \\
\hline 20 & $\begin{array}{l}\text { Tasa de mortalidad prematura por Cardiopatía } \\
\text { isquémica, ajustada por edad, por } 100000 \text { hab. }\end{array}$ & 0.0297778 & 0.0500000 & Rejected coincidence & $\begin{array}{l}\text { Diferencia } \\
\text { significativa }\end{array}$ \\
\hline 21 & Porcentaje global de reingresos & 0.1404444 & 0.0500000 & $\begin{array}{l}\text { Failed to reject } \\
\text { Coincidence }\end{array}$ & Coincidencia \\
\hline 22 & Tasa de infección hospitalaria & 0.1006667 & 0.0500000 & $\begin{array}{l}\text { Failed to reject } \\
\text { Coincidence }\end{array}$ & Coincidencia \\
\hline 23 & $\begin{array}{l}\text { Tasa de fracturas de cadera en pacientes } \\
\text { ingresados }\end{array}$ & 0.0133333 & 0.0500000 & Rejected coincidence & $\begin{array}{l}\text { Diferencia } \\
\text { significativa }\end{array}$ \\
\hline 24 & $\begin{array}{l}\text { Tasa de mortalidad intrahospitalaria global por } \\
\text { 100altas hospitalarias }\end{array}$ & 0.0044444 & 0.0500000 & Rejected coincidence & $\begin{array}{l}\text { Diferencia } \\
\text { significativa }\end{array}$ \\
\hline
\end{tabular}

Resultados de análisis de tendencias con Programa Joint Point

\section{Análisis}

- Bienestar:

- La esperanza de vida ha aumentado más en La Rioja y es más alta que en el País Vasco y más alta que en el resto de España.

- La esperanza de vida con buena salud al nacer ha aumentado más en España. Mucha diferencia con el País Vasco. Pero la esperanza sigue siendo más alta en País Vasco.

- El porcentaje de personas mayores de 65 años con una percepción positiva de su salud ha aumentado más en País Vasco, lo cual parece reforzar los resultados de indicadores anteriores. Parece ser que la estrategia de mayores y crónicos está más implantada en País Vasco o al menos tiene mejores resultado.

- Mortalidad:

- La tasa de mortalidad prematura por cáncer ha mejorado en La Rioja donde más. La Rioja presenta menor tasa de mortalidad y más mejoría en este periodo. Todo esto podría estar relacionado con la puesta en marcha en La Rioja de nuevas infraestructuras y servicios sanitarios

- La tasa de mortalidad prematura por cardiopatía isquémica ha disminuido en España en general y en menor medida en País Vasco. La Rioja ha sufrido un aumento. La Rioja dispone de menos recursos en este campo.

- La tasa de mortalidad prematura por diabetes y por enfermedad vascular presenta el mayor descenso en La Rioja y el mejor valor absoluto. En este aspecto influye de manera importante la dieta y el estilo de vida. 
- En las tasas de mortalidad prematura por enfermedades respiratorias crónicas el mayor descenso se haya producido en La Rioja, no obstante los valores absolutos en País Vasco y La Rioja son muy similares

- La tasa de mortalidad infantil presenta el mayor descenso en La Rioja, aunque los valores absolutos en País Vasco y La Rioja son muy similares. No obstante, la tasa de mortalidad perinatal empeoró durante el periodo estudiado más en La Rioja que en el País Vasco. En España se mantuvo igual.

- Morbilidad:

- La incidencia de la tuberculosis ha sufrido una mejoría importante en La Rioja hasta situarse en incidencias menores que en País Vasco y España. Tradicionalmente por climatología los enfermos respiratorios del País Vasco acudían a La Rioja. Este indicador tiene hoy en día una fuerte relación con la pobreza y la inmigración, por lo que el descenso del número de inmigrantes y el porcentaje de ellos en la población de cada Comunidad determina en gran medida el valor del indicador.

- La prevalencia de diabetes mellitus se mantiene en valores similares. La prevalencia de trastornos mentales en adultos ha aumentado en todas las CCAA y mucho más en País Vasco.

- Empeoramiento de la Salud Mental o mayor capacidad de diagnóstico o relacionado con las condiciones sociales y laborales durante el periodo de crisis.

- Eficacia:

- Las tasas de hospitalización por infarto agudo de miocardio y de mortalidad ajustada por cardiopatía isquémica y por enfermedad cerebrovascular presentan una importante mejora en País Vasco. La Rioja ha empeorado y mantiene tasas más altas.

- La tasa de mortalidad perinatal es bastante más alta en La Rioja que en España y en País Vasco. La Rioja no dispone de recursos especializados en Cuidados Intensivos Pediátricos.

- La tasa de fracturas de cadera en pacientes ingresados y de infección hospitalaria son indicadores de la calidad de los cuidados dispensados en los hospitales y tienen mucha relación con los profesionales de enfermería. Los valores son muy similares en todas las CCAA.

- La tasa de comunicación de efectos adversos relacionados con los medicamentos nos proporciona una idea de la mejora en la concienciación de los profesionales con un aumento de notificación en España, algo menor en País Vasco y un empeoramiento claro en La Rioja. Otra teoría diría que esta disminución de la tasa es debida a un menor número de casos producidos por lo que sería positivo en el caso de La Rioja.

- La mortalidad intrahospitalaria global mejoran los datos en La Rioja. La mortalidad intrahospitalaria tras intervención quirúrgica mejora datos en todos, pero los mejores valores globales son en La Rioja. 


\subsubsection{Satisfacción de los ciudadanos con el sistema sanitario}

La satisfacción de los ciudadanos es, en último lugar, indicativo de que el sistema sanitario responde a las necesidades y expectativas de los ciudadanos. En ambas comunidades autónomas en toda la serie de datos del periodo estudiado, se mejoran los resultados de la media española. Son dos comunidades reconocidas por sus ciudadanos entre las que mejores sistemas sanitarios tienen del país.

Tras el análisis estadístico sólo se aprecian diferencias significativas en el grado de satisfacción global de los ciudadanos (tabla75)

Tabla 75. Tendencia de indicadores de satisfacción de los ciudadanos

\begin{tabular}{|c|c|c|c|c|c|c|c|c|}
\hline & $\begin{array}{l}\text { Number of } \\
\text { Joinpoints }\end{array}$ & $\begin{array}{c}\text { Numerator } \\
\text { Degrees of } \\
\text { Freedom }\end{array}$ & $\begin{array}{c}\text { Denominator } \\
\text { Degrees of } \\
\text { Freedom }\end{array}$ & $\begin{array}{l}\text { Number of } \\
\text { Permutations }\end{array}$ & P-Value & Significance Level & $\begin{array}{c}\text { Final selected } \\
\text { model }\end{array}$ & Conclusión \\
\hline $\begin{array}{c}\text { Grado de satisfacción de los } \\
\text { ciudadanos con el } \\
\text { funcionamiento del } \\
\text { sistema sanitario público }\end{array}$ & $\begin{array}{c}1 \\
\text { Joinpoint(s) }\end{array}$ & 4 & 10 & 4500 & 0.0022222 & 0.0500000 & $\begin{array}{c}\text { Rejected } \\
\text { coincidence }\end{array}$ & $\begin{array}{c}\text { Diferencia } \\
\text { significativa }\end{array}$ \\
\hline
\end{tabular}

Resultados de análisis de tendencias con Programa Joint Point

\section{Análisis}

En el grado de satisfacción de los ciudadanos con el funcionamiento del sistema sanitario la tendencia es negativa en todas las CCAA menos en País Vasco. A pesar de partir de índices más bajos ahora muestran mejores valores. En La Rioja se realizó un gran esfuerzo en la construcción de nuevas infraestructuras como la construcción del nuevo hospital de referencia, Hospital San Pedro, y algunos centros de salud y de alta resolución. Todo ello antes de 2008. Se puede ver el efecto en la satisfacción de los ciudadanos en los primeros datos que se exponen en las gráficas de este trabajo, pero con el paso de los años se acaba el efecto de nuevas instalaciones, a lo que se añade el posible efecto que ha tenido sobre este ítem las campañas mediáticas en televisión y prensa sobre crisis, recortes, manifestaciones., etc.

En el grado de satisfacción con la información y el seguimiento de sus problemas hay mejores valores globales en La Rioja. En este caso es muy probable que la mayor accesibilidad o el sentimiento de proximidad con los médicos al ser una población más diseminada contribuya a una relación más personal que influya en el grado de satisfacción. El grado de satisfacción con la información recibida parece confirmar el resultado anterior. En La Rioja está mejor considerada la Atención Primaria que la Especializada. Esto también confirma la percepción de que a mayor proximidad y cercanía del profesional, mejor es su valoración. 


\subsubsection{Seguridad de pacientes y cobertura sanitaria}

Los indicadores de seguridad y cobertura muestran información sobre la capacidad de las organizaciones sanitarias de prever algunos problemas como las reacciones adversas a los medicamentos, las complicaciones postinfarto y las amputaciones, y la accesibilidad de los pacientes a las instituciones sanitarias.

\section{Análisis}

- La notificación de reacciones adversas ha aumentado en todas las CCAA, pero en La Rioja la tasa es considerablemente más baja que la de España y sobre todo que la del País Vasco. Probablemente esto no se deba a un problema real con un aumento de reacciones adversas sino que en La Rioja el sistema de notificación no está implementado en su totalidad y de esta forma se puede adivinar que no existe un registro exhaustivo de todos los casos.

- La mortalidad intrahospitalaria postinfarto mejora en todas CCAA, sobre todo en País Vasco, que presenta los mejores valores absolutos. En La Rioja no existen unidades coronarias y la propia dispersión de la población determina que sea más complejo comenzar el tratamiento de forma inmediata para que aumenten las posibilidades de supervivencia.

- En la tasa de amputaciones de miembro inferior hay mejores datos en La Rioja. Esto no se corresponde con los datos de la prevalencia de la Diabetes, mayores en La Rioja, aunque si puede guardar relación con los accidentes de tráfico y lesiones en el trabajo. Por otro lado, el La Rioja, aunque no sean muchos casos, no están incluidos los pacientes más graves que son derivados a otros centros fuera de la comunidad autónoma.

- Accesibilidad. No se pueden valorar las diferencias entre comunidades autónomas porque no existen datos desagregados

\subsection{Factores internos de las organizaciones}

\subsubsection{Procesos, productos y servicios}

En la actualidad no existe un método sistemático de gestión por procesos en el Hospital San Pedro. Se realizan, sin embargo, de forma habitual muchas actividades encaminadas hacia la mejora de procesos, que sin responder a un modelo de organización preestablecido, han ido desplegándose en el Hospital de forma paulatina como consecuencia de diferentes normativas o iniciativas dirigidas, en muchos casos, desde otros niveles de decisión central.

Los Contratos de Gestión entre el hospital San Pedro y la Consejería de salud llegaron a desaparecer. Desde 2015 se han vuelto a retomar y anualmente el centro los firma y en ellos están identificados, al menos de forma tácita, los procesos clave que realiza el hospital (Hospitalización, Consultas externas, Urgencias, etc.) y en cada uno de estos procesos se pactan indicadores y objetivos específicos para su gestión y control.

Todas las actividades explicadas hasta ahora se realizan de forma un tanto aislada e inconexa, sin un plan organizador común que favorezca la coordinación y unión de las 
diferentes iniciativas. Por ello, debería definirse el mapa de procesos del hospital, y establecerse un cauce oficial para canalizar las diferentes propuestas de mejora hacia una comisión que, con carácter ejecutivo, se encargará de establecer sus prioridades de implantación y facilitar y vigilar todos los aspectos necesarios para su adecuada puesta en marcha, proceso de pruebas y posterior evaluación. La mayor parte de las innovaciones tecnológicas y organizativas que tienen que ver con la atención directa a los pacientes surgen de las iniciativas de los profesionales, basadas en el aprendizaje de la mejor evidencia científica disponible. El Hospital San Pedro no realiza ningún trabajo o investigación propia de mercado tendente a averiguar las necesidades y expectativas de los pacientes y de otros grupos de interés. No, al menos, de forma explícita y planificada. Existen, sin embargo, numerosos canales más o menos implícitos o soterrados, pero que funcionan y que sirven tanto para ajustar los procesos existentes como para desarrollar otros nuevos de acuerdo con esas expectativas. Entre estos canales de transmisión se pueden reseñar los siguientes:

- La Consejería de salud, que como organismo financiador y comprador de la prestación, traslada las necesidades y expectativas de la población, recogidas en muchos casos por iniciativa política, a través de los Contratos de Gestión.

- Sugerencias vertidas por diferentes grupos de interés en las reuniones de la Dirección con los servicios.

- Opiniones que los pacientes y familiares hacen en el SIAP o en encuesta sobre satisfacción que realizaban hasta ahora unidades o servicios de forma aislada.

- Control social y la comunicación a través de los medios de información.

- Otras vías mucho menos explícitas pero asimismo efectivas como puede ser el contacto directo entre enfermos y profesionales. También la participación de los profesionales en congresos y reuniones de carácter científico o técnico sirve para conocer e introducir innovaciones a partir de las experiencias punteras de otros centros.

La OSI Bilbao Basurto trabaja gestionando sus actividades integradas en procesos. La efectividad de la prestación de los procesos que desarrolla se realiza a través de la consecución de los objetivos estratégicos, los indicadores de proceso y las encuestas de satisfacción. Ejemplo de esta gestión es la sección en 2009 del HUB como referente de la Gestión del Proceso de Docencia para extrapolar su método a todos los hospitales de España siendo este el modelo exigido por el misterio para acreditar los centros actualmente.

\subsubsection{Liderazgo}

El concepto de liderazgo en la OSI Bilbao-Basurto, según indican en sus memorias EFQM, ha ido evolucionando en diferentes etapas en las que se fueron identificando y formando en el modelo. Ya en 2004 como consecuencia del avance en la implantación del sistema de gestión de procesos, del benchmarking externo y de las evaluaciones realizadas, se amplió el concepto de liderazgo desde el Equipo Directivo hasta los jefes de servicio/unidad y los responsables de procesos, 160 personas en aquel momento. En 2008 continuando con el avance en el modelo se extendió el liderazgo a las personas que coordinaban equipos de trabajo y equipos de mejora, aumentando los líderes reconocidos por la organización hasta un total de 220 definiendo funciones y competencias. 
Todo esto implica que el número de personas que han participado en la revisión de la misión, visión y valores (MVV) de la organización ha ido creciendo con el paso de los años aumentando el número de personas implicadas, según relatan en sus memorias EFQM. Los líderes están implicados personalmente en comunicar la MVV y principios éticos a todas las personas de la OSI Bilbao-Basurto y al resto de los grupos de interés, y actúan como modelo de referencia. Los líderes transmiten el concepto de cultura de la organización para asegurar su futuro.

Mientras tanto, en 2007 en el Hospital San Pedro de Logroño se paralizó la implantación del modelo y la política de calidad y los valores de la organización se anularon sin ser actualizados o sustituidos por otros. En cuanto al reconocimiento de los líderes, el Hospital San Pedro eliminó en esas mismas fechas la figura de los propietarios de procesos, las comisiones del centro y la participación de las personas, volviendo a una estructura clásica vertical con un organigrama de gerencia, direcciones médicas y de recursos económicos y humanos (Decreto 122/2007). La dirección de enfermería se eliminó en una modificación posterior del organigrama. Según los datos recogidos en las entrevistas la principal idea o estrategia transmitida por los líderes en este momento era lograr el ahorro que permitiera cumplir con los presupuestos.

En la OSI Bilbao-Basurto los líderes decidieron propiciar un cambio organizativo. Fruto de las sucesivas revisiones y el aprendizaje de los líderes y de la propia organización se fue modificado el modelo adaptándolo a la organización. Se realizaron varias autoevaluaciones, y se crearon comités y equipos de trabajo mientras, que se realizó por otro lado, la certificación de Procesos como herramienta para afianzar el sistema y lograr a la vez un reconocimiento para las personas implicadas en esos procesos.

Cada proceso contó con su cuadro de mandos integral que permitió su seguimiento por parte del Equipo Directivo y el alineamiento con la política de toda la organización (memoria 2008). Para revisar la efectividad de estas acciones se realizaron análisis del grado de cumplimiento de los objetivos pactados, análisis de quejas y reclamaciones, encuestas de satisfacción a clientes, personas y otros grupos de interés, auditorías internas y autoevaluaciones.

En el Hospital San Pedro no se ha realizado ninguna evaluación del liderazgo y la implicación de las personas se ha realizado en momentos puntuales creando grupos de trabajo para eventos puntuales sin continuidad, como cuando el ministerio realizó auditorías de las unidades docentes. No obstante, en el último año se observa un cambio de tendencia coincidiendo con el cambio de Equipo Directivo y la apuesta de este por aumentar la participación de las personas reforzando su liderazgo, como evidencia la creación de diferentes comités y de la comisión de calidad.

Ambos centros son centros formativos de especialistas sanitarios, pero además de ello abren sus puertas a la formación pregrado de profesionales sanitarios. Además, ambos centros, están abiertos para ser visitados por colegios, institutos o centros de Formación Profesional. Personal de ambos centros también participa como docentes en centros externos como la Universidad del País Vasco y la Universidad de La Rioja. La única diferencia entre ambos centros es que el Hospital de Basurto aporta más personas a la 
universidad, pero ello no es significativo puesto que en la Universidad de País Vasco se imparten las titulaciones de medicina y enfermería, y en La Rioja tan solo enfermería.

En cuanto a relaciones con proveedores externos, la diferencia entre ambas organizaciones está en el desarrollo de métodos de comunicación novedosos como el "desayuno con proveedores" o la presentación anual de los resultados del centro a los proveedores. Todo ello se inició en el Hospital de Basurto, y ahora se mantiene en la OSI Bilbao-Basurto. El propio modelo EFQM obliga a revisar la relación con los proveedores introduciendo la mejora continua en este ámbito también. Eso no quiere decir que en el SERIS no se mantengan buenas relaciones con proveedores, si no que estas no son revisadas, ni analizadas de forma sistemática.

Pero tal vez donde más podría apreciarse la diferencia entre ambas organizaciones es en la implicación con la sociedad. Respecto al fomento, apoyo y participación en acciones dirigidas a mejorar el medioambiente y la contribución de la organización, podemos afirmar que ambas organizaciones han trabajado en ello. No obstante, el planteamiento es diferente. Mientras el Hospital de Basurto ha trabajado con la idea de contribuir a la sociedad respetando el derecho y los intereses de las generaciones futuras, es decir de la sostenibilidad medioambiental, el planteamiento del Hospital San Pedro ha sido de carácter económico tratando de ahorrar mejorando su eficiencia energética y disminuyendo sus consumos.

Actualmente, la OSI Bilbao Basurto cuenta con diferentes certificaciones y reconocimientos relacionados con el medioambiente en los cuales es una parte muy importante potenciar la formación y la concienciación de las personas de la organización y de todos los grupos de interés que tienen relación con ella.

Los líderes se han propuesto que la organización sea flexible y tratan de gestionan el cambio de manera eficaz. En ambas organizaciones los líderes trabajan de forma activa para tratar de anticiparse y estar preparados de cara a los cambios que se avecinan, como por ejemplo, la definición de puestos de trabajo reservados a enfermeras especialista ante el inminente desarrollo de las especialidades enfermeras. .

La diferencia entre ambas organizaciones la introduce la adopción del modelo EFQM por parte de la OSI Bilbao-Basurto en su gestión. Hasta la implantación de este sistema los cambios que se introducían en la OSI Bilbao-Basurto lo hacían de forma análoga a como lo ha hecho el SERIS durante todo este periodo. Los cambios son responsabilidad exclusiva de la Consejería y del Equipo Directivo. Se trabaja con un sistema de dirección por objetivos. Con la introducción del modelo, la totalidad de los líderes intervienen de forma activa en la gestión del cambio. Ello se logra con el papel desarrollado por los líderes en la elaboración de política y estrategia, donde se marcan los objetivos y las metas de la OSI Bilbao-Basurto. El propio modelo apoya la introducción de cambios tratando de que los líderes participen de forma intensiva en el desarrollo de planes de cambios y desarrollen una labor de motivación, posibilitando su participación en comisiones, equipos de proceso y mejora.

Un aspecto importante para la flexibilidad y la introducción de los cambios en las organizaciones es trasladar la información relevante a todas las personas. Para ello la OSI Bilbao-Basurto realiza desde hace años reuniones periódicas del Gerente y el Equipo Directivo con el resto de las personas de la organización para trasladarles los 
nuevos cambios y el porqué de los mismos. También se realizan comunicaciones vía correo electrónico o trípticos para tratar de llegar de forma personalizada a todos. Por su parte, el SERIS en el último año ha habilitado una revista periódica en la que informa con carácter general de noticias. Aunque no entra en aspectos relevantes de la gestión, sí que es un primer paso para mejorar la comunicación con las personas de la organización.

\subsubsection{Estrategia}

La estrategia y sus políticas de apoyo se desarrollan, revisan y actualizan. Las necesidades y expectativas actuales y futuras de los grupos de interés son el fundamento de la política y la estrategia. La OSI Bilbao-Basurto, y en su momento cada una de las organizaciones que hoy la conforman, realizaban la revisión y adecuación de su estrategia y políticas según la metodología introducida por el modelo de forma sistemática. Anualmente se realiza la revisión de la misión, visión y valores, los grupos de interés y las fuentes de información relevantes para definir la estrategia. Se utilizan herramientas como el DAFO y se identifican los factores críticos de éxito, así como los riesgos y los modos de abordarlos. Todo este proceso de revisión, mejora y planificación se realiza de forma sistemática siguiendo el modelo PDCA de mejora continua o de Deming, es decir planificando $(P)$, haciendo $(D)$, midiendo $(C)$ y mejorando $(A)$. A su vez se realiza un despliegue de esta política hacia las unidades y procesos que la incorporan en sus propias revisiones y posteriores planificaciones. Toda la política y la estrategia se comunican y despliega en toda la organización facilitando la implicación de las personas.

La política y estrategia del SERIS tiene como referencia el Plan de Salud de La Rioja que se revisa cada cuatro años. A pesar de que hasta ahora se planteaban objetivos para la organización estos no eran comunicados a todos los interesados y no estaban realizados tras una revisión sistemática y completa de la situación. Como se ha dicho hasta ahora, la percepción de las personas era que toda la política del SERIS estaba dirigida al cumplimiento de objetivos económicos y todo lo demás estaba supeditado a esta idea. Como se ha expresado también anteriormente la situación del SERIS ha cambiado en el último año y se ha abierto la participación y mejorado la comunicación. El cuadro de mandos se ha abierto a los jefes de servicio y los objetivos se pactan con ellos. No obstante, existen colectivos importantes (p.e. el colectivo enfermero, procesos de apoyo y otros) por su número y relevancia asistencia, que no participan en la definición de la política y estrategia de la organización.

\subsubsection{Personas}

A diferencia de la OSIBB, el Hospital San Pedro carece de una autentica planificación de los recursos humanos, aunque sus necesidades se canalizan a través de las propuestas realizadas por los responsables de las unidades, por la representación sindical y por el estudio de necesidades realizado por responsables de cada área, que también incluye la previsión de las sustituciones en periodos vacacionales.

Otro aspecto muy relevante en los recursos humanos de cualquier organización es la formación que se da a sus trabajadores. EI SERIS cuenta con un servicio de formación continuada, que elabora el plan de formación, tratando de dar respuesta a las 
necesidades formativas del personal, previamente detectadas a través de los diversos responsables. También en el Plan de Salud de La Rioja se establecen unas líneas institucionales de formación, que no anulan la existencia de planes de formación específicos destinados a la puesta en marcha de nuevos procesos. La OSIBB se beneficia de pertenecer a una organización más grande como Osakidetza y elabora sus planes formativos propios y compartidos con otras organizaciones del sistema vasco de salud.

Durante el periodo estudiado se ha producido un "ajuste" de plantillas y la pérdida de poder adquisitivo y beneficios por parte de los trabajadores de todas las organizaciones sanitarias. En la OSI Bilbao-Basurto se dejó de realizar la encuesta de satisfacción de personas aunque se están planteando su reedición, mientras que en el SERIS no se ha realizado ni se ha planteado. Esta falta de comunicación ha contribuido a que se produzca malestar y falta de implicación de las personas. Reflejo de la escasez de fomento de la implicación de las personas durante el periodo 2008-2015 es la carencia de un sistema de recogida de ideas creativas en el SERIS, esto sólo ocurre de forma reactiva, es decir, a iniciativa de terceros relacionados con la organización, y en escasa ocasiones es el hospital quien toma la iniciativa. Parte de esta falta de participación e implicación de los trabajadores en el SERIS es fruto de la inexistencia de un Plan de Comunicación Interna y de Incentivación y Reconocimiento. Durante este periodo el Servicio Riojano de Salud (SERIS) congeló el reconocimiento ligado a carrera profesional, así como el reconocimiento de trienios y días de libre disposición. No obstante, existía una amplia red de comunicación informal, así como la utilización habitual de instrumentos tradicionales (tablones de anuncios, carteles, etc.) y de nuevas tecnologías (correo electrónico, página web, intranet...).

\subsubsection{Alianzas y recursos}

Gestión de los recursos económicos-financieros para asegurar un éxito sostenido

Este quizá sea el apartado en el que menos diferencia existe entre ambas organizaciones. No obstante, el modelo EFQM, y por tanto así lo hace la OSIBB, considera que este criterio tiene la misma relevancia que el resto de los criterios agentes otorgándole la misma puntuación. El objetivo de esta igualdad es que las organizaciones crezcan de manera equilibrada.

EI SERIS ha priorizado este criterio durante el periodo 2008-2015 y ha logrado unos buenos resultados al respecto como lo demuestra el premio TOP 20 en Gestión Económica en 2015. El Hospital San Pedro ha logrado unos resultados económicos que han permitido mantener un presupuesto adecuado a la disponibilidad de recursos. Pero esta situación ha hecho que surjan problemas de déficit de recursos humanos creando una situación de malestar que se ha venido manifestado a través de sus representantes, en diferentes publicaciones, en las redes sociales o a través de movilizaciones de grupos como la Plataforma para la Defensa de la Sanidad Riojana.

En la OSI Bilbao-Basurto también ha crecido el malestar entre las personas por los ajustes durante la crisis. Aunque, tal y como demuestran los indicadores económicos, el ajuste de presupuesto en Osakidetza haya sido menor que en el SERIS, y este se haya producido teniendo en cuenta todos los criterios del modelo, no por ello ha dejado de 
tener también gran repercusión entre las personas de la organización y los demás grupos de interés.

Como ya se ha dicho en este trabajo en varias ocasiones, las organizaciones dependen de la financiación pública dotando el presupuesto de la sanidad pública de un carácter político que transciende a las propias organizaciones sanitarias.

Respecto a la implantación de modelo EFQM, la gestión económica es vista como un resultado crítico para la organización y como tal debe ser trabajado. No obstante, el modelo le otorga un valor semejante a los resultados obtenidos en clientes por lo que, de alguna forma, el modelo propone por un lado el crecimiento equilibrado de todos los criterios agentes, y por otro la orientación de todo el sistema hacia la satisfacción de las necesidades del cliente, en el caso de la sanidad pública, el paciente. Todo ello pone en primer lugar al paciente y aquellas organizaciones que orientan todos sus esfuerzos hacia él están cumpliendo lo que el propio modelo y la misión del sistema sanitario proponen.

Gestión sostenible de edificios, equipos, materiales y recursos naturales.

Todas las organizaciones sanitarias deben asegurarse del correcto funcionamiento y disponibilidad de sus instalaciones a través del mantenimiento y gestión del aprovisionamiento. La organización de los mismos en la OSI Bilbao-Basurto se concibe como procesos de apoyo y como tal se gestionan. La situación en el SERIS es muy similar, y en ambas existe un servicio propio de mantenimiento del hospital cuya función es dar servicio a los procesos asistenciales y supervisar las diferentes empresas contratadas para realizar los mantenimientos correctivos y preventivos de equipos e instalaciones.

En la política de la OSI Bilbao-Basurto se definió como unos de sus retos estratégicos la sostenibilidad y el compromiso con la sociedad. Se marcaron como objetivo contribuir a la sostenibilidad medioambiental y desde 2004 existe una comisión medioambiental. Como resultado de esta política la OSI Bilbao-Basurto certificó en 2005 su sistema de gestión medioambiental en base a la norma Ekoscan y en 2008 en base a la norma ISO 14001. A lo largo de estos años se han introducido diversas mejoras fruto de la sistemática apoyada por el sistema de gestión de seguimiento, revisión y benchmarking con otras organizaciones.

El Hospital San Pedro no dispone de ningún reconocimiento en la gestión medioambiental aunque si han elaborado estos años planes para la mejora de su eficiencia energética que incluyen la disminución del consumo de papel, agua y energía. Estos planes son propuestos desde el Gobierno de La Rioja y no existe en el SERIS ningún comité o grupo de trabajo que desarrolle este aspecto. No obstante, algunos servicios del SERIS, como el Servicio de Alimentación, la Unidad de Mama o la Central de Esterilización, han desarrollado algunas iniciativas en colaboración con la Fundación Rioja Salud para la implementación de acciones medioambientales dentro del alcance de sus actividades. 


\subsubsection{Sistema de gestión}

A nivel general, se preguntó a los entrevistados sobre su percepción sobre el modelo EFQM.

"EFQM es útil porque todo lo que te haga reflexionar, escribir y modificar por supuesto que vale" (OS/3)

"A mí el EFQM me vino muy bien porque me dio una herramienta de trabajo, me ayudó a ordenar, a elaborar protocolos, a saber que eso era bueno" (OSI9)

"Nos ayudó el modelo porque lo tienes ahí siempre presente a la hora de establecer y de medir y valorar la eficiencia de todo el proceso, la satisfacción de los proveedores con reuniones anuales con los más potentes y se hablan de resultados del centro y se plantean nuevos proyectos, es decir se les hace copartícipes de la progresión de la organización... (OS/10)

Partiendo de la idea general de si el modelo EFQM es útil para las organizaciones sanitarias, la respuesta, en general, en ambas organizaciones ha sido que sí, que se trata de una herramienta útil.

De todas formas, es necesario hacer una puntualización antes de comparar las respuestas de las personas de ambas organizaciones. Por un lado el $100 \%$ de las personas entrevistadas en la OSI Bilbao-Basurto conocen el modelo y han trabajado en él, si entendemos como tal la organización a la que han pertenecido hasta ahora (Hospital de Basurto y Comarca de Bilbao han llegado a presentar memoria EFQM). Por el contrario a pesar de que existe conocimiento sobre el modelo, tan solo uno de los entrevistados del Hospital San Pedro pertenece a una organización que haya trabajado con el modelo y haya presentado memoria, cuyo alcance es el Servicio de Alimentación del hospital.

Esto es consecuencia de la apuesta estratégica de cada una de las organizaciones. Mientras en el País Vasco se apostaba por la gestión de la calidad mediante la implementación del modelo EFQM y de normas ISO en Osakidetza, en el SERIS no se realizaba una apuesta global por ello, sino que se dejaba al interés o la oportunidad que detectaban los responsables de unidades o servicios.

No obstante, las personas entrevistadas del SERIS introducen en sus respuestas la experiencia obtenida mediante su participación en sistemas de gestión de calidad con normas ISO, asimilando estas con el modelo EFQM.

"Prácticamente cualquier sistema. No soy capaz de juzgar si uno es mejor que otro, pero creo que prácticamente cualquier sistema que intente poner orden y medir las cosas es esencial. Es un poco analizar qué haces, para qué lo haces, cómo lo haces, ver o que tienes y me da igual un sistema que otro" (SRS10).

En general se aprecia un mejor conocimiento del modelo en las personas de la OSIBB. Algunas de las personas entrevistadas forman parte de los equipos de evaluación preparados y organizados para hacer evaluaciones en diferentes organizaciones según el modelo EFQN con el apoyo de Euskalit. 
Las mejoras que aporta el modelo EFQM son globales incluyendo aspectos de enfoque y despliegue de la política y la estrategia de toda la organización.

"Para tener las cuestiones medianamente planificadas y para cuando no había crisis. Tener las cuestiones medianamente planificadas ayuda a escala práctica... Planificar merece siempre la pena". (OS/11)

"Este modelo facilita mucho el enfoque y el despliegue en organizaciones que son tan complejas de aspectos como las alianzas con proveedores, proveedores de servicios con colaboraciones con otras organizaciones sanitarias". (OSI10)

"El EFQM te permite trabajar de una forma mucho más organizada, básicamente tú tienes que tener la política y a estrategia". (OSI10)

"Independientemente del cogollo de nuestro negocio que es la asistencia hay que incorporar otra serie de aspectos como la innovación, la calidad, la investigación, y luego la parte sociosanitaria y comunitaria de relaciones con terceros". (OS/10)

"Otro de los aspectos que hemos cuidado muy mucho es el aspecto de las personas... dentro del modelo tu sí que tienes capacidad de establecer reconocimientos, formación, fomentar el hecho de gestionar el conocimiento de la mejor forma posible". (OSI10)

También inciden los entrevistados en los beneficios que aporta el modelo a la hora de reconocimiento de las personas de la propia organización. Para una organización sanitaria el capital humano es fundamental para desarrollar su misión y el componente humano de su producto es fundamental para sus clientes tanto en lo referente a conocimientos y habilidades como a actitudes, trato, respeto y cumplimiento de códigos éticos.

"A mí sí que me parece que el modelo ayuda mucho. A mí por ejemplo en personas me ayuda muchísimo sobre todo en el tema del reconocimiento que es algo fundamental para los profesionales......muchas veces te engulle el día a día y es complicado". (OSI10)

El siguiente verbatin también hace incidencia en el reconocimiento de las capacidades de las personas de la organización. Además está expresado por una persona que ejerce el liderazgo y que es consciente de que este debe hacerse de forma coherente y coordinada dentro de la organización. Todo ello redunda en la importancia del modelo como herramienta de cohesión y de unificación de estrategia

"Los logros que hemos conseguido son gracias a todos, a los equipos que tiene que estar formados por personas con potencialidades, con conocimientos, con ganas, con inquietudes. Tener la capacidad de liderazgo visionario y no encasquetarte en lo que trabajas en el día a día e ir más allá. La apuesta tiene que ser esa. Aunque aquí el equipo directivo somos 16 personas y cada uno defiende lo suyo y tira para un lado y hay que saber manejar las situaciones". (OSI10)

"Cualquier premio o cualquier reconocimiento que recibas como organización siempre sirve a los profesionales como un reconocimiento a decir vamos por el buen camino. Al final aunque dices yo no trabajo por premios, yo no trabajo por conseguir tal, eso irá 
llegando, pero al final sí que es un estímulo decir, bueno iremos por buen camino". (OSI8)

Otro aspecto que destacan es la capacidad de estructuración, ordenamiento y mejora continua que aporta el modelo a las organizaciones

"Trabajas mejor. Te sirve para tener tu documentación ordenada, es una manera de hacer las cosas, que no quiere decir que si no lo tienes no trabajes, pero a mí la experiencia me dice que prefiero tenerlo aunque me da mucho trabajo y a veces echo pestes. Me parece importante". (SRS6)

"En organizaciones grandes como la nuestra la calidad es básica. El equipo directivo para una organización de nuestro tamaño somos escasos y necesitamos a alguien para gestión y para calidad, para que nos echen una mano". (OSI8)

"Yo creo que no vino nada más que a ordenar y a darle nombre a algo que de forma inherente, innata, ya se estaba haciendo en el hospital. Por supuesto que mejoró mucho. Yo tengo un antes y un después en ese sentido. A mí el EFQM me vino muy bien porque me dio una herramienta de trabajo, me ayudó a ordenar, a elaborar protocolos, a saber que eso era bueno. Antes no tenías una metódica de trabajo, trabajabas por instinto y eso nos ayudó a tener método. Ya lo hacíamos pero ahora había que ordenarlo. A mí me ayudó a tener una visión de orden, de reglas, de primero, segundo y tercero. A tener las ideas estructuradas y darles forma y además te da seguridad, que elabores protocolos consensuados, que hagas objetivos comunes, que vayas luego haciendo una revisión sistemática, ver qué áreas de mejora en la consecución de objetivos tenemos que implantar: todo eso nos ha ayudado a seguir trabajando de forma muy unida y muy hacia la misma idea". (OSI9)

En el caso del entrevistado anterior de la OSI Bilbao-Basurto, se trata de un responsable de unidad a la que la implantación del modelo le aportó orden y sistemática en la estructuración del trabajo en su unidad. Añade, además que toda esta sistemática ha servido para unir a las personas del servicio con un objetivo común y compartido.

El texto siguiente expresa la opinión sobre el modelo de una de las pocas personas del SERIS que ha trabajado con el modelo EFQM. Esta persona señala que el modelo ha introducido en la organización la identificación de los grupos de interés y la identificación de las potenciales ganancias de los grupos y de la propia organización,

"Si lo mismo, cuando empezamos con la EFQM como tuvimos que valorar quienes eran esos grupos externos, proveedores, clientes. Vimos que aunque lo hiciéramos un poco según iban surgiendo los temas el amplio grupo que tenemos había aumentado en grupos de enfermos concretos, en asociaciones que hemos trabajado con ellos como los del champiñón de La Rioja, con proveedores directos, que han trabajado con nosotros para llevar a congresos carteles para darnos a conocer". (SRS1)

Según los entrevistados, el modelo debe integrarse dentro del quehacer diario de la organización para mostrar todo su potencial y propiciar un cambio de cultura.

"Todo lo que te haga reflexionar, escribir y modificar por supuesto que vale: ES muy difícil pero siempre me propongo que la vorágine no te envuelva y no te impida sentarte un poco y reflexionar y decir vamos a mejorar esto, vamos a ver". (SRS3) 
"Yo creo que sí. No estoy hablando en boca de todos pero yo creo que te hace tomar más conciencia. Luego también depende de la responsabilidad de cada uno. Por mucho modelo, al final la responsabilidad y el buen hacer de cada uno es lo que más vale, pero yo creo que somos conscientes de un buen hacer o premiado ese buen hacer te lleva a seguir en esa línea por lo menos". (OSI5)

"Yo no me acuerdo que tengo la EFQM. Todo lo que nosotros hacemos a lo largo del día está basado en la EFQM. Evidentemente si nosotros como servicio o como hospital estamos a un nivel del 8 para arriba, de notable digamos, debo de suponer que es por el modelo EFQM. Todo lo que nosotros somos viene del EFQM. Yo en su momento me lo creí. Igual que me dieron la ISO. Pero en tu día normal, a diario, no lo tienes en cuenta". (OSI6)

"En un momento determinado tuvimos aquí un grupo de gente como Mikel Álvarez que desarrollo un sistema con el modelo EFQM basado en la calidad que a pesar de que no somos conscientes de que funciona la verdad es que ha calado hondo en la forma de trabajar y de funcionar. Casi todo el mundo utiliza estándares de calidad. Es una cosa que es bueno en el sentido de que nadie entiende que trabaja en ello, nadie es consciente de que lo trabaja pero sí que es cierto que ha influido mucho en nuestra forma de funcionar. El proceso de mejora continua forma parte del ADN de los sistemas de calidad es la que nosotros continuamente hacemos. Nos pasamos la vida analizando lo que hacemos e intentándolo mejorar. Casi es instintivo. No lo hacemos porque lo tengamos establecido en una estructura de proceso de mejora continua sino porque sale de dentro, ¿se debe eso al establecimiento de la EFQM? No lo sé, igual sí que tiene influencia pero yo no soy muy consciente. Si sé que cada año periódicamente cuando hay que renovar unas ISOs todo el mundo se pone loco con esto, pero bueno...no nos supone...no soy consciente de que sea ..." (OSI7)

Aunque también se evidencian problemas a la hora de trabajar con el modelo como el uso de un lenguaje difícilmente comprensible y poco adaptado a la realidad de los profesionales sanitarios:

"Aquí la calidad no es para conseguir premios, eso es la guinda del pastel, nuestro objetivo es ir mejorando y tenemos que simplificar y simplificar a los profesionales el lenguaje y la unidad de calidad siempre lo ha intentado hacer así, acercarlo más. A lo mejor ese ha sido el mérito más que el espíritu basurtiano. Los responsables de calidad siempre lo han intentado hacer fácil, entonces toda la parte más técnica la asumía calidad, lo traducía calidad de tal forma que para los profesionales sea más amable, que es el problema de la calidad y de la EFQM. Es un lenguaje que te echa para atrás, la primera vez que lo lees dices pero qué es esto, no entiendo esto con mis años de formación. Necesitas casi una traducción y luego ya". (OSI8)

"El hospital es muy operativo, la labor es asistencial y el proceso está interiorizado porque hay una necesidad de funcionamiento que sea así, al menos en los procesos asistenciales... Es lo que hay que hacer, llevar el lenguaje del modelo a la práctica. $A$ veces cuando empiezas a hablar del EFQM te preguntan y esto qué me está diciendo, cómo lo interiorizo y cómo me lo llevo yo...yo creo que si se funciona en el aspecto operativo y además sabemos que tenemos que ir a estructuras transversales porque te lo pide el día a día". (OSI12) 
El modelo EFQM también aporta ventajas como herramienta de evaluación para que la organización pueda poder conocerse mejor:

"Las auditorías externas sirven para ponerse las pilas. Las que más aportan son las internas. Esto es una ventaja de las normas sobre la EFQM". (OSI4)

"Cuando empezamos con la EFQM, bueno a ver, nosotros tenemos la ISO 9001y ese tema no lo exige tan abiertamente a la hora de pasar las auditorías: cuando empezamos con la EFQM como esos apartados son los que estábamos un poco más débiles los estamos empezando a tocar. Pero sí que es verdad que cuesta muchísimo los cambios pero se están poniendo medidas". (SRS1)

Este entrevistado del SERIS añade la dificultad y el esfuerzo que supone para las organizaciones implantar el modelo. El modelo es más exigente que las norma ISO9001 porque aspectos gestión del personal y las relaciones con la sociedad están más desarrollados en el modelo.

Aunque no se ha recogido ningún caso en un entrevistado que estuviese totalmente en desacuerdo con las ventajas del uso del modelo, si se han recogido opiniones (pocas) de quienes se muestran escépticos ante su uso. El siguiente entrevistado preguntado por las ventajas manifestaba que no las veía.

"Desde luego no lo aprecio así. Puede ser que sí pero yo no lo veo". (OS/3)

"No salgas hay a la palestra a decir que aquí EFQM, modelos de gestión de tal y cuál .Absoluta patraña y mentira todo. Sin embargo el Hospital de Basurto está en los mejores puestos en los rankings de centro. Si bueno aquí se va a montar al año que viene un acelerador lineal que es lo último de lo último... esta voracidad que tienen las direcciones de los organismos sanitarios públicos de salir en la prensa porque somos los EFQM y somos los 14000, EMAS, RSC, tal y tal y una colección del copón de la baraja cuando tenemos un montón de gente trabajando en ello para disfrazarnos un poco de toda esa historia. Yo estoy en la tesis de que mira yo soy la administración pública a mí lo que se me exige es el cumplimiento estricto de la ley. Todo lo que sea el cumplimiento de la legalidad exíjaseme. A partir de ahí dedicar recursos, personas y tiempo a cosas que no están funcionando, porque cada vez que viene una auditoría el hospital todo dios se tira un mes nada más que contando mentiras para poner en los papeles para enseñarles a os auditores. Es que esto es así y el que diga lo contrario miente como un bellaco. Estoy seguro que a calzón quitado nadie me lo niega porque es así, sé que es así..." (OSI3)

En el caso de este entrevistado, el mensaje expresa dificultades de implantación en las organizaciones, y la posibilidad de que la implantación de sistemas de calidad responsa sólo a dar una imagen positiva de la organización, a la burocratización, o la legitimación de prácticas que se justifican a sí mismas, aunque luego los resultados no se correspondan. Que se implanten porque parece una buena herramienta aunque luego no se valore la verdadera eficacia de la misma.

O quienes ni siquiera conocían el modelo.

"Las cosas cambian mucho y poco o mucho algunas cosas se van haciendo. ...Como servicios a nosotros lo que nos interesa es que los pacientes estén contentos y no estén 
todo el tiempo protestando...vas poniendo cosas porque sabes que son mejoras. Mejoras no solamente para el hospital sino también para las listas de espera, utilizar huecos para los preferentes, una mejora para nosotros pero luego nos dimos cuenta que también lo era para el hospital". (SRS2)

Las personas de ambas organizaciones que tenían un concepto negativo de la utilidad del modelo EFQM están relacionadas en ambas organizaciones con servicios de apoyo y creían que sus procesos no eran tenidos en cuenta y se volcaba todo el esfuerzo de la organización en la parte asistencial y principalmente con el colectivo médico.

"La fuerza que tienen los médicos para exigir equipamiento hospitalario está a años luz de la importancia que se le concede al envoltorio, al resto..." (OSI3)

"Creo desde mi punto de vista que con mi experiencia de tantos años, los hospitales están comidos por el día a día, un poco la defensa gremial de cada entorno, y una sensación de pensar a medio plazo que no es para tanto acaba afectando. Acaba afectando, normalmente lo vemos más en las unidades de apoyo porque es cierto que al final la comunidad sanitaria es la que tira". (OSI11)

\subsection{Análisis global}

Los indicadores analizados parecen demostrar que los factores que influyen en la salud de los riojanos y de los vascos (tabla71) son el nivel de estudios y las campañas de vacunación, mientras que no existen diferencias significativas en cuanto a la proporción de personas dependientes.

No obstante, en general, las cifras de cobertura de la vacunación son mejores en La Rioja. El nivel de estudios es más alto en el País Vasco

Respecto al presupuesto empleado se aprecia una diferencia sostenida de aproximadamente 200 euros por persona en los último años de la serie. En 2007 los datos de La Rioja se ven afectados por la inversión realizada en la construcción del Hospital San Pedro, el Centro de Investigación Biomédica, el Centro de Alta Resolución y otras infraestructuras sanitarias.

La estancia media es más alta en el País Vasco en todo el periodo estudiado hasta el último dato disponible en el que se ha igualado e incluso mejorado los resultados de La Rioja. La tendencia también marca diferencias, en La Rioja está creciendo y en el País Vasco disminuyendo. La estancia media de un paciente en el hospital es un indicador válido para evidenciar la eficiencia de los procesos asistenciales y de los recursos empleados.

Respecto a los recursos empleados, el número de camas hospitalarias por habitantes es más alto en La Rioja aunque tienden a igualarse.

El gasto en farmacia también es más elevado en La Rioja y en ambas comunidades está disminuyendo como muestra del trabajo realizado en busca de la eficiencia del sistema. 
Otra apuesta por la búsqueda de la eficiencia y la eficacia del sistema es el aumento de la cirugía mayor ambulatoria. En este caso los datos son mejores en La Rioja, aunque muestra una tendencia a disminuir, mientras que en el País Vasco la tendencia es a crecer. Esto puede ser otra muestra de falta de planificación en La Rioja'

En cuanto a personal, existen más recursos en Atención Primaria (médicos) en La Rioja, aunque en este caso el crecimiento es más rápido en el País Vasco. Todo ello se apoya en un mayor gasto en la remuneración de su personal en el País Vasco que en La Rioja. También se puede observar que la repercusión de los recortes en personal ha sido más acentuada en La Rioja. En ambos casos se muestra un crecimiento moderado de este gasto.

Todo ello ha permitido lograr unos resultados clave (tabla70), que sirven para mostrar en líneas generales resultados relevantes del sistema de salud sobre la salud de los ciudadanos.

Existen coincidencias de resultados globales como la esperanza de vida en ambas comunidades. A esto se une que los años de vida saludable o calidad de vida de las personas de más de 65 años también son semejantes. También son semejantes los resultados obtenidos en tasas de mortalidad infantil, aunque existen diferencias en cuanto a la mortalidad perinatal, más bajas en el País Vasco, tal vez por la existencia de más recursos y personal especializados.

En cuanto a algunas de las patologías más prevalentes se puede afirmar que existen diferencias significativas en los resultados obtenidos en:

- Cardiopatía isquémica. Mejores resultados en País Vasco. En La Rioja no se dispone de unidades coronarias.

- Tuberculosis y enfermedades respiratorias. Mejores resultados en La Rioja. Influencia del clima en la salud. Históricamente enfermos del País Vasco acudían a sanarse a La Rioja.

- Enfermedades vasculares. En este caso no existen grandes diferencias, salvo que la tendencia en los últimos dos años de la serie indica que el País Vasco ha mejorado y supera los resultados obtenidos en La Rioja. No obstante en La Rioja se han puesto en marcha recursos (unidad de ictus), que pueden mejorar los resultados en próximos años.

Además se aprecian también diferencias significativas en resultados relacionados con la seguridad de los pacientes en el medio hospitalario como la tasa de mortalidad global intrahospitalaria o la tasa de fracturas de cadera producidas por caídas en pacientes ingresados o las infecciones nosocomiales. En todas ellas se aprecian mejores resultados en el País Vasco.

Los resultados obtenidos en el apartado de seguridad de pacientes, del área de pediatría, de la utilización de CMA y las tendencias mostradas en la disminución del gasto farmacéutico y de la estancia media parecen estar relacionadas con diferencias en la asignación de recursos financieros y de personal. Todo ello enmarcado en diferencias organizativas o de gestión, en las cuales tiene una repercusión innegable las diferentes opciones políticas y estratégicas respecto a la sanidad pública. 
Por otro lado, si se comparan los diagramas (ilustración25 e ilustración34) surgidos de las entrevistas realizadas en ambas organizaciones se pueden extraer varias similitudes:

- Las personas entrevistadas sostienen que la sostenibilidad de la organización depende de la cantidad de dinero público que se invierta. La financiación depende de la voluntad política. No obstante, el derecho a la salud de los ciudadanos, junto al valor de la sanidad pública en España mantiene la financiación del sistema.

- La orientación al paciente y la cobertura de sus necesidades son la principal preocupación de los profesionales. No obstante, este aspecto queda relegado en ocasiones por las necesidades de organización de los servicios y los profesionales, principalmente médicos.

- Los servicios o procesos de apoyo, no asistencial, no se sienten integrados en la estrategia de las organizaciones y creen que no se les hace partícipes de las decisiones.

- La implantación de sistemas de gestión de calidad o de normas de calidad, medioambiente, RSC o seguridad son beneficiosas para la organización porque aportan método proporcionando orden y permitiendo priorizar los procesos con criterios de continuidad y eficacia. Además en la OSI también se reconoce que aporta seguridad para los pacientes y la posibilidad de tener objetivos compartidos.

La principal diferencia que se puede apreciar en los diagramas es lo referente a la cultura organizacional. La cultura organizacional es el conjunto de ideas que integran la organización (Schein, 1988). La cultura se manifiesta a través del discurso de las personas. La saturación de contenidos manifestados por las personas de la OSIBB tardó más en producirse por lo que podemos decir que tienen una cultura compartida más extensa y que incluye ideas que se corresponden con los conceptos fundamentales de la excelencia. Sin embargo estos no se encuentran tan presentes en el discurso de las personas del SERIS.

Todo ello parece reforzar el sentimiento de identidad de los miembros de la OSIBB (Robbins, 1999) y facilita la generación de un compromiso con la propia organización, así como un conjunto de imágenes mentales y creencias que dan lugar a una imagen positiva de futuro y una visión de sostenibilidad (Dopplet, 2003).

Otra forma de poder valorar los resultados obtenidos por las organizaciones estudiadas es mediante su situación respecto a las diferentes teorías de la sostenibilidad presentadas en el capítulo de fundamentos teóricos.

\subsubsection{Rueda del cambio}

En la siguiente tabla (tabla 77) se compara la sostenibilidad de ambas organizaciones mediante la rueda del cambio hacia la sostenibilidad de Doppelt (2003). 
Tabla 76. Aspectos Sostenibles "The wheel of change". Comparación SERIS/OSI BB

\begin{tabular}{|c|c|c|}
\hline PROBLEMAS/ Organización no sostenible & SERIS & OSIBB \\
\hline $\begin{array}{l}\text { Organización vertical que lleva a un falso } \\
\text { sentimiento de seguridad }\end{array}$ & Vertical & $\begin{array}{l}\text { Combinación de } \\
\text { vertical y horizontal }\end{array}$ \\
\hline $\begin{array}{l}\text { Los temas medioambientales y } \\
\text { socioeconómicos se aíslan, no hay relación } \\
\text { entre ellos }\end{array}$ & No hay relación & $\begin{array}{l}\text { Integración } \\
\text { estratégica. } \\
\text { Memorias RSC }\end{array}$ \\
\hline No hay una visión clara de la sostenibilidad & $\begin{array}{l}\text { Centrada en el } \\
\text { aspecto económico }\end{array}$ & $\begin{array}{l}\text { Visión amplia e } \\
\text { introducida en } \\
\text { sistemas de gestión }\end{array}$ \\
\hline Confusión sobre causa y efecto & $\begin{array}{l}\text { Conocidas causas y } \\
\text { efectos }\end{array}$ & $\begin{array}{l}\text { Conocidas causas y } \\
\text { efectos }\end{array}$ \\
\hline Falta de información & $\begin{array}{lr}\text { Falta } & \text { información } \\
\text { sobre } & \text { algunos } \\
\text { grupos de interés }\end{array}$ & $\begin{array}{lr}\text { No se } & \text { recoge } \\
\text { información } & \text { sobre } \\
\text { personas de la } \\
\text { organización }\end{array}$ \\
\hline Mecanismos de aprendizaje insuficientes & $\begin{array}{l}\text { Auditorías en pocas } \\
\text { unidades, escasa } \\
\text { colaboración }\end{array}$ & $\begin{array}{l}\text { Benchmarking, } \\
\text { colaboraciones, } \\
\text { formación de líderes, } \\
\text { Autoevaluaciones, } \\
\text { Auditorías, Mejora } \\
\text { continua }\end{array}$ \\
\hline $\begin{array}{l}\text { Fallo en la institucionalización de la } \\
\text { sostenibilidad }\end{array}$ & $\begin{array}{l}\text { No existe estrategia. } \\
\text { Se cita en el II Plan } \\
\text { de Salud desde } \\
2015\end{array}$ & $\begin{array}{l}\text { Integrada en la } \\
\text { estrategia. Política } \\
\text { apoyada desde la } \\
\text { organización central }\end{array}$ \\
\hline
\end{tabular}

La teoría de la rueda de cambio (Doppelt, 2003) se basa en un conjunto de siete principios que ha de cumplir toda organización que quiera triunfar a la hora de incorporar la sostenibilidad en su estrategia. Estos siete puntos surgen a partir del estudio de los problemas con que se encuentran las organizaciones a la hora de lograr un desarrollo sostenible y son los expuestos en la tabla 76. Como se puede apreciar, según esta teoría el avance de la OSIBB en el camino de la sostenibilidad es mayor que el del SERIS.

\subsubsection{Teoría de los grupos de interés}

La Teoría de los Grupos de Interés (Carrión, 2009) señala que se deben generar estrategias y políticas que garanticen que el desarrollo de los procesos sea sostenible y no impacte contra los derechos sociales y ambientales de los grupos de interés implicados. El objetivo de la organización ha de ser lograr un equilibrio entre los intereses de todos los colectivos. Para ello es necesario que las organizaciones identifiquen a las diferentes partes interesadas y sus intereses. En las organizaciones sanitarias dos grupos de interés primordiales son los pacientes (clientes) y las personas (trabajadores).

Pacientes. En el grado de satisfacción de los ciudadanos con el funcionamiento del sistema sanitario la tendencia es negativa en todas las CCAA menos en País Vasco. A pesar de partir de índices más bajos ahora muestran mejores valores. En los resultados de La Rioja parece apreciarse el final del efecto de las nuevas instalaciones construidas hasta el inicio de la crisis sobre la percepción de los ciudadanos.

En el grado de satisfacción con la información y el seguimiento de sus problemas hay mejores valores globales en LA RIOJA. Mayor cercanía con los médicos al ser una población más diseminada. Mejor valoración de la Atención Primaria en La Rioja. 
Personas de la organización. En ambas organizaciones a día de hoy no se realizan encuestas de clima laboral de forma generalizada y la impresión en ambas es que "el ambiente es bastante difícil como para hacerlas". No obstante a través de las entrevistas se ha podido detectar que el ambiente laboral es más difícil en el Servicio Riojano donde se tiene la percepción de que en estos años no se ha cuidado al persona, sino por el contrario se le han pedido muchos esfuerzos que no han tenido ningún reconocimiento. Por otro lado en la OSIBB, se piensa que se ha "apretado" mucho a los trabajadores aunque se detecta menor malestar y un sentimiento de pertenencia que a pesar de todo hace defender y justificar los recortes y esfuerzos de estos últimos años por parte del personal.

En el informe de OSALAN (Matthies, 2016) sobre el impacto del modelo EFQM en las organizaciones sanitarias vascas se afirma que el modelo EFQM en Osakidetza y el avance de sus organizaciones en el mismo, tuvo un impacto positivo en la percepción de las personas referida a elementos gestionables de forma diferenciada en cada organización, mientras que no se apreciaron diferencias en aquellos aspectos más homogéneos o centralizados. Además, se observó que cuanto mayor es el avance (Qoro) mayor es la satisfacción de las personas respecto a las organizaciones menos avanzadas (sin reconocimiento).

\subsubsection{Triple cuenta de resultados}

El objetivo del desarrollo sostenible es definir estrategias viables teniendo en cuenta los aspectos económico, social y ambiental de las actividades humanas; "tres pilares" que deben tenerse en cuenta por parte de organizaciones.

Medioambiental. En este apartado podemos recoger los reconocimientos obtenidos por la OSIBB y su participación en auditorías y programas de gestión medioambiental. Aunque el SERIS no se haya sometido a ninguna auditoría ni reconocimiento externo sí que ha trabajado en la mejora de la eficiencia energética aunque haya sido desde una perspectiva económica.

También se ha valorado el nivel alcanzado por las organizaciones en su camino hacia la sostenibilidad medioambiental (ilustración 37) 


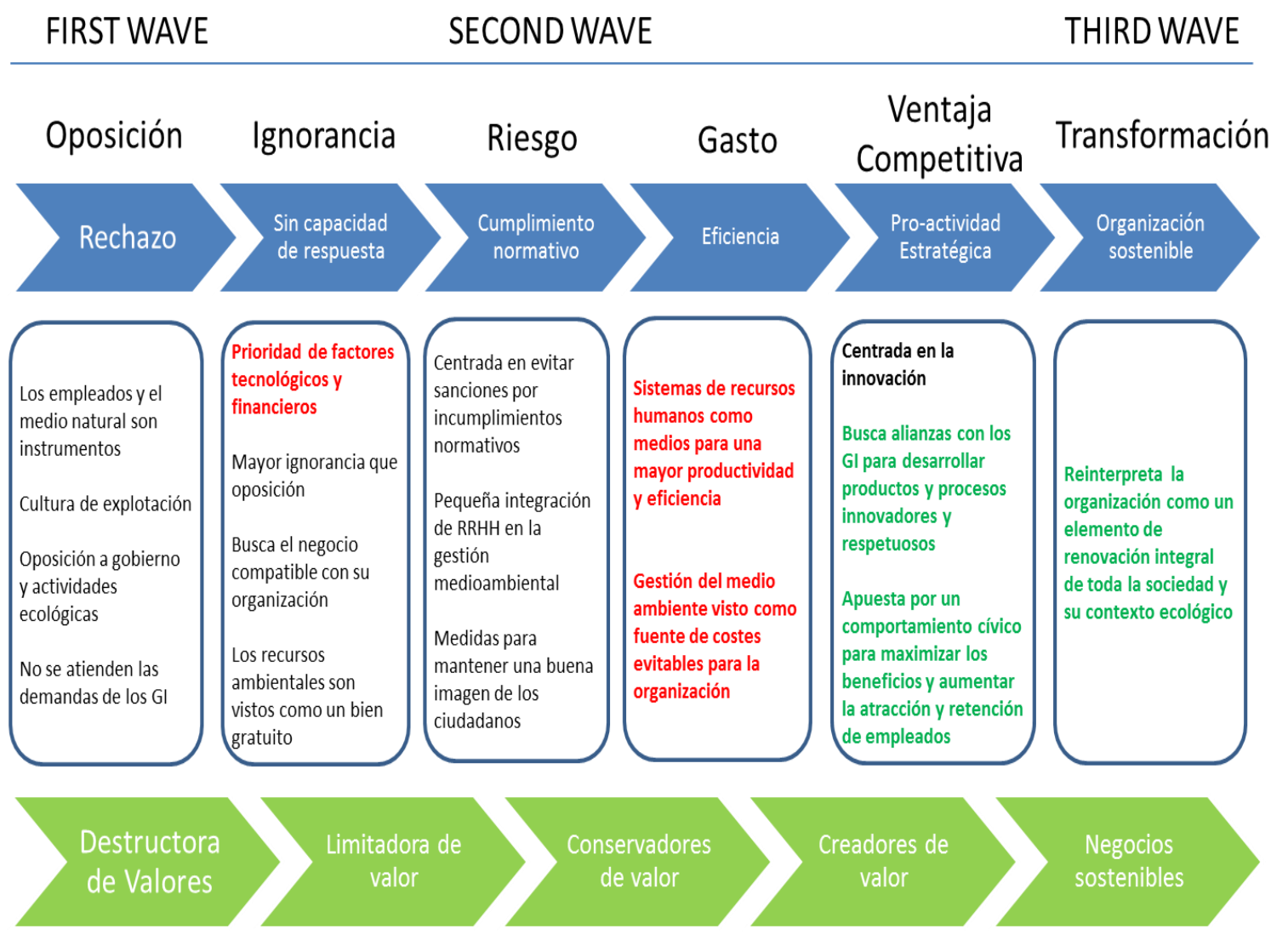

Fuente: Elaboración propia a partir de Sloan K, Klingenberg B y Rider C. Towards Sustainability: Examining the Drivers and Change Process within SMEs. Journal of Management and Sustainability; Vol. 3, No. 2; 2013

En la anterior ilustración se puede ver el grado de avance en sostenibilidad medioambiental de ambas organizaciones estudiadas.

- El Servicio Riojano de Salud da prioridad a los factores tecnológicos y financieros y sus sistemas de recursos humanos son gestionados para lograr mayor productividad y eficiencia. Así mismo la gestión medioambiental es vista como fuente de costes evitables. Según Sloan (2013) el SERIS se encuentra en una fase de contención del gasto entre la conservación del valor y la limitación por el celo financiero.

- La OSI Bilbao-Basurto se encuentra en una fase en la que busca alianzas con los grupos de interés, por el comportamiento ético y tras la constitución de la OSI está reinterpretando la organización como instrumento de renovación de su entorno social. La OSI está en la fase de trasformación en una organización medioambientalmente sostenible.

Económica._En el aspecto económico es necesario tener en cuenta varios aspectos y comparar resultados en el País Vasco y La Rioja dentro del contexto general de España y de la crisis económica sufrida en este periodo. Para ello tomemos como referencia el estudio presentado por Bacigalupe y otros (2016). En este estudio se muestra el comportamiento de las comunidades autónomas en diferentes indicadores. 
Se observa una gran variabilidad entre comunidades autónomas, siendo el País Vasco la que muestra un comportamiento más claro tanto hacia una escasa o nula política de austeridad como de privatización, al contrario que La Rioja.

En la aplicación de reformas legales (tabla 77), el País Vasco y Andalucía destacan por la aplicación más limitada del RD 16/2012, mientras que el resto de las comunidades autónomas se dividen en una aplicación muy intensa de las reformas (especialmente Madrid) y una aplicación media, algo menos restrictiva en la gestión del copago a pensionistas o en la limitación del acceso a la población sin permiso de residencia.

En relación a la privatización Islas Baleares, Cantabria, Extremadura, Madrid y La Rioja destacan por haber aumentado su gasto sanitario en contratación con centros privados, y excepto Madrid, por haber reducido su proporción de camas hospitalarias públicas respecto a las privadas. Aragón, Asturias, Castilla-La Mancha, Comunidad Valenciana, Galicia, Murcia y País Vasco disminuyeron el gasto destinado a financiar centros privados, y excepto Asturias y Murcia, aumentaron la proporción de camas públicas en los hospitales.

A pesar de partir en 2008 de un elevado gasto público destinado a centros privados y una alta proporción de camas privadas, Cataluña redujo el primero y aumentó la segunda a lo largo del periodo.

Solamente el País Vasco mantuvo su gasto sanitario público y aumentó la tasa de personal público en atención primaria y atención especializada en el periodo. El resto de las comunidades autónomas, excepto Cantabria, redujeron de forma relevante su gasto público, y excepto Cataluña y la Comunidad Valenciana, redujeron también su personal público.

Tabla 77.Aplicación de las reformas legales en busca de la eficiencia.

Cambios en la privatización sanitaria y en financiación, y recursos sanitarios, en País Vasco y La Rioja; pesos de cada dimensión y puntuaciones por dimensión y total

\begin{tabular}{|c|c|c|c|}
\hline \multicolumn{2}{|c|}{0 mejor comportamiento 3 peor comportamiento } & País Vasco & La Rioja \\
\hline \multirow{4}{*}{$\begin{array}{l}\text { Aplicación } \\
\text { de reformas } \\
\text { legales }\end{array}$} & Gestión de copago a pensionistas & 1 & 3 \\
\hline & Limitación de acceso a población sin permiso de residencia & 1 & 3 \\
\hline & Aplicación del euro por receta & & \\
\hline & Total & 3 & 9 \\
\hline \multirow{3}{*}{$\begin{array}{l}\text { Privatización } \\
\text { Sanitaria } \\
2008-2013\end{array}$} & Porcentaje de gasto en contratación de centros privados & 1 & 3 \\
\hline & Proporción de camas hospitalarias públicas/privadas & 0 & 3 \\
\hline & Total & 2 & 10 \\
\hline \multirow{4}{*}{$\begin{array}{l}\text { Financiación } \\
\text { y recursos } \\
\text { sanitarios } \\
2008-2013\end{array}$} & Gasto sanitario público total & 1 & 3 \\
\hline & Tasa de personal de atención primaria por 1000 habitantes & 0 & 1 \\
\hline & Tasa de personal de atención especializada por 1000hab. & 0 & 3 \\
\hline & Total & 3 & 9 \\
\hline
\end{tabular}

Fuente: Elaboración propia tomada de Bacigalupe (2016)

Social. Para valorar este aspecto se estudió si las organizaciones habían implementado alguna de las acciones propuestas (tabla 78) por la Federación de Asociaciones para la Defensa de la Sanidad Pública (FADESP; 2011) para la sostenibilidad del sistema sanitario público, por ser un grupo representativo de la sociedad formado por pacientes, ciudadanos y profesionales. 
Tabla 78. Implantación de medidas propuestas por la FADESP

(Federación de Asociaciones para la Defensa de la Sanidad Pública)

\begin{tabular}{|c|c|c|}
\hline & OSI Bilbao Basurto & SERIS \\
\hline $\begin{array}{l}\text { 1. Mejora de la } \\
\text { financiación sanitaria. }{ }^{1}\end{array}$ & $\begin{array}{l}\text { Diferencia gasto por habitante } \\
\text { protegido en periodo } 2007- \\
2014:+9,92 \%\end{array}$ & $\begin{array}{l}\text { Diferencia gasto por habitante } \\
\text { protegido en periodo } 2007- \\
2014: 28,14 \%\end{array}$ \\
\hline 2.Tipo de financiación & \multicolumn{2}{|c|}{ Sistemas de financiación no comparables } \\
\hline $\begin{array}{l}\text { 3.Mejorar la cohesión del } \\
\text { SNS }\end{array}$ & \multicolumn{2}{|c|}{$\begin{array}{l}\text { No depende de las organizaciones. } \\
\text { Acuerdo político entre comunidades }\end{array}$} \\
\hline 4. Rechazo al copago & Se rechaza el copago & Se rechaza el copago \\
\hline $\begin{array}{l}\text { 5. Reducir el gasto } \\
\text { farmacéutico }\end{array}$ & $\begin{array}{l}\text { Evolución gasto farmacéutico } \\
\text { 2009-2013: -18,63 }\end{array}$ & $\begin{array}{l}\text { Evolución gasto farmacéutico } \\
\text { 2009-2013: -24,63 }\end{array}$ \\
\hline \multirow{2}{*}{$\begin{array}{l}\text { 6. Disminuir la utilización } \\
\text { tecnológica ineficiente y } \\
\text { la variabilidad de la } \\
\text { práctica clínica }\end{array}$} & $\begin{array}{l}\text { Variación estancia media } \\
\text { ajustada por la casuística } \\
2008-2014:-9,14 \%\end{array}$ & $\begin{array}{l}\text { Variación estancia media } \\
\text { ajustada por la casuística } \\
2008-2014:-5,26 \%\end{array}$ \\
\hline & $\begin{array}{l}\text { Variación cirugía ambulatoria } \\
2008-2014: 13.28 \%\end{array}$ & $\begin{array}{l}\text { Variación cirugía ambulatoria } \\
2008-2014:-4,92 \%\end{array}$ \\
\hline $\begin{array}{l}\text { 7. Incrementar el número } \\
\text { de camas de media y } \\
\text { larga estancia }^{3}\end{array}$ & $\begin{array}{l}\text { Variación del no de camas de } \\
\text { media y larga estancia } 2012- \\
\text { 2015: }-52,57 \%\end{array}$ & $\begin{array}{l}\text { Variación del nº de camas de } \\
\text { media y larga estancia 2012- } \\
2015:+78,38 \%\end{array}$ \\
\hline $\begin{array}{l}\text { 8. Potenciar la Atención } \\
\text { Primaria de Salud }\end{array}$ & $\begin{array}{l}\text { Porcentaje del gasto sanitario } \\
\text { en atención primaria: }-0,35 \%\end{array}$ & $\begin{array}{l}\text { Porcentaje del gasto sanitario } \\
\text { en atención primaria: }-0,83\end{array}$ \\
\hline $\begin{array}{l}\text { 9.Favorecer la } \\
\text { integración de la } \\
\text { Atención Primaria y la } \\
\text { especializada }\end{array}$ & $\begin{array}{l}\text { Creación de Organización } \\
\text { Sanitaria Integrada }\end{array}$ & 然 \\
\hline $\begin{array}{l}\text { 10.Despolitizar la gestión } \\
\text { sanitaria }\end{array}$ & No & No \\
\hline $\begin{array}{l}\text { 11. Revertir el proceso de } \\
\text { privatización }\end{array}$ & $\begin{array}{l}\text { Porcentaje del gasto dedicado } \\
\text { a conciertos: }-2,25 \%\end{array}$ & $\begin{array}{l}\text { Porcentaje del gasto dedicado } \\
\text { a conciertos: }+94,61 \%\end{array}$ \\
\hline $\begin{array}{l}\text { 12. Crear una agencia de } \\
\text { compras del SNS }\end{array}$ & \multicolumn{2}{|c|}{$\begin{array}{l}\text { No depende de las organizaciones. Acuerdo político entre } \\
\text { comunidades }\end{array}$} \\
\hline
\end{tabular}

Fuente: Elaboración propia a partir de FADESP (2011). 1 Fuente: Indicadores 2007-2014. INCLASS (MSSSI). 2 Fuente: Estadística de gasto sanitario público, MSSSI. Tomado de Bandrés (2015). 3. Fuente: Portal estadístico (MSSSI) 


\subsubsection{Diferencias encontradas}

A partir de los discursos recogidos en las entrevistas, se han realizado otros análisis complementarios.

Recuento de palabras. Se han tenido en cuenta las palabras que representan conceptos, principalmente sustantivos, en ambas organizaciones y luego se ha ponderado su presencia en el discurso de las personas en función de su presencia por cada mil palabras (tabla 79). De esta forma se establece una medida que puede ser comparada entre ambas organizaciones.

Tabla 79. Palabras presentes en el discurso de las personas.

\begin{tabular}{|c|c|c|c|c|c|}
\hline & SRS & & & OSIBB & \\
\hline & Concepto & $\begin{array}{c}\text { no apariciones } \\
\text { por } \\
\text { 1000palabras }\end{array}$ & & Concepto & $\begin{array}{c}\text { no apariciones } \\
\text { por } \\
\text { 1000palabras }\end{array}$ \\
\hline 1 & Hospital & 6,06 & 1 & hospital & 9,25 \\
\hline 2 & paciente/s & 5,65 & 2 & pacientes/s & 5,04 \\
\hline 3 & Gente & 5,31 & 3 & gestión & 3,13 \\
\hline 4 & Cosas & 5,15 & 4 & servicios & 3,06 \\
\hline 5 & ejemplo & 4,07 & 5 & nosotros & 2,93 \\
\hline 6 & ahora & 4,07 & 6 & servicio & 2,56 \\
\hline 7 & nivel & 3,57 & 7 & proceso/s & 2,52 \\
\hline 8 & gestión & 3,49 & 8 & modelo & 2,49 \\
\hline 9 & servicios & 3,07 & 9 & calidad & 2,39 \\
\hline 10 & servicio & 2,99 & 10 & Organización & 2,35 \\
\hline 11 & trabajo & 2,49 & 11 & trabajo & 2,32 \\
\hline 12 & personal & 2,41 & 12 & efqm & 2,29 \\
\hline 13 & centro & 2,16 & 13 & equipo/s & 2,25 \\
\hline 14 & personas & 1,66 & 14 & Profesional/es & 2,09 \\
\hline 15 & calidad & 1,58 & 15 & personas & 1,92 \\
\hline 16 & tiempo & 1,58 & 16 & primaria & 1,88 \\
\hline 17 & económico & 1,49 & 17 & dirección & 1,85 \\
\hline 18 & sistema & 1,49 & 18 & ejemplo & 1,82 \\
\hline 19 & proceso/s & 0,66 & 19 & enfermería & 1,78 \\
\hline & & & 20 & centro & 1,68 \\
\hline & & & 21 & nivel & 1,58 \\
\hline & & & 22 & mantenimiento & 1,51 \\
\hline & & & 23 & formación & 1,48 \\
\hline
\end{tabular}

El cuadro recoge las palabras que aparecen en una proporción superior a 1.50 por mil o valores muy próximos que por significativos se han recogido. 
La palabra proceso se ha recogido porque muestra un concepto que impulsa el modelo EFQM y puede ser indicativo del grado de penetración del modelo en las organizaciones.

El significado de los términos más repetidos es representativo de la cultura de las organizaciones.

Aparición de ideas relacionadas con los conceptos fundamentales de la excelencia (tabla 80).

Tabla 80. Aparición de ideas

\begin{tabular}{|l|c|c|c|c|}
\hline & \multicolumn{2}{|c|}{$\mathrm{n}^{\circ}$ apariciones total del } & \multicolumn{2}{c|}{$\begin{array}{c}\mathrm{n}^{\circ} \text { apariciones por } \\
\text { entrevista del concepto }\end{array}$} \\
\hline \multicolumn{1}{|c|}{ EFQM } & 29 & 6 & 2,42 & 0,86 \\
\hline $\begin{array}{l}\text { Aparición en las entrevistas de ideas } \\
\text { relacionadas con los conceptos } \\
\text { fundamentales de la excelencia (Club } \\
\text { excelencia -EFQM 2013) }\end{array}$ & \multicolumn{2}{|c}{$\begin{array}{c}\mathrm{n}^{\circ} \text { apariciones total del } \\
\text { concepto }\end{array}$} & $\begin{array}{c}\mathrm{n}^{\circ} \text { apariciones por } \\
\text { entrevista del concepto }\end{array}$ \\
\cline { 2 - 5 } & OSIBB & SERIS & OSIBB & SERIS \\
\hline $\begin{array}{l}\text { Alcanzar el éxito mediante el talento } \\
\text { de las personas }\end{array}$ & 23 & 5 & 1,92 & 0,71 \\
\hline Añadir valor para los clientes & 22 & 7 & 1,83 & 1,00 \\
\hline $\begin{array}{l}\text { Aprovechar la creatividad y la } \\
\text { innovación }\end{array}$ & 7 & 0 & 0,58 & 0,00 \\
\hline $\begin{array}{l}\text { Liderar con visión, inspiración e } \\
\text { integridad }\end{array}$ & 20 & 1 & 1,67 & 0,14 \\
\hline Crear un futuro sostenible & 43 & 12 & 3,58 & 1,71 \\
\hline $\begin{array}{l}\text { Mantener en el tiempo resultados } \\
\text { sobresalientes }\end{array}$ & 7 & 2 & 0,58 & 0,29 \\
\hline $\begin{array}{l}\text { Desarrollar la capacidad de la } \\
\text { organización }\end{array}$ & 24 & 3 & 2,00 & 0,43 \\
\hline
\end{tabular}

La aparición en las entrevistas de la expresión EFQM y de ideas relacionadas con los conceptos fundamentales de la excelencia es notablemente mayor en la OSI BilbaoBasurto lo cual refuerza la sensación de que el modelo y los valores que este toma como referencia se encuentran más presentes en la cultura de la OSIBB

\section{Otros conceptos relevantes identificados}

Para completar el estudio también se han buscado aquellos conceptos que no tendrían relación directa con el modelo EFQM.

En este caso se puede observar (tabla 81) que en el caso de los conceptos que han aparecido en ambas organizaciones, la capacidad de adaptación, planificación y gestión medioambiental aparecen con mayor intensidad en el SERIS.

Tal vez esto sea debido a la presencia de una percepción negativa sobre la organización, que ya se ha identificado en las entrevistas. Según los entrevistados el SERIS necesita mejorar su capacidad de adaptación, mejorar su planificación y su gestión medioambiental. 


\begin{tabular}{|c|c|c|c|c|c|c|}
\hline \multicolumn{3}{|c|}{ Conceptos no EFQM Comunes } & Número & $\begin{array}{l}\text { Frecuencia } \\
\text { OSIBB }\end{array}$ & Número & $\begin{array}{l}\text { Frecuencia } \\
\text { SERIS }\end{array}$ \\
\hline \multicolumn{3}{|c|}{ Capacidad de adaptación } & 6 & 0,5 & 9 & 1,29 \\
\hline \multicolumn{3}{|c|}{ Enfermería } & 8 & 0,67 & 3 & 0,43 \\
\hline \multicolumn{3}{|c|}{ Planificación } & 2 & 0,17 & 8 & 1,14 \\
\hline \multicolumn{3}{|c|}{ Gestión por procesos } & 6 & 0,5 & 3 & 0,43 \\
\hline \multicolumn{3}{|c|}{ Gestión medioambiental } & 3 & 0,25 & 7 & 1 \\
\hline \multicolumn{3}{|l|}{ Recortes } & 1 & 0,08 & 2 & 0,29 \\
\hline \multicolumn{7}{|c|}{ Aparición en las entrevistas de otras ideas relacionadas con las organizaciones } \\
\hline IDEAS OSIBB & Número & Frecuencia & \multicolumn{2}{|c|}{ IDEAS SERIS } & Número & Frecuencia \\
\hline $\begin{array}{l}\text { Cultura } \\
\text { organizacional }\end{array}$ & 20 & 1,67 & \multicolumn{2}{|c|}{ Falta de Tiempo } & 2,00 & 0,29 \\
\hline Espíritu basurtiano & 23 & 1,92 & \multicolumn{2}{|c|}{ Proveedores } & 3,00 & 0,43 \\
\hline Integración OSIBB & 4 & 0,33 & \multicolumn{2}{|c|}{ Recursos } & 1,00 & 0,14 \\
\hline $\begin{array}{l}\text { Mantenimiento } \\
\text { negativo }\end{array}$ & 3 & 0,25 & \multicolumn{2}{|c|}{$\begin{array}{l}\text { Oportunidad } \\
\text { desaprovechada }\end{array}$} & 3,00 & 0,43 \\
\hline $\begin{array}{l}\text { Mantenimiento } \\
\text { positivo }\end{array}$ & 4 & 0,33 & \multicolumn{2}{|c|}{$\begin{array}{l}\text { Percepción negativa } \\
\text { del centro }\end{array}$} & 6,00 & 0,86 \\
\hline \multirow{2}{*}{$\begin{array}{l}\text { Mantenimiento } \\
\text { RRHH }\end{array}$} & \multirow{2}{*}{1} & \multirow{2}{*}{0,08} & \multicolumn{2}{|c|}{$\begin{array}{l}\text { Relación con la } \\
\text { sociedad }\end{array}$} & 3,00 & 0,43 \\
\hline & & & \multicolumn{2}{|c|}{$\begin{array}{c}\text { Sostenibilidad y } \\
\text { EFQM }\end{array}$} & 6,00 & 0,86 \\
\hline
\end{tabular}

También resultan significativas las ideas que más se repiten en los entrevistados de ambas organizaciones. La aparición del "espíritu basurtiano" como manifestación de cultura organizacional, orgullo de pertenencia a la organización y rasgo diferenciador, y la integración son aspectos positivos. Aunque en la OSIBB también se identifican aspectos relacionados con la falta de reconocimiento de la importancia y un sentimiento de falta de consideración en la planificación de la organización de los procesos de apoyo, en especial de mantenimiento.

Por otro lado en el SERIS se manifiestan problemas derivados de los ajustes financieros y de la priorización económica como falta de personal (falta de tiempo), exigencia a los proveedores, disminución de recursos. Todo ello se ve como una oportunidad desaprovechada y la necesidad de mejorar la relación con la sociedad. Se vuelve a identificar la percepción negativa de los trabajadores hacia su propia organización. 


\subsubsection{Reflexión final}

El sistema sanitario español, como institución fundamental de servicio público, es hoy un instrumento social insustituible en el proceso de legitimación del estado de bienestar, que contribuye con sus actuaciones al proceso de socialización y desarrollo de una sociedad integrativa en un marco de convivencia, igualdad y derechos de ciudadanía.

La sostenibilidad del sistema sanitario en los años de crisis económica se ha puesto en duda. Según diferentes autores, el sistema público de salud necesita una serie de reformas para encarar el futuro y poder cumplir su fin.

La sostenibilidad de sistema sanitario no es solo una cuestión de índole económica o financiera. Tal y como se ha planteado en capítulos anteriores la sostenibilidad se plantea desde tres diferentes esferas interrelacionadas entre sí: económica, social y ambiental. Para alcanzarla es preciso planificar una estrategia para seguir el camino sostenible y que ineludiblemente pasa por dar una respuesta coordinada a las necesidades de todos los grupos de interés.

Ámbito Económico. Según la opinión de CCOO (2013) la Sanidad Pública Española es una de las más eficientes del mundo, pues tiene unos excelentes indicadores sanitarios y sin embargo el porcentaje de PIB dedicado a la misma es de los más bajos de nuestro entorno (menor que el promedio de la UE15, UE27 y OCDE). España gasta en sanidad menos que lo que le correspondería gastarse en relación al nivel de riqueza y el gasto sanitario público per cápita es sólo el $79,5 \%$ del gasto sanitario público promedio de la UE-15.

Por otro lado el BBVA (Abellán, 2013) afirma que en comparación al promedio de la OCDE, el gasto sanitario público en España en porcentaje del PIB es prácticamente idéntico. Este mismo estudio reconoce que si el IPC crece según lo previsto por el FMI la financiación no es un problema.

No obstante sí parece necesario que el sistema sea más eficiente, que mejore sus procesos, que optimice sus recursos, que controle el gasto en farmacia y el tecnologías (Cabrera, 2010). Todo ello precisa una mejora en la gestión económica de las organizaciones que implica a su vez una mejora en los sistemas de gestión.

Ámbito medioambiental. Las organizaciones sanitarias no son empresas altamente contaminantes. No bastante deben cumplir con una legislación que les obliga a evitar contaminaciones de carácter biológico y radiológico. Además la propia sociedad reclama a las organizaciones sanitarias y al resto de organizaciones que extremen su cuidado con el medioambiente tanto en la eliminación de residuos como en el consumo de los recursos naturales. A este respecto son muchas las organizaciones que trabajan con EMAS, ISO 14001 u otras diferentes herramientas que permiten introducir, mantener y mejorar en la organización un sistema de gestión medioambiental y concienciar a las personas que forman parte de ella de la importancia de preservar el entorno. 
Ámbito Social. En este apartado partimos de la premisa ética que obliga a los profesionales sanitarios a buscar siempre lo mejor para sus pacientes. A ser eficaces, a proporcionar siempre los mejores y más actualizados cuidados basados en la evidencia en situaciones de máxima seguridad para los pacientes. Esto no es nada más que cumplir con el objetivo de prevenir, curar, rehabilitar del sistema sanitario. Pero la sociedad también reclama, y lo ha traducido a leyes, que el acceso al sistema sanitario sea universal, equitativo e igualitario.

Por otro lado el sistema sanitario también debe cuidar a sus trabajadores, debe procurarles un ambiente seguro, y una formación y motivación que haga que mejore continuamente el desempeño de su trabajo.

A continuación se presenta un cuadro de factores limitantes internos y externos y de factores facilitadores (tabla 82) como resumen de la bibliografía revisada sobre la sostenibilidad del sistema sanitario.

Tabla 82. DAFO Sostenibilidad sistema sanitario público

\begin{tabular}{|c|c|c|c|}
\hline \multirow{2}{*}{$\begin{array}{l}\text { Factores } \\
\text { limitantes }\end{array}$} & Interno & Debilidades & $\begin{array}{l}\text { - Rigidez organizacional } \\
\text { - Falta de motivación } \\
\text { - Discontinuidad asistencial (AP/AE) } \\
\text { - Falta de personal } \\
\text { - Desmotivación }\end{array}$ \\
\hline & Externo & Amenazas & $\begin{array}{l}\text { - Batallas políticas } \\
\text { - Privatizaciones. Salud como negocio } \\
\text { - Disminución de recursos por la crisis } \\
\text { - económica y social } \\
\text { - Tecnologías caras y rápida obsolescencia }\end{array}$ \\
\hline \multirow{2}{*}{$\begin{array}{l}\text { Factores } \\
\text { facilitadores }\end{array}$} & Interno & Fortalezas & $\begin{array}{l}\text { - Buena percepción de los ciudadanos } \\
\text { - Experiencia en sistemas de gestión } \\
\text { - Orientación al paciente } \\
\text { - Profesionalidad }\end{array}$ \\
\hline & Externo & Oportunidades & $\begin{array}{l}\text { - Benchmarking } \\
\text { - Alianzas } \\
\text { - Legislación actual: Derecho a la Salud. } \\
\text { - Reconiversalidad y equidad } \\
\text { - Recimiento internacional }\end{array}$ \\
\hline
\end{tabular}

Elaboración propia a partir de bibliografía revisada

En el momento actual, después de los efectos negativos de la crisis económica de 2008, que supuso un verdadero test de estrés sobre la sostenibilidad de las organizaciones, se aprecian indicios que fortalecen su mantenimiento. Por un lado, la mejora en los niveles de satisfacción de los usuarios que aparecen en las encuestas (INCLASS), por otro el aseguramiento de la financiación del sistema gracias al crecimiento del PIB según indica el BBVA (Abellán, 2013). 


\section{CONCLUSIONES}

\subsection{Conclusiones}

La sostenibilidad tiene relación con la capacidad de las organizaciones de adaptarse a entornos cada vez más cambiantes y a las necesidades de sus grupos de interés.

La realización de este trabajo ha puesto de manifiesto la importancia del desarrollo sostenible de las organizaciones sanitarias en el presente y de cara al futuro, a partir de la gestión eficaz de los grupos de interés. La organización debe trabajar hacia un futuro basado en valores que sean soporte de los principios del desarrollo sostenible. Identificar e integrar aquellos que favorezcan la mejora continua y la satisfacción de las necesidades de todos los grupos de interés de forma equilibrada, contribuye a la formulación de una estrategia que permita el desarrollo sostenible.

Las estrategias basadas en la excelencia permiten analizar la realidad y los diferentes agentes implicados (grupos de interés) y proponer soluciones, para orientar a la organización a una visión u horizonte en un plazo de tiempo determinado. Dicha visión de futuro puede suponer capacitar a ésta para dar respuesta a los grandes retos.

Según los hallazgos, parece evidente que la gestión de las organizaciones necesita de enfoques que promuevan la excelencia en los resultados y guíen las mejoras en los servicios de salud. Para ello es necesario utilizar herramientas de gestión que hayan demostrado su utilidad a partir de estudios científicos.

Los enfoques basados en la excelencia o calidad total permiten a las organizaciones tener conciencia del efecto que las acciones de la organización provocan sobre los grupos de interés. Estos enfoques proporcionan una interpretación holística de la realidad, ocupando un lugar fundamental la visión finalista de los grupos de interés (a cuya satisfacción orienta su actividad la organización), la asunción de responsabilidades, la implicación de las personas que integran la organización, la orientación a los clientes y a los resultados, el liderazgo efectivo y la coherencia con los objetivos que persigue la organización, y la adopción de una cultura de la mejora continua.

Además el carácter inalcanzable de la excelencia, hace que las organizaciones tengan que estar siempre atentas al entorno, a las necesidades de sus grupos de interés, y a sus propios recursos, capacidades y rendimiento, con la intención de mejorar continuamente y adaptarse a los diferentes escenarios de forma sostenible.

El modelo europeo de excelencia EFQM puede ser una oportunidad que permite llevar a cabo la transformación del SNS de una forma organizada. Es una herramienta suficientemente validada en otros ámbitos, e incluso en el propio ámbito de la salud

El modelo EFQM es un marco de trabajo no prescriptivo que reconoce que la Excelencia de una organización se puede lograr de manera sostenida mediante diferentes enfoques (económico, social, ambiental). El modelo EFQM aporta una serie de ventajas como: 
- No es prescriptivo y permite libertad de interpretación para definir las estrategias adecuadas para una organización sanitaria, teniendo en cuenta su cultura, origen y entorno político

- Permite la incorporación de otros sistemas de gestión para trabajar de forma complementaria en diversos aspectos de la mejora de la organización (ISO, DAFO, RSC, etc.)

- Permite la mejora de la gestión en todos los criterios de forma simultánea porque la adopción de un modelo de gestión de la calidad no conlleva necesariamente la obtención de resultados superiores, si la implantación no se hace de forma integrada. Ello favorece a demás que no aparezcan desequilibrios que pueden llevar a la insostenibilidad de la organización.

- Facilita la integración, utilizado en organizaciones como el HU Basurto y la Comarca de AP de Bilbao por separado durante años, ha permitido que hablasen el mismo idioma y tuviesen unos valores compartidos.

- Favorece la colaboración con otras empresas, organizaciones e instituciones (grupos de interés), favoreciendo el éxito de los procesos de cambio hacia la sostenibilidad.

En este estudio se ha evidenciado que el modelo EFQM apoya la creación de una cultura organizacional fuerte formada de valores y normas que permite a cada uno de los individuos identificarse con ellos y, poseer conductas positivas dentro de la misma obteniendo mayor productividad por parte de los mismos, así como fuera proyectando una imagen positiva de la organización.

La reciente publicación del informe sobre el impacto de la implantación de EFQM en Osakidetza (Matthies-Baraibar, 2016) publicado por Osalan respalda este hallazgo. Este informe respalda lo percibido en esta investigación respecto a la cultura propia de cada organización como elemento potenciado e influido por la implantación de EFQM, que tiene un impacto positivo en la introducción de elementos que sitúan a la propia organización en el camino de la sostenibilidad.

La implantación del modelo EFQM en Osakidetza, y más concretamente en la OSI Bilbao-Basurto, ha introducido en el discurso de las personas que la forman los términos de mejora continua, orientación al paciente, gestión por procesos y hechos, indicadores, eficacia y otros. No obstante, también recibe críticas por su uso como "venta de imagen" o la falta de relevancia de los procesos no asistenciales.

Con la implantación del modelo europeo de excelencia EFQM, se ha apoyado una cultura organizacional (Ej. espíritu basurtiano) de carácter perdurable en el tiempo, sostenible, manifestada a través de un conjunto compartido de creencias y de imágenes mentales comunes que muestra una imagen positiva de la organización, orgullo de pertenencia y confianza en el futuro, en oposición al sentimiento negativo sobre la organización detectado en el personal del SERIS.

Las funciones de integración interna y la capacidad de adaptación externa se encuentran vinculadas y son interdependientes, la primera condiciona la segunda en el 
sentido que posibilita la propia existencia del grupo y, a su vez, el esfuerzo por la supervivencia y la adaptación al y del entorno hace que se alcance la integración. Todo ello favorece la sostenibilidad.

Este proceso según los resultados de las entrevistas al personal de la OSIBB y en especial a los que proceden del Hospital de Basurto se conoce en la organización como "espíritu basurtiano". Según el personal de Basurto implica disciplina, compañerismo, profesionalidad, orientación al paciente, mejora continua e innovación por un lado, y cierto clasismo según los que lo ven desde fuera. Como ya se ha indicado, la implantación del modelo EFQM parece haber reforzado este sentimiento de pertenencia y el orgullo de pertenencia a la organización, a la vez que ha introducido conceptos y valores relacionados con la excelencia en la organización, y que se manifiestan a través de las actitudes, comportamientos y expresiones utilizadas por el personal de la OSIBB tal y como demuestran los resultados obtenidos del análisis de sus discursos.

Por todo lo anterior, y porque no podemos señalar la hipótesis planteada en este estudio es cierta. Existen diferencias entre las organizaciones estudiadas en aspectos de sostenibilidad debidas a la implantación del modelo EFQM.

Como se está señalando, el modelo EFQM es una herramienta que permite reflejar como la organización piensa y opera y qué forma parte de su cultura, la que es soporte de la estrategia hacia una organización sostenible.

No obstante, como se ha podido observar a través de los discursos de las personas existen problemas a la hora de trabajar con el modelo en el ámbito sanitario, tales como:

- La dificultad de su lenguaje

- La percepción como trabajo añadido o la dificultad de la integración del modelo en estructuras verticales dominadas por los médicos.

- Introducir como objetivo la obtención de premios o reconocimientos basados en EFQM u otras normas como estrategia de marketing sin una implantación validada y crítica de los mismos.

En línea con lo anterior es necesario tener en cuenta, a lo largo de todo el proceso de implantación de un modelo de gestión de la calidad, el problema de la continuidad. Este problema representa un condicionante importante en el sector público por la falta de continuidad en políticas marcadas por los líderes políticos. Es necesario crear planes estratégicos a varios años (varias legislaturas) para poder ver los resultados y las bondades de los sistemas de gestión.

Otra de las cuestiones patentes en los discursos de los entrevistados tiene que ver con las condiciones laborales y la falta de motivación en los profesionales. La introducción en la cultura de la organización de conceptos como orientación al paciente, mejora continua, grupos de interés, indicadores, procesos, etc. Es decir, de elementos de gestión de calidad parece favorecer a esta motivación a la par que fortalece la sostenibilidad del Sistema Nacional de Salud.

No obstante, en esta investigación y con los datos obtenidos de indicadores y de las entrevistas realizadas no se puede afirmar que el modelo EFQM mejore los resultados 
de satisfacción de pacientes y otros resultados clave. A este respecto las diferencias encontradas en los indicadores analizados no pueden ser atribuidos a la implantación de modelos de gestión de calidad, si no a factores económicos, poblacionales o de recursos.

Además existen otra serie de herramientas o de aspectos propuestos por diversos autores y organizaciones sociales que deben ser trabajados para lograr la sostenibilidad de las organizaciones sanitarias (Anexo I). Es decir, el modelo EFQM puede ser el marco en el que todo se todo se incluya, pero lo fundamental es identificar e implantar acciones de mejora concretas en cada uno de los criterios.

Por otro lado, tampoco se puede afirmar que el modelo EFQM es la única razón que justifica las diferencias encontradas entre las dos organizaciones, aunque sí parece haber indicios de ello. Sería necesario disponer de una serie más extensa de datos y la realización de un estudio más amplio que incluyese todos los factores. Por ello no podemos señalar con rotundidad que el modelo EFQM es una herramienta que apoye la sostenibilidad de las organizaciones sanitarias públicas. No obstante, si se ha podido verificar la existencia de una cultura de la excelencia que apoya la sostenibilidad de forma cualitativa.

Finalmente, este trabajo de investigación refuerza la idea de que el método de caso es una herramienta útil para estudios dentro del ámbito de la salud y más concretamente de la gestión sanitaria. La utilización del método en estudios cualitativos en ciencias sanitarias, requiere que el investigador sea prudente en la selección de casos a comparar, tarea que ha de desarrollarse siguiendo criterios metodológicos, lo cual significa que los casos elegidos presenten variables similares que puedan ser constantes, y variables diferenciadoras interesantes de ser contrastadas. En el caso de este trabajo la variable diferenciadora ha sido el uso del modelo EFQM como apuesta estratégica por la organización.

\subsection{Limitaciones de la investigación}

Las limitaciones de este trabajo de investigación tienen que ver con la propia metodología utilizada. En la investigación cualitativa el concepto de transferencia o de representatividad de los hallazgos es limitado (Patton, 2002; Yin, 2009). La población y la muestra elegida no están basadas en datos estadísticos, por lo que los resultados de esta investigación están relacionados con los contextos específicos en que se llevó a cabo.

Se deben separar aquellos conceptos o elementos que podrían en un momento dado ser aplicados a diferentes contextos, lo que puede llamarse en todo caso una generalización teórica, al poder comparar los casos de diferentes Organizaciones Sanitarias. También, Lincoln y Guba (1985), indican que las conclusiones se podrían generalizar (en cierta medida) si los contextos en su esencia son extremadamente parecidos como sucede en los Hospitales.

De esta manera, partiendo de estas ideas previas, los resultados de esta investigación podrían ser tenidos en cuenta por las organizaciones sanitarias que se planteen cómo abordar el tema de la sostenibilidad desde una perspectiva global. 
Asimismo, es posible que se pueda cuestionar que la metodología cualitativa empleada centrada en dos casos no sea suficiente para una generalización teórica a pesar de la validez y fiabilidad indicada. No obstante, el propósito de esta investigación no fue la generalización de los datos, ni la elaboración de una «gran teoría» o un «modelo», el estudio se limitó a la construcción de esquemas o marcos conceptuales, compuesto por conclusiones y proposiciones teóricas y prácticas que pretenden comprender y describir lo que ha sucedido con la sostenibilidad de las organizaciones sanitarias en el periodo de tiempo estudiado.

En cuanto al diseño de la investigación, después de haber pasado por todo el proceso utilizar dos casos de estudio puede parecer escaso y podría plantearse, con el fin de profundizar aún más en el fenómeno y en las dinámicas encontradas, haber incluido otras. No obstante, debido a la limitación de recursos y otros aspectos logísticos y personales no fue posible realizar este diseño. Cabe destacar en este sentido, que dentro de esta investigación se inició y se desarrolló la recolección de datos para un Hospital más seleccionado, la Fundación Hospital Calahorra, como tercer caso de estudio. Sin embargo, y a pesar que se disponía de datos, las diferentes características de organización, tamaño y dependencia funcional desaconsejaron continuar el estudio y se decidió no incluir este caso de estudio dentro de la tesis.

En los métodos del diseño de la investigación concretos a utilizar, sobre todo en los dos principales, la observación participativa no intrusiva y las entrevistas en profundidad semiestructuradas, el investigador juega un rol muy importante ya que es la herramienta fundamental de la investigación (Patton, 2002), lo que puede representar una limitación, ya que se depende de la interpretación, experiencia e integridad del investigador. Por otro lado, las entrevistas en profundidad dependen en gran medida de la honestidad y capacidad de expresión del entrevistado, que muchas veces representa una limitación. Sobre todo en una organización pública y jerárquica, en dónde el entorno juega un rol fundamental, hecho que puede conducir a que los entrevistados desconfíen de la investigación, pensando que podría llegar a ser perjudicial para su puesto de trabajo. En este sentido, como ya se indicó en el capítulo de metodología se trató de minimizar en la medida de lo posible esta limitación, haciendo preguntas abiertas y realizando las entrevistas en lugares donde los entrevistados se sintiesen cómodos.

Asimismo, la codificación de los datos se realizó de manera manual, lo que me permitió una mayor profundidad del análisis debido al involucramiento total del investigador en el proceso completo del estudio. Pero por otro lado, también es cierto, que el uso del programa informático, utilizado de manera complementaria, ha resultado de mucha ayuda aunque también puede haber introducido errores por la falta de experiencia inicial con el mismo.

Otra posible limitación fue el proceso de aprendizaje del propio investigador. Esta investigación tiene como objetivo la consecución del grado de doctor en Ciencias Sociales y como tal, corresponde al trabajo de un investigador en formación en la doble vertiente de las Ciencias Sociales y de la propia metodología de investigación, y no al trabajo de un investigador ya formado y con experiencia en la aplicación de metodologías cualitativas en Ciencias Sociales. No obstante, el trabajo de la directora de tesis fue fundamental en guiar el proceso de aprendizaje del doctorando, para minimizar en la medida de lo posible esta posible limitación. 
Finalmente, la complejidad y lo político del tema, además de realizar el estudio en este ámbito de aplicación (la sanidad pública) es otro elemento importante que puede representar una limitación. En este caso, la sostenibilidad de la sanidad pública es un tema que lleva aparejado un importante componente ideológico del que se ha intentado huir siempre para poder reflejar de una forma lo más objetiva posible todos los puntos de vista.

\subsection{Futuras investigaciones}

A la luz de las contribuciones teóricas discutidas en este capítulo, de la relevancia social del tema y del momento histórico en el que nos encontramos se puede indicar, que las investigaciones futuras pueden dirigirse hacia diferentes vertientes en las que se valore cada uno de los aspectos tratados y con una perspectiva de tiempo que permita ver cómo han reaccionado las organizaciones sanitarias al periodo de crisis económica que ha supuesto una situación de estrés al que se han sometido las organizaciones.

Desde dichos antecedentes, se puede continuar el análisis desde una perspectiva, también, cuantitativa de la sostenibilidad para evaluar los elementos encontrados y las medidas propuestas y perfilarlas hacia un modelo, ya sea EFQM o cualquier otro modelo, que apuntale la sostenibilidad del sistema sanitario público.

De igual manera, se podría evaluar el camino hacia la sostenibilidad, para perfilarlo y caracterizarlo, comparándolo con otros entornos del sector público, e incluso privado y en otros países de nuestro entorno.

Para completar este estudio en el futuro es necesario identificar los elementos claves que componen la cultura organizacional, que tiene impacto en los procesos de la organización y son significativos. Se trataría de identificar las estructuras organizativas, los estilos de dirección, la productividad, la tecnología, los sistemas de información y comunicación, la organización del trabajo, los sistemas de control, el enfoque estratégico, es decir, sería necesario disponer de más información de los sistemas culturales y humanos, además de los sistemas de gestión.

Además, de que también se puede profundizar en el impacto desde un marco metodológico cuantitativo que tienen las diferentes apuestas por la sostenibilidad en los indicadores de salud de la población. Así como profundizar en el estudio de las políticas y de los sistemas de gestión adoptados como determinantes sociales de la salud.

Finalmente, otras investigaciones también pueden dirigirse a profundizar algunos hallazgos inesperados de este estudio tales como el proceso de enculturación de las organizaciones o la evaluación a largo plazo del cambio de cultura inducido por la implantación del modelo EFQM. Se puede analizar desde la perspectiva teórica de la gestión del conocimiento, el aprendizaje, el cambio organizacional, las rutinas organizacionales y de las capacidades dinámicas de las propias organizaciones y sus personas. 


\section{BIBLIOGRAFÍA}

1. Abad, E. et al. (2008). Lectura crítica de una investigación cualitativa en salud. Disponible en: https://www.murciasalud.es/archivo.php?id=136632. Acceso: 16/08/2015.

2. Abellán Perpiñán, J. et al (2013). El sistema sanitario público en España y sus Comunidades Autónomas. Sostenibilidad y reformas. Fundación BBVA. Bilbao.

3. Abravanel, H.; Allaire,Y.; Firsirotu, M; Hobbs, B; Poupart, R.; Simard, J. (1992). Cultura organizacional: aspectos teóricos, prácticos y metodológicos. Leggis. Bogotá.

4. Abril Martorell, F. (1991). Comisión de política social y empleo. Diario de sesiones del Congreso de los Diputados.IV legislatura. Núm.306.

5. ACCIONA (2016). Alternativas al PIB para medir el bienestar. Sostenibilidad para todos. http://www.sostenibilidad.com/alternativas-pib-medir-bienestar. Acceso: 29/12/2016.

6. AES-Asociación Economía de la Salud. (2011). La sanidad pública ante la crisis. Recomendaciones para una actuación pública sensata y responsable. Documento de Debate. Asociación de Economía de la Salud. Disponible en: http://www.aes.es/Publicaciones/DOCUMENTO_DEBATE_SNS_AES.pdf. Acceso: 22/03/2016.

7. AEVAL-Agencia Estatal de Evaluación de las Políticas Públicas y la Calidad de los Servicios (2013). Documento de interpretación de la versión 2013 del modelo EFQM para las Administraciones Públicas. Ministerio de Hacienda y Administraciones Públicas. http://www.aeval.es/es/difusion_y_comunicacion/publicaciones/Guias/Guias_Marco_G eneral_Mejora_Calidad/guia_efqm2013.html. Acceso: 18/10/2014.

8. AEVAL Agencia Estatal de Evaluación de las Políticas Públicas y la Calidad de Los Servicios (2011). Hacia una Administración Pública Sostenible. Informes AEVAL. http://www.aeval.es/export/sites/aeval/comun/pdf/calidad/informes/Informe_AP_soste nible.pdf. Acceso: 18/10/2014.

9. ADER-Asociación de Empresarios de La Rioja (2013). Modelo de Excelencia EFQM.

10. Aguilar Villanueva, L. F. (2006). Gobernanza y gestión pública. México, D.F., Fondo de Cultura Económica.

11. Alonso, L. E. (1998). La mirada cualitativa en sociología. Una aproximación interpretativa. Madrid: Editorial Fundamentos.

12. Alonso Ramos, E. (2004). Modelo de la contingencia y eficacia organizacional. Una evaluación del impacto de programas de empleo. Volumen 171 de Tesis doctorales. Universidad Almería.,

13. Álvarez Cáceres, R. (1996). El método científico en las ciencias de la salud. Las bases de la investigación biomédica. Madrid: Díaz de Santos.

14. Álvarez Castaño, L. (2009). Los determinantes sociales de la salud: más allá de los factores de riesgo. Revista Gerencia y Políticas de Salud, 8 (17), 69-79. 
15. Alvira, F. y Serrano, A. (2015). Diseños y estrategias de investigación social, en García,M.; Alvira, F.; Alonso, L.E. y Escobar, M.: El análisis de la realidad social. Métodos y técnicas de investigación social, Alianza. Madrid.

16. Amezcua, M. y Gálvez, A.(2002) Los modos de análisis en investigación cualitativa en salud: perspectiva crítica y reflexiones en voz alta. Rev Esp Salud Pública 2002; 76: 423-436. N. 5 - Septiembre-Octubre.

17. Angrosino, M. (2012). Etnografía y observación participante en investigación cualitativa. Madrid: Morata2012.

18. Antequera, J. y González, E. (2005). ¿Medir la sostenibilidad? Una aproximación al tema de los indicadores de sostenibilidad. Cátedra Unesco de la Sostenibilidad. Universidad Politécnica de Barcelona. Sostenible - 2005, núm. 7 Disponible en: http://dx.doi.org/10.5821/sostenible.v0i7.1159. Acceso: 20/08/2016.

19. Anxo, M. (2014). Experiencias en tecnología para la eficiencia. XII Jornadas de Gestión y Evaluación de Costes Sanitarios. Fundación Signo. Huesca 2014. Disponible en: http://www.fundacionsigno.com/archivos/20160118181559.pdf (acceso 6/10/2015).

20. Apezetxea, A. (2017). Efqm avanzado país vasco. I curso grupo de estudios de normalización en alimentación hospitalaria. Disponible en http://hospifood.com/jornadas/. Acceso: 06/03/2017.

21. Aragón, L. (2001). Modelo Europeo de Excelencia. Ministerio de Educación, Cultura y Deporte. Disponible en: https://sede.educacion.gob.es/publiventa/. Acceso: 20/11/2016.

22. Arenas Díaz, C.A. (2012). Sostenibilidad del sistema sanitario en España. Sedisa Siglo XXI. http://www.sedisasigloxxi.com/spip.php?article242. Acceso 29/12/2016.

23. Arenas, D.; Fosse, J; Emily Huc, E. (2010). El giro hacia la empresa verde. Estudio sobre el proceso de transformación de las empresas hacia la sostenibilidad. Instituto de Innovación Social. ESADE. Universidad Ramón LLull.

24. Arcelay, A. et al. (2000). Adaptación de un modelo de gestión de calidad total al sector sanitario. Rev. Calidad Asistencial 2000; 15:184-191.

25. Arcelay, A. (2010). EFQM: Veinte años alumbrando el camino de la excelencia. El modelo se remodela. RevCalidAsist.2010; 25(3):117-119.

26. Arias Menéndez, E. (2010). La burbuja competencial. Rev Adm Sanit. 2010; 8(1):3950.

27. Arranz, J.A. (2014). Experiencias en tecnología para la eficiencia. XII Jornadas de Gestión y Evaluación de Costes Sanitarios. Fundación Signo. Huesca 2014. Disponible en: http://www.fundacionsigno.com/archivos/20160118181559.pdf (acceso 6/10/2015).

28. Arratibel, P. (2014). La transformación sanitaria: el camino hacia la sostenibilidad. XII Jornadas de Gestión y Evaluación de Costes Sanitarios. Huesca 2014. Disponible en: http://www.fundacionsigno.com/archivos/20160118181559.pdf (acceso 6/10/2015).

29. AES (2013). Asociación de Economía de la Salud. Sistema Nacional de Salud: diagnóstico y propuestas de avance. Barcelona, noviembre, 2013.Disponible en: http://www.aes.es/Publicaciones/SNS_version_completa.pdf 
30. Bacigalupe, A. et al (2015). Austeridad y privatización sanitaria en época de crisis: ¿Existen diferencias entre las comunidades autónomas? Gac Sanit.2016; 30(1):47-51.

31. Bandrés, E. y González, R. (2015). La reducción del gasto sanitario en España durante la crisis. Cuadernos de información económica. Septiembre/octubre.

32. Barcellos, L. (2011). Modelos de gestión aplicados a la sostenibilidad empresarial. Tesis Doctoral. Facultad de Economía y Empresa. Universidad de Barcelona.

33. Barrasa, J.I. (2013) la calidad de la atención sanitaria. Indicadores de efectividad clínica. Sociedad Española de Calidad Asistencial.

34. Batthyány, K. y Cabrera, M. (2011) .Metodología de la investigación en Ciencias Sociales. Apuntes para un curso inicial. Universidad de la República. Montevideo. www.universidadur.edu.uy/bibliotecas/dpto_publicaciones.htm

35. Beltrán, A.; Forn, R.; Garicano, L.; Martínez, M.M.; Vázquez, P. (2009). Impulsar un cambio posible en el sistema sanitario. Fundación de Estudios De Economía Aplicada (FEDEA). Disponible en: www.cambioposible.es/sanidad

36. Bermejo, R. (2001). Economía sostenible, principios, conceptos e instrumentos. Bakeaz.

37. Bengoa, R. (2016). Gobierno Clínico: Organización y Gobernanza. Conferencia Plenaria. XXXIV congreso nacional de la sociedad de calidad asistencial. Córdoba 2016.

38. Bermúdez, L. (2012). 31 obstáculos en la implantación de un sistema de gestión de la calidad. https://blogbvelearning.wordpress.com/2012/10/08/31-obstaculos-en-laimplantacion-de-un-sistema-de-gestion-de-la-calidad-iso-9001/ Acceso 2 de marzo de 2016.

39. Bernal-Delgado, E. y Ortún-Rubio, C. (2010). La calidad del Sistema Nacional de Salud: Base de su deseabilidad y sostenibilidad. Gac Sanit.2010; 24(3):254-258.

40. Bernal-Delgado, E.; Campillo-Artero, C.; García-Armesto, S., (2014). Oferta sanitaria y crisis: financiamos los bienes y servicios según su valor o caemos en la insolvencia. Informe SESPAS 2014. Gac Sanit. 2014; 28(S1):69-74.

41. Bernard, H. R. (2013). Social Research Methods: Qualitative and quantitative approaches. Thousand Oaks, CA, Sage Publications.

42. Bessant, J. (2005). "Enabling Continuous and Discontinuous Innovation: Learning from the private sector". Public Money \& Management, vol. 25, no.1. pp. 35-42.

43. Berwick, D.; Nolan, T.; Whittington, J. The triple aim: Care, cost, and quality. Health Affairs. 2008; 27:759---69.

44. Blazquez, S. (2016). En la cima de la gestión. Responsabilidad Social Corporativa. El País. http://elpais.com/elpais/2016/12/16/planeta_futuro/1481906509_706884.html

45. Borràs, J. (2016). http://cincodias.com/cincodias/2016/03/05/empresas/1457133983_ 175355.html 
46. Bou-Llusar, J.C. et al. (2008), An empirical assessment of the EFQM Excellence Model: Evaluation as a TQM framework relative to the MBNQA Model, J Operations Manage ,doi:10.1016/j.jom.2008.04.001

47. Boulter, L .et al (2005). Report on EFQM and BQF funded study into the impact of the effective implementation of organizational excellence strategies on key perfomance results. University of Leicester. European Fundation for Quality Management.

48. Brundtland, G. H. (1987). Our Common Future. United Nations.

49. Brunet, I.; Catalin, L. (2016). Las organizaciones. La Sociedad desde la Sociología. ED. Tecnos. Cap. 15, pp415-440.

50. Cabasés, J.M.; Martín, J.J.; López del Amo, M.P. (2003). La eficiencia de las organizaciones hospitalarias. Papeles de Economía, 35: 95-225.

51. Cabrera, A. (2010). Garantizar el futuro del Sistema Nacional de Salud. Rev Adm Sanit. 2010; 8(1):161-3.

52. Calderón, C. (2002). Criterios de calidad en la investigación cualitativa en salud (ics): Apuntes para un debate necesario. Rev Esp Salud Pública 2002, Vol. 76, № 5 pp 473482.

53. Camisón, C. (2006). Gestión de la calidad: Conceptos, enfoques, modelos y sistemas. Pretice Hall.

54. Cantero, J. (2014). A vueltas con el Real Decreto-ley 16/2012 y sus medidas urgentes para garantizar la sostenibilidad del Sistema Nacional de Salud. Gac Sanit. 2014; 28(5):351-353.

55. Carroll, A. B. (1999).Corporate Social Responsibility. Evolution of a Definitional Construct, Business \& Society, volumen 38(3).

56. Castillo López, J.M. y Alonso Arenal, F. (2011). Memoria general de responsabilidad social en la administración general del estado. $3^{\text {a }}$ conferencia estatal de calidad en los servicios públicos. Bilbao 29 y 30 de noviembre de 2011.

57. Castro Beiras, A. et al. (1998). El «Área del Corazón» del Complejo Hospitalario Juan Canalejo. Una nueva forma de gestión clínica. Rev Esp Cardiol. 1998;51:611-9 - Vol. 51 Núm.8

58. CEE-Comisión de las Comunidades Europeas (2001). Libro Verde: fomentar un maco europeo para la responsabilidad social de las empresas. Bruselas.

59. CEG-Club de Excelencia en Gestión (2014). Guía de interpretación para el Sector Sanidad. Modelo EFQM de Excelencia 2013. Club de Excelencia en Gestión. Madrid.

60. CES-Consejo Económico y Social de España (2010). Informe 01/2010 desarrollo autonómico, competitividad y cohesión social en el sistema sanitario. Consejo Económico y Social. Madrid 2010.

61. CLUBEXCELENCIA - Club de Excelencia en Gestión (2014). Infografías. Disponibles en: http://www.agoraceg.org/search/knowledge/?filters=tid\%3A605. Acceso: $26 / 01 / 2015$ 
62. Club de la excelencia en sostenibilidad (2013). Informe Consumo responsable y desarrollo sostenible, año 2016. Disponible en: http://www.clubsostenibilidad.org/f publicaciones/informe\%20consumo\%20responsable\%202013(2).PDF. Acceso: 23/02/2015.

63. Chiavenato, I. (2004). Comportamiento organizacional. International Thomson.

64. Chinoy, E. (1990). INTRODUCCIÓN A LA SOCIOLOGÍA. Paidós, Colección Biblioteca del Hombre Contemporáneo ํํ두 3ª Reimpresión.

65. Cilla, A. (2005). Los Recursos Humanos en el Modelo EFQM de Excelencia. Anuario Jurídico y Económico Escurialense, XXXVIII (2005) 469-500.

66. Cinco Días (2005). La gestión sostenible de los recursos. Manual de la empresa responsable. Cap. 3.

67. CMMAD (1987). Nuestro Futuro Común, Madrid, Alianza Editorial.

68. Comarca Bilbao (2012). Hobekuntza. Una trayectoria de mejora hacia a Excelencia y el buen Gobierno.

69. ComunicaRSEweb (2016) .http://www.comunicarseweb.com.ar/noticia/5-claves-deempresas-lideres-que-lograro... 13/06/2016.

70. Constanza, R. et al. (1998).An Introduction to Ecological Economics, CRC Press, Washington DC.

71. Corcuera, J.M., et al. Unidad para la gestión integrada de la calidad, evaluación y mejora de la eficiencia de la atención sanitaria de La Rioja. Rev Calidad Asistencial 2004; 19(3):200-4.

72. Creswell, J.W. (1998). Qualitative inquiry and research design. Choosing among five traditions. California: Sage Publications Inc.

73. Dale, G.B. y Plunkett, J.J. (1993). Los costos en la calidad. Grupo editorial Iberoamericano. México.

74. Dale, B. G., Boaden, R. J., Wilcox, M., McQuarter, R., (1997). Sustaining total quality management: what are the key issues? The TQM Magazine, vol. 9, no. 2, pp. 372-380.

75. Darpón, J. (2014). Entrevista en Todo Hospital 2014. Enero 2014.Disponible en www. puntex.es. Acceso 25/11/2016.

76. Davies, R. (1998). Methods of standardization, and calculation of rates and confidence intervals. Welsh Health Survey http://wales.gov.uk/docrepos/40382/40382313/statistics/reference/age-standard.

77. Dávila, C.D.y González, B. (2009) GacSanit.2009; 23(4):261-265.

78. Delgado, E. (2015). De la Integración Asistencial a la implantación efectiva de un nuevo modelo asistencial integrado a través de la gestión por procesos y la mejora continua. Revista de Innovación Sanitaria y Atención Integrada. Vol. 7, Núm. 1

79. Denzin, K.D. (1978). The research act. New York: McGraw-Hill Book; 1978.

80. Denzin, N. K. y Linconl, Y. S. (2011). The Handbook of Qualitative Research. (4a edition). London, Sage Publications, Inc. 
81. Denver, G. (1976). An Epidemiological Model for Health Analysis. Soc Ind Res 1976; vol.2, pág.465.

82. DNVGL (2014). Asistencia 2050. Https://www.dnvgl.com/assurance/sustainable-healthcare/healthcare-publicationsresearch-papers.html (acceso 12 sept 2016).

83. Agencia Estatal de Evaluación de las Políticas Públicas y la Calidad de Los Servicios.Documento de Interpretación de la versión 2013 del Modelo EFQM para las Administraciones Públicas. Ministerio de Hacienda y Administraciones Públicas

84. Donabedian, A. (1984).La calidad de la atención médica. Definición y métodos de evaluación. La Prensa Médica Mexicana.

85. Donabedian, A. (1991). Una aproximación a la monitorización de la Calidad Asistencial (primera parte). Control de Calidad Asistencial, 6, 1 (1-6). 1991 Disponible en http://scholar.google.es/scholar_url?url=http://www.calidadasistencial.es/images/gesti on/biblioteca/34.pdf\&hl=es\&sa=X\&scisig=AAGBfm1k8VN9tpbBV9sSPhGVbmA2t4Z3g\&nossl=1\&oi=scholarr\&ved=0ahUKEwiwjNiPMXPAhWFUhQKHccyASgQgAMIHigAMAA

86. Donaldson, T. y Preston, L.E. (1995). The Stakeholder Theory of the Corporation: Concepts, Evidence, and Implications. The Academy of Management Review, Vol. 20, No. 1 (Jan., 1995), pp. 65-91.

87. Doppelt, B. (2003). Leading change toward sustainability. A change management guide for Business, Government and Civil Society. Sheffield: Greenleaf Publishing Limited.

88. Doppelt, B. (2012). The Power of Sustainable Thinking. Earthscan. Londres.

89. Durán, M.A. (2016). Salud, sanidad y dependencia. La Sociedad desde la Sociología. ED. Tecnos. Cap. 21, pp607-629.

90. EFQM (2013). Introducción al Modelo EFQM de Excelencia. Accesible en: https://www.clubexcelencia.org/sites/default/files/modelo_efqm_2013.pdf

91. EFQM (2015). Marco EFQM para la Sostenibilidad. Disponible: http://www.efqm.org/efqm-framework-for-sustainability. Acceso: 07/08/2015.

92. ELECONOMISTA.ES 5/08/2015: La prensa internacional opina sobre la 'recuperación' económica de España.

93. Elkington, J. (1994).Towards the sustainable corporation: Win-win-win Business Strategies for sustainable development. California Management Review, vol 36 (2.)

94. Eisenhardt, K. y Graebner, M., (2007). Theory building from cases: opportunities and challenges. Academy of Management Journal 2007, Vol. 50, No. 1, 25-32.

95. Echániz, J.I. (2014). El impacto de la crisis en el SNS. ¿Qué estamos aprendiendo? XII Jornadas de Gestión y Evaluación de Costes Sanitarios. Fundación Signo. Huesca 2014. Disponible en: http://www.fundacionsigno.com/archivos/20160118181559.pdf (acceso 6/10/2016).

96. Escobar, M. y Mena, L. (2016). Cuestiones de metodología en el análisis de los problemas sociales. Cap 4 pp67-82 en Trincada. y Sánchez, M. Marcos de análisis de problemas sociales. Una mirada desde la sociología. Ed. Catarata. 2016. 
97. Euskalit. (2014). Modelo de gestión avanzada 2015. Disponible en http://www.euskalit.net/archivos/201602/modelo20152.pdf?0

98. FADESP. Federación de Asociaciones para la Defensa de la Sanidad Pública (2011). La sostenibilidad del sistema sanitario público. 12 propuestas para garantizarla. Disponible en www.nodo50.org/fadsp/pdf/12propSostenibilidadSNS.doc

99. Fernández, J.L. y Bajo, A. (2012). La teoría del stakeholder o de los grupos de interés, pieza clave de la RSE, del éxito empresarial y de la sostenibilidad. Revista Internacional de Investigación en Comunicación aDResearch ESIC. № 6 Vol 6. Segundo semestre, julio-diciembre 2012. Págs. 130 a 143.

100. Fernández Buey, F. (2004).filosofía de la sostenibilidad. Ética y Filosofía Política Septiembre de 2004. Universidad Pompeu_Fabra. http://www.upf.edu/materials/polietica/_pdf/sosfilosofiasostenibilidad.pdf. Acceso $18 / 08 / 2015$.

101. Ferrándiz-Santos, J. et al. (2010). Utilización de los ejes transversales del modelo EFQM en el ámbito sanitario público. Revista de Calidad Asistencial. Vol. 25. Núm. 3. Mayo - Junio 2010.

102. Fideli, R. (1998) La comparazione. Milán. Agneli.

103. Fortuny, B. (2009). La gestión de la excelencia en los centros sanitarios. PFIZER. Madrid 2009.

104. Forum for the Future (2006). http://www.forumforthefuture.org.uk/. Acceso: 10/11/2016.

105. Francés, F. (2015). Técnicas de Investigación Social. Departamento de Sociología II. Universidad de Alicante http://personal.ua.es/es/franciscofrances/materiales/tema4/la_entrevista_en_profundidad.html Acceso 9 de septiembre de2015

106. Freeman, E. (1984). Strategic Management: A Stakeholder Approach, (Pitman, Boston).

107. García-BernaL, J.; Gargallo-Castel, A.; Pastor-Agustin, G.; Ramirez-Alesón, M. (2004): "Total Quality Management in Firms: Evidence from Spain". Quality Management Journal, vol. 11, issue 3 .

108. García, E.I. et al (2014). Indicadores de eficiencia para contribuir a la sostenibilidad de los servicios de salud en España. Revista de Calidad Asistencial 2014; 29(5):287-290.

109. García-Marzá, D. (2006), La responsabilidad social de la empresa: Una definición desde la ética empresarial, Universitat Jaume I.

110. Gil, V.; Barrubés, J.; Álvarez, J.A.; Portella, E. (2010). Sostenibilidad financiera del sistema sanitario. 10 medidas estructurales para afrontar las causas del crecimiento del gasto. Barcelona: Antares Consulting; 2010.

111. Gil Lafuente, A.M.y Paula, L.B. (2011). La gestión de los grupos de interés: una reflexión sobre los desafíos a los que se enfrentan las empresas en la búsqueda de la sostenibilidad empresarial. Revista de métodos cuantitativos para la economía y la empresa .Junio de 2011.pp 71-90. 
112. Gobierno de La Rioja. Logroño. (acceso 08/03/2016). Disponible en:http://www.larioja.org/

113. González, B. (2016). Eficiencia y sostenibilidad en la gestión clínica. Conferencia Plenaria. XXXIV congreso nacional de la sociedad de calidad asistencial. Córdoba 2016.

114. González-Lombide, E.; Fernández-Martína, J.; Santos-Gómez, A.; Retes Saratxaga, R. (2009). Desayuno con expertos: calidad e innovación. Rev Calid Asist. 2009; 24(4):171176.

115. González, O. (2008): "Sistemas de información de Andalucía". Documento de trabajo. Escuela Andaluza de Salud Pública. Granada.

116. GRI- Global Reporting Initiative (2011). Guía para la elaboración de Memorias de Sostenibilidad. Disponible en: https://www.globaLa Riojaeporting.org/resourcelibrary/Spanish-G3.1-Complete.pdf

117. Gutiérrez, R. y Peñalver, R. (2009). El futuro de la Calidad Asistencial. Manual de Calidad Asistencial. SESCAM. Servicio de Salud de Castilla-La Mancha.

118. Gutiérrez-Sequera, J.L. y Serrano-Ortega, N. (2014). Los cuidados y la sostenibilidad del sistema sanitario público. Enferm Clin. 2014; 24(6):311---314.

119. Hall, D. (2010). "Why we need public spending", Reports, PSIRU, University of Greenwich, Londres. Disponible en: http://www.psiru.org/reports/2010-10-QPSpubspend.pdf. Acceso: 31/10/2016.

120. Hanley, N.; Moffatt, I.; Faichney, R; Wilson, M. (1999) Measuring sustainability: A time series of alternative indicators for Scotland, Ecological Economics, 28 (1), pp. 55-73.

121. Hart, S.L. y Milstein, M. (2003). Creating Sustainable Value. Academy of Management Executive, 2003, vol.17 núm. 2.

122. Haseltine, W. (2016). "El sitio más peligroso de este planeta es un hospital". Entrevista en El País. http://elpais.com/elpais/2016/12/21/ciencia/1482320930_489052.html

123. Hendricks, K.B. y Singhal, V.R. (1997). Does implementing an effective TQM program actually improve operating perform Management Science; Sep 1997; 43, 9; ABI/INFORM Global.

124. Hollings, C. S. (1973). Resilience and Stability of Ecological Systems. Annual Review of Ecology and Systematics, 4, 1-23.

125. Hollings, C. S. (1987). Simplifying the Complex: The Paradigms of Ecological Function and Structure. European Journal of Operational Research, 30, 139-146.

126. Houston, D. y Katavic, M. (2006). "Quality in a New Zealand Local Authority: A case study". Total Quality Management and Business Excellence, vol. 17, no.4, pp. 425-438.

127. HUB-Hospital Universitario de Basurto (2009). Borrador avanzado de memoria EFQM.

128. Huberman, M. y. Miles, M.B. (1994), Métodos para el manejo y análisis de datos, en Norman Denzin \& Yvonnas Lincoln (eds.), Handbook of Qualitative Research, Sage Publications. Citado en Documento de Cátedra 꾸1. Sautu R. Metodología III. Facultad de Ciencias Sociales. Universidad de Buenos Aires. 
129. Huckle, J. y Sterling, S.R. (1996). Education for Sustainability. Earthscan, Business \& Economics.

130. IASIST (2016). Programa Hospitales TOP 20. Disponible en: http://www.iasist.com.es/es/1524/TOP-20-Que-es Acceso: 20/05/2016.

131. Ignacio, E. (2007). Validación de un modelo para medir la calidad asistencial en los hospitales. Tesis doctoral. Universidad de Cádiz.

132. INSALUD (1999). Plan de calidad total del Insalud. Disponible en: http://www.ingesa.msssi.gob.es/estadEstudios/documPublica/pdf/calidadTotal.pdf. Acceso (23/04/2015).

133. Jiménez, L.M. (2002). La sostenibilidad como proceso de equilibrio dinámico y adaptación al cambio. ICE-Desarrollo Sostenible. Junio-julio 2002 numero 800. 65-84.

134. Jones, R. (2000). "Managing the green spaces: problems of maintaining quality in a local government service department". Managing Service Quality, vol. 10, no.1, pp. 1931.

135. Juran, J.M. (1990). Juran y la planificación para la calidad. Ediciones Díaz de Santos.

136. Juran, J.M. y Gryna, F.M. (1988). Juran's quality control handbook. McGraw-Hill.1988.

137. Juvinya-Cana, D. (2013). Salutogénesis, nuevas perspectivas para promover la salud. Enferm Clin 2013; 23:87-8.

138. Kawulich, B.B. (2005). La observación participante como método de recolección de datos. Forum: qualitative social research. Volumen 6, No. 2, Art. 43. Mayo 2005.

139. Khön, J. y Gowdy, J. (2001). Sustainability as a Management Concept en Jiménez L.M. (2002). La sostenibilidad como proceso de equilibrio dinámico y adaptación al cambio. ICE-Desarrollo Sostenible. Junio-julio 2002 número 800. 65-84.

140. Kim, H.J.; Fay, M.P; Feuer, E.J; Midthune, D.N. (2000). Pruebas de permutación para regresión de punto de unión con aplicaciones a tasas de cáncer. Statistics in Medicine 2000; 19: 335 - 351: (corrección: 2001; 20: 655).

141. Kornblit, A .L. (2007) Metodología cualitativa: modelos y procedimientos de análisis. Buenos Aires. Biblos.

142. Kotter, J. P. (1996). Leading change. Cambridge, Mass: Harvard Business School Press.

143. Krick, T.; Forstater, M.; Monaghan, P.; Sillanpää, M.; Van der Lugt, C.; Partridge, K.; Jackson, C. y Zohar, A. (2005) From words to action. The Stakeholder engagement Manual. Vol. 2: The practitioner's handbook on stakeholder engagement. London. Accountability, United Nations Environment Programme, Stakeholder Research Associates Canada Inc.

144. Ladrón de Guevara, J.M. (2003). El trayecto seguido por Osakidetza / Servicio Vasco de Salud en el camino de la excelencia. Ponencia Foro de RRHH 16 de septiembre de 2003.La Comunicación Interna y el Modelo EFQM de Excelencia.

145. Lalonde, M. (1974). Social values and public health. Can J Public Health.1974; 65:2608. 
146. La Vanguardia (2016). Acceso: 16 enero 2017. Disponible en: http://www.lavanguardia.com/vida/20160120/301546331443.

147. Legido-Quigley, H. (2006). La calidad asistencial en la Unión Europea. MSSSIMinisterio de Sanidad, Servicios Sociales e Igualdad (2005). Disponible en: http://www.msc.es/organizacion/sns/informeAnualSNS/docs/general2005/Cap3Calida dAsistencialEuropa.pdf (Acceso 10/08/2015).

148. Leonard-Barton, D. (1990). "A dual methodology for case studies: Synergistic use of a longitudinal single site with replicated multiple sites". Organization Science, vol. 1, no. 3, pp. 248-266.

149. Lijphart, A. (1971) Comparative Politics and Comparative Method. The American Political Science Review, vol. 65, no3 pp. 682-693.

150. Lincoln, Y. S. y Guba, E. (1985). Naturalistic Inquiry. Beverly Hills, CA, Sage Publications Inc.

151. Lledó, R. (2005) Derechos de los pacientes y calidad asistencial. Revista de Calidad Asistencial. Sociedad Española de Calidad Asistencial Vol20, №6 pp318-326.

152. Loomba, A. y Spencer, M. (1997). "A model for institutionalizing TQM in a state government agency." International Journal of Quality \& Reliability Management 14(8).

153. Lorenzo, S. (2000). Evidencias de aplicación del Modelo EFQM de Excelencia al sector sanitario en nuestro medio. Rev Calidad Asistencial 200; 15:129-130.

154. Losada, C. (2007). "Aportaciones al enfoque del liderazgo en la Administración Pública”. En Díaz-Méndez, A., y Cuellar-Martín, E. (eds.), Administración Inteligente, Madrid, Agencia de Evaluación y Calidad, MAP y Ayuntamiento de Alcobendas, pp. 99118.

155. Lucena, J.J. y Ling, D. (2010). Análisis multi-stakeholders como estrategia de responsabilidad social corporativa en el contexto sanitario. Ética y Responsabilidad ante la crisis. Ediciones S.C. pág.501-524.

156. Marshall, C. y Rossman, G. B. (1989). Designing qualitative research. Newbury Park, CA: Sage.

157. Martín-Castilla, J.I. (2002). El modelo EFQM de excelencia: Marco óptimo para la gestión ética. Disponible en: http://www.eticaed.org/Mart\%EDn.pdf. Acceso: 20/01/2015.

158. Martín-Castilla, J.I. (2007). La consideración de aspectos sostenibles en los enfoques de excelencia. Boletín económico de ICE № 2909; 57-66.

159. Martínez Salcedo, F. (2009). Sostenibilidad medioambiental y empresa. Revista Ambienta. Revista oㅜ 88, 01-09-2009.

160. Marx, M.H. y Hillix, W.A. (1980) Sistemas y teorías psicológicos Contemporáneos. Buenos Aires: Paidós.

161. Mateo, J.P. (2011). Lo que hay que hacer. Una hoja de ruta de política económica para salir de la crisis. Sociedad y Utopía. Revista de Ciencias Sociales, no 38. Diciembre de 2011 (pp. 221-242). 
162. Matthies-Baraibar, C. et al (2014). Is organizational progress in the EFQM model related to employee satisfaction? BMC Health Services Research 2014, 14:468 http://www.biomedcentral.com/1472-6963/14/468.

163. Matthies-Baraibar, C. el al (2016). Impacto de la implantación de Efqm en Osakidetza. Osteba. Disponible en: www.euskadi.eus/publicaciones. Acceso: 25/10/2016.

164. McAdam, R.; Reid, R.; Saulters, R. (2002). "Sustaining quality in the UK public sector. Quality measurement frameworks". The international Journal of Quality \& Reliability Management, vol. 19, no. 5, pp. 581-595.

165. McDonough, W. y Braungart, M. (2005): Cradle to Cradle (de la cuna a la cuna): rediseñando la forma en que hacemos las cosas. Madrid: McGraw Hill.

166. Merriam, S. B. (1998). Qualitative research and case study applications in education. San Francisco: Jossey-Bass, 1998.

167. Huberman, M. y Miles, M.B. (1994), "Métodos para el manejo y análisis de datos", en Norman Denzin \& Yvonnas Lincoln (eds.), Handbook of Qualitative Research, Sage Publications.

168. Mompart, M. y Duran, M. (2001). Sistemas sanitarios: conceptos y tipos. En: Administración y gestión. Ediciones DAE. Madrid.

169. Moore, M. H. (2005). "Break-Through Innovations and Continuous Improvement: Two different models of innovative processes in the public sector". Public Money \& Management, vol.25, no. 1.

170. Moreno, A. (2015). Sanidad, tesoro terrenal. Editorial UOC. Barcelona.

171. Morse, J. M. y Richards, L., (2002). Read me first: for users guide for qualitative methods. Thousand Oaks, CA, Sage Publications.

172. MSSSI Ministerio de Sanidad, Servicios Sociales e Igualdad (2009) Estándares de calidad de cuidados para la seguridad del paciente en los hospitales del SNS. Proyecto SENECA: informe técnico 2008. Madrid Disponible en: http://www. msc.es/organizacion/sns/planCalidadSNS/docs/SENECA.pdf. Consultado 4/10/ 2015.

173. MSSSI-Ministerio de Sanidad, Servicios Sociales e Igualdad (2014). Relación de Centros, Servicios y Unidades de Referencia (CSUR) del Sistema Nacional de Salud. https://www.msssi.gob.es/profesionales/CentrosDeReferencia/docs/09mayo2016lista CSUR.pdf. Consultado 14/02/2017.

174. MSSSI- Ministerio de Sanidad, Servicios Sociales e Igualdad (2016). INDICADORES CLAVE del SISTEMA NACIONAL DE SALUD (INCLASNS. Versión 2). Disponible en http://inclasns.msssi.es/main.html

175. MSSSI- Ministerio de Sanidad, Servicios Sociales e Igualdad (2017). ESTADÍSTICA DE GASTO SANITARIO PÚBLICO 2015: Principales resultados. Edición mayo 2017. Disponible en: https://www.msssi.gob.es/estadEstudios/estadisticas/docs/EGSP2008/egspPrincipale sResultados.pdf. Consultado: 20/08/2017. 
176. Murcia, N. y Jaramillo, L. 2001. La complementariedad como posibilidad en la estructuración de diseños de investigación cualitativa. Cinta moebio 12: 194-204. www.moebio.uchile.cl/12/murcia.htm

177. Narbate, C. (2007). Autoevaluación con el modelo EFQM. http://aularagon.catedu.es/materialesaularagon2013/TratamientoDeLenguas/Modulo_ 5/autoevaluacion_efqm_valenciacontiks.pdf. Acceso: 20/07/2015.

178. Naredo, J. M. (1997). Sobre el origen, el uso y el contenido del término sostenible. Disponible en: http://habitat.aq.upm.es/cs/p2/a004.html. Acceso: 25/03/2015.

179. Nebot-Marzal, C.M. et al (2013). Conjunto de indicadores de calidad y seguridad para hospitales de la Agencia Valenciana de Salud. Revista de Calidad Asistencial. Vol. 29. Núm. 1. Enero - Febrero 2014.

180. Net, A. y Suñol, R. (2003). La calidad de la Atención Sanitaria. http://docplayer.es/5393710-Ponencies-i-jornades-rosa-sunol-i-alvar-net-la-calidad-dela-atencion-alvar-net-presidente-de-la-fundacion-avedis-donabedian.html (acceso 12 agosto 2016).

181. NIELSEN Company (2015). The Nielsen Global Survey of Corporate Social Responsibility and Sustainability 2015. Disponible en: http://www.nielsen.com/content/dam/nielsenglobal/co/docs/Reports/2015/globalsustainability-report.pdf. Acceso: 01/11/2016.

182. Nieves, C. y Ros, L. (2006). Comparación entre los Modelos de Gestión de Calidad Total: EFQM, Gerencial de Deming, Iberoamericano para la Excelencia y Malcon Baldrige. Situación frente a la ISO 9000. X Congreso de Ingeniería de Organización. Valencia, 7 y 8 de septiembre de 2006.

183. Nomen, E. y Nieto, J. (2004) El conocimiento protegido. Harv Deusto Bus Rev. 2004; 124:53-62.

184. Norgaard, R. B. (1988). Sustainable Development: A Coevolutionary View. Futures, diciembre en Jiménez L.M. (2002). La sostenibilidad como proceso de equilibrio dinámico y adaptación al cambio. ICE-Desarrollo Sostenible. Junio-julio 2002 número 800. 65-84.

185. Observatorio RSC (2014). Las políticas públicas en torno a la Responsabilidad Social Corporativa. Observatorio de RSC. http://observatoriorsc.org/wpcontent/uploads/2014/08/Ebook_Politicas_Publicas_modificado-06.06.14_OK.pdf. Acceso: 20/9/2016.

186. OCDE (2013), Health at a Glance 2013: OECD Indicators, OECD Publishing. http://dx.doi.org/10.1787/health_glance-2013-en

187. Olcese, A. (2008), Manual de la Empresa Responsable y Sostenible, McGraw-Hill, Madrid.

188. Oliván, R. (2014) El impacto de la crisis en el SNS. ¿Qué estamos aprendiendo? XII Jornadas de Gestión y Evaluación de Costes Sanitarios. Fundación Signo. Huesca 2014.Disponible en: http://www.fundacionsigno.com/archivos/20160118181559.pdf (acceso 6/10/2016).

189. Oliver, R. (2016). A trabajar pero sin jefes. Diario El País. (14 de febrero de 2016). Consultado el 4 de Noviembre de 2016. 
190. OMS (2011). Declaración política de Río sobre determinantes sociales de la salud. Río de Janeiro (Brasil), 21 de octubre de 2011.

191. ONU-Commission on Sustainable Development (2001). Indicators of Sustainable Development: Framework and Methodologies. Disponible en: http://www.un.org/esa/sustdev/csd/csd9_indi_bp3.pdf. Acceso: 25/07/2016

192. Ortí, A. (1995). La confrontación de modelos y niveles epistemológicos en la génesis e historia de la investigación social. En: Delgado JM, Gutiérrez J. Métodos y técnicas cualitativas de investigación en ciencias sociales. Madrid: Síntesis; 1995. pp. 85-95.

193. Ortí, A. (1999). La confrontación de modelos y niveles epistemológicos en la génesis e historia de la investigación social. En Métodos y técnicas cualitativas de investigación en ciencias sociales. Edited by J. M. Delgado and J. Gutiérrez. Madrid: Síntesis SA.

194. Osakidetza (2014). Acerca del sistema sanitario público vasco. http://www.osakidetza.euskadi.eus/r85-

skacer01/es/contenidos/informacion/acerca_sistema_sanitario/es_sanidad/acerca_sis tema_sanitario.html. Acceso: 06/08/2015

195. OSIBB-Organización Sanitaria Integrada Bilbao Basurto (2015). Política de Gestión. Disponible en http://www.osakidetza.euskadi.eus/r85gkobib01/es/contenidos/informacion/obiba_estrategia_gestion/es_def/index.shtml. Acceso: 28/08/2017.

196. Oteo Ochoa, L.A. (2010). La sostenibilidad del Sistema Nacional de Salud: los profesionales sanitarios y la ciudadanía. ¿Hemos agotado nuestro Sistema Nacional de Salud? Contextualización y determinantes del cambio y la innovación. Rev Adm Sanit. 2010; 8(1):5-32.

197. Oteo Ochoa, L.A; Pérez Torrijos, G; Silva Sánchez D. (2002). Cuadro de mandos integral a nivel hospitalario basado en indicadores del modelo EFQM de excelencia. Gestión Hospitalaria 2002; 13(1):9-25.

198. Pardo, A. (2015). Despliegue del Modelo EFQM en el Servicio Madrileño de Salud. Jornada 20 aniversario EMCA. Disponible en: https://sms.carm.es/somosmas/documents/. Acceso: 15/01/2016.

199. Parra, P. ; Calle, J.E. ; Ramón, T. ; Meneu, R. (2011). Indicadores de calidad para el Sistema Nacional de Salud. Sociedad Española de Calidad Asistencial. Disponible en:http://www.calidadasistencial.es/images/gestion/biblioteca/335.pdf. Consultado 10/12/ 2015.

200. Paternoster, A. (2011). Herramientas para medir la sostenibilidad corporativa. Cátedra de sostenibilidad UNESCO. Universidad Politécnica de Catalunya.

201. Patton, M. Q. (2002). Qualitative Research and Evaluation Methods (3a edition). Thousand Oaks, Sage Publications Inc.

202. Pedroza, A. (2013). Sostenibilidad y responsabilidad social. http://www.eoi.es/blogs/mtelcon/2013/04/17/sostenibilidad-y-responsabilidad-social/. Acceso: 20/09/2016.

203. Peiró, S. y Casas, M. (2002): Análisis comparado de la actividad y resultados de los hospitales. Situación en España y perspectivas", en Cabases, J.M; Villalba, J.R y Aibar, Invertir para la Salud. Prioridades en salud pública. Informe SESPAS. 
204. Peiró, S. (2006): Algunas reflexiones sobre la organización de la información sanitaria en el Sistema Nacional de Salud. Revista de Administración Sanitaria 4 (I): 81-94.

205. Perdomo, J. y González, J. (2004). Medición de la Gestión de la Calidad Total: Una revisión de la literatura. Cuad. Adm. Bogotá (Colombia), 17 (28): 91-109, julio-diciembre de 2004.

206. Pettigrew, A. M. (1990). "Longitudinal Field Research: Theory and Practice". Organization Science, vol. 1, no. 3, pp. 267-292.

207. Phillips, R. (2004). Some key questions about stakeholder theory. Ivey Business journal Marzo/abril de 2004.

208. Pita Fernández, S.; Pértegas Díaz, S., (2002).Unidad de Epidemiología Clínica y Bioestadística. Complexo Hospitalario- Universitario Juan Canalejo. A Coruña (España) Cad Aten Primaria 2002; 9:76-78.

209. Pollit, C. (2006). Ten ways to make quality improvement unsustainable. En EU2006.fi (eds.), 4th Quality Conference for Public Administration, 27-29 de septiembre de 2006. Tampere, Finland, pp. 95-106.

210. Portales, L.; García de la Torre, C; Camacho, G.y Arandia O. (2009). Modelo de sustentabilidad empresarial penta-dimensional: aproximación teórica. Administración y Organizaciones No. 23; Año 12, diciembre 2009 Págs. 113-129.

211. Post, J.E.; Preston, L.E.; Sachs, S. (2002). Redefining the Corporation Stakeholder Management and Organizational Wealth. Stanford University Press.

212. Prajogo, D., y Sohal, A., (2004). "The sustainability and evolution of quality improvement Programmes- an Australian case study". Total Quality Management, vol. 15, no. 2, pp.205-220.

213. PricewaterhouseCoopers (2006). The quality conundrum: Practical approaches for enhancing patient care. Health Research Institute 2006 PricewaterhouseCoopers.

214. Rayén Quiroga, M. (2001). Indicadores de sostenibilidad ambiental y desarrollo sostenible: Estado del arte y perspectivas. ONU-CEPAL, Santiago de Chile.

215. Reguera, M.C. (2010). Algunas consideraciones sobre el diálogo social en el Sistema Nacional de Salud. Rev Adm Sanit. 2010; 8(1):101-111.

216. Repullo, J.R. (2012).Taxonomía práctica de la «desinversión sanitaria» en lo que no añade valor, para hacer sostenible el Sistema Nacional de Salud. Rev Calid Asist. 2012; 27(3):130---138.

217. Riojasalud (2014). Estrategia de atención al paciente crónico de La Rioja. Documento General. Disponible en: http://www.riojasalud.es/f/rs/docs/estrategia-cronicos.pdf. Consultado el 17/03/2017.

218. Ritchie, J. et al (2013). Qualitative Research Practice. London England, Sage Publications.

219. Rivera, F. (2014). Calidad de los Cuidados. Tema 1.Introduccion a la Calidad Escuela Universitaria de Enfermería. Universidad de La Rioja. 
220. Rivera, F.; López de Dicastillo, R.; Martínez, M.J. (2016). El Modelo EFQM como herramienta para la sostenibilidad del Servicio de Alimentación de un hospital público. (Sostenibilidad en tiempos de crisis). Gest y Eval Cost Sanit 2016; 17(3):313-25.

221. Rivera, F. et al (2017). Informe de Autoevaluación EFQM 2017. Hospital San Pedro de La Rioja.

222. Robbins, S. (1999). Comportamiento organizacional. 8va. ed. México DF: Prentice Hall; p.601.

223. Robertson, R., y Ball, R., (2002). Innovation and Improvement in the delivery of Public Services: The use of quality management within local government in Canada. Public Organization Review, no. 2, pp. 387-405.

224. Rubia, F.J. et al (2011). Libro blanco sobre el sistema sanitario español. Academia Europea de Ciencias y Artes. Madrid 2011.

225. Russo, M. y Fouts, P. (1997). Resource-Based Perspective on Corporate Environmental Performance and Profitability. Academy of Management Journal, 40 (3), p.534-559.

226. Sanabria, N.; \& Acosta-Prado, J.; \& Rodríguez Albor, G. (2015). Condiciones para la innovación, cultura organizacional y sostenibilidad de las organizaciones. Semestre Económico, 18 (37), 157-175.

227. Sandín, M.P. (2000). Criterios de validez de la investigación cualitativa. Revista de Investigación Educativa, vol.18, ํ1, págs...223-242.

228. Sánchez, M. et al. (2013). Sostenibilidad de la sanidad pública en España: hay alternativas a la privatización sanitaria. Fundación $1^{\circ}$ de Mayo. CCOO. Colección Estudios, Núm. 67. Madrid, Julio 2013.

229. Sánchez, N. (2012). La sostenibilidad en el sector empresarial. Importancia de los distintos grupos de interés en el proceso de cambio. Universidad Politécnica de Catalunya. Disponible en: http://upcommons.upc.edu/handle/2099.1/18820. Acceso: 15/09/2015.

230. Sandoval, C. (1996). La formulación y el diseño de los procesos de investigación social cualitativos. Investigación Cualitativa. Instituto Colombiano para el Fomento de la Educación Superior; pp. 111-128. Bogotá 1996.

231. Sangüesa, M. (2003). Manual de Gestión de la Calidad. Cátedra de Calidad Volkswagen Navarra. Universidad de Navarra.

232. Sartori, G. (2002) La política, lógica y método de las ciencias sociales. México. Fondo de Cultura Económico.

233. Savitz, A.W. (2013). The Triple Bottom Line: How today's Best-Run Companies are Achieving Economic, Social and Environmental Success - and How You Can Too. Jossey-Bass. San Francisco. CA.

234. Senior, B.; Fleming, J. (2006). Organizational Change, Third Edition. Essex: Prentice Hall.

235. Senge, P. (2008). The necessary Revolution. Londres: Nicholas Brealey Publishing. 
236. Sermeus, W. (2012). Efectos de la crisis económica y de la crisis de trabajadores sanitarios en la sostenibilidad del sistema sanitario: ¿qué es lo siguiente? Enferm Clin. 2012; 22(4):179---181.

237. Serrano, A. (1998): La Agenda 21 de Gijón. Primer Borrador. Mimeo. Citado por Sosa, A. (2003). La participación pública en el camino hacia la sostenibilidad y en las políticas y programas de desarrollo. Revista Utopía y Sociedad no 21 Mayo 2003, pp209-225.

238. Servicio Riojano de Salud. Logroño. (Acceso: 12/01/2016). Disponible en: http://www.riojasalud.es

239. Sevillano, E. (2016). La sostenibilidad del sistema sanitario público, un debate aparcado. EL PAís 24/6/2016. Disponible en: http://politica.elpais.com/politica/2016/06/22/actualidad/1466618237_570934.html 4/7 (acceso: 24/06/2016).

240. Schein, E. (1988). La cultura empresarial y el liderazgo. Una visión dinámica. Plaza \& Janes Editores. $P$.

241. Schneider, B.; Brief, A.; Guzzo, R. (1996). Creating climate and culture for sustainable organizational change. Organizational Dynamics, vol. 24, no. 4, pp. 7-19.

242. Schutz, A. (2003). "El sentido común y la interpretación científica de la acción humana". En el problema de la realidad social. Escritos 1. Buenos Aires, Argentina, Amorrortu.

243. Scott, W.R. (1992). Organizations: Rational, natural and open systems, $3^{\text {a }}$ ed.Prentice Hall, Homewood. Citado por Brunet, I. y Catalin, L. (2016). Las organizaciones. La Sociedad desde la Sociología. ED. Tecnos. Cap. 15, pp415-440.

244. Schein, E.H. (2004). Organizational Culture and Leadership. San Francisco: John Wiley \& Sons.

245. Siggelkow, N. (2007). "Persuasion with case studies". Academy of Management Journal, vol.50, no. 1, pp. 20-24.

246. SIGNO (2014). El impacto de la crisis en el SNS. ¿Qué estamos aprendiendo? XII Jornadas de Gestión y Evaluación de Costes Sanitarios. Fundación Signo. Huesca 2014. Disponible en: http://www.fundacionsigno.com/archivos/20160118181559.pdf (acceso 6/10/2016).

247. Silverman, D. (2000). Doing qualitative research: A practical Handbook. London, Sage Publications Inc.

248. Sloan, K.; Klingenberg, B.; Rider, C. (2013) Towards Sustainability: Examining the Drivers and Change Process within SMEs. Journal of Management and Sustainability; Vol. 3, No. 2; 2013.

249. Sosa, A. (2003). La participación pública en el camino hacia la sostenibilidad y en las políticas y programas de desarrollo. Revista Utopía y Sociedad № 21 Mayo 2003, pp209-225.

250. Suárez, M.F. (2007). La sostenibilidad de la mejora continua de procesos en la administración pública: un estudio en los ayuntamientos. Tesis Doctoral. Disponible en: http://www.tesisenred.net/bitstream/handle/10803/9178/Sostenibilidad-MFSB-TesisPhD-vf.pdf?sequence=2 
251. Tonón, G. (2011). La utilización del método comparativo en estudios cualitativos en ciencia política y ciencias sociales: Diseño y desarrollo de una tesis doctoral. Kairos. Revista de Temas Sociales. Universidad Nacional de San Luís. Año 15 no22.

252. Turban, D.; Greening, D. (1997). Corporate Social Performance and Organitational Attractiveness to Prospective Employees. Academy Of management Journal, 40 (3), p.658-672.

253. Uriarte Ruiz de Eguino, K. (2011). ECOEUSKADI 2020, estrategia de desarrollo sostenible para la comunidad autónoma del País Vasco. 3a conferencia estatal de calidad en los servicios públicos. Bilbao 29 y 30 de noviembre de 2011.

254. Valles, M.S. (1999). Técnicas cualitativas de investigación social. Reflexión metodológica y práctica profesional. ED. Síntesis. Madrid

255. Valles, M.S. (2014). Entrevistas cualitativas (Vol. 32). CIS-Centro de Investigaciones Sociológicas.

256. Vernaz, N.; Haller, G.; Girardin, F.; Huttner, B.; Combescure, C. et al. (2013) Patented Drug Extension Strategies on Healthcare Spending: A Cost-Evaluation Analysis. PLoS Med 10(6): e1001460. doi:10.1371/journal.pmed.1001460

257. Vidal E. y Soto E. (2012). Principios de la RSC en los modelos de excelencia. Book of Proceedings - Tourism and Management Studies International Conference Algarve 2012 vol.4. University of the Algarve, Portugal.

258. Villasante, T. (1994). De los movimientos sociales a las metodologías participativas. Métodos y técnicas cualitativas de investigación en ciencias sociales. Madrid: Síntesis, 399-422.

259. Vonk, J. (2005). "Process Improvement in Business Permits through Kaizen". Innovations Management, no. Spring, pp. 33-34.

260. Wagner, C. et al (2014). The associations between organizational culture, organizational structure and quality management in European hospitals. International Journal for Quality in Health Care 2014; Volume 26, Number S1: pp. 74-80.

261. WCED- World Commission on Environment and Development (1987). Our Common Future. Oxford: Oxford University Press, 1987, p.43.

262. WWF (1991). Caring for the Earth. A Strategy for Sustainable Living. Gland, Switzerland.

263. Yacuzzi, E. (2005): El estudio de caso como metodología de investigación: Teoría, mecanismos causales, validación, Serie Documentos de Trabajo, Universidad del CEMA: Área: negocios, No. 296. Disponible en: http://hdl.handle.net/10419/84390

264. Yin, R. (2009). Case Study Research, Design and Methods-4th edition. Thousands Oaks, California Estados Unidos, Sage Publications.

265. Zairi, M. (2005). TQM Sustainability: How to maintain its gains through Transformational Change. En ASQ World Conference on Quality and Improvement Proceedings, ABI/Inform Global, pp. 1-35. 
266. Zardoya Alegría, A. I.; Guevara Grateron, I. R.; Marzo Navarro, M.; García Bernal, J. (2004). Gestión de la calidad de los servicios sanitarios: caso de autoevaluación según el EFQM. Revista Iberoamericana de Contabilidad de Gestión, 4, 3-40.

267. Zardoya, A.I.; Guevara, I.R.; García, J.; Marzo, M. (2007). El modelo EFQM en el Sector, Salud. Cuadernos de CC.EE. y EE. n52, 2007, pp103-125. 


\section{TABLAS E ILUSTRACIONES}

\section{Tablas}

Tabla 1. Riesgo de pobreza o exclusión social (indicador AROPE) …...................................... 12

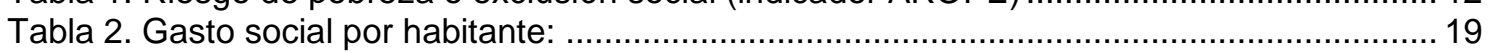

Tabla 3. Gasto sanitario total, público y privado. Millones de euros. España, 2010-2014 .........20

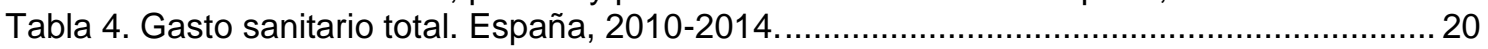

Tabla 5. Sustitución de gasto público por privado. ............................................................ 20

Tabla 6. Gasto en medicamentos en 2015 en el SNS España (miles de millones euros) .......... 22

Tabla 7. Porcentaje de ciudadanos para quienes la sanidad es el área de mayor interés .........30

Tabla 8. Acontecimientos internacionales relacionados con la sostenibilidad. .......................... 32

Tabla 9 Grupos de interés del Servicio de Alimentación del Hospital San Pedro de Logroño... 45

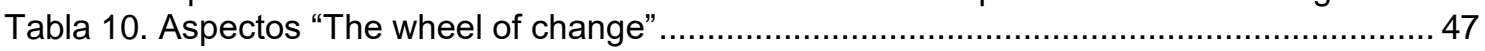

Tabla 11. Normas y Estándares relacionados con la sostenibilidad........................................ 51

Tabla 12. Estructura de los modelos de sostenibilidad. AEVAL ............................................ 71

Tabla 13. Ventajas del modelo EFQM de Excelencia, aplicado en el sector sanitario ................ 77

Tabla 14. Resumen de la evolución histórica de la calidad ...................................................... 79

Tabla 15.Conceptos que fundamentan el modelo. (Aragón, 2001) …...................................... 87

Tabla 16. Evolución del concepto de sostenibilidad en el modelo EFQM .................................. 91

Tabla 17. Evolución del modelo en relación a la sostenibilidad............................................... 93

Tabla 18. Cambios organizacionales que origina el modelo ................................................. 96

Tabla 19. Crecimiento económico de España (Incremento del PIB en \%): .............................113

Tabla 20. Características de los centros seleccionados como casos de estudio ........................ 128

Tabla 21. Información y métodos de obtención ................................................................ 130

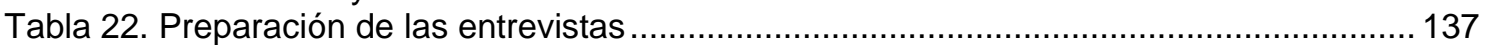

Tabla 23. Personas entrevistadas en cada organización ..................................................... 138

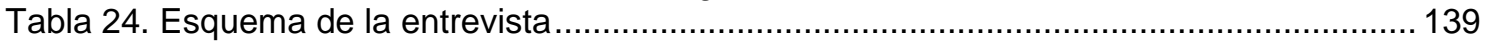

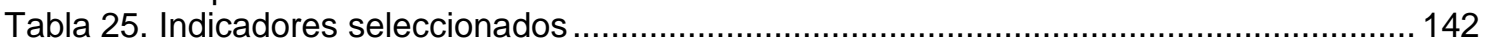

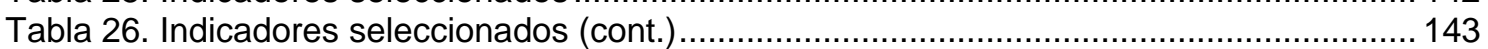

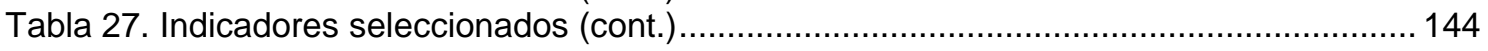

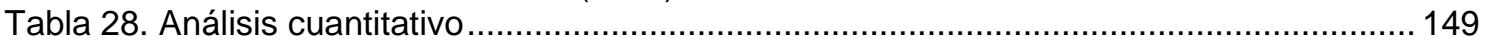

Tabla 29: Camino de la sostenibilidad (Rueda del Cambio) ................................................. 151

Tabla 30. Cultura de la organización: Valores que aporta EFQM .......................................... 152

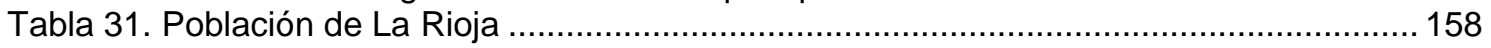

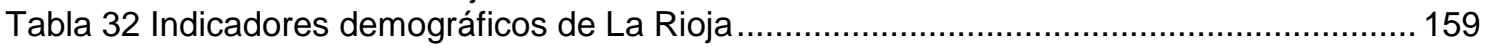

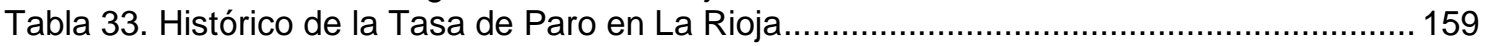

Tabla 34. Distribución de la actividad por sectores y PIB per cápita (2015) ............................ 160

Tabla 35. Riesgo de pobreza o exclusión social en La Rioja ................................................. 160

Tabla 36. Indicadores de determinantes de salud en La Rioja ............................................... 160

Tabla 37. Indicadores de determinante de la salud (La Rioja/España) .................................. 161

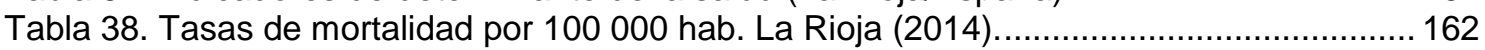

Tabla 39. Distribución de altas de hospitalización y tipo de hospital (2015) ............................. 162

Tabla 40. Tasas de morbilidad por 10000 hab en La Rioja (2014) ....................................... 162

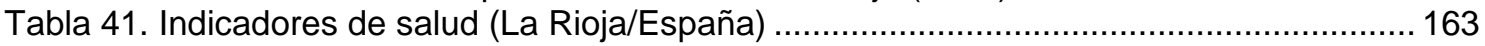

Tabla 42. Recursos sanitarios Atención Especializada en La Rioja a 31/12/2015........................ 166

Tabla 43. Equipamiento y cartera de servicios Hospital San Pedro ....................................... 167

Tabla 44. Personal vinculado al sistema sanitario. La Rioja y España..................................... 168

Tabla 45. Indicadores de recursos, uso y pertinencia (La Rioja/España) ................................ 168

Tabla 46. Indicadores de gasto (La Rioja/España) ............................................................ 169

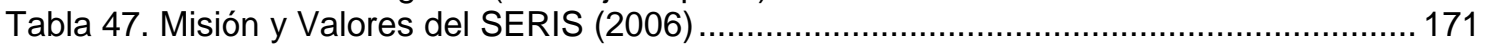

Tabla 48. Situación de la gestión de la calidad en el SERIS en 2014 …............................... 172

Tabla 49. Beneficios esperados de la transformación del modelo asistencial del SERIS ......... 174

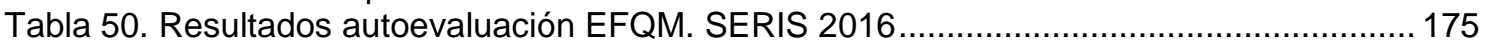

Tabla 51. Indicadores de resultados en calidad (La Rioja/España) ....................................... 176

Tabla 52. Verbatines correspondientes a conceptos fundamentales de la excelencia ............. 176

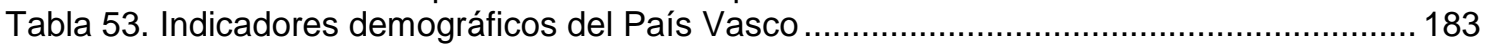

Tabla 54. Riesgo de pobreza o exclusión social en País Vasco ...................................................... 184 
Tabla 55. Indicadores de determinante de la salud (País Vasco/España) ............................... 185

Tabla 56. Indicadores de salud (País Vasco/España) .......................................................... 187

Tabla 57. Distribución de altas de hospitalización y tipo de hospital (2015). .......................... 189

Tabla 58.Gasto sanitario público territorializado, por habitante protegido (euros) .................... 190

Tabla 59. Objetivos relacionados con la sostenibilidad del sistema (Osakidetza). .................... 192

Tabla 60. Indicadores de recursos (País Vasco/España) ....................................................... 193

Tabla 61. Indicadores de recursos económicos (País Vasco/España) ................................... 193

Tabla 62. Misión, visión y valores del Hospital de Basurto en el periodo 2008-2012 ................ 198

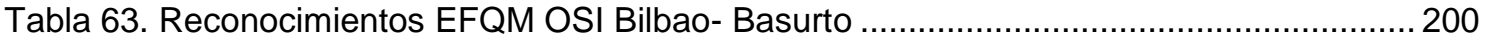

Tabla 64. Premios relacionados con la calidad de las organizaciones de la OSIBB.................200

Tabla 65. Reconocimientos externos. Certificaciones (octubre 2013)................................... 201

Tabla 66. Misión, Visión y Valores de la OSI Bilbao Basurto ..................................................2 203

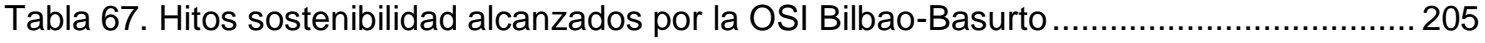

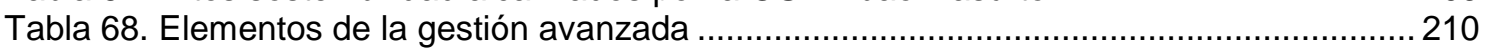

Tabla 69. Indicadores de resultados en calidad (La Rioja/España)....................................... 211

Tabla 70. Verbatines correspondientes con conceptos fundamentales de la excelencia ......... 211

Tabla 71. Tendencia de indicadores determinantes sociales de la salud .................................225

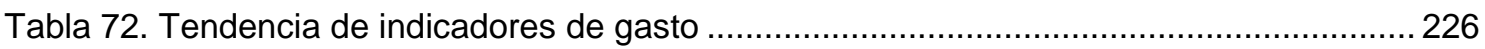

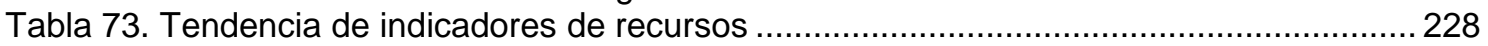

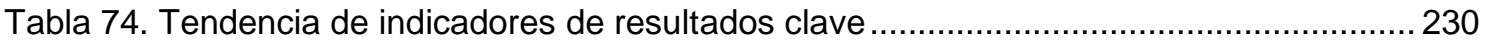

Tabla 75. Tendencia de indicadores de satisfacción de los ciudadanos ................................2232

Tabla 76. Aspectos Sostenibles "The wheel of change". Comparación SERIS/OSI BB ........... 248

Tabla 77. Aplicación de las reformas legales en busca de la eficiencia................................... 251

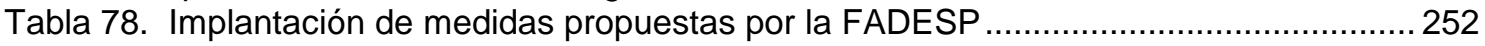

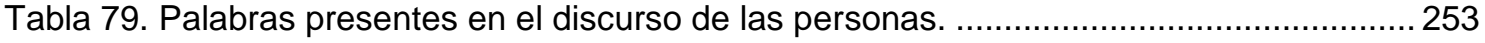

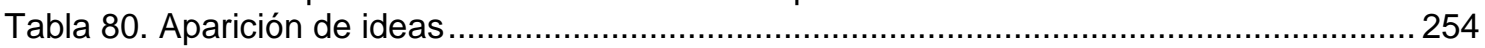

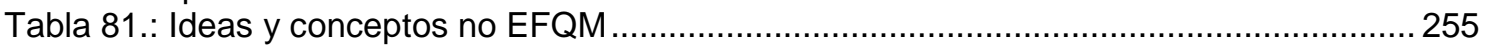

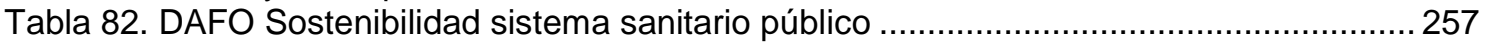




\section{Ilustraciones}

Ilustración 1. Conceptualización de los efectos de las crisis económicas sobre la salud. ..........21

llustración 2. Las tres dimensiones de la sostenibilidad ............................................................. 38

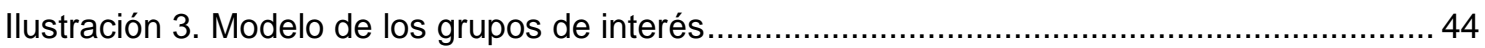

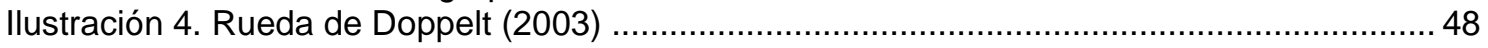

llustración 5.Teoría del Cubo de Rubik sobre la sostenibilidad de las organizaciones .............. 49

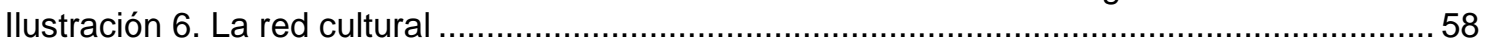

llustración 7. Modelo de conceptual de la implementación del TQM en el sector público .........67 67

llustración 8. Organigrama del Hospital Provincial de Madrid (Gregorio Marañón) en 1980 ..... 73

llustración 9. Organigrama del Hospital San Nicolás .................................................................. 74

llustración 10. Organigrama del área del corazón del complejo hospitalario Juan Canalejo ..... 75

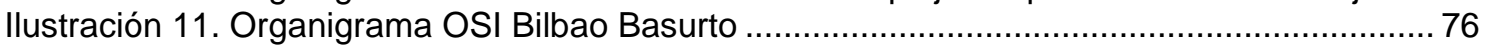

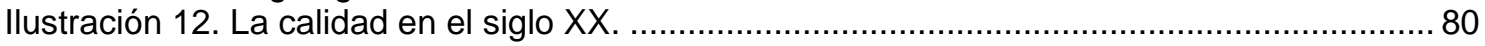

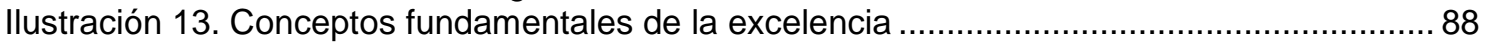

llustración 14. Relación entre subcriterios y conceptos fundamentales. ...................................90

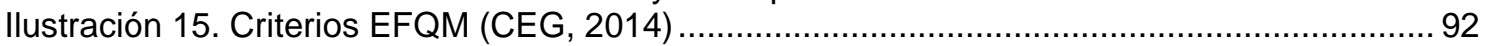

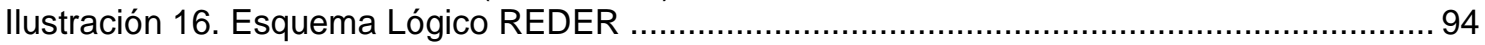

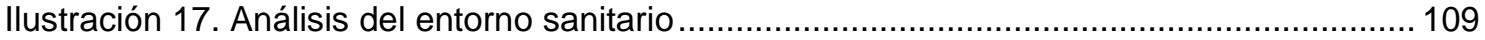

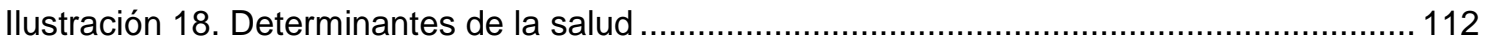

Ilustración 19. Diagrama de flujo de la investigación.......................................................... 129

Ilustración 20. Marco conceptual de los Indicadores Clave del SNS ........................................ 145

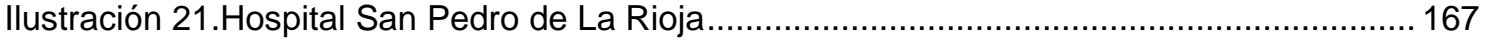

Ilustración 22. Organigrama del Servicio Rojano de Salud (2005) ....................................... 170

Ilustración 23. Mapa de procesos SERIS (2006) ........................................................... 171

llustración 24. Modelo de atención sanitaria en La Rioja (2014) ............................................. 175

Ilustración 25. Entrevistas SERIS sostenibilidad ............................................................. 177

llustración 26. Evolución de esperanza de vida al nacer por sexo. País Vasco 2001-2015 .... 186

llustración 27. Organizaciones con reconocimientos de calidad en Osakidetza ...................... 190

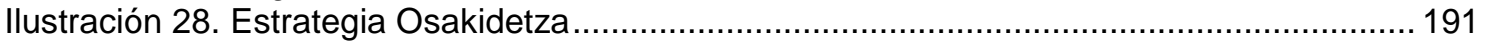

Ilustración 29. Hospital Universitario Basurto (Bilbao) ......................................................... 194

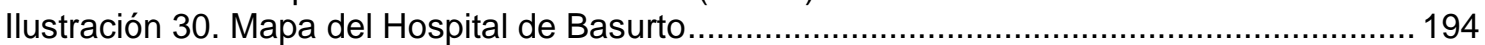

Ilustración 31. Mapa de procesos OSI Bilbao Basurto 2017 ................................................. 202

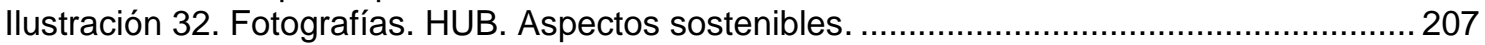

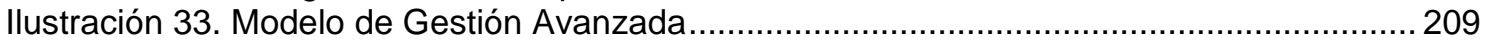

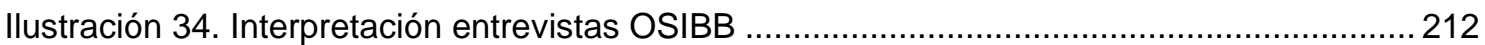

Ilustración 35. Gasto sanitario por habitante.................................................................. 227

llustración 36. Porcentaje de inversión en atención primaria y atención especializada .............228

llustración 37. Camino de la sostenibilidad ambiental. ......................................................... 250 


\section{ABREVIATURAS}

ADER: Agencia de Desarrollo Económico de La Rioja

AE: Atención Especializada

AP: Atención Primaria

CARPA: Centro de Alta Resolución de Procesos Asistenciales

CCAA : Comunidades Autónomas

CEG: Club Excelencia en Gestión

E: España

EFQM: European Foundation for Quality Management

FADESP: Federación de Asociaciones para la Defensa de la Sanidad Pública

FHC: Fundación Hospital Calahorra

FMI: Fondo Monetario Internacional

GI: Grupos de Interés

HSP: Hospital San Pedro

HUB: Hospital Universitario Basurto

INE: Instituto Nacional de Estadística

INSALUD: Instituto Nacional de la Salud

ISO: International Standard Organization

LR: La Rioja

MIR: Médico Interno Residente

MSSSI: Ministerio de Salud, Servicios Sociales e Igualdad

OCDE: Organización para la Cooperación y el Desarrollo Económico

ODS: Objetivos de Desarrollo Sostenible 
OMS: Organización Mundial de la Salud

OSI: Organizacuión Sanitaria Integrada

OSIBB: Organización Sanitaria Integrada Bilbao-Basurto

PIB: Producto Interior Bruto

PV: País Vasco

REDER: Resultados, Enfoques, Despliegue, Evaluación y Revisión I

Riojasalud: Sistema Público de Salud de La Rioja

RRHH: Recursos Humanos

RSC: Responsabilidad Social Corporativa.

SERIS: Servicio Riojano de Salud

SNS: Sistema Nacional de Salud

SOE: Seguro Obligatorio de Enfermedad

TQM: Total Quality Management 


\section{ANEXO I. Recomendaciones prácticas para la sostenibilidad del sistema sanitario}

En este anexo se van a mostrar aquellas actuaciones, propuestas como relevantes para la sostenibilidad del sistema público de salud, que se recogen en la literatura analizada y que se han visto de alguna manera refrendadas en las entrevistas realizadas.

El SNS español está bien considerado tanto por los ciudadanos como a nivel internacional. No obstante, la crisis económica ha puesto al descubierto una situación de riesgo de insostenibilidad del mismo.

La oferta de servicios ha sufrido modificaciones a consecuencia de la crisis por varios mecanismos. Aún hoy en día, al realizar este trabajo es pronto para determinar con base científica (cuando menos con un ejercicio antes-después que tome como exposición el $\mathrm{RD}$ de 2012 partiendo de la fecha en que se produjeron las primeras restricciones presupuestarias en 2011) si estos efectos sobre la oferta tienen efectos a la larga en la salud de los pacientes y la población.

EI SNS debe reorientarse hacia una política de financiación selectiva de los servicios y las tecnologías que añadan valor. En España se dispone de herramientas validadas para apoyar este cambio: regulación, legislación y organismos con capacidad técnica para identificar tecnologías de bajo valor, guiar las decisiones y evaluar oportunamente sus efectos.

Los obstáculos son numerosos, pero no hacer nada es una de las peores opciones: altos costes derivados de la pérdida de efectividad y seguridad de los servicios y prestaciones, de la equidad y, en definitiva, de la eficiencia económica del SNS, que de producirse se traducirán a corto y medio plazo en el empeoramiento de las condiciones de salud de los ciudadanos (Bernal-Delgado, 2014).

A lo largo de esta investigación se han identificado herramientas para intentar minimizar este riesgo. Las herramientas están disponibles, pero hay que empeñarse en utilizarlas. Algunas afectan más a lo macro (transparencia, regulaciones correctas, salud en todas las políticas, banco de bienestar) y otras más a lo meso (como el desarrollo de sistemas de información inteligentes, o la evaluación de la adecuación y el desempeño que permitan incentivar los resultados y fomentar la autonomía responsable de las organizaciones sanitarias). Pero entre las más importantes están aquellas que pongan en primer plano los microsistemas, los profesionales sanitarios y su microentorno, la medicina bien hecha. (Bernal- Delgado 2010). A continuación se presentan una serie de propuestas recogidas de la FSS-CCOO (Cabrera 2010), Gutiérrez-Sequera J.L. (2014), Anxo (2014), Arranz (2014), Arias (2010), y de la Asociación de Economía de la Salud (AES, 2011), formada por reconocidos expertos como Enrique Bernal Delgado, Carlos Campillo Artero, Beatriz González López -Varcárcel Ricard Meneu de Guillerna, Jaume Puig-Junoy, José Ramón Repullo Labrador y Rosa Urbanos Garrido. 


\section{Potenciar el papel de la enfermería}

Para comenzar y en línea con lo recogido en las entrevistas hay que destacar el protagonismo que debería tomar la enfermería en los sistemas de salud. Durante las entrevistas y la observación participante se ha recogido las opiniones de diferentes responsables de enfermería, gestión e incluso jefes de servicio que reconocen la importancia de la enfermería ante el crecimiento de la esperanza de vida, el incremento del número de crónicos y la, cada vez mayor, demanda de cuidados integrales.

Según muchos expertos es necesario un rediseño de los modelos organizativos asistenciales actuales tratando de romper la rigidez del sistema centrado en la enfermedad y en lo biomédico, y tender hacia sistemas más flexibles, que primen la accesibilidad al resultado, y que acerquen al paciente y sus necesidades al proveedor más adecuado en cada momento, médico o enfermera. (Gutiérrez-Sequera, 2014). Esta no es la única clave de la sostenibilidad. Pero existen estudios publicados que señalan que iniciativas como «nurseled» o similares, ponen a la organización en la senda de la eficiencia. (Gutiérrez-Sequera, 2014):

Lógicamente todo ello requiere una mejor definición de los marcos competenciales enfermeros, y una reflexión sobre cómo deben adquirirse aquellas competencias que se necesiten.

En este sentido, un nuevo enfoque orientado a la generación de activos en salud, basado en la teoría de la salutogénesis de Antonovsky (Juvinya-Cana D, 2013) destaca la importancia de los recursos personales para el mantenimiento de la salud y el bienestar. Un sistema que genera salud frente al sistema tradicional favorece la sostenibilidad. Po otro lado, la apuesta por el paciente activo, y el uso de los recursos personales y colectivos para el mantenimiento y mejora de la salud necesitan de los cuidados comunitarios para su éxito. Las enfermeras comunitarias parecen estar llamadas a liderar estos cambios, aunque es necesario un análisis del rol actual de la enfermera de atención primaria.

El camino hacia la eficiencia parece pasar por rediseños organizativos asistenciales en los que la clave de la eficiencia está en ofrecer un sistema más versátil, adaptado a cada nivel de complejidad, que acerque al paciente al proveedor más adecuado en cada caso. Esto hace necesaria una potenciación del desarrollo del marco competencial enfermero, de manera que la respuesta que la mirada holística de los cuidados puede ofrecer no encuentre obstáculos en modelos asistenciales que ya no dan respuesta a las nuevas necesidades basadas en conceptos como cronicidad, complejidad clínica, vulnerabilidad o fragilidad.

\section{Orientación al paciente}

Tanto los profesionales de la salud, como los gestores y políticos manifiestan que el sistema sanitario debe estar al servicio de los pacientes. No obstante la realidad, en muchas ocasiones, pone de manifiesto que esto no es del todo así. Los procesos asistenciales se organizan, en muchas ocasiones, en función de las necesidades de algunos profesionales o de la organización de los servicios $u$ otras razones que no tienen relación con los pacientes. El sistema necesita dar respuesta a sus grupos de interés para ser sostenible, y en especial a los pacientes. Para ello debería: 
- Dotarse de transparencia, garantizando que la ciudadanía conoce, se informa y manifiesta su opinión en torno al SNS y su proyecto de futuro, dado que les afecta directamente.

- Potenciar la información y la participación de los pacientes y de las asociaciones que los representan.

- Garantizar un tiempo de espera máximo, según patología, tanto para procesos quirúrgicos, médicos o diagnósticos. Se debe tender a protocolizar todo lo relacionado con la gestión de las listas de espera.

- Procurar la continuidad de los cuidados, así como la eficacia y la seguridad de los diagnósticos y tratamientos basándose en la evidencia científica y protocolizando sus actuaciones.

\section{Implicar a los profesionales}

La sociedad y las entidades profesionales deben propiciar un cambio en la forma en la que se abordan los problemas, desarrollando un sistema de análisis y una propuesta de soluciones que deje de lado posturas partidistas y corporativistas y se apoye en la mejor evidencia disponible.

- Potenciar la corresponsabilidad en la toma de decisiones por parte de los profesionales, avanzando en la gestión clínica como forma de organizar el trabajo sanitario basado en la evidencia científica, acompañada de un modelo retributivo más incentivador para quien hace más eficiente el sistema.

- Crear un modelo de carrera profesional que permita la circulación de profesionales sin necesidad de merma económica, inseguridad en cuanto a su aplicación, etc. Conseguir retribuciones y condiciones laborales similares en el conjunto del Estado.

- Abrir un proceso en el conjunto del Estado de equiparación y homologación, a medio plazo, de las condiciones de acceso, laborales y retributivas en el conjunto de las comunidades.

- Adecuar la oferta de plazas universitarias de medicina y enfermería, así como las plazas de formación de especialistas sanitarios a las necesidades mediante la elaboración de planes de ordenación de recursos, donde se prevean las necesidades de profesionales, no sólo a corto plazo, sino a medio y largo plazo.

- Potenciar y reconocer el trabajo de los profesionales de enfermería y desarrollar sus especialidades.

- Profesionalizar y despolitizar la gestión.

- Trabajar en un proceso de cualificación profesional que permita al personal de gestión y servicios la adecuación continua a su puesto y el desarrollo de su carrera profesional. 


\section{Mejorar la organización y la planificación}

La Sanidad Pública necesita un centro de evaluación nacional que pueda evaluar, no sólo las tecnologías, sino los procedimientos, los modelos de organización del sistema sanitario, de tal forma que se disponga de un centro de excelencia, que pueda identificar cuáles son los comportamientos positivos que se están desarrollando en los diecisiete modelos y que deben ser referentes desde el punto de vista de coste-efectividad. (Anxo, 2014). Se debería apostar por un modelo colaborativo de los distintos esfuerzos y conocimiento que hay en los diferentes sitios, que pueda ser unificado o supervisado bajo un paraguas global (Arranz, 2014). Esta idea apoya la colaboración entre organizaciones y el benchmarking no solo a nivel asistencial sino también a nivel de investigación e innovación y de gestión en todas las vertientes de la sostenibilidad.

Diferentes autores también proponen una serie de aspectos relevantes para mejorar el funcionamiento del sistema

- Adaptar el paradigma asistencial a las patologías del siglo XXI. Cambio de foco hacia pacientes crónicos, frágiles y terminales.

- Garantizar que los fondos destinados a sanidad sean finalistas y, por tanto, suficientes para cubrir el gasto sanitario.

- Revisar las necesidades asistenciales y realizar el análisis de infraestructuras y recursos humanos y materiales, desde la perspectiva de las necesidades asistenciales a corto y medio plazo.

- Desarrollar las Organizaciones Sanitarias Integradas y los procesos asistenciales que favorezcan la orientación del sistema hacia los pacientes y la continuidad de los cuidados.

- Apostar por la atención primaria, dotándola de mayor capacidad de respuesta (mejoras en medios diagnósticos); aumento de las plantillas, y una mayor apuesta por los programas y la prevención, como forma de desmasificar la red hospitalaria.

- Evitar la duplicidad de costes a través una mayor coordinación entre el sistema sanitario y el sociosanitario buscando una mayor eficiencia

- Mejorar la coordinación entre los sistemas de información para poder compartir información entre las distintas comunidades.

- Impulsar la investigación y el desarrollo tecnológico en el sector sanitario, como motor de generación de conocimiento, de empleo, e incluso de generación de riqueza. 


\section{Implantar modelos o sistemas de gestión}

Los expertos también consideran necesario trabajar en implantar, evaluar y mejorar los modelos de gestión buscando beneficios en salud y mejorando los resultados económicos.

Los resultados del trabajo de García-Bernal et al. (2004) muestran que la mejora de la gestión debe ser en todos los criterios de forma simultánea ya que la adopción de un modelo de gestión de la calidad no conlleva necesariamente la obtención de resultados superiores, si la implantación no se hace de forma integrada.

A lo largo de todo el proceso de implantación de un modelo de gestión de la calidad, debe tenerse en cuenta el problema de la continuidad, que en el sector público representa un condicionante en la mayoría de las ocasiones por la falta de continuidad de sus líderes políticos, aspecto que no depende de la organización ni de los logros alcanzados en etapas anteriores (Zardoya, 2004).

Actualmente en el entorno sanitario español, la aplicación del modelo EFQM, ya es una realidad y, su implantación en el sector sanitario aunque desigual, queda constatada en los originales que han ido apareciendo en revistas del propio ámbito.

No obstante el número de centros que han desarrollado experiencias es todavía escaso, con la excepción de los centros de Osakidetza, que desde 1995 han incorporado la Autoevaluación mediante el modelo EFQM como herramienta de desarrollo estratégico.

Por otra parte, las conclusiones de los distintos grupos que han aplicado el modelo en sus respectivos centros son coincidentes, a la hora de destacar los beneficios de la utilización del mismo destacando las propias características del modelo EFQM: diagnóstico de situación interna, detección de áreas de mejora, enfoque global y sistemático, orientación al cliente, etc. Destacando aquellos aspectos que se refieren a la sensibilización de los equipos directivos por la Excelencia y, el aprendizaje de los propios miembros de la organización, lo que favorece la comunicación interna, su cohesión y finalmente fomenta la cultura de organización.

Como se ha comentado, una de las premisas del modelo es la absoluta implicación y compromiso de los equipos directivos, requisito sin el cual la experiencia se convertirá en un mero divertimento. En este sentido se ha apuntado que la falta de una profesionalización de la gestión de las organizaciones sanitarias y la falta de estabilidad de los equipos directivos, frecuente en el sector público, pueden comprometer la viabilidad de los proyectos (Fortuny, 2009).

De igual forma, los estudios de utilización alertan sobre las barreras, limitaciones y precauciones a tener en cuenta en la elaboración del plan de implantación del modelo. El origen empresarial del modelo puede originar ciertas dificultades no sólo en lo que se refiere a la terminología utilizada, poco habitual en el ámbito sanitario, sino también en lo que se refiere a las diferentes características de las organizaciones empresariales en comparación con los centros sanitarios, especialmente en lo relativo a la estrategia de gestión. Argumentos que han propiciado la adaptación del modelo a las peculiaridades del sector sanitario (Fortuny, 2009). 
Ante los cambios cada vez más frecuentes y menos previsibles del entorno sanitario, todas las organizaciones sanitarias tienen que adaptar su estrategia a los nuevos tiempos y dar muestras evidentes de flexibilidad para propiciar su sostenibilidad. Es un proceso continuo y dinámico. En el que las organizaciones deben plantearse las siguientes preguntas: ¿qué hacer?, ¿cómo hacerlo?, ¿cuándo hacerlo? y, ¿quién lo hace? (Fortuny, 2009). El modelo EFQM proporciona un método sistemático para llevarlo a cabo.

El modelo EFQM no se tiene que tomar como una amenaza, sino como una verdadera oportunidad. No se trata de «ir a por nota», pero aprovechando el bagaje práctico que ofrece, identificar y trabajar las áreas de mejor dentro de las organizaciones (Fortuny, 2009).

El modelo EFQM de Excelencia permite respetar e incorporar al trabajo realizado con otros modelos, sistemas y procedimientos como, por ejemplo, el cuadro de mando integral (BSC), la planificación Hoshin, la gestión por valores, Six-Sigma, la inteligencia emocional, la certificación ISO, y los sistemas de acreditación y garantía de calidad específicos de cada país (Fortuny, 2009).

Es necesario recordar que el modelo EFQM de Excelencia es un marco de trabajo no prescriptivo que reconoce que la Excelencia de una organización se puede lograr de manera sostenida mediante diferentes enfoques. Existe pues, una libertad de interpretación considerable a la hora de reflejar las estrategias adecuadas para una organización sanitaria, teniendo en cuenta su cultura, origen y entorno político (Fortuny, 2009).

Dentro de este marco, para trabajar con la sostenibilidad en las organizaciones, sería necesario que estas abordasen el tema desde una perspectiva estratégica y que se incorporase un enfoque que integre en una sola teoría las principales teorías propuestas sobre la sostenibilidad. La sostenibilidad debe lograrse en todos los ámbitos descritos en la teoría de Triple Cuenta de Resultados, para todos los grupos de interés y siguiendo unos procedimientos concretos que lleven a la organización a alcanzar sus objetivos tal y como se muestra en el siguiente llustración que muestra la teoría propuesta a partir de este estudio y que se ha denominado "Teoría del Cubo de Rubik" (Ilustración4) 


\section{ANEXO II. Gráficos estadísticos}

llustración 1- Índice de dependencia (0 País Vasco / 1 La Rioja)

0: 0 Joinpoints versus 1: 0 Joinpoints

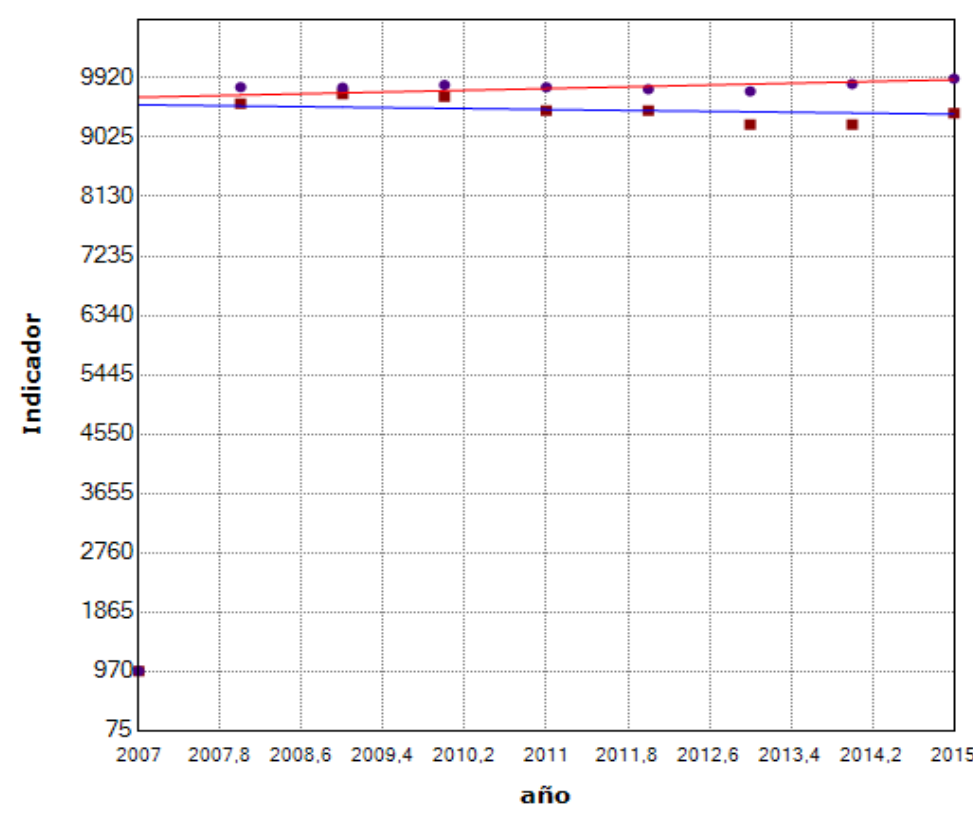

- $2007-2015$ APC $=-0.19$

$2007-2015$ APC $=0.34$

^The Annual Percent Change (APC) is significantly different from zero at alpha $=0.05$

Final Selected Model: 0 - 0 Joinpoints, 1 - 0 Joinpoints. Rejected Coincidence.

llustración 2- Nivel de estudios (0 País Vasco / 1 La Rioja)

0: 0 Joinpoints versus 1: 0 Joinpoints

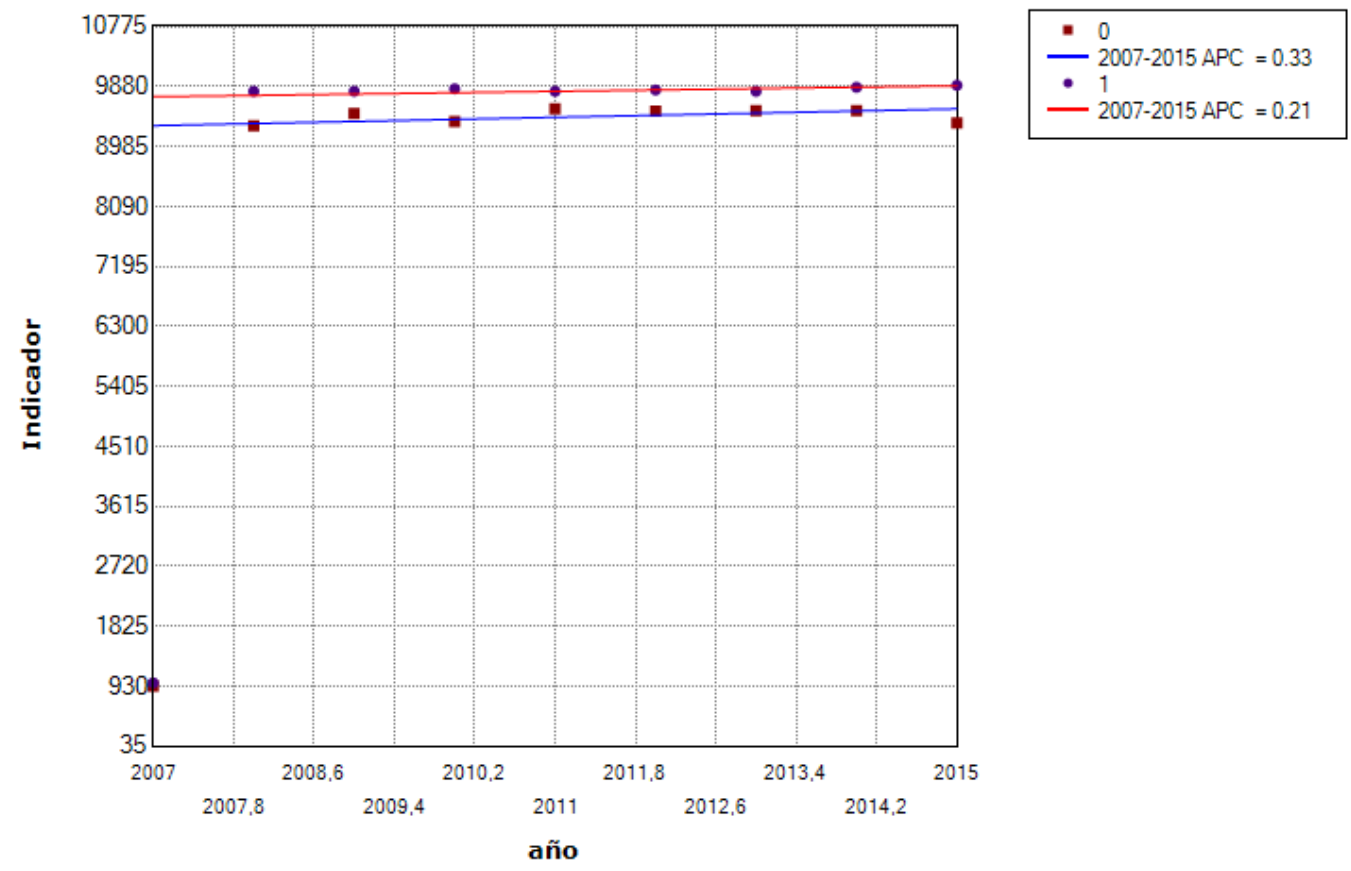

^ The Annual Percent Change (APC) is significantly different from zero at alpha $=0.05$

Final Selected Model: 0 - 0 Joinpoints, 1 - 0 Joinpoints. Rejected Coincidence. 
Ilustración 3- Cobertura de vacunación, gripe en más de 65 (0 País Vasco / 1 La Rioja)

0: 0 Joinpoints versus 1: 0 Joinpoints

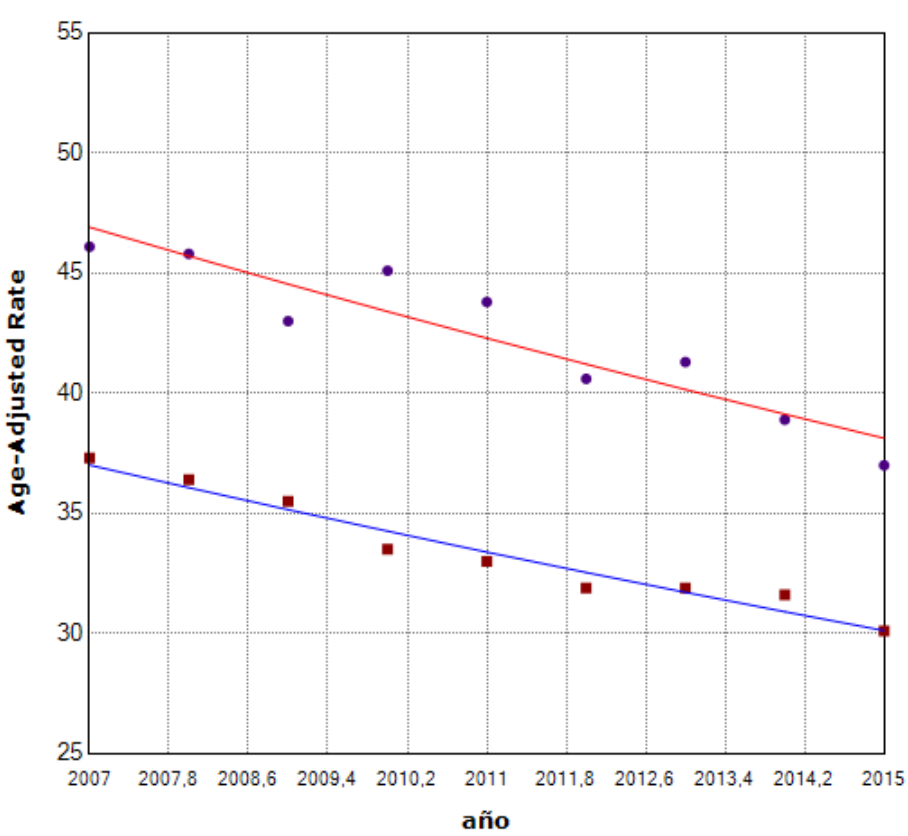

^ The Annual Percent Change (APC) is significantly different from zero at alpha $=0.05$

Final Selected Model: 0 - 0 Joinpoints, 1 - 0 Joinpoints. Rejected Coincidence.

Ilustración 4- Cobertura vacunación poliomielitis (0 País Vasco / 1 La Rioja)

0: 1 Joinpoint versus 1: 1 Joinpoint

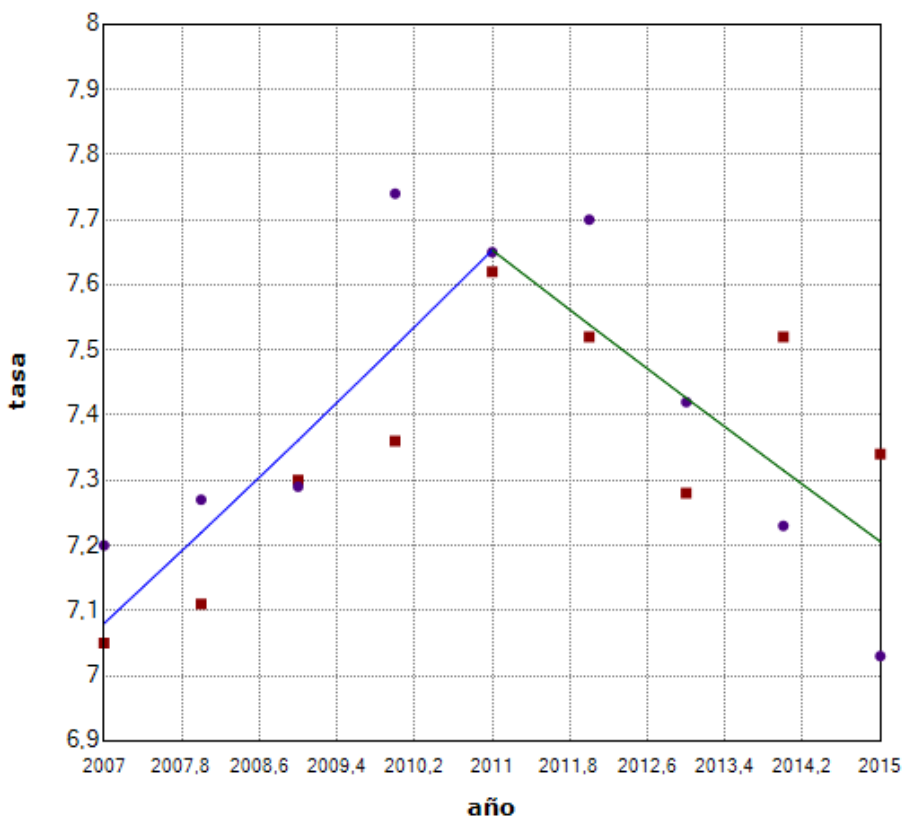

${ }^{\wedge}$ The Annual Percent Change (APC) is significantly different from zero at alpha $=0.05$ Final Selected Model: 0 - 1 Joinpoint, 1 - 1 Joinpoint. Failed to reject Coincidence. 
Ilustración 5- Cobertura vacunación triple vírica (0 País Vasco / 1 La Rioja)

0: 0 Joinpoints versus 1: 0 Joinpoints

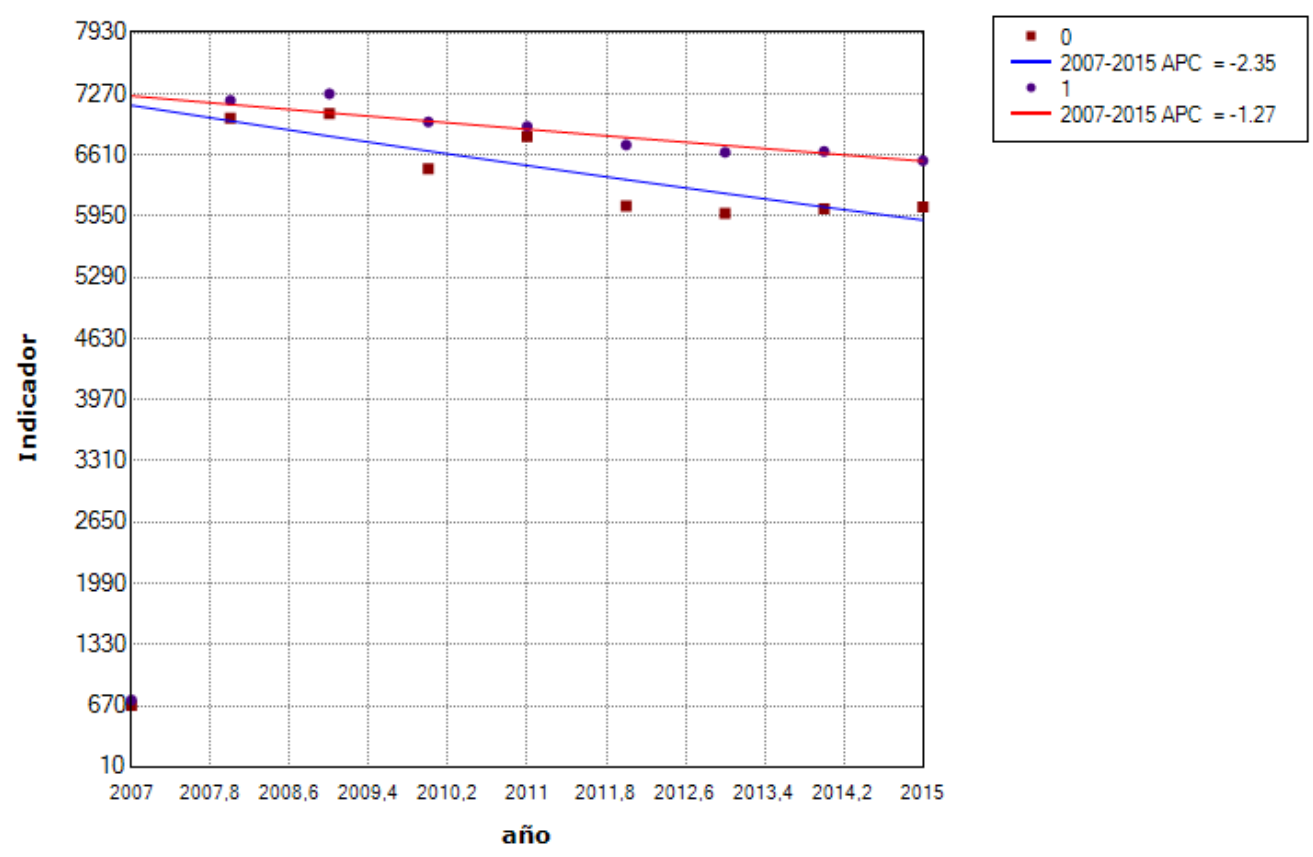

${ }^{\wedge}$ The Annual Percent Change (APC) is significantly different from zero at alpha $=0.05$

Final Selected Model: 0 - 0 Joinpoints, 1 - 0 Joinpoints. Rejected Coincidence.

llustración 6- Índice de estancia media ajustada (0 País Vasco / 1 La Rioja)

0: 0 Joinpoints versus 1: 0 Joinpoints

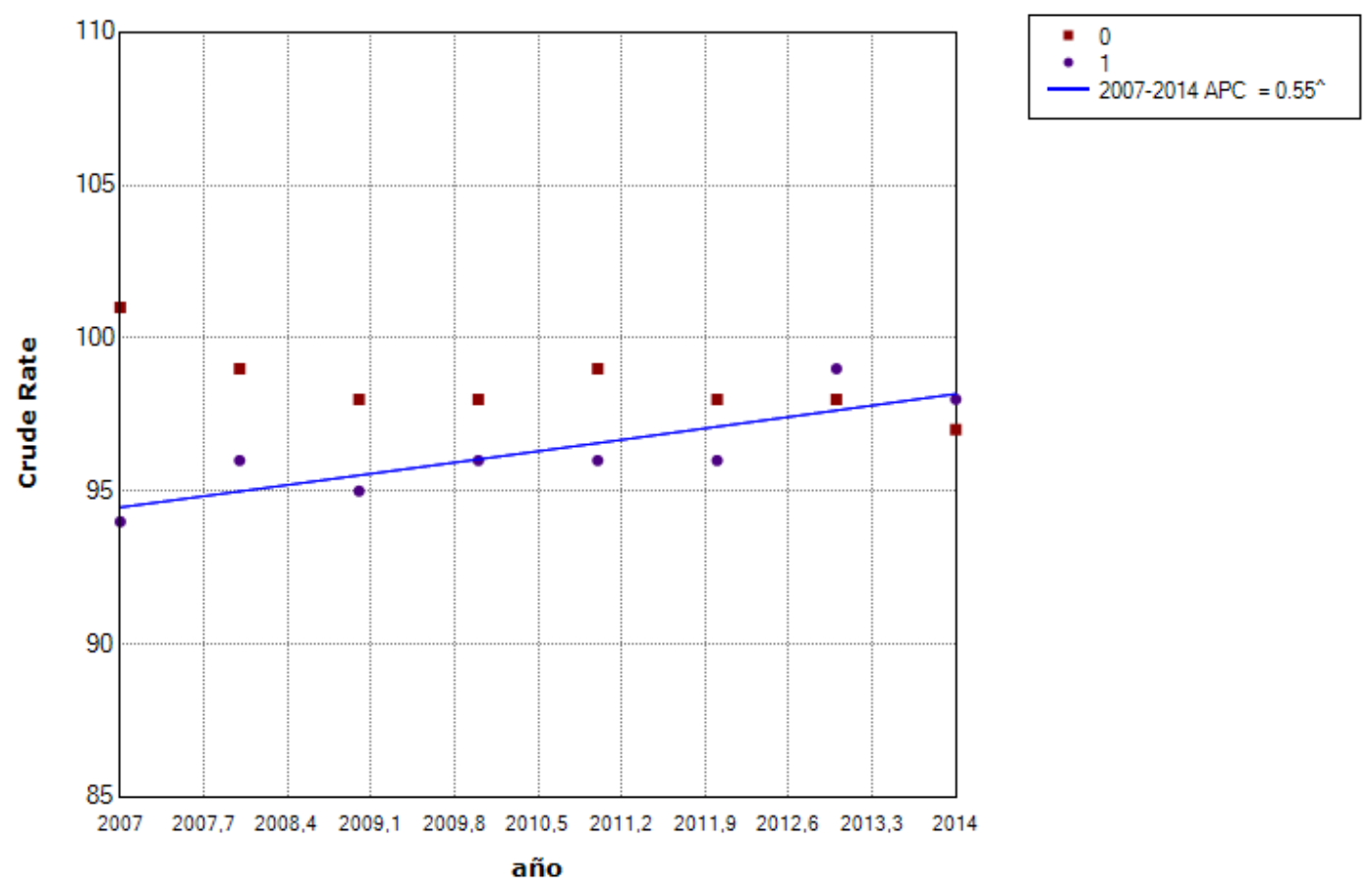

^The Annual Percent Change (APC) is significantly different from zero at alpha $=0.05$ Final Selected Model: 0 - 0 Joinpoints, 1 - 0 Joinpoints. Failed to reject Coincidence. 
Ilustración 7- Porcentaje de cirugía ambulatoria (0 País Vasco / 1 La Rioja)

0: 1 Joinpoint versus 1: 1 Joinpoint
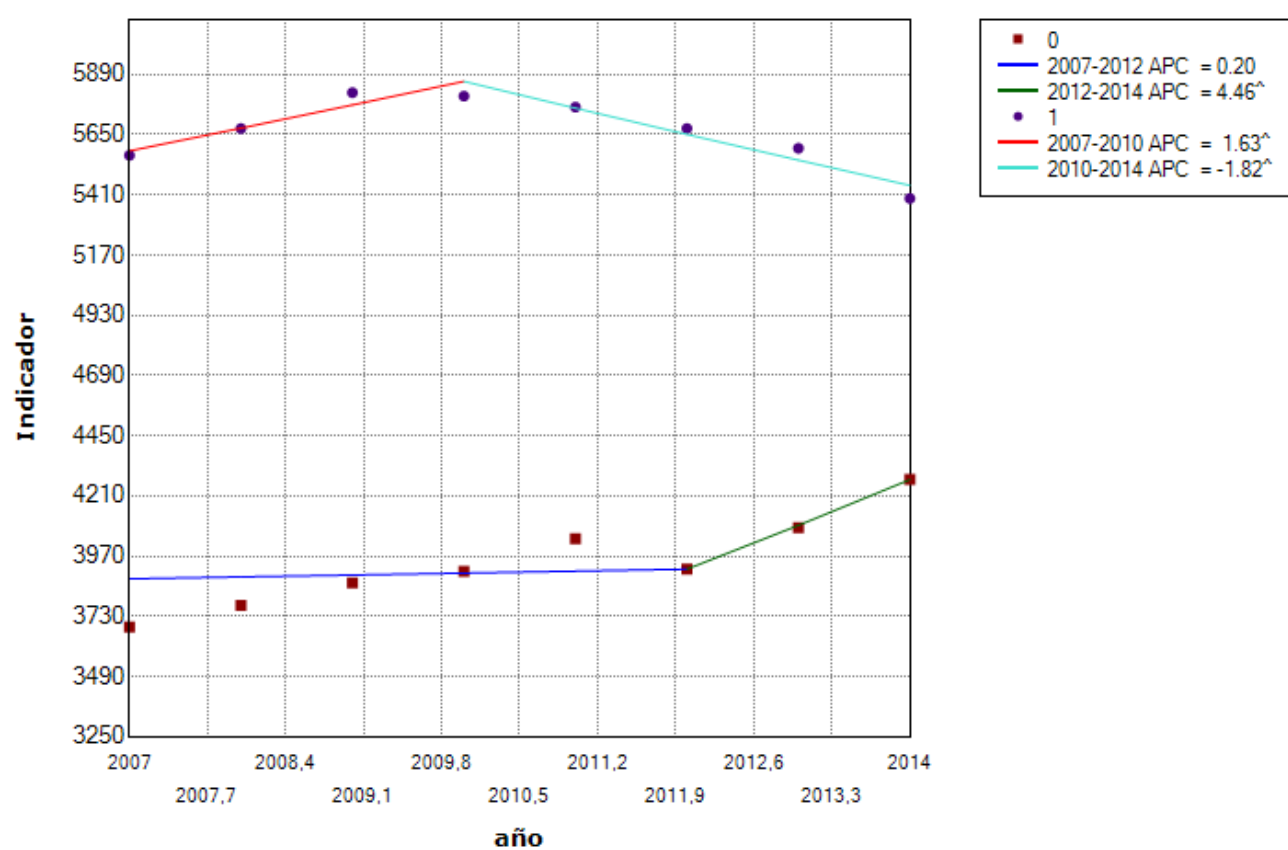

${ }^{\wedge}$ The Annual Percent Change (APC) is significantly different from zero at alpha $=0.05$

Final Selected Model: 0 - 1 Joinpoint, 1 - 1 Joinpoint. Rejected Coincidence.

\section{Ilustración 8-Personal médico en Atención Primaria (0 País Vasco / 1 La Rioja)}

0: 0 Joinpoints versus 1: 0 Joinpoints

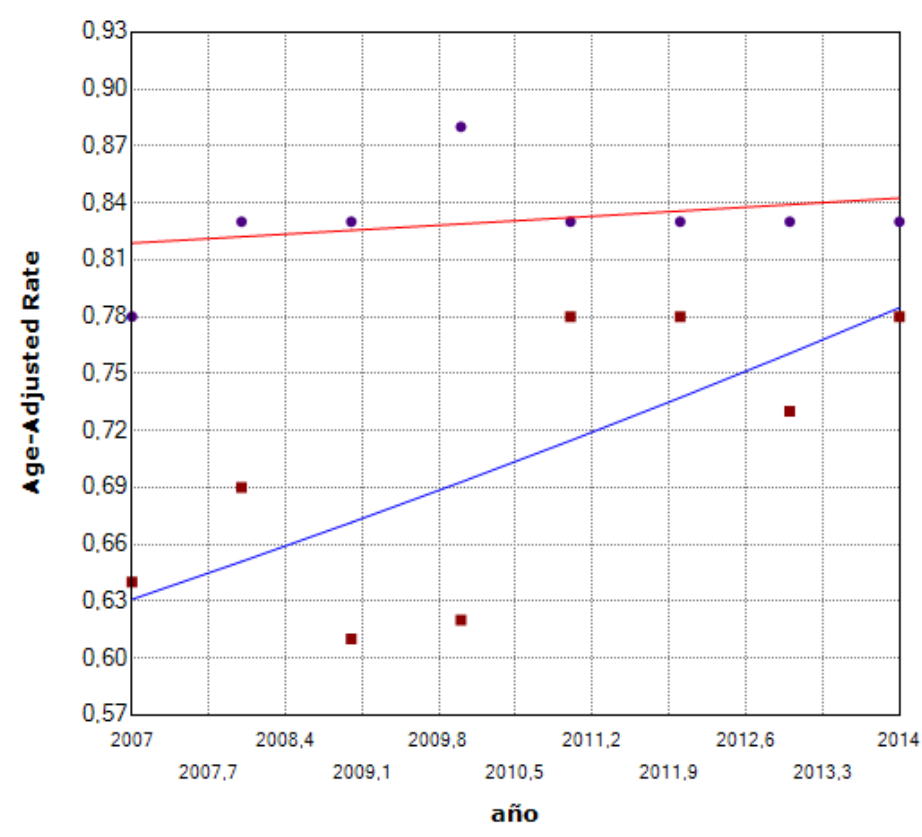


Ilustración 9-Camas hospitalarias (0 País Vasco / 1 La Rioja)

0: 1 Joinpoint versus 1: 1 Joinpoint
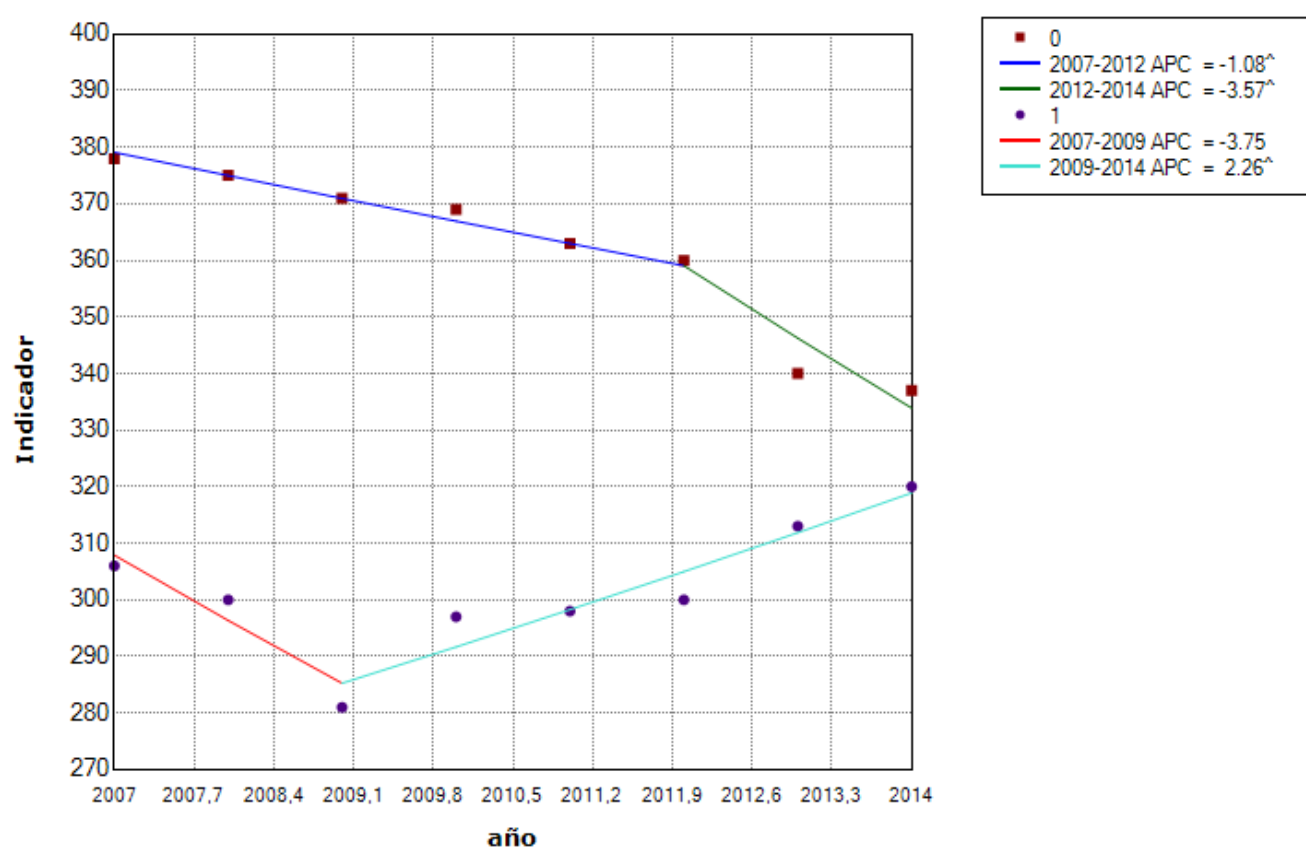

${ }^{\wedge}$ The Annual Percent Change (APC) is significantly different from zero at alpha $=0.05$

Final Selected Model: 0 - 1 Joinpoint. 1 - 1 Joinpoint. Rejected Coincidence.

\section{Ilustración 10-Gasto en farmacia (0 País Vasco / 1 La Rioja)}

0: 1 Joinpoint versus 1: 0 Joinpoints

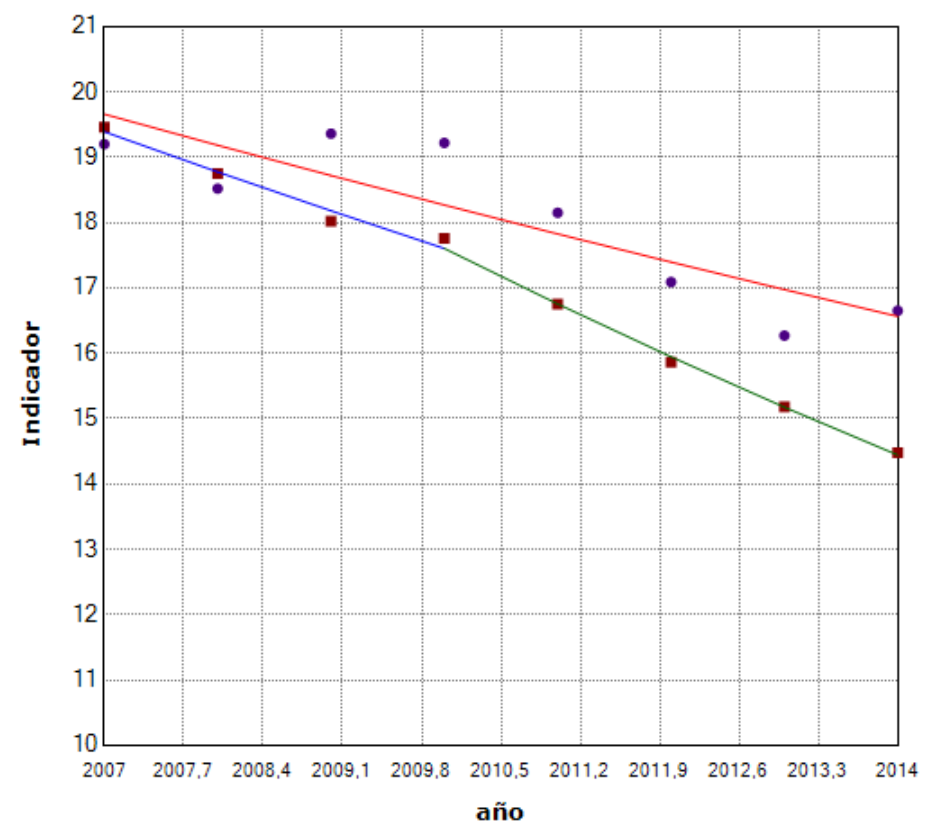

0
-
$2007-2010 \mathrm{APC}=-3.17^{\wedge}$ - 2010-2014 APC $=-4.83^{\wedge}$

$2007-2014$ APC $=-2.42^{\wedge}$

^The Annual Percent Change (APC) is significantly different from zero at alpha $=0.05$ Final Selected Model: 0 - 1 Joinpoint, 1 - 0 Joinpoints. Rejected Coincidence. 
Ilustración 11-Gasto en remuneración del personal (0 País Vasco / 1 La Rioja)

0: 0 Joinpoints versus 1: 0 Joinpoints

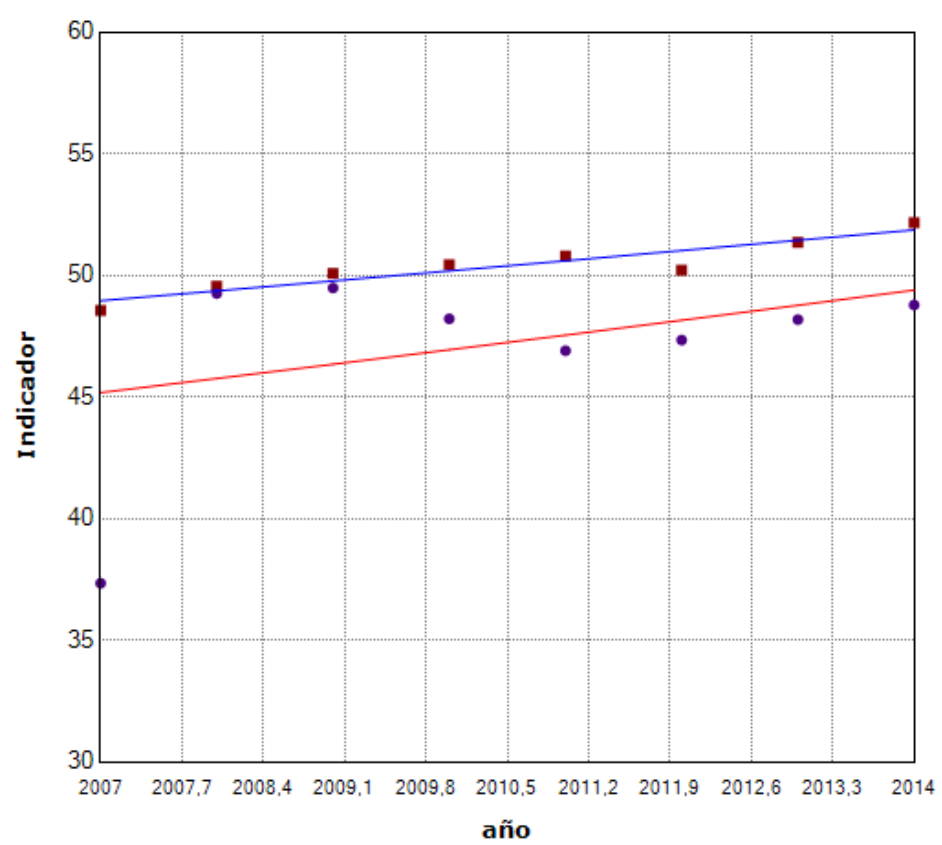

- $2007-2014 \mathrm{APC}=0.83$ $\begin{aligned} & 1 \\ & -\end{aligned} 2007-2014 \mathrm{APC}=1.28$

A The Annual Percent Change (APC) is significantly different from zero at alpha $=0.05$ Final Selected Model: 0 - 0 Joinpoints, 1 - 0 Joinpoints. Rejected Coincidence.

\section{llustración 12-Años de vida saludable a los 65 (0 País Vasco / 1 La Rioja)}

0: 0 Joinpoints versus 1: 0 Joinpoints

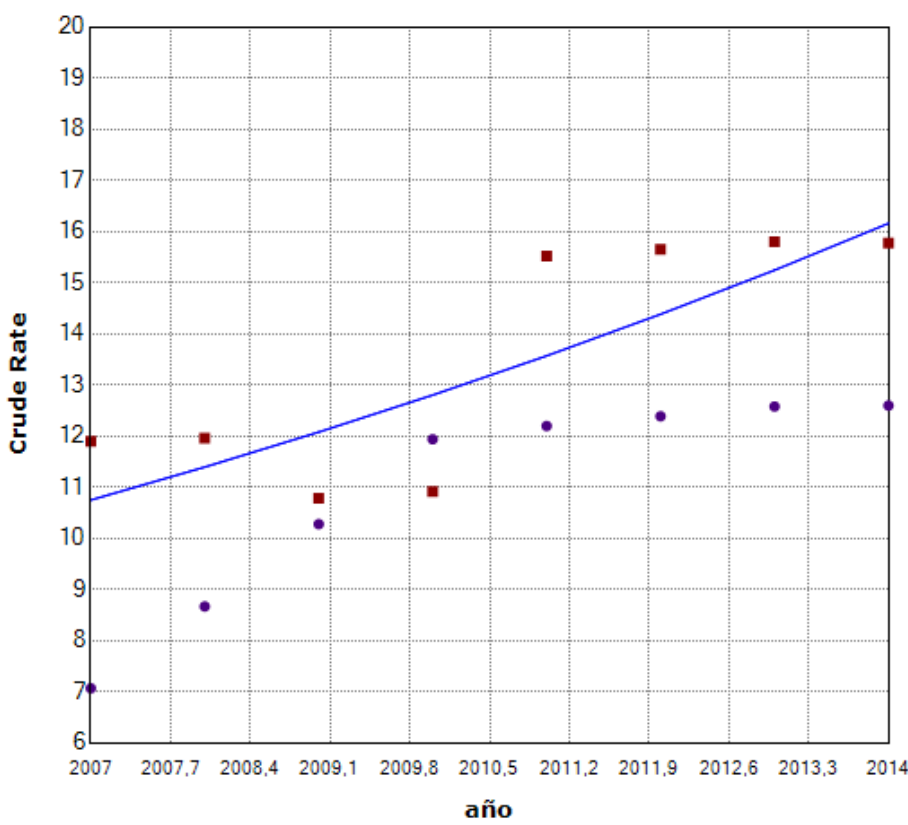

- 0 $2007-2014 \mathrm{APC}=6.00^{\wedge}$

^ The Annual Percent Change (APC) is significantly different from zero at alpha $=0.05$ Final Selected Model: 0 - 0 Joinpoints. 1 - 0 Joinpoints. Failed to reject Coincidence. 


\section{Ilustración 13-Mortalidad por Cardiopatía Isquémica (0 País Vasco / 1 La Rioja)}

0: 0 Joinpoints versus 1: 0 Joinpoints

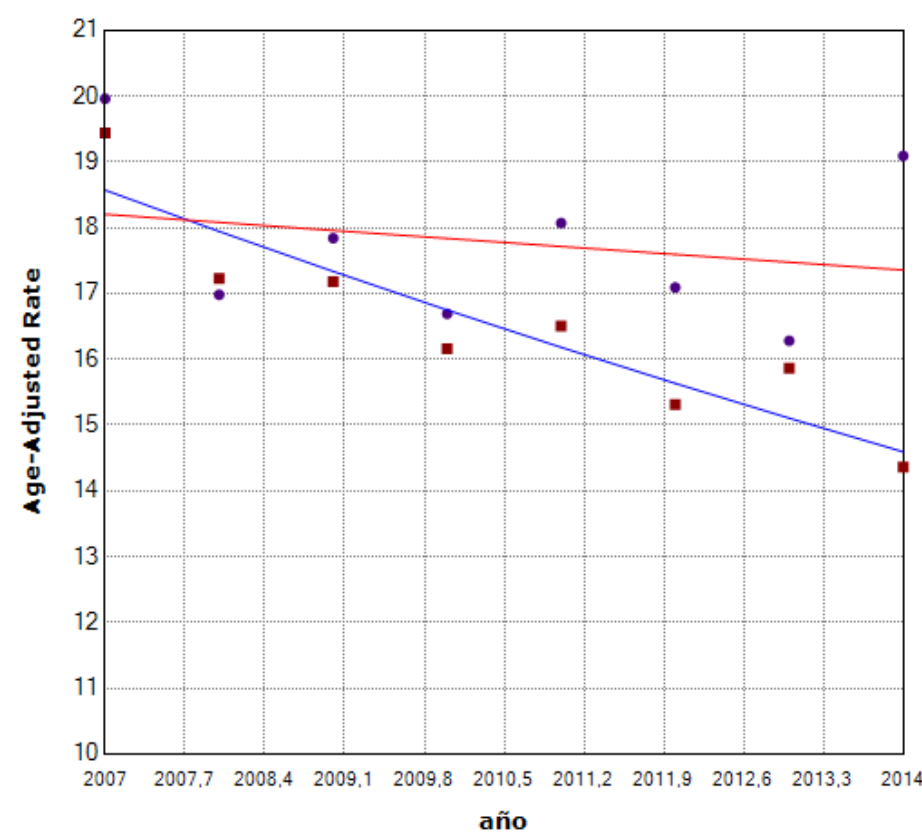

${ }^{\wedge}$ The Annual Percent Change (APC) is significantly different from zero at alpha $=0.05$ Final Selected Model: 0 - 0 Joinpoints, 1 - 0 Joinpoints. Rejected Coincidence.

\section{llustración 14-Esperanza de vida al nacer (0 País Vasco / 1 La Rioja)}

0: 0 Joinpoints versus 1: 0 Joinpoints

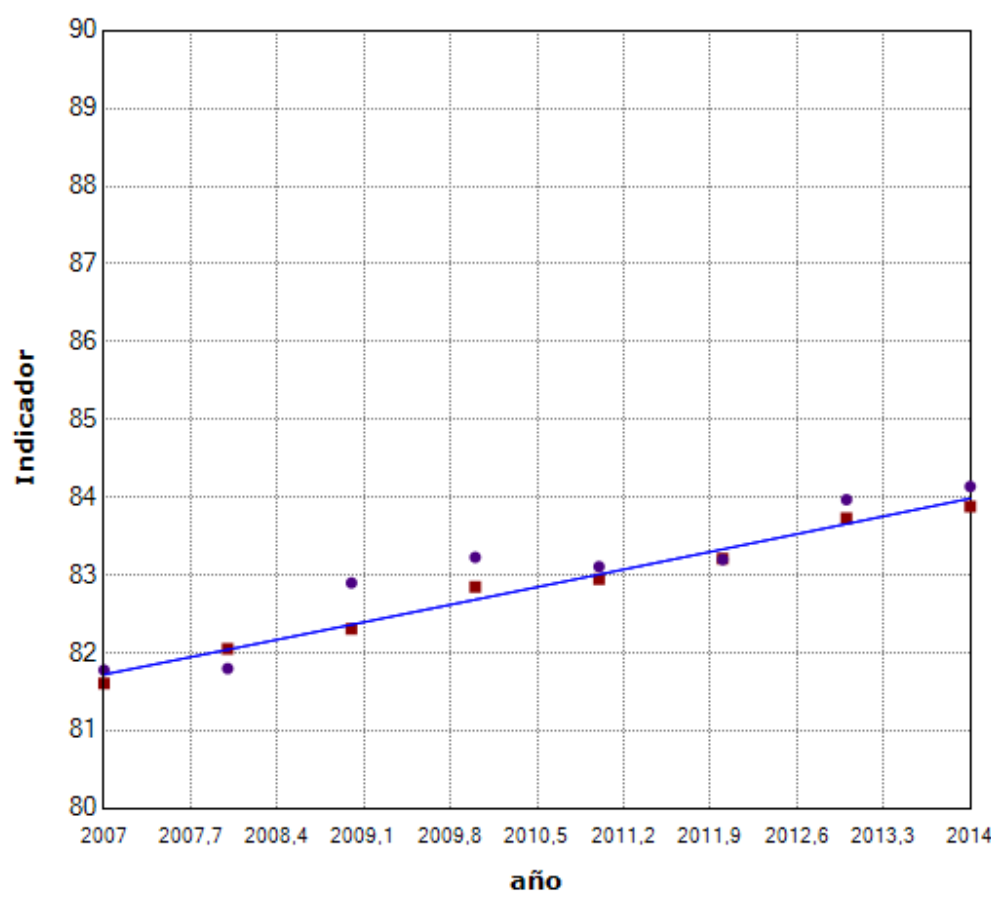

- 0

$2007-2014 \mathrm{APC}=0.39^{\wedge}$

${ }^{\wedge}$ The Annual Percent Change (APC) is significantly different from zero at alpha $=0.05$ Final Selected Model: 0 - 0 Joinpoints, 1 - 0 Joinpoints. Failed to reject Coincidence 


\section{Ilustración 15-Mortalidad infantil (0 País Vasco / 1 La Rioja)}

0: 0 Joinpoints versus 1: 0 Joinpoints

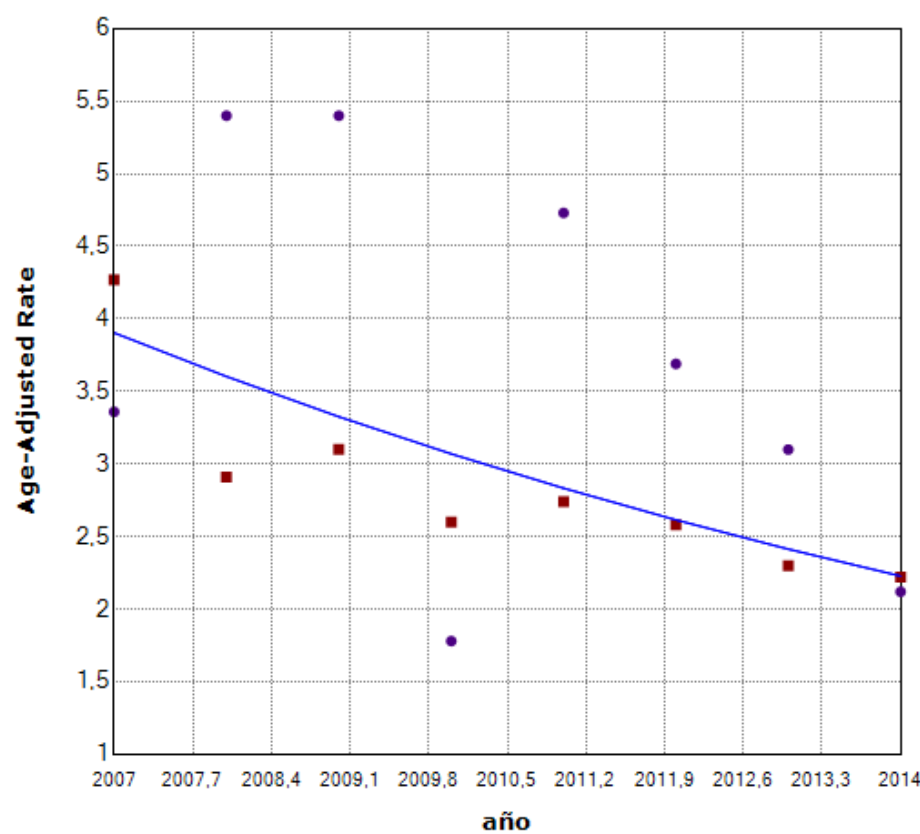

- 0

2007-2014 APC $=-7.70^{\wedge}$

^The Annual Percent Change (APC) is significantly different from zero at alpha $=0.05$ Final Selected Model: 0 - 0 Joinpoints, 1 - 0 Joinpoints. Failed to reject Coincidence.

\section{Ilustración 16-Mortalidad perinatal (0 País Vasco / 1 La Rioja)}

0: 1 Joinpoint versus 1: 1 Joinpoint

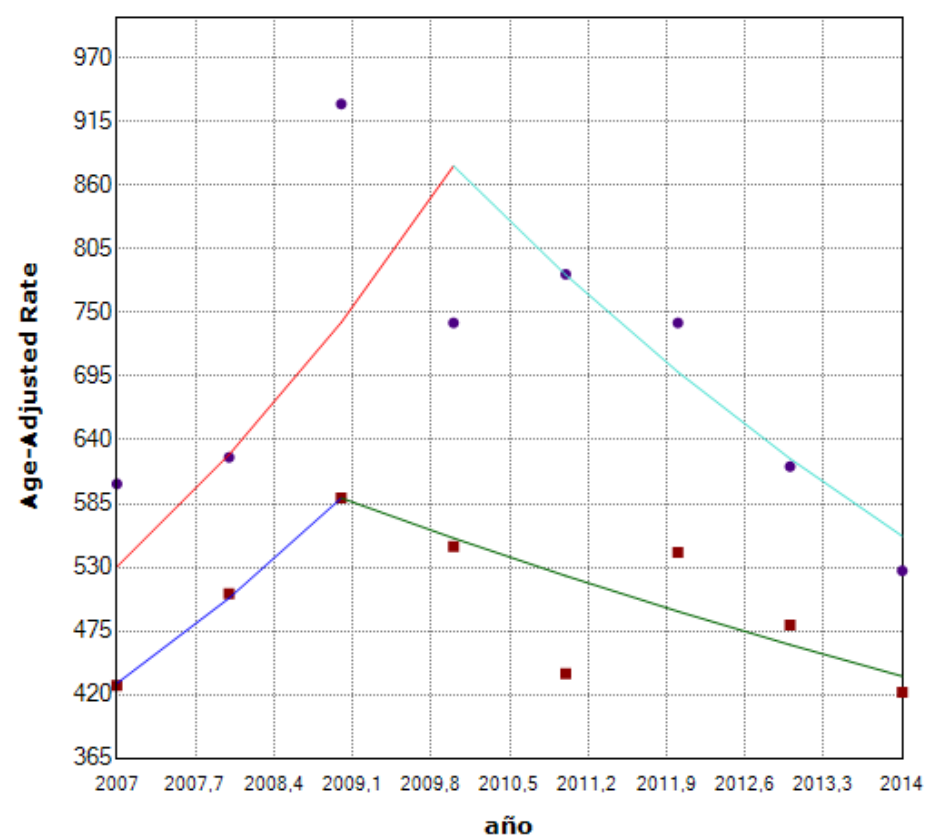

- $2007-2009$ APC $=17.14$ - 2009-2014 APC $=-5.87$ - 1

$1007-2010$ APC $=18$ $2007-2010$ APC $=18.21$
$-2010-2014$ APC $=-10.72$

^The Annual Percent Change (APC) is significantly different from zero at alpha $=0.05$ Final Selected Model: 0 - 1 Joinpoint, 1 - 1 Joinpoint. Rejected Coincidence. 


\section{Ilustración 17-Incidencia de Tuberculosis (0 País Vasco / 1 La Rioja)}

0: 0 Joinpoints versus 1: 0 Joinpoints
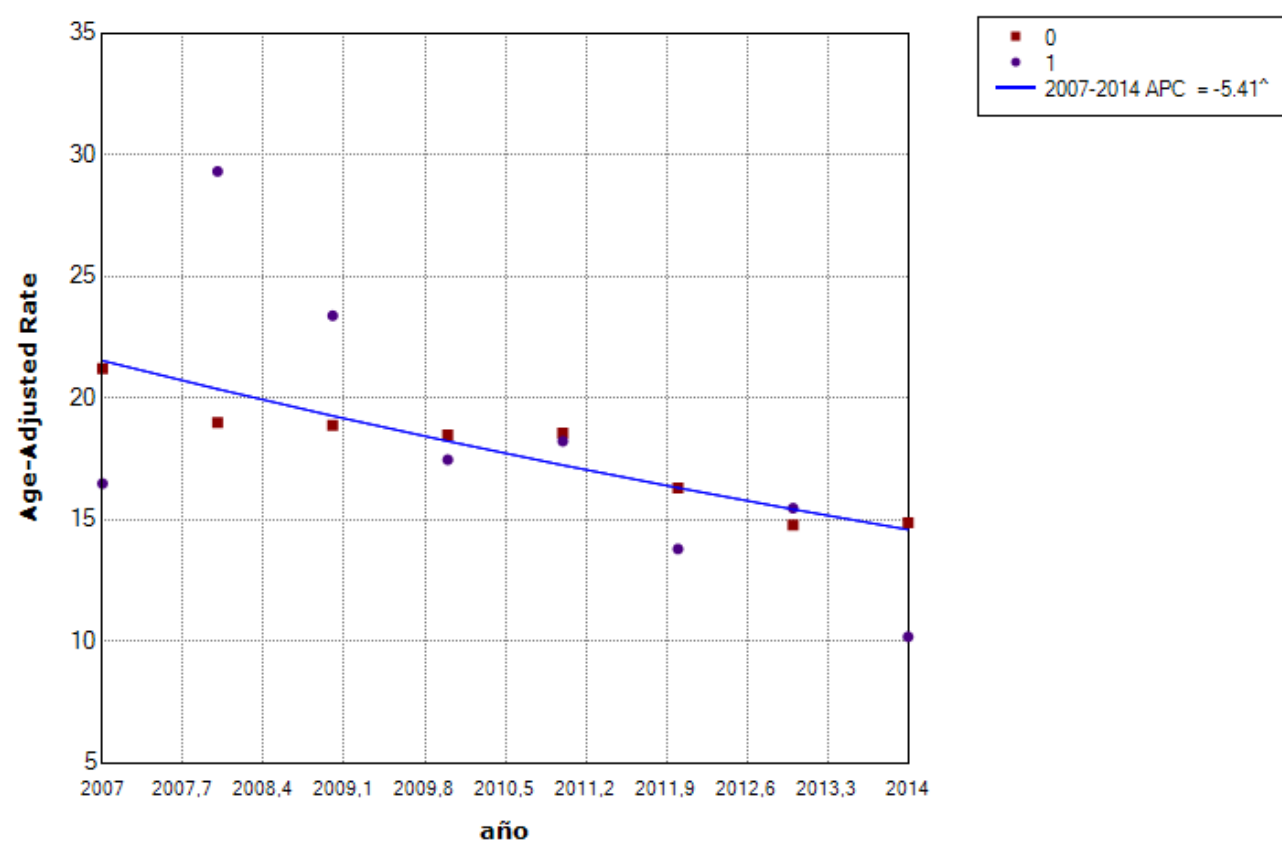

${ }^{\wedge}$ The Annual Percent Change (APC) is significantly different from zero at alpha $=0.05$ Final Selected Model: 0 - 0 Joinpoints, 1 - 0 Joinpoints. Failed to reject Coincidence.

\section{Ilustración 18-Mortalidad enfermedad respiratoria (0 País Vasco / 1 La Rioja)}

0: 0 Joinpoints versus 1: 0 Joinpoints

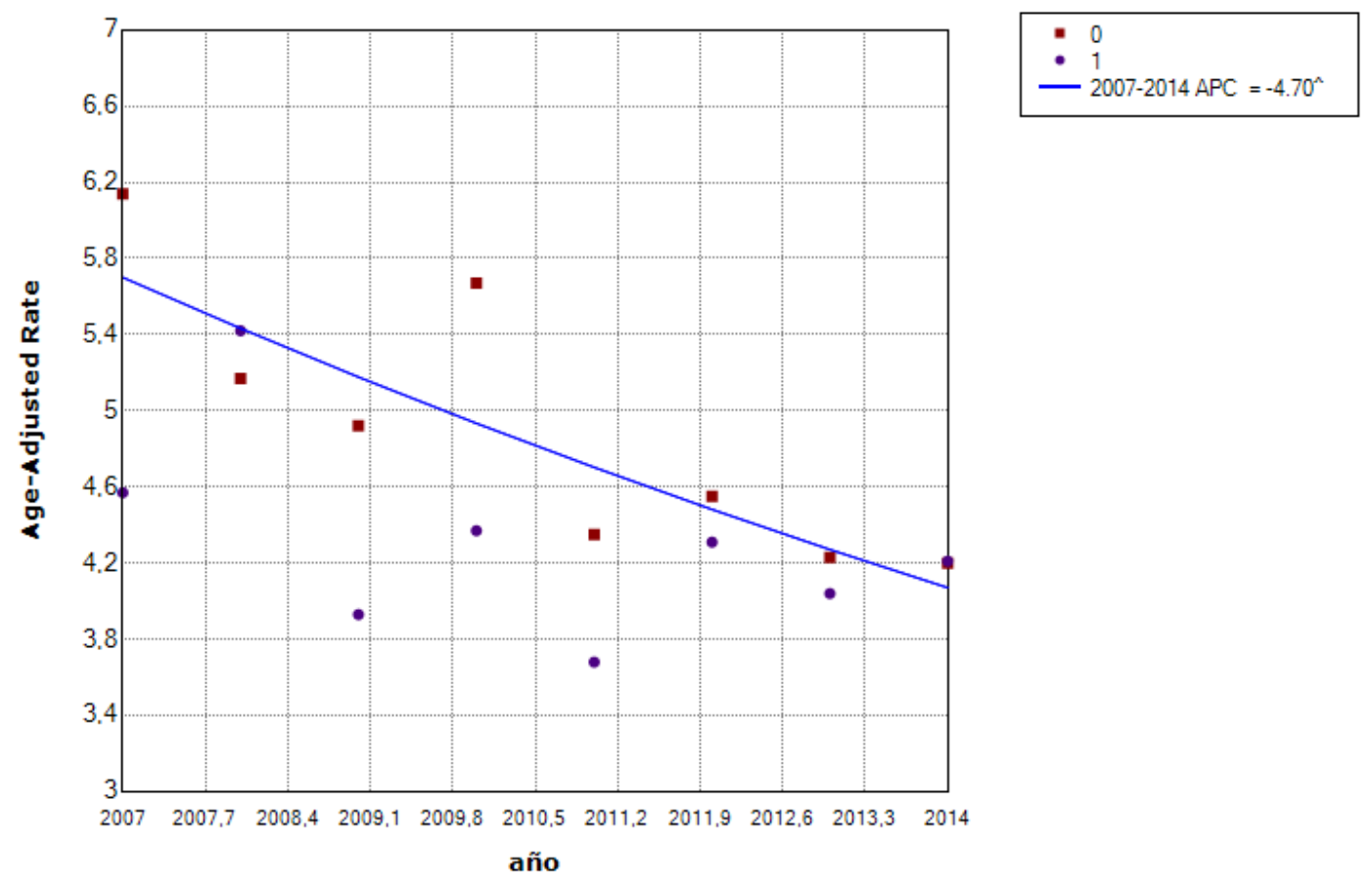

${ }^{\wedge}$ The Annual Percent Change (APC) is significantly different from zero at alpha $=0.05$ Final Selected Model: 0 - 0 Joinpoints, 1 - 0 Joinpoints. Failed to reject Coincidence 


\section{Ilustración 19-Mortalidad enfermedad vascular (0 País Vasco / 1 La Rioja)}

0: 0 Joinpoints versus 1: 0 Joinpoints

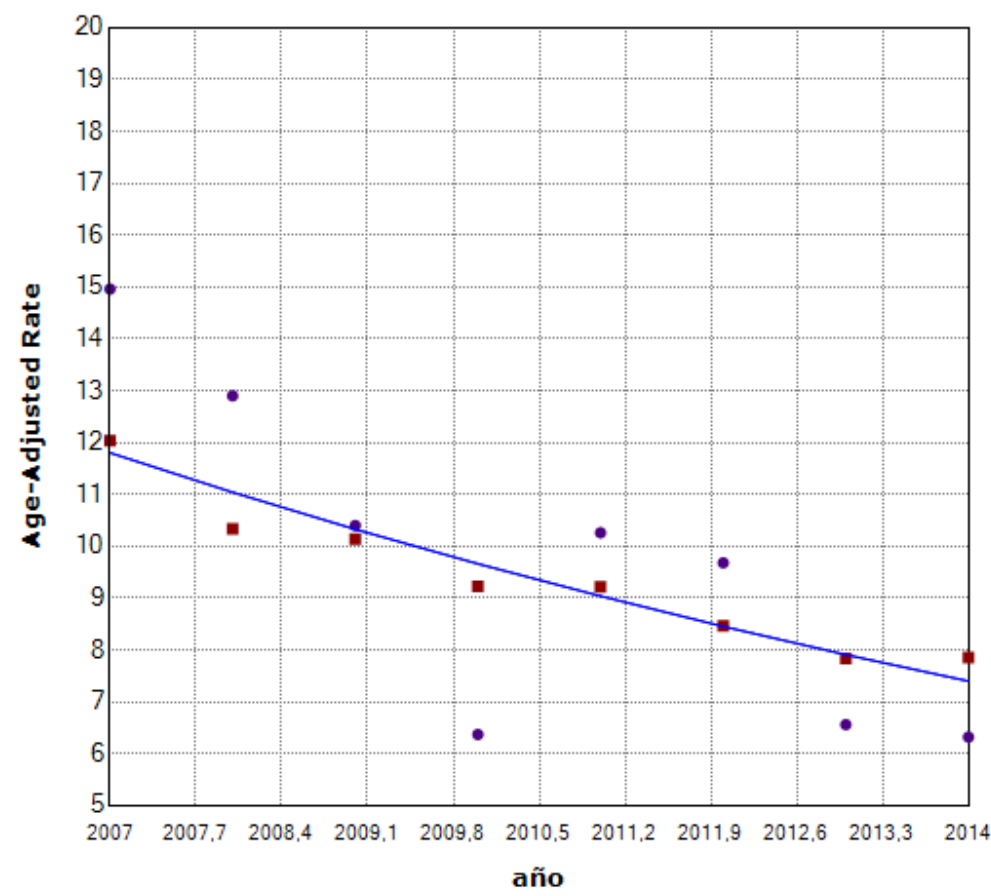

\section{- 0}

- 2007-2014 APC $=-6.45^{\wedge}$

${ }^{\wedge}$ The Annual Percent Change (APC) is significantly different from zero at alpha $=0.05$

Final Selected Model: 0 - 0 Joinpoints, 1 - 0 Joinpoints. Failed to reject Coincidence.

\section{Ilustración 20-Mortalidad cardiopatía isquémica (0 País Vasco / 1 La Rioja)}

0: 0 Joinpoints versus 1: 0 Joinpoints

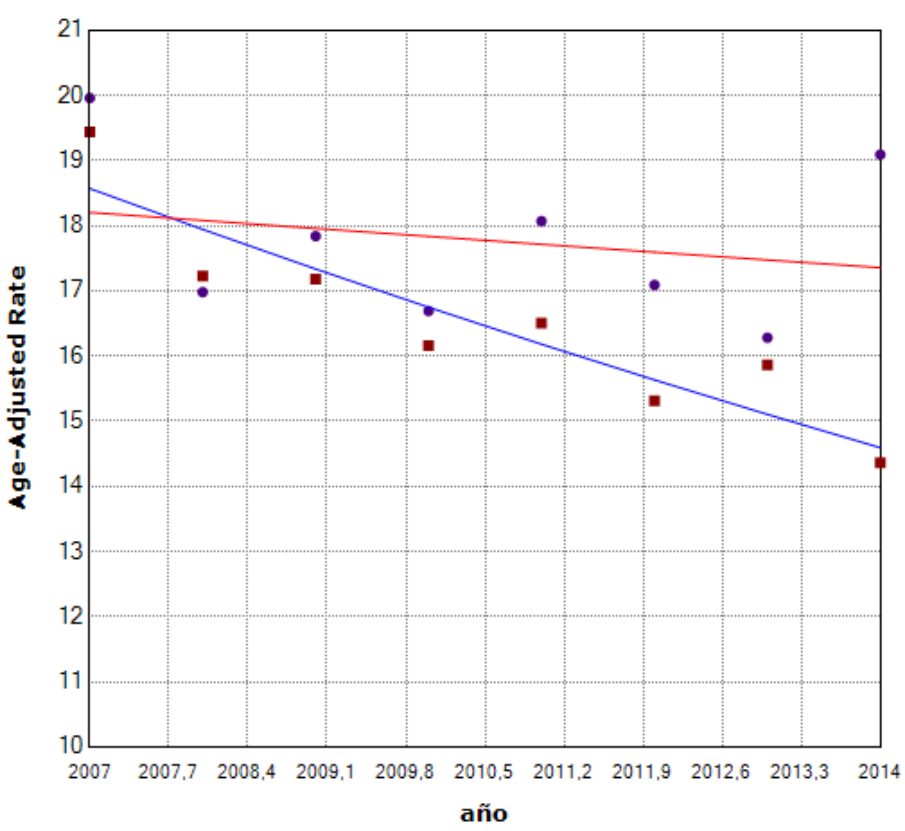




\section{Ilustración 21-Porcentaje de reingresos (0 País Vasco / 1 La Rioja)}

0: 1 Joinpoint versus 1: 1 Joinpoint
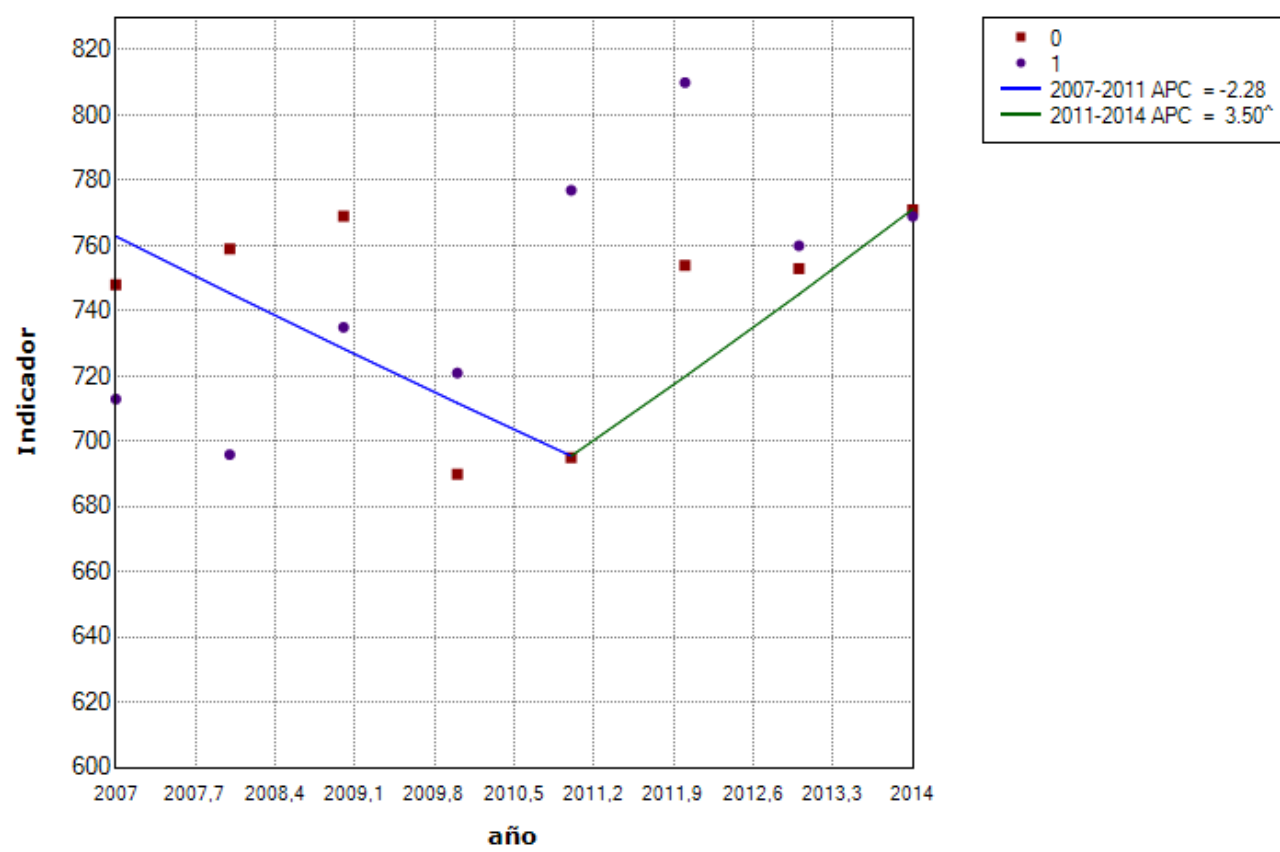

$2011-2014 \mathrm{APC}=3.50^{\wedge}$

${ }^{\wedge}$ The Annual Percent Change (APC) is significantly different from zero at alpha $=0.05$

Final Selected Model: 0 - 1 Joinpoint, 1 - 1 Joinpoint. Failed to reject Coincidence.

Ilustración 22-Tasa de infección nosocomial (hospitalaria) (0 País Vasco / 1 La Rioja)

0: 0 Joinpoints versus 1: 0 Joinpoints

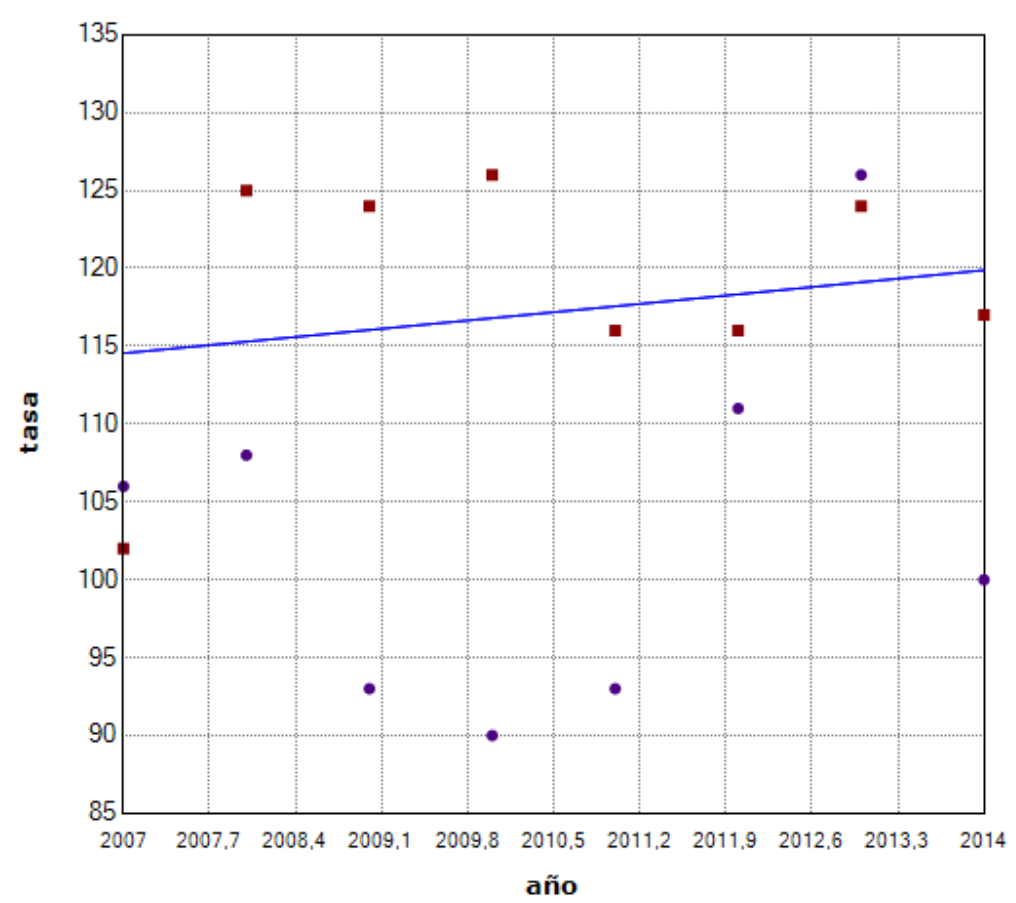

- 0

2007-2014 APC $=0.65$

${ }^{\wedge}$ The Annual Percent Change (APC) is significantly different from zero at alpha $=0.05$

Final Selected Model: 0 - 0 Joinpoints, 1 - 0 Joinpoints. Failed to reject Coincidence. 
Ilustración 23-Fracturas de cadera en pacientes ingresados (0 País Vasco / 1 La Rioja)

0: 0 Joinpoints versus 1: 0 Joinpoints

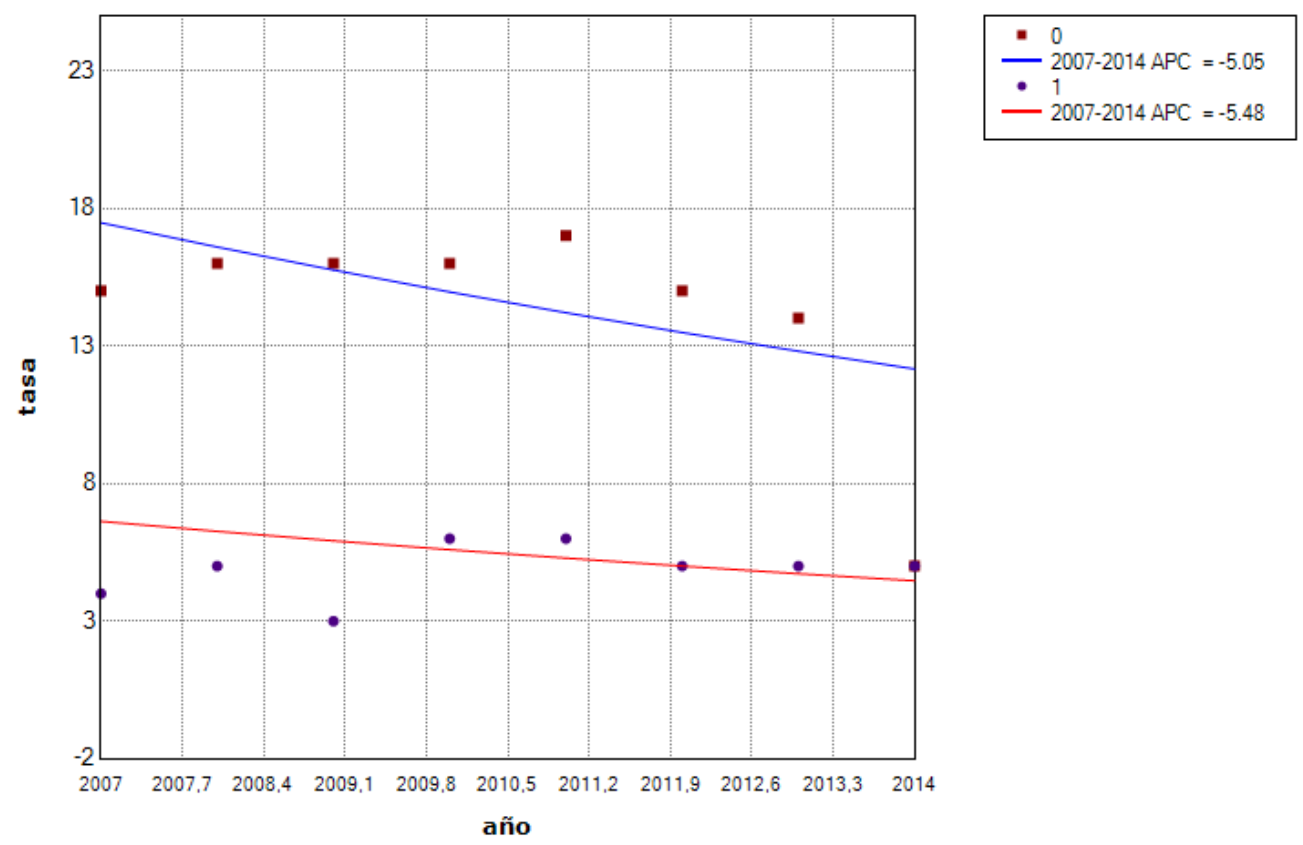

^The Annual Percent Change (APC) is significantly different from zero at alpha $=0.05$ Final Selected Model: 0 - 0 Joinpoints, 1 - 0 Joinpoints. Rejected Coincidence.

Ilustración 24-Mortalidad intrahospitalaria (0 País Vasco / 1 La Rioja)

0: 1 Joinpoint versus 1: 1 Joinpoint

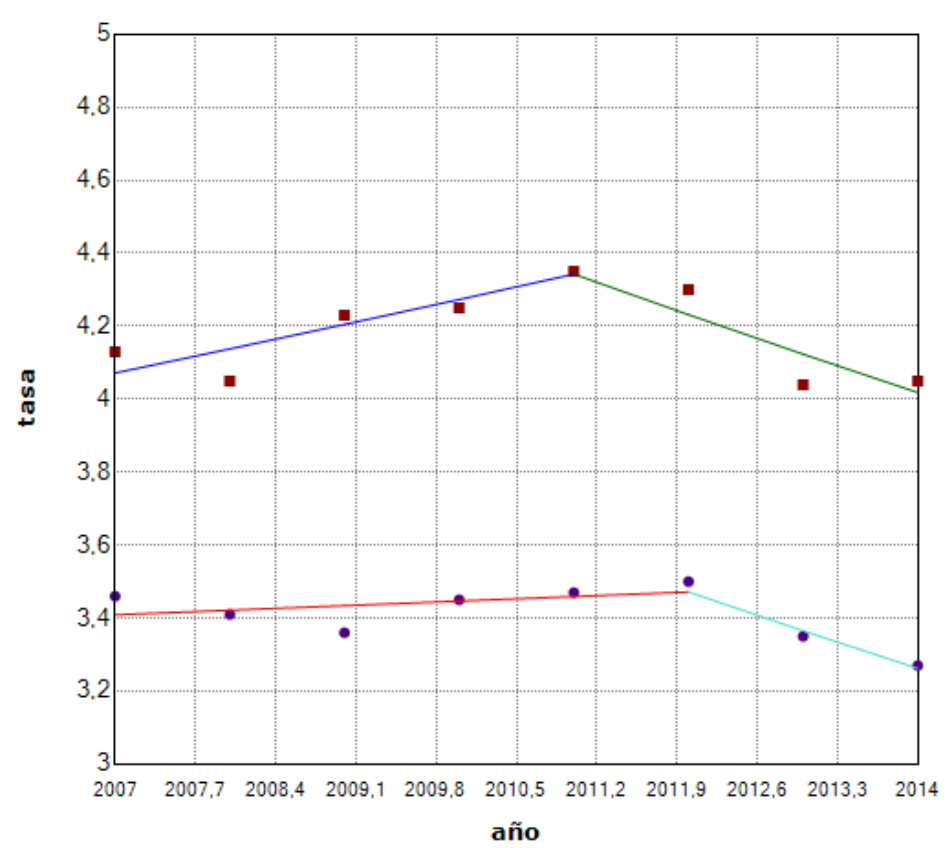

- $2007-2011 \mathrm{APC}=1.62$ 2011-2014 APC $=-2.55$

2007-2012 APC $=0.37$ 2012-2014 APC $=-3.07$

The Annual Percent Change (APC) is significantly different from zero at alpha $=0.05$

Final Selected Model: 0 - 1 Joinpoint, 1 - 1 Joinpoint. Rejected Coincidence. 


\section{ANEXO III. Guion de entrevistas}

\section{Entrevista}

Duración: sesiones de 60 minutos

Lugar: Centro. Sala a elegir por el entrevistado (para que se sienta cómodo y no sienta que está organizado por el hospital y así disminuir su influencia a la hora de responder).

\section{Presentación}

○ Breve personal: Breve currículo. Doctorando Ciencias Sociales USAL

○ Breve del estudio.

- El estudio como una investigación personal en la que el centro no está involucrado (sólo participa), pero no implicado directamente

- Solicitar autorización para tomar notas, grabar la conversación y para posteriormente elaborar los datos de forma objetiva. Asegurar la confidencialidad y la imparcialidad

- Objetivos: identificar qué es lo que la organización hace o tiene para asegurar su sostenibilidad, qué cultura existe al respecto.

- Sistemática: Estudio cuantitativo y entrevistas. Personal seleccionado por considerar su pertenencia a áreas de especial relevancia en el tema.

- Solicitar la posibilidad de futuros contactos si es necesario. Compromiso de Información de resultados si lo desean.

\section{Fase inicial}

Temas generales, fáciles, "romper el hielo" pero sin trivialidades, dejar hablar al sujeto, que se explaye, para que se sienta importante porque cuenta lo que hace y demostrar interés:

¿Cuánto tiempo llevas en este hospital? ¿Has estado en otros? ¿Hay diferencia con otros hospitales? ¿Este tiene algo especial? ¿Cuáles son tus tareas? ¿Siempre han sido esas o has ido cambiando?

\section{Temas entrevista}

\begin{tabular}{|c|c|c|}
\hline $\begin{array}{l}\text { Tema } \\
\text { Princip } \\
\text { al } \\
\text { (criteri } \\
\text { os) }\end{array}$ & $\begin{array}{c}\text { Sub-Tema } \\
\text { (subcriterios) }\end{array}$ & Guion entrevista \\
\hline General & $\begin{array}{l}0.1 \text { Definición de } \\
\text { sostenibilidad } \\
0.2 \text { Sostenibilidad } \\
\text { de la organización } \\
\text { en su conjunto } \\
0.3 \text { Obstáculos a la } \\
\text { sostenibilidad }\end{array}$ & $\begin{array}{l}\text { A la hora de desarrollar vuestro trabajo: } \\
\text { ¿Qué tipo de obstáculos encontráis (de donde vienen los } \\
\text { obstáculos, qué motivan los obstáculos, qué hacéis para } \\
\text { minimizarlos, qué impacto tienen... habéis tenido que renunciar } \\
\text { a algo por los obstáculos...?? (0.3) } \\
\text { ¿Crees que el centro da respuesta a las necesidades de los } \\
\text { pacientes, usuarios, sociedad...? ¿Por qué? ¿Qué debería }\end{array}$ \\
\hline $\begin{array}{l}\text { Estrate } \\
\text { gia } \\
\text { (criterio } \\
\text { 2) }\end{array}$ & $\begin{array}{l}\text { 2.c La estrategia y } \\
\text { sus políticas de } \\
\text { apoyo se } \\
\text { desarrollan, revisan } \\
\text { y actualizan }\end{array}$ & $\begin{array}{l}\text { hacer? (5.b) } \\
\text { ¿Sabes si existen políticas, planes, ideas, estrategias para el } \\
\text { buen funcionamiento del centro? ¿Las conoces? ¿Sabes si se } \\
\text { revisan y actualizan? (2.c) }\end{array}$ \\
\hline $\begin{array}{l}\text { Proceso } \\
\text { s, } \\
\text { product } \\
\text { os y } \\
\text { Servicio }\end{array}$ & $\begin{array}{l}\text { 5.b Los productos y } \\
\text { servicios se } \\
\text { desarrollan para dar } \\
\text { un valor óptimo a } \\
\text { los clientes }\end{array}$ & $\begin{array}{l}\text { ¿Crees que el centro es flexible y capaz de adaptarse a los } \\
\text { cambios de manera eficaz? ¿Conoces algún ejemplo? Si no es } \\
\text { así porqué y qué debería hacer el centro.(1.e) }\end{array}$ \\
\hline
\end{tabular}




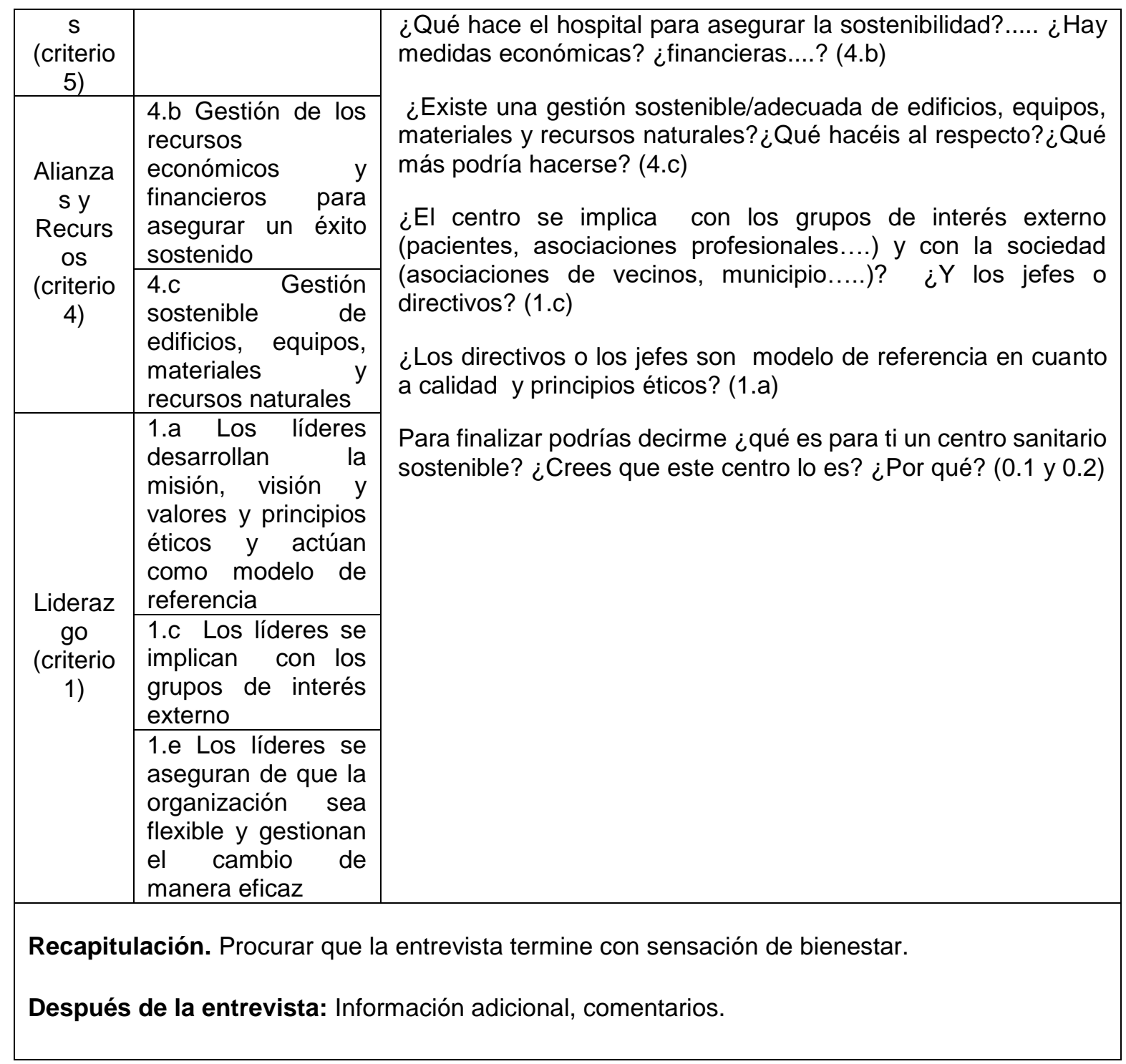




\section{ANEXO IV. Cronograma de las entrevistas OSI Bilbao Basurto}

\begin{tabular}{|l|c|c|c|}
\hline \multicolumn{1}{|c|}{ Área } & Día1 & Día2 & Día3 \\
\hline Responsable de Formación & 9 a 10 & & \\
\hline Subdirector económica & & & $12: 30$ a 14 \\
\hline Técnico de gestión medioambiental & 13 a 14 & & \\
\hline Director de mantenimiento & 11 a 12 & & 14 a 15 \\
\hline $\begin{array}{l}\text { Responsable de unidad de gestión } \\
\text { sanitaria }\end{array}$ & & & \\
\hline Supervisora de atención al paciente & 14 a 15 & & 9 a 10 \\
\hline Jefe de servicio de calidad & 10 a 11 & & 11 a 12 \\
\hline Directora médica & & & \\
\hline Directora de enfermería & & $10: 30$ a 12 & 9 a 10 \\
\hline Jefe de estudios & & & 10 a 11 \\
\hline Jefe de oncología & & & \\
\hline $\begin{array}{l}\text { Supervisora de hospital de día } \\
\text { quirúrgico }\end{array}$ & & & \\
\hline
\end{tabular}

Servicio Riojano de Salud. Hospital San Pedro

\begin{tabular}{|l|c|c|}
\hline \multicolumn{1}{|c|}{ Área } & Día & Horario \\
\hline Jefa de servicio de formación & 1 & 10 a 11 \\
\hline Directora económica & 1 & 12 a 13 \\
\hline Subdirector de mantenimiento & 2 & 12 a 13 \\
\hline Jefe de servicio de admisión & 3 & 10 a 11 \\
\hline Jefe de servicio de atención sociosanitaria & 3 & 12 a 13 \\
\hline $\begin{array}{l}\text { Responsable de calidad del servicio de } \\
\text { alimentación }\end{array}$ & 4 & 9 a 10 \\
\hline Director médico & 5 & 9 a 10 \\
\hline Subdirectora de enfermería & 5 & 12 a 13 \\
\hline Jefe de estudios & 6 & 11 a 12 \\
\hline Jefe de hospitalización a domicilio & 7 & 9 a 10 \\
\hline Supervisora de hospital de día & 7 & 11 a 12 \\
\hline
\end{tabular}

